AFONSO HENRIQUE TEIXEIRA MENDES

DIAGNÓSTICO DE ESTABILIDADE DIMENSIONAL DE PAPEL REPROGRÁFICO POR ANÁLISE DE IMAGEM 


\section{DIAGNÓSTICO DE ESTABILIDADE DIMENSIONAL DE PAPEL REPROGRÁFICO POR ANÁLISE DE IMAGEM}

Tese apresentada à Escola Politécnica da Universidade de São Paulo, para obtenção do título de Doutor em Engenharia

Área de concentração:

Engenharia Química

Orientador:

Prof. Dr. Song Won Park 
Este exemplar foi revisado e alterado em relação à versão original, sob responsabilidade única do autor e com a anuência do seu orientador.

São Paulo, 08 de julho de 2011.

Assinatura do autor

Assinatura do orientador

Mendes, Afonso Henrique Teixeira

Diagnóstico de estabilidade dimensional de papel reprográfico por análise de imagem / A.H.T. Mendes. -- ed. rev. -- São Paulo, 2011.

274 p.

Tese (Doutorado) - Escola Politécnica da Universidade de São Paulo. Departamento de Engenharia Química.

1. Tecnologia de celulose e papel 2. Propriedades físicas do papel I. Universidade de São Paulo. Escola Politécnica. Departamento de Engenharia Química II. t. 


\section{AGRADECIMENTOS}

Ao Prof. Dr. Song Won Park, pela amizade, incentivo e dedicação às atividades de orientação, fatores fundamentais que nortearam a realização desta tese;

Ao Prof. Dr. Hae Yong Kim, pela disponibilidade, ajuda nos desvendamentos das técnicas de análise de imagem e importantes sugestões na fase de qualificação;

Ao Prof. Dr. Cláudio Roberto de Freitas Pacheco, pela análise do trabalho preliminar e valiosas sugestões no exame de qualificação;

Ao Prof. Dr. Reinaldo Giudici, pela leitura atenta e contribuições feitas ao trabalho no exame de qualificação;

Ao Prof. Dr. Paulo Jorge Tavares Ferreira, da Universidade de Coimbra, pelo suporte oferecido para as medições de higroexpansibilidade e proveitosas discussões sobre o tema;

Aos amigos Fabio Sergio Almeida, João Marcelo Lopes e Nilson Donizeti Pereira, pela confiança e envolvimento que dedicaram ao trabalho laboratorial;

À Silma, minha querida esposa e companheira, pela presença, luz, coragem e verdadeiro amor, que dedicou a mim, em todos os momentos desta trajetória;

À Juliana e Daniel, filhos que a vida providencialmente me ofereceu, pela serenidade, compreensão e apoio nos momentos de isolamento e angústia. 
"O papel é plural, natural, profano, interativo, igualitário e mutante, um espetáculo que refuta a perda de significados ocultos e se estabelece, ele mesmo, como significante"

Ana Virgínia Pinheiro [A Cultura do Papel] 


\section{RESUMO}

MENDES, A. H. T. Diagnóstico de estabilidade dimensional de papel reprográfico por análise de imagem. 2011. $274 \mathrm{f}$. Tese (Doutorado) - Escola Politécnica da Universidade de São Paulo, São Paulo, 2011.

A estabilidade dimensional representa uma das mais importantes propriedades do papel, dentre aquelas que governam seu desempenho no uso final. Esta propriedade determina a funcionalidade do papel em processos de impressão, de conversão e, particularmente, na aplicação em máquina copiadoras e impressoras comerciais. O monitoramento da estabilidade dimensional oferece possibilidades de interferência em parâmetros do processo de fabricação, com a finalidade de estabelecer condições de produção de papel mais eficientes e econômicas, promovendo ainda, melhor suporte para atividades de assistência técnica ao usuário final. $\mathrm{O}$ objetivo deste trabalho é apresentar uma metodologia factível para avaliação da estabilidade dimensional de papel reprográfico, por meio da medição do perfil do encolhimento transversal (CD) diferencial, utilizando técnicas de processamento e análise de imagem, a fim de detectar marcas periódicas (da tela formadora) existentes na estrutura do papel. O método apresentado baseia-se em protocolos simplificados de amostragem e medição, que permitem simples implantação nos ambientes industriais das fábricas de papel. A partir da captação de imagens de amostras de papel coletadas na direção transversal de uma bobina jumbo, na saída da enroladeira da máquina de papel e utilização de técnicas de análise de imagem baseadas na transformada bidimensional rápida de Fourier (2D-FFT), obtiveram-se perfis relativos e absolutos do perfil de encolhimento transversal (CD) diferencial do papel, elemento chave para a análise e diagnóstico da estabilidade dimensional, dada a forte correlação encontrada, neste trabalho, entre o encolhimento e a higroexpansibilidade do papel. Para desenvolvimento da presente tese, foram examinadas amostras de papel reprográfico, com gramatura nominal de $75 \mathrm{~g} . \mathrm{m}^{-2}$, fabricado em máquina industrial com velocidades operacionais de $1256 \mathrm{~m} . \mathrm{m}^{-1} \mathrm{e}$ $1362 \mathrm{~m} \cdot \mathrm{min}^{-1}$, com larguras na enroladeira de $5278 \mathrm{~mm}$ e $5300 \mathrm{~mm}$, respectivamente. Os resultados mostraram a viabilidade da aplicação do método, que se mostrou adequado para implementação em fábricas de papel e vantajoso com relação aos métodos tradicionais de medição, e.g., aqueles utilizados para medição de higroexpansibilidade do papel, dependentes de equipamentos sofisticados e demandantes de longos tempos de execução e retorno de resultados . Este trabalho oferece, adicionalmente, contribuições de diversas naturezas, tanto metodológicas, como o esclarecimento do processo de medição do encolhimento do papel por meio da detecção e medição das marcas de telas formadoras e o desenvolvimento de programa de análise de imagem específico, para automatização da busca de informações de interesse no espectro de freqüências de Fourier, como ainda, para aumentar a base de dados sobre o comportamento higroexpansivo do papel reprográfico fabricado totalmente com pasta branqueada de fibras de eucalipto do Brasil.

Palavras-chave: estabilidade dimensional, encolhimento, Fourier, higroexpansibilidade, papel reprográfico. 


\begin{abstract}
MENDES, A. H. T. Diagnosis of reprographic paper dimensional stability by image analysis. 2011. 274 f. Tese (Doutorado) - Escola Politécnica da Universidade de São Paulo, São Paulo, 2011.
\end{abstract}

Dimensional stability represents on of the most important properties of paper, among the ones that controls its performance in end-use. This property fixes the paper functionality in printing and converting processes and, particularly, in copier machines and commercial printers applications. Dimensional stability monitoring can bring opportunities for interfering in manufacturing process parameters, in order to establish operating conditions suitable for a more efficient and economic production and better support for technical assistance to endusers. The objective of this work is to present a feasible methodology for evaluating the dimensional stability of reprographic paper by measuring the CD differential shrinkage profile of paper using image analysis and digital processing to detect periodic marks (from the forming fabric) in the structure of paper. The method presented is based on simplified sampling and measuring protocols, which allow for its simple introduction in the paper mill industrial environment. From digital images of paper samples acquired along the transverse direction of a jumbo reel at the end of the paper machine and by using image analysis techniques based on two-dimensional fast Fourier transform (2D-FFT), relative and absolute $\mathrm{CD}$ differential shrinkage profiles were obtained as the key element for analysis and diagnoses of the paper dimensional stability, given the strong correlation found out in this study, between shrinkage and hygroexpansivity of paper. For development of this thesis, reprographic paper with nominal basis weight of 75 g.m ${ }^{-2}$, manufacture in industrial paper machine at operating speeds of $1256 \mathrm{~m} . \mathrm{m}^{-1}$ and $1362 \mathrm{~m} \cdot \mathrm{min}^{-1}$ and having width of $5278 \mathrm{~mm} \mathrm{e}$ $5300 \mathrm{~mm}$, respectively, were investigated. The results showed the feasibility of the method, which proved to be suitable for implementation in paper mills and advantageous over traditional measurement methods, e.g., those used for paper hygroexpansivity measurement, which depend on sophisticated equipment and long lead times for getting it executed and having the measurement results. This work offers, in addition, contributions of various natures, such as methodological ones, like to elucidate the paper shrinkage measurement method by means of forming fabrics marks detection and develop of a specific image analysis computer program for automation of data searching in the Fourier frequency spectrum and yet, to improve the database related to higroexpansive behavior of reprographic paper manufactured totally from eucalyptus fiber bleached pulp from Brazil.

Keywords: dimensional stability, Fourier, hygroexpansivity, reprographic paper, shrinkage. 


\section{LISTA DE SIGLAS E ABREVIATURAS}

BRACELPA Associação Brasileira de Celulose e Papel

BMP Bitmap

$\mathrm{BW}_{\mathrm{f}} \quad$ Bond Water (freezing)

$\mathrm{BW}_{\mathrm{nf}} \quad$ Bond Water (non-freezing)

CCD Charge Coupled Device

CD Cross Direction

CLSM Confocal Laser Scanning Microscopy

DFT Discrete Fourier Transform

DL Double Layer

DL EWA Double Layer Extra Weft Added

DI Drainage Index

DSC Differential Scanning Calorimetry

FFT Fast Fourier Transform

FSI Fiber Support Index

FW Free Water

IPT Image Processing Toolbox

ISO International Organization for Standardization

LA Lado de acionamento da máquina de papel

LC Lado de comando da máquina de papel

LWC Light Weight Coated

MATLAB Matrix Laboratory

MD Machine Direction

OA Open Area

PPI Pixels per inch

SL Single Layer

SLM Scan Laser Microscope

SP Support Points

SR Schopper-Riegler

SSB Self Support Binding

TAPPI Technical Association of the Pulp and Paper Industry

TIP Technical Information Paper 
TL

TMA Transparent Media Adapter

TMP Thermo-Mechanical Pulp

TSI Tensile Stiffness Index

TSO Tensile Stiffness Orientation

TW Triple Weft

WRV Water Retention Value

2D-DFT Two-Dimensional Discrete Fourier Transform

2D-FFT Two-Dimensional Fast Fourier Transform

2D-IDFT Two-Dimensional Inverse Discrete Fourier Transform 


\section{LISTA DE SÍMBOLOS}

$a$

$a^{\prime}$

$a^{\prime \prime}$

$a_{s}$

$a_{u s}$

$d$

$d^{\prime}$

$d^{\prime}$

$d^{\prime \prime}$

$d_{c d}$

$d_{c d}^{\prime}$

$d_{c d}^{*}$

$d^{*}{ }_{c d}(u s)$

$d_{i}$

$d_{i}^{\prime}$ separação das marcas dos fios longitudinais (MD) da tela formadora alinhada com o eixo transversal (CD) da máquina de papel

separação das marcas dos fios longitudinais (MD) da tela formadora alinhada com o eixo transversal (CD) da máquina de papel (no caso de distorção anti-horária)

separação das marcas dos fios longitudinais (MD) da tela formadora alinhada com o eixo transversal (CD) da máquina de papel (no caso de distorção horária)

separação das marcas dos fios longitudinais (MD) da tela formadora, após encolhimento do papel

separação das marcas dos fios longitudinais (MD) da tela formadora, antes do encolhimento do papel

separação das marcas de tela formadora sobre o papel, detectadas por análise de imagem, na direção do ângulo $\alpha$, pixel

separação das marcas de tela formadora sobre o papel, detectadas por análise de imagem (no caso de distorção anti-horária), pixel

distância entre o pico de amplitude e a origem do espectro de Fourier, pixel

separação das marcas de tela formadora sobre o papel, detectadas por análise de imagem (no caso de distorção horária), pixel

distância entre as marcas transversais (CD) da tela formadora, pixel

distância entre o pico de amplitude referente a marcas transversais (CD) da tela formadora e o centro do espectro de Fourier, pixel

distância entre as marcas transversais (CD) da tela formadora, $\mathrm{mm}$

distância entre marcas encontradas no papel antes do encolhimento, produzidas transversais $(\mathrm{CD})$ da tela formadora, $\mathrm{mm}$

distâncias entre marcas longitudinais (MD), transversais (CD) e separações diagonais, da amostra $i$, detectadas na imagem da tela formadora, pixel

distância entre a posição do pico de amplitude e a origem do espectro de Fourier, referente à amostra $i$, pixel 


$$
\begin{aligned}
& d_{i}^{*} \quad \text { distâncias entre marcas longitudinais (MD), transversais (CD) e } \\
& d_{m d} \\
& d_{m d}^{\prime} \\
& d_{m d}^{*} \\
& d^{*}{ }_{m d}(u s) \\
& e_{i} \\
& E D_{\text {ac }} \\
& F_{c, i} \\
& k_{0} \\
& \hat{k_{0}} \\
& k_{1} \\
& \hat{k_{1}} \\
& \text { l } \\
& l_{c, i} \\
& l_{0} \\
& l_{s, i} \\
& l_{\text {us }} \\
& L_{e n r} \\
& L_{\text {ini }} \\
& L_{S, i} \\
& \text { M }
\end{aligned}
$$


$S_{a}$

$S_{a, i}$

$S_{a \text { max }}$

$S_{a p, i}$

$S_{c d}$

$S_{m}$

$S_{m d}$

$S_{r}$

$S_{r, i}$

$S_{r p, i}$

$u$

$u_{\mathrm{e}}$

$u_{\mathrm{e}, i}$

$v$

$v_{\mathrm{e}}$

$v_{\mathrm{e}, i}$

dimensão da imagem, pixel

numero de posições transversais amostradas

dimensão da imagem, pixel

no. de elementos de imagem na direção $y$

umidade relativa do ar medida no patamar de $33 \pm 2 \%, \%$

umidade relativa do ar medida no patamar de $66 \pm 2 \%, \%$

resolução de da imagem, na direção longitudinal (CD), ppi

resolução de da imagem, na direção longitudinal (MD), ppi

encolhimento transversal (CD) absoluto do papel, \%

encolhimento transversal (CD) absoluto da amostra $i, \%$

encolhimento transversal (CD) absoluto máximo do papel

encolhimento transversal (CD) absoluto (preliminar), \%

encolhimento do papel na direção $\mathrm{CD}, \%$

encolhimento médio da folha de papel, $\%$

encolhimento do papel na direção $\mathrm{MD}, \%$

encolhimento transversal (CD) relativo do papel, \%

encolhimento transversal (CD) relativo da amostra $i, \%$

encolhimento transversal (CD) relativo (preliminar), \%

coordenada horizontal de freqüências, no espectro de Fourier

coordenada no eixo $u$, do pico de encolhimento, no espectro de Fourier

coordenada no eixo $u$, do pico de encolhimento da amostra $i$, no espectro de Fourier

coordenada vertical de freqüências, no espectro de Fourier

coordenada no eixo $v$, do pico de encolhimento, no espectro de Fourier

coordenada no eixo $v$, do pico de encolhimento da amostra $i$, no espectro de Fourier

coordenada no eixo $x$, do pico de distorção, no espectro de Fourier

coordenada no eixo $x$, do pico de distorção da amostra $i$, no espectro de Fourier 
$\alpha_{i}$ coordenada no eixo $x$, do pico de encolhimento, no espectro de Fourier coordenada no eixo $x$, do pico de encolhimento da amostra $i$, no espectro de Fourier

dimensão horizontal da imagem, mm

higroexpansibilidade da amostra $i, \%$

higroexpansibilidade estimada pelo método dos mínimos quadrados

higroexpansibilidade da amostra $i$, estimada por mínimos-quadrados, \%

higroexpansibilidade média da amostra $i$

coordenada no eixo $y$, do pico de distorção, no espectro de Fourier

coordenada no eixo $y$, do pico de distorção da amostra $i$, no espectro de Fourier

coordenada no eixo $y$, do pico de encolhimento, no espectro de Fourier

coordenada no eixo $y$, do pico de encolhimento da amostra i, no espectro de Fourier

dimensão vertical da imagem, $\mathrm{mm}$

ângulo de inclinação das marcas dos fios longitudinais da tela formadora, em relação à direção de fabricação (MD), grau

ângulo de inclinação adicional a $\alpha$, grau

ângulo de inclinação da marcas da tela formadora em relação à direção longitudinal (MD), referente à amostra $i$, grau

ângulo de inclinação da marcas dos fios horizontais da tela formadora, em relação à direção transversal (CD)

ângulo de inclinação adicional a $\beta$, grau

ângulo de inclinação da marcas da tela formadora, em relação à direção transversal (CD), referente à amostra $i$, grau

ângulo de distorção da tela formadora, na marca do papel, antes do encolhimento, grau

ângulo de distorção, na marca da tela formadora, após encolhimento do papel, grau

variação no comprimento do corpo de prova, correspondente à variação da umidade relativa do ambiente, de $22 \pm 3 \%$ a $33 \pm 2 \%, \mu \mathrm{m}$ 
variação no comprimento do corpo de prova, correspondente à variação da umidade relativa do ambiente, de $22 \pm 3 \%$ a $66 \pm 2 \%, \mu \mathrm{m}$

$\Delta x$

resolução de imagem na direção $x, \mathrm{~mm}$

$\Delta y$

resolução de imagem na direção $y, \mathrm{~mm}$

$\varepsilon$

componte de erro, $\%$

$\gamma_{i}$

ângulo de orientação de fios longitudinais (MD), transversais (CD) e das separações diagonais, referentes à amostra $i$, grau 


\section{LISTA DE FIGURAS}

Figura 2.1 Encolhimento do papel em três etapas $c f$. Rance [1954]. O teor de umidade representa a razão entre a massa de água $[\mathrm{g}]$ e a massa de sólidos [g].

Figura 2.2 Diminuição sucessiva da interligação entre fibrilas celulósicas causada pela absorção de água, de "A" para " $D$ " (inchação) ou, contrariamente, aumento da interligação causada pela remoção de moléculas de água, de "D" para "A" (encolhimento), cf. Scallan ${ }^{36}$ [1974 apud Kajanto; Niskanen,1998].

Figura 2.3 Remoção de frações de água e modificações na seção transversal das fibras vs. teor de sólidos nas operações de fabricação de papel. As dimensões transversais foram medidas por microscópio de varredura a laser (CLSM) e as frações de água, medidas por calorimetria diferencial de varredura (DSC) [Weise 1997]....

Figura 2.4 Frações de água livre e água ligada $v s$. teor de umidade, para pasta termomecânica (TMP) [Weise, 1997]. O teor de umidade representa a razão entre a massa de água $[\mathrm{g}]$ e a massa de sólidos $[\mathrm{g}]$.

Figura 2.5 Encolhimento do papel: (a) rede de fibras antes da secagem e (b) a mesma rede de fibras após a secagem [Kiiskinen; Pallakari; Pakarinen, 2000].

Figura 2.6 Elemento da folha de papel e variação da força de atrito na direção transversal [Kiiskinen; Pallakari; Pakarinen, 2000].

Figura 2.7 Representação do perfil do encolhimento transversal (CD) com variação da força de atrito [Kiiskinen; Pallakari; Pakarinen, 2000].

Figura 2.8 (a) Seção de secagem com secadores dispostos em duas fileiras e (b) perfil típico de encolhimento transversal (CD) [Wedel, 1989a].

Figura 2.9 Seção de secagem com cilindros secadores dispostos em fileira única [Wedel, $1899 \mathrm{a}]$

Figura 2.10. Encolhimento da folha nas direções $M D$ e $C D$ de amostras de papel secadas livremente [Wedel, 1989a]..

Figura 2.11 Transporte do papel entre componentes da seção de secagem [Wahlström; Lif , 2003].

Figura 2.12 Geometria de uma amostra de papel secada em passe simples. $W_{\max }=600 \mathrm{~mm}$ e $L_{\max }=500 \mathrm{~mm}$ [Wahlström; Lif, 2003]....

Figura 2.13 Perfil do encolhimento transversal (CD) para diversos valores da razão $[W / L]$ : (a) para largura da amostra (W) constante de comprimento (L) variável, (b) para comprimento constante e variação de largura da amostra [Wahlström; Lif, 2003]... 37

Figura 2.14 Resultados modelados usando a equação (2.11): (a) mantendo $W$ constante (=600 $\mathrm{mm})$ e variando o valor de $L$ e, (b) mantendo $L$ constante $(=18,5 \mathrm{~mm})$ e variando o valor de $W$. Os parâmetros utilizados encontram-se na Tabela 2.1 [Constantino; I'Anson; Sampson, 2005]. 
Figura 2.15 Modificação de encolhimento transversal (CD) causada pela desativação de caixas estabilizadoras da seção de secagem em uma máquina de papel imprensa de alta velocidade [Hoole et. al., 1999]

Figura 2.16 Encolhimento relativo modelado, a partir da equação (2.12), mostrando a diferença resultante da alteração do comprimento efetivo do passe entre secadores [Hoole et. al., 1999]

Figura 2.17 Perfis de encolhimento transversal em máquinas de papel imprensa, gramaturas de 45,5 e 48,8 g.m ${ }^{-2}$, pasta termomecânica (B e D) e papel para impressão, gramaturas de 75,0 e 65,0 g.m $\mathrm{m}^{-2}$, pasta kraft branqueada $(\mathrm{G}$ e H), respectivamente. A abscissa indica a distância a partir do lado de comando da máquina (frente). $\mathrm{O}$ encolhimento médio foi ajustado para $\varepsilon_{w}=0$. As cruzes indicam incerteza experimental, $c f$. equação (2.15) [Viitaharju; Niskanen, 1993].

Figura 2.18 Perfil de encolhimento transversal obtido com uso de técnica óptica com transformação de Fourier [Hansson; Manneberg, 1999].

Figura 2.19 Correlação entre alongamento e encolhimento - pasta química sulfito de fibra longa, branqueada, refinada a $50^{\circ} \mathrm{SR}$ [Gates; Kenworthy, 1963].

Figura 2.20 Relação entre higroexpansão e encolhimento para folhas secadas sob restrição ao encolhimento e para folhas produzidas a partir de 10 tipos de pastas celulósicas, refinadas e secadas livremente [Nordman, 1958]

Figura 2.21 Higroexpansão (medida para a variação de umidade relativa do ar de $30 \%$ a $60 \%$, com $\left.\mathrm{T}=23^{\circ} \mathrm{C}\right) v s$. densidade do papel, para folhas isotrópicas produzidas com pasta química (kraft) de fibras longas, refinada, com diferentes conteúdos de finos, para folhas secadas livremente (linhas contínuas) e secadas com restrição ao encolhimento (linhas tracejadas). A densidade foi variada por meio da carga de prensagem [Salmén et al., 1987].

Figura 3.1 Configurações de sensores para aquisição de imagem: (a) sensor simples. (b) sensor linear e (c) matriz de sensores [Gonzales; Woods, 2008]

Figura 3.2 Sistema de aquisição de imagem utilizando uma barra linear de sensores [Gonzales; Woods, 2008].

Figura 3.3 Exemplo de um processo de captação de imagem digital [Gonzales; Woods, 2008].

Figura 3.4 Geração de uma imagem digital: (a) imagem continua; (b) varredura na imagem continua, entre os pontos $A$ e $B$; (c) amostragem e quantização; (d) linha digitalizada.

Figura 3.5 Representação de uma imagem digital: (a) plotada como uma superfície; (b) visualizada como conjunto de intensidades; (c) mostrada como arranjo numérico os valores $0,0,5$ e 1 representam preto, cinza e branco, respectivamente [Gonzalez; Woods, 2008].

Figura 3.6 Decomposição da função indicada na posição inferior, em quatro componentes senoidais [Gonzalez; Woods, 2008] ...................................................................... 76

Figura 3.7 Interpretação da transformada de Fourier [Brigham, 1988, p.5] ............................... 77 
Figura 3.8 Trem de impulsos bidimensional [Gonzales; Woods, 2008, p.228].

Figura 3.9 (a) imagem de um retângulo, (b) espectro de amplitude mostrando pontos brilhantes nos quatro vértices, (c) espectro centrado, (d) resultado mostrando mais detalhes, pela aplicação de uma transformação logarítmica [Gonzales; Woods, 2008, p.246]

Figura 3.10 (a) retângulo da Figura 3.9 transladado, (b) espectro de amplitude correspondente (idêntico ao da imagem original), (c) retângulo girado, (d) espectro correspondente [Gonzales; Woods, 2008, p.246].

Figura 3.11 Centragem da transformada de Fourier: (a) infinitos períodos de uma 1D-DFT, (b) DFT deslocada, por meio da multiplicação de $f(x)$ por $(-1)^{\mathrm{x}}$ antes da computação de $F(u)$, (c) infinitos períodos de uma 2D-DFT. A área sólida representa o conjunto de dados $M \times N, F(u, v)$, obtido com a equação (3.29), (d) DFT deslocada, obtida pela multiplicação de $f(x, y)$ por $(-1)^{x+y}$ antes da computação de $F(u, v)$. [Gonzales; Woods, 2008, p.238]

Figura 3.12. Diagrama de Argand.

Figura 3.13 Esquema de visualização da transformada de Fourier $F(u, v)$, no domínio de freqüências, correspondente a uma função $f(x, y)$ do domínio espacial, com dimensões $N$ x $N$.

Figura 3.14 Espectro de amplitude, obtido a partir da imagem digitalizada de uma amostra de papel. Os pontos brancos encontrados na imagem do espectro correspondem a picos de amplitude produzidos por variações periódicas no papel [I'Anson et.al., 2008].

Figura 3.15 Seções transversais das telas formadoras comumente utilizadas nas máquinas de papel [Kilpeläinen et al., 2000, p.254]..

Figura 3.16 Estrutura básica de uma formadora de camada tripla, destacando o sistema de fios de amarração entre as camadas individuais [Hender, 2009].

Figura 3.17 Exemplos de teceduras de telas formadoras de simples-camada, dupla-camada e tripla-camada [Kilpeläinen et al., 2000, p.255].

Figura 3.18 Tipos de tecedura das superfícies da tela formadora tripla-camada mostrada na Figura 3.17: (a) lado do papel tecido em (02) quadros (configuração plana) e (b) lado de desgaste com 5 quadros, tecido no estilo 1/4 [Barros, 2002].

Figura 3.19 Estruturas de telas formadoras tripla-camada: (a) configuração básica com um fio CD de amarração simples e (b) padrão SSB com fios CD dispostos em pares [Hender, 2009].

Figura 3.20 Representação esquemática das etapas da fabricação de uma tela formadora [Kilpeläinen et al., 2000, p.256]..

Figura 3.21 Transferência de ondulação entre fios durante a etapa de termo-fixação na fabricação da tela formadora [Adanur, 1997, p.78].

Figura 3.22 Definição de malha (mesh) e trama (count), sendo $\mathrm{n}_{\mathrm{MD}} \mathrm{o}$ número de fios longitudinais (warp yarns) e $\mathrm{n}_{\mathrm{CD}}$ o número de fios transversais (weft yarns) por unidade de comprimento da tela formadora. 
Figura 3.23 Alongamento diagonal para diferentes configurações de telas formadoras: TW triplo fio longitudinal, DL - dupla-laje, TL - tripla-laje [Kilpeläinen et al., 2000, p.262].

Figura 3.24 Marcas produzidas por tela formadora [Kilpeläinen et al., 2000].

Figura 3.25 Geometria da distorção causada nas marcas da estrutura têxtil sobre o papel em formação, pelo movimento da tela sobre rolos-guia. A seção (b) mostra o caso em que não há desvio do posicionamento dos fios transversais. Em (a) observa-se o caso em que a distorção da tela produz uma rotação do fio transversal no sentido anti-horário em relação à direção transversal $(\mathrm{CD})$ da máquina e em $(\mathrm{c})$ observa-se uma distorção que causa rotação do fio transversal no sentido horário [I'Anson et al., 2008].

Figura 3.26 Representação de uma função de duas variáveis, no domínio do espaço (a) e a sua transformada no domínio de freqüências (b), pela aplicação da 2D-FFT [Praast, 1990].

Figura 4.1 Máquina de papel industrial.

Figura 4.2 Fotografias da máquina de papel industrial: (a) extremo úmido, onde se encontra o formador de tela dupla do tipo Gap Former e (b) extremo seco, mostrando a bobina de papel "jumbo".

Figura 4.3 Formador de tela dupla, modelo "Duoformer TQ” [Porchia, 2004]

Figura 4.4 Representação esquemática do método usado na coleta de amostras da bobina "jumbo", para medição do encolhimento e da higroexpansibilidade transversais (CD) do papel

Figura 4.5 Representação esquemática do método usado na coleta de amostras da bobina "jumbo", para medição do encolhimento transversal (CD) na largura total da folha de papel na enroladeira...

Figura 4.6 Procedimento utilizado para determinação do perfil do encolhimento transversal (CD) do papel

Figura 4.7 Estação de trabalho para análise de imagens de papel.

Figura 4.8 Esquema do digitalizador fotográfico configurado no modo de iluminação por transmissão de luz, utilizando o dispositivo TMA

Figura 4.9 Imagem digitalizada de uma área de $32.5 \mathrm{~mm}$ x $32.5 \mathrm{~mm}$ de uma amostra de papel, com resolução de 400 ppi e formato de 512 pixels x 512 pixels, em escala de cinza de 256 níveis ( 8 bits), correspondendo à faixa de 0 (preto) a 255 (branco). A imagem foi obtida por transmissão de luz, com a face superior do papel voltada para os sensores de imagem do digitalizador e a borda vertical orientada na direção longitudinal (MD)......

Figura 4.10 Espectro de amplitudes obtido da imagem mostrada na Figura 4.9, indicando pontos brilhantes (brancos) produzidos por variações periódicas no papel, tais como marcas criadas por telas formadoras. 
Figura 4.11 Picos de amplitude produzidos pelos fios longitudinais (MD) de uma tela formadora de tripla-camada, estilo SSB, utilizados para medição da separação transversal (CD) da marcas produzidas pela tela na direção longitudinal (MD)........ 137

Figura 4.12 Picos de amplitude produzidos pelos fios transversais (CD) de uma tela formadora de tripla-camada, estilo SSB, utilizados para medição de eventuais distorções da tela em relação ao eixo transversal $(\mathrm{CD})$ da máquina de papel.

Figura 4.13 Representação esquemática de um espectro da 2D-FFT de uma imagem de papel com dimensões $N$ x $N$, indicando os picos de amplitude simétricos de encolhimento $\left(p_{1}\right.$ e $\left.p^{\prime}{ }_{1}\right)$, os picos de amplitude simétricos de distorção $\left(p_{2}\right.$ e $\left.p^{\prime}{ }_{2}\right)$ e os ângulos de inclinação $\alpha$ e $\beta$ em relação aos eixos horizontal e vertical, respectivamente. Os eixos x e y representam o sistema de coordenadas espaciais e os eixos $u$ e $v$, o sistema de coordenadas de freqüência do espectro de Fourier.

Figura 4.14 Picos de amplitude utilizados no processo de determinação do perfil de encolhimento transversal (CD) diferencial do papel.

Figura 4.15 Sistema de controle da umidade relativa e da temperatura do ar na câmara de teste do higroexpansímetro.

Figura 4.16 Higroexpansímetro do Departamento de Engenharia Química da Faculdade de Ciências e Tecnologia da Universidade de Coimbra, Portugal....

Figura 5.1 Ilustração da tecedura de uma tela formadora de três camadas (SSB) vista pelo lado de contato com o papel (a) e o espectro de Fourier correspondente (b), obtido a partir da sua imagem digital $c f$. indicada na Figura 5.3. Os pontos marcados com asterisco $(*)$ referem-se a pontos simétricos aos indicados com a mesma numeração. Os pontos foram destacados para melhor visualização.

Figura 5.2 Imagem monocromática de uma amostra de tela formadora, obtida por digitalização com resolução de imagem de 400 ppi, no formato de 512 pixels $\mathrm{x}$ 512 pixels e com 8 bits de profundidade de cor (256 níveis de cinza). O contraste foi realçado para melhorar a visualização

Figura 5.3 Fotogafia de uma tela formadora de três camadas, estilo SSB, vista pela face de contato com o papel.

Figura 5.4 Imagem ampliada da tela formadora indicada na Figura 5.3. Observam-se os fios longitudinais (a), transversais (b) e os de ligação (c). A imagem original foi ampliada (100X) para visualização, em microscópio óptico Olympus modelo BX50F4, monitorado em computador por software de análise de imagens ImagePro Plus......

Figura 5.5 Separações entre os fios longitudinais $(\diamond)$ e entre fios transversais $(\square)$ da superfície correspondente ao lado de contato com o papel, em 4 pontos uniformemente distribuídos, ao longo da largura da tela formadora.

Figura 5.6 Imagem digital de amostra de papel, digitalizada em modo de transmissão de luz, no formato de 512 x 512 pixels (com resolução de 400 ppi) em 256 níveis de cinza. Papel reprográfico de $75 \mathrm{~g} . \mathrm{m}^{-2}$, fabricado com pasta química branqueada de eucalipto 
Figura 5.7 Espectro de freqüências da imagem digital da Figura 5.4, mostrando picos de amplitude (pontos mais claros) gerados por variações periódicas no papel e, em destaque, os picos de freqüência selecionados, para determinação de parâmetros de cálculo do encolhimento transversal (CD) do papel.

Figura 5.8 Distribuição do espaçamento entre as marcas dos fios longitudinais (MD) da tela formadora ao longo das posições transversais do papel. Velocidade da máquina de papel: $1256 \mathrm{~m} \cdot \mathrm{min}^{-1}$

Figura 5.9 Distribuição dos ângulos de inclinação $\left(\alpha_{i}\right)$, representados com quadrados vazios ( $\square)$ e de distorção $\left(\beta_{i}\right)$, representados com triângulos cheios $(\mathbf{\Lambda})$, da tela formadora, ao longo das posições transversais. Velocidade da máquina de papel: $1256 \mathrm{~m} \cdot \mathrm{min}^{-1}$......

Figura 5.10 Perfil transversal do encolhimento CD relativo, obtido a partir de amostras de papel reprográfico de 75 g.m $\mathrm{m}^{-2}$, produzido com pasta química de fibras de eucalipto. Velocidade da máquina de papel: $1256 \mathrm{~m} \cdot \mathrm{min}^{-1}$

Figura 5.11 Perfil transversal do encolhimento $C D$ absoluto, obtido a partir de amostras de papel reprográfico de 75 g. $\mathrm{m}^{-2}$, produzido com pasta química de fibras de eucalipto. Velocidade da máquina de papel: $1256 \mathrm{~m} \cdot \mathrm{min}^{-1}$

Figura 5.12 Perfil transversal da higroexpansibilidade CD, obtido a partir de amostras de papel reprográfico de $75 \mathrm{~g} . \mathrm{m}^{-2}$, produzido com pasta química de fibras de eucalipto. Velocidade da máquina de papel: $1256 \mathrm{~m} \cdot \mathrm{min}^{-1}$.

Figura 5.13 Correlação entre higroexpansibilidade e encolhimento transversal (CD), medida em amostras de papel reprográfico de $75 \mathrm{~g} . \mathrm{m}^{-2}$ produzido com pasta química de fibras de eucalipto. Velocidade da máquina de papel: $1256 \mathrm{~m} \cdot \mathrm{min}^{-1}$.

Figura 5.14 Distribuição do espaçamento entre as marcas dos fios longitudinais (MD) da tela formadora ao longo das posições transversais do papel. Velocidade da máquina de papel: $1362 \mathrm{~m} \cdot \mathrm{min}^{-1}$

Figura 5.15 Distribuição dos ângulos de inclinação $\left(\alpha_{i}\right)$, representados com quadrados vazios $(\square)$ e de distorção $\left(\beta_{i}\right)$, representados com triângulos cheios $(\mathbf{\Lambda})$, da tela formadora, ao longo das posições transversais. Velocidade da máquina de papel: $1362 \mathrm{~m} \cdot \mathrm{min}^{-1}$.....

Figura 5.16 Perfil transversal do encolhimento CD relativo, obtido a partir de amostras de papel reprográfico de 75 g.m $\mathrm{m}^{-2}$, produzido com pasta química de fibras de eucalipto. Velocidade da máquina de papel: $1362 \mathrm{~m} \cdot \mathrm{min}^{-1}$

Figura 5.17 Perfil transversal do encolhimento CD absoluto, obtido a partir de amostras de papel reprográfico de 75 g.m $\mathrm{m}^{-2}$, produzido com pasta química de fibras de eucalipto. Velocidade da máquina de papel: $1362 \mathrm{~m} \cdot \mathrm{min}^{-1}$

Figura 5.18 Perfis transversais de $\mathrm{TSO}_{\text {angle }}$ e $\mathrm{TSI}_{\mathrm{MD} / \mathrm{CD}}$, obtidos a partir de amostras de papel reprográfico de $75 \mathrm{~g} . \mathrm{m}^{-2}$, produzido com pasta química de fibras de eucalipto. Velocidade da máquina de papel: $1362 \mathrm{~m} \cdot \mathrm{min}^{-1}$

Figura 6.1 Perfil do encolhimento transversal (CD) absoluto, obtido a partir de amostras de papel reprográfico de $75 \mathrm{~g} . \mathrm{m}^{-2}$, produzido com pasta química branqueada de fibras de eucalipto, mostrando seleção de regiões em função da estabilidade dimensional. Velocidade da máquina: $1362 \mathrm{~m} / \mathrm{min}^{-1}$ 
Figura 6.2 Interpretação qualitativa do gráfico da Figura 6.1 sob o ponto de vista de estabilidade dimensional resultante no papel reprográfico analisado.

Figura 6.3 Geometria das marcas da tela formadora, $c f$. Figura 3.25, para o caso de um desvio dos fios horizontais (CD) em relação ao eixo transversal da máquina de papel, no sentido horário, caracterizado pelo ângulo $\beta$.

Figura 6.4 Imagem ampliada da tela formadora para medição da separação entre fios alinhados na direção longitudinal (MD). A imagem original foi ampliada (100X), para visualização, em microscópio óptico Olympus modelo BX50F4, monitorado em computador por software de análise de imagens Image-Pro Plus.

Figura B.1 Perfis de $\mathrm{TSO}_{\text {angle }} \mathrm{MD}$ e $\mathrm{TSI}_{\mathrm{MD} / \mathrm{CD}}$. Papel reprográfico de 75 g.m2, produzido com velocidade operacional de 1362 m.min-1 e largura na enroladeira de $5300 \mathrm{~mm}$

Figura C.1 Representação esquemática do espectro de Fourier de uma imagem digital com dimensões $N \times N$, indicando as máscaras usadas para delimitação das áreas onde se encontram os picos de amplitude referentes ao encolhimento do papel e à eventual distorção da tela formadora. As coordenadas espaciais estão representadas com fonte arial e as de freqüência com times new roman itálico.

Figura C.2 Fluxograma simplificado do programa de análise de imagens utilizado no procedimento de determinação do encolhimento transversal (CD) do papel.

Figura E.1 Coleta de uma faixa de papel ao longo da direção transversal da bobina jumbo, com auxílio do equipamento auxiliar de corte [fonte: Lorentzen \& Wettre, 2010]... 229

Figura E.2 Faixa de papel de $300 \mathrm{~mm}$ x $5300 \mathrm{~mm}$, retirada da bobina jumbo e enrolada e amostras cortadas com dimensões de $100 \mathrm{~mm}$ x $300 \mathrm{~mm}$.

Figura E.3 Estação de trabalho para digitalização das amostras de papel composta por um computador acoplado a um digitalizador de mesa.

Figura E.4 Amostra (papel branco) disposta no digitalizador de mesa, sob a máscara de suporte (acessório original do digitalizador).

Figura E.5 Exemplo de configuração do perfil de digitalização, para aquisição de imagens digitais das amostras de papel.

Figura E.6 Propriedades típicas de uma imagem digital de amostra de papel, conforme padrão deste procedimento (denominada imdl.bmp).

Figura E.7 Visualização de uma imagem digital de papel com dimensões de 512 pixels x 512 pixels, digitalizada em escala de cinza de 256 níveis.

Figura E.8 Visualização do espectro da transformada de Fourier da imagem imd1.bmp (propriedades indicadas na Figura E.6) em (a), e da máscara-filtro para identificação de pico de amplitude de interesse em (b).

Figura E.9 Exemplo de visualização de tela durante processamento do programa PET1_0, os parâmetros de entrada digitados pelo operador, os parâmetros pré-definidos (default) e dados de saída para as doze primeiras imagens analisadas. 
Figura E.10 Exemplo de visualização da planilha PET1_0.xls em (a) e do perfil de encolhimento transversal $(\mathrm{CD})$ relativo em (b).....

Figura E.11 Exemplo de perfil do encolhimento transversal (CD) absoluto do papel obtido por análise de imagem.

Figura F.1 Esquema de uma imagem digital representando marcas longitudinais (a) e transversais (b) encontradas no papel acabado, provenientes de uma tela formadora, no domínio espacial, à esquerda e seus respectivos espectros de Fourier (no domínio das freqüências), à direita. O ângulo $\alpha$ representa a inclinação das marcas provenientes de fios longitudinais em relação à direção longitudinal (MD) e $\beta$ a inclinação de fios transversais em relação à direção transversal da máquina de papel. Os parâmetros $d_{m d}$ e $d_{c d}$ representam as distâncias entre marcas de fios longitudinais e transversais respectivamente, no papel acabado (em pixels). Os parâmetros $d^{\prime}{ }_{m d}$ e $d^{\prime}{ }_{c d}$ representam as distâncias entre os picos de amplitude referentes às marcas longitudinais e transversais, respectivamente, e o centro do espectro. Os picos de amplitude estão representados pelos pontos $p_{1}$ e $p_{2}$ (e seus simétricos $p^{\prime}{ }_{1}$ e $p^{\prime}{ }_{2}$ ) 


\section{LISTA DE TABELAS}

Tabela 2.1 Parâmetros utilizados para as curvas mostradas na Figura 2.14 usando a equação (2.11)

Tabela 2.2 Parâmetros da equação (2.12) ajustados a partir de resultados experimentais. Os valores em negrito representam as variações para cada categoria [Hoole et. al., 1999]......

Tabela 4.1 Etapas do procedimento de medição da higroexpansibilidade.

Tabela 5.1 Coordenadas espaciais $\left(x_{i}, y_{i}\right)$, freqüências características $\left(u_{i}, v_{i}\right)$, amplitudes relativas, distâncias entre fios longitudinais (MD) e transversais (CD), distâncias diagonais da tela formadora $\left(d_{i}\right)$ e ângulo de orientação $(\gamma)$, referentes aos picos destacados no espectro de Fourier da Figura 5.1(b).

Tabela 5.2 Parâmetros resultantes da análise de imagens de amostras de uma tela formadora, por meio da transformada de Fourier (2D-FFT), referente aos pontos 1 e 3 indicados na Figura 5.1(b).

Tabela 5.3. Resultado dos perfis do encolhimento transversal (CD) relativo e absoluto, obtidos por meio de análise de imagens do papel. Velocidade da máquina de papel: $1256 \mathrm{~m} . \mathrm{min}^{-1}$. Largura da folha: $5278 \mathrm{~mm}$.

Tabela 5.4 Resultados das medições de higroexpansibilidade transversal (CD) realizadas nas amostras coletadas ao longo da largura da folha de papel.

Tabela 5.5 Resultado dos perfis do encolhimento transversal (CD) relativo e absoluto, obtidos por meio de análise de imagens do papel. Velocidade da máquina de papel: $1362 \mathrm{~m} . \mathrm{min}^{-1}$. Largura da folha: $5300 \mathrm{~mm}$.

Tabela A.1 Resultados de medições de propriedades realizadas em amostras de papel reprográfico de 75 g.m ${ }^{-2}$, utilizado neste trabalho, referente à produção com velocidade de máquina de $1256 \mathrm{~m} \cdot \mathrm{min}^{-1}$ e largura do papel na enroladeira de $5278 \mathrm{~mm}$ [Mendes, 2006].

Tabela B.1. Resultados de medições de propriedades realizadas em amostras de papel reprográfico de $75 \mathrm{~g} . \mathrm{m}^{-2}$, utilizado neste trabalho, referente à produção com velocidade de máquina de $1362 \mathrm{~m} \cdot \mathrm{min}^{-1}$ e largura do papel na enroladeira de $5300 \mathrm{~mm}$

Tabela D.1 Características técnicas de telas formadoras de tripla-laje (TL), estilo SSB, comumente utilizadas em formadores de tela dupla do tipo Gap Formers. 


\section{SUMÁRIO}

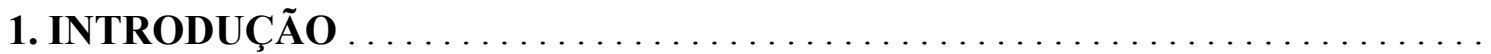

1.1. Papel reprográfico: produção e requisitos de qualidade $\ldots \ldots \ldots \ldots \ldots \ldots \ldots \ldots \ldots$

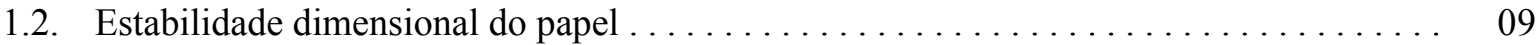

1.3. Alterações dimensionais na estrutura do papel durante a fabricação . . . . . . . . . 12

1.4. O perfil do encolhimento transversal (CD) e a caracterização do papel . . . . . . . . . . 14

\section{O ENCOLHIMENTO DO PAPEL DURANTE A SECAGEM E SEU IMPACTO SOBRE A QUALIDADE DO PRODUTO FINAL}

2.1. Encolhimento do papel durante a operação de secagem $\ldots \ldots \ldots \ldots \ldots \ldots \ldots \ldots \ldots$

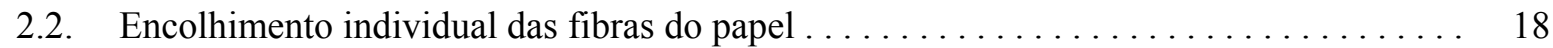

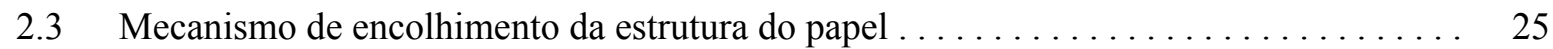

2.4. O perfil de encolhimento transversal do papel $\ldots \ldots \ldots \ldots \ldots \ldots \ldots \ldots \ldots \ldots \ldots$

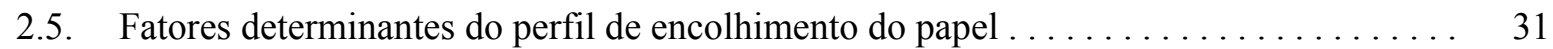

2.5.1. Configuração da seção de secagem da máquina de papel . . . . . . . . . . . . . . 31

2.5.2. Geometria do passe entre os cilindros secadores . . . . . . . . . . . . . . 34

2.5.3. Condições operacionais da máquina de papel . . . . . . . . . . . . . . . . 39

2.6. Técnicas para medição do perfil do encolhimento transversal (CD) do papel . . . . . . 43

2.7. Efeitos do encolhimento sobre as propriedades do papel . . . . . . . . . . . . . . . 49

2.8. Efeito do encolhimento sobre a estabilidade dimensional do papel $\ldots \ldots \ldots \ldots \ldots \ldots$

2.8.1. A higroexpansibilidade do papel........................ 51

2.8.2. Efeito do encolhimento na higroexpansibilidade do papel............. 53

3. APLICAÇÃO DE ANÁLISE DE IMAGEM EM DIAGNÓSTICOS DO PAPEL . .

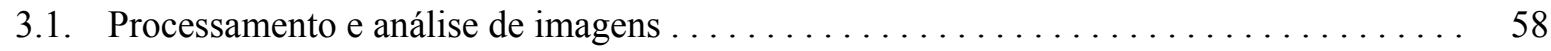

3.2. Utilização da Análise de Imagem na industria de papel e celulose $\ldots \ldots \ldots \ldots \ldots \ldots$. . 59

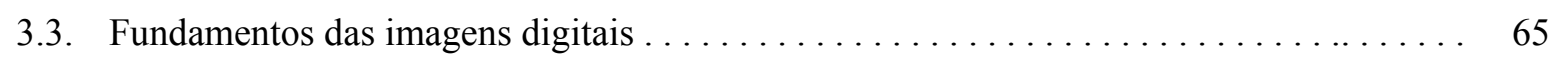

3.3.1. Aquisição de imagens . . . . . . . . . . . . . . . . . . . . . . . . . . . . 65

3.3.2. Amostragem e quantização de imagens ....................... 69

3.3.3. Representação das imagens digitais . . . . . . . . . . . . . . . . . . 71

3.4. Transformadas de Fourier . . . . . . . . . . . . . . . . . . . . . . . . . . . 74

3.4.1. Transformada de Fourier de funções com duas variáveis contínuas . . . . . . . . . 77 
3.4.2. Interpretação unidimensional da transformada bidimensional. ............ 78

3.4.3. Amostragem em duas direções e o teorema da amostragem bidimensional . . . . 79

3.4.4. Transformada bidimensional discreta de Fourier $(2 D-D F T) \ldots \ldots \ldots \ldots \ldots . . \ldots 1$

3.4.5. Algumas propriedades da transformada discreta de Fourier (2D-DFT) . . . . 82

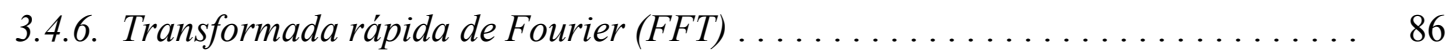

3.4.7. Visualização e interpretação da $2 D-F F T \ldots \ldots \ldots \ldots \ldots \ldots \ldots \ldots \ldots . \ldots . \ldots . \ldots . \ldots 7$

3.5. Identificação de marcas periódicas no papel $\quad 91$

3.5.1. Marcas das vestimentas da máquina de papel .................. 91

3.5.2. Telas formadoras para máquinas de papel. ................... 92

3.5.3. Identificação de marcas de telas formadoras . . . . . . . . . . . . . . . . 105

3.5.4. Aspectos geométricos de marcas produzidas por telas formadoras aplicados na determinação do encolhimento transversal (CD) do papel. ............ 108

3.5.5. Relação entre as dimensões das marcas das telas formadoras no domínio espacial e no domínio de freqüências no espectro de Fourier. . . . . . . . . . . 114

\section{MEDIÇÃO E CORRELAÇÃO ENTRE OS PERFIS DO ENCOLHIMENTO E}

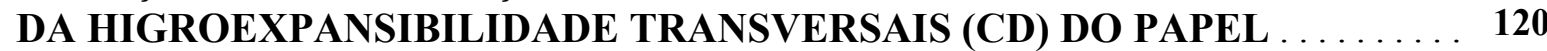

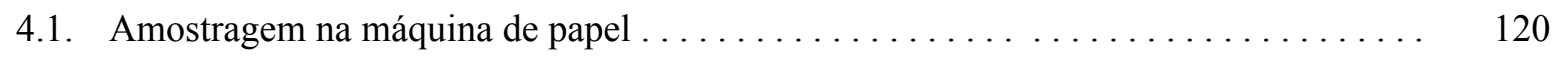

4.1.1. A máquina de papel ................................ 121

4.1.2. As amostras de papel ................................ 127

4.2. Determinação do perfil de encolhimento transversal (CD) do papel . . . . . . . . . . . 129

4.2.1. Estação de trabalho para aquisição, processamento e análise de imagem para computação do perfil do encolhimento transversal (CD) do papel. . . . . . . . 130

4.2.2. Digitalização das amostras de papel. ..................... 131

4.2.3. Processamento das imagens das amostras de papel pela transformadas de

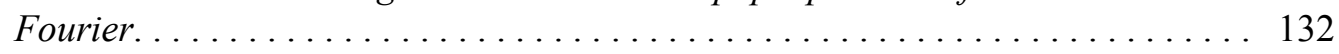

4.2.4. Determinação do encolhimento transversal (CD) médio do papel. . . . . . . . 138

4.2.5. Determinação do perfil do encolhimento transversal (CD) diferencial do papel. . 139

4.3. Determinação da higroexpansibilidade do papel. ...................... 148

4.3.1. O higroexpansimetro laboratorial ............................ 149

4.3.2. Medição da higroexpansibilidade do papel ........ . . . . . . . . . . . . 149

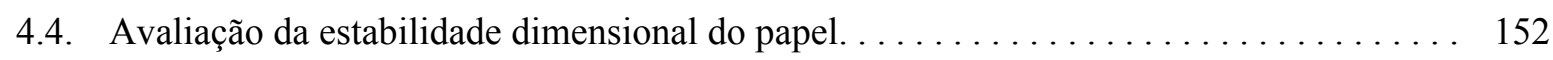

4.4.1. Análise gráfica e regressão linear . . . . . . . . . . . . . . . . . . . . . 152

\section{PERFIS TRANSVERSAIS RESULTANTES E A CORRELAÇÃO ENTRE} ENCOLHIMENTO E HIGROEXPANSIBILIDADE DO PAPEL . . . . . . . . . . .

5.1. Espectro de Fourier característico de uma tela formadora de três camadas 
5.1.1. Uniformidade estrutural da tela formadora ....................... 160

5.2. Imagens digitalizadas das amostras de papel $\ldots \ldots \ldots \ldots \ldots \ldots \ldots \ldots \ldots \ldots \ldots \ldots$

5.3. Processamento das imagens pela transformada rápida de Fourier (2D-FFT) . . . . . . 161

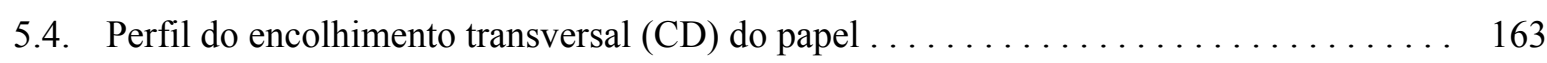

5.5. Perfil da higroexpansibilidade transversal (CD) do papel . . . . . . . . . . . . . . . 169

5.6. Correlação entre encolhimento e higroexpansibilidade transversais (CD) . . . . . . . . 170

5.7. Medição do encolhimento transversal (CD) do papel na largura total da máquina ..... 171

\section{CONSIDERAÇÕES SOBRE O MÉTODO DE DIAGNÓSTICO DA}

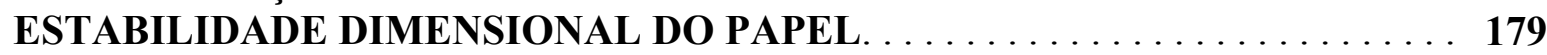

6.1. Encolhimento e higroexpansibilidade (estabilidade dimensional) do papel . . . . . . . . 179

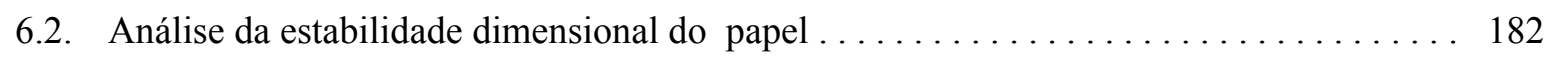

6.3. Diagnóstico de estabilidade dimensional de papel por análise de imagem . . . . . . . . 184

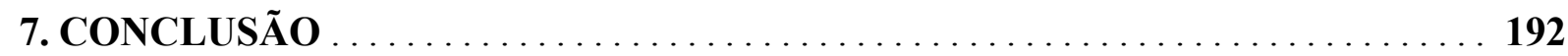

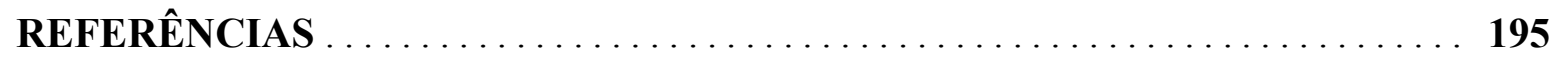

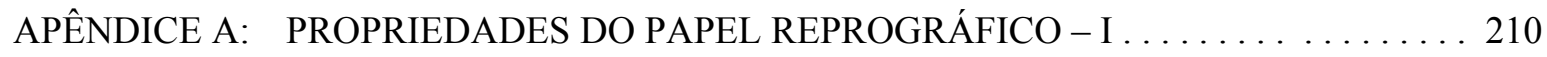

APÊNDICE B: PROPRIEDADES DO PAPEL REPROGRÁFICO - II . . . . . . . . . . . 212

APÊNDICE C: PROGRAMA DE ANÁLISE DE IMAGEM . . . . . . . . . . . . . 214

APÊNDICE D: DADOS ESTRUTURAIS DE TELAS FORMADORAS DE TRIPLA

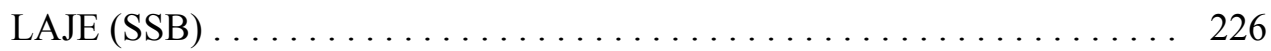

APÊNDICE E: PROCEDIMENTO INDUSTRIAL PARA MEDIÇÃO DO PERFIL DE ENCOLHIMENTO TRANSVERSAL (CD) DO PAPEL . . . . . . . . . . 229

APÊNDICE F: SELEÇÃO DA RESOLUÇÃO DE IMAGEM PARA DETECÇÃO DE MARCAS DE TELAS FORMADORAS . . . . . . . . . . . . . . 239

APÊNDICE G: CONDIÇÕES TÍPICAS DE OPERAÇÃO DA MÁQUINA DE PAPEL

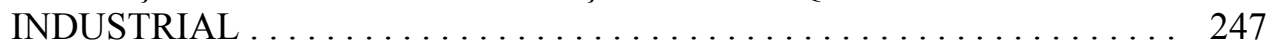




\section{CAPÍTULO 1}

\section{INTRODUÇÃO}

A estabilidade dimensional é de primordial importância tecnológica para os papéis utilizados em processos de impressão, em operações de conversão ${ }^{1}$ e nas demais aplicações ou situações em que o papel esteja sujeito a variações de teor de umidade. Esta propriedade, inerente ao processo de fabricação do papel, determina seu desempenho funcional no pósprocessamento ou no uso final e estabelece o comportamento dimensional dos produtos derivados do papel. A deficiência de estabilidade dimensional pode afetar, direta ou indiretamente, a capacidade de produção das impressoras gráficas industriais, a qualidade de impressão e a funcionalidade do papel nas máquinas copiadoras usadas para duplicação de documentos e em impressoras comerciais (e.g., impressoras a jato de tinta e impressoras do tipo laser).

O interesse pela estabilidade dimensional se renova continuamente, especialmente quando se refere a papéis usados na área de comunicação e nos produtos para embalagem. Embora o encanoamento e a dilatação do papel ainda constituam os principais problemas associados a esta propriedade, os requisitos atuais de qualidade extrapolam estes aspectos tradicionais da estabilidade dimensional, fator que pode significar grande barreira para o desenvolvimento de novos produtos. No âmbito dos papéis inseridos nos mercados de commodities, tais como o papel imprensa (newsprint) e o papel reprográfico (copy paper), as tendências contínuas em direção ao aumento das velocidades operacionais das máquinas de papel e as demandas crescentes por altas eficiências de produção nas impressoras industriais, determinam desafios mais rigorosos ao controle da estabilidade dimensional. Portanto, a utilização de técnicas de diagnóstico de estabilidade dimensional do papel, em conjunto com os fatores que interferem nesta propriedade, torna-se essencial para novos desenvolvimentos, especialmente na área de produtos mais especializados, bem como para direcionar ajustes em parâmetros de processo, não apenas no contexto da preparação da pasta, mas igualmente naqueles ligados às operações na máquina de papel, visando uma produção mais eficiente e econômica.

\footnotetext{
${ }^{1}$ As operações de conversão compreendem processos de transformação do papel, tais como: revestimento, redução de tamanho, super-calandragem, laminação e impregnação [Waterhouse, 1985].
} 


\section{Objetivo}

O objetivo deste trabalho é apresentar uma metodologia factivel para avaliação da estabilidade dimensional de papel reprográfico destinado ao uso final, por meio da medição do perfil do encolhimento transversal (CD) diferencial, utilizando técnicas de processamento e análise de imagem, a fim de detectar marcas periódicas (da tela formadora ${ }^{2}$ ) existentes na estrutura do papel. O método apresentado baseia-se em protocolos simplificados de amostragem e medição, que permitem fácil implantação nos ambientes industriais das fábricas de papel. Adicionalmente, a análise dos resultados providos por este método de diagnóstico pode ser utilizada para estabelecer ações que visam ao controle e à melhoria da estabilidade dimensional do papel, por meio de ajustes em parâmetros operacionais no processo de fabricação e considerações sobre a configuração da máquina de papel.

A ênfase deste trabalho recai sobre a avaliação da estabilidade dimensional diferencial de papel reprográfico, fabricado em máquina comercial de alta velocidade, considerando efeitos do encolhimento da folha, decorrente da operação de secagem, sobre as propriedades higroelásticas do produto final, particularmente sobre a higroexpansibilidade ${ }^{3}$ do papel e sua variação ao longo da direção transversal da máquina. Esta propriedade, tida como o principal indicador da estabilidade dimensional, encontra-se diretamente correlacionada com o grau de encolhimento sofrido pelo papel na etapa de secagem. Desta forma, do perfil do encolhimento transversal $(\mathrm{CD})^{4}$ do papel acabado, podem-se retirar importantes informações para avaliação da estabilidade dimensional através da largura total da folha de papel.

A técnica de análise de imagem, conectada ao processamento digital pela aplicação da transformada rápida bidimensional de Fourier $\left(2 \mathrm{D}-\mathrm{FFT}^{5}\right)$, tem sido freqüentemente usada para

\footnotetext{
${ }^{2}$ A tela formadora é utilizada no formador da máquina de papel, a fim de servir como suporte plano e meio filtrante para desaguamento da massa de papel (ver Figura 4.2).

${ }^{3}$ Propriedade responsável por modificações dimensionais do papel em conseqüência de variações no seu teor de umidade, determinada de acordo com a norma ISO 8226-1 [International Organization for Standardization, 1994].

${ }^{4}$ As propriedades do papel são avaliadas em duas direções principais, i.e., na direção longitudinal ou MD (coincidente com a direção de fabricação do papel, também denominada direção longitudinal da máquina) e na direção transversal ou $\mathrm{CD}$ (coincidente com a direção perpendicular à direção de fabricação do papel, também denominada direção transversal da máquina). Os perfis das propriedades do papel podem ser determinados para pontos localizados através das duas direções da máquina, para representar o comportamento das propriedades na direção de interesse. Desta forma, um perfil transversal de encolhimento CD tem o significado de representar o comportamento da propriedade através da direção transversal da máquina ou da folha de papel. Este critério será mantido doravante para as indicações encontradas neste trabalho.

${ }^{5}$ Transformada rápida bidimensional de Fourier (two-dimensional Fast Fourier Transform).
} 
diagnóstico e pesquisa no campo da ciência do papel e celulose. Mais recentemente, sua aplicação tem evidenciado de forma marcante que a análise de imagem pode prover respostas em termos quantitativos para várias questões referentes à estrutura e às propriedades funcionais das fibras celulósicas e do papel. A avaliação da estabilidade dimensional diferencial do papel por meio do perfil do encolhimento transversal (CD) é, certamente, um campo de aplicação em que a técnica de análise de imagem oferece vantagens notáveis. Assim, parte da metodologia desenvolvida neste estudo foi direcionada ao estabelecimento de rotinas de trabalho para amostragem, aquisição de imagens digitais e definição de técnicas de análise de imagem adequadas para o levantamento do perfil do encolhimento transversal (CD) do papel.

\section{Motivação}

O processo de avaliação da estabilidade dimensional do papel, ao longo do tempo, empregou diversos tipos e estratégias de medição, tais como variação de teor de umidade [Gallay, 1973], contração térmica [Watanabe; Sawa; Abe, 1991], alongamento transversal [Wadhams et al.,1991], encolhimento, expansão úmida, encanoamento [Uesaka,2002] e, mais recentemente, por meio da higroexpansibilidade [Salmén; Fellers; Htun, 1985, Salmén et al., 1987, Uesaka; Moss; Nanri, 1992, Uesaka, 2002].

A higroexpansibilidade do papel, em particular, tem sido utilizada com mais freqüência como índice indicativo da estabilidade dimensional, em função da boa correlação com o encolhimento do papel durante a fase de secagem [Pulkowski, 1991; Uesaka; Moss; Nanri, 1992, Wedel; Mendes, 1992]. A metodologia usual para a medição desta propriedade consiste na determinação da higroexpansão do papel $^{6}$, para uma dada variação da umidade relativa do ambiente [Kajanto; Niskanen, 1998]. Este procedimento exige uso de equipamentos específicos ${ }^{7}$ (importados e de elevado custo), requer operadores especializados e demanda grande consumo de tempo, para preparação, monitoramento, execução e registro de dados durante os ensaios, a fim de permitir o cálculo do índice de higroexpansibilidade.

\footnotetext{
${ }^{6}$ Os procedimentos para determinação do índice de higroexpansibilidade são definidos em normas técnicas, e.g., ISO 8226-1 [International Organization for Standardization, 1994], SCAN-P 28:88 [Scandinavian Pulp, Paper and Board Testing Committee, 1988] e UM 549 [Technical Association of the Pulp and Paper Industry, 1991].

${ }^{7}$ Citam-se alguns exemplos de equipamentos automatizados, tais como o VARIDIM Dimensional Stability Analyser (TECHPAP, França), o emcoNDT 100 Hygroexpansivity Tester (emco Elektonische Me $\beta$ u.Steuerungstechnik GmbH, Alemanha, o INNVENTIA Hygroexpansivity Tester (INVENNTIA AB, Suécia) e o OPTDIM (STFI-Packforsk, atualmente INVENNTIA AB, Suécia).
} 
Tais demandas significam grande limitação para utilização destes equipamentos nas fábricas de papel do Brasil, as quais, não dispondo de equipamentos apropriados, são forçadas a buscar suporte externo (em geral em instituições de ensino ou de pesquisa, muitas vezes no exterior), para avaliações mais precisas, quando enfrentam situações de perda de qualidade do produto, provenientes de deficiência de estabilidade dimensional do papel. Em casos particulares, em que mesmo havendo na fábrica algum equipamento de medição, geralmente com versão mais antiga, não automatizada, as limitações para execução dos ensaios em tais aparelhos, transformam o teste de higroexpansibilidade e a correspondente avaliação de estabilidade dimensional em atividades menos priorizadas [ $c f$. Almeida (informação pessoal) ${ }^{8}$ ].

A metodologia apresentada neste trabalho surge, então, como alternativa para facilitar a avaliação da estabilidade dimensional diferencial do papel, na direção transversal da máquina, mesmo nas fábricas em que há limitações de recursos. Assim, onde tradicionalmente as ações de melhoria têm caráter corretivo e são tomadas somente depois do emprego do papel nos processos subseqüentes à fabricação (são comumente disparadas por realimentação provocada pelas reclamações e reivindicações do usuário final, após a consolidação de perdas de produto ou de eficiência de máquina) pode ter lugar uma nova prática de cunho preventivo, que permite ao fabricante de papel melhorar a caracterização da estabilidade dimensional diferencial do produto fabricado, antes da sua remessa aos consumidores finais. Esta perspectiva abre também novos rumos para o aperfeiçoamento das atividades de assistência técnica, conferindo ao fabricante, a priori, subsídios importantes e necessários para uma análise mais apropriada de desempenho do papel nas diversas aplicações a que se destina, in loco, diretamente no processo final de uso do papel.

Adicionalmente, a medição do perfil do encolhimento transversal (CD) diferencial, que constitui etapa integrante do método de diagnóstico da estabilidade dimensional apresentado nesta tese, representa uma prática extremamente incomum nas fabricas de papel no Brasil, certamente por falta de métodos apropriados e de fácil realização, e oferece, com vantagens, possibilidade de superação de antigos métodos de medição desta característica, em que se utilizaram diferentes práticas de marcação da folha de papel no extremo úmido, que se

\footnotetext{
${ }^{8}$ Informação fornecida por Almeida, L.F., em correspondência com o autor deste trabalho, onde comenta caso específico de utilização de higroexpansímetro manual, em fábrica de papel, ressaltando que “...não era um ensaio rápido e muito menos automático. Dependia de um laboratorista acompanhando o instrumento a intervalos regulares e demandava tempo. Por este motivo não o usávamos com muita freqüência.”.
} 
seguiam de laboriosa medição no papel acabado, significando sempre um método demorado e de baixa resolução.

No método agora apresentado, a simplicidade dos protocolos de amostragem, de medição e análise, bem como dos equipamentos envolvidos representam os pontos-chave de maior interesse para sua implantação nas fábricas de papel. Além dos mencionados avanços na caracterização do produto fabricado, oferece também oportunidades para elaboração de ações específicas, voltadas para a melhoria de qualidade.

\section{Estrutura da tese}

\section{Introdução}

Neste capítulo introdutório, apresentam-se, de forma concisa, aspectos sobre a produção e as propriedades requeridas para os papéis destinados à reprografia e usos afins, a conceituação da estabilidade dimensional e fatores de controle e as alterações dimensionais na estrutura do papel determinadas durante de fabricação em máquinas industriais para, finalmente, introduzir o perfil do encolhimento transversal (CD) como elemento constitutivo para a caracterização de qualidade do papel.

\section{Revisão da literatura}

No capítulo 2, encontra-se uma revisão das publicações mais relevantes que tratam do fenômeno de encolhimento do papel durante a operação de secagem em máquinas industriais e seu impacto na qualidade do produto final. A seção foi organizada para apresentar informações relacionadas ao mecanismo de encolhimento do papel, observado no nível das fibras celulósicas e na sua transmissão para a rede de fibras que compõe o papel, enfatizando a formação do perfil transversal, os fatores que determinam sua intensidade e forma, as técnicas já utilizadas para sua medição e, ao final, sua influência sobre várias propriedades do papel e, especificamente, sobre a estabilidade dimensional.

O capítulo 3 apresenta, inicialmente, dados da literatura sobre a aplicação de técnicas de análise de imagem em diagnósticos do papel, abordando os objetivos desta prática, sua aplicação na indústria de papel e celulose, os fundamentos das imagens digitais e do 
processamento das imagens pela transformada de Fourier, para então convergir para temas relativos ao uso destas ferramentas na identificação de marcas periódicas contidas no papel, e em particular, daquelas produzidas por telas formadoras, usadas na medição do perfil de encolhimento transversal (CD).

\section{Materiais e métodos}

O capítulo 4 descreve o método adotado para diagnóstico a estabilidade dimensional, que consistiu inicialmente na medição dos perfis de encolhimento, utilizando técnicas de análise de imagem, e da higroexpansibilidade transversais (CD) do papel, a fim de determinar a correlação entre estes dois parâmetros, que representa o fator chave para futuras avaliações da estabilidade dimensional ao longo da largura da folha, por meio do encolhimento transversal (CD) diferencial do papel.

\section{Resultados e discussão}

O capítulo 5 mostra os resultados obtidos na medição dos perfis transversais de encolhimento e da higroexpansibilidade transversais (CD), através da largura da folha de papel, a partir de amostras coletadas em uma bobina "jumbo" e na determinação da correlação entre as duas propriedades.

O capítulo 6 foi dedicado à discussão dos resultados encontrados para os perfis de encolhimento e higroexpansibilidade transversais (CD) e análise da correlação entre estas propriedades, a fim de validar o método empregado e, principalmente, da sua adequação para a avaliação da estabilidade dimensional transversal (CD) do papel. Discute-se também um perfil do encolhimento transversal (CD) obtido de amostra com a largura total da máquina e a correspondente avaliação de estabilidade dimensional.

\section{Conclusão}

O capítulo 7 contém conclusões e comentários finais sobre a avaliação da estabilidade dimensional de papel reprográfico, apresentando também considerações sobre potenciais interferências no processo de fabricação para seu controle e esclarecimentos acerca das contribuições oferecidas pelo presente trabalho e para estudos complementares. 


\section{Trabalhos e publicações decorrentes desta tese}

Os estudos concernentes aos temas desenvolvidos na presente tese propiciaram a produção de trabalhos para congressos técnicos e científicos e de artigos para publicação em periódicos ligados ao setor de celulose e papel:

- A.H.T. Mendes, S.W.Park, P.J.T.Ferreira, F.S.Almeida. Higroexpansibilidade de papel reprográfico produzido com fibras de eucalipto: Parte 1 - Princípios de medição de higroexpansibilidade. ABTCP-ZELLCHEMING 2007: 40 Congresso e Exposição Internacional de Celulose e Papel, São Paulo.

- A.H.T. Mendes, S.W.Park, P.J.T.Ferreira, F.S.Almeida. Higroexpansibilidade de papel reprográfico produzido com fibras de eucalipto: Parte 2 - Variação na direção longitudinal da máquina. ABTCP-ZELLCHEMING 2007: 40 Congresso e Exposição Internacional de Celulose e Papel, São Paulo.

- A.H.T. Mendes, S.W.Park, P.J.T.Ferreira, F.S.Almeida. Higroexpansibilidade de papel reprográfico produzido com fibras de eucalipto: Parte 3 - Variação na direção transversal da máquina. ABTCP-ZELLCHEMING 2007: 40 Congresso e Exposição Internacional de Celulose e Papel, São Paulo, Brasil.

- A.H.T. Mendes, S.W.Park, F.S.Almeida, P.J.T.Ferreira. Características do papel reprográfico produzido com fibras de eucalipto e suas relações com a estabilidade dimensional. CIADICYP 2008: V Latin American Congress of Research in Cellulose and Paper, Guadalajara, México.

- A.H.T. Mendes, S.W.Park, P.J.T.Ferreira, F.S.Almeida. Hygroexpansivity of reprographic paper manufactured from eucalyptus fibers - measurement principles and results from an industrial paper machine. ACOTEPAC 2009: XVII Congresso Internacional, Cali, Colombia.

- A.H.T. Mendes, S.W.Park, H.Y.Kim. Determinação do perfil de encolhimento transversal na estrutura do papel. ABTCP-PI 2009, 42 Congresso e Exposição Internacional de Celulose e Papel, São Paulo, Brasil.

- A.H.T. Mendes, S.W.Park, H.Y.Kim. A importância da medição do encolhimento transversal (CD) diferencial do papel. ABTCP-TAPPI 2010: $43^{\circ}$ Congresso e Exposição Internacional de Celulose e Papel, São Paulo, Brasil.

- A.H.T. Mendes, S.W.Park, P.J.T.Ferreira, F.S.Almeida. Higroexpansibilidade $e$ estabilidade dimensional em uma máquina de papel reprográfico. CIADICYP 2010: XXI Encontro Nacional Tecnicelpa / VI Ciadicyp, Lisboa, Portugal.

- A.H.T. Mendes, H.Y.Kim, S.W.Park. Aplicação de análise de imagem para avaliação da estabilidade dimensional de papel reprográfico produzido com fibras curtas. CIADICYP 2010: XXI Encontro Nacional Tecnicelpa / VI Ciadicyp, Lisboa, Portugal. 
- A.H.T. Mendes, S.W.Park, H.Y.Kim. Medição do encolhimento transversal (CD) diferencial para avaliação de qualidade do papel. ACOTEPAC 2011: XX Congresso Internacional, Cali, Colombia.

- A.H.T. Mendes, S.W.Park, F.S.Almeida, P.J.T.Ferreira. Características do papel reprográfico produzido com fibras de eucalipto e suas relações com a estabilidade dimensional. O Papel, vol.71, n.8, p.63-73, ago. 2010.

- A.H.T. Mendes, S.W.Park, F.S.Almeida, P.J.T.Ferreira. Hygroexpansivity profiles in a commercial paper machine. Nordic Pulp and Paper Research Journal. Submetido em 08 nov. 2010 (em processo de revisão).

- A.H.T. Mendes, H.Y.Kim, P.J.T.Ferreira, S.W.Park. The importance of the measurement of paper differential CD shrinkage. Tappi Journal. Submetido em 12 nov. 2010 (em processo de revisão).

\subsection{Papel reprográfico: produção e requisitos de qualidade}

As estatísticas industriais do setor papeleiro mostram que a fabricação de produtos do tipo imprimir e escrever representa uma parcela significativa da produção brasileira. Em 2009, a manufatura de papéis desta categoria correspondeu a 29,2\% da produção total de papel e cartão no Brasil, ocupando a segunda posição na produção nacional, totalizando 2.750.049 toneladas produzidas ${ }^{9}$ [BRACELPA, 2010]. Fabricados predominantemente com pasta química branqueada de fibras de eucalipto, os papéis destinados à reprografia ${ }^{10}$ (copy papers) são enquadrados numa classe de produtos denominados papéis $W F U^{11}$ (wood free uncoated) ou offset ${ }^{12}$, que, no Brasil, representa $21,4 \%$ da produção total de papel e cartão [BRACELPA, 2010]. Fornecidos mais comumente em folhas cortadas para consumo final (cut-size paper), são utilizados em máquinas copiadoras, impressoras comercias e máquinas de cópias fac-símile (fax), bem como em outros processos de impressão sem impacto (e.g., impressoras de jato de tinta e impressoras do tipo laser). A gramatura deste tipo de papéis varia comumente de $70-90$ g.m ${ }^{-2}$, cujo índice de brancura padrão ISO encontra-se na faixa de $80-96 \%$. A maior parte destes papéis é fabricada com fibras virgens, porém podendo

\footnotetext{
${ }^{9}$ Inclui a produção de papel imprensa, que embora destinado principalmente à impressão, tem suas estatísticas, em geral, calculadas separadamente.

10 Conjunto de técnicas que permitem reproduzir um documento. O processo também é denominado de xerografia ou eletro-fotografia [Oittinen; Saarelma, 1998].

${ }^{11}$ Os papéis $W F U$ ou offset são fabricados sem revestimento, com $90-100 \%$ de pasta química, ou seja, isento ou contendo apenas pequena parcela de pasta mecânica na composição (em geral, $<10 \%$ ).

${ }^{12}$ Os papéis offset ou $W F U$ se destinam a livros e manuais, catálogos, revistas, mala direta, envelopes, formatos comerciais e, em maior quantidade, cortados em folhas (cut-size) nos formatos carta, ofício, A3 e A4 mais comumente. Este tipo de papel é acabado em máquina, recebendo tratamento superficial com amido.
} 
conter fibras recuperadas, desde pequenas quantidades até a totalidade da composição [Haarla, 2000], no caso de tipos especiais de papéis reciclados.

Os papéis reprográficos requerem propriedades estruturais, mecânicas, térmicas, ópticas e elétricas específicas, a fim de permitir um desempenho adequado na sua utilização final. Este tipo de papel requer, e.g., uma alta resistência ao calor e uma condição química superficial compatível, a fim de suportar as condições térmicas da fusão do toner e garantir sua correta adesão sobre o papel, em processos de reprodução ou de impressão em máquinas copiadoras e impressoras laser. Adicionalmente, outras características de extrema importância para este tipo de papel se referem à habilidade de ser deslocado através das copiadoras e impressoras sem dificuldades e possuir estabilidade dimensional superior, i.e., sem apresentar deformações higroscópicas, tais como encanoamento, enrugamento, ondulações superficiais e higroexpansão. A contínua demanda por melhores níveis de qualidade do papel usado em reprografia e impressão offset, bem como a exigência de alta eficiência (runnability) nas máquinas de conversão e nas impressoras gráficas industriais de alta velocidade têm colocado em destaque na indústria de papel, a busca por melhores padrões de estabilidade dimensional e por meios de controle de produção mais rígidos, dados os persistentes e recorrentes problemas causados pela falta desta propriedade, que constituem uma das principais razões registradas para devolução de papel ao fabricante, por motivo de desvios em padrões de qualidade.

\subsection{Estabilidade dimensional do papel}

O termo estabilidade dimensional tem sido usado na indústria de papel e cartão, em vários contextos relacionados a fenômenos higroscópicos diversos, resultantes da variação do teor de umidade do papel, tais como encolhimento durante a secagem, higroexpansibilidade, encanoamento, enrugamento e ondulações superficiais, por exemplo.

Com sentido mais restrito, a estabilidade dimensional tem sido vista apenas como a habilidade do papel em manter suas dimensões físicas sem variação, mesmo se submetido a alterações de conteúdo de umidade. Desta maneira, estabelece-se uma relação imediata entre a estabilidade dimensional e a higroexpansibilidade do papel. Esta conceituação foi adotada em vários trabalhos sobre este tema. Casey [1961], quando abordou a estabilidade dimensional, mencionou que "a alteração que ocorre nas dimensões do papel, devido a mudanças no teor de 
umidade, é uma consideração importante no uso do papel”. Gallay [1973] considerou o termo “instabilidade dimensional" para relacionar variações de comprimento, largura e espessura da folha com alterações de teor de umidade do papel e citou o fenômeno de dilatação ou contração das fibras celulósicas em condições de maior ou menor teor de umidade, i.e., a higroexpansibilidade, como causa de eventual desenvolvimento não apenas de alterações dimensionais, mas também de outros mecanismos de deformação do papel, tais como encanoamento (curl), saliências superficiais $\left(\operatorname{cockles}{ }^{13}\right)$ e bordas onduladas. Kajanto e Niskanen [1998] se referiram à estabilidade dimensional por meio da indicação da variação do teor de umidade como causa de alteração nas dimensões e na forma da folha de papel. Boström [2001] menciona que esta particularidade, i.e., a estabilidade dimensional, tem sido tradicionalmente caracterizada como higroexpansão e calculada a partir do grau de alongamento de amostras, quando expostas a diferentes níveis de umidade relativa do ambiente. O mesmo conceito foi utilizado por outros autores, dentre os quais, podem ser citados Nordman [1958], Back e Klinga [1963a,b], Eklund [1969] e Gess e Wilson [2001].

Com percepção mais ampliada, o termo estabilidade dimensional foi associado a outros fenômenos, além da propriedade higroexpansiva do papel e, neste contexto, seu uso está relacionado a efeitos derivados da higroexpansibilidade. De acordo com esta abordagem, Uesaka [1991] considerou a higroexpansão, o encolhimento do papel durante a secagem, o encanoamento (curl), as rugas (wrinkles), as ondulações superficiais (cockles) e as bordas granulosas, entre outros, como diferentes manifestações de problemas relacionados à estabilidade dimensional. Scott e Abott [1995], em consideração sobre a influência do teor de umidade sobre as propriedades mecânicas e estruturais do papel, enumeram, como efeitos ligados à estabilidade dimensional, os fenômenos de expansão e contração, variação de espessura, ondulações, encanoamento, enrugamento e bordas esticadas ou onduladas. Da mesma maneira, encontra-se este enfoque mais abrangente nos trabalhos de Uesaka et al. [1989] e Nanri e Uesaka [1993].

A estabilidade dimensional é uma das características mais significativas para o desempenho do papel em operações de conversão e impressão, podendo se constituir na maior barreira para o desenvolvimento de novos produtos derivados do papel [Uesaka, 1991]. Na conversão, se torna aspecto relevante, pois a planicidade e a uniformidade da espessura do

\footnotetext{
${ }^{13} \mathrm{O}$ cockle é uma rugosidade em macro escala, circunscrita a uma região do papel, em forma de "morros e
} vales", causada por tensões induzidas na folha, ao longo do processo de formação e de secagem. 
papel são de interesse primordial. A deficiência na estabilidade dimensional está relacionada a diversos problemas encontrados na utilização do papel para impressão industrial, bem como para reprografia, pois estão sujeitos a alterações dimensionais causadas pela variação do teor de umidade. Casos típicos das dificuldades observadas na qualidade do papel e nos processos de impressão se referem, e.g., à perda de registro de impressão ou registro de cor $^{14}$ entre estações das impressoras off-set coloridas (devido às variações dimensionais do papel resultantes da absorção de água das blanquetas, cujo fenômeno se denomina hidroexpansibilidade ${ }^{15}$ ), ao encanoamento ou curl (em conseqüência da expansão ou contração não uniforme das camadas do papel), ao cockling (caracterizado por saliências que distorcem a planicidade do papel em posições aleatórias), à criação de bordas onduladas ou esticadas (comuns em situações em que existem diferenças de umidade relativa ou temperatura entre o local de estocagem e de uso do papel), que provocam tipicamente problemas de alimentação de papel em impressoras industriais e ao encolhimento assimétrico, provocado pela aplicação de altas temperaturas durante a fusão térmica do toner em máquinas copiadoras ou na secagem da tinta em impressoras gráficas comerciais.

De forma generalizada, verifica-se que certas limitações em padrões de qualidade, bem como dificuldades operacionais decorrentes de instabilidade dimensional, estão essencialmente conectados a deformações na estrutura do papel derivadas de alterações de teor de umidade, ou seja, do grau de higroexpansibilidade do papel. Vários fatores influenciam esta propriedade e, conseqüentemente, a estabilidade dimensional do papel. Scott e Abbott [1995] enumeraram variáveis ligadas à composição do papel (e.g., tipo de fibra, cargas minerais e aditivos), à preparação da pasta (refinação) e também ao processo de fabricação na máquina de papel (operações de formação, prensagem, secagem, calandragem e conversão). Além destes fatores, Casey [1966] menciona a influência da porosidade do papel e das condições de operação da máquina de papel na estabilidade dimensional. Uesaka [1991] se refere a aspectos de refinação, modificações químicas, falta de uniformidade e anisotropia das propriedades mecânicas e higrotérmicas e condições de operação da máquina de papel, associados à estabilidade dimensional, indicando efeitos da caixa de entrada, do formador, das prensas e dos secadores. Kajanto; Niskanen [1998] apresentam considerações quanto ao tipo

\footnotetext{
${ }^{14}$ Alinhamento necessário da área de impressão em todas as estações da impressora, a fim de evitar a distorção da imagem impressa.

15 Expressão usada para indicar variações dimensionais do papel, em virtude de alterações no teor de umidade causadas pela exposição à água na fase líquida, equivalendo-se ao termo higroexpansão, no caso de exposição à umidade do ar ambiente.
} 
de fibras e utilização de aditivos, na composição do papel, sobre a aplicação de amido interno e sobre os efeitos das operações de prensagem, secagem e calandragem. De forma similar, outros autores também reconhecem os efeitos das operações de fabricação sobre a estabilidade dimensional, dentre os quais, Gates e Kenworthy [1963], Setterholm e Chilson [1965], Setterholm e Kuenzi [1970], Shands e Genco [1988], Wedel [1989b], Pulkowiski [1991], Weise [1997] e MacGregor [2001].

A operação de secagem do papel por vaporização da água produz um dos mais importantes efeitos sobre a higroexpansibilidade do pape ${ }^{16}$, uma vez que esta propriedade depende do encolhimento transversal observado durante a secagem do papel. Estudos de Nordman [1958], Gates e Kenworthy [1965], Salmén et al. [1987], Wedel [1989a], por exemplo, mostraram a influência do encolhimento sobre a higroexpansibilidade do papel. Pulkowisky [1990; 1991] e, mais recentemente, Juppi e Kaihovirta [2002] e Constantino et al. [2005] também abordaram o tema e demonstraram efeitos da operação de secagem e das condições de operação da máquina sobre o encolhimento e outras propriedades do papel.

\subsection{Alterações dimensionais na estrutura do papel durante a fabricação}

No processo de fabricação em máquinas comerciais, as transformações estruturais que ocorrem durante a formação, prensagem e secagem causam importantes variações dimensionais no papel. Produzido a partir de uma suspensão muito diluída (composta por fibras celulósicas, cargas minerais, aditivos e água) que alimenta a caixa de entrada na seção de formação, o produto final se consolida em uma manta contínua, com alto teor de sólidos, com a qual se produzem bobinas, com grandes dimensões e peso, na enroladeira da máquina de papel. A intensidade das alterações dimensionais mencionadas pode apresentar diferenças significativas entre as bordas e a parte central da folha, sendo a redução na largura do papel, i.e., o encolhimento transversal (ou encolhimento $\mathrm{CD}$ ), especificamente, o parâmetro mais afetado. Tais deformações podem interferir de forma adversa na qualidade do produto final, pois, em geral, produzem distúrbios nos perfis transversais de várias propriedades do papel. $\mathrm{O}$ encolhimento que ocorre na seção de secagem corresponde à maior parte da deformação estrutural imposta ao papel durante a fabricação.

\footnotetext{
${ }^{16}$ A influência da operação de secagem sobre a higroexpansibilidade do papel está apresentada com detalhes na subseção 2.8.2.
} 
A secagem industrial do papel se realiza tradicionalmente pelo emprego de cilindros secadores aquecidos a vapor e dispostos em duas fileiras (two-tier drying). Este método, que utiliza múltiplos cilindros secadores, representa a forma mais comum de secagem de papéis de imprimir e escrever e cartões, embora novos métodos, e.g., baseados em insuflamento de ar quente e em secadores especiais com cinta metálica aquecida ${ }^{17}$, tenham sido concebidos e provados em aplicações comerciais. As seções de secagem formadas por cilindros secadores distribuídos em duas fileiras sobrepostas permaneceram praticamente sem alterações durante quase dois séculos, sendo por este motivo denominadas, mesmo atualmente, de seção de secagem "convencional". Neste tipo de configuração, o papel se desloca de cilindro a cilindro, através de percursos livres (i.e., trajetos sem suporte). A passagem do papel pela seção de secagem se faz com alternância de contato entre as superfícies do papel (inferior e superior) e as superfícies aquecidas dos cilindros secadores sucessivos.

Até o final da década de 1970, pouco ocorreu em relação ao desenvolvimento e modificações conceituais nas seções de secagem. Porém, as alterações situacionais do meio de produção e dos mercados de papel determinaram demandas e oportunidades para a melhoria no controle de qualidade. Nesse sentido, estudos produzidos para esclarecer o efeito da seção de secagem sobre as propriedades do papel tiveram início, em larga escala, na década de 1980, resultando em considerável desenvolvimento para o processo de secagem com cilindros secadores. O grande marco desta nova abordagem foi o advento da configuração de secadores dispostos em fileira única (single-tier drying), combinados com rolos de sucção a vácuo, usado na indústria a partir de 1985, aproximadamente. O novo arranjo proveu mais suporte para a folha de papel, melhorou a eficiência das máquinas e ofereceu mais restrição do encolhimento do papel durante a evaporação da água, produzindo vantagens na qualidade do produto final.

As condições de secagem influenciam a estabilidade dimensional do papel de diversas formas. A distribuição de tensões internas e deformações depende em grande parte do grau de restrição imposto ao encolhimento do papel durante a operação de secagem. Durante a evaporação de água, o papel tende a se contrair em todas as direções, sendo que o menor grau de encolhimento natural ocorre na direção da máxima orientação de fibras. As tensões resultantes internamente se desenvolvem ao longo da direção na qual a restrição ao

\footnotetext{
${ }^{17}$ Secador de alto desempenho, que utiliza cintas metálicas aquecidas para secagem de cartões e outros tipos de papéis de embalagem, desenvolvido pela Metso Paper Oy, Finlândia [Kiviranta et al., 2000, Fellers et al., 2003].
} 
encolhimento for aplicada. Sob condições típicas de secagem, o papel é submetido à restrição quase total ao encolhimento, ou até mesmo ligeiramente estirado, na direção longitudinal da máquina (MD). Tal retenção não ocorre com a mesma intensidade na direção transversal da máquina $(\mathrm{CD})$, de forma que certa liberdade para a contração transversal é provida ao papel nesta direção, destacadamente durante o percurso entre os componentes da seção de secadores (denominados open draws $^{18}$ ou passes abertos) sendo este mecanismo mais acentuado nas bordas que no centro da folha de papel. A exposição subseqüente do papel a ambientes com umidade relativa elevada provocará então, uma expansão maior na direção transversal (CD). Uma vez que o papel não pode encolher na direção longitudinal (MD), não ocorrerá expansão nesta direção quando exposto a umidades relativas elevadas, podendo até mesmo ocorrer uma ligeira contração (nos casos em que o papel foi submetido a estiramento nesta direção, durante a fase de secagem).

As intensidades das deformações que o papel experimenta com o aumento de conteúdo de umidade, quando exposto a altas umidades relativas, é proporcional à diferença de magnitude de forças que atuam em direções opostas: a) por um lado, encontram-se as tensões internas geradas pela restrição ao encolhimento que, uma vez relaxadas pelo aumento de umidade do papel, tendem a produzir contração na direção de atuação; b) na direção oposta é gerada uma força expansiva (i.e., higroexpansão), cuja tendência é produzir dilatação do papel. A distribuição das tensões e deformações no papel determina o nível de estabilidade dimensional diferencial, que varia com o tipo da seção de secagem utilizada. Configurações que ofereçam mais restrição ao encolhimento, e.g., secadores Yankee ${ }^{19}$, secadores dispostos em fileira única (single-tier drying ${ }^{20}$ ), produzirão melhor distribuição de encolhimento e conseqüentemente de estabilidade dimensional.

\subsection{O perfil do encolhimento transversal (CD) e a caracterização do papel}

Por muitas décadas, a seção de secagem foi utilizada apenas como um instrumento para retirar água do papel, sem nenhuma função adicional. Atualmente, este conceito foi

\footnotetext{
${ }^{18}$ Percurso entre os cilindros secadores em que o papel permanece sem suporte e livre de forças restritivas ao encolhimento transversal (ver subseção 2.5.1).

${ }^{19}$ Secadores de grande diâmetro, usualmente em torno de $5 \mathrm{~m}$, usados na secagem de papéis para fins sanitários. Neste caso, o papel permanece aderido ao secador durante a secagem e não sofre contração em nenhuma direção.

${ }^{20}$ Arranjo de secadores em que o papel é totalmente suportado pelos secadores e telas secadoras, durante sua passagem pela seção de secagem, sendo submetido a maior nível de restrição ao encolhimento transversal (ver subseção 2.5.1).
} 
superado, dando lugar ao reconhecimento da extrema importância desta operação para o controle de qualidade do papel produzido.

O conhecimento detalhado do perfil transversal do encolhimento CD tornou-se essencial para a caracterização do papel produzido e para a análise do seu potencial de qualidade, pois é específico para cada condição de produção. $\mathrm{O}$ encolhimento $\mathrm{CD}$ em cada ponto através da folha de papel depende da distância do ponto considerado até as bordas do papel e, também, da configuração geométrica do percurso entre os componentes da seção de secadores, i.e., da relação entre sua largura e o comprimento efetivo e das condições de operação da máquina de papel [Wahlström et al., 1999; Phillips; I'Anson; Hoole, 2002; Wahlström; Lif, 2003; Constantino; I'Anson; Simpson, 2005]. O levantamento do perfil real do encolhimento $\mathrm{CD}$ e da sua forma característica (prática atualmente incomum nas fábricas de papel) traz o benefício de tornar possíveis certas verificações sobre a extensão do efeito do encolhimento higroscópico em diversas propriedades do papel produzido, e.g., sobre a higroexpansibilidade e conseqüente estabilidade dimensional. $\mathrm{O}$ aprofundamento da análise em torno do perfil transversal real do encolhimento CD pode viabilizar a determinação de ações de investigação com o objetivo de buscar alternativas para tratar os fatores que determinam a acuidade do perfil mencionado, a saber, verificar qualitativamente e quantitativamente como ajustes em parâmetros de produção e de processo, e.g., composição do papel, orientação de fibras, passe ${ }^{21}$ entre prensas úmidas e secagem, gramatura, restrição ao encolhimento na seção de secagem, e até mesmo modificações na configuração da seção de secagem, podem melhorar aspectos de qualidade do papel produzido, de eficiência de produção da máquina de papel (runnability) em altas velocidades e de maximização da largura do papel na enroladeira, o que pode significar melhores possibilidades de conjugação de formatos na rebobinadeira.

O papel selecionado para este trabalho foi produzido, em máquina industrial, à velocidades operacionais de $1256 \mathrm{~m} \cdot \mathrm{min}^{-1}$ e $1362 \mathrm{~m} \cdot \mathrm{min}^{-1}$, a partir de pasta branqueada de fibras virgens de eucalipto, com gramatura nominal de 75 g.m $\mathrm{m}^{-2}$ e largura na enroladeira de $5278 \mathrm{~mm}$ e $5300 \mathrm{~mm}$, respectivamente. A avaliação da estabilidade dimensional foi realizada pela análise do perfil do encolhimento transversal (CD), encontrado entre o lado de comando (LC) e lado de acionamento (LA) da máquina de papel, usando amostras coletadas de uma

\footnotetext{
${ }^{21}$ Diferença de velocidade imposta entre a seção de prensas e a de secagem a fim de produzir a tensão necessária para manter o papel adequadamente esticado nesta passagem entre seções da máquina.
} 
bobina "jumbo ${ }^{22 \%}$. Os resultados obtidos na determinação do perfil de encolhimento transversal (CD) associados aos encontrados para a higroexpansibilidade, em pontos coincidentes, demonstraram a validade do método para examinar o potencial de estabilidade dimensional diferencial do papel. O método de avaliação apresentado oferece vantagens em relação às tradicionais formas de medição da higroexpansibilidade do papel, as quais requerem considerável trabalho de preparação de amostras e realização de ensaios de difícil e demorada execução. Ao contrário, o método apresentado permite sua implementação no ambiente industrial de forma prática, a partir da geração de imagens por um digitalizador convencional de mesa e processamento / análise de imagem executada por meio de algoritmo específico - elaborado com recursos disponíveis na caixa de ferramentas $\left(I P T^{23}\right)$ do programa $M A T L A B^{\circledR 24}$, suportadas pela aplicação da transformada discreta bidimensional de Fourier $\left(2 \mathrm{D}-\mathrm{DFT}^{25}\right)$, na versão especializada para cálculo computacional, a transformada rápida bidimensional de Fourier (2D-FFT ${ }^{26}$ ) - com características de maior tolerância e simplicidade para os protocolos de amostragem e de análise mais independente do operador, sem prejuízo para a precisão do processo.

\footnotetext{
${ }^{22}$ Denominação dada às bobinas de grande diâmetro e peso produzidas na enroladeira de máquina de papel.

${ }^{23}$ Image Processing Toolbox

${ }^{24}$ MATLAB®, sistema desenvolvido para computação técnica por The Math Works, Inc., EUA.

${ }^{25}$ Two dimensional Discrete Fourier Transform.

${ }^{26}$ Two dimensional Fast Fourier Transform.
} 


\section{CAPÍTULO 2}

\section{O ENCOLHIMENTO DO PAPEL DURANTE A SECAGEM E SEU IMPACTO SOBRE A QUALIDADE DO PRODUTO FINAL}

Esta seção apresenta os principais aspectos sobre alterações dimensionais impostas ao papel no processo de fabricação, especialmente durante a operação de secagem em máquinas comerciais e seus principais efeitos sobre a qualidade do produto destinado ao usuário final. Inicialmente, apresenta-se uma introdução ao efeito de encolhimento da folha de papel (2.1), expondo-se a seguir sua origem, na contração individual das fibras durante a remoção de água (2.2) para, então, explicar o mecanismo de encolhimento da estrutura completa formada pela rede de fibras celulósicas (2.3), tratar da formação do perfil irregular do encolhimento transversal (CD) do papel (2.4) e dos fatores que influenciam na sua forma (2.5), rever as técnicas usadas para sua medição (2.6) e, finalmente, abordar os efeitos sobre a qualidade do papel acabado e, em particular, sobre a estabilidade dimensional (2.7).

\subsection{Encolhimento do papel durante a operação de secagem}

O estiramento da folha úmida na saída da seção de prensas ${ }^{27}$ e a operação de secagem subseqüente produzem deformações estruturais no papel, as quais têm particular efeito sobre a redução na largura da folha. Entretanto, a maior intensidade da variação dimensional ocorre na seção de secagem. Durante a vaporização da água, verifica-se uma inevitável deformação lateral, causada pelo encolhimento das fibras de celulose de forma diferenciada ao longo da direção transversal da folha. Neste processo, tensões internas são geradas na estrutura do papel, cujas magnitudes dependem das forças de secagem induzidas e da sua influência sobre a conformação das ligações interfibrilares. Essas tensões residuais interferem nas propriedades do papel, apresentando importante influência sobre a estabilidade dimensional.

O encolhimento potencial (ou encolhimento livre ${ }^{28}$ ) do papel é observado em todas as direções, ainda que de forma diferenciada. A contração da folha tem efeito quando as forças

\footnotetext{
${ }^{27} \mathrm{O}$ estiramento da folha na direção de fabricação produz encolhimento na direção transversal. Nas máquinas modernas, os sistemas de suporte para a folha, comercialmente conhecidos como sistemas estabilizadores de folha, reduzem fortemente o estiramento na passagem para a seção de secagem, com o objetivo de minimizar impactos sobre a qualidade do papel.

${ }^{28}$ Encolhimento total que ocorre durante a secagem, quando não há retenção mecânica do papel se opondo ao encolhimento natural.
} 
de secagem $^{29}$ excedem as forças restritivas ${ }^{30}$ aplicadas. O balanço destas forças poderá em certas circunstâncias, inversamente, provocar o estiramento do papel, desde que as forças externas aplicadas superem as forças de secagem. Na direção de fabricação, ou direção longitudinal (MD) da máquina, o papel normalmente se encontra tensionado, porém na direção perpendicular, i.e., na direção transversal (CD), o papel se encontra relativamente livre para se contrair, no percurso aberto entre os cilindros secadores e entre os grupos de secagem. $\mathrm{O}$ encolhimento resultante nas bordas tem maior intensidade que as porções centrais, levando à formação de um perfil diferencial do encolhimento transversal (CD) na direção transversal da folha. Adicionalmente, devido à inerente natureza anisotrópica das fibras, as quais apresentam um grau de encolhimento na direção radial maior que na direção axial, o papel com orientação de fibras predominante na direção de fabricação (MD) estará sujeito a maior força de encolhimento na direção transversal (CD).

O conteúdo de água nas células das paredes controla o encolhimento das fibras. Tipicamente, a contração individual das fibras tem início quando o papel atinge um teor de sólidos de $50 \%$ a $60 \%$ e o encolhimento máximo ocorre na faixa de teor de sólidos entre $70 \%$ e $85 \%$, continuando até o estágio final de secagem do papel [Kiiskinen; Pallakari; Pakarinen, 2000]. O potencial de encolhimento atinge a intensidade máxima quando pelo menos uma das superfícies da folha se encontra livre, como acontece, e.g., em passes abertos entre os cilindros secadores, em seções de secagem com tela secadora única (single-felted dryers ${ }^{31}$ ), situação em que o papel se desloca sobre a superfície da tela secadora e, também, na transferência da folha da seção de prensas para a seção de secagem em máquinas com passe aberto, condição que determina certo grau de encolhimento transversal (CD) em função do estiramento na direção longitudinal (MD) da máquina de papel.

\subsection{O encolhimento individual das fibras do papel}

No processo de fabricação do papel, normalmente se dá mais atenção ao encolhimento total da folha, resultante da remoção de água na operação de secagem, que ao encolhimento individual das fibras. Contudo, dado que existe uma relação direta da deformação das fibras

\footnotetext{
${ }^{29}$ Forças e tensões internas no papel causadas pelo encolhimento das fibras durante a secagem.

${ }^{30}$ Forças externas que agem sobre o papel durante a operação de secagem, podendo produzir tensão ou retenção da folha.

31 Nesta configuração, o papel é conduzido na superfície de uma tela secadora única, que abraça simultaneamente os secadores superiores e inferiores do grupo de secagem.
} 
com o encolhimento da folha de papel, bem como com as tensões internas induzidas do papel, $c f$. considerações de Page e Tydeman [1962] e de Nanko e Wu [1995], torna-se importante conhecer o mecanismo que determina o seu encolhimento individual.

Rance [1954] encontrou três etapas para o mecanismo de encolhimento, usando uma folha formada com polpa muito refinada (Figura 2.1):

Estapa 1 - [A-B]: Contração na espessura da folha sem contração significante nas direções longitudinal e transversal;

Estapa 2 - [B-C]: Tensão de contração superficial, com contração da folha em todas as direções;

Estapa 3 - [C-D]: Inflexão brusca na curva de encolhimento, a partir do ponto de $33 \%$ de conteúdo de água (0,33 grama de água / grama de sólidos).

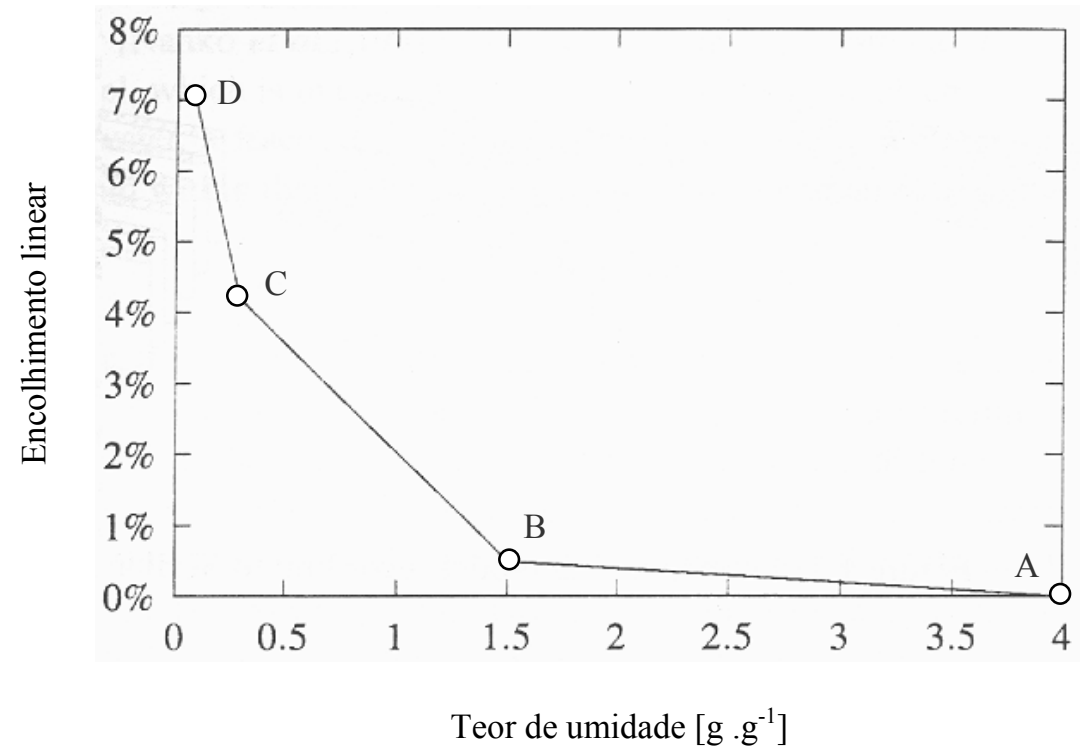

Figura 2.1. Encolhimento do papel em três etapas $c f$. Rance [1954]. O teor de umidade representa a razão entre a massa de água [g] e a massa de sólidos [g].

Neste trabalho, Rance [1954] não apresentou uma explicação para o comportamento observado no terceiro estágio. Tydeman, Wembridge e Page [1966] embora também não tenham encontrado uma justificativa para a transição abrupta, confirmaram a existência de uma taxa de encolhimento notadamente crescente, durante a remoção dos últimos $20 \%$ a $30 \%$ de água. Uma curva com formato semelhante à mostrada na Figura 2.1 havia sido encontrada 
por Lyne e Gallay [1950] quando secaram pasta celulósica parcialmente até diferentes teores de umidade e, a seguir, plotaram a redução de densidade em função do teor de sólidos. Robertson $^{32}$ [1963 apud Weise, 1997] propôs cinco etapas para o processo de encolhimento do papel, onde a contração das fibras ocorre na última etapa ${ }^{33}$.

O encolhimento individual ocorre principalmente na direção radial da fibra e a magnitude da deformação depende do nível inicial do conteúdo de água, sendo que a intensidade de encolhimento será proporcional ao grau de absorção de água antes da secagem. O mecanismo de absorção de água (inchação da fibra) é influenciado diretamente pela operação de refinação da pasta celulósica, a qual provoca um aumento de fibrilação das paredes das fibras, o que facilita o estabelecimento de ligações químicas com as moléculas de água [Page ${ }^{34} 1989$ apud Kajanto; Niskanen, 1998].

O comportamento anisotrópico na contração se deve ao alinhamento das micro-fibrilas presentes nas paredes das fibras, principalmente na direção paralela ao eixo longitudinal, facilitando, assim, a deformação dimensional na direção perpendicular (radial) da fibra, durante a remoção de moléculas de água ${ }^{35}$. Foram encontrados valores médios de encolhimento transversal da ordem de $20 \%$, enquanto na direção axial observaram-se valores bem menores, em torno de 1\% apenas, $c f$. estudos realizados por Gallay [1973]. Contrações axiais na faixa de $1 \%$ a $2 \%$ e radiais de $20 \%$ a $50 \%$ haviam sido observadas em pesquisas de Page e Tydeman [1962].

O modelo desenvolvido por Scalan ${ }^{36}$ [1974 apud Kajanto; Niskanen, 1998], com a finalidade de demonstrar os mecanismos de dilatação (swelling) e de encolhimento (shrinkage) das fibras está ilustrado na Figura 2.2. De acordo com este modelo, as paredes das fibras se dilatam com o aumento do teor de umidade, devido à penetração de moléculas de

\footnotetext{
32 ROBERTSON, A.A. The physical properties of wet webs. Svensk Paperstidning, vol.66, n.12, p.477-497, 1963.

${ }^{33}$ As cinco etapas identificadas são as seguintes: (a) o decréscimo da quantidade de água nos capilares interfibras, sem entrada de ar, (b) o esvaziamento dos capilares inter-fibras, (c) a alteração da magnitude e ação das forças de tensão superficiais, em função da redução dos meniscos de água da dimensão das fibras para a dimensão das fibrilas ou dimensões da lacuna inter-fibras, (d) o desaparecimento da água entre as fibras e no lúmen e, finalmente, (e) o encolhimento das fibras.

${ }^{34}$ PAGE, D.H. In: Fundamentals of Papermaking, ed. C. F .Baker; V. W. Puton, London: MEP 1989, vol.1, p.18.

${ }^{35}$ As micro-fibrilas celulósicas, que se encontram proximamente paralelas ao eixo longitudinal das fibras, oferecem resistência efetiva ao encolhimento dos polímeros amorfos presentes nesta direção.

${ }^{36}$ SCALLAN, A.M. The structure of the cell wall of wood: A Consequence of Anisotropic Inter-Microfibrillar Bonding. Wood Science, vol.6, n.3, p.266-271, 1974.
} 
água nas interligações por pontes de hidrogênio existentes entre as fibrilas ${ }^{37}$. A quantidade de moléculas de água ligada (bond water $^{38}$ ) aumenta, produzindo diminuição no grau de interligação interna nas paredes das fibras. O fenômeno oposto, que ocorre durante a remoção da água interligada, presente entre as fibrilas, i.e., durante a secagem do papel, determina a contração (encolhimento) das paredes das fibras.

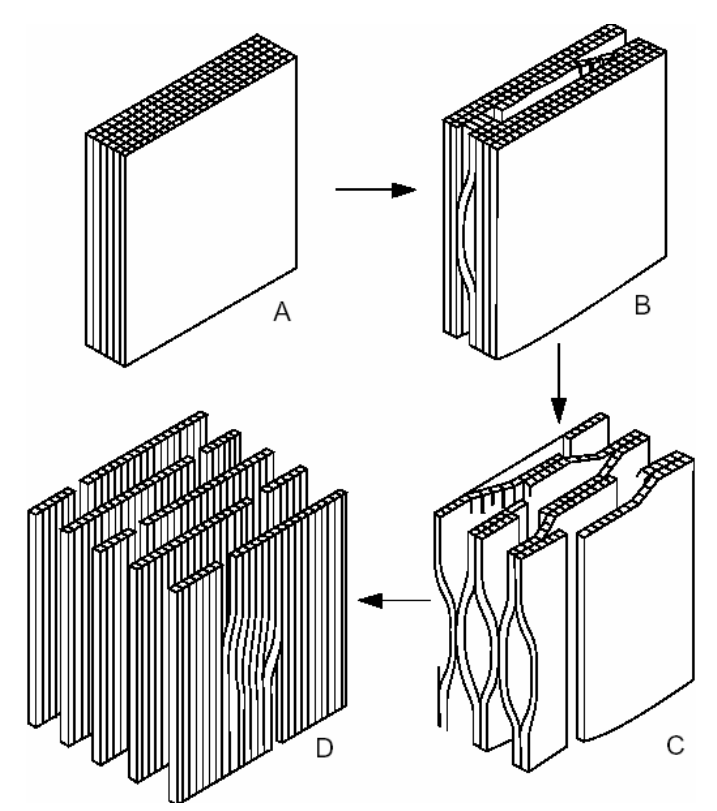

Figura 2.2. Diminuição sucessiva da interligação entre fibrilas celulósicas causada pela absorção de água, de "A" para "D" (inchação) ou, contrariamente, aumento da interligação causada pela remoção de moléculas de água, de " $D$ " para "A" (encolhimento), cf. Scallan ${ }^{36}$ [1974 apud Kajanto; Niskanen,1998].

Nanko e Oshawa ${ }^{39}$ [1989 apud Kiisknen; Paltakari; Pakarinen, 2000] constataram, por microscopia a laser, a existência de cinco etapas no processo de secagem, que afetam as fibras individualmente:

\footnotetext{
${ }^{37}$ Elementos filiformes presentes na estrutura da parede das fibras celulósicas, as quais agregam as microfibrilas, reunião de lamelas, onde se encontram as cadeias de moléculas de celulose.

${ }^{38}$ A água ligada (bond water) é definida como a água que interage e forma ligações químicas com as fibras celulósicas. As moléculas de água formam pontes de hidrogênio com as hidroxilas livres presentes na celulose e hemiceluloses. A água é também retida nas partes amorfas, na micro-estrutura das fibras e nas vizinhanças das moléculas de água ligadas à celulose. Adicionalmente, a água é retida em poros e interstícios e imobilizada, até certos limites, em poros e espaços entre as fibras [Weise, 1997].

${ }^{39}$ NANKO, H.; OHSAWA, J. Mechanism of fibre bonding formation. In: BAKER, C.F.; PUTON, V.W. (Ed.).

Fundamentals of Papermaking. London: MEP, 1989, vol.2, p.783-830.
} 
Fase 1 - Conteúdo de sólidos de 50\% a 55\%: o teor de sólidos aumenta, sem nenhuma alteração morfológica das fibras;

Fase 2 - Conteúdo de sólidos entre $50 \%$ a $55 \%$ e $60 \%$ a $65 \%$ : remoção de água do lúmen e início de compressão nas áreas de contato entre as fibras, sem alterações na superfície da folha de papel;

Fase 3 - Conteúdo de sólidos entre $60 \%$ a $65 \%$ e $70 \%$ a $75 \%$ : remoção de água da parede da fibra e enrugamento da superfície;

Fase 4 - Conteúdo de sólidos entre $70 \%$ a $75 \%$ e $80 \%$ a $85 \%$ : início de encolhimento transversal das regiões sem ligações, tais como nas seções livres das fibras;

Fase 5 - Conteúdo de sólidos de $80 \%$ a $85 \%$ e superior: encolhimento transversal nas regiões com ligações inter-fibras. A estruturação final da folha ocorre na região acima de $90 \%$ de teor de sólidos.

O teor de umidade na região em que se inicia o encolhimento transversal indicado acima, concorda com a região de teor de umidade em que ocorre o encolhimento mais acentuado da folha, $c f$. observado anteriormente por Rance [1954] e Tydeman, Wembridge e Page [1966].

Antes do início da fase de secagem, as moléculas de água se encontram distribuídas nas superfícies das fibras, nos poros entre as fibras e, internamente, nas paredes e lumens. $\mathrm{O}$ processo de secagem se inicia pela evaporação da água presente em lacunas e poros interfibras, sem alteração morfológica (Fase 1). A evaporação continua a partir da superfície das fibras, embora a água entre as fibras também seja removida, pois ocorre um processo de difusão da água, de dentro do lúmen para a superfície da fibra. A evaporação da água presente no lúmen e as forças de tensão superficial provocam a compressão das áreas de contato entre as fibras (Fase 2). Depois da remoção da água contida no lúmen, a secagem continua com a remoção da água presente nas celas da parede da fibra. $\mathrm{O}$ encolhimento das paredes da fibra se inicia quando as moléculas de água são removidas das lacunas entre as micro-fibrilas na celulose e da parede da fibra, que se encontra delaminada nesta etapa. A formação de rugas indica o inicio da contração das células das paredes da fibra (Fase 3). A remoção de água das paredes causa encolhimento transversal da fibra, nas seções onde não há ligações e, portanto, a parede da fibra pode contrair-se livremente (Fase 4). O encolhimento nas regiões de interligação entre as fibras tem início quando a maior parte da água contida nas paredes já tenha sido removida (Fase 5). 
As deformações, que ocorrem nas fibras, dependem de vários fatores, tais como a natureza da matéria prima, o histórico de polpação e preparação de massa e o ambiente químico e físico em que se encontram. As fibras provenientes de polpação mecânica, química e de processos de reciclagem apresentam diferentes potenciais de formação de ligações interfibras e, portanto, diferentes comportamentos durante a secagem. A Figura 2.3 resume os principais resultados obtidos por Weise [1997], no estudo em que analisou as alterações que ocorrem na seção transversal de fibras celulósicas, causadas pela remoção de água. As faixas de teor de umidade características, encontradas nas três principais operações presentes em uma máquina de papel estão indicadas na parte superior para referência.

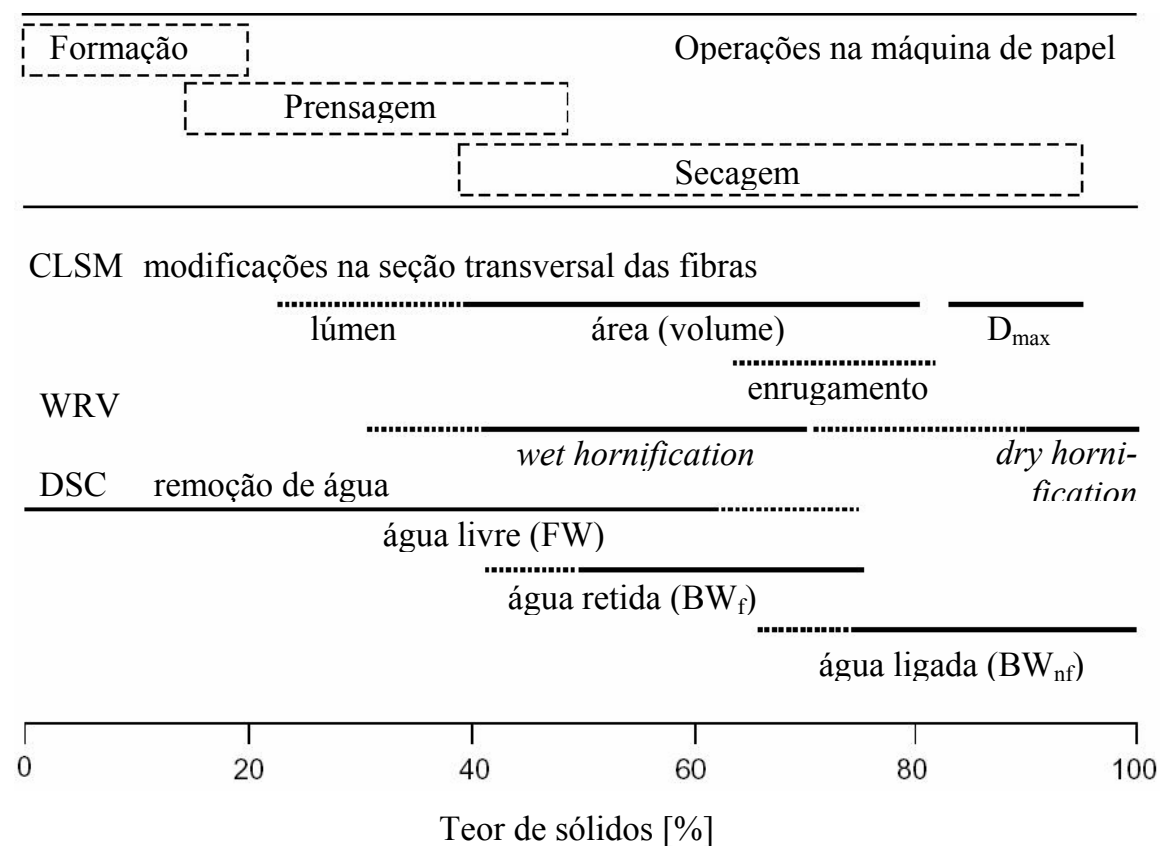

Figura 2.3. Remoção de frações de água e modificações na seção transversal das fibras vs. teor de sólidos nas operações de fabricação de papel. As dimensões transversais foram medidas por microscópio de varredura a laser (CLSM) e as frações de água, medidas por calorimetria diferencial de varredura (DSC) [Weise 1997].

Nas máquinas de papel atuais, a seção de prensas pode remover água até que a folha atinja níveis de $45 \%$ a $48 \%$ de teor de sólidos. Neste estágio, as fibras sofrem modificações morfológicas causadas pela remoção de água e alterações estruturais devido à operação de prensagem. $\mathrm{O}$ encolhimento das fibras, em termos de diminuição de volume, foi observado em uma faixa larga de umidade. Uma acentuada diminuição na largura aparente da fibra 
$\left(D_{\max }\right)$ foi observada no final do processo de secagem. O efeito denominado hornification ${ }^{40}$ foi observado durante a remoção de água na zona equivalente a da seção de prensas (wet hornification) e, também, pela operação de secagem (dry hornification). A remoção de água livre (free water $\left.^{41}\right), \mathrm{FW}$, ocorreu com taxa constante até o teor de sólidos atingir níveis de $62 \%$ a $65 \%$, embora alguns traços tenham sido detectados até o nível de $70 \%$ de teor de sólidos ou mesmo em níveis ligeiramente superiores. Observou-se que água livre e parte da água retida no interior das paredes das fibras (freezing bound water ${ }^{42}$ ), $\mathrm{BW}_{\mathrm{f}}$, foram, até certo ponto, removidas simultaneamente, enquanto que em apenas uma pequena faixa de teor de umidade, a água retida nas fibras $\left(\mathrm{BW}_{\mathrm{f}}\right)$ e a água ligada quimicamente (nonfreezing bound water $\left.^{43}\right), \mathrm{BW}_{\mathrm{nf}}$, foram removidas ao mesmo tempo. $\mathrm{O}$ enrugamento superficial das células das fibras teve início quando a maior parte de água livre havia sido removida. A diminuição na largura aparente da fibra $\left(\mathrm{D}_{\max }\right)$, observada no final do processo de secagem, ocorreu durante a remoção da última parcela de água ligada $\left(\mathrm{BW}_{\mathrm{nf}}\right)$.

Em resumo, observam-se duas fases no processo de secagem apresentado por Weise [1997], em que a primeira é dependente e a segunda, independente da morfologia das fibras. $\mathrm{Na}$ fase inicial de secagem, o encolhimento é provocado por mudança de unidades morfológicas nas células das paredes da fibra. Na fase final, o encolhimento ocorre por remoção da água ligada, que consiste em um fenômeno supramolecular.

A Figura 2.4 ilustra a distribuição das frações de água mencionadas acima e sua variação em função do teor de umidade do papel.

O encolhimento, assim como outras alterações estruturais, que ocorrem durante a secagem, cessam no momento em que as fibras atingem o estado de equilíbrio com o ambiente, a uma dada temperatura e umidade relativa.

\footnotetext{
${ }^{40}$ Termo utilizado por Jayme [1958] para expressar o decréscimo percentual do WRV observado em pastas celulósicas após a secagem e posterior re-umedecimento (literalmente, irreversible cornification, do alemão irreversible verhornung). Está fortemente relacionado aos ciclos de umedecimento e ao histórico de temperatura cf. pode ser visto em estudo de Kato e Cameron [1999] e possui interpretação química, de acordo com Diniz, Gil e Castro [2004]. O WRV (Water Retention Value) consiste de teste utilizado para determinar, empiricamente, a habilidade que têm as fibras de celulose de reter água no interior da sua estrutura.

${ }^{41}$ A água livre encontra-se nos poros, entre as fibras, e no lúmen das fibras. O conteúdo total de água na fibra corresponde à soma da parcelas de água livre e água ligada.

42 Freezing bound water - parcela de água retida nos poros das paredes das fibras, detectada e quantificada por meio de Calorimetria Diferencial de Varredura (DCS - Differential Scanning Calorimetry) [Weise, 1997].

${ }^{43}$ Nonfreezing bound water - parcela de água ligada quimicamente a grupos hidroxilas e carboxilas, presentes nas paredes das fibras de celulose.
} 


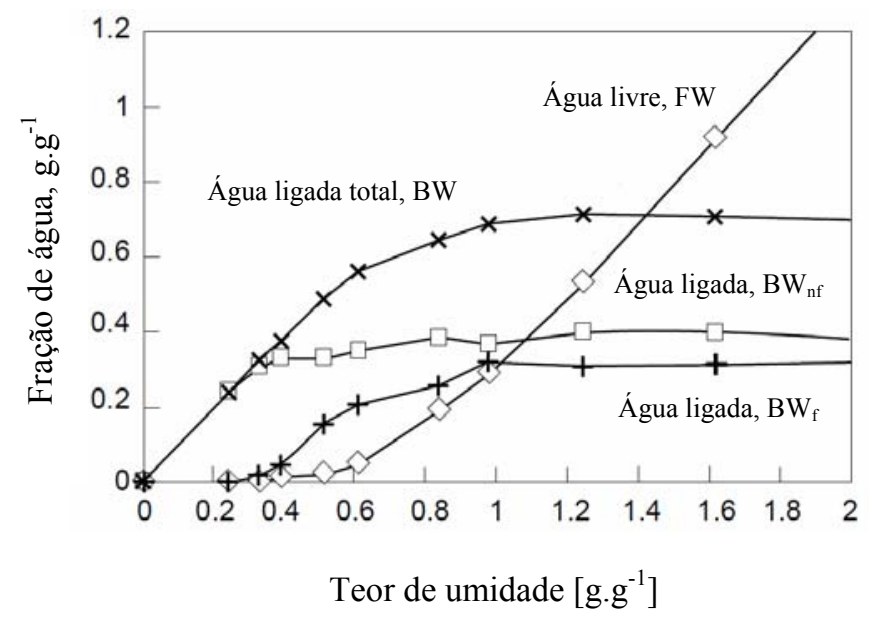

Figura 2.4. Frações de água livre e água ligada vs. teor de umidade, para pasta termomecânica (TMP) [Weise, 1997]. O teor de umidade representa a razão entre a massa de água [g] e a massa de sólidos [g].

\subsection{Mecanismo de encolhimento da estrutura do papel}

A teoria da micro-compressão, apresentada por Page e Tydeman [1962], pode descrever a ação das ligações interfibras no encolhimento do papel. Foi baseada em descobertas de ordem qualitativa, estabelecendo que o encolhimento radial das fibras causa contrações longitudinais naquelas com as quais estão interligadas, criando micro-compressões nos pontos de ligação (Figura 2.5), responsáveis pelo encolhimento de toda a estrutura fibrosa que constitui o papel. No caso, as ligações interfibra devem ser suficientemente fortes para evitar rupturas durante a compressão.

A contração transversal das fibras, que ocorre durante o processo de secagem, foi medida por Nanko, Asano e Ohsawa [1991] com a utilização de microscópio de varredura a laser $\left(\mathrm{SLM}^{44}\right)$. $\mathrm{O}$ estudo demonstrou que a maior parte do encolhimento ocorria quando as fibras alcançam um teor de sólidos específico na fase final de secagem e que dependia do tipo de polpa utilizada. Entretanto, situava-se em uma faixa estreita, entre $85 \%$ e $88 \%$, a despeito das grandes diferenças morfológicas das fibras e de composição química entre as polpas testadas.

\footnotetext{
${ }^{44}$ Scan Laser Microscope (Microscópio de Escaneamento a Laser)
} 


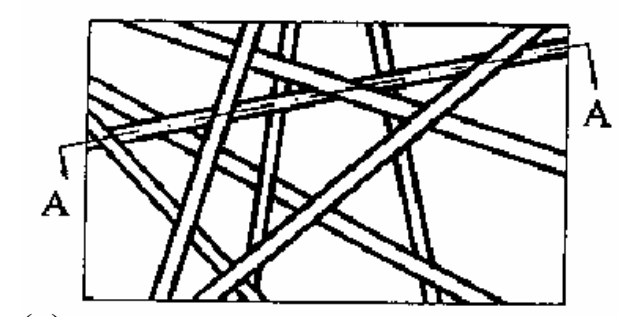

(a)

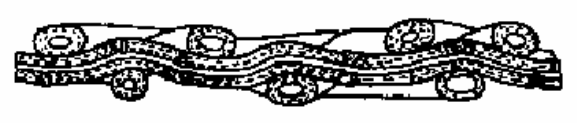

seção A-A (b)

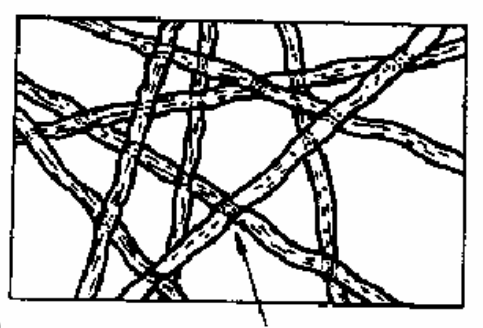

microcompressão

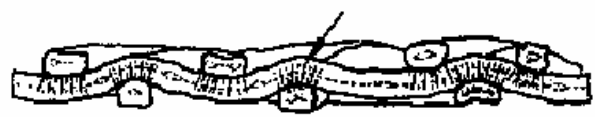

Figura 2.5. Encolhimento do papel: (a) rede de fibras antes da secagem e (b) a mesma rede de fibras após a secagem [Kiiskinen; Pallakari; Pakarinen, 2000].

Após atingir o ponto de colapso das fibras, apenas as moléculas de água que apresentavam forte interação com a celulose permaneciam na fibra e, aparentemente, a evaporação desta água ligada produzia contrações significativas das paredes das fibras, responsáveis pela criação de altas tensões internas de secagem, as quais determinavam o encolhimento do papel. Nanko e Wu [1995] também produziram estudos sobre o encolhimento do papel com uso de microscopia de varredura a laser (SLM), cujos resultados confirmaram o mecanismo proposto por Page e Tydeman [1962]. Adicionalmente, o trabalho revelou que segmentos livres da rede de fibras podem ser comprimidos ou tensionados, passivamente, para manter o equilíbrio com as fibras adjacentes que se contraíram. Os resultados mostraram ainda que: (a) durante a secagem sem restrição ao encolhimento (secagem livre), a contração dos seguimentos interligados causa o encolhimento da folha inteira; (b) durante a secagem com restrição ao encolhimento, a contração dos segmentos interligados causa estiramento dos segmentos livres que se encontram situados entre os segmentos interligados.

As propriedades higroexpansivas das fibras celulósicas são fortemente anisotrópicas, determinando que, devido ao maior potencial de encolhimento na direção radial que na longitudinal, o papel, normalmente com orientação de fibras predominante na direção da máquina (MD), esteja sujeito a um encolhimento de maior intensidade na direção transversal (CD). Os problemas decorrentes do encolhimento irregular na direção transversal (CD) serão abordados adiante (ver seção 2.7). 


\subsection{O perfil do encolhimento transversal do papel}

O papel produzido em máquinas convencionais ${ }^{45}$ exibe, invariavelmente, um perfil irregular de encolhimento transversal desenvolvido na operação de secagem e durante a passagem pelo passe livre entre a última prensa úmida e o primeiro cilindro secador, região em que o papel sofre um estiramento . Na seção de secadores, o papel se encontra sob tensão na direção de fabricação (MD), condição que oferece forte restrição ao encolhimento, podendo, em condições específicas de tensão, produzir certo grau de alongamento do papel. Entretanto, na direção perpendicular da máquina (CD), a folha se encontra relativamente livre para se contrair, ainda que parcialmente retida pela tela secadora e pelo atrito de contato com a superfície dos cilindros secadores. De fato, a folha se encontra muito mais retida no centro da máquina que nas bordas e, assim, diferenças correspondentes de encolhimento são observadas entre estas áreas. O resultado do diferencial de contração do papel conduz à formação de um perfil não uniforme para o encolhimento transversal (CD) ${ }^{46}$. A abordagem, a seguir, apresentada por Kiiskinen, Pallakari e Pakarinen [2000], considera os mecanismos físicos básicos que ocorrem durante a secagem do papel e o correspondente perfil transversal do encolhimento transversal (CD) que determinam.

A única força de restrição ao encolhimento, na seção de secagem, origina-se no atrito entre o papel e a superfície dos secadores, que restringe o movimento da folha de papel na direção transversal da máquina. As tensões transversais geradas no processo serão transferidas para os próximos passes abertos ou passes sem atrito, de forma exponencialmente amortecida com respeito à distância em relação à linha de centro da máquina de papel. As forças de restrição ocorrem quando o papel é pressionado entre o cilindro e a tela secadora ou quando é submetido à ação de sucção (vácuo) contra a tela secadora (e.g., em máquinas com cilindros secadores dispostos na configuração de fileira única ${ }^{47}$ ). Em uma dada seção de secagem, as forças de atrito podem resultar do tensionamento da folha entre dois grupos de secadores com acionamentos próprios (embora sem relevância em função da baixa magnitude de seu efeito). $\mathrm{Na}$ condição em que o papel se encontra sob a ação das forças de atrito nas superfícies de

\footnotetext{
${ }^{45}$ Máquinas de papel que possuem seções de secagem constituídas por cilindros secadores, aquecidos a vapor, dispostos em duas fileiras. Nesta configuração, a passagem do papel de um secador para o subseqüente é aberta, i.e., sem suporte para o papel.

${ }^{46}$ As propriedades mecânicas e higroelásticas do papel são, em geral, medidas nas duas direções principais da máquina, i.e., longitudinal (MD) e transversal (CD). Para maior rigor na definição, o perfil em questão poderia ser denominado de perfil transversal de encolhimento transversal (CD).

${ }^{47}$ Ver seção 2.1.4.1.
} 
suporte, cada elemento infinitesimal $d y$ da folha estará sujeito à uma força $d F_{\mu}$, de acordo com a equação abaixo:

$$
d F_{\mu}=\mu p s d \mathbf{y}
$$

onde:

$\mu \quad$ coeficiente de atrito

$p \quad$ pressão normal da tela secadora sobre o papel

$s \quad$ comprimento da superfície de suporte na direção longitudinal

Considerando que a pressão $p$, gerada pela tela secadora sob tensão $T$, sobre uma superfície curva com raio de curvatura $R$, é dada por:

$$
p=T / R
$$

e que o comprimento da superfície de suporte (ou abraçamento no cilindro secador), $s$, pode ser expresso em termos do ângulo de abraçamento da tela, $\alpha$, e do raio de curvatura, $\mathrm{R}$, pela relação:

$$
s=R \alpha
$$

após a substituição de (2.2) e (2.3) em (2.1), vem que:

$$
d F_{\mu}=\mu T \alpha d y
$$

Quando um determinado elemento da folha de papel se contrai na direção transversal, deve exercer tração sobre a folha inteira, a partir das vizinhanças imediatas, em toda extensão, até as bordas. A magnitude da força de atrito que deve ser superada, no processo, pela força de encolhimento, resulta da integração da equação (2.4):

$F_{\mu}=\mu T \alpha(D / 2-|\mathrm{y}|)$

onde:

D largura da folha de papel 
|y módulo da distância do elemento considerado, a partir do centro da folha de papel

A equação (2.5) estabelece que a força de atrito é nula na extremidade da folha e cresce linearmente em direção ao ponto central, onde atinge o valor máximo, dado por $\mathrm{F}_{\mu}=\mu T \alpha(D / 2), c f$. ilustrado graficamente na Figura 2.6.

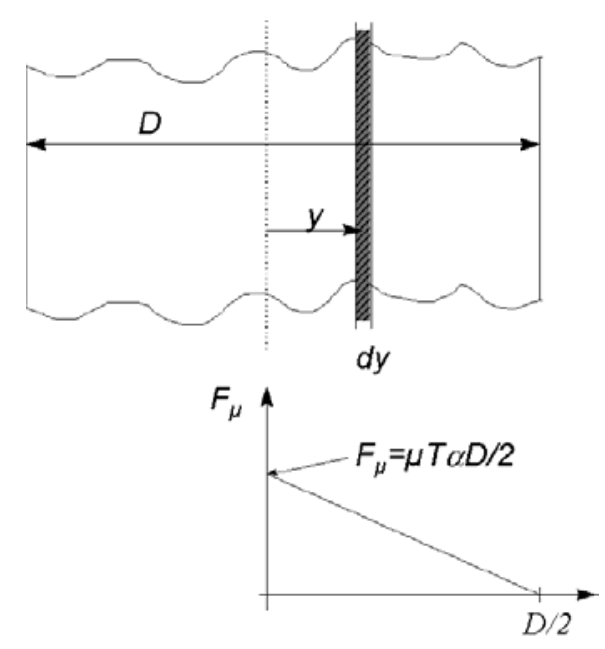

Figura 2.6. Elemento da folha de papel e variação da força de atrito na direção transversal [Kiiskinen; Pallakari; Pakarinen, 2000].

A vaporização da água do papel e a aproximação das fibras, resultante da contração das suas paredes criam a força de encolhimento, $F_{s h}$. Assumindo que a quantidade de água evaporada seja denominada por $m_{e v}$ e o encolhimento do papel por $\varepsilon_{s h}$ (sendo $\varepsilon_{s h}>0$, por definição), a correspondente força de encolhimento, $F_{s h}$, será proporcional ao potencial de encolhimento do papel, $H$ (dado que $\varepsilon_{s h}=H m_{e v}$ ), ao módulo de elasticidade $\mathrm{CD}, E_{C D}$, e à gramatura do papel, $m$ :

$$
F_{s h}(\varepsilon)=E_{C D} m s\left(\varepsilon_{s h}-\varepsilon\right)
$$

onde:

$s \quad$ comprimento do abraçamento do papel sobre o cilindro secador

$\varepsilon \quad$ encolhimento real do papel 
Na condição dada por $F_{s h}>F_{\mu}$, que determina o encolhimento $\varepsilon(y)$ na posição $y$ a partir do centro da folha de papel, tem-se que:

$$
\begin{aligned}
& \varepsilon(y)=H m_{e v}-[\mu p(D / 2)-|y|] /\left(m E_{C D}\right), \\
& \text { se } \varepsilon>0 \\
& \text { ou } \\
& \varepsilon(y)=0, \text { se } \varepsilon<0
\end{aligned}
$$

A equação (2.7) determina que o formato do perfil do encolhimento transversal (CD) depende da magnitude do coeficiente de atrito " $\mu$ ", i.e., valores baixos de " $\mu$ " resultam em uma média de encolhimento maior, porém produzem perfis mais uniformes que para valores maiores de " $\mu$ ". Na situação real, o perfil do encolhimento não corresponde rigorosamente à equação (2.7), pois também sofre interferência na passagem pelo passe livre entre componentes da secagem, onde não há forças de atrito presentes (como ilustrado na Figura 2.7).

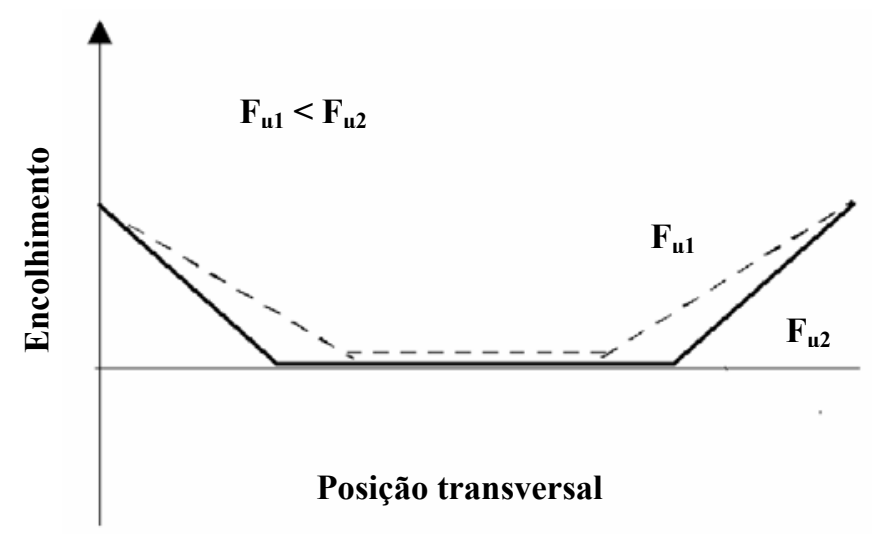

Figura 2.7. Representação do perfil do encolhimento transversal (CD) com variação da força de atrito [Kiiskinen; Pallakari; Pakarinen, 2000].

Kiiskinen, Pallakari e Pakarinen [2000] mencionam também que as tensões internas aumentam o encolhimento transversal (CD) no passe aberto da secagem durante a transição do papel de um ponto de atrito para outro, porém se amortecem exponencialmente segundo a forma $e^{(-k x / D)}$, onde $D$ representa a largura da folha de papel e $x$ representa a distância na direção da máquina (i.e., o comprimento do passe aberto). Considerando o comportamento exponencial da atenuação das tensões transversais de encolhimento, o coeficiente de atrito $\mu$, 
na equação (2.7), pode ser substituído por $\mu_{\mathrm{eff}}(x)=\mu e^{(-k x / D)}$. Após a substituição, a equação (2.7) torna-se:

$$
\begin{aligned}
& \varepsilon(x, y)=H m_{e v}-\left[\mu p e^{(-k x / D)}(D / 2)-|y|\right] /\left(m E_{C D}\right), \\
& \text { se } \varepsilon>0 \\
& \text { e } \\
& \varepsilon(x, y)=0, \text { se } \varepsilon<0
\end{aligned}
$$

O exame da equação (2.8) mostra que, para valores pequenos de $x$, ou seja, no caso de passes livres curtos, o encolhimento transversal (CD) no centro da folha é claramente inferior ao das bordas do papel. Para valores grandes de $x$, ou seja, no caso de passes livres longos, o centro da folha apresentará um índice de encolhimento transversal (CD) muito maior e desenvolverá um perfil de encolhimento mais uniforme.

\subsection{Fatores determinantes do perfil de encolhimento do papel}

A magnitude das variações dimensionais e a forma do perfil do encolhimento transversal (CD), ao longo da largura do papel, são determinadas, principalmente, por características intrínsecas das fibras de celulose, as quais regem os meios de interação com a água, pela configuração da máquina de papel, particularmente da seção de secagem e por suas condições operacionais. Nenhuma máquina de papel industrial, atualmente, está imune ao efeito de encolhimento transversal irregular, porém as mais modernas, que operam com velocidades elevadas, tendem a demonstrar as maiores diferenças entre as bordas e o centro da folha, embora o encolhimento total seja baixo [I'Anson et al., 2008].

\subsubsection{Configuração da seção de secagem da máquina de papel}

Durante a operação de secagem em máquinas convencionais, o papel permanece muito tensionado na direção de fabricação (MD). Porém, na direção transversal da máquina (CD), a folha se encontra relativamente livre, apesar de ser pressionada pelas telas secadoras contra a superfície dos cilindros secadores, pois no percurso entre a saída de um secador e a entrada no 
secador subseqüente (passe entre secadores), quase não há restrição à contração transversal do papel, principalmente na região das bordas.

De fato, como ressaltaram Hoole, l'Anson e Hoyland [2000], a folha de papel sofre mais restrição ao encolhimento na região central da máquina que nas extremidades e, portanto, há correspondentes diferenças de encolhimento entre estas áreas, o que resulta em um perfil transversal bastante irregular. Experimentos desenvolvidos por Hoole et al. [1999] a fim de estudar o encolhimento do papel ao longo da máquina, comprovaram que o perfil irregular de encolhimento da folha de papel tem origem na seção de secagem.

Estudos de Pulkowiski [1990, 1991] demonstraram que seções de secagem com fileira dupla de secadores (double tier) produzem maior irregularidade no perfil transversal de encolhimento e, conseqüentemente, maior variação de propriedades transversais (CD) do papel. A Figura 2.8 mostra parte de uma seção de secagem convencional, com duas fileiras de secadores, e um perfil típico de encolhimento transversal da folha.
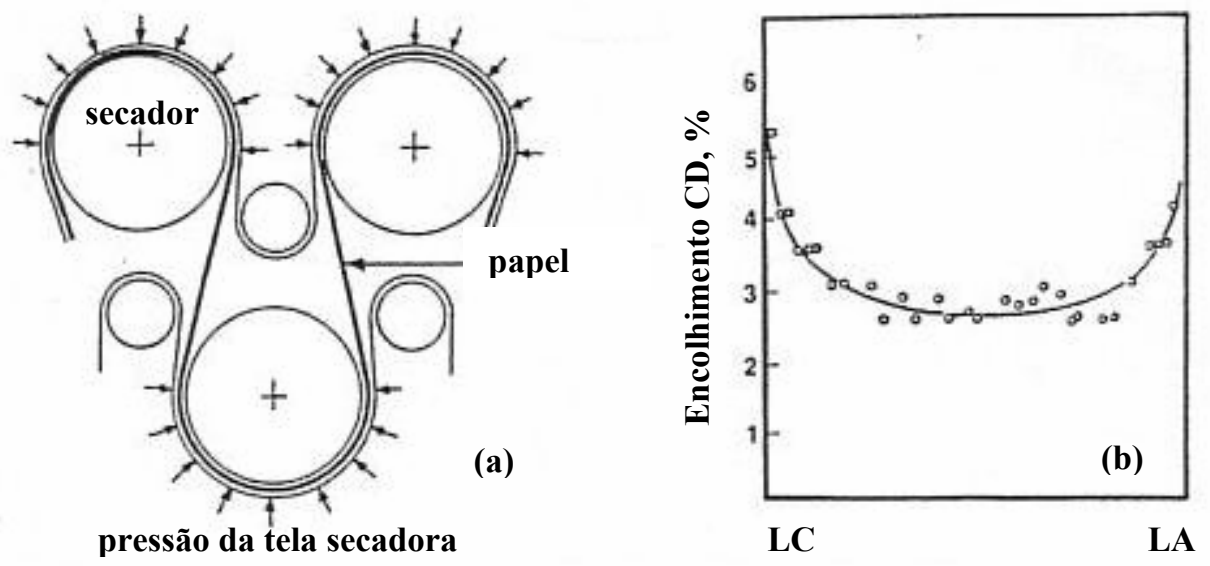

Figura 2.8. (a) Seção de secagem com secadores dispostos em duas fileiras e (b) perfil típico de encolhimento transversal (CD) [Wedel, 1989a].

Estudos comparativos entre seções formadas por secadores dispostos em duas fileiras e seções formadas por fileira única (single-tier) $^{48}$ foram desenvolvidos por Wedel [1989a, 1989b], Palazzolo [1990], Pulkowiski [1990, 1991], Sims Jr. e Grunder [1991] e Chance

\footnotetext{
${ }^{48}$ Neste tipo de configuração, os cilindros secadores estão dispostos em fileira única na parte superior da bateria de secagem. Rolos guia-tela a vácuo são instalados nas posições inferiores. Desta forma o papel atravessa a seção de secagem totalmente suportado pelas telas e pela força de sucção (ver Figura 5.11).
} 
[1992], a fim de verificar os efeitos do encolhimento transversal nas propriedades do papel (a Figura 2.9 mostra parte de uma seção de secagem com fileira única de secadores). Estes trabalhos revelaram que as seções de secagem compostas por cilindros secadores dispostos em fileira única, possibilitam uma maior restrição à contração transversal da folha e, portanto, produzem menor redução da largura total e perfis mais uniformes de encolhimento e de propriedades do papel.

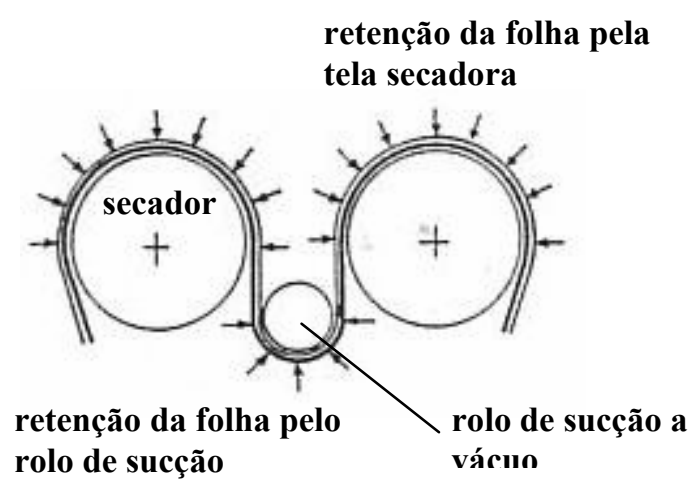

Figura 2.9. Seção de secagem com cilindros secadores dispostos em fileira única [Wedel, 1899a].

A operação de secagem em máquinas configuradas com fileira única de secadores produz também, uma redução significativa no índice de higroexpansibilidade, ou seja, o papel produzido apresenta maior estabilidade dimensional e, portanto, menor potencial para o desenvolvimento de defeitos (Wedel, 1989a). Ainda $c f$. Wedel [1989a, 1989b], para prevenir ou reduzir o encolhimento transversal do papel, é necessário que a retenção seja aplicada à folha nas regiões da seção de secagem onde o papel tem a maior tendência ao encolhimento. Sims Jr. e Grunder [1991] indicaram que estas regiões têm início quando o teor seco do papel se situa em torno de $60 \%$ (ver Figura 2.10).

O estudo teórico desenvolvido por Asensio e Seyed-Yagoobi [1992], a fim de comparar a configuração convencional de secadores dispostos em duas fileiras com o arranjo em fileira única introduzido comercialmente para controlar o encolhimento transversal da folha, avaliou questões de transferência de calor e de massa nas duas configurações e concluiu que as capacidades de secagem são similares e que ambas requerem, aproximadamente, o mesmo comprimento de secagem para obtenção de um determinado teor seco para o papel. 


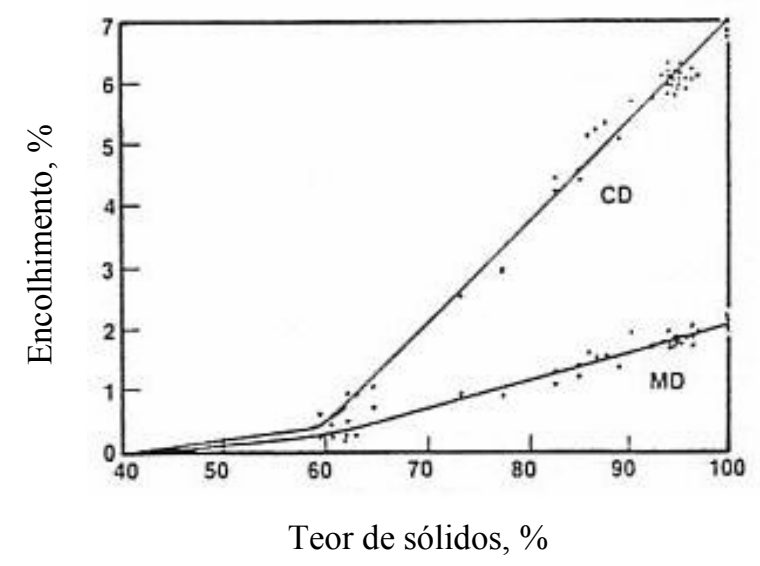

Figura 2.10. Encolhimento da folha nas direções MD e CD de amostras de papel secadas livremente [Wedel, 1989a].

\subsubsection{Geometria do passe entre os cilindros secadores}

Wahlström et al.[1999] criaram um modelo numérico para simular as alterações dimensionais que ocorrem durante a secagem do papel, no qual puderam separar as forças motoras envolvidas, de natureza mecânica e higroscópica.

Este modelo, pela primeira vez, sugeriu a importância fundamental do encolhimento que ocorre nos passes livres entre os componentes da seção de secagem (Figura 2.11) e a razão dimensional entre sua largura $(W)$ e comprimento $(L)$. Philips et al. [2002] aperfeiçoaram as técnicas experimentais utilizadas, apresentando um método de ajuste de curva para os perfis de encolhimento, que permitiu que os valores dos parâmetros-chave quantitativos pudessem ser robustamente e repetidamente estimados.

Mais recentemente, Wahlström e Lif [2003] executaram medições experimentais do encolhimento ao longo da linha central do papel entre dois grampos que fixavam amostras durante a secagem (Figura 2.12).

Os resultados confirmaram a importância da forma do passe livre entre cilindros secadores, demonstrando que valores da razão $[W / L]$ - obtidos tanto pela variação de $W$ (largura do papel), de $L$ (comprimento ou extensão do passe aberto), como por ambos controlaram o perfil de encolhimento resultante. 

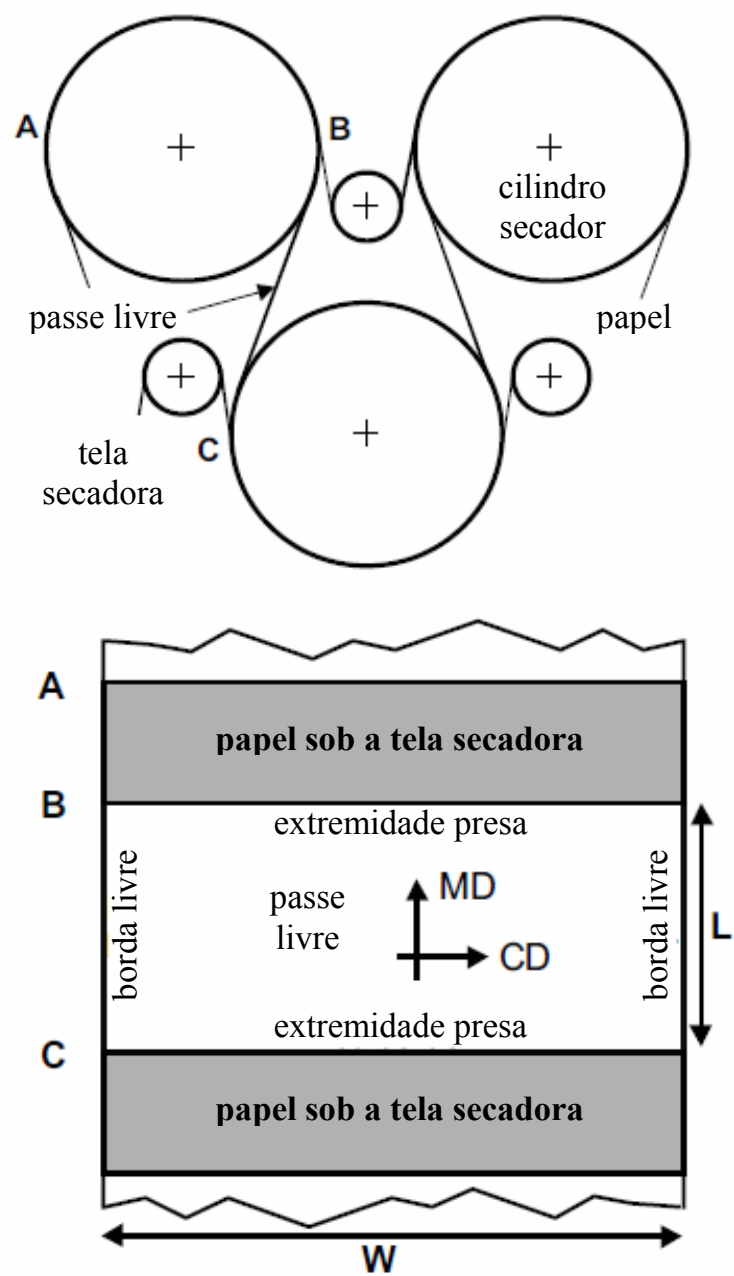

Figura 2.11. Transporte do papel entre componentes da seção de secagem [Wahlström; Lif, 2003].

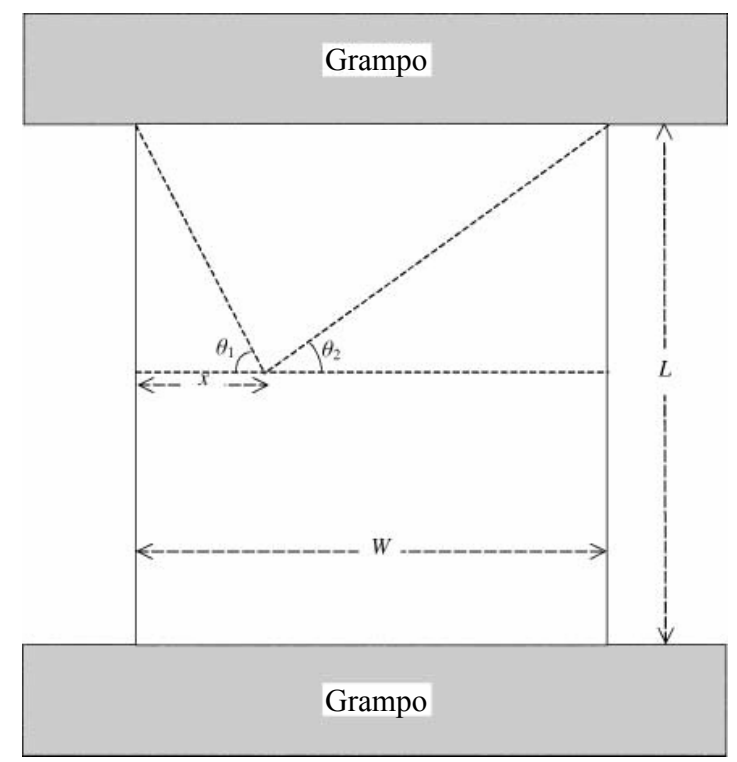

Figura 2.12. Geometria de uma amostra de papel secada em passe simples. $W_{\max }=600 \mathrm{~mm}$ e $L_{\max }=500 \mathrm{~mm}$ [Wahlström; Lif, 2003]. 
Em experimentos laboratoriais, Wahlström e Lif [2003] verificaram que, para uma amostra com comprimento constante, $L$, havia uma diferença de retenção do papel, a qual dependia da distância entre o ponto considerado e as bordas da amostra, implicando que o encolhimento ao longo da linha central era uma função de $x$ e $W-x$. Observaram também que o grau de retenção na posição $x$ diminuía de acordo com o aumento do comprimento da amostra, $L$, e que deveria ser esperado que a retenção dependesse, de alguma forma, dos ângulos de inclinação das linhas que conectam os pontos com as extremidades dos grampos de fixação (i.e., $\theta_{1}$ e $\theta_{2}$ ). Desta maneira, sugeriram que o encolhimento higroscópico num ponto $x$ a partir de uma borda do papel fosse dado pela função abaixo, $c f$. foi verificado nos resultados experimentais:

$$
S_{h}(x)=f\left(\frac{x}{L}, \frac{W-x}{L}\right)
$$

A Figura 2.13 mostra resultados obtidos por Wahlström e Lif [2003], na medição do perfil de encolhimento transversal $(\mathrm{CD})$, para diferentes valores da relação $[W / L]$.

Na Figura 2.13(a), encontram-se os resultados obtidos para a variação do comprimento da amostra, $L$, mantendo a largura $W$ constante (o comprimento $L$ representa a extensão de um passe livre, em uma máquina comercial). Observa-se que o aumento da relação $[W / L]$ está relacionado com a diminuição do grau de encolhimento no centro da amostra e com um gradiente acentuado do encolhimento nas bordas do papel. A combinação entre o gradiente proeminente nas bordas e o baixo grau de encolhimento no centro, produziu um perfil em que, na maior parte, o encolhimento transversal $(\mathrm{CD})$ é pequeno.

Na Figura 2.13(b), encontram-se os resultados obtidos para a variação da largura da amostra, $W$, mantendo o comprimento $L$ constante. Neste caso, com relação ao encolhimento central, a tendência se manteve a mesma que a anterior, ou seja, o aumento da razão $[W / L]$ corresponde à diminuição do encolhimento. $O$ gradiente nas bordas, entretanto, não apresentou variação em função da largura da amostra. De forma similar, medições realizadas por Hoole et al. [1999] com a folha de papel dividida em metades, em uma máquina comercial, também mostrou que o gradiente do perfil de encolhimento não se modificou com a mudança na largura. 

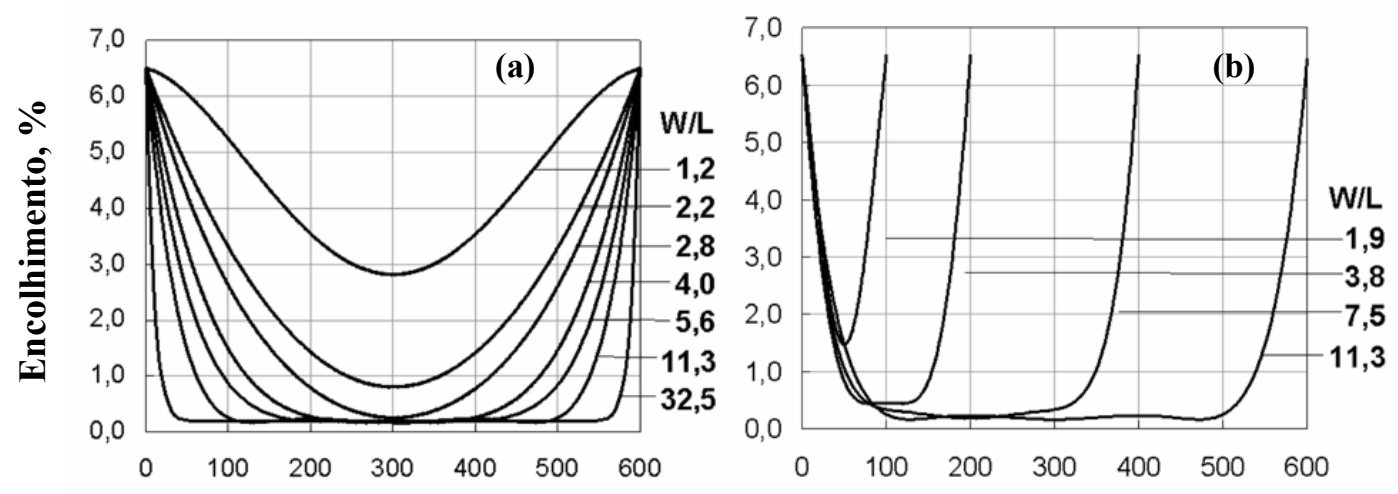

Largura da amostra $(W), \mathbf{m m}$

Figura 2.13. Perfil do encolhimento transversal (CD) para diversos valores da razão $[W / L]$ : (a) para largura da amostra $(\mathrm{W})$ constante de comprimento $(\mathrm{L})$ variável, (b) para comprimento constante e variação de largura da amostra [Wahlström; Lif, 2003].

O interesse de Constantino, I'Anson e Sampson [2005] em prognosticar a forma do perfil do encolhimento transversal (CD) e relacionar a função $f$ [da expressão (2.9)] com o processo físico de encolhimento, resultou na constatação de que uma função de amortecimento exponencial da restrição ao encolhimento com a distância poderia ser usada para tal finalidade:

$$
S_{h}(x)=S_{F C D}\left(e^{-K_{1} x / L}+e^{-K_{1}(W-x) / L}\right)
$$

onde:
$K_{1} \quad$ constante experimental
$S_{F C D}$ encolhimento transversal (CD) livre

No experimento de Wahlström e Lif [2003] a deformação aplicada na direção longitudinal (MD) foi nula, porém, cf. Constantino, I'Anson e Sampson [2005], de acordo com o progresso da secagem, uma tensão deve ter sido desenvolvida, produzindo um efeito de contração, assumido constante em toda a largura da amostra. Após a secagem final, o efeito teria sido o mesmo se a amostra tivesse sido deformada em um grau correspondente exatamente ao encolhimento MD livre $\left(S_{F M D}\right)$ e a magnitude do estreitamento seria dada por este valor multiplicado por um fator $K_{2}$, que pode ser considerado como equivalente à razão de Poisson para o papel, durante a secagem. Para determinar a largura final e o encolhimento 
do papel, em cada posição $x$, os dois efeitos devem ser combinados, resultando na equação a seguir:

$$
S(x)=1-\left[1-S_{F C D}\left(e^{-K_{1} x / L}+e^{-K_{1}(W-x) / L}\right)\right]\left(1-K_{2} S_{F M D}\right)
$$

A Figura 2.14 indica os resultados do modelo, utilizando a equação (2.11), os quais correspondem aos resultados experimentais obtidos por Wahlström e Lif [2003], mostrados na Figura 2.13. Os parâmetros usados na equação (2.11) estão listados na Tabela 2.1. Observa-se que, na maior parte da faixa de valores de $[W / L]$, os perfis de encolhimento obtidos a partir da equação (2.11) são muito similares àqueles determinados experimentalmente.

Tabela 2.1. Parâmetros utilizados para as curvas mostradas na Figura 2.14 usando a equação (2.11).

\begin{tabular}{cc}
\hline Parâmetro & Valor \\
\hline$S_{F C D}$ & $6,5 \%$ \\
$S_{F M D}$ & $2,1 \%$ \\
$K_{1}$ & 2,5 \\
$K_{2}$ & 0,09 \\
\hline
\end{tabular}
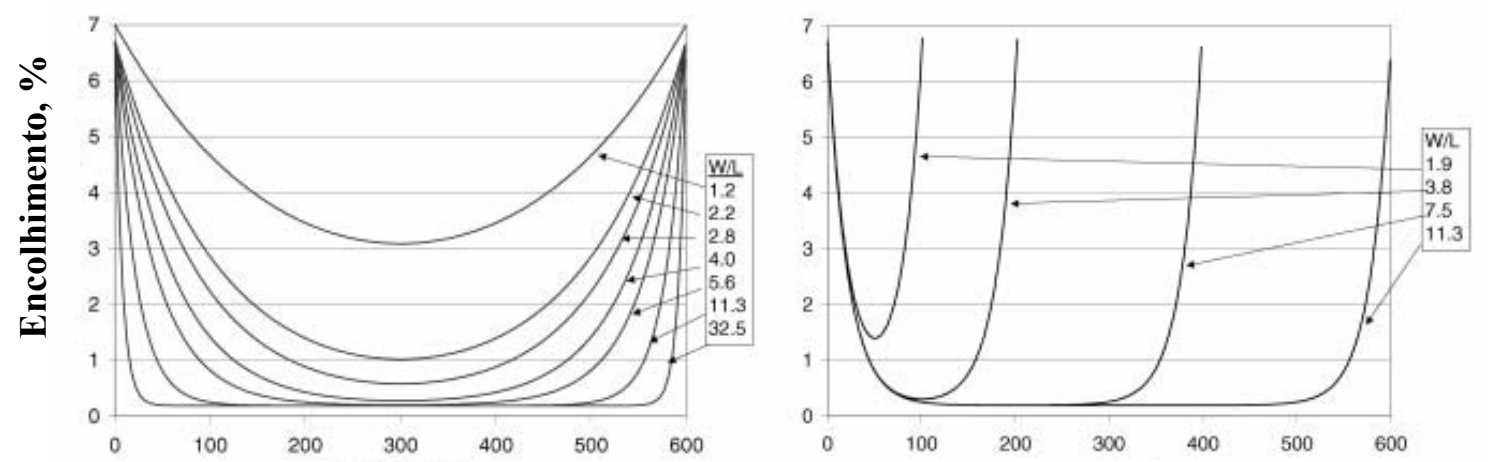

Largura da amostra $(W), \mathbf{m m}$

Figura 2.14. Resultados modelados usando a equação (2.11): (a) mantendo $W$ constante $(=600 \mathrm{~mm})$ e variando o valor de $L$ e, (b) mantendo $L$ constante $(=18,5 \mathrm{~mm})$ e variando o valor de $W$. Os parâmetros utilizados encontram-se na Tabela 2.1 [Constantino; I'Anson; Sampson, 2005]. 


\subsubsection{Condições operacionais da máquina de papel}

Considerando o êxito obtido no prognóstico da forma do perfil do encolhimento transversal (CD) encontrado experimentalmente em laboratório, por meio da equação (2.11), Constantino, I'Anson e Sampson [2005] usando a mesma abordagem, desenvolveram um modelo mais abrangente, a fim de predizer efeitos da composição da massa, da configuração da máquina e das condições operacionais sobre a mudança na forma do perfil transversal do encolhimento transversal (CD), considerando três fatores de contração do papel: o estreitamento mecânico produzido na seção de prensas, o estreitamento mecânico e encolhimento higroscópico produzidos na seção de secagem. O efeito global combinado para os três fatores foi expresso pela equação a seguir, que representa o encolhimento transversal $(\mathrm{CD}), S(x)_{2}$ em um ponto situado à distância $x$ da borda do papel:

$$
S(x)=1-\left(1-S_{p}\right)\left(1-S_{h}(x)\right)\left(1-S_{d 1}\right)\left(1-S_{d 2}\right)
$$

onde:

$S_{p} \quad$ estreitamento mecânico na seção de prensas. $S_{p}=K_{p} D_{p}$, sendo $K_{p}$ o coeficiente de estreitamento nas prensas e $D_{p}$ o passe livre equivalente.

$S_{h}(x)$ encolhimento transversal (CD) higroscópico em função da distância $x$ a partir da borda do papel,

$$
S_{h}(x)=S_{F C D}\left(e^{-K x / L}+e_{h}^{-K(W-x) / L}\right)
$$

sendo $S_{F C D}$ o encolhimento transversal (CD) livre, $L$ o comprimento do passe livre na seção de secadores, $W$ a largura do papel no rolo $\operatorname{couch}^{49}$ e $x$ a distância a partir de uma borda.

$S_{d 1} \quad$ estreitamento mecânico na seção de secagem referente ao efeito dos passes entre os componentes da secagem. $S_{d 1}=K_{d} D_{d}$, sendo $K_{d}$ o coeficiente de estreitamento na secagem, $D_{d}$ um fator de acomodação do efeito do passe da seção de secagem.

$S_{d 2} \quad$ estreitamento mecânico na seção de secagem referente ao efeito da tensão de contração na direção longitudinal do papel. $S_{d 2}=K_{d} S_{F M D}$, sendo o $K_{d}$ o coeficiente de estreitamento na secagem e $S_{F M D}$ o encolhimento MD livre.

\footnotetext{
${ }^{49}$ Rolo de sucção que ocupa a última posição no formador da máquina de papel, de onde a folha é transferida para a seção de prensas úmidas.
} 
Seção de prensas: Para a seção de prensas, assumiu-se que os diversos passes existentes no percurso da folha entre o rolo couch (na saída do formador) até atingir o primeiro cilindro secador, pudessem ser aproximados a um passe equivalente, $D_{p}$, cujo efeito produz estreitamento da folha proporcional ao fator $K_{p}$. O passe $D_{p}$ pode variar em função da operação da máquina, especialmente para diferentes tipos de papel, devido ao seu efeito de controle sobre a tensão no papel na seção de secagem, dependendo também do grau de adesão do papel aos rolos das prensas, entre vários outros fatores. Segundo Constantino, I'Anson e Sampson [2005], medições realizadas em uma máquina comercial $^{50}$, sugeriram que o estreitamento da folha entre a saída do formador e o início da seção de secagem pode ser de pequena magnitude $(<0,6 \%)$, a despeito do passe total nesta seção, de mais de $6 \%$. Hoole et al.[1999] encontraram valores semelhantes para uma máquina de papel imprensa, em torno de $0,4 \%$ entre o rolo pick-up ${ }^{51}$ da seção de prensas e o primeiro cilindro secador (neste caso o encolhimento total medido no produto final foi de $3.4 \%$ ).

Encolhimento higroscópico: O encolhimento transversal (CD) higroscópico depende da distância entre o ponto considerado e a borda do papel (similar à 2.11). A equação (2.13) determina a forma do perfil do encolhimento transversal (CD). O parâmetro $L$ usado na mesma equação representa o comprimento do passe.

Encolhimento mecânico na seção de secagem: Dois componentes de estreitamento da folha foram assumidos, de forma a produzirem uma contração uniforme em toda a largura da folha. O primeiro $\left(S_{d l}\right)$ se refere ao estreitamento mecânico que ocorre em resposta ao efeito dos passes entre componentes da seção de secagem. O segundo resulta da tensão criada no papel pelo potencial de encolhimento na direção longitudinal (MD).

O modelo descrito acima foi aplicado em uma máquina comercial, a fim de analisar a variação dos perfis de encolhimento transversal (CD) observados para diversos papéis produzidos. Com a seleção adequada de parâmetros para a equação (2.12), Constantino, I'Anson e Sampson [2005] encontraram curvas para diferentes perfis de encolhimento transversal $(\mathrm{CD})$ correspondentes a diferentes condições de operação, e.g., variações de

\footnotetext{
${ }^{50}$ Máquina de papel para imprimir e escrever e similares, produzindo papel reprográfico (copy paper), com gramaturas de 70-100 g.m $\mathrm{m}^{-2}$, a velocidades operacionais de até $1.000 \mathrm{~m} \cdot \mathrm{min}^{-1}$, contendo uma faixa diversa de fibras recicladas na composição do papel.

${ }^{51}$ Rolo de sucção a vácuo, utilizado para a função de destaque da folha de papel da tela formadora, na passagem do formador para a seção de prensas.
} 
conteúdo de fibras recicladas e de carga mineral na composição da massa, variação do passe entre a seção de prensas e secagem, alteração da gramatura do papel e mudanças no grau de restrição ao encolhimento.

Conteúdo de fibras recicladas: A variação do conteúdo de fibras recicladas produziu variação significativa no grau de encolhimento transversal (CD). O papel produzido com $100 \%$ de fibras recicladas, comparado ao fabricado com $15 \%$ na composição, apresentou aproximadamente a mesma forma de perfil, porém com grau de encolhimento transversal (CD) superior, tanto na região central do papel - em torno de $1 \%$ - quanto nas bordas, onde a variação encontrada atingiu até 3\%, aproximadamente.

Conteúdo de carga mineral: A análise da variação da carga mineral na composição do papel, na faixa de $26 \%$ a $21 \%$, mostrou que o aumento na quantidade provocou redução no encolhimento transversal (CD), sendo que o efeito mais significante foi observado nas bordas, enquanto a alteração do encolhimento transversal (CD) na parte central da folha apresentou valores similares em todas as condições.

Passe na seção de prensas: A verificação do efeito da redução da diferença de passe na seção de prensas, de 3.6\% para 2,5\%, mostrou efeito mínimo nas bordas e mais significativo na redução do encolhimento transversal (CD) na região central do papel, porém com baixo impacto no encolhimento total (aproximadamente $0.1 \%$ ).

Gramatura do papel: A diferença de encolhimento transversal (CD) encontrada para papéis com composição similar e gramaturas de 70, 80, 90 e 100 g.m $\mathrm{m}^{-2}$ mostrou tendência de aumento de encolhimento lateral com o aumento da gramatura, provavelmente resultantes da utilização de menores diferenças de passe na seção de prensas e diferenças de orientação de fibras, devido a velocidades operacionais menores.

Restrição ao encolhimento na seção de secagem: Estudos realizados em máquina de papel imprensa de alta velocidade, $c f$. Hooole et al. [1999], mostraram o efeito de retenção do papel por meio de caixas estabilizadoras em seção de secagem com fileira única de secadores (single tier dryer) e a correspondente influência sobre o encolhimento transversal (CD). Os resultados demonstraram que o encolhimento transversal (CD) relativo (i.e., comparado com o encolhimento transversal (CD) médio) apresentou aumento significativo em posições 
transversais intermediárias, na condição em que as caixas estabilizadoras se encontravam inoperantes (Figura 2.15). Este resultado permitiu interpretar quantitativamente a variação de encolhimento por meio da modulação do parâmetro $L(m)$, na equação (2.12), como sendo causado por aumento no comprimento do passe entre secadores, introduzindo assim, o conceito de comprimento efetivo de passe na seção de secagem (Figura 2.16).

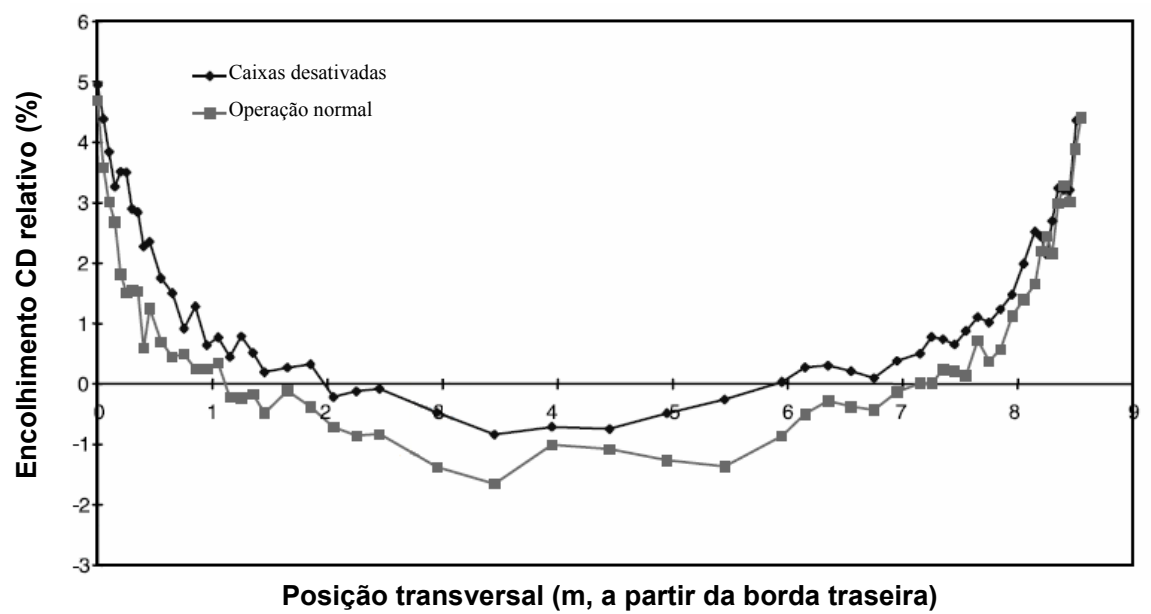

Figura 2.15. Modificação de encolhimento transversal (CD) causada pela desativação de caixas estabilizadoras da seção de secagem em uma máquina de papel imprensa de alta velocidade [Hoole et. al., 1999].

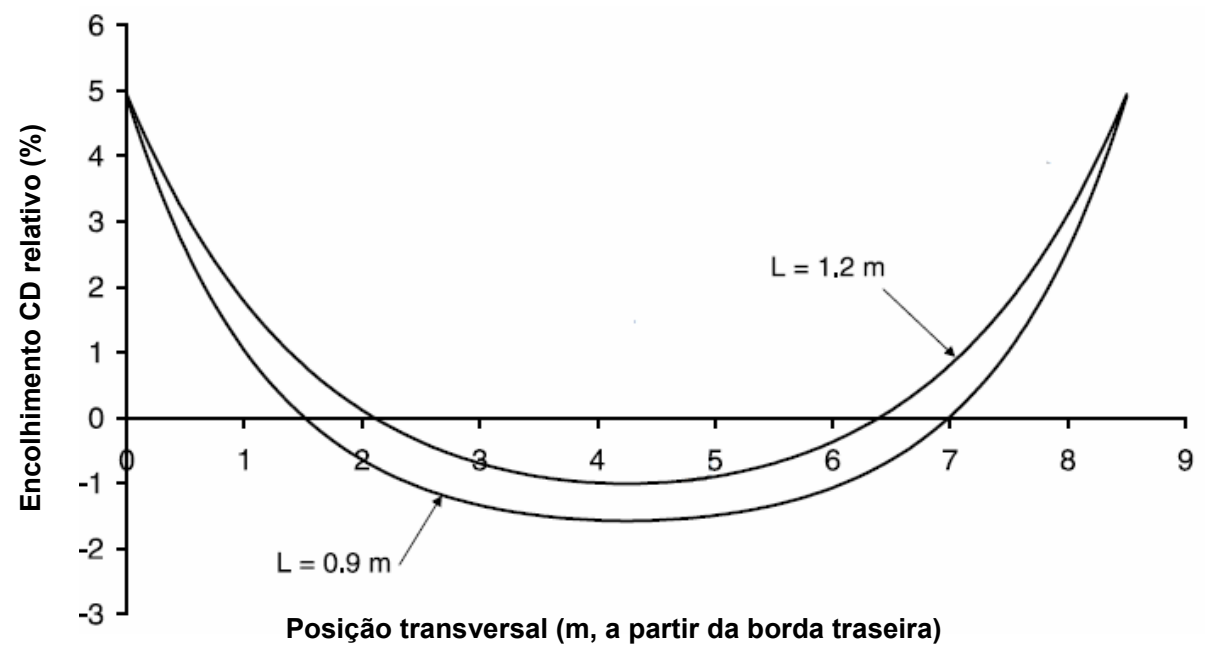

Figura 2.16. Encolhimento relativo modelado, a partir da equação (2.12), mostrando a diferença resultante da alteração do comprimento efetivo do passe entre secadores [Hoole et. al., 1999]. 
A Tabela 2.2 indica valores de ajuste para os parâmetros da equação (2.12), a fim de representar os fatores determinantes do perfil do encolhimento transversal (CD), referentes às condições operacionais da máquina de papel apresentadas nesta seção.

Tabela 2.2. Parâmetros da equação (2.12) ajustados a partir de resultados experimentais. Os valores em negrito representam as variações para cada categoria [Hoole et. al., 1999].

\begin{tabular}{ccccccccc}
\hline Parâmetros & \multicolumn{2}{c}{ Fibras recicladas } & \multicolumn{2}{c}{ Carga mineral } & \multicolumn{2}{c}{ Gramatura } & \multicolumn{2}{c}{ Caixas estabilizadoras } \\
Eq. (2.12) & $\mathbf{1 0 0 \%}$ & $\mathbf{1 5 \%}$ & $\mathbf{2 6 \%}$ & $\mathbf{2 1 \%}$ & $\mathbf{7 0} \mathbf{g} \cdot \mathbf{m}^{-2}$ & $\mathbf{1 0 0} \mathbf{~ g . \mathbf { m } ^ { - 2 }}$ & Ligadas & Desligadas \\
\hline$K_{p}$ & 0,1 & 0,1 & 0,1 & 0,1 & 0,1 & 0,1 & 0,1 & 0,1 \\
$K_{h}$ & 0,75 & 0,75 & 0,75 & 0,75 & 0,75 & 0,75 & 0,75 & 0,75 \\
$K_{d}$ & 0,45 & 0,45 & 0,375 & 0,375 & 0,375 & 0,375 & 0,18 & 0,18 \\
$L(m)$ & 0,5 & 0,5 & 0,5 & 0,5 & 0,5 & 0,5 & $\mathbf{0 , 9}$ & $\mathbf{1 , 2}$ \\
$\mathrm{W}(m)$ & 7,02 & 7,02 & 7,08 & 7,08 & 7,03 & 7,03 & 8,5 & 8,5 \\
$S_{F C D}$ & $\mathbf{0 , 0 6 4 1}$ & $\mathbf{0 , 0 3 8 9}$ & $\mathbf{0 , 0 6 6}$ & $\mathbf{0 , 0 7 0}$ & $\mathbf{0 , 0 6 3}$ & $\mathbf{0 , 0 5 1}$ & 0,0675 & 0,0675 \\
$S_{F M D}$ & $\mathbf{0 , 0 3}$ & $\mathbf{0 , 0 2}$ & $\mathbf{0 , 0 3 0}$ & $\mathbf{0 , 0 3 2}$ & $\mathbf{0 , 0 2 5}$ & $\mathbf{0 , 0 2 0}$ & 0,03 & 0,03 \\
$D_{d}$ & 0,016 & 0,016 & 0,016 & 0,016 & 0,016 & 0,016 & 0,02 & 0,02 \\
$D_{p}$ & $\mathbf{0 , 0 4}$ & $\mathbf{0 , 0 2 5}$ & $\mathbf{0 , 0 3 7}$ & $\mathbf{0 , 0 3 6}$ & $\mathbf{0 , 0 3 1}$ & $\mathbf{0 , 0 2 1}$ & 0.04 & 0.04 \\
\hline
\end{tabular}

\subsection{Técnicas para medição do perfil do encolhimento transversal (CD) do papel}

Nas últimas décadas, o interesse crescente pelo conhecimento e controle do perfil do encolhimento transversal (CD) do papel provocou a condução de pesquisas específicas sobre o tema e a produção de diversos trabalhos que se dedicaram tanto ao esclarecimento dos mecanismos envolvidos nas alterações dimensionais quanto à modelagem do fenômeno, bem como ao aprimoramento das técnicas para medição do perfil real de encolhimento transversal (CD) imposto ao papel durante a operação de secagem. Brecht e Wanka ${ }^{52}$ [1967 apud Constantino, I'Anson e Sampson, 2005] obtiveram uma estimativa para o perfil de encolhimento transversal do papel (produzido com pastas mecânica e química), a partir de amostras retiradas de uma faixa de posições transversais em máquina piloto, por meio de

52 BRECHT, W.; WANKA, R. Neue Beiträge zur Kenntniss der Dimensionsstabilität von Papieren. Das Papier, vol. 21, n. 7, p. 354, 1967. 
medição da hidroexpansão ${ }^{53}$. Este trabalho utilizou um princípio, discutido posteriormente de forma mais abrangente por Gallay [1973], que estabelece que o grau de expansão do papel, quando exposto ao vapor d'água ou à água na fase líquida, apresenta estreita correlação com o grau de encolhimento que ocorreu durante a operação de secagem. Até o início da década passada, havia pouco conhecimento sobre forma detalhada do perfil de encolhimento e sobre a sua dependência do processo de fabricação e da estrutura do papel, fato causado principalmente pela falta de técnicas apropriadas de medição. O valor da redução total na largura da folha desde a tela formadora até a enroladeira, apenas, não era suficiente para o entendimento do fenômeno, pois não fornecia informações sobre o encolhimento pontual através da direção transversal da máquina.

Um método disponível até então, para obtenção do perfil transversal, era direto e consistia na marcação de certos intervalos na folha úmida, para posterior medição da variação dimensional destes mesmos intervalos na folha seca, $c f$. apresentado por Wedel [1989a], que mencionou em seu trabalho, a aplicação de gotas finas de tinta sobre a folha, ainda na parte úmida da máquina (e.g., na parte final do formador). Os espaçamentos entre as marcas originais, neste caso, eram comparados com as distâncias entre as próprias marcas após a secagem do papel. Este tipo de procedimento, além de difícil realização prática, não oferecia boa resolução e precisão nos resultados.

Alguns pesquisadores, na mesma época, para suprir a falta de técnicas apropriadas de medição do encolhimento diferencial, usavam a variação de certas propriedades físicas do papel, na direção transversal da máquina (e.g., o alongamento, a higroexpansibilidade ou o módulo de elasticidade) como indicação indireta do perfil de encolhimento [Wedel, 1989b; Pulkowiski, 1990, 1991; Palazzolo, 1990].

Wadhams et al. [1991] mostraram que as marcas deixadas no papel pela tela formadora $^{54}$, sobre o papel, durante a formação da folha, poderiam ser usadas para medir as deformações impostas ao papel na fase de secagem. Seu método para avaliação do encolhimento transversal (CD) consistiu em medição direta, no domínio espacial, da separação das marcas periódicas da tela formadora, no papel seco, as quais foram

\footnotetext{
${ }^{53}$ Hidroexpansão: termo que denomina o efeito de expansão da estrutura do papel, por aumento de teor de umidade, quando exposto ao contato com água na fase líquida.

54 Marcas da tela formadora: sinais incorporados ao papel pela tela formadora durante a etapa de formação da folha, no extremo úmido da máquina de papel.
} 
identificadas por transmitância óptica. Uma vez que o encolhimento transversal (CD) altera a periodicidade das marcas observadas, i.e., diminui o espaçamento entre elas, na direção transversal da máquina, as separações medidas em marcas consecutivas puderam ser convertidas em graus de deformação correspondentes, tomando o espaçamento original entre os fios da tela formadora como referência de alteração dimensional nula.

O método de Wadhams et al. [1991] foi aperfeiçoado por Viitaharju e Niskanen [1993], por meio da utilização de análise de imagem, no domínio de freqüências, a partir da transformada bidimensional de Fourier, a fim de identificar e medir variações dimensionais nas marcas de tela sobre a folha de papel. As deformações produzidas na secagem foram determinadas a partir do espectro bidimensional de gramatura (ou "espectro de formação") onde as marcas da tela aparecem como picos nítidos (as coordenadas destes picos são inversamente proporcionais aos comprimentos de onda das marcas de tela - longitudinais e transversais - e aos seus harmônicos). As imagens do papel foram obtidas com um analisador de imagens, por transmitância de luz e digitalizadas em escala de cinza com 256 níveis, no formado de 512 x 512 pixels. Dois picos do espectro de freqüências bidimensional de Fourier foram selecionados, de tal forma que se encontravam próximos dos eixos transversal e longitudinal do espaço de fases e possuíam um número de onda $(s)$ pequeno. O comprimento de onda correspondente $(\lambda)$ foi calculado pela relação a seguir:

$$
\lambda=d / s
$$

onde:

$$
\begin{array}{ll}
d & \text { tamanho da imagem, } \mathrm{mm} \\
s & \text { número de onda }
\end{array}
$$

O maior valor possível para o comprimento de onda é $\lambda=d$ (um comprimento de onda por imagem) e o menor, correspondia a $\lambda=d / 256$ (dois pixels por período e 256 períodos por imagem). A resolução $(\Delta \lambda / \lambda)$ é limitada pelos valores discretos do número de onda $(s)$ e expresso pela equação, a seguir, usando (2.14):

$$
\Delta \lambda / \lambda=\lambda / d=0.7 \%-1.7 \%
$$


Para:

$\lambda=0.4 \mathrm{~mm}-1 \mathrm{~mm}$

$\mathrm{d}=60 \mathrm{~mm}$

Uma referência de encolhimento foi necessária para a determinação do valor absoluto do encolhimento transversal (CD). Uma vez que a redução total de largura da folha, entre o formador e a enroladeira, i.e., o encolhimento médio, $\varepsilon_{w}$, pode ser utilizada como referência, para estimar os graus das deformações transversais, o perfil de encolhimento transversal, $\varepsilon(y)$, foi expresso pela equação a seguir:

$$
\varepsilon(y)=1-\left[\left(1-\varepsilon_{w}\right) \cdot \lambda(y) / \lambda_{A V G}\right]
$$

onde:

$\lambda(y) \quad$ perfil transversal do comprimento de onda

$\lambda_{A V G} \quad$ valor médio do perfil $\lambda(y)$

Mesmo que nenhuma referência de encolhimento da folha de papel esteja disponível, o perfil pode ser determinado, a partir da equação (2.16), assumindo $\varepsilon_{w}=0$. O perfil se desloca para cima ou para baixo em função de $\varepsilon_{w}$, mas as amplitudes não sofrem variações significativas, pois $\left(1-\varepsilon_{w}\right) \approx 1$. A Figura 2.17 mostra resultados obtidos para perfis de encolhimento medidos em máquinas de papel comerciais.

Praast e Göttsching [1995] colaboraram para o refinamento da técnica de medição do perfil de encolhimento, criando um método que permitiu introduzir correções no cálculo das deformações do papel, considerando possíveis distorções da tela formadora em operação na máquina de papel. Um método analítico baseado na medição da geometria do padrão de marcação do papel pela tela formadora foi usado, a fim de considerar deformações causadas por características de fabricação da tela ou pelo formador da máquina. Adicionalmente, observou que a tela superior de formadores de dupla tela pode apresentar deformações significantes (considerações detalhadas sobre a geometria das distorções, $c f$. apresentadas por I'Anson et al. [2008], poderão ser encontradas mais adiante). 

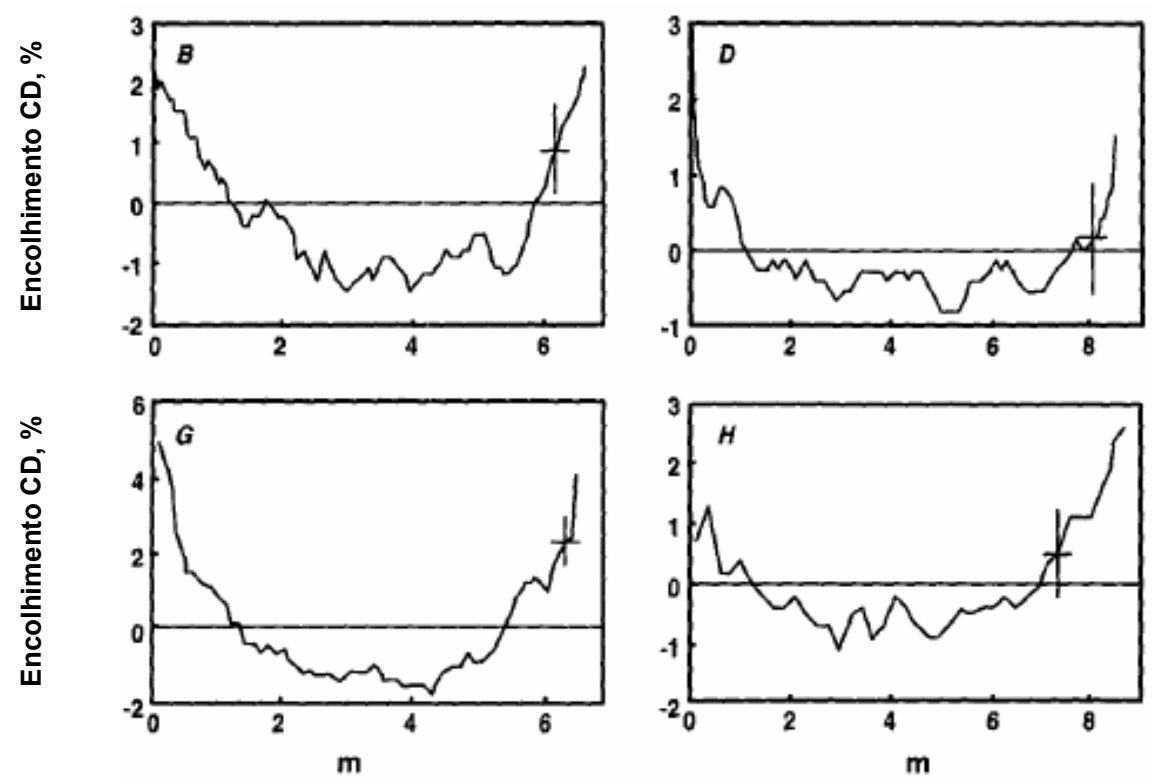

Figura 2.17. Perfis de encolhimento transversal em máquinas de papel imprensa, gramaturas de 45,5 e 48,8 g.m , $^{-2}$, pasta termomecânica (B e D) e papel para impressão, gramaturas de 75,0 e 65,0 g.m ${ }^{-2}$, pasta kraft branqueada $(\mathrm{G} \mathrm{e} \mathrm{H})$, respectivamente. A abscissa indica a distância a partir do lado de comando da máquina (frente). $\mathrm{O}$ encolhimento médio foi ajustado para $\varepsilon_{w}=0$. As cruzes indicam incerteza experimental, $c f$. equação (2.16) [Viitaharju; Niskanen, 1993].

Este método de medição, mais preciso, foi utilizado com pequenas modificações e melhorias por Hoole et al. [1999] e Hoole, I'Anson e Hoyland [2000], com a finalidade de estimar o perfil de encolhimento transversal (CD) de papel imprensa, em uma máquina comercial, para uma série de condições experimentais.

A medição do perfil de encolhimento transversal (CD) na máquina, em tempo real, foi discutida por diversos autores. Guesalaga et al. [1994] utilizaram a transformada rápida bidimensional de Fourier (2D-FFT) ${ }^{55}$, fazendo medições em máquina piloto e em máquinas de papel comerciais. Hansson e Manneberg [1999] mostraram a utilização de técnica de óptica clássica associada à transformação de Fourier (Fourier optics), para geração de imagens e análise das marcas periódicas da tela formadora, para aplicação da medição em tempo real das variações dimensionais do papel em máquinas comerciais, simulando operações em velocidades compatíveis com casos reais (de 10 a $20 \mathrm{~m} \cdot \mathrm{s}^{-1}$ ). O método foi utilizado para análise de amostras retiradas de uma tira de papel tomada na direção transversal da máquina,

\footnotetext{
55 Transformada bidimensional rápida de Fourier (two dimensional Fast Fourier Transform).
} 
onde se mediu o encolhimento relativo em 17 posições eqüidistantes ao longo da largura da máquina, $c f$. mostrado na Figura 2.18. Kaestner e Nilsson [2003] utilizaram a transformada rápida de Fourier (FFT) em conjunto com um sensor unidimensional de fluorescência, a fim de detectar as variações de conteúdo de lignina nas marcas da tela formadora (embora aparentemente não tenha sido considerado o efeito da distorção da tela em seus cálculos). I'Anson, Sampson [2004] apresentaram uma técnica que utilizava o deslocamento do lábio da caixa de entrada (ou os níveis de diluição) em posições ao longo da direção transversal em conjunto com o perfil de gramatura, com a finalidade de estimar, em tempo real, o encolhimento transversal (CD), depois de calibração, considerando o perfil medido em laboratório.

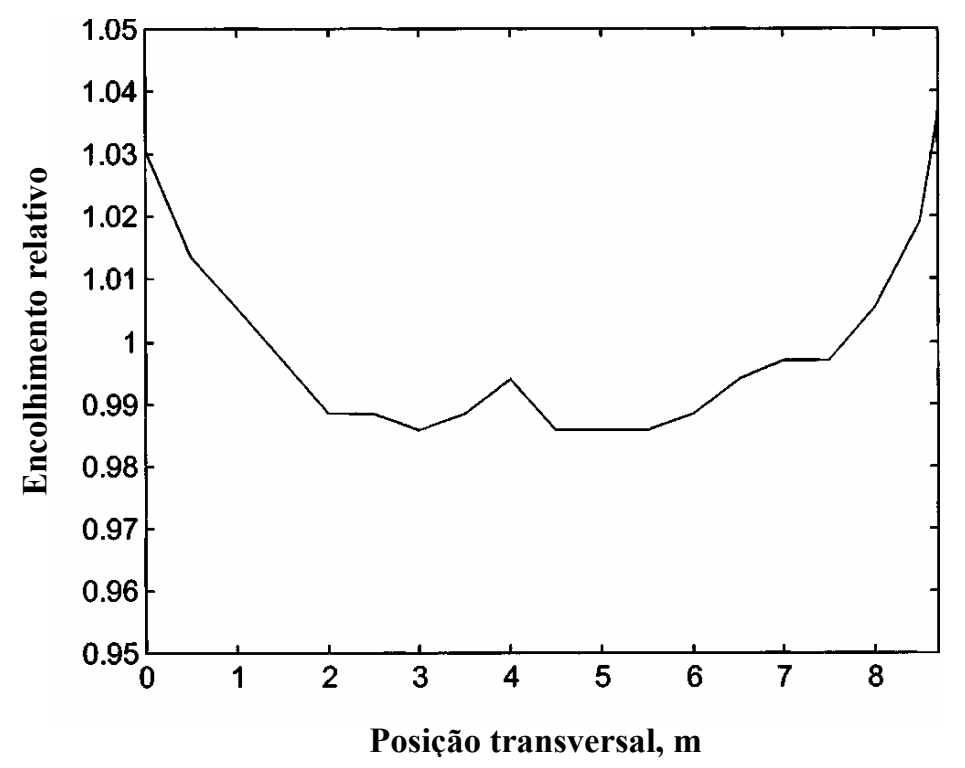

Figura 2.18. Perfil de encolhimento transversal obtido com uso de técnica óptica com transformação de Fourier [Hansson; Manneberg, 1999].

Recentemente, I'Anson et al. [2008] apresentaram novo enfoque para método de medição do perfil transversal de encolhimento transversal (CD) baseado na transformada rápida de Fourier e nas marcas da tela formadora, deixadas no papel, porém, retomando as considerações de Praast e Göttsching [1995] com respeito às distorções que a tela formadora pode sofrer em operação na máquina. Nesta abordagem, os autores demonstram que o método usado permite a utilização de relações geométricas da tela formadora em conjunto com a medição das alterações dimensionais das marcas periódicas, para estimar o encolhimento. Segundo os autores, o método apresenta a vantagem de ser mais tolerante quanto aos 
protocolos de amostragem, ter certa independência em relação à análise do operador e apresentar melhor precisão.

\subsection{Efeito do encolhimento sobre as propriedades do papel}

O perfil de encolhimento transversal (CD) representa, inequivocadamente, um fator de grande importância no processo de fabricação, dada sua forte interferência em várias propriedades transversais do papel. O encolhimento do papel, durante a etapa de secagem, se reflete de forma adversa na sua qualidade. As diferenças de encolhimento transversal (CD) na direção transversal da máquina levam a grandes variações nas propriedades das bordas, em comparação com a parte central da folha, o que representa um problema comum para os fabricantes de papel.

As propriedades mecânicas medidas na direção transversal (CD) podem apresentar variações percentuais significativas ao longo da largura da folha. Nas bordas, a resistência à tração e o módulo de elasticidade, ou módulo de Young, são menores que na região central, porém o alongamento, ao contrário, apresenta valores maiores. Em contraste, propriedades medidas na direção longitudinal (MD), exibem pouca variação ao longo da direção transversal da folha. Segundo Niskanen e Kärenlamp [1998] a variação do módulo de elasticidade CD pode atingir até $30 \%$, enquanto variações da ordem de $10 \%$ podem ser encontradas na propriedade MD. A relação praticamente linear que existe entre o grau de encolhimento e o índice de alongamento do papel já é bem conhecida, desde a divulgação do trabalho de Gates e Kenworthy [1963], cujos resultados se encontram na Figura 2.19.

Na mesma época, estudos desenvolvidos por Setterholm e Chilson [1965] também haviam constatado o efeito do encolhimento sobre várias propriedades do papel. Observaram que um aumento na restrição ao encolhimento resultava em acréscimo no valor de elasticidade, diminuição no alongamento e aumento na resistência à tração.

O encolhimento irregular do papel também deforma o perfil de gramatura, levando ao aumento proporcional nas bordas que devem ser compensados pela diminuição da abertura entre os lábios da caixa de entrada, na região correspondente, o que induz o aparecimento de 
fluxos transversais no jato de massa e conseqüente desalinhamento na orientação de fibras ${ }^{56}$ [Vitaharju; Niskanen, 1993].

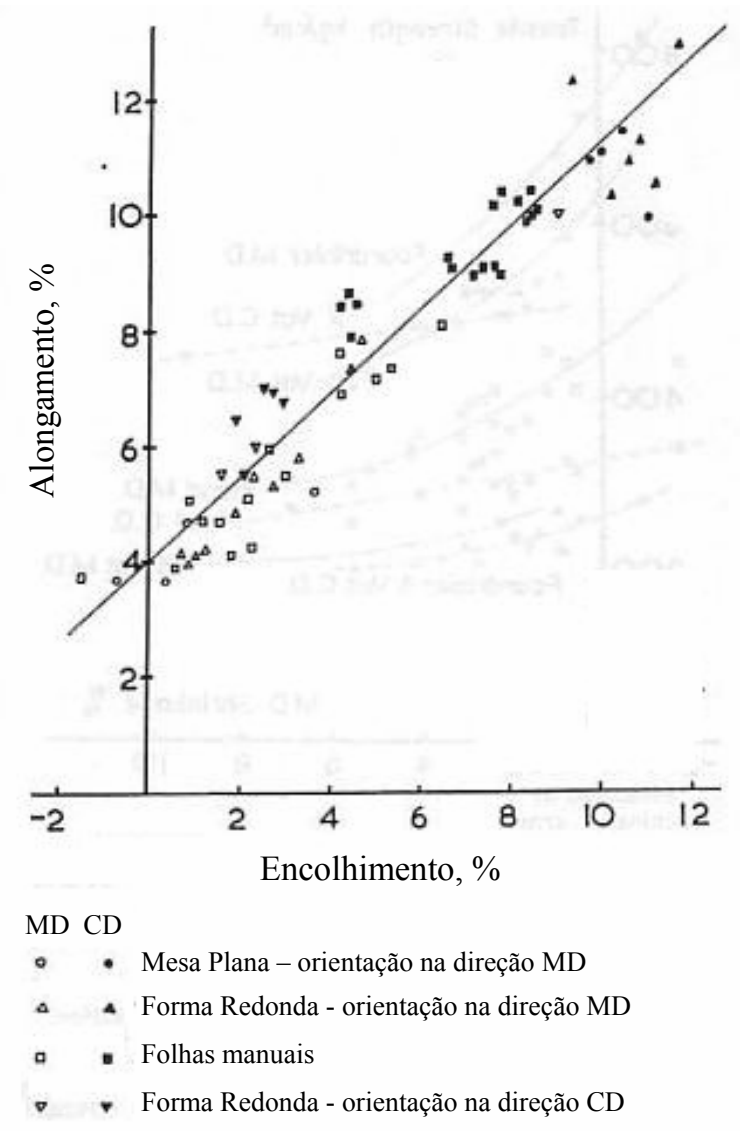

Figura 2.19. Correlação entre alongamento e encolhimento - pasta química sulfito de fibra longa, branqueada, refinada a 50 SR [Gates; Kenworthy, 1963].

\subsection{Efeito do encolhimento sobre a estabilidade dimensional do papel}

A estabilidade dimensional do papel é uma das características mais fundamentais para maximizar o desempenho na sua utilização final e pode representar uma grande barreira para o desenvolvimento de novos produtos derivados do papel [Uesaka, 1991]. A estabilidade dimensional depende diretamente da higroexpansibilidade do papel. Baixos índices desta propriedade caracterizam o maior grau de estabilidade dimensional do papel. O conhecimento

\footnotetext{
${ }^{56}$ Nas caixas de entrada mais modernas, foi incorporado um sistema de controle de perfil de peso por diluição da massa através de setores na largura da caixa de entrada, que permite melhorar a distribuição de gramatura nas bordas da folha, com menor impacto sobre distúrbios na orientação de fibras.
} 
da higroexpansibilidade, da sua relação com outras propriedades e da interação com o encolhimento transversal do papel, resultam em possibilidade efetiva de controle de qualidade do produto final.

\subsubsection{A higroexpansibilidade do papel}

A higroexpansibilidade do papel tem origem na interação das fibras celulósicas presentes na sua composição com água. Esta propriedade, responsável por alterações dimensionais do papel em conseqüência de variações do teor de umidade do papel, constituise, em geral, em uma função complexa da estrutura do papel e das propriedades higroelásticas das fibras celulósicas, que se dilatam ou se contraem sob a influência da absorção ou da dessorção de água, respectivamente. A variação do teor de umidade do papel pode ser determinada por diversas situações, tais como nas alterações de umidade relativa ou de temperatura do ambiente no qual o papel se encontra em equilíbrio, na aplicação de água, na fase líquida, sobre a superfície do papel (e.g., em processos de impressão off-set) ou, também, durante o aquecimento da folha em processos reprográficos, como acontece nas máquinas copiadoras, na etapa de fusão do toner sobre o papel.

Kajanto e Niskanen [1998] apresentaram o coeficiente de higroexpansibilidade do papel definido pela razão entre a higroexpansão e a variação correspondente do teor de umidade, ou seja:

$$
\beta=\frac{\varepsilon_{h}}{\Delta W_{p}}
$$

onde:

$\beta \quad$ coeficiente de higroexpansibilidade

$\varepsilon_{h} \quad$ higroexpansão, \%

$\Delta W p \quad$ variação do teor de umidade do papel, $\%$

O coeficiente de higroexpansibilidade $\beta$ corresponde ao gradiente da região linear e reversível da curva de higroexpansão em função da variação do teor de umidade do papel [Nanri; Uesaka, 1993]. Embora Uesaka, Moss e Nanri [1991] defendam que o coeficiente de higroexpansibilidade deva ser monitorado em função do teor de umidade do papel e não da 
umidade relativa do ar, devido ao forte efeito de histerese encontrado entre a umidade do papel e a umidade relativa do ar, por praticidade, a caracterização da higroexpansibilidade do papel é feita por meio de medição da higroexpansão de uma amostra, quando submetida a uma dada variação na umidade relativa do ambiente.

A norma ISO 8226-1 [International Organization for Standardization, 1994], que estabelece a metodologia atualmente utilizada como padrão internacional de medição, define a higroexpansibilidade como a alteração dimensional do papel que ocorre em função da relaxação de tensões residuais e da dilatação ou contração das fibras causada por absorção ou dessorção de água, respectivamente. A proporção entre os dois mecanismos que causam higroexpansão depende do limite superior da umidade relativa do ambiente. Para o propósito da norma mencionada, foi estabelecido o limite superior de $68 \%$, a fim de minimizar os efeitos da relaxação de tensões internas sobre a higroexpansão do papel. A expressão a seguir define o cálculo da higroexpansibilidade, na faixa de umidade relativa do ar de 33 a $66 \%$ :

$$
X=\frac{\left(l_{66}-l_{33}\right)}{l_{0}} \times 100
$$

onde:

$X \quad$ higroexpansibilidade, $\%$

$l_{0} \quad$ comprimento inicial do corpo de prova, em equilíbrio, na condição de umidade relativa do ar de $(50 \pm 5) \%$, $\mathrm{mm}$

$l_{33}$ comprimento do corpo de prova, em equilíbrio, na condição de umidade relativa do ar de $(33 \pm 2) \%$, $\mathrm{mm}$

$l_{66} \quad$ comprimento do corpo de prova, em equilíbrio, na condição de umidade relativa do ar de $(66 \pm 2) \%$, $\mathrm{mm}$

Tradicionalmente, para as determinações experimentais de higroexpansibilidade, $\mathrm{o}$ padrão atual adotado baseia-se, então, em caracterizar a higroexpansão do papel. O método consiste em levar amostras ao equilíbrio com um ambiente a uma dada umidade relativa e temperatura. Após alteração da umidade relativa da câmara de teste, as amostras são novamente levadas ao equilíbrio, porém com um nível mais elevado de umidade relativa. A higroexpansão, i.e., a variação dimensional do papel causada pela alteração de umidade relativa do ar é, então, medida e usada para caracterizar a higroexpansibilidade do papel, $c f$. 
determinado pela norma ISO 8226-1 [International Organization for Standardization, 1994], mencionada anteriormente.

$\mathrm{Na}$ verdade, a higroexpansão do papel é extremamente dependente do histórico de variação da umidade. Uesaka, Moss e Nanri [1991] caracterizaram experimentalmente a higroexpansibilidade por meio da determinação da razão entre a deformação dimensional do papel e a correspondente variação do teor de umidade, na região linear e reversível da curva de higroexpansão, em função do teor de umidade da folha. Lif et al. [1995] apresentaram um método de caracterização da higroexpansibilidade do papel, obtida diretamente de fotografias eletrônicas, a partir de disparos de laser. Böstrom [2001] utilizou metodologia similar para medir a higroexpansão dinâmica de amostras de papel. Nanko e Ohsawa [1990]; Nanko, Asano e Ohsawa [1991]; Nanko e Tada [1995] e Nanko e Wu [1995] utilizam microscópio de varredura a laser para verificar o mecanismo de higroexpansibilidade em amostras de papel. Embora indiretamente ligada à medição de higroexpansibilidade, têm-se medições da anisotropia de orientação das fibras, na superfície do papel por difração de laser, em Fiadeiro et al. [2002]. Um novo método para medição da deformação dinâmica da higroexpansão do papel em impressora off-set foi introduzido por Paukku e Parola [2004], que consiste em monitoramento da folha de papel por meio de câmeras de varredura contínua, a fim de medir a posição e a largura da folha, antes e depois das unidades de impressão.

Vários fatores influenciam na higroexpansibilidade do papel, $c f$. apresentado por Caufield [1988], bem como por outros pesquisadores, que também estudaram os efeitos da composição da pasta celulósica, da refinação, da efetividade da interligação entre as fibras e das operações presentes na fabricação do papel em máquinas industriais, e.g., da formação da folha e orientação das fibras, prensagem úmida, secagem e acabamento do papel. De especial interesse, destaca-se a operação de secagem, que produz forte impacto sobre o perfil de higroexpansibilidade do papel e, por conseqüência, sobre a estabilidade dimensional.

\subsubsection{Efeito do encolhimento na higroexpansibilidade do papel}

A higroexpansibilidade do papel é bastante afetada pelo encolhimento transversal. Nas bordas encontram-se valores maiores que na região central, podendo atingir diferenças acima de $50 \%$ em papéis reprográficos produzidos com fibras de eucalipto [Mendes, 2006]. Distúrbios desta natureza provocam impacto negativo sobre o nível e a uniformidade da 
estabilidade dimensional ao longo da largura do papel acabado. Na utilização final, o papel proveniente de bobinas correspondentes às extremidades da máquina apresentará estabilidade dimensional inferior àquele retirado da parte central da folha. A instabilidade dimensional leva a diversos problemas nas operações de conversão e de impressão do papel.

Vários estudos mostram que a higroexpansibilidade do papel é influenciada, de forma significativa e diretamente proporcional, pela intensidade do encolhimento da folha durante o processo de secagem. Sua minimização nesta etapa de fabricação torna-se fator primordial para a melhoria significativa da estabilidade dimensional $c f$. discutido por Juppi e Kaihovirta [2002, 2003]; Fellers et al. [2003] e por vários outros autores, desde a publicação dos trabalhos de Nordman [1958], que encontrou uma correlação essencialmente linear entre o encolhimento de folha e a higroexpansibilidade do papel (Figura 2.20), mostrando que o aumento da restrição ao encolhimento pode diminuir o nível de higroexpansibilidade do papel e aumentar a estabilidade dimensional.

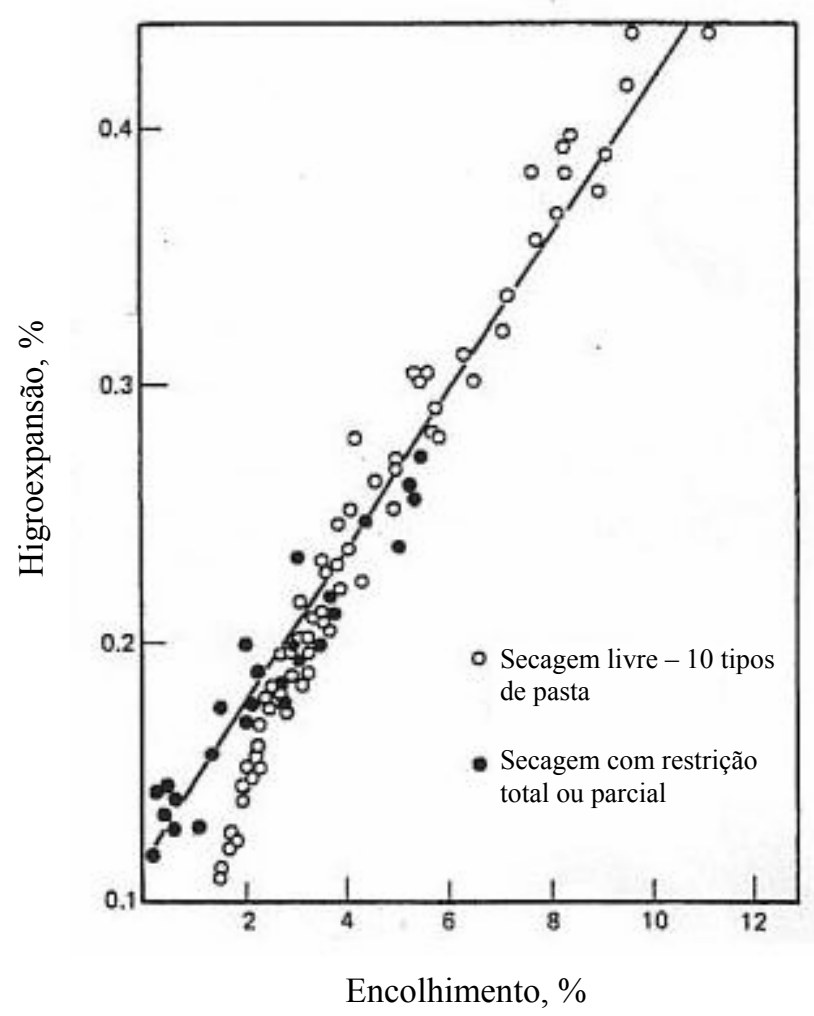

Figura 2.20. Relação entre higroexpansão e encolhimento para folhas secadas sob restrição ao encolhimento e para folhas produzidas a partir de 10 tipos de pastas celulósicas, refinadas e secadas livremente [Nordman, 1958]. 
$\mathrm{Na}$ mesma direção, experimentos realizados por Eklund [1969] demonstraram a melhoria na estabilidade dimensional em função da tensão aplicada à folha durante a secagem. Os resultados indicaram que o aumento da tensão produzia diminuição na higroexpansibilidade. Resultados semelhantes foram encontrados e descritos por George ${ }^{57}$ [1958 apud Pulkowski, 1990] e Salmén et al. [1987] cf. mostrado na Figura 2.21.

Em função destes resultados, Pulkowski [1991] utilizou as medições de alongamento de folhas produzidas em máquinas de papel industriais, como indicadores para medição indireta de encolhimento ${ }^{58}$. Setterholm e Chilson [1965] verificaram que o encolhimento controlado, por meio da restrição ao movimento da folha durante a secagem, desenvolveu as propriedades elásticas do papel. Da mesma forma que Gates e Kenworthy [1963], observaram que o aumento na restrição ao encolhimento proporcionou um incremento no módulo de elasticidade, diminuição no alongamento e aumento na resistência à tração para uma dada densidade da folha de papel.

O encolhimento de papel tem efeito peculiar em uma máquina de papel: o encolhimento transversal (CD) é inversamente proporcional à resistência à tração nesta mesma direção, o que pode ser visualizado ao longo do presente trabalho. Isto pode permitir, segundo Paukku e Parola [2004], tomar a resistência à tração em CD como uma estimativa de encolhimento. Por outro lado, Viitaharju e Niskanen [1993], comparando o encolhimento lateral com o perfil $\mathrm{CD}$ de propriedades, mostram que, em geral, estas propriedades não podem ser utilizadas como medida indireta de encolhimento do papel.

Salmén et al. [1987] realizaram estudos para investigar o efeito da curvatura (curl) das fibras, do conteúdo de finos na massa e da intensidade de prensagem sobre a higroexpansibilidade do papel secado com ou sem restrição ao encolhimento. Seus experimentos mostraram que o processo de secagem com restrição ao encolhimento resulta em menor higroexpansibilidade do papel e, adicionalmente, mostraram que o grau de refinação, o conteúdo de finos e a intensidade de prensagem têm pouco efeito sobre a higroexpansibilidade, quando a secagem é feita com restrição ao encolhimento (ver Figura 2.21). Nanri e Uesaka [1993] estudaram a estabilidade dimensional de pastas mecânicas e a

\footnotetext{
${ }^{57}$ George, H.O. Methods of affecting the Dimensional Stability of Paper, TAPPI, vol.41, n.1, 1958, p. 31-33.

${ }^{58}$ Segundo Viitaharju e Niskanen [1993], em geral, a variação transversal (CD) de propriedades não pode ser usada como medida indireta do encolhimento para o papel jornal.
} 
relação entre encolhimento durante a secagem e higroexpansibilidade do papel. Os resultados obtidos indicaram que a aplicação de restrição ao encolhimento da folha na máquina de papel, com o objetivo de reduzir a higroexpansibilidade, pode ser menos efetiva para papéis fabricados a partir de polpas mecânicas, devido ao menor encolhimento durante a secagem, se comparado a papéis fabricados com pastas químicas.

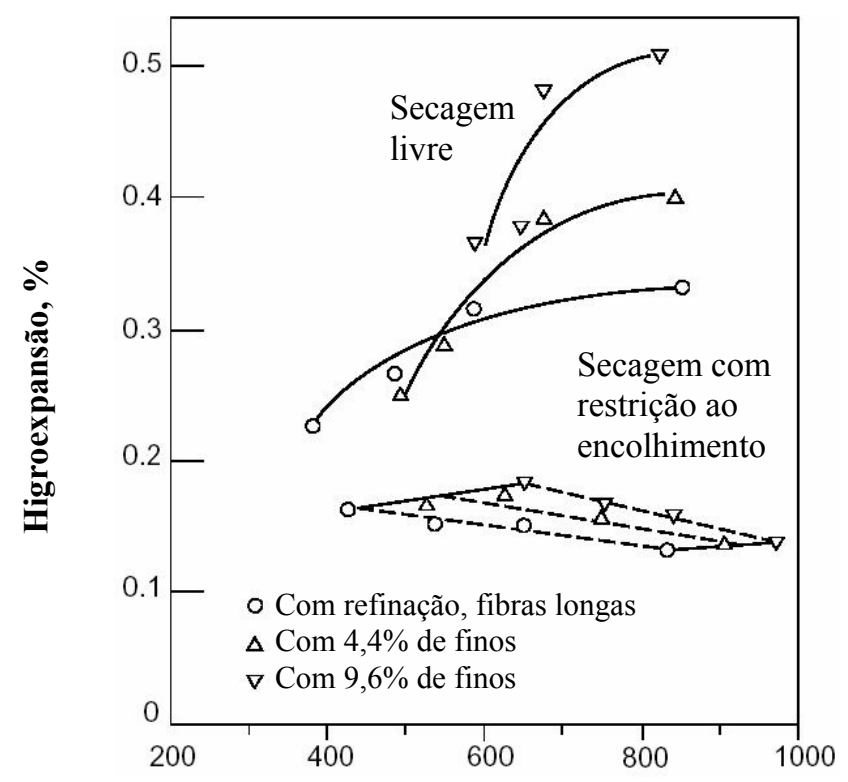

Densidade do papel, kg. $\mathrm{m}^{3}$

Figura 2.21. Higroexpansão (medida para a variação de umidade relativa do ar de $30 \%$ a $60 \%$, com $\mathrm{T}=23^{\circ} \mathrm{C}$ ) $v s$. densidade do papel, para folhas isotrópicas produzidas com pasta química (kraft) de fibras longas, refinada, com diferentes conteúdos de finos, para folhas secadas livremente (linhas contínuas) e secadas com restrição ao encolhimento (linhas tracejadas). A densidade foi variada por meio da carga de prensagem [Salmén et al., 1987].

O estudo realizado por Parsons ${ }^{59}$ [1972 apud Pulkowski, 1990] revelou a existência de uma interação na direção $\mathrm{CD}$ durante o processo de secagem. Observou que maiores intensidades de restrição na direção MD produziam maiores encolhimentos na direção CD. Mais recentemente, Lindem [1994] determinou que uma deformação na folha úmida de 1\% na direção longitudinal causava uma contração de $1 \%$ na direção transversal, em experimento com papel contendo $65 \%$ de sólidos.

\footnotetext{
${ }^{59}$ Parsons, S.R. Effect of Drying Restraint Before and During Drying on Edgewise Compressive Properties of handsheets. TAPPI, vol.55, n.3, 1972, p.1516-1521.
} 


\section{CAPÍTULO 3}

\section{APLICAÇÃO DE ANÁLISE DE IMAGEM EM DIAGNÓSTICOS DO PAPEL}

As técnicas de análise de imagem têm sido aplicadas de forma ampla e crescente em métodos de pesquisa e de melhoria de processos na indústria de papel e celulose. Disponíveis em formas mais acessíveis a partir de meados da década de 1970, os sistemas de medição suportados por processamento e análise de imagem têm sido usados com diversas finalidades, desde a medição de propriedades das fibras de celulose, até a avaliação da qualidade de impressão do papel. A norma TIP 0804-09 [Technical Association of the Pulp and Paper Industry, 2001] apresenta diretrizes básicas concernentes à utilização de técnicas de análise de imagem para determinação de propriedades visuais da polpa celulósica, do papel e cartão e de produtos correspondentes submetidos a operações de impressão ou revestimento.

Os equipamentos destinados a estas aplicações evoluíram de forma marcante nas últimas décadas. Inicialmente, dispositivos complexos e caros eram tipicamente utilizados somente em laboratórios de pesquisa e desenvolvimento. Atualmente, encontra-se disponível no mercado uma variedade de dispositivos para aquisição de imagem, baseados em conjuntos bidimensionais de sensores $\mathrm{CCD}^{60}$, tais como câmeras eletrônicas e digitalizadores de mesa (flatbed scanners) de diversos tipos. A partir de meados da década de 1980, os computadores de mesa passaram a apresentar velocidades de processamento suficientes para disponibilizar amplamente os programas de processamento de imagem, embora até o início da década de 1990 fosse ainda necessário realizar a maior parte do processamento das imagens em áreas de memória especialmente criadas para esta função, denominadas "estruturas de armazenamento (framestores)" [I'Anson, 2001]. Nos dias atuais, é possível executar programas específicos para processamento e análise de imagem, em qualquer computador pessoal (PC).

Este capítulo apresenta aspectos gerais sobre processamento e análise de imagens de papel (3.1), exemplos específicos de aplicação na indústria de papel e celulose (3.2), os fundamentos das imagens digitais (3.3), as transformadas de Fourier (3.4) e a utilização da

\footnotetext{
${ }^{60}$ Charge-Coupled Diode (Dispositivo de Carga Acoplada). É um sensor para captação de imagens formado por um circuito integrado contendo uma matriz de capacitores ligados (acoplados). Os CCDs são usados em fotografia digital, imagens de satélites, equipamentos médico-hospitalares (como por exemplo os endoscópios), e na astronomia (particularmente em fotometria, óptica e espectroscopia UV e técnicas de alta velocidade).
} 
análise de imagem para identificação de marcas periódicas de telas formadoras deixadas no papel durante a etapa de formação da folha (3.5).

\subsection{Processamento e análise de imagens}

A Análise de Imagem se refere a um conjunto de técnicas de medição, cujo objetivo recai na extração de informações contidas em imagens. Está relacionada, usualmente, à captura de imagens digitais, ao seu processamento e a subseqüente análise por meios computacionais. A técnica de análise de imagem permite a obtenção de conjuntos de dados bidimensionais, a partir de várias fontes, e seu tratamento adequado para medições dos parâmetros de interesse. Em geral, estes dados se assemelham ao que pode descrito como uma fotografia digital obtida com uma câmera ou um digitalizador, dentre outras possíveis fontes (e.g., por meio de raios- $\beta$ e raios-X). A literatura mostra que não é muito evidente o ponto de separação entre os procedimentos de Processamento de Imagem e Análise de Imagem. Uma vertente possível assume que o processamento de imagem tem como característica principal que a entrada e saída do processo consistem de imagens digitais, conceito este apresentado por Gonzales e Woods [2008, p.2] e bastante apropriado para o desenvolvimento deste trabalho, considerando o processamento das imagens de papel por meio da transformada de Fourier como meio de preparação para a medição de parâmetros de interesse, no domínio das freqüências.

A principal força motora que impulsionou o desenvolvimento das técnicas de análise de imagem pode ser facilmente entendida dada a tendência humana de se fixar fortemente ao sentido da visão, determinando a busca de meios de medição alinhados com este forma de percepção do mundo. Embora não se constitua na única forma de se obter informações contidas em imagens, freqüentemente representa a mais prática e conveniente. Como exemplo, sabe-se que é possível, manualmente, medir e contar a quantidade de partículas de tinta (ink specks) contidas em uma amostra de celulose utilizando-se um microscópio e um gabarito quadriculado. Porém, o procedimento de análise de imagem oferece a vantagem de fazer computacionalmente a separação, a medição e contagem destas partículas de forma rápida e precisa.

As imagens digitais analisadas não são contínuas, mas formadas por uma grande quantidade de pontos, que assumem valores discretos, dentro de uma faixa limitada, os quais 
definem sua aparência. Freqüentemente estes valores representam um nível de cinza (gray scale) ou uma cor, embora possam também representar uma altura ou uma pressão, por exemplo. Cada ponto que forma uma imagem é denominado pel ou pixel ${ }^{61}$. A quantidade de pixels em uma imagem define a sua resolução, porém a faixa de valores que cada pixel pode assumir determina os limites de contraste de brilho da imagem. Tipicamente, uma imagem digital contém 512 x 512 pixels, sendo que cada pixel assume 1 dentre 256 valores possíveis da escala de intensidades, correspondendo a uma profundidade de níveis de cinza de 8 bits ${ }^{62}$ [I'Anson, 1995a, 1995b, 2001, I'Anson et al., 2008]. Neste caso, a imagem digital ocupa um espaço de memória do computador em torno de $260 \mathrm{kB}$ e apresenta aparência similar à de uma fotografia formada por gradações contínuas de preto e branco. Para os propósitos de diagnósticos de propriedades do papel, a análise de imagem pode ser considerada como um método com o objetivo de obter informações da imagem captada após seu processamento para remover as informações não desejadas, ou seja, um método com a finalidade de filtrar e disponibilizar os dados de interesse.

A análise de imagem, utilizada para medição analítica ${ }^{63}$ e observação fora-de-máquina (i.e., em procedimentos laboratoriais), constitui-se freqüentemente na solução mais adequada para os requisitos de diagnósticos e de atividades de controle estatístico de qualidade.

\subsection{Utilização da Análise de Imagem na indústria de papel e celulose}

As técnicas de análise de imagem têm uma história longa e de sucesso, ligada à tecnologia do papel e de impressão. A maioria dos estabelecimentos de pesquisa, ao redor do mundo, dispõem de recursos para análise de imagem, o que tem direcionado o desenvolvimento de uma base substancial de conhecimento e um extenso campo de aplicações. Na indústria de papel e celulose, tais aplicações podem ser classificadas, em geral, em três áreas principais de interesse: o estudo das propriedades das fibras celulósicas, da estrutura do papel e da qualidade de impressão [Praast, 1996]. Humphrey [1998, p.21] destaca aplicações específicas mais comumente usadas na análise de formação, medições de partículas e de qualidade do processo de impressão.

\footnotetext{
${ }^{61}$ Pel ou pixel são abreviaturas utilizadas para picture element (elemento de imagem).

${ }^{62}$ Bit é a menor unidade na notação numérica binária; a menor unidade de dado que um sistema pode tratar.

${ }^{63}$ A medição analítica tem o objetivo de produzir uma "representação fiel" da amostra de papel sob análise.
} 
Vários trabalhos fornecem descrições de sistemas dedicados à análise de imagem e sumários dos seus recursos e oportunidades que apresentam para aplicações na indústria de papel e celulose.

Praast, Greeve e Gottsching [1986] apresentaram configurações de sistemas de análise de imagem computadorizados associados ao seu uso para análise de propriedades do papel. Demonstraram que os sistemas apresentados proviam um bom compromisso entre eficiência e flexibilidade, dado que certos algoritmos para solução de problemas particulares podiam ser facilmente integrados ao programa operacional (software) do analisador de imagens, dispensando a necessidade de componentes (hardware) adicionais. Humphrey [1998] discutiu diferentes aplicações da análise de imagem dentro da indústria de papel, apresentou equipamentos para captação de imagens e considerações sobre o desenvolvimento de diversas aplicações, e.g., da caracterização das fibras até a análise da qualidade de impressão, prevendo o uso crescente destas técnicas nos laboratórios das fábricas de papel. Danilewicz [1991], em seu trabalho, justificou o uso de técnicas de análise de imagem em laboratórios de desenvolvimento, com aplicações em análises quantitativas de micro e macro-variações, análise de destruição de carga mineral na direção $z$ e estudos do efeito da formação na uniformidade de impressão.

MacGregor [1992] mostrou técnicas de análise de imagem aplicadas ao monitoramento de propriedades de papel, tais como formação, lisura, propriedades superficiais e qualidade de impressão. Discutiu, ainda, aspectos do uso destas técnicas, para direcionar critérios, tais como orientação de fibras, distribuição de partículas pequenas, mecanismos de formação, estabilidade superficial e efeitos do encolhimento diferencial e da higroexpansibilidade do papel. Brasher [1992] descreveu os princípios de análise de imagens digitais e sua utilização nos métodos de teste do papel. Apresentou, em seu trabalho, as etapas de digitalização, a partir de imagens de vídeo, que mostraram as fases de detecção e análise de objetos de interesse por meios computadorizados, enfatizando o uso vantajoso da análise de imagens para execução de testes no papel, pois permite quantificar parâmetros normalmente difíceis de serem medidos de outras formas e também, observar características que, de outra maneira, se tornaria muito difícil, mesmo impossível, de serem visualizadas. A detecção de marcas produzidas por telas formadoras e a medição da formação do papel são exemplos dessas aplicações. 
Johansson e Aléxis [1992] descreveram o desenvolvimento da análise de imagem como técnica de medição e suas aplicações na indústria de papel, em procedimentos de laboratório e também em medições online, a fim de examinar matérias primas, cargas minerais, propriedades de fibras, propriedades do papel, características de impressão, contagem de impurezas em pastas produzidas com fibras recicladas e contagem de elementos em colônias de bactérias. Scott e Bliss [1993] apresentaram estudos mostrando a utilidade da análise de imagem como ferramenta apropriada para contagem de impurezas, testes de formação, análise de partículas microscópicas de tinta e análise de stickies. Segundo estes autores, as vantagens da análise de imagem referem-se à velocidade do processo e da repetibilidade de resultados. Praast [1996] discutiu aplicações de análise de imagem como ferramenta para testes de papel e seu uso na determinação de encolhimento transversal e de deformações da tela formadora.

\section{Diagnósticos por métodos transmissivos de captação de imagens}

A variabilidade de pequena escala apresentada em todos os papéis é responsável por vários defeitos relacionados ao desempenho dos produtos finais. A formação deficiente do papel pode contribuir diretamente para perdas de resistência e de opacidade e ser também responsável por problemas mais sutis, tais como aparência e marmorização de impressão. A formação do papel é tradicionalmente vista na forma de uma imagem bidimensional, cuja intensidade está relacionada à quantidade de massa em qualquer ponto considerado. $\mathrm{O}$ objetivo da análise da formação do papel incide na medição do grau e da natureza desta variabilidade de pequena escala e sumarização das informações de forma que possam ser interpretadas.

Os métodos indicados a seguir representam os mais comumente usados na captação de imagens para análise de aspectos referentes à formação ${ }^{64}$ do papel:

- Radiografia por radiação $\beta$

- Radiografia por radiação $x$

- Captação ótica (transmissão de luz)

\footnotetext{
${ }^{64}$ Métodos também aplicados à identificação de marcas produzidas por telas formadoras durante a formação da folha de papel.
} 
A técnica de radiografia com raios- $\beta$ tem sido tradicionalmente utilizada na indústria de papel $^{65}$. Foi desenvolvida para prover informação da distribuição de densidade de massa na folha. A intensidade da radiação detectada quando a amostra de papel é submetida à radiação no modo transmissivo é dependente da massa do material contida na amostra. A transmissão da radiação $\beta$ é determinada pela relação abaixo:

$$
I=I_{0} e^{(-U m W)}
$$

onde:

I Intensidade medida

$I_{0} \quad$ Intensidade original

Um Coeficiente de absorção da massa, $\mathrm{m}^{2} \cdot \mathrm{g}^{-1}$

$W \quad$ Gramatura, g.m ${ }^{-2}$

As técnicas de captação ótica são favorecidas por seu baixo custo, simplicidade e segurança. O tempo para aquisição das imagens é praticamente nulo (processo quase instantâneo), sendo que a faixa de gramaturas mensuráveis depende da natureza do material. Uma característica que deve ser considerada, entretanto, refere-se à atenuação da luz transmitida (especialmente em papéis brancos), que ocorre principalmente por dispersão (scattering) mais acentuada que nos casos da radiação $\beta$. De acordo com a lei de Beer, a transmitância de um material não dispersor pode ser definida como:

$$
I=I_{0} \cdot 10^{-O D}
$$

onde:

I Intensidade da luz transmitida

$I_{0} \quad$ Intensidade da luz incidente

$O D \quad$ Densidade ótica do material

A densidade ótica do material resulta do produto entre a sua gramatura $\left(\mathrm{g} \cdot \mathrm{m}^{-2}\right)$ e o coeficiente geral de absorção $\left(\mathrm{m}^{2} \cdot \mathrm{g}^{-1}\right)$. Uma vez que a densidade ótica do papel não varia

\footnotetext{
${ }^{65}$ Os medidores de formação AMBERTEC, comumente encontrados nos laboratórios de teste das fábricas de papel, utilizam este tipo de radiação.
} 
proporcionalmente com a gramatura, a teoria de Kubelka-Munk prediz que a transmissão de luz pode ser descrita da seguinte forma:

$$
T=\theta /(K+S) e^{(-\theta W)}
$$

onde:

$\theta \quad=K(K+2 S)^{0,5}$

$S \quad$ Coeficiente de dispersão devido à refração na interface fibra-ar $\left(\mathrm{m}^{-2} \cdot \mathrm{g}\right)$

$K \quad$ Coeficiente de absorção característico do material $\left(\mathrm{m}^{-2} . \mathrm{g}\right)$

$W \quad$ Gramatura (g.m $\left.{ }^{-2}\right)$

Portanto, a densidade ótica da amostra pode ser escrita como:

$$
O D s=0.4343 . \theta-\log _{10}[\theta /(K+S)]
$$

Para a análise estatística da formação do papel utilizam-se vários métodos de descrição da variabilidade, os quais incluem histogramas, análise de gradiente, perímetro específico e a análise de Fourier, que se refere a uma técnica matemática de decomposição de um sinal (ou de uma imagem digital) em um conjunto de componentes senoidais. Este procedimento pode ser usado para gerar um espectro bidimensional de freqüências e amplitudes relativo à imagem analisada. O espectro de Fourier contém informações sobre as amplitudes das variações, sobre a escala de variação e sua orientação. Convencionalmente, este espectro é transformado em um conjunto de comprimentos de onda, de forma que as características periódicas observadas podem ser relacionadas a objetos na imagem. Alguns pesquisadores produziram mapeamento da imagem por processo de autocorrelação e produziram medições que se relacionaram com o tamanho médio de flocos de fibras.

O principal benefício das técnicas de captação de imagens pela utilização de raios-X refere-se a imagens com melhor resolução, comparadas com aquelas obtidas com raios- $\beta$, além da possibilidade e medição de gramaturas mais altas com menores tempos de exposição, pois a intensidade da fonte de radiação pode ser modulada de acordo com o produto a ser analisado. Porém, apresentam desvantagens do alto custo e da variação espacial de intensidade das imagens. 
A transformada de Fourier e a autocorrelação constituem técnicas apropriadas para a análise de variações determinísticas (e.g., marcas de telas formadoras), porém questionáveis, segundo Humphrey [1998, p.25], para a análise de variações estocásticas. Não obstante, estes métodos continuarão sendo usados com freqüência, devido à popularidade destas técnicas no processamento de sinais em geral.

Vários trabalhos foram produzidos com a finalidade de abordar métodos de avaliação da formação do papel, baseados na aplicação de técnicas de análise de imagem, tais como os apresentados a seguir.

Jordan [1984] apresentou vantagens da técnica de análise de imagem sobre a varredura com digitalizador em linha para testes de formação, incluindo estudos que mostraram vantagens obtidas com a análise de imagem, especificamente quando se trata da estrutura de objetos discretos bidimensionais. Praast e Gottsching [1987] abordaram os benefícios encontrados no processamento de imagens offline sobre o uso de sensores online para avaliação de formação e de marcas encontradas no papel, visto que o primeiro método permitia realizar uma caracterização bidimensional, em contraste com o segundo, limitado à avaliação em apenas uma dimensão. Mostraram que por meio de imagens geradas por transmissão de luz e tratadas por um analisador de imagens, marcas de tela formadora puderam ser isoladas com precisão e informações valiosas sobre o tamanho de flocos puderam ser obtidas.

Jordan e Nguyen [1988] e Klein, Mraz e Grossmann ${ }^{66}$ [1995 apud I'Anson, 2001] apresentaram trabalhos relacionados à medição e contagem de partículas de tinta e outras impurezas, utilizando técnicas computacionais e de escaneamento de papel. I'Anson e Eghterati [1992] desenvolveram método de análise de distribuição de minerais no papel, por meio de análise de imagem. Szikla e Paulapuro [1989] mediram a distribuição de densidade do papel na direção $z$, em folhas submetidas a diferentes operações de prensagem úmida, por meio de microscópio óptico. Os resultados foram usados para demonstrar a produção de gradientes de densidade na direção $z$ durante a prensagem.

\footnotetext{
${ }^{66}$ KLEIN, R.; MRAZ, C.; GROSSMANN, H. Evaluation of optical inhomogeneities (dirt count) in waste paper pulp by using a scanning system. In: European Research Symposium on Image Analysis for Pulp and Paper Research and Production, 3rd, 1995, Stockholm. Proceedings... Steckholm: STFI, 1995.
} 


\subsection{Fundamentos das imagens digitais}

Uma imagem pode ser definida como uma função bidimensional, $f(x, y)$, onde $x$ e $y$ representam as coordenadas espaciais (no plano) e a amplitude de $f$ em qualquer par de coordenadas $(x, y)$ é denominada de intensidade da imagem naquele ponto. $\mathrm{O}$ termo nível de cinza é freqüentemente utilizado para referência à intensidade de imagens monocromáticas. As imagens coloridas são formadas pela combinação de imagens bidimensionais individuais. Como exemplo, no sistema de cores RGB, a imagem colorida consiste de três componentes: o vermelho $(\mathrm{R}$, red $)$, o verde $(\mathrm{G}$, green) e o azul $(\mathrm{B}$, blue). Por esta razão, as técnicas desenvolvidas para imagens monocromáticas podem ser estendidas às imagens coloridas, por meio do processamento individual de cada componente.

Uma imagem pode ser contínua em relação às coordenadas $x$ e $y$ e também à amplitude. A conversão para a forma de imagem digital requer que as coordenadas, bem como a amplitude, sejam digitalizadas. Este procedimento aplicado às coordenadas recebe a denominação de amostragem e à amplitude, de quantização. Portanto, quando os valores de $x$ e $y$ e da intensidade de $f$ são todos finitos, i.e., são quantidades discretas, a imagem é denominada de imagem digital. Uma imagem digital é formada por um número finito de elementos, sendo que cada um possui posição e valor particulares. Estes elementos são denominados pelos termos pel ou pixel, sendo que a última forma representa a denominação mais comumente usada.

\subsubsection{Aquisição de imagens}

Em geral, as imagens são geradas por meio da combinação de uma fonte de iluminação e a reflexão, absorção ou transmissão da energia proveniente desta fonte pelos elementos dos quais se deseja captar a imagem. A iluminação mencionada pode originar-se em vários tipos de fontes de radiação de energia, consideravelmente diferentes das situações mais comuns, nas quais a luz visível ilumina elementos tridimensionais típicos do cenário cotidiano. Por exemplo, a iluminação pode provir de fontes de energia eletromagnética, tais como radar, radiação infravermelha ou sistemas de raios-X. A iluminação pode também ter origem em outras fontes menos tradicionais, como ultra-som, raios- $\beta$ ou mesmo padrões especiais gerados por computadores. Similarmente, os elementos das imagens podem se constituir de 
objetos familiares ou, tão facilmente, de moléculas, formações rochosas encobertas ou mesmo amostras de papel.

Dependendo da natureza da fonte, a iluminação utilizada poderá ser transmitida através dos objetos ou refletida por eles. Como exemplo da primeira categoria, podem-se citar os sistemas de raios-X ou raios- $\beta$, cujo objetivo é gerar filmes com imagens para diagnósticos. Em algumas aplicações, a energia refletida ou transmitida é submetida a um foto-conversor (e.g.uma tela fosfórica), que transforma a energia em luz visível. Esta abordagem é utilizada em microscopia eletrônica e em algumas aplicações de sistemas com raios-gama.

A Figura 3.1 mostra as principais configurações de sensores usadas para transformar a energia de iluminação em imagens digitais. O princípio básico de conversão é simples: a energia que incide no sensor é transformada em voltagem, por meio da combinação da energia elétrica de alimentação com o material do sensor, que responde ao tipo particular de energia a ser detectada. A forma de onda de tensão elétrica de saída corresponde à resposta do sensor e um valor digital é obtido de cada sensor por digitalização do sinal de saída.

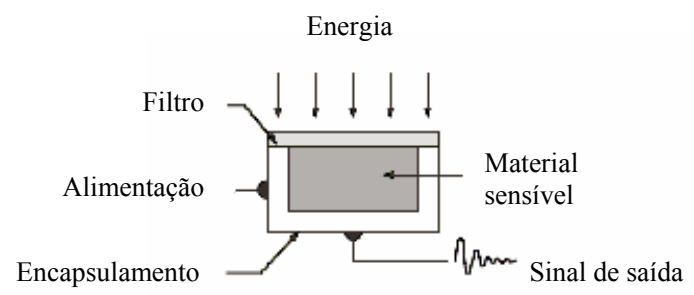

(a)

(b)

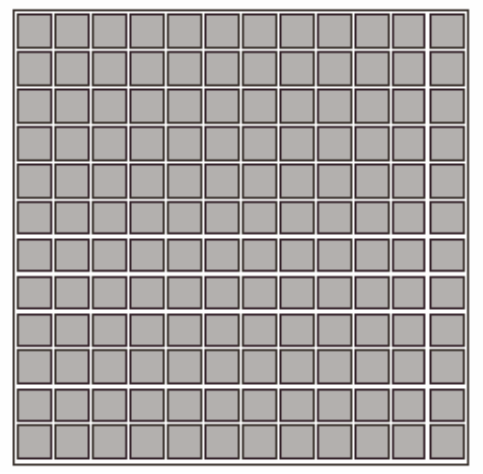

(c)

Figura 3.1. Configurações de sensores para aquisição de imagem: (a) sensor simples. (b) sensor linear e (c) matriz de sensores [Gonzales; Woods, 2008]. 
A Figura 3.1(a) mostra os componentes de um sensor do tipo simples, cujo exemplo mais comum de aplicação consiste de um foto-diodo, construído com materiais à base de silício, no qual o sinal de saída é proporcional à quantidade de luz incidente. $O$ filtro usado na frente do sensor tem a função de melhorar sua seletividade de detecção de diferentes bandas do espectro de cores.

A geometria utilizada com mais freqüência que a dos sensores simples refere-se a um arranjo em linha, na forma de uma barra de sensores, $c f$. indicado na Figura 3.1(b). A barra de sensores contém elementos para captação de imagem em uma direção e o movimento na direção perpendicular ( $c f$. mostrado na Figura 3.2) permite a captação bidimensional. Dessa forma, a barra de sensores capta uma única linha da imagem por vez e a saída dos sensores deve ser processada por algoritmos de reconstrução, cujo objetivo é transformar os dados captados em uma imagem completa. Este é o tipo de arranjo utilizado na maioria dos digitalizadores de mesa (flat bed scanners), onde são comuns dispositivos de varredura compostos por 4000, ou mais, sensores [Gonzales; Woods, 2008, p.48].

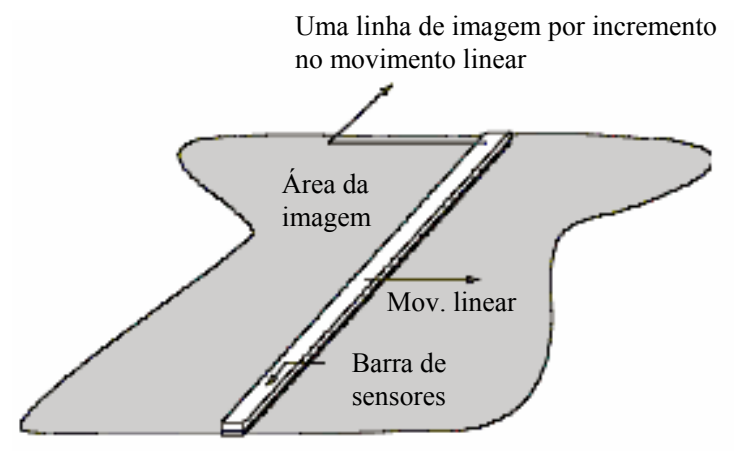

Figura 3.2. Sistema de aquisição de imagem utilizando uma barra linear de sensores [Gonzales; Woods, 2008].

$\mathrm{O}$ arranjo de forma matricial de sensores individuais dispostos em duas dimensões, $c f$. indicado na Figura 3.1(c), representa a forma predominante de utilização em câmeras digitais, além de inúmeros dispositivos eletromagnéticos ou ultra-sônicos. Componentes CCD representam o tipo de sensor freqüentemente utilizado em câmeras digitais e em digitalizadores de mesa. Os conjuntos bidimensionais são fabricados com grande faixa de 
propriedades de detecção, em estruturas robustas contendo 4000 x $4000^{67}$ ou mais sensores [Gonzales; Woods, 2008, p.50]. Por se tratar de um arranjo bidimensional, sua principal vantagem consiste na capacidade de obtenção de uma imagem completa por meio da focalização do padrão de energia de iluminação sobre o dispositivo, $c f$. ilustra a Figura 3.3.

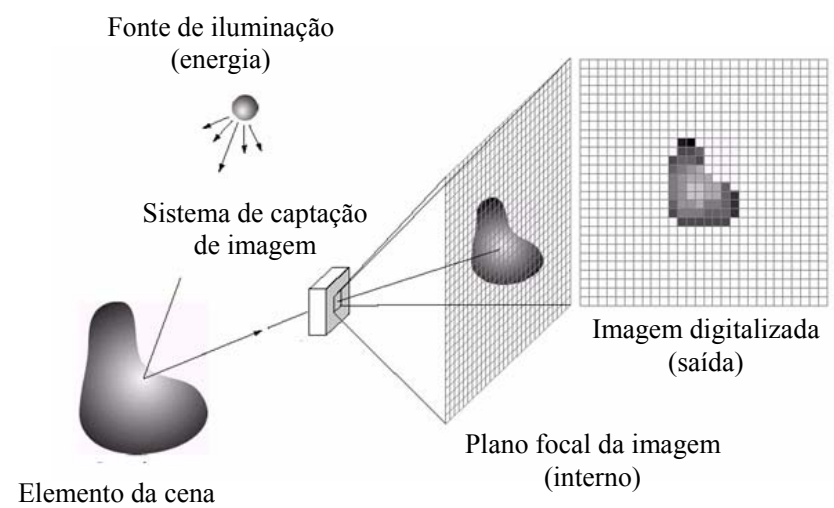

Figura 3.3. Exemplo de um processo de captação de imagem digital [Gonzales; Woods, 2008].

Como apresentado no início da presente seção (3.3), as imagens digitais são denotadas por funções bidimensionais da forma $f(x, y)$. O valor ou amplitude de $f$ nas coordenadas espaciais $(x, y)$ é uma quantidade escalar positiva, cujo significado físico é determinado pela origem da imagem. Assim, uma imagem proveniente de um processo físico, seus valores de intensidade serão proporcionais à quantidade de energia radiada pela fonte física (e.g. ondas eletromagnéticas). Conseqüentemente, $f(x, y)$ deve ser diferente de zero e finito, isto é:

$$
0<f(x, y)<\infty
$$

A função $\mathrm{f}(\mathrm{x}, \mathrm{y})$ pode ser caracterizada por dois componentes: (a) pela quantidade de energia da fonte de iluminação incidente sobre os elementos que compõe o objeto da capitação e (b) pela quantidade de iluminação refletida por estes mesmos elementos. Apropriadamente, estes componentes são denominados iluminação e refletância, expressos por $i(x, y)$ e $r(x, y)$, respectivamente. O produto entre as componentes iluminação e refletância define a função $f(x, y)$ :

\footnotetext{
${ }^{67}$ Cada sensor CCD corresponde a um elemento de imagem (pixel). No caso, o tamanho do conjunto indicado corresponde a 16 megapixels (16 MP).
} 


$$
\begin{aligned}
& f(x, y)=i(x, y) \cdot r(x, y) \\
& \text { onde: } \\
& 0<i(x, y)<\infty \\
& \mathrm{e} \\
& 0<r(x, y)<1
\end{aligned}
$$

A expressão acima indica as condições limítrofes da refletância, situadas entre 0 (absorção total) e 1 (reflexão total). A natureza de $r(x, y)$ é determinada pela fonte de iluminação e $i(x, y)$ pela característica dos objetos da imagem. Observe-se que as expressões acima são aplicáveis também para imagens formadas por transmissão de iluminação através de um meio (e.g. transmissão de luz através de papel e raios-X do corpo humano). Nesse caso, trata-se da função transmissibilidade, ao invés da reflexibilidade, porém, seus limites seriam os mesmos indicados na expressão (3.8) e a função imagem modelada como produto, na forma da expressão (3.6).

\subsubsection{Amostragem e quantização de imagens}

Na seção anterior, os diversos modos de aquisição de imagens apresentados denotam um objetivo comum referente à geração de imagens digitais. Como a maioria dos sensores, disponíveis atualmente, exibem como saída um sinal contínuo de voltagem (cuja amplitude e forma de onda dependem do processo físico detectado), há necessidade de transformar esse sinal, a fim de possibilitar a formação de imagens digitais. Os processos envolvidos na conversão de um sinal contínuo em um sinal digital denominam-se amostragem e quantização.

Os conceitos básicos contidos nos processos de amostragem e quantização encontramse ilustrados na Figura 3.4, que mostra uma função imagem contínua $f$, a qual se deseja converter para a forma digital [uma imagem pode ser contínua em relação às coordenadas espaciais $(x, y)$ e também à amplitude]. A conversão consiste em amostrar a função $f$ nas duas 
coordenadas e na amplitude, processos então denominados amostragem, para a digitalização dos valores das coordenadas e quantização, para a digitalização dos valores de amplitude.

A função unidimensional mostrada na Figura 3.4(b) corresponde à representação gráfica dos valores de intensidade (amplitude) da imagem contínua ao longo do segmento $A B$ na Figura 3.4(a). A fim de amostrar esta função, as amostras são tomadas ao longo da linha $A B$, com espaçamento igual entre elas, como mostrado na Figura 3.4(c). A localização espacial de cada amostra está representada por linhas verticais na parte inferior da figura.
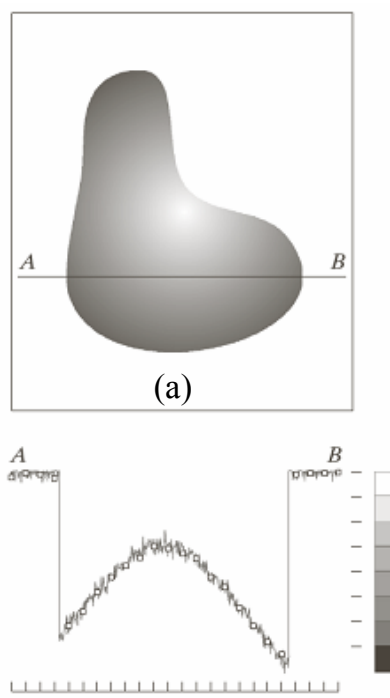

(c)

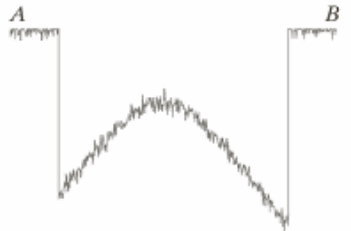

(b)

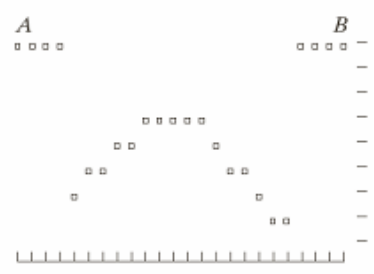

(d)

Figura 3.4. Geração de uma imagem digital: (a) imagem contínua; (b) varredura na imagem continua, entre os pontos $A$ e $B$; (c) amostragem e quantização; (d) linha digitalizada.

A amostragem da imagem contínua está representada por pequenas marcas (quadrados) sobrepostas à função [Figura 3.4(c)]. Porém, os valores das amostras ainda variam verticalmente numa faixa contínua de valores de intensidade. A fim de formar uma função digital, os valores de intensidade devem ser convertidos (quantizados) em quantidades discretas. O lado direito da Figura 3.4(c) apresenta uma escala de intensidade, dividida em oito intervalos discretos, variando do preto ao branco. As marcas verticais indicam os valores específicos atribuídos a cada um dos oito intervalos de intensidade. A amplitude contínua da função é, então, quantizada por meio da designação de um dos oito valores para cada amostra (feita em função da proximidade de cada amostra em relação às marcas verticais). As 
amostras digitais resultantes dos processos de amostragem e quantização estão indicadas na Figura 3.4(d). Uma imagem digital bidimensional é obtida pela aplicação dos procedimentos de amostragem e quantização, linha por linha, a partir do topo da imagem contínua. A precisão alcançada no processo de quantização depende não somente do número de níveis discretos utilizados, mas também, de forma importante, do conteúdo de ruído do sinal amostrado.

As limitações impostas ao processo de amostragem, na prática, são determinadas pelos tipos de configuração de sensores utilizados para captação da imagem. Sensores individuais [Figura 3.1(a)] são combinados com sistemas de movimentação precisos nas duas dimensões e, em princípio, não apresentam limitações significativas para o número de amostras que podem ser obtidas, usando o método descrito acima (Figura 3.4).

No caso de aquisição de imagens por meio de dispositivos equipados com barras lineares de sensores [e.g., em digitalizadores de mesa, cf. Figura 3.1(b)], a limitação de amostragem fica determinada pelo número de sensores presentes na barra de digitalização, em uma direção, o que normalmente determina a limitação na outra direção (onde a amostragem é executada pela movimentação dos sensores). Quando conjuntos matriciais de sensores são utilizados [Figura 3.1(c)], a quantidade de sensores dispostos nas duas direções define o grau de amostragem.

\subsubsection{Representação das imagens digitais}

Uma imagem contínua pode ser amostrada e quantizada para conversão à forma digital, $c f$. discutido na seção anterior. Supondo que tal imagem haja sido amostrada de maneira a compor um arranjo matricial bidimensional de pontos representado por $f(x, y)$, contendo $M$ linhas e $N$ colunas, onde $(x, y)$ são coordenadas discretas, para as quais valores inteiros são usados para clareza e conveniência de notação, i.e., $x=0,1,2, \ldots, M-1$ e $y=0$, $1,2, \ldots, N-1$, o valor da imagem digital na origem corresponde a $f(0,0)$ e o próximo valor, ao longo da primeira linha, corresponde a $f(0,1)$. A notação $(0,1)$ é usada para indicar a segunda amostra ao longo da primeira linha, mas não significa que estes sejam os valores das coordenadas físicas quando a imagem foi amostrada. Em geral, o valor da imagem em quaisquer coordenadas $(x, y)$ é denotado por $f(x, y)$, onde $x$ e $y$ são inteiros. A região abarcada 
no plano real pelas coordenadas de uma imagem digital é denominada de domínio espacial, sendo $x$ e $y$ referidos como variáveis espaciais ou coordenadas espaciais.

A Figura 3.5 mostra algumas formas básicas de representação gráfica de $f(x, y)$. A Figura 3.5(a) apresenta a função plotada em dois eixos, determinando as posições espaciais e um terceiro, representando os valores da intensidade de $f$ em função das duas variáveis espaciais $x$ e $y$. A representação indicada na Figura 3.5(b), mais comumente encontrada, representa $f(x, y)$ da forma como seria observada em um monitor ou em uma fotografia. Neste tipo de representação, a intensidade de cada ponto é proporcional à amplitude de $f$ no respectivo ponto. Assim, como a imagem apresenta apenas três níveis de valor de intensidade, igualmente espaçados, uma normalização no intervalo de $[0,1]$ determinaria que cada ponto tivesse o valor $0,0,5$ ou 1 . Um monitor ou uma impressora simplesmente converteria estes valores em preto, cinza ou branco, respectivamente.

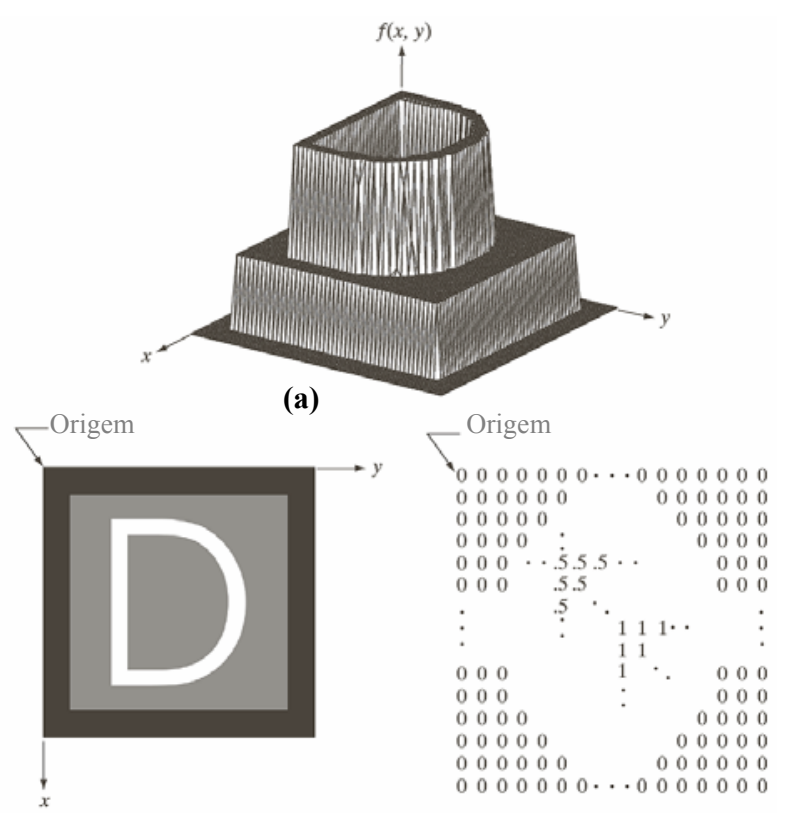

(b)

(c)

Figura 3.5. Representação de uma imagem digital: (a) plotada como uma superfície; (b) visualizada como conjunto de intensidades; (c) mostrada como arranjo numérico - os valores $0,0,5$ e 1 representam preto, cinza e branco, respectivamente [Gonzalez; Woods, 2008]. 
A Figura 3.5(c) representa, em forma matricial, os valores numéricos de $f(x, y)$. No exemplo em questão, a função $f$ é formada por um conjunto de 600 x 600 elementos, ou seja, 360.000 números. Esta representação é bastante útil quando se trata de desenvolvimento de algoritmos e processamento digital de imagens.

$\mathrm{Na}$ forma de equação, uma imagem digitalizada (amostrada e quantizada) contendo $M \mathrm{x} N$ elementos pode ser representada numericamente da seguinte forma:

$$
f(x, y)=\left[\begin{array}{cccc}
f(0,0) & f(0,1) & \ldots & f(0, N-1) \\
f(1,0) & f(1,1) & \ldots & f(1, N-1) \\
\ldots & \ldots & & \ldots \\
f(M-1,0) & f(M-1,1) & & f(M-1, N-1)
\end{array}\right]
$$

Ambos os lados da equação acima correspondem a formas equivalentes para expressar uma imagem digital quantitativamente, encontrando-se no lado direito uma matriz de números reais. Cada elemento desta matriz é denominado elemento de imagem, pixel ou pel. Como indicado por Gonzáles, Woods e Eddins [2004, p.14], uma imagem digital pode ser também representada na forma de uma matriz do $\mathrm{MATLAB}^{68}$, da seguinte forma:

$$
f=\left[\begin{array}{cccc}
f(1,1) & f(1,2) & \cdots & f(1, N) \\
f(2,1) & f(2,2) & \cdots & f(2, N) \\
\cdots & \cdots & & \cdots \\
f(M, 1) & f(M, 2) & \cdots & f(M, N)
\end{array}\right]
$$

(A fonte arial foi utilizada para expressar as quantidades do MATLAB)

De fato, as duas equações são idênticas [i.e., $\mathrm{f}(1,1)=f(0,0)]$, exceto pelo deslocamento da origem, $c f$. convenção utilizada na documentação do aplicativo para processamento de imagens (IPT ${ }^{69}$ ) do MATLAB.

\footnotetext{
${ }^{68}$ MATLAB significa Matrix Laboratory (laboratório de matrizes) e consiste de uma linguagem de alto desempenho para computação técnica. Produto da MathWorks, EUA.

${ }^{69}$ Image Processing Toolbox (aplicativo para processamento de imagens).
} 
O processo de amostragem e quantização requer algumas definições para os valores dos parâmetros $M, N$ e para a quantidade $L$ de níveis discretos de intensidade. A única condição para $M$ e $N$ determina que devem ser números positivos e inteiros. Entretanto, em função de considerações a respeito dos componentes requeridos para armazenamento e quantização, o número de níveis de intensidade é definido tipicamente como uma potência inteira de 2:

$$
L=2^{k}
$$

Assume-se que os níveis discretos são valores inteiros contidos no intervalo $[0, L-1] \mathrm{e}$ encontram-se igualmente espaçados. A faixa dinâmica de um sistema de imagens é definida como a razão entre o valor máximo de intensidade mensurável e o valor mínimo detectável, sendo o valor superior determinado pela saturação e o valor mínimo pelo ruído. Basicamente, a faixa dinâmica estabelece os níveis máximo e mínimo que um sistema pode representar e que, conseqüentemente, uma imagem poderá assumir (esta característica está proximamente conectada, e influi diretamente, na capacidade de contraste).

A quantidade $b$ de bits necessários para armazenar uma imagem digital é dada pela expressão a seguir:

$$
b=M \times N \times k
$$

Nos casos em que $M=N$,

$$
b=N^{2} \times k
$$

\subsection{Transformadas de Fourier}

A grande contribuição cientifica do matemático e físico francês Jean Baptiste Joseph Fourier (1768 - 1830) se consolidou na publicação, em 1822, da sua obra intitulada "Teoria Analítica do Calor ${ }^{70}$ ". Fourier estabeleceu que qualquer função periódica pode ser expressa por uma soma ponderada de funções circulares seno e/ou cosseno, com diferentes freqüências,

\footnotetext{
${ }^{70}$ Fourier, J.B.J. Théorie Analitique de la Chaleur. Paris: Firmim Didot, 1822. 639 p.
} 
sendo cada uma dessas funções multiplicada por coeficientes apropriados. Esta soma recebeu posteriormente a denominação de série de Fourier. Independentemente da complexidade da função original, sendo ela periódica e satisfazendo algumas condições matemáticas brandas, poderá ser representada por tal soma (na Figura 3.6, a função encontrada na posição inferior resulta da soma das quatro senóides acima dela). As funções não-periódicas, desde que apresentem áreas finitas sob suas curvas, podem ser expressas por uma integral de senos e cossenos multiplicados por uma função de ponderação. A formulação, neste caso, conhecida como transformada de Fourier, tem utilização ainda mais abrangente que a série de Fourier em várias disciplinas teóricas e aplicadas. Ambas as representações compartilham a característica importante de que uma função expressa por meio da série ou da transformada de Fourier, pode ser reconstruída (recuperada) completamente, pelo processo inverso, sem perda de informações. Esta particularidade viabiliza uma análise e intervenção no domínio de Fourier, para retornar, em seguida, ao domínio original da função, sem perda de dados. A extrema utilidade da série e da transformada de Fourier, para resolução de problemas práticos, tornaram-nas amplamente estudadas e usadas como ferramenta fundamental.

Inicialmente, os conceitos de Fourier foram aplicados no campo de difusão do calor. Durante o século passado, e especialmente nos últimos 50 anos, várias disciplinas acadêmicas e industriais surgiram completamente como resultado das idéias de Fourier. O advento dos computadores digitais e a formulação do algoritmo da transformada rápida de Fourier $\left(\mathrm{FFT}^{71}\right)$, na década de 1960, revolucionaram o campo de processamento de sinais, permitindo a realização de novos trabalhos, como alguns de excepcional importância, em aplicações que compreendem desde o monitoramento médico e escaneamento, até as modernas comunicações eletrônicas. No campo das imagens digitais (funções discretas bidimensionais de duração finita), a transformada de Fourier constitui-se em ferramenta de análise de grande interesse. A técnica de processamento no domínio de freqüências proporciona um modo prático de estudar e implementar inúmeras abordagens para a análise de imagens.

A Figura 3.6 ilustra uma interpretação simplificada da transformada de Fourier de uma função periódica de uma variável contínua. Como mostrado, a essência da transformada de Fourier consiste na decomposição ou separação de uma função em uma soma ponderada de senóides, em que cada componente possui diferentes freqüências. A transformada de Fourier

\footnotetext{
${ }^{71}$ Fast Fourier Transform.
} 
de uma função de entrada corretamente determinada permite a recuperação da função original por meio da soma das suas componentes senoidais. A representação gráfica da transformada de Fourier pode ser feita por meio de um diagrama com duas coordenadas, onde se exibem a amplitude e a freqüência de cada senóide individual, tal como mostrado na Figura 3.6 abaixo. Neste exemplo, a função original consiste de uma forma de onda periódica simples, cuja transformada de Fourier se constitui de duas componentes senoidais que, somadas entre si, recuperam a forma de onda inicial.

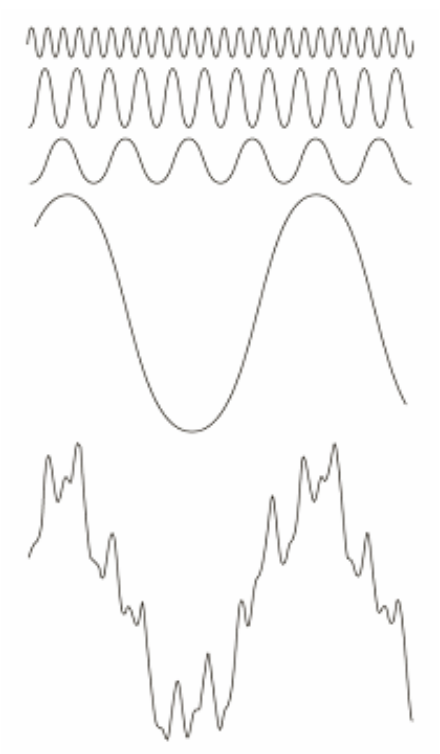

Figura 3.6. Decomposição da função indicada na posição inferior, em quatro componentes senoidais [Gonzalez; Woods, 2008].

A transformada de Fourier identifica ou distingue as diferentes freqüências das componentes senoidais (e suas respectivas amplitudes) que se combinam, a fim de gerar uma forma de onda arbitrária. Matematicamente, esta relação se expressa pela equação a seguir:

$$
F(u)=\int_{-\infty}^{\infty} f(x) e^{-j 2 \pi u x} d t
$$

$\mathrm{Na}$ expressão acima, $f(x)$ representa a função a ser decomposta em uma soma de componentes senoidais, $F(u)$ a transformada de $f(x)$ e $j=(-1)^{1 / 2}$. No diagrama apresentado na Figura 3.7, as amplitudes e freqüências das duas componentes senoidais estão mostradas de acordo com a convenção usual, $c f$. Brigham [1988], indicando freqüências positivas e 
negativas para cada componente (em conseqüência, as amplitudes foram divididas em partes iguais).

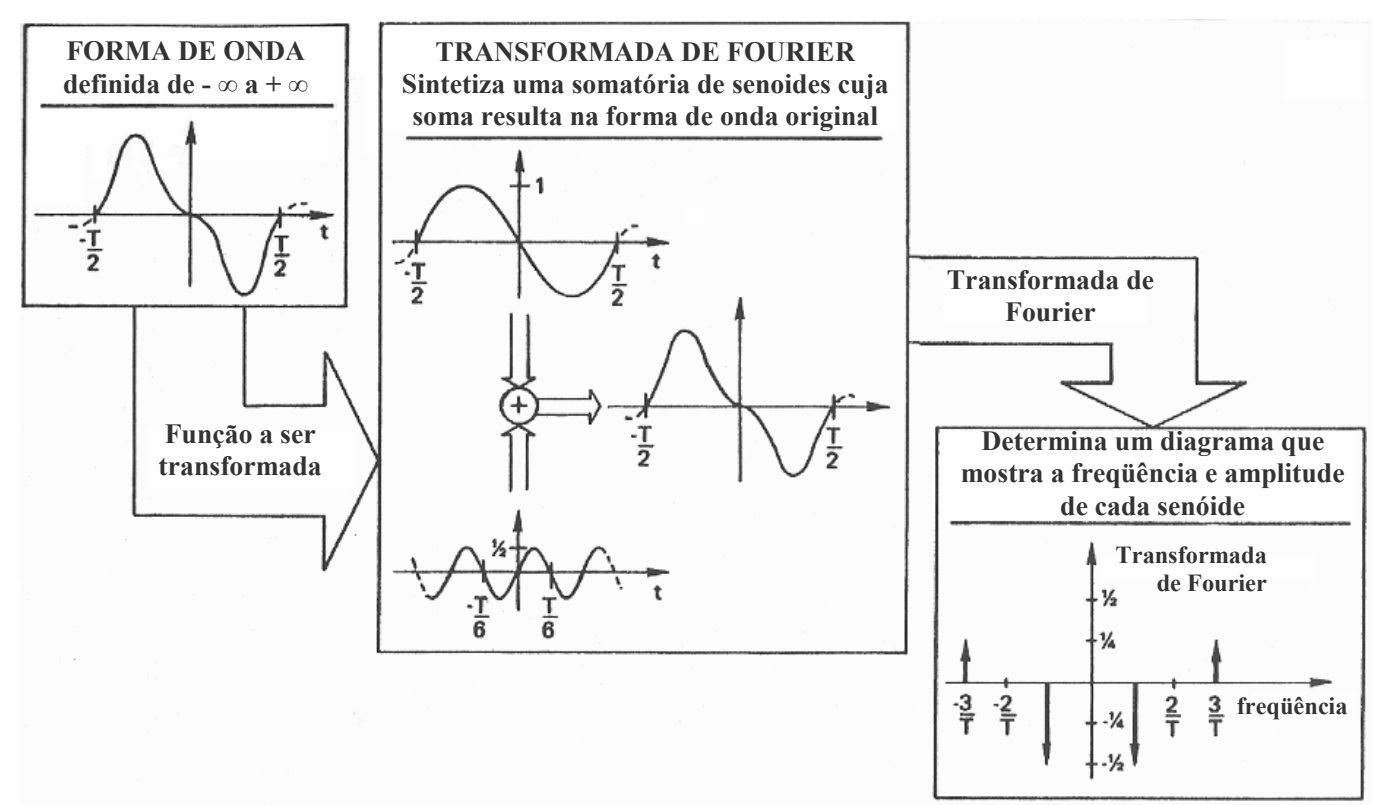

Figura 3.7. Interpretação da transformada de Fourier [Brigham, 1988, p.5].

A análise das funções periódicas, como a indicada acima, está normalmente associada à série de Fourier e não à transformada de Fourier, porém, a série de Fourier representa um caso particular da transformada de Fourier. No caso em que $f(x)$ não é uma função periódica, a transformada de Fourier será definida com uma função contínua da freqüência, i.e., a função $f(x)$ será representada pelo somatório de componentes senoidais de todas as freqüências. A Figura 3.7 mostra um exemplo desta situação, considerando uma função com forma de um pulso e sua respectiva transformada. Neste exemplo, observa-se que a freqüência de cada componente senoidal se torna indistinguível da próxima, tornando necessária, portanto, a consideração de todas as freqüências. A transformada de Fourier se torna, assim, a representação de uma função no domínio da freqüência.

\subsubsection{Transformada de Fourier de uma função com duas variáveis contínuas}

A transformada de Fourier de uma função contínua $f(t, z)$ de duas variáveis contínuas $t$ e $z$, denotada por $F(u, v)$, é definida pela equação a seguir, onde $u$ e $v$ são também variáveis contínuas: 


$$
F(u, v)=\int_{-\infty}^{\infty} \int_{-\infty}^{\infty} f(t, z) e^{-j 2 \pi(u t+v z)} d t d z
$$

Contrariamente, dada a transformada $F(u, v)$, pode-se retornar à função original $f(t, z)$, por meio da transformada inversa de Fourier, expressa por:

$$
f(t, z)=\int_{-\infty}^{\infty} \int_{-\infty}^{\infty} F(u, v) e^{-j 2 \pi(u t+v z)} d u d v
$$

As equações (3.15) e (3.16) compõem um conjunto denominado par de transformadas de Fourier. Elas denotam o fato importante de que uma função pode ser recuperada de sua transformada. Aplicando-se a formula de Euler $^{72}$ na equação (3.15), obtém-se:

$$
F(u, v)=\int_{-\infty}^{\infty} \int_{-\infty}^{\infty} f(t, z)[\cos 2 \pi(u t+v z)-j \operatorname{sen} 2 \pi(u t+v z)] d t d z
$$

Se $f(t, z)$ for uma função real, sua transformada geralmente apresentará termos complexos. A equação (3.17) mostra que a transformada de Fourier consiste de uma expansão da função $f(t, z)$ multiplicada por termos senoidais, cujas freqüências são determinadas pelos valores de $u$ e $v$. Uma vez que as únicas variáveis restantes após integração são freqüências, diz-se que o domínio da transformada de Fourier é o domínio das freqüências. Nas expressões acima, $t$ e $z$ representam variáveis contínuas e as unidades das variáveis de freqüência $u$ e $v$ dependem das unidades de $t$ e $z$, ou seja, são expressas em ciclos por unidade da variável independente da função original. Quando as variáveis $t$ e $z$ representarem, e.g., distâncias em metros, as variáveis de freqüência $u$ e $v$ serão expressas em ciclos.m ${ }^{-1}$. Quando se referem a imagens, $t$ e $z$ são interpretadas como variáveis espaciais contínuas e os domínios das variáveis $u$ e $v$ definem o domínio contínuo de freqüências.

\subsubsection{Interpretação unidimensional da transformada bidimensional}

A transformada bidimensional de Fourier, $F(u, v)$, pode ser vista como uma sucessão de duas transformadas unidimensionais [Brigham, 1988, p.237]. A fim de desenvolver esta forma de interpretação, inicialmente se retoma a expressão (3.15), re-escrita como segue:

\footnotetext{
${ }^{72}$ A fórmula de Euler estabelece que $e^{j \theta}=\cos \theta+j \operatorname{sen} \theta$, onde $e=2,71828 \ldots$ e $j=(-1)^{1 / 2}$.
} 


$$
F(u, v)=\int_{-\infty}^{\infty} e^{-j 2 \pi v z}\left[\int_{-\infty}^{\infty} f(t, z) e^{-j 2 \pi u t} d t\right] d z
$$

Note-se que o termo entre colchetes representa, simplesmente, a transformada unidimensional de $f(t, z)$, com respeito a $t$, ou seja,

$$
Z(u, z)=\int_{-\infty}^{\infty} f(t, z) e^{-j 2 \pi u t} d t
$$

e, portanto, a equação (3.18) pode ser reescrita como:

$$
F(u, v)=\int_{-\infty}^{\infty} Z(u, z) e^{-j 2 \pi u t} d t
$$

Um exame de (3.20) revela que $F(u, v)$ representa a transformada unidimensional de $Z(u, z)$ com respeito à variável $z$. Conseqüentemente, a transformada bidimensional $F(u, v)$ pode ser interpretada como duas transformadas unidimensionais sucessivas dadas por (3.19) e (3.20). Esta interpretação tem particular importância para a aplicação da FFT na computação da transformada bidimensional de Fourier.

\subsubsection{Amostragem em duas dimensões e o teorema de amostragem bidimensional}

As funções contínuas devem ser convertidas em uma série de valores discretos, a fim de permitir seu processamento em computadores. Este objetivo é alcançado pela utilização de técnicas de amostragem e quantização ${ }^{73}$. No caso de funções bidimensionais, a amostragem pode ser modelada pela utilização um trem de impulsos bidimensional como função de amostragem:

$$
S_{\Delta T \Delta Z}(t, z)=\sum_{m=-\infty}^{\infty} \sum_{n=-\infty}^{\infty} \delta(t-m \Delta T, z-n \Delta Z)
$$

$\mathrm{Na}$ expressão acima, $\Delta T e \Delta Z$ representam os intervalos entre as amostras ao longo dos eixos $t$ e $z$, respectivamente, da função contínua $f(t, z)$.

\footnotetext{
${ }^{73} C f$. subseção 3.3.2.
} 
A equação (3.21) descreve um conjunto de impulsos que se estendem infinitamente ao longo dos dois eixos ( $c f$. Figura 3.8). O produto de $f(t, z)$ por $s_{\triangle T \Delta Z}(t, z)$ resulta na função amostrada:

$$
\tilde{f}(t, z)=f(t, z) s_{\Delta T \Delta Z}(t, z)=\sum_{m=-\infty}^{\infty} \sum_{n=-\infty}^{\infty} f(t, z) \delta(t-m \Delta T, z-n \Delta Z)
$$

onde $\tilde{f}(t, z)$ denota a função amostrada.

Cada componente desta somatória consiste de um impulso ponderado pelo valor de $f$ $(t, z)$ na posição do impulso. O valor de cada amostra é obtido por integração, i.e., o valor $f_{k, l}$ de uma amostra arbitrária, $c f$. a propriedade seletiva do impulso ${ }^{74}$, é dado por:

$$
\begin{aligned}
& f_{k, l}=\int_{-\infty}^{+\infty} \int_{-\infty}^{+\infty} f(t, z) \delta(t-k \Delta T, z-l \Delta Z) d t d z \\
& f_{k, l}=f(k \Delta T, l \Delta Z)
\end{aligned}
$$

A função $f(t, z)$ é denominada de banda limitada se sua transformada de Fourier for nula fora do retângulo delimitado pelos intervalos $\left[-u_{\max }, u_{\max }\right]$ e $\left[-v_{\max }, v_{\max }\right]$, ou seja:

$$
F(u, v)=0, \text { para }|u| \geq u_{\max } \mathrm{e}|v| \geq v_{\max }
$$

O teorema de amostragem bidimensional define que uma função contínua, de banda limitada, $f(t, z)$, pode ser recuperada, sem erro, a partir de um conjunto de amostras, se os intervalos de amostragem tiverem as dimensões a seguir:

$$
\begin{gathered}
\Delta T<\frac{1}{2 u_{\max }} \\
\Delta Z<\frac{1}{2 v_{\max }}
\end{gathered}
$$

\footnotetext{
${ }^{74}$ A propriedade seletiva do impulso, com respeito à integração, é dada por: $\int_{-\infty}^{+\infty} f(t) \delta\left(t-t_{0}\right) d t=f\left(t_{0}\right)$ [Gonzalez, Woods, 2008, p.240].
} 
ou, expressando em termos das taxas de amostragem,

$$
\begin{aligned}
& \frac{1}{\Delta T}>2 u_{\max } \\
& \frac{1}{\Delta Z}>2 v_{\max }
\end{aligned}
$$

Em outras palavras, nenhuma informação será perdida, se uma função de banda limitada, contínua e bidimensional for representada por amostras adquiridas com taxas de amostragem maiores que o dobro da maior freqüência contida na função, nas direções $u$ e $v^{75}$.

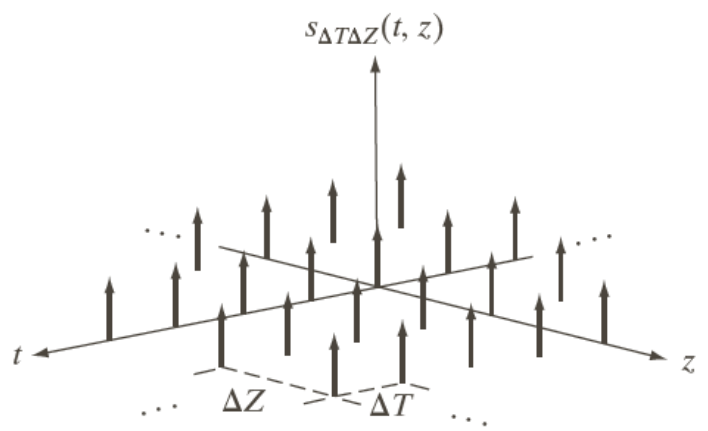

Figura 3.8. Trem de impulsos bidimensional [Gonzales; Woods, 2008, p.228]

\subsubsection{Transformada bidimensional discreta de Fourier (2D-DFT ${ }^{76}$ )}

A transformada discreta deriva da transformada contínua de Fourier, como um caso especial para funções amostradas:

$$
\begin{aligned}
& F(u, v)=\sum_{x=o}^{M-1} \sum_{y=0}^{N-1} f(x, y) e^{-j 2 \pi(u x / M+v y / N)} \\
& \text { para } u=0,1, \ldots, M-1 \text { e } v=0,1, \ldots, N-1
\end{aligned}
$$

\footnotetext{
${ }^{75}$ Esta condição satisfaz o teorema da amostragem. A taxa de amostragem exatamente igual ao dobro da maior freqüência contida na função é conhecida por taxa de Nyquist ou Lei de Nyquist, referido-se ao teorema da amostragem formulado pioneiramente por Harry Nyquist, engenheiro e cientista dos Laboratórios Bell, em 1929.

${ }^{76}$ Two-Dimensional Discrete Fourier Transform.
} 
onde $f(x, y)$ representa uma função de duas variáveis, e.g., uma imagem digital com dimensões $M$ x $N$.

Dada a transformada $F(u, v)$, pode-se obter $f(\mathrm{x}, \mathrm{y})$, usando a transformada discreta de Fourier inversa (2D-IDFT $\left.{ }^{77}\right)$ :

$$
\begin{aligned}
& f(x, y)=\sum_{u=o}^{M-1} \sum_{v=0}^{N-1} F(u, v) e^{j 2 \pi(u x / M+v y / N)} \\
& \operatorname{para} x=0,1, \ldots, M-1 \text { e } y=0,1, \ldots, N-1
\end{aligned}
$$

\subsubsection{Algumas propriedades da transformada discreta de Fourier (2D-DFT)}

\section{a. Relação entre os intervalos espaciais e os de freqüência:}

Supondo que uma função contínua $f(t, z)$ seja amostrada, a fim de formar uma imagem digital $f(x, y)$, consistindo de $M \times N$ amostras tomadas nas direções $t$ e $z$, respectivamente, se $\Delta \mathrm{T}$ e $\Delta Z$ denotam as separações entre as amostras ( $c f$. Figura 3.8) no domínio espacial, então as separações entre as variáveis discretas correspondentes no domínio de freqüências serão dadas, respectivamente, por:

$$
\begin{aligned}
& \Delta u=\frac{1}{M \Delta T} \\
& \Delta v=\frac{1}{M \Delta Z}
\end{aligned}
$$

Observe-se que a separação das amostras no domínio de freqüência é inversamente proporcional ao espaçamento entre as amostras no domínio espacial e ao número de amostras.

\section{b. Translação e rotação:}

Por meio de substituição direta nas equações (3.29) e (3.30), pode ser mostrado que o par de transformadas de Fourier satisfaz a seguinte propriedade de translação:

\footnotetext{
${ }^{77}$ Two-Dimensional Inverse Discrete Fourier Transform.
} 


$$
\begin{aligned}
& f(x, y) e^{j 2 \pi\left(u_{0} x / M+v_{0} y / N\right)} \Leftrightarrow F\left(u-u_{0}, v-v_{0}\right) \\
& f\left(x-x_{0}, y-y_{0}\right) \Leftrightarrow F(u, v) e^{-j 2 \pi\left(u_{0} x / M+v_{0} y / N\right)}
\end{aligned}
$$

Multiplicando-se a função $f(x, y)$ pelo termo exponencial indicado, a origem da DFT se desloca para $\left(u_{0}, v_{0}\right)$ e, contrariamente, multiplicando $F(\mathrm{u}, v)$ pelo negativo do mesmo termo exponencial, a origem de $f(x, y)$ se desloca para $\left(x_{0}, y_{0}\right)$. A translação não altera a magnitude (espectro) de $F(\mathrm{u}, v)$ [Gonzales; Woods, 2008, p.237].

Usando as coordenadas polares abaixo:

$$
x=r \cos \theta, y=r \operatorname{sen} \theta, u=\omega \cos \varphi, v=\omega \operatorname{sen} \varphi
$$

encontra-se o seguinte par de transformadas:

$$
f\left(r, \theta+\theta_{0}\right) \Leftrightarrow F\left(\omega, \varphi+\theta_{0}\right)
$$

A relação acima indica que uma rotação de $f(x, y)$ em um ângulo $\theta_{0}$, produz a mesma rotação $\left(\theta_{0}\right)$ em $F(\mathrm{u}, v)$. Inversamente, a rotação de $F(\mathrm{u}, v)$ produz o mesmo efeito em $f(x, y)$.

A Figura 3.9 mostra a transformação de uma imagem e centralização do espectro de Fourier correspondente. A Figura 3.10 exemplifica as propriedades de translação e rotação da 2D-DFT da imagem mostrada na Figura 3.9.

\section{c. Periodicidade:}

A transformada bidimensional de Fourier é infinitamente periódica nas direções $u$ e $v$, significando que:

$$
\begin{aligned}
& F(u, v)=F\left(u+k_{1} M, v\right)=F\left(u, v+k_{2} N\right)=F\left(u+k_{1} M, v+k_{2} N\right) \\
& f(x, y)=F\left(x+k_{1} M, y\right)=F\left(x, y+k_{2} N\right)=F\left(x+k_{1} M, y+k_{2} N\right)
\end{aligned}
$$

onde $k_{1}$ e $k_{2}$ são inteiros. 


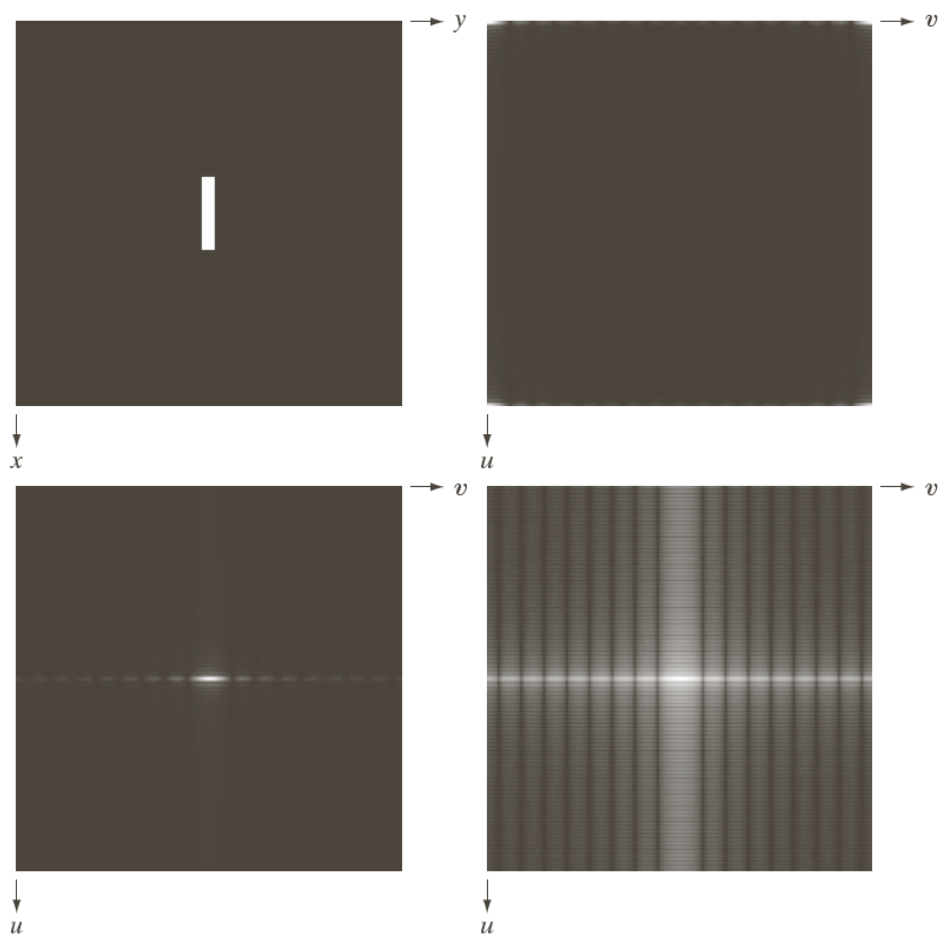

Figura 3.9. (a) imagem de um retângulo, (b) espectro de amplitude mostrando pontos brilhantes nos quatro vértices, (c) espectro centrado, (d) resultado mostrando mais detalhes, pela aplicação de uma transformação logarítmica [Gonzales; Woods, 2008, p.246].
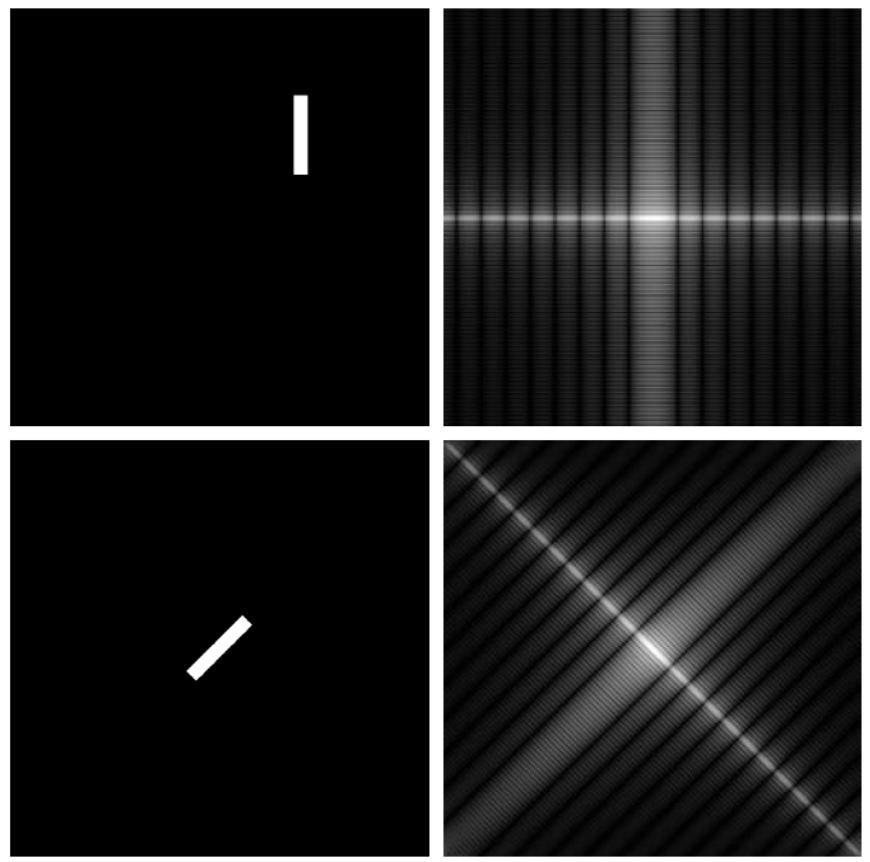

Figura 3.10. (a) retângulo da Figura 3.9 transladado, (b) espectro de amplitude correspondente (idêntico ao da imagem original), (c) retângulo girado, (d) espectro correspondente [Gonzales; Woods, 2008, p.246]. 
As periodicidades da transformada e da sua inversa são características importantes para a implementação de algoritmos baseados na DFT. Considerando o espectro representado na Figura 3.11(a) (unidimensional), os dados transformados contidos no intervalo de 0 a $M-$ 1 consistem de dois meio-períodos contrapostos, que se encontram no ponto $M / 2$. Para visualização e filtragem, torna-se mais conveniente ter, neste intervalo, um período completo da transformada, no qual os dados são contíguos, $c f$. Figura 3.11(b).
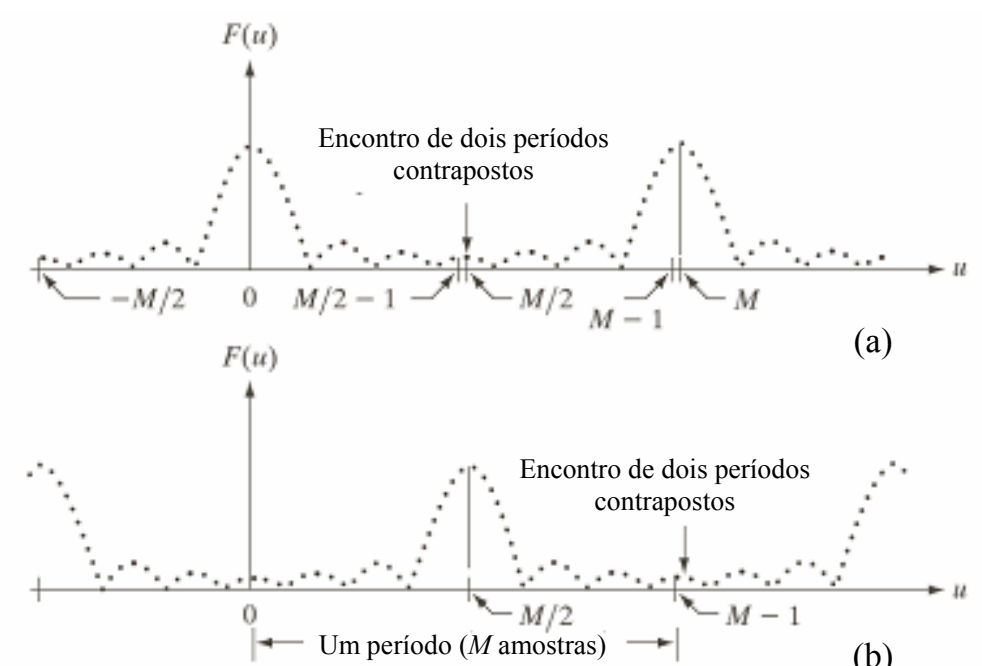

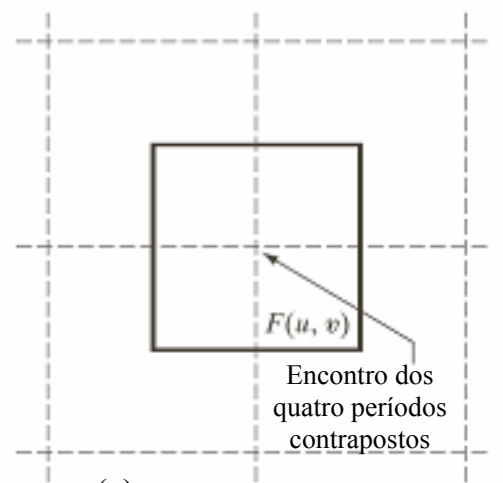

(c)

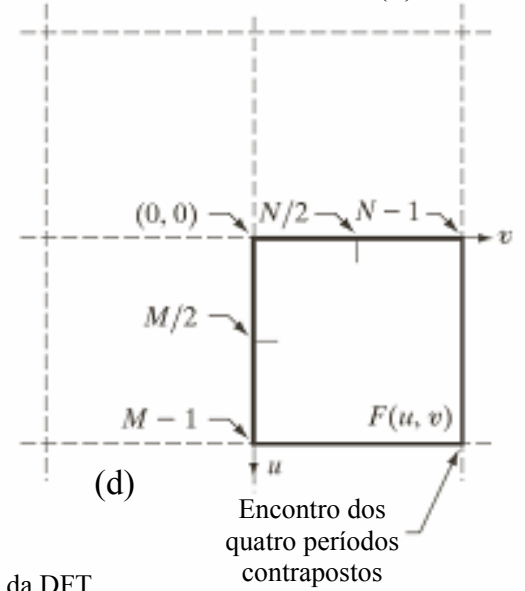

$\left.r_{-}^{-}\right]=$Períodos da DFT contrapostos

$\square=$ Conjunto de dados $M \times N, F(u, v)$

Figura 3.11. Centragem da transformada de Fourier: (a) infinitos períodos de uma 1D-DFT, (b) DFT deslocada, por meio da multiplicação de $f(x)$ por $(-1)^{\mathrm{x}}$ antes da computação de $F(u)$, (c) infinitos períodos de uma 2D-DFT. A área sólida representa o conjunto de dados $M \times N, F(u, v)$, obtido com a equação (3.29), (d) DFT deslocada, obtida pela multiplicação de $f(x, y)$ por $(-1)^{x+y}$ antes da computação de $F(u, v)$. [Gonzales; Woods, 2008, p.238]. 
Obtém-se da equação (3.33) que:

$$
f(x) e^{j 2 \pi\left(u_{0} x / M\right)} \Leftrightarrow F\left(u-u_{0}\right)
$$

Ou seja, multiplicando $f(x)$ pelo termo exponencial indicado, os dados são deslocados, de maneira que a origem, $F(0)$, se encontra em $u_{0}$. Fazendo $u_{0}=M / 2$, o termo exponencial se torna $e^{j \pi x}$, que é igual a $(-1)^{x}$, dado que $x$ é inteiro. Neste caso:

$$
f(x)(-1)^{x} \Leftrightarrow F(u-M / 2)
$$

Então, multiplicando $f(x)$ por $(-1)^{x}$, os dados são deslocados, de forma que $F(0)$ se encontre no centro do intervalo [0, $M-1]$, como desejado.

No caso bidimensional, mostrado na Figura 3.11(c), ao invés de dois meio-períodos há quatro quartos de período se encontrando no ponto $(M / 2, N / 2)$. O retângulo tracejado corresponde ao número infinito de períodos da 2D-DFT. Como mostrado no caso da 1D-DFT, a visualização se torna mais simplificada se os dados são deslocados, de maneira que $F(0,0)$ se encontre em $(M / 2, N / 2)$. Fazendo $\left(u_{0}, v_{0}\right)=(M / 2, N / 2)$ na equação (3.33), encontra-se a seguinte expressão:

$$
f(x, y)(-1)^{x+y} \Leftrightarrow F(u-M / 2, v-N / 2)
$$

Utilizando-se a equação acima, ocorre um deslocamento dos dados, de tal forma que $F(0,0)$ se move para o centro do retângulo de freqüências definido pelos intervalos $[0, M-1]$ e $[0, N-1]$, conforme desejado. O resultado está ilustrado na Figura 3.11(d).

\subsubsection{Transformada rápida de Fourier (FFT)}

A transformada rápida de Fourier (FFT) tornou-se uma ferramenta fundamental de análise e resolução de problemas em diversos setores (e.g., educacional, industrial e médico, entre outros), a partir do desenvolvimento e divulgação, por Cooley e Tukey [1965], de um 
algoritmo matemático para a implantação mais eficiente da DFT em computadores ${ }^{78}$, o qual posteriormente se tornou conhecido pela denominação de "transformada rápida de Fourier". Sua utilização crescente, a partir de então, foi ainda mais impulsionada pelo desenvolvimento contínuo dos computadores pessoais, dando origem a grande diversidade de aplicações. Brigham [1988, p.1] menciona a onipresença da FFT e seu papel como um dos maiores desenvolvimentos na tecnologia de processamento de sinais. As diversas aplicações da FFT estão ligadas com sua origem, na transformada discreta de Fourier (DFT) e, portanto, na transformada de Fourier. A proliferação das aplicações da FFT em inúmeros campos, aparentemente não relacionados, de fato, se encontram interligadas por uma entidade comum: a transformada de Fourier. Com o advento da FFT, a análise de Fourier se transformou rapidamente em um módulo-padrão de análise, que pode ser aplicado efetivamente sem dificuldade, devido a sua grande utilidade e fácil acessibilidade. As aplicações típicas de FFT se estendem por inúmeras áreas de análise, encontrando usos importantes na mecânica aplicada, sônica e acústica, eletromagnetismo, engenharia biomédica, métodos numéricos, comunicações, instrumentação, processamento de sinais e diversas outras, tal como o processamento digital de imagens. Com mencionado anteriormente, o ponto de ligação entre a grande variedade de aplicações da FFT se encontra na transformada de Fourier, cujo pontochave consiste na possibilidade de análise de uma função ou de uma forma de onda, a partir de perspectivas simultâneas no domínio do espaço ou tempo e no domínio da freqüência.

\subsubsection{Visualização de interpretação da $2 \mathrm{D}-\mathrm{FFT}^{79}$}

A interpretação dos resultados da FFT não demanda conhecimento detalhado do seu próprio algoritmo, porém, em seu lugar, requer o entendimento completo da DFT. Isso se deve ao fato de a FFT se constituir, simplesmente, de um algoritmo que permite processar a DFT muito mais rapidamente que outros algoritmos disponíveis.

O resultado da transformada de Fourier de funções reais contém, em geral, termos complexos da forma $C=a+j b$ (onde $j=-1^{1 / 2}$ ), $c f$. diagrama de Argand da Figura 3.12. A posição do ponto $C$ pode, também, ser descrita pela distância a partir do centro do diagrama,

\footnotetext{
${ }^{78}$ A FFT consiste de um algoritmo matemático que reduz o tempo de computação da DFT na proporção de $N^{2}$ para $N \log _{2} N$, onde $N$ indica o número de dados amostrais da função considerada. Este aumento na velocidade computacional revolucionou completamente vários aspectos da análise científica [Hamming, 1987; Brigham, 1988, p.3; Diniz et al., 2004].

${ }^{79}$ Two-Dimensional Fast Fourier Transform.
} 
$A$, e pelo ângulo $\theta$ formado com o eixo real. O parâmetro $A$ é denominado de amplitude (ou módulo) e $\theta$ de ângulo de fase (ou argumento). Algebricamente, tem-se que:

$$
\begin{aligned}
& A=\sqrt{a^{2}+b^{2}} \\
& \theta=\tan ^{-1}\left(\frac{b}{a}\right)
\end{aligned}
$$

A forma usual de visualizar o resultado da transformada consiste em utilizar sua parte real e mostrar as amplitudes ou seus quadrados (denominados potências) em um espectro de amplitude ou de potência, respectivamente.

Os algoritmos para cálculo da 2D-FFT apresentam melhores eficiências quando as imagens de entrada são quadradas com dimensões correspondentes a uma potência de 2, i.e., quando são formadas por $2^{n} \times 2^{n}$ elementos (sendo $n$ um número real e inteiro). Quando esta pratica não é possível, a imagem de entrada pode ser expandida pela técnica de adição de elementos (zero-padding ${ }^{80}$ ), a fim de levar suas dimensões até o próximo quadrado $\left(2^{n}\right)$ disponível $^{81}$.

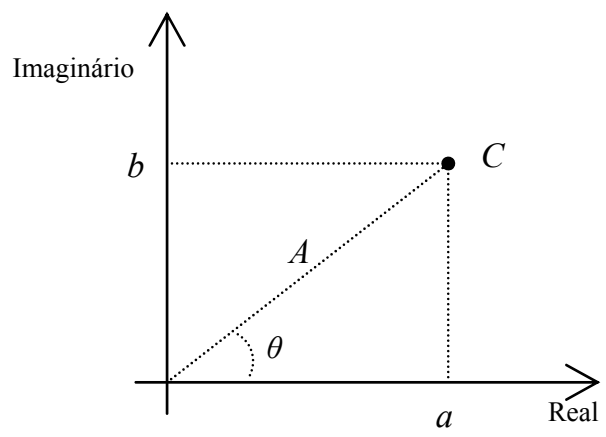

Figura 3.12. Diagrama de Argand ${ }^{82}$

\footnotetext{
${ }^{80}$ Adição de zeros. Procedimento que consiste em adicionar "zeros" (pixels com valor nulo) em torno das bordas de uma imagem (e.g., de papel), a fim de aumentar suas dimensões antes do seu processamento (e.g. pela transformada de Fourier). Segundo I'Anson [2008], este procedimento produz um espectro de Fourier contendo dados adicionais capazes de melhorar a utilidade de algumas imagens-fonte. Em I'Anson et al.[2008], os autores mencionam a possibilidade de melhorar a precisão na medição das marcas de tela formadora, usando este procedimento.

${ }^{81}$ Embora o processo seja denominado "adição de zeros ou zero-padding", é executado pela centralização da imagem original no centro de uma imagem quadrada, preenchida com um nível de cinza que corresponde ao valor médio dos elementos da imagem de entrada. Desta forma, mantém-se o valor médio da imagem aumentada, a ser processada, com a mesma magnitude encontrada na imagem original.

${ }^{82}$ Criado por Jean Robert Argand (1768-1882), matemático amador francês, para representação geométrica dos números complexos.
} 
O espectro da 2D-FFT é comumente exibido na forma de uma imagem, para representação visual das amplitudes e freqüências do conjunto de formas de onda senoidais bidimensionais resultantes da decomposição da imagem original. Considerado como um mapa de intensidade, cada ponto do espectro de amplitudes representa uma combinação de parâmetros de um conjunto de linhas ou faixas da imagem original, sendo que o brilho de cada ponto (valor de amplitude) é um indicativo do contraste destas linhas ou faixas e a posição dos pontos no espectro, uma indicação do espaçamento e da orientação das linhas ou das faixas mencionadas. Para uma imagem digital com dimensões de $N$ x $N$ pixels, a 2D-FFT calcula parâmetros em $(N / 2)$ freqüências horizontais no intervalo $[0$ a $(N-1)]$ e $(N / 2)$ freqüências verticais, dentro do mesmo intervalo. Freqüências superiores a este limite não são consideradas, com o objetivo de manter a taxa de amostragem adequada, $c f$. estabelece a lei de Nyquist ${ }^{83}$.

A Figura 3.13 ilustra a configuração convencional para visualização do espectro de amplitude de Fourier. O ponto relativo à freqüência "zero" representa a soma das amplitudes individuais dos pontos contidos no espectro e, assim, usualmente corresponde ao componente com a maior magnitude do espectro, diferindo dos demais por um fator que pode atingir várias ordens de grandeza. Este ponto se localiza sempre no centro do espectro. A partir da posição central, pontos correspondentes a $[(N / 2)-1]$ freqüências são representados em duplicidade, à direita e à esquerda e para cima e para baixo. O ponto correspondente à freqüência $(N / 2)$ aparece apenas no extremo esquerdo e extremo superior do espectro (somente uma vez em cada eixo), resultando num total de $N$ x $N$ pontos no espectro completo. Seria possível mostrar todos os pontos de interesse no espectro utilizando somente metade da quantidade normalmente usada. A forma convencional é preferida, pois a redundância facilita a visualização dos padrões contidos no espectro.

$\mathrm{Na}$ Figura 3.14, encontra-se um espectro de amplitude típico, obtido a partir da imagem digitalizada de uma amostra de papel. Os pontos brancos encontrados na imagem do espectro correspondem a picos de amplitude produzidos por variações periódicas no papel.

\footnotetext{
${ }^{83}$ Ver subseção 3.4.3.
} 


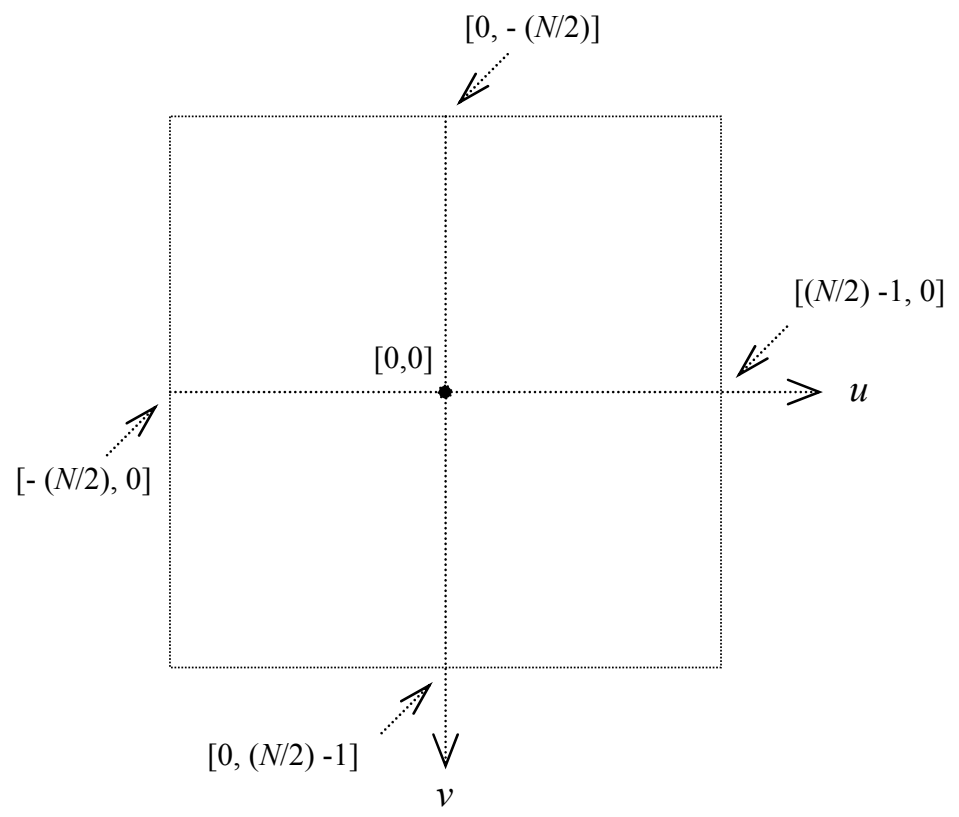

Figura 3.13. Esquema de visualização da transformada de Fourier $F(u, v)$, no domínio de freqüências, correspondente a uma função $f(x, y)$ do domínio espacial, com dimensões $N$ x $N$.

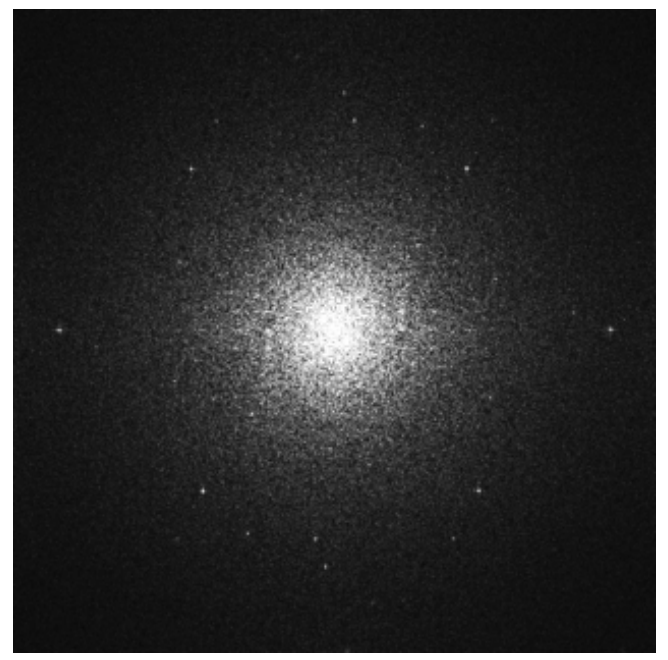

Figura 3.14. Espectro de amplitude, obtido a partir da imagem digitalizada de uma amostra de papel. Os pontos brancos encontrados na imagem do espectro correspondem a picos de amplitude produzidos por variações periódicas no papel [I'’Anson et.al., 2008]. 


\subsection{Identificação de marcas periódicas no papel}

As marcas encontradas no papel acabado se referem usualmente a variações periódicas na aparência da folha causadas por diferenças estruturais de grande escala, se comparadas às dimensões das fibras presentes na composição do papel. Algumas dessas marcas podem ter origem em pulsações de pressão ou em fenômenos do escoamento fluido a montante da tela formadora (denominados "wet-end barring"). Estes distúrbios são comumente estudados por análise espectral do equipamento e da folha de papel [Leadbeater, 1990]. Outras marcas, mais randômicas, são caracterizadas por faixas ("streaks") produzidas por fluxos secundários na caixa de entrada. Estes defeitos podem ser identificados por meio de medições de peso em alta resolução [Aidun, 1997] e interferometria holográfica [Olofsson; Molin; Kyosti, 1992].

O método mais comum para o estudo de marcas periódicas envolve a utilização de técnicas de análise de imagem e aplicação da transformada bidimensional rápida de Fourier (2D-FFT). As marcas determinísticas originadas por telas formadoras, por rolos de sucção ou por feltros das prensas e por telas secadoras, podem ser identificadas e separadas das variações estocásticas da superfície do papel por meio de filtragem por aplicação da transformada rápida de Fourier [I’Anson, 1995a, 1995b; Jackson, 1999; Koukoulas, 1994].

\subsubsection{Marcas das vestimentas da máquina de papel}

No processo de fabricação, o papel encontra-se em contato com vestimentas ${ }^{84}$, de um ou de ambos os lados da folha, durante quase toda sua passagem pela máquina de papel. As vestimentas (telas e feltros) desempenham funções específicas e, portanto, são projetadas e fabricadas com diferentes características, dependendo do tipo de papel produzido, da posição na máquina de papel e suas dimensões, bem como da velocidade de operação.

As vestimentas da máquina de papel, de forma mais intensa ou tênue, produzem marcas superficiais que podem ser identificadas na folha de papel acabado. Alguns estudos indicam a relevância deste mecanismo, identificando formas para estabelecer sua origem e seus efeitos sobre as propriedades do papel. Como exemplo, citam-se os trabalhos de

\footnotetext{
${ }^{84}$ Denominam-se vestimentas os componentes tecidos (telas) utilizados nas seções de formação, prensagem e secagem da máquina de papel. O conjunto de vestimentas compõe-se de: tela formadora, tela da prensa (mais comumente denominadas de feltro) e tela secadora (também, em geral, denominada de feltro).
} 
MacGregor e Cornners [1987] sobre a influência das marcas de tela formadora sobre a qualidade de impressão offset colorida de papel $\mathrm{LWC}^{85}$, utilizando métodos microscópicos combinados com técnicas de análise de imagens e I'Anson [1998, 2001], que apresentou casos e técnicas de análise de imagens, baseadas na transformada de Fourier, para identificação de marcas originadas por diferentes vestimentas usadas na parte úmida e na parte seca da máquina (telas de feltros) e, adicionalmente, abordou a questão de marcas produzidas por rolos usados na seção de prensas (rolos de sucção, ranhurados ou com furação cega), que representam problemas freqüentes de perda de qualidade por irregularidade na estrutura e aparência do papel (defeito conhecido por shadow mark). Recentemente, Antoine [2007] estudou o efeito de marcas de telas formadoras sobre a qualidade de impressão de papel imprensa (jornal) e Forel et al. [2009] estudaram a influência das características da tela formadora na qualidade do papel, sobretudo no desprendimento de fibras e finos (linting), drenagem e estrutura da folha, incluindo a medição de tamanho, orientação e intensidade das marcas produzidas por diferentes tipos de telas formadoras.

\subsubsection{Telas formadoras para máquinas de papel}

Os componentes têxteis empregados no extremo úmido das máquinas de papel, denominados "telas formadoras", exercem simultaneamente diferentes funções durante a formação da folha: atuam como meio filtrante da massa de papel ${ }^{86}$, permitindo que a água seja drenada através de suas aberturas; constituem um suporte plano, no qual as fibras de celulose são retidas e se entrelaçam, a fim de formar a folha de papel e, adicionalmente, funcionam como meio de transporte, com a finalidade de transferir a folha em direção à seção de prensagem.

A água extraída da massa de papel, durante a formação de folha, é drenada pela ação combinada da gravidade e de diversos elementos desaguadores do formador (e.g., rolos desaguadores, lâminas formadoras e rolos e caixas de sucção a vácuo). Nos modernos formadores de tela dupla ${ }^{87}$, são utilizadas duas telas com características similares, que operam simultaneamente, produzindo desaguamento pelos dois lados da folha de papel. Uma vez que a etapa de formação da folha corresponde a uma das operações mais críticas da fabricação do

\footnotetext{
${ }^{85}$ Light Weight Coated (papel revestido de baixa gramatura, tipicamente produzido com pasta mecânica).

${ }^{86}$ A massa de papel constitui-se de uma suspensão aquosa muito diluída, contendo fibras de celulose, cargas minerais e aditivos.

${ }^{87}$ Ver subseção 4.1.1.
} 
papel, telas formadoras especializadas foram desenvolvidas para cada aplicação, de forma a contribuir para a obtenção das propriedades requeridas para cada tipo de papel, tais como formação, perfil de distribuição de cargas minerais, lisura, minimização de dupla face e propriedades superficiais para impressão.

Atualmente, as telas formadoras são sintéticas, fabricadas principalmente com fios de poliéster e poliamida ${ }^{88}$. São produzidas em teares, onde os fios longitudinais (warps) e os fios transversais (weft) são entrelaçados, para formar uma manta contínua, com acabamento do tipo "sem fim" e comprimentos que variam de $25 \mathrm{~m}$ a $105 \mathrm{~m}$ e larguras desde $2,5 \mathrm{~m}$, até $11 \mathrm{~m}$. Os comprimentos típicos das telas usadas em formadores de dupla tela da classe dos gap formers situam-se tipicamente entre 25 m e 30 m [Westerkamp, 2006].

Os principais requisitos técnicos para uma tela formadora incluem capacidade de desaguamento, formação uniforme com alta retenção de fibras, estabilidade dimensional, resistência ao desgaste e planicidade superficial, a fim de prover suporte uniforme e distribuído, a fim de minimizar a marcação da folha de papel.

\section{Estrutura e classificação das telas formadoras}

Diversas estruturas foram desenvolvidas para as telas formadoras, a fim de atender às condições específicas de aplicação, na fabricação de diferentes tipos de papel, e de diferentes configurações de formador. A Figura 3.15 mostra exemplos de diferentes tipos construtivos. Os tipos mais comumente aplicados consistem de telas com simples-camada $\left(\mathrm{SL}^{89}\right)$, duplacamada (DL ${ }^{90}$ ), dupla-camada com adição de fio transversal extra (DL EWA ${ }^{91}$ ), tripla-camada $\left(\mathrm{TL}^{92}\right)$, triplo fio transversal $\left(\mathrm{TW}^{93}\right)$ e as modernas telas triplas com fio de ligação autosuportante $\left(\mathrm{SSB}^{94}\right)$ [Kilpeläinen et al., 2000]. As telas de tripla-camada, de fato, são formadas por duas telas com estruturas individuais (superior e inferior), unidas entre si por um

\footnotetext{
${ }^{88}$ Utiliza-se, em geral, o poliéster para os fios longitudinais (warp yarns) devido à sua boa resistência à tração e baixo alongamento sob carga. Para o sistema de fios transversais (weft yarns) utiliza-se o poliéster e a poliamida, introduzida com a finalidade de aumentar a resistência ao desgaste. Em função da tendência de absorver água e alto coeficiente de alongamento, a poliamida não é usada no sistema de fios longitudinais e nem como material único para o sistema de fios transversais.

${ }^{89}$ SL: Single Layer.

${ }^{90}$ DL: Double Layer.

${ }^{91}$ DL EWA: Double Layer Extra Weft Added.

${ }^{92}$ TL: Triple Layer.

${ }^{93}$ TW: Triple Weft

${ }^{94}$ SSB: Self Support Binding
} 
sistema de fios de ligação (binder yarn ou stitch), $c f$. ilustra a Figura 3.16. Em geral, este tipo de tela é formado por dois ou mais sistemas de fios longitudinais (MD), dois ou mais sistemas de fios transversais (CD) e fios transversais adicionais na camada superior.

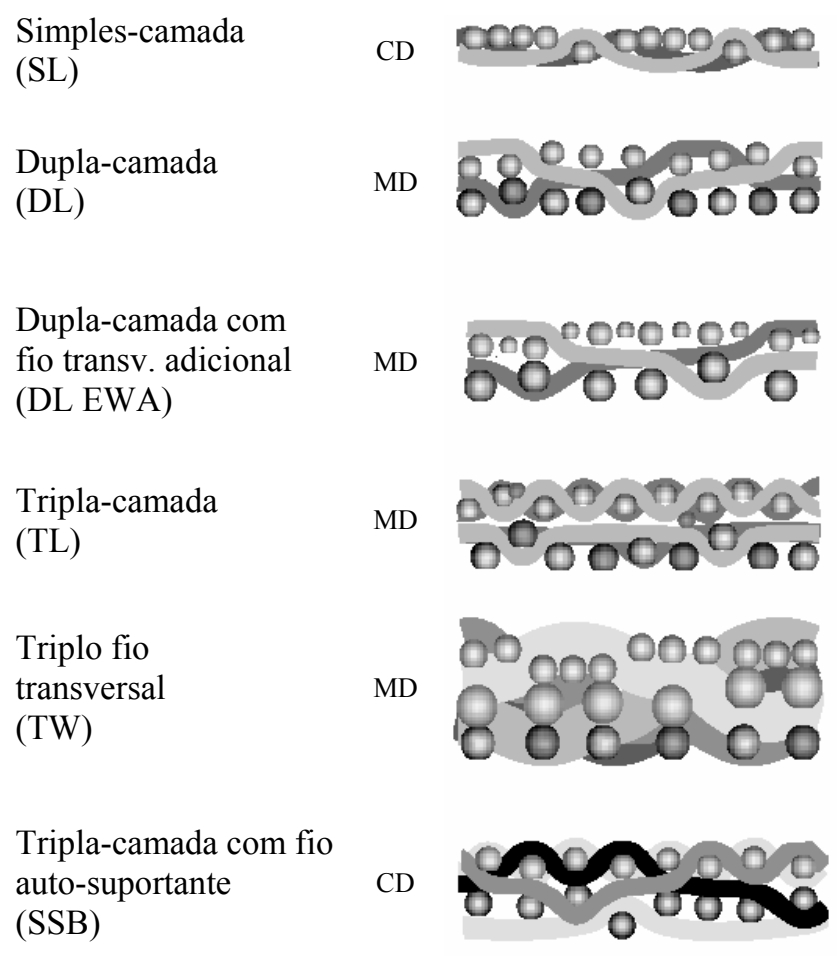

Figura 3.15. Seções transversais das telas formadoras comumente utilizadas nas máquinas de papel [Kilpeläinen et al., 2000, p.254].

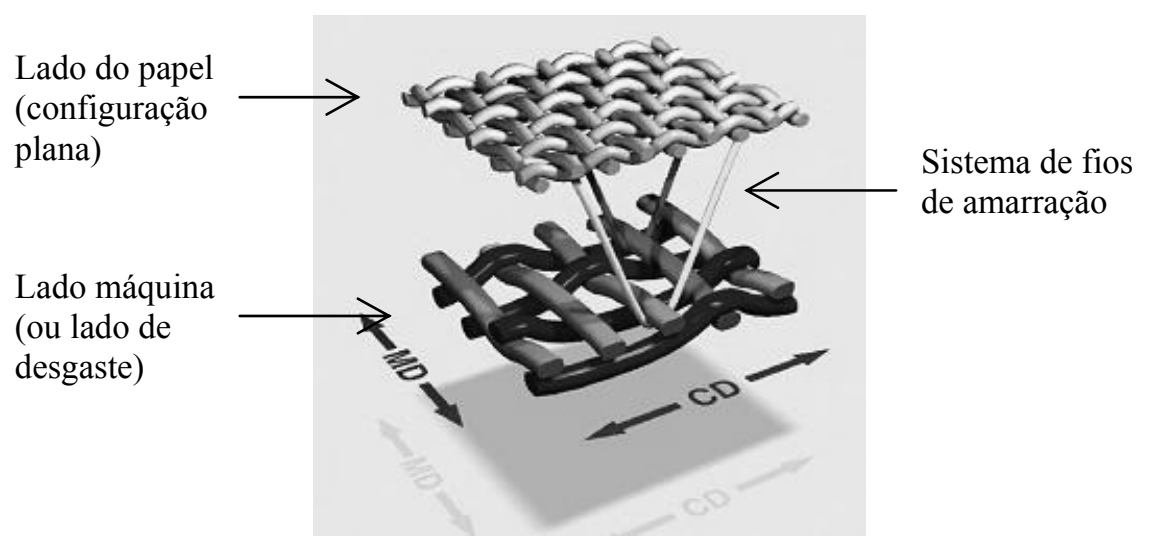

Figura 3.16. Estrutura básica de uma formadora de camada tripla, destacando o sistema de fios de amarração entre as camadas individuais [Hender, 2009]. 
Os padrões de tecedura das telas formadoras são denominados de acordo com a "quantidade de quadros" (shed count ou harness count), que se define por um número de fios encontrados na direção longitudinal da tela, de forma que, após esta quantidade, o padrão de entrelaçamento se repete (ver Figura 3.17).

Observe-se que, nas telas de dupla-camada e tripla-camada, o lado do papel pode ter um padrão de entrelaçamento de fios diferente daquele existente no lado de desgaste da mesma tela. Por exemplo, a tela de tripla-camada mostrada na Figura 3.17 apresenta, no lado do papel, um número de quadros igual a 2, i.e., o padrão de tecedura se repete a cada 2 fios longitudinais. Uma vez que, no lado de desgaste, o padrão se repete a cada 5 fios longitudinais, a denominação completa para esta tela se torna 2/5-quadros (2/5-shed), que constitui o arranjo típico aplicado em telas formadoras de tripla-camada SSB [Mattijssen, 2008]. A Figura 3.18 ilustra estes padrões de tecedura.

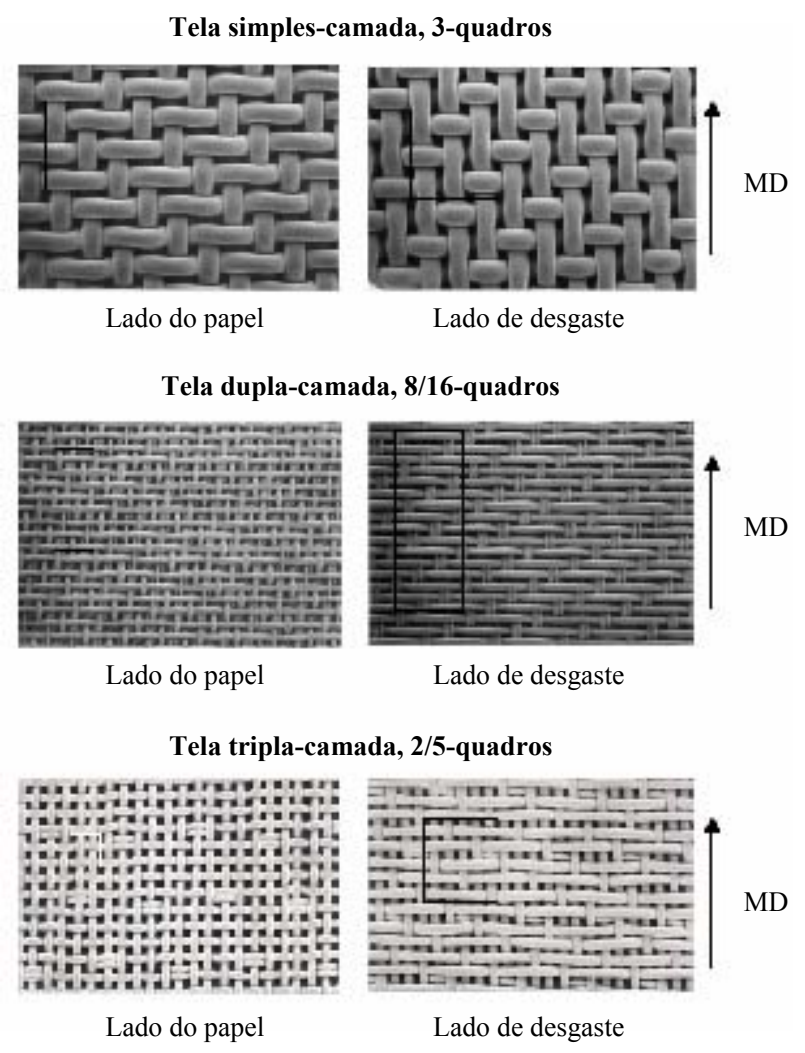

Figura 3.17. Exemplos de teceduras de telas formadoras de simples-camada, dupla-camada e tripla-camada [Kilpeläinen et al., 2000, p.255]. 


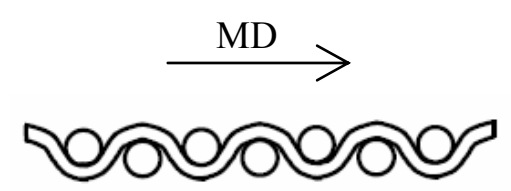

(a)

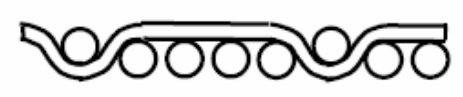

(b)

Figura 3.18. Tipos de tecedura das superfícies da tela formadora tripla-camada mostrada na Figura 3.17: (a) lado do papel tecido em (02) quadros (configuração plana) e (b) lado de desgaste com 5 quadros, tecido no estilo 1/4 [Barros, 2002].

\section{Telas de tripla-camada estilo SSB}

As telas formadoras com estrutura básica de tripla-camada ( $c f$. Figura 3.17) foram usadas por mais de trinta anos na indústria de papel, pois este conceito estrutural permite diferentes abordagens para otimização das funções de cada superfície separadamente, a fim de corresponderem às demandas específicas de cada processo. Uma malha fina na superfície de contato com o papel, composta por fios de pequeno diâmetro, associada à tecedura plana (2-quadros), produziu propriedades superiores para a fabricação de papel. A camada inferior pôde ser aperfeiçoada para prover mais resistência ao desgaste e maior estabilidade mecânica e dimensional ${ }^{95}$ ao conjunto, processo que envolveu a utilização de fios com maiores diâmetros e teceduras de 5-quadros ou 6-quadros [Kershaw, 2010].

A primeira geração de telas triplas usava fios transversais simples para integrar as duas camadas [cf. Figura 3.19 (a)], cuja fragilidade advinha principalmente de problemas de durabilidade limitada dos fios de ligação, quando as telas formadoras estavam sujeitas a aplicações mais severas ao desgaste. A segunda geração de telas de tripla-camada, introduzida no mercado em torno de 1999, também incorporou fios transversais para a integração das camadas, porém dispostos em pares na nova configuração que, dessa forma, passaram a desempenhar dupla função: (a) fixar as camadas entre si e (b) melhorar a superfície de contato com o papel, pois os fios de amarração foram incorporados à estrutura da tela e, assim, possibilitaram um aumento na quantidade de pontos de suporte para o papel [cf. ilustra a Figura 3.19 (b)]. Esta configuração, comumente denominada como SSB resolveu potenciais

\footnotetext{
${ }^{95}$ A aplicação deste tipo de tela formadora contribui para obtenção de melhores perfis para o papel, em função da sua estrutura estável. Uma alta quantidade de fios transversais na laje inferior e fios de pequeno diâmetro na laje superior são utilizados sem prejuízo para a estabilidade dimensional da tela [Roy, 2009].
} 
problemas de delaminação encontrados na geração anterior e encontra ampla aplicação na fabricação de todos tipos de papel, especialmente para aqueles destinados à impressão [Hay, 2002; Taylor, 2008; Hender, 2009]. Atualmente, a configuração das telas formadoras SSB representa grande um potencial para obtenção de propriedades melhoradas do papel e para produção mais econômica com maiores índices de estabilidade operacional (runnability) da máquina [Mattijssen, 2007].

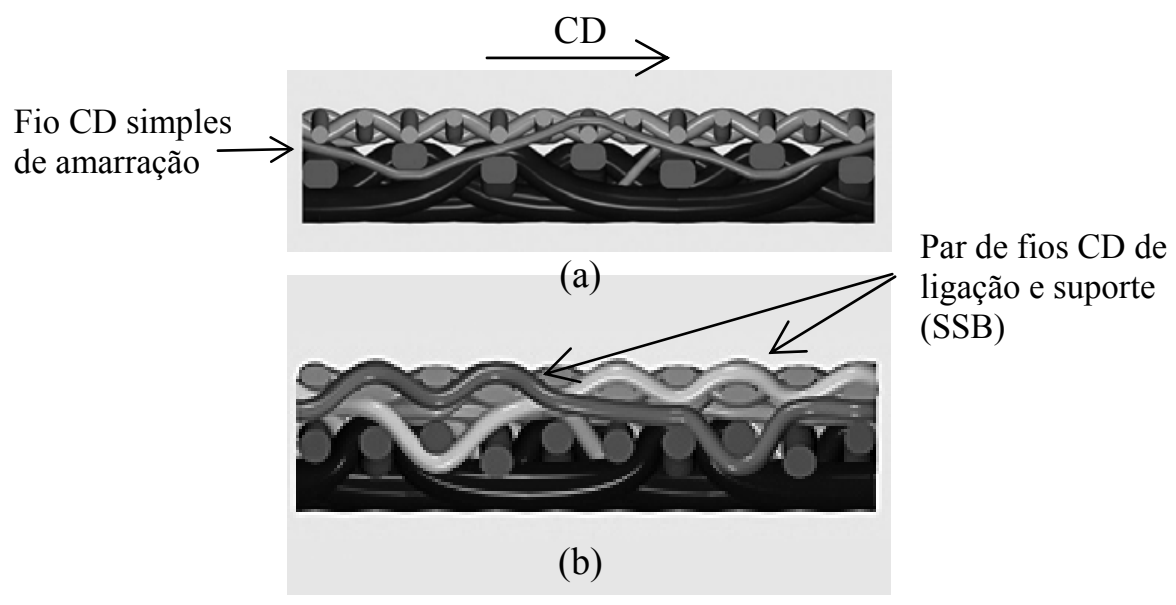

Figura 3.19. Estruturas de telas formadoras tripla-camada: (a) configuração básica com um fio $C D$ de amarração simples e (b) padrão SSB com fios CD dispostos em pares [Hender, 2009].

A introdução da configuração SSB estabeleceu sua supremacia na aplicação de telas formadoras para a maioria dos tipos de papel e de formadores ${ }^{96}$. Atualmente, estas telas são empregadas em formadores do tipo mesa plana (fourdrinier), em formadores de tela dupla híbridos (top wire fomers) e, principalmente em formadores de dupla tela do tipo gap formers $^{97}$ [Rühl; Hölsl, 2008; Taylor, 2008; Roy, 2009; Kershaw, 2010]. Segundo Blom [2010], as telas com estilo SSB tem tido aplicação crescente nos formadores de dupla tela, em função da sua longa vida útil, melhoria da qualidade do papel, economia no uso de agentes de retenção, operação limpa e melhor eficiência operacional, devido à potencial redução de quebras da folha em produção. Normalmente, as telas utilizadas na posição superior e inferior são do mesmo tipo a fim de produzir características semelhantes nas duas faces do papel,

\footnotetext{
${ }^{96}$ Segundo Roy [2009], as telas com tecnologia SSB são utilizadas em mais de $70 \%$ das unidades fornecidas globalmente, especialmente em máquinas de alta velocidade.

${ }_{97}$ Ver Figura 4.3 na subseção 4.1.1.
} 
podendo em casos particulares divergir no aspecto da relação (ou razão) de fios entre as lajes da tela (yarn stacking) ${ }^{98}$ (informação verbal) ${ }^{99}$.

Uma variante do conceito SSB tradicional, denominado warp exchange design foi apresentado por Hender [2009]. Este arranjo estrutural de tripla-camada consiste também na aplicação de pares de fios com função de integração das lajes e suporte da folha, porém orientados na direção da máquina (MD). Segundo Hender [2009], esta configuração resulta em telas menos espessas, com menor volume livre.

Fabricação das telas formadoras

A Figura 3.20 mostra esquematicamente as etapas do processo de fabricação das telas formadoras.

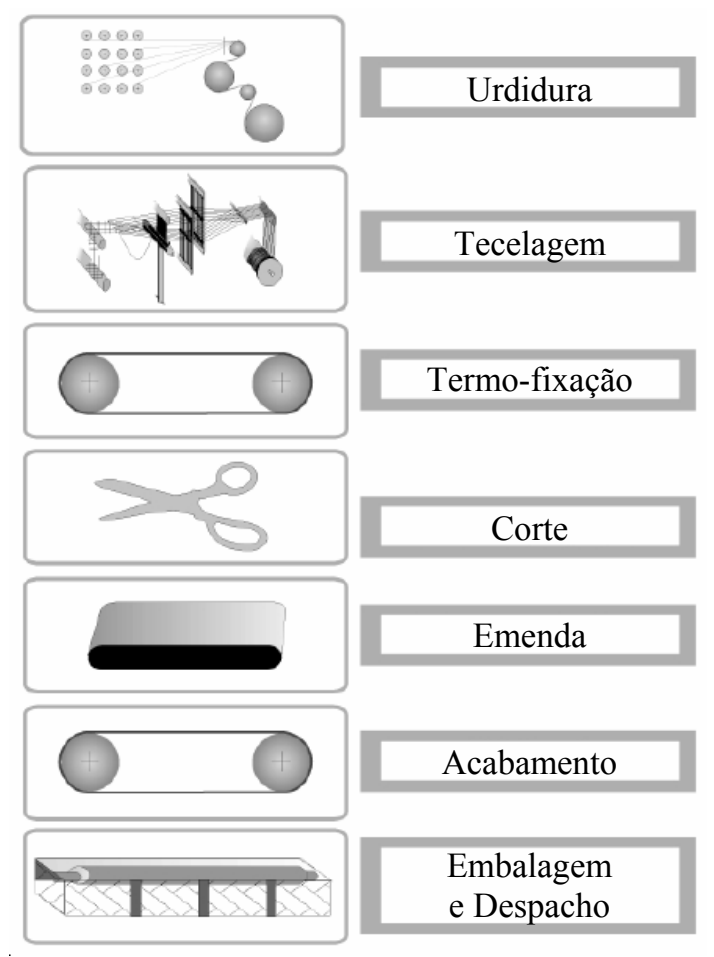

Figura 3.20. Representação esquemática das etapas da fabricação de uma tela formadora [Kilpeläinen et al., 2000, p.256].

\footnotetext{
${ }^{98}$ A razão entre fios das lajes da tela revela o alinhamento relativo entre fios transversais (CD) das lajes superior e inferior em telas formadoras multicamada [Barros, 2002].

${ }_{99}$ Informação fornecida por Bloom, M. (Metso Fabrics) em Sorocaba, em 2010.
} 
$\mathrm{Na}$ primeira etapa (urdidura), os fios são retirados dos carretéis e posicionados nos compartimentos individuais do urdidor, a fim de formar um feixe de fios. Na etapa seguinte (tecelagem), ocorre a tecedura, quando o padrão de entrelaçamento dos fios é definido.

Na próxima etapa (termo-fixação), a tela é aquecida durante movimento sobre dois cilindros. Por meio de controle na aplicação de calor e tensão, a tela se dilata na direção longitudinal e se contrai na direção transversal. O objetivo do tratamento térmico consiste em aliviar as tensões internas da tela tecida, com a finalidade de aumentar o módulo de elasticidade e a estabilidade dimensional e fixar sua forma construtiva, de forma que o lado papel se torne o mais plano e liso possível e o lado reverso ganhe resistência ao desgaste. No processo de termo-fixação, a estrutura da tela também é fixada, a fim de minimizar deformações em operação na máquina de papel. Durante a tecedura, os fios transversais apresentam pequena ondulação, comparada a dos fios longitudinais. Durante o processo de termo-fixação, ocorre redução na ondulação dos fios longitudinais e aumento na ondulação dos fios transversais, fenômeno denominado de transferência ou permuta de ondulação, $c f$. ilustrado na Figura 3.21 [Adanur, 1997].

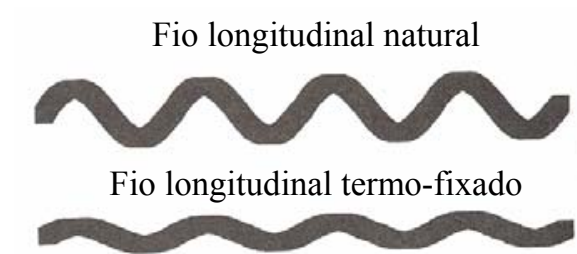

Fio transversal natural

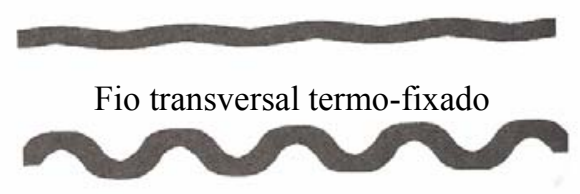

Figura 3.21. Transferência de ondulação entre fios durante a etapa de termofixação na fabricação da tela formadora [Adanur, 1997, p.78].

A seguir vem a operação de emenda, com o propósito de transformar a tela formadora numa manta sem fim. Na fase final de fabricação (acabamento), os fios protuberantes remanescentes da etapa de emenda são cortados e as bordas recebem terminação apropriada 
para evitar que desfiem. A face de contato com papel poderá ser polida com a finalidade de aumentar a lisura superficial. Após o estágio de acabamento, a tela formadora encontra-se pronta para embalagem e despacho.

\section{Especificações técnicas para telas formadoras}

Alguns parâmetros são definidos com a finalidade de permitir a caracterização das telas formadoras, com respeito a sua configuração estrutural e suas propriedades funcionais, bem como de estabelecer critérios para comparação entre diferentes tipos. Os principais parâmetros, descritos a seguir, são normalmente controlados em cada aplicação, a fim de satisfazer os requisitos exigidos das telas formadoras no processo de fabricação de diferentes tipos de papel [Adanur, 1997, p.85; Foti, 2010 (informação verbal) ${ }^{100}$; Weavexx, 2010; Huyck Wangner, 2010].

Malha e Trama: Os termos "malha" (ou mesh) e "trama" (ou count) representam a quantidade de fios por unidade de comprimento ${ }^{101}$ de uma tela formadora, na direção da máquina de papel (MD) e na direção transversal (CD), respectivamente. Os fios longitudinais (warp yarns) que compõem a malha encontram-se alinhados com a direção da máquina de papel, enquanto os fios transversais (weft ou filling yarns), que formam a trama, encontramse alinhados com a direção transversal, $c f$. Figura 3.22. O termo "malha" e o termo "trama" são também, em casos específicos, denominados genericamente de "contagem de fios" (ou yarn count).

À soma entre malha e trama (i.e., $\mathrm{n}_{\mathrm{MD}}+\mathrm{n}_{\mathrm{CD}}$ ) denomina-se contagem total (ou t-count), índice usado como referência à quantidade total de material contido em uma tela formadora, para fins de comparação ente produtos de diferentes fabricantes.

Consiste prática comum indicar, na especificação de malhas e tramas, primeiramente a quantidade de fios na direção longitudinal (MD), seguida da quantidade na direção transversal (CD), e.g., 76 × 70 fios/pol. Ou 30 × 27,5 fios/cm - especificação típica para a face de contato

\footnotetext{
${ }^{100}$ Informações fornecidas por Foti, A., durante palestras sobre vestimentas para máquina de papel proferidas na Metso Paper e no evento "Technology Seminar: Products and Services of Paper and Board Business Line", em Sorocaba, em 2010.

${ }^{101} \mathrm{Na}$ literatura relativa às telas formadoras encontram-se referências de quantidade de fios por polegada (pol.), bem como número de fios por centímetro $(\mathrm{cm})$.
} 
com o papel de uma tela formadora de tripla laje. A contagem total de fios (i.e., malha total e trama total) depende do tipo de construção ${ }^{102}$ das camadas da tela e da distribuição dos fios de amarração.

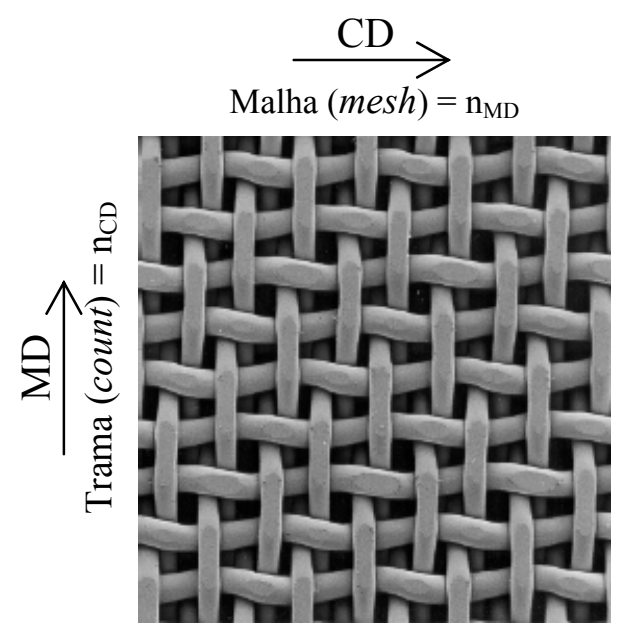

Figura 3.22. Definição de malha (mesh) e trama (count), sendo $\mathrm{n}_{\mathrm{MD}} \mathrm{o}$ número de fios longitudinais (warp yarns) e $\mathrm{n}_{\mathrm{CD}}$ o número de fios transversais (weft yarns) por unidade de comprimento da tela formadora.

Pontos de suporte: A contagem dos pontos de suporte (SP-count) indica a quantidade de pontos de cruzamentos de fios que fazem contato com a folha de papel, por unidade de área da tela formadora, i.e., pontos $/$ pol. ${ }^{2}$ ou pontos $/ \mathrm{cm}^{2}$.

Permeabilidade: A permeabilidade ao ar representa a medição do fluxo de ar que atravessa uma tela formadora por unidade de área, sob um diferencial de pressão padronizado. Este parâmetro é comumente expresso em pés cúbicos por minuto por pé quadrado $\left(\mathrm{cfm} / \mathrm{ft}^{2}\right)$ sob pressão diferencial de 0,5 polegada de coluna de água (in.WC) ou em metros cúbicos por segundo por metro quadrado $\left(\mathrm{m}^{3} / \mathrm{s} / \mathrm{m}^{2}\right.$ ou, simplesmente $\left.\mathrm{m} / \mathrm{s}\right)$ sob pressão diferencial de 100 Pascais $(\mathrm{Pa})$.

Este parâmetro foi amplamente utilizado na época em que as telas formadoras de simples laje eram predominantemente empregadas nas máquinas de papel, pois forneciam ao fabricante de papel uma boa indicação do potencial de drenagem e representavam também uma boa ferramenta de controle de qualidade para o fabricante da tela. Entretanto, nas telas formadoras multicamadas, cada laje pode exercer influência considerável na permeabilidade da tela, mas não necessariamente na capacidade de drenagem.

\footnotetext{
${ }^{102}$ Ver item "estrutura e classificação das telas formadoras", na subseção 3.5.2.
} 
Índice de Suporte de Fibras: O conceito do índice de suporte de fibras $\left(F S I^{103}\right)$ foi desenvolvido por Beran [1979]. Seu trabalho, baseado em modelo estatístico, prediz características de suporte de fibras das telas formadoras, a partir da especificação da malha e trama, do tipo de construção e do comprimento da superfície de suporte dos fios sobre a qual a folha de papel é formada. Reconheceu que o suporte na direção transversal representava maior influência que os suporte na direção longitudinal e, portanto, deveria duplamente ponderado (recebeu fator $=2$ ). Para tal, assumiu quatro premissas:

1 - as telas formadoras são planas e não tem espessura;

2 - o suporte dos fios é baseado em uma linha sem espessura;

3 - os fios são retos e paralelos;

4 - os fios estão uniformemente distribuídos.

Do modelo matemático desenvolvido por Beran [1979], foi derivada a seguinte expressão simplificada, para o índice de suporte de fibras:

$$
F S I=\frac{2}{3}\left(a \times n_{M D}+2 \times b \times n_{C D}\right)
$$

onde:

FSI índice de suporte de fibras

a fator de suporte, referente aos fios longitudinais.

$b \quad$ fator de suporte, referente aos fios transversais presentes na face em contato com o papel.

$n_{M D} \quad$ quantidade de fios longitudinais (MD) / pol. de comprimento da tela

$n_{C D} \quad$ quantidade de fios transversais (CD) / pol. de largura da tela

Os fatores de suporte dependem da configuração da tela e são calculados por meio das expressões a seguir:

$$
a=\frac{f_{t l}+1}{q}
$$

${ }^{103}$ FSI: Fiber Support Index. 
$b=\frac{f_{l t}+1}{q}$

onde:

a fator de suporte, referente aos fios longitudinais.

$b$ fator de suporte, referente aos fios transversais presentes na face em contato com o papel.

$f_{t l} \quad \mathrm{n}^{\mathrm{o}}$ de fios CD sob a extensão de suporte do fio MD (warp knuckle)

$f_{l t} \quad \mathrm{n}^{\mathrm{o}}$ de fios MD sob a extensão de suporte do fio CD (weft knuckle)

$q \quad \mathrm{n}^{\mathrm{o}}$ de quadros da estrutura da tela

O trabalho de Beran (1979) foi originalmente desenvolvido para telas de simples camada e posteriormente extrapolado para as telas multicamadas. Entretanto, não fornece nenhuma indicação da uniformidade da distribuição das superfícies de suporte.

Índice de Drenagem: Este índice foi desenvolvido por Johnson [1986] como ferramenta para classificar as telas formadoras a partir das taxas relativas de drenagem. $\mathrm{O}$ cálculo do índice de drenagem $\left(D I^{104}\right)$ leva em conta a permeabilidade, a quantidade de fios transversais (CD) e o fator de suporte de Beran (1979) para a mesma direção, $c f$. expressão a seguir:

$$
D I=b \times P \times n_{C D} \times 10^{-3}
$$

onde:

DI índice de drenagem

$b \quad$ fator de suporte, referente aos fios transversais presentes na face da tela em contato com o papel.

$P \quad$ permeabilidade ao ar da tela, $\mathrm{cfm} / \mathrm{ft}^{2}$

$n_{C D} \quad$ quantidade de fios transversais (CD) / pol. de largura da tela

Área Percentual Aberta da Superficie Superior: A área percentual aberta indica a área total da combinação dos espaços de drenagem existentes na superfície superior da tela

${ }^{104}$ DI: Drainage Index. 
formadora. É calculada usando uma imagem plana projetada da camada superficial da tela, da qual de obtém a área total e se subtrai a área ocupada pelos fios. A área aberta $\left(O A^{105}\right)$, expressa como percentual da área total, é dada pela expressão a seguir:

$$
O A=\left[1-\left(n_{M D} \times s_{M D}\right)\right] \times\left[1-\left(n_{C D} \times s_{C D}\right)\right] \times 10^{2}
$$

onde:

$O A$ área aberta, \%

$n_{M D} \quad$ quantidade de fios longitudinais (MD) por unidade de largura

$n_{C D} \quad$ quantidade de fios transversais (CD) por unidade de comprimento

$s_{M D} \quad$ diâmetro dos fios longitudinais (MD)

$s_{C D} \quad$ diâmetro dos fios transversais (CD)

A experiência tem mostrado que, em formas construtivas multicamadas, este parâmetro pode indicar o potencial de drenagem de forma mais apropriada que a permeabilidade da tela.

Adicionalmente, parâmetros tais como gramatura $\left(\mathrm{g} \cdot \mathrm{m}^{-2}\right)$, volume livre $\left(\mathrm{ml} / \mathrm{m}^{-2}\right)$, margem de desgaste $(\mathrm{mm})$, espessura $(\mathrm{mm})$, material e diâmetro dos fios $(\mathrm{mm})$ e a razão de fios entre camadas completam o elenco de propriedades das telas formadoras usadas na especificação técnica do produto.

\section{Estabilidade das telas formadoras}

A estabilidade mecânica e dimensional das telas formadoras tem importante impacto na qualidade do papel produzido. No que se refere à drenagem inicial, a estabilidade diagonal da tela representa fator relevante, a fim de prevenir deformações causadas por eventual falta de uniformidade de pressão do jato de massa na saída da caixa de entrada. A avaliação deste parâmetro, por meio de aplicação de estiramento diagonal, em diversas configurações de telas, apresentada por Kilpeläinen et al. [2000], cf. Figura 3.23, mostra que a tela de tripla-laje (TL) oferece a maior estabilidade dimensional, na comparação com os tipos dupla-laje $(D L)$ e triplo fio transversal $(T W)$.

${ }^{105}$ OA: Open Area. 


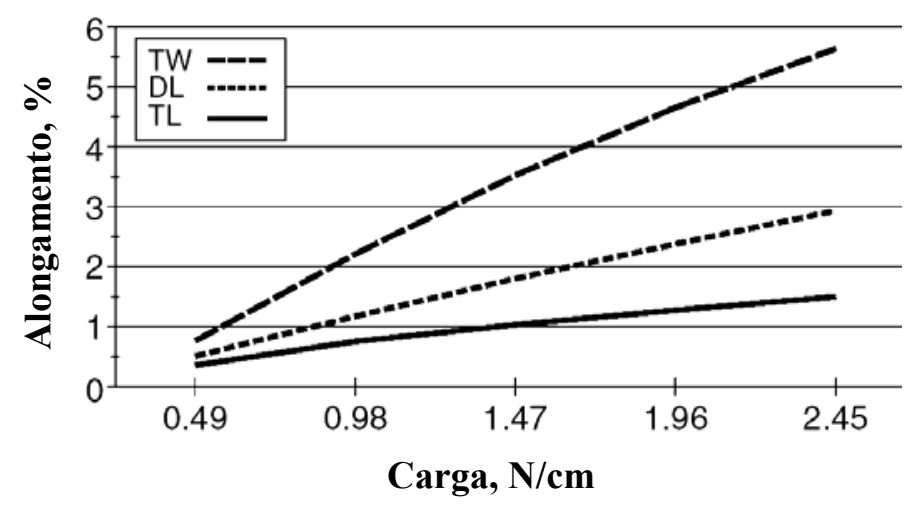

Figura 3.23. Alongamento diagonal para diferentes configurações de telas formadoras: TW - triplo fio longitudinal, DL - dupla-laje, TL - tripla-laje [Kilpeläinen et al., 2000, p.262].

A importância da estabilidade diagonal de uma tela formadora tem sido demonstrada em máquinas de papel, durante a produção, por meio da obtenção de redução de variação do perfil de gramatura observada após a instalação de telas de tripla-laje em formadores de dupla tela do tipo gap formers.

\subsubsection{Identificação de marcas de telas formadoras}

As marcas provenientes de telas formadoras encontradas no papel acabado estão associadas a diferentes mecanismos de geração, sendo classificadas em duas categorias: as marcas topográficas e as marcas de drenagem (ou marcas hidrodinâmicas).

As marcas topográficas se referem à reprodução do padrão estrutural de uma tela formadora sobre a superfície do papel durante a formação da folha. Este tipo de marca é causado por arrastamento de fibras pelos fluxos de água ao longo da etapa de desaguamento do papel. As marcas topográficas são normalmente acentuadas pela ação de sucção aplicada por elementos desaguadores a vácuo ou por compressão da folha contra a tela formadora. As marcas hidrodinâmicas se relacionam a distribuições irregulares de cargas minerais e de finos no plano da folha produzidas de acordo com os canais de drenagem da tela formadora. Marcas visíveis de uma tela formadora resultam, em geral, da combinação das duas classes de marcação (topográfica e hidrodinâmica). 
A Figura 3.24 mostra um exemplo de marcas de uma tela formadora, observadas em uma folha formada em laboratório. Nas áreas de compressão das saliências dos fios, a folha apresenta aparência de maior densidade. Entre as posições referentes às saliências dos fios, observa-se uma penetração parcial da folha na tela. Nestas áreas, a folha tem mais porosidade e teor reduzido de finos.

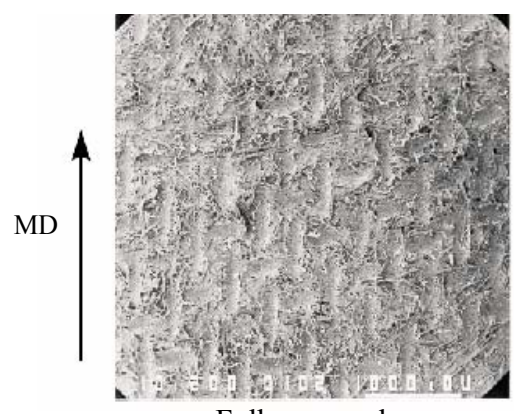

Folha manual

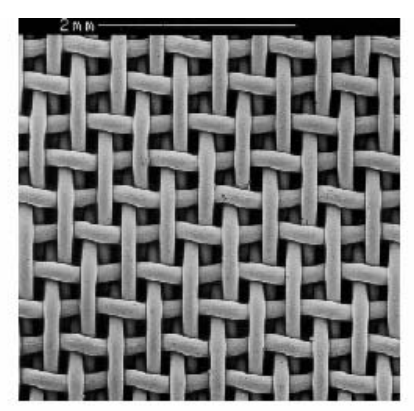

Tela de dupla-camada

Figura 3.24. Marcas produzidas por tela formadora [Kilpeläinen et al., 2000].

Nas máquinas de papel industriais, as principais marcas encontradas na folha de papel são freqüentemente provenientes da seção de formação, i.e., de telas utilizadas em formadores do tipo fourdrinier (mesa plana), formadores de tela dupla (twin wire former) ou em arranjos com cilindros formadores (cylinder former). Estas marcas consistem basicamente de variações do peso específico (gramatura) em escala fina, acompanhadas de variações de densidade e de forma da superfície do papel.

Estes tipos de irregularidades normalmente são revelados por técnicas de radiografia com raios- $\beta$, por transmissão de luz, iluminação indireta e provavelmente por outros métodos. A dimensão do padrão de repetição dos fios das telas formadoras que causam estas marcas, ou seu período situa-se na faixa de $1-3 \mathrm{~mm}$, na maioria dos casos. Segundo I'Anson [2001], o tamanho da imagem da amostra de papel usada para detecção destes padrões de repetição deve ser suficiente para a caracterização da presença de um arranjo periódico, porém não tão grande que possa provocar efeitos indesejados de sub-amostragem ${ }^{106}$, o que significa que, em geral, imagens com dimensões de $30-100 \mathrm{~mm}$ são adequadas, em função da forma particular da tela formadora e das marcas transferidas para o papel. A iluminação por transmissão de luz tem sido a preferida para este tipo de medição, pois associada à

\footnotetext{
${ }^{106}$ Referir-se à subseção 3.4 .3
} 
transformada de Fourier, compõe um método sensível para detecção de marcas de telas formadoras, mesmo que invisíveis a olho nu.

De acordo com Humphrey [1998, p.39], dois tipos de análise para diagnósticos de papel têm sido aplicados, baseados nas marcas periódicas produzidas pelas telas formadoras: (a) a reconstrução do padrão estrutural da vestimenta, e (b) a determinação do encolhimento do papel $^{107}$. A análise de aspectos de formação do papel, utilizando técnicas fundamentadas na análise de imagem no domínio de freqüências (transformada rápida de Fourier), permite identificar variações sistemáticas no papel, atribuídas a marcas de feltros de prensas ou de telas formadoras.

Os procedimentos para identificação de marcas de telas atualmente em uso mostram a preferência pela adoção da transformada de Fourier como algoritmo para o processamento de imagens digitais de amostras de papel ${ }^{108}$. A transformada de Fourier permite medir a amplitude das variações, sua escala e sua orientação. Como a natureza do aspecto sob análise na imagem digital (marcas periódicas no papel) consiste de uma função no domínio do espaço (e não do tempo), a extração de informações do conteúdo de freqüências da função imagem por meio da transformada de Fourier é perfeitamente adequada, pois tal conteúdo não varia com o tempo, i.e., trata-se de um sinal estacionário ${ }^{109}$.

No trabalho de I'Anson et al.[1990], verifica-se a aplicação da transformada de Fourier para processamento de imagens digitais de papel, com a finalidade de identificar marcas de tela formadora, no formato de 256 x 256 pixels e profundidade de cor de 128 níveis de cinza (7 bits). I' Anson [1995a, 1995b] descreve a utilização da transformada rápida bidimensional de Fourier (2D-FFT) para a identificação de marcas periódicas em papel e cartão, a partir de imagens digitais obtidas em digitalizador convencional, por meio de transmissão de luz, com dimensões de 512 x 512 pixels e profundidade de cor de 8 bits (256 níveis de cinza). Este método facilitou visualizar as marcas e, sem ambigüidade, identificar

\footnotetext{
${ }^{107}$ Ver capítulos 4 e 5.

${ }^{108}$ Existem outras transformadas matemáticas aplicáveis para análise de sinais, tais como a transformada de Hilbert, a distribuição de Wigner, a transformada randômica e a transformada Wavelet, dentre tantas outras de uma longa lista. Porém, em geral, são mais utilizadas para sinais no domínio do tempo. Cada técnica de transformação tem seu campo de aplicação específico.

109 A transformada de Fourier tem a característica de não informar uma relação temporal das componentes de freqüência do sinal analisado (i.e., em qual intervalo de tempo existem as componentes de freqüência detectadas), o que constituiria uma limitação para sinais no domínio do tempo, que apresentam freqüências como variáveis dependentes.
} 
sua origem. As dimensões espaciais das imagens das amostras de papel usadas variaram de 30 - 34 mm. Em I'Anson [1998], encontra-se a aplicação da 2D-FFT para processamento de imagens digitais produzidas por digitalizador de perfil superficial a laser, com dimensões de 512 x 512 pixels $(100 \times 100 \mathrm{~mm})$ e também com profundidade de cor de 256 níveis de cinza (8 bits).

Hoole et al.[1999]; Hoole, I'Anson e Hoyland [2000], Hoole [2002], I'Anson [2001, 2008] utilizaram métodos para identificação de marcas de tela formadora, com a finalidade de avaliar o perfil de encolhimento transversal do papel, usando imagens obtidas a partir de digitalização por transmissão de luz, no formato de 512 x 512 pixels, com profundidade de cor de 8 bits e dimensões espaciais de 70-72 x 70-72 mm, processadas pela transformada rápida de Fourier (2D-FFT). Em I'Anson et al.[2008], verifica-se que as imagens inicialmente tomadas com dimensões de 512 x 512 pixels foram expandidas para 1024 x 1024 pixels

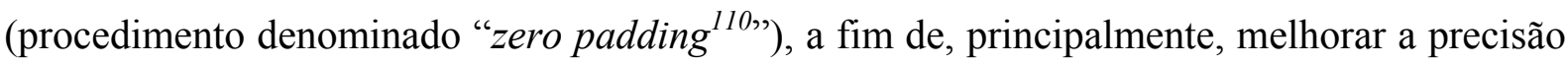
da medição das marcas periódicas detectadas no papel.

\subsubsection{Aspectos geométricos de marcas produzidas por telas formadoras aplicados na determinação do encolhimento transversal (CD) do papel.}

Como exposto na subseção anterior, é possível detectar padrões periódicos produzidos pelas estruturas das vestimentas ${ }^{111}$ empregadas na máquina de papel, utilizando-se técnicas de análise de imagem por meio da transformada rápida bidimensional de Fourier (2D-FFT). Um método para identificação de marcas provenientes da tela formadora pode ser implementado utilizando-se o aplicativo IPT do MATLAB ${ }^{112}$. Uma vez que as marcas encontradas na superfície do papel decorrem de características topográficas associadas à dinâmica de drenagem das telas formadoras, suas eventuais deformações ou falta de alinhamento, resultantes das condições de operação na máquina de papel, podem produzir padrões de marcação diferentes entre os pontos de amostragem, o que acarreta a necessidade de se considerar aspectos geométricos das telas formadoras e das marcas correspondentes, a fim de possibilitar uma melhor análise e um cálculo mais preciso do encolhimento transversal (CD), cf. salientado por Praast e Gotsching [1995] e, também, por I'Anson et al. [2008].

\footnotetext{
${ }^{110}$ Ver subseção 3.4.7.

${ }^{111}$ Denominam-se vestimentas da máquina de papel ao conjunto de componentes de tratamento e suporte da folha, constituídos pelas telas formadoras, feltros e mantas das prensas e telas secadoras.

${ }^{112}$ Ver metodologia na subseção 4.2.3.
} 
A Figura 3.25 exibe, cf. apresentado por I'Anson et al. [2008], configurações geométricas típicas correspondentes a eventuais distorções da estrutura de uma tela formadora em operação, geralmente decorrente do seu movimento em alta velocidade sobre rolos-guia, associado a variações casuais de tensão de esticamento na direção transversal (CD) e ilustra casos de desvio de alinhamento de marcas dos fios verticais em relação à direção longitudinal (MD) e de posicionamento de fios horizontais em relação à direção transversal (CD) da máquina de papel. Estas distorções são caracterizadas pelos ângulos $\alpha$ e $\beta^{113}$. Os afastamentos das marcas detectadas, dos eixos verdadeiros da máquina de papel (MD e CD), podem ser causados também pelas características construtivas das telas formadoras que, em situações específicas, determinam pontos mais salientes de cruzamentos dos fios em direções diagonais.

Na Figura 3.25, as distâncias entre as linhas detectadas nas imagens das amostras (por tratamento e análise de imagem pela transformada de Fourier), representadas por $d$, $d^{\prime}$ e $d^{\prime \prime}$, são utilizadas para, inicialmente, determinar o comprimento $l$ do segmento do fio transversal da tela, entre cruzamentos com fios longitudinais e, posteriormente, para computar as distâncias $a, a^{\prime}$ e $a^{\prime \prime}$, que representam os parâmetros de maior interesse, a fim de expressar o encolhimento transversal do papel.

No caso de ausência de distorção da tela formadoras, de acordo com a Figura 3.25(b), as linhas de marcas detectadas estão separadas por uma distância $d$ e determinam um ângulo $\alpha$ com o eixo longitudinal (MD) da máquina. A separação entre as marcas projetada na direção transversal (CD), designada por a pode, então, ser encontrada pela relação a seguir:

$$
a=\frac{d}{\cos \alpha}
$$

Na expressão acima, os parâmetros $d$ e $\alpha$ são determinados por análise de imagem, usando a transformada de Fourier. O caso representado pela expressão (3.48), encontrado durante produção normal, pode em algumas situações, sofrer certos desvios, conforme abordado nos próximos parágrafos.

${ }^{113}$ Segundo I'Anson et al. [2008], os ângulos $\alpha$ e $\beta$ têm valores usualmente inferiores a $10^{\circ}$, devido, principalmente, ao fato das telas secadoras apresentarem pouca flexibilidade nas direções longitudinal (MD) e transversal $(\mathrm{CD})$. 


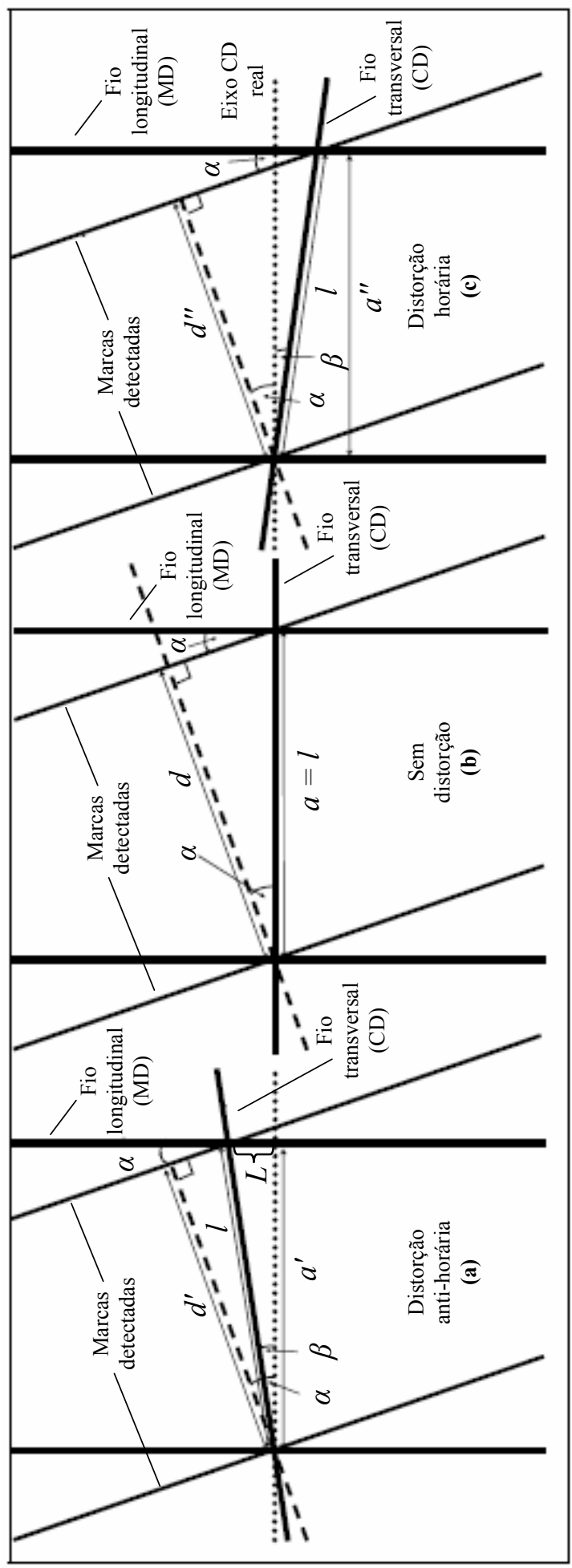

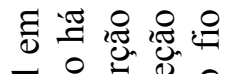

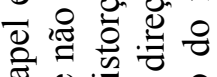

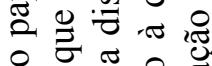

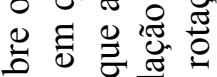
क 芯 0 월 तु

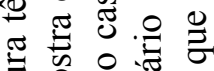

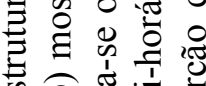

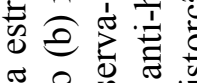
ช

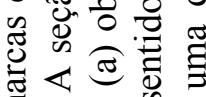

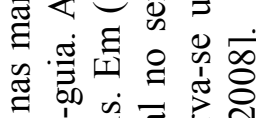

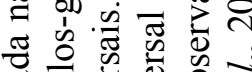

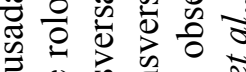
चु 我品

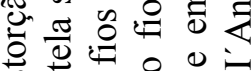
:

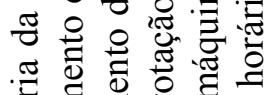

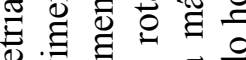

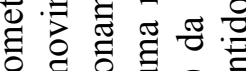

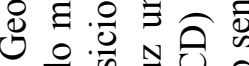
ज : ஸे

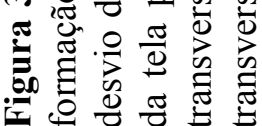


Em vários casos práticos, a distância $d$ e o ângulo $\alpha$ são influenciados tanto pelo encolhimento do papel, como por distorções da tela formadora. Este efeito encontra-se ilustrado nas seções (a) e (c) da Figura 3.25, correspondendo a desvios no sentido anti-horário e horário, respectivamente, que determinam o ângulo de inclinação $\beta$ de fios horizontais em relação ao eixo transversal (CD) da máquina de papel.

Na situação sem distorção transversal, $c f$. indicada na Figura 3.25(b), $a=l$, sendo que $l$ pode corresponder a um múltiplo do espaçamento dos fios longitudinais (MD) existentes nas marcas da tela. A dimensão $l$ é assumida como um parâmetro fixo (na tela formadora e na marca no papel, antes do encolhimento), pois se refere a comprimentos de ligamentos de fios transversais (CD), entre cruzamentos com fios longitudinais (MD). Assim, mesmo nos casos em que há distorção, a dimensão $l$ continua a mesma (sua dimensão variará somente sob influência do encolhimento transversal do papel), porém desalinhada do eixo transversal (CD), com o qual forma o ângulo $\beta$.

Com referência à situação de distorção na direção anti-horária [Figura 3.25(a)], a relação entre a distância $l$ e os ângulos de desvio $\alpha$ e $\beta$ resume-se a:

$$
l=\frac{d^{\prime}}{\cos (\alpha-\beta)}
$$

Similarmente, para a situação de distorção no sentido horário [Figura 3.25(c)]:

$$
l=\frac{d^{\prime}}{\cos (\alpha+\beta)}
$$

As expressões (3.48), (3.49) e (3.50) mostram como a distância $l$ é afetada pelos parâmetros $d, d$ ' e $d$ ', que se alteram durante o processo de encolhimento transversal (CD) do papel, tanto em situação em que ocorrem deformações, como na ausência delas. Por meio de análise de imagem aplicada ao diagnóstico do papel, determinam-se as distâncias $d, d$ ' ou $d$ ', e, também, os ângulos $\alpha$ e $\beta$.

Adotando-se as convenções que seguem, na medição dos ângulos $\alpha$ e $\beta$, obtidos no espectro de freqüências de Fourier, i.e.: 
(a) O ângulo $\alpha$ será positivo para incrementos no sentido anti-horário, a partir do eixo longitudinal (MD) da máquina.

(b) $\mathrm{O}$ ângulo $\beta$ será positivo para incrementos no sentido horário, a partir do eixo transversal $(\mathrm{CD})$ da máquina.

vem que:

$$
l=\frac{d^{\prime}}{\cos (\alpha+\beta)}=\frac{d^{\prime \prime}}{\cos (\alpha+\beta)}
$$

Para os dois casos de desvios apresentados pelas relações acima (anti-horário e horário, respectivamente), tem-se que as distâncias de interesse sobre o eixo transversal (CD), para a determinação do encolhimento transversal (CD) do papel, i.e., $a, a^{\prime}$ ou $a^{\prime \prime}, c f$. Figura 3.25, são dadas pelas expressões a seguir:

(a) após o encolhimento:

$$
a_{s}=a_{s}^{\prime}=a_{s}^{\prime \prime}=l_{s} \cos \beta_{s}
$$

(b) que correspondem, antes do encolhimento, a:

$$
a_{u s}=a_{u s}^{\prime}=a_{u s}^{\prime \prime}=l_{u s} \cos \beta_{u s}
$$

Nas expressões acima, os subscritos " $s$ " e " $u s$ " representam as condições do papel depois e antes da ocorrência do encolhimento transversal, respectivamente.

O encolhimento transversal (CD) absoluto do papel $\left(S_{a}\right)$ resulta, então, da relação entre os parâmetros definidos pelas expressões (3.52) e (3.53), as quais representam as condições pré- e pós-encolhimento, da seguinte forma:

$$
S_{a}=1-\frac{a_{s}}{a_{u s}}
$$


A substituição de (3.52) e (3.53) em (3.54) resulta na expressão abaixo:

$$
S_{a}=1-\frac{l_{s} \cos \beta_{s}}{l_{u s} \cos \beta_{u s}}
$$

A dimensão $l_{s}$ (referente à condição pós-encolhimento) pode ser determinada pelo tratamento e análise de imagem do papel, porém a dimensão $l_{u s}$ (referente à condição préencolhimento), raramente poderá ser obtida em virtude da dificuldade de se realizar medições deste tipo diretamente sobre a tela formadora instalada na máquina de papel.

Considerando-se que o grau de encolhimento transversal (CD) do papel situa-se tipicamente abaixo de $10 \%$ e que o ângulo $\beta$, usualmente, apresenta valores inferiores a $10^{\circ}$ [I'Anson et al., 2008], uma boa aproximação para o encolhimento absoluto $\left(S_{a}\right)$ pode ser expressa por:

$$
S_{a} \approx 1-\frac{l_{s}}{l_{u s}}
$$

assumindo-se que $\left(\cos \beta_{s} / \cos \beta_{u s}\right) \approx 1$.

A hipótese acima resulta da constatação de que o encolhimento em níveis inferiores a $10 \%$ produz efeito irrelevante na variação do ângulo $\beta$, pois:

$$
\tan \beta_{s}=\frac{\tan \beta_{u s}}{\left(1-S_{a}\right)}
$$

assumindo-se que o grau de encolhimento na direção longitudinal (MD) seja desprezível, i.e., que o encolhimento se dá somente na direção transversal (CD) ${ }^{114}$

\footnotetext{
114 A partir da Figura 3.25(a), tem-se que tan $\beta=L / a^{\prime}$. Para as condições de pré- e pós-encolhimento, $\tan \beta_{u s}=L / a^{\prime}{ }_{u s}$ e $\tan \beta_{s}=L / a_{s}^{\prime}$, respectivamente. Dado que, pela expressão (3.54), $1-S_{a}=a_{s}^{\prime} / a^{\prime}{ }_{u s}$, vem que: $1-S_{a}=\tan \beta_{u s} / \tan \beta_{s}$.
} 
A estimativa para a dimensão $l_{u s}$ vem da situação prática, observando-se que o encolhimento transversal (CD) total do papel, medido em máquina ${ }^{115}$, o qual coincide com o encolhimento médio da folha $\left(S_{m}\right)$, dimensionado por análise de imagem, é expresso por:

$$
S_{m} \approx 1-\frac{\sum_{i=1}^{n} l_{s i}}{n l_{u s}}
$$

onde " $n$ " representa o número de imagens das amostras de papel coletadas através da largura da máquina e o subscrito " $i$ ” denota o valor referente à $i$-ésima posição transversal (CD).

Usando a expressão (3.58), torna-se possível encontrar um valor para $l_{u s}$ e substituí-lo em (3.56), a fim de determinar um encolhimento aproximado. A partir dessa estimativa, usando-se (3.57) pode-se calcular um valor para $\beta_{u s}$ e aplicá-lo em (3.55), com a finalidade de encontrar uma valor mais preciso para o encolhimento transversal (CD) absoluto $\left(S_{a}\right)$.

\subsubsection{Relação entre as dimensões das marcas de telas formadoras no domínio espacial e no domínio de freqüências no espectro de Fourier}

A aplicação da transformada rápida de Fourier (2D-FFT) em imagens digitalizadas de papel constitui-se em um procedimento bastante útil e eficiente para revelar características determinísticas da geometria das marcas produzidas por telas formadoras sobre o papel. Um trabalho de Praast e Göttsching [1990] mostra como estas marcas podem ser caracterizadas, tanto no que tange à sua geometria como à sua intensidade. $\mathrm{O}$ espectro de Fourier destas marcas contém informações concernentes à distância entre os fios longitudinais (MD) e transversais (CD) da tela formadora, enquanto que as intensidades dos componentes de freqüência individuais evidenciam quais deles são dominantes na marca analisada. Segundo estes autores, as folhas formadas em telas de tripla camada podem conter marcas dos fios superficiais e dos fios que compõem o sistema de ligação entre as camadas da tela formadora.

Nos parágrafos que seguem, encontra-se uma análise do espectro de amplitude de Fourier, com respeito ao esclarecimento sobre a relação entre as dimensões espaciais e no

${ }^{115} \mathrm{O}$ encolhimento total do papel pode ser medido diretamente na máquina, comparando-se a largura da folha na enroladeira com a largura antes do encolhimento, e.g., na saída da seção das prensas ou entrada da seção de secagem. 
domínio de freqüências, que se aplica diretamente na identificação e caracterização de marcas de telas formadoras.

A Figura 3.26 exibe esquematicamente a transformação de uma imagem genérica com dimensões espaciais $X$ (na direção do eixo $x$ ) e $Y$ (na direção do eixo $y$ ), para obtenção do espectro de freqüências correspondente. A aplicação da 2D-FFT considerando-se $M$ pontos de amostragem na direção $x$ e $N$ pontos na direção $y$, de tal forma que:

$$
\begin{aligned}
& X=M \Delta x \\
& Y=N \Delta y
\end{aligned}
$$

onde:

X dimensão horizontal da imagem, $\mathrm{mm}$

$Y \quad$ dimensão vertical da imagem, $\mathrm{mm}$

$M \quad$ no. de elementos de imagem na direção $x$

$N \quad$ no. de elementos de imagem na direção $y$

$\Delta x \quad$ resolução de imagem na direção $x, \mathrm{~mm}$

$\Delta y \quad$ resolução de imagem na direção $y, \mathrm{~mm}$

e, tratando-se de uma função discreta, os pontos amostrados no domínio espacial, ou seja, na imagem original, podem ser descritos na seguinte forma:

$$
\begin{aligned}
& x_{m}=m X / M[\mathrm{~mm}] \\
& \operatorname{para} m=1,2, \ldots, M-1 \\
& y_{n}=n Y / N \quad[\mathrm{~mm}] \\
& \operatorname{para} n=1,2, \ldots, N-1
\end{aligned}
$$

No espectro de Fourier, as freqüências de amostragem correspondentes aos pontos do domínio espacial descritos pelas expressões (3.61) e (3.62) estão relacionadas como segue:

$$
\begin{aligned}
& u_{\mathrm{m}}=m / M \Delta x\left[\mathrm{~mm}^{-1}\right] \\
& \operatorname{para} n=1,2, \ldots, M-1
\end{aligned}
$$




$$
\begin{aligned}
& v_{\mathrm{n}}=n / N \Delta y=\left[\mathrm{mm}^{-1}\right] \\
& \operatorname{para} n=1,2, \ldots, N-1
\end{aligned}
$$

As linhas inclinadas encontradas na imagem da Figura 3.26(a) são similares às linhas de alinhamento das marcas dos fios longitudinais de uma tela formadora, separadas por uma distância $d$. Esta configuração produz a transformada encontrada na Figura 3.26(b), onde se identifica o ponto $p$, correspondente ao pico de amplitude na freqüência que caracteriza o padrão de repetição das marcas da imagem real. O ângulo $\alpha$ simboliza uma inclinação das marcas por efeito da configuração da tela formadora ou eventual inclinação da amostra no posicionamento para digitalização ${ }^{116}$.

A equação abaixo define a transformada direta de Fourier para uma função amostrada de duas variáveis $f(x, y)$, ou seja, para uma função imagem digital:

$$
\begin{aligned}
& F(u, v)=\sum_{x=o}^{M-1} \sum_{y=0}^{N-1} f(x, y) e^{-j 2 \pi(u x / M+v y / N)} \\
& \operatorname{para} u=1,2, \ldots, M-1 \text { e } v=1,2, \ldots, N-1
\end{aligned}
$$

A inclinação observada na transformada da imagem [Figura 3.26 (b)] tem fundamento na propriedade da rotação da transformada discreta de Fourier, a qual estabelece que se uma função $f(x, y)$ for girada em um ângulo $\alpha$, como mostrado na Figura 3.26 (a), a transformada $F(u, v)$ será girada com o mesmo ângulo. Usando a notação polar, em que:

$$
\begin{aligned}
& x=r \cos \theta, y=r \operatorname{sen} \theta, \mathrm{e} \\
& u=w \cos \varphi, v=w \operatorname{sen} \varphi
\end{aligned}
$$

vem que:

$$
f(r, \theta+\alpha) \Leftrightarrow F(w, \varphi+\alpha)
$$

A aplicação da equação (3.65) no processamento da imagem digital representada pela Figura 3.26(a) resulta no espectro de freqüências mostrado na Figura 3.26(b).

\footnotetext{
${ }^{116}$ Ver subseção 3.5.4, que trata da geometria das telas formadoras em operação na máquina de papel.
} 
(a)

domínio espacial

$f(x, y)$

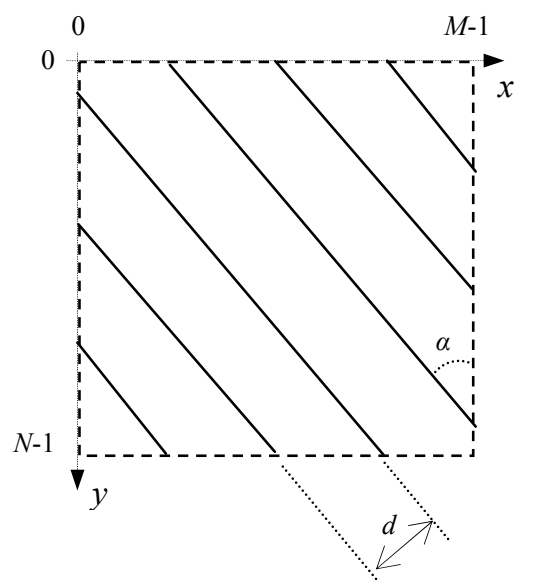

(b)

domínio de freqüências $F(u, v)$

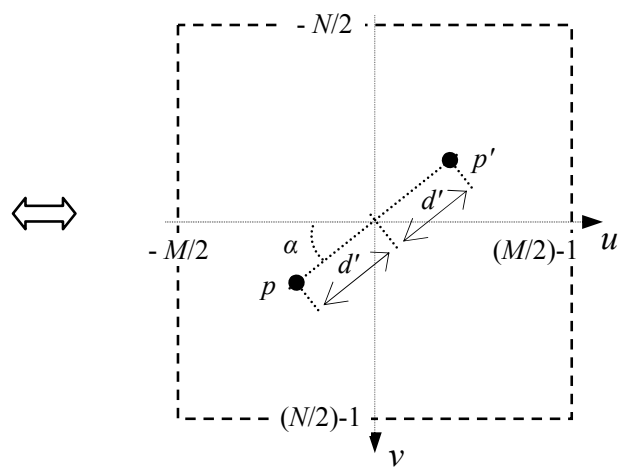

Figura 3.26. Representação de uma função de duas variáveis, no domínio do espaço (a) e a sua transformada no domínio de freqüências (b), pela aplicação da 2D-FFT [Praast, 1990].

Sendo os pontos $p$ e p', identificados na Figura 3.26(b), simétricos e relativos ao pico de amplitude decorrente da transformação da forma geométrica apresentada na Figura 3.26(a), vem da equação (3.65) que a freqüência $f_{d}$ associada ao período $d$ das linhas contidas na imagem da Figura 3.26(a), fica definida pela combinação das componentes ortogonais, da seguinte forma:

$$
f_{d}=\left[(u / M)^{2}+(v / N)^{2}\right]^{1 / 2}
$$

onde:

$u, v \quad$ coordenadas de freqüência do ponto $p$, no espectro de Fourier

$M, N$ no. de elementos horizontais e verticais da imagem, respectivamente

Na imagem do espectro de Fourier [Figura 3.26(b)], encontra-se que:

$$
d^{\prime}=\left(u^{2}+v^{2}\right)^{1 / 2}
$$

onde:

d' distância entre o ponto $p$ e a origem do espectro de Fourier 
$u, v \quad$ coordenadas de freqüência do ponto $p$, no espectro de Fourier

Dado que:

$d=1 / f_{d}$

Obtém-se:

$$
d=\frac{1}{\left[(u / M)^{2}+(v / N)^{2}\right]^{1 / 2}}
$$

Considerando uma imagem com igual quantidade de elementos de amostragem e resolução de imagem nas duas direções, ou seja:

$$
\begin{aligned}
& M=N \\
& X=Y \\
& \Delta x=\Delta y
\end{aligned}
$$

De (3.70) vem que:

$$
d=\frac{N}{\left(u^{2}+v^{2}\right)^{1 / 2}}
$$

Portanto, substituindo (3.68) em (3.71), encontra-se a distância $d$ expressa em número de elementos de imagem (pixels):

$$
d=\frac{N}{d^{\prime}}
$$

E, para expressar a mesma distância em milímetros, tem-se que:

$$
d^{*}=\frac{N}{d^{\prime}} \Delta x
$$


onde:

$\Delta x \quad$ resolução de imagem, $\mathrm{mm}$

As expressões acima mostram que a distância entre o pico de amplitude e a origem do espectro de Fourier ( $d$ '), no domínio de freqüências, é inversamente proporcional à separação entre as marcas periódicas correspondentes ( $d$ ou $\left.d^{*}\right)$, no domínio espacial.

A análise apresentada acima, desenvolvida para um padrão periódico com inclinação definida pelo ângulo $\alpha$ em relação à direção vertical, comparável à direção longitudinal (MD) de uma máquina de papel, pode, da mesma forma, ser aplicada para a mesma análise na direção perpendicular, ou seja, aplicada na caracterização de separações e inclinações de marcas horizontais ${ }^{117}$.

${ }^{117}$ Sobre este aspecto, ver no Apêndice F, considerações deste autor sobre a seleção apropriada da resolução de imagem, para análise de marcas de telas secadoras nas duas direções principais da máquina de papel (MD e CD). 


\section{CAPÍTULO 4}

\section{MEDIÇÃO E CORRELAÇÃO ENTRE OS PERFIS DO ENCOLHIMENTO E DA HIGROEXPANSIBILIDADE TRANSVERSAIS (CD) DO PAPEL}

Este capítulo aborda a metodologia empregada para amostragem na máquina (4.1) e determinação dos perfis do encolhimento (4.2) e da higroexpansibilidade (4.3) transversais (CD) do papel ao longo da largura folha. A medição do encolhimento do papel incluiu etapas de aquisição de imagens digitais das amostras, por meio de um digitalizador de mesa, e de processamento destas imagens, pela aplicação da transformada rápida bidimensional de Fourier (2D-FFT), com a finalidade de medir a separação entre marcas periódicas existentes no papel, produzidas pelas telas formadoras utilizadas no extremo úmido da máquina. Tais marcas foram usadas como referência para a determinação da contração do papel em cada ponto de amostragem. A medição do perfil de higroexpansibilidade envolveu o uso de um higroexpansímetro laboratorial para determinação da higroexpansão do papel, de acordo com a norma ISO 8226-1 [International Organization for Standardization, 1994]. A correlação entre o encolhimento e a higroexpansibilidade transversais (4.4) foi usada posteriormente, para avaliação da estabilidade dimensional diferencial do papel.

\subsection{Amostragem na máquina de papel}

As amostras de papel utilizadas neste trabalho foram coletadas em uma máquina industrial, durante período de operação em regime estável. Foram selecionados 10 pontos para amostragem na direção transversal da folha, em posições adjacentes e eqüidistantes de uma bobina de papel recém formada na enroladeira da máquina, comumente denominada bobina “jumbo". As amostras coletadas desta forma foram destinadas às medições do encolhimento e da higroexpansibilidade transversais (CD), a fim de verificar a correlação entre estas propriedades. Adicionalmente, foi coletada uma amostra de outra bobina "jumbo", consistindo de uma faixa de papel retirada através da largura total da folha na enroladeira da máquina. Desta faixa foram retiradas 53 amostras de posições uniformemente distribuídas ao longo da largura da folha de papel. Estas amostras foram destinadas à determinação de um perfil completo do encolhimento transversal (CD) diferencial, para avaliação da estabilidade dimensional do papel. 


\subsubsection{A máquina de papel}

A Figura 4.1 ilustra uma máquina industrial, da qual foram retiradas as amostras para este estudo, cuja produção principal consiste de papel reprográfico. Denomina-se "extremo úmido" ao setor constituído pela caixa de entrada, formador e prensas, devido à grande quantidade de água livre manipulada nesta área. A parte da máquina que contém a seção de secagem, prensa de colagem, calandra e enroladeira, recebe a denominação de "extremo seco", correspondentemente. A Figura 4.2 apresenta fotografias dos dois extremos da máquina de papel. O formador da máquina, indicado na Figura 4.3, utiliza telas formadoras com larguras de $6050 \mathrm{~mm}$ e $6000 \mathrm{~mm}$ nas posições superior e inferior, respectivamente.

O papel reprográfico com gramatura de 75 g.m $\mathrm{m}^{-2}$, coletado na primeira amostragem, foi produzido à velocidade de $1256 \mathrm{~m} \cdot \mathrm{min}^{-1}$, com largura de $5278 \mathrm{~mm}$ na enroladeira. O papel coletado na segunda amostragem foi produzido a $1362 \mathrm{~m} \cdot \mathrm{min}^{-1}$, com largura de $5300 \mathrm{~mm}$.

As características principais de cada seção da máquina de papel, da caixa de entrada até a enroladeira, encontram-se descritas a seguir:

Caixa de Entrada: A caixa de entrada recebe a pasta de papel, proveniente da seção de preparação de massa, para distribuição entre as telas formadoras ${ }^{118}$, em forma de jato, com consistência aproximada de 1\%. A caixa de entrada, equipada com um sistema para controle do perfil transversal de gramatura da folha, que consiste em adição de água de diluição com baixa consistência ao fluxo principal, seletivamente, em pontos distribuídos ao longo da largura do jato de massa, permite influenciar a gramatura da folha em pontos localizados. Os módulos de aplicação de água de diluição encontram-se uniformemente espaçados e permitem o controle efetivo do perfil de gramatura na largura total da folha de papel. Recursos de controle da pressão interna da caixa de entrada permitem modular a razão entre as velocidades do jato de massa e da tela formadora, a fim de atuar sobre a uniformidade de formação da folha, bem como sobre o grau de orientação das fibras.

\footnotetext{
${ }^{118}$ A posição da caixa de entrada pode ser ajustada para definir o melhor ângulo de descarga da massa na região delimitada pelas telas formadoras, a fim de estabelecer o melhor ponto de maximização de drenagem e formação do papel.
} 


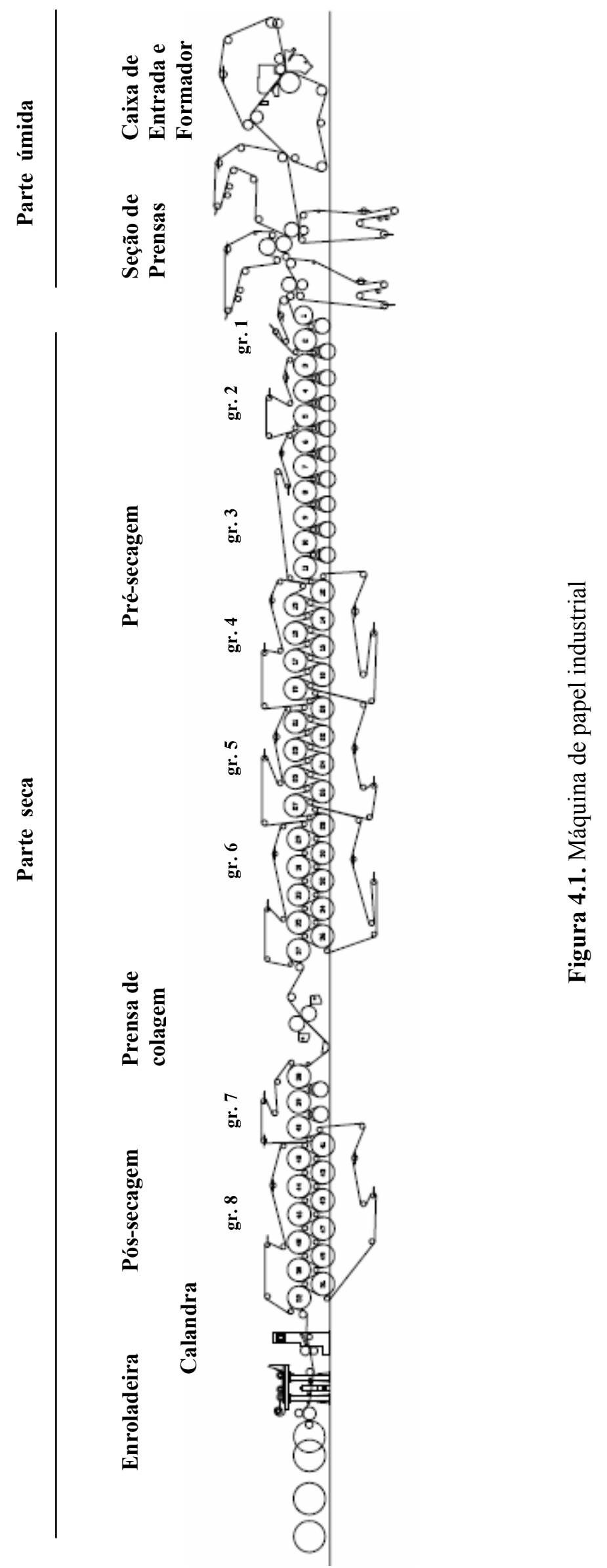




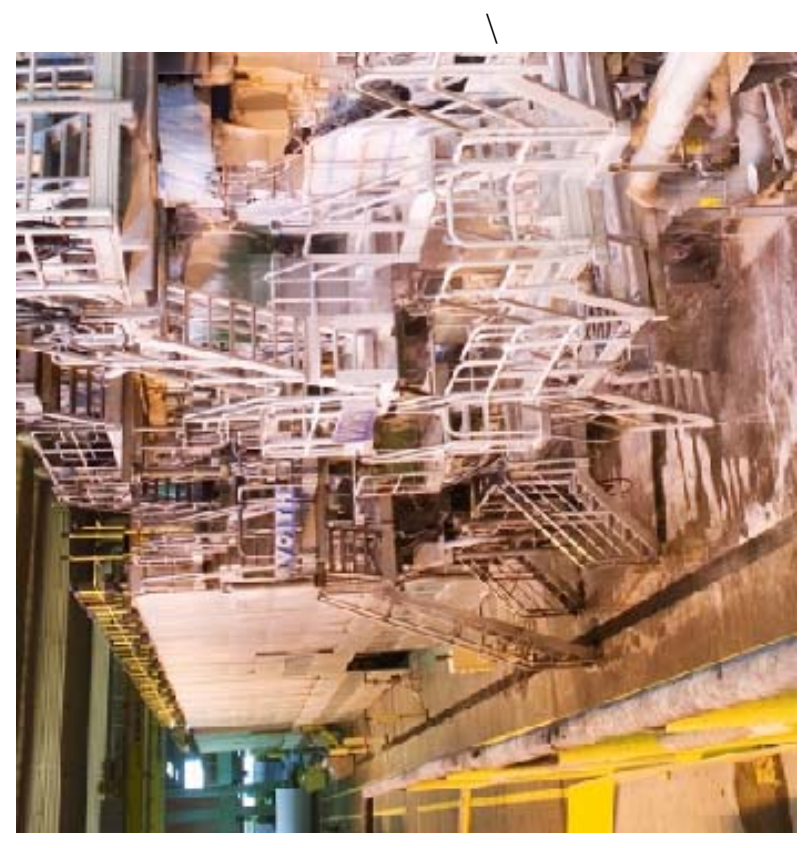

త

ఫ̄

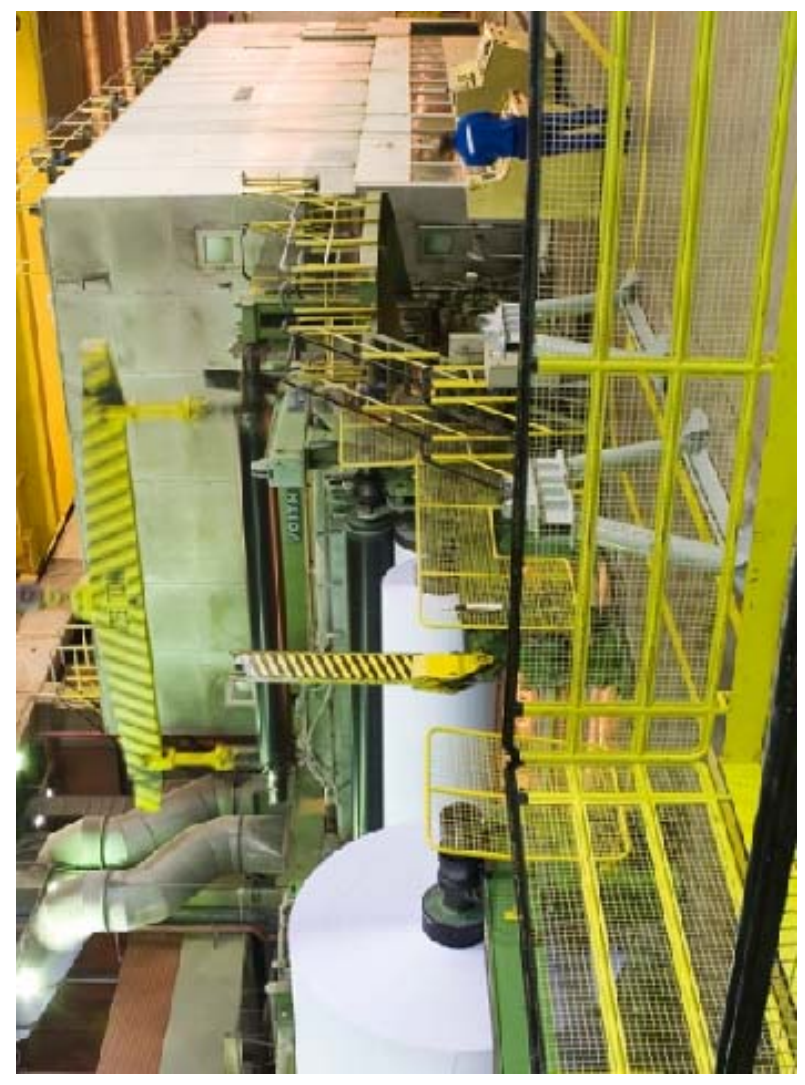

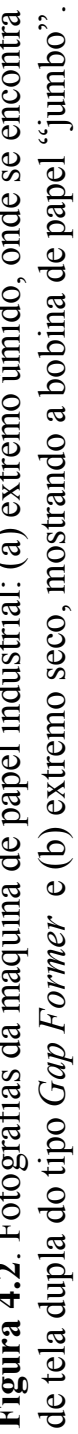


Formador: O formador de tela dupla ${ }^{119}$, ilustrado na Figura 4.3, inclui componentes destinados ao desaguamento da folha de papel por meio de pulsos de pressão (lâminas formadoras) e componentes de sucção a vácuo (caixas de vácuo). A drenagem se inicia no rolo formador de sucção e continua pela passagem da folha por uma caixa de sucção com três compartimentos localizada sobre a tela superior e pelas lâminas formadoras instaladas sob a tela inferior. Na seqüência, encontram-se duas caixas de sucção e um rolo com duas zonas de vácuo $^{120}$, denominado de rolo "couch". O último elemento de drenagem compõe-se de uma caixa de sucção de alto vácuo, localizada antes da transferência da folha para a seção das prensas, com consistência em torno de $21 \%$. As telas formadoras consistem de malhas sintéticas tecidas, estruturadas em três camadas e montadas como mantas contínuas, cujas funções principais se resumem em suporte e meio filtrante para promover o desaguamento da folha de papel em formação.

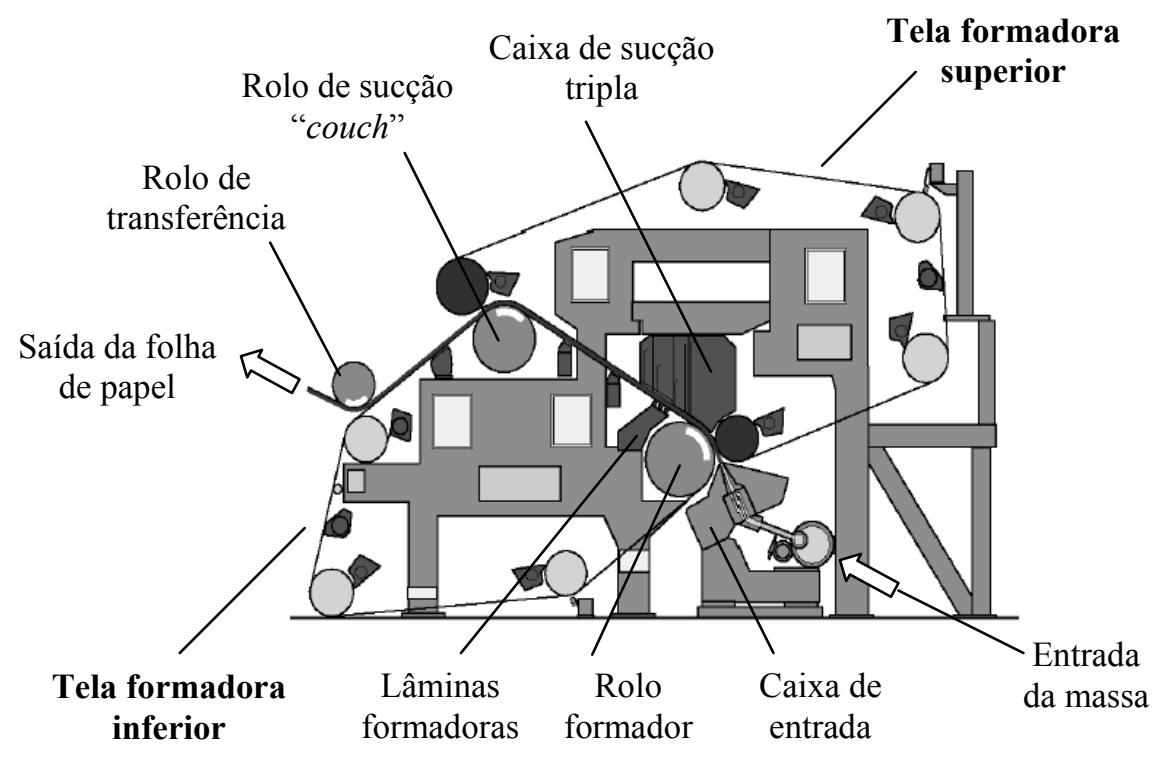

Figura 4.3. Formador de tela dupla, modelo "Duoformer $T Q$ "121 [Porchia, 2004].

Seção de Prensas: Na seção das prensas, a remoção de água contida no papel, realizase por meio de compressão mecânica, entre rolos de pressão e feltros sintéticos, que promove

\footnotetext{
${ }^{119}$ No caso, do tipo Gap Former ou Twin-wire Former. Neste estilo de formador, o jato de massa de papel é direcionado para uma região em forma de cunha ( $g a p)$, delimitada pelas duas telas formadoras.

${ }^{120}$ A primeira zona de vácuo produz uma drenagem adicional e a segunda facilita a transferência da folha para a tela inferior e condução para a seção de prensagem.

${ }^{121}$ Fabricado por Voith Paper Máquinas e Equipamentos Ltda., São Paulo, Brasil.
} 


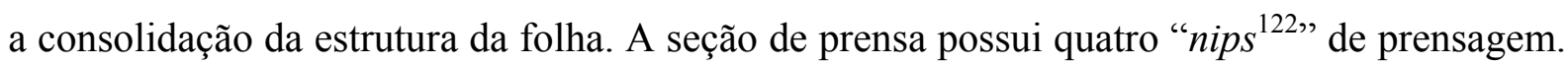
A primeira parte da operação se realiza por meio de uma prensa "tri-nip ${ }^{123}$ ", seguida pela quarta unidade, destinada ao controle de dupla face do papel. Na prensa "tri-nip", o último ponto de prensagem contém uma prensa de sapata, com capacidade máxima de carga de 1150 $\mathrm{kN} . \mathrm{m}^{-1}$. As demais foram dimensionadas para cargas lineares máximas de $70 \mathrm{kN} \cdot \mathrm{m}^{-1}$ na primeira prensa, $90 \mathrm{kN} . \mathrm{m}^{-1}$ na segunda e $55 \mathrm{kN} . \mathrm{m}^{-1}$ na quarta. A primeira prensa possui feltro superior e inferior e, portanto, a água pode ser removida pelos dois lados da folha. Na segunda e terceira prensas, os feltros fazem contato somente com o lado superior da folha, produzindo desaguamento unilateral. A quarta prensa, utilizada para compensação de dupla face, utiliza somente um feltro inferior. Após a prensagem, a folha, com teor seco em torno de $47 \%$, é transferida para a seção de secagem.

Seção de Secagem: Os cilindros secadores, com diâmetro externo de 1800 mm, estão distribuídos em 6 grupos mecânicos na área de pré-secagem (antes da prensa de cola), totalizando 37 secadores e em 2 grupos mecânicos na região da pós-secagem (após a prensa de colagem), contendo 15 secadores. Os 52 secadores são aquecidos com vapor proveniente de linhas de distribuição com pressões nominais de 3,7 bar e 10,0 bar. As três primeiras baterias da pré-secagem e a primeira bateria da pós-secagem são formadas por secadores dispostos em fileira única (localizados na parte superior) e por rolos guia-tela de sucção, com caixas estabilizadoras, na parte inferior. Com este arranjo, a folha é suportada pela tela secadora, desde a entrada na seção de secagem, até a saída da terceira bateria de secadores. As caixas estabilizadoras, bem como os rolos guia-tela de sucção operam com pressões subatmosféricas da ordem de 1,5 mca. A quarta e a quinta baterias de secadores possuem arranjo de fileira dupla, com deslocamento dos rolos guia-tela situados nos bolsões ${ }^{124}$ dos secadores, a fim de reduzir o passo livre e fornecer melhor suporte para a folha. Os secadores da sexta e da oitava baterias também estão arranjados no estilo de fileira dupla, porém com rolos guia-tela centralizados.

Sistema de Vapor e Condensado: O sistema de vapor e condensado consiste na distribuição dos secadores em grupos térmicos, cuja finalidade é aquecer o papel de forma controlada, a fim de maximizar a capacidade de secagem e preservar a qualidade do papel

\footnotetext{
${ }^{122}$ Denomina-se de nip a área de contato entre dois rolos pressionados entre si, como ocorre nas prensas e calandras das máquinas de papel.

${ }^{123}$ Denominação dada à prensa com três nips de prensagem.

${ }^{124}$ Região delimitada pelo secador, tela secadora e papel nos grupos dispostos em fileira dupla.
} 
produzido. As pressões de vapor nos secadores da pré-secagem são ajustadas de forma a obter o teor seco desejado para o papel antes da prensa de cola. De forma similar, as pressões nos secadores da pós-secagem são ajustadas convenientemente, a fim de estabelecer o teor seco da folha na enroladeira. Na pré-secagem, os três primeiros secadores dispõem de controles individuais, podendo operar com diferentes pressões de vapor. Os demais se encontram divididos em 5 grupos térmicos, formados por 2, 2, 4, 8 e 18 secadores, respectivamente. $\mathrm{Na}$ pós-secagem, os três primeiros secadores dispõem de controle individual, enquanto que os demais foram distribuídos em 2 grupos, formados por secadores superiores e inferiores, com 6 cilindros cada, os quais podem ser utilizados para correção de encanoamento da folha (curl), pois permitem a operação com pressões de vapor diferentes nos secadores que fazem contato com cada face do papel.

Coifas e Sistemas de Ventilação: As coifas instaladas sobre os secadores são do estilo "totalmente fechadas". Na seção de pré-secagem existem três unidades de exaustão e três unidades de insuflamento de ar de ventilação nos bolsões e na região inferior dos grupos com secadores dispostos em fileira única. A seção da pós-secagem dispõe de uma unidade de exaustão e duas unidades de insuflamento, as quais fornecem ar para ventilação. Nas linhas de exaustão foram instalados trocadores de calor de fluxo cruzado (ar/ar), com a finalidade de pré-aquecer o ar utilizado para ventilação.

Prensa de Colagem: Na prensa de colagem, do tipo aplicador por filme ("film size press"), uma solução de amido é aplicada sobre a superfície da folha já formada e seca. A quantidade de amido a ser aplicada no papel é inicialmente dosada nos cabeçotes de aplicação, os quais criam filmes de solução que, a seguir, são transferidos para a folha, durante sua passagem pelo "nip"125 formado entre os rolos aplicadores. Os objetivos principais desta operação consistem em aumentar a resistência superficial da folha e a resistência à penetração de água, características importantes para os papéis utilizados em processos de impressão.

Calandra: A calandra da máquina, do tipo "nip duro", contém dois rolos metálicos sem revestimento superficial A carga linear de calandragem, usada com a finalidade de controlar a lisura e espessura da folha, situa-se tipicamente na faixa de $10-30 \mathrm{kN} \cdot \mathrm{m}^{-1}$.

\footnotetext{
${ }^{125}$ Área formada pelo contato entre dois rolos pressionados um contra o outro.
} 
Enroladeira: A enroladeira em estilo convencional, constitui-se de braços primários de transferência e braços secundários com ajuste de carga linear. As bobinas "jumbo" são formadas com diâmetro final de $2500 \mathrm{~mm}$ sobre estangas ${ }^{126}$ de $570 \mathrm{~mm}$ de diâmetro. Neste ponto, o teor de umidade da folha é de aproximadamente 3,5\%.

\subsubsection{As amostras de papel}

a. Para a verificação da correlação entre o encolhimento e a higroexpansibilidade transversais (CD) do papel

As amostras foram retiradas de uma bobina "jumbo", recém-formada, em 10 posições adjacentes e uniformemente distribuídas ao longo da direção transversal da máquina de papel, $c f$. indicado esquematicamente na Figura 4.4. As amostras destas posições foram usadas para medição de higroexpansibilidade e para aquisição de imagens digitais, destinadas à medição do encolhimento. Duas faixas de papel, com a largura aproximada de $800 \mathrm{~mm}$ e comprimento igual à largura total da folha na enroladeira $(5278 \mathrm{~mm})$, foram retiradas da bobina "jumbo" e utilizadas para corte das amostras, que foram cortadas cuidadosamente nas posições de amostragem, de tal forma que suas bordas ficassem da melhor forma possível, paralelas entre si e alinhadas com a direção longitudinal (MD) e transversal (CD) da máquina de papel.

A porção de papel proveniente da bobina "jumbo" foi manuseada no interior de um laboratório de testes da fábrica, de forma que as amostras fossem retiradas em local com controle da temperatura e umidade relativa do ambiente ${ }^{127}$. De cada posição de amostragem foram retiradas amostras de papel com formato de $250 \mathrm{~mm}$ x $340 \mathrm{~mm}$. A fim de melhor preservar o material para uso futuro, foram acondicionadas em embalagens plásticas opacas. Das amostras provenientes de cada um dos 10 pontos de amostragem foram tiradas 5 tiras para digitalização e 5 tiras para medição da higroexpansibilidade que, no total, geraram 50 medições de encolhimento transversal (CD) e 50 medições de higroexpansibilidade transversal do papel.

\footnotetext{
${ }^{126}$ Designação dada ao eixo, ou carretel, sobre o qual o papel é enrolado, a fim de formar bobinas, antes de ser retirado da enroladeira da máquina.

${ }^{127}$ A norma T 402 sp-08 [Technical Association of Pulp and Paper Industry, 2008] estabelece os parâmetros de temperatura e umidade relativa
} 


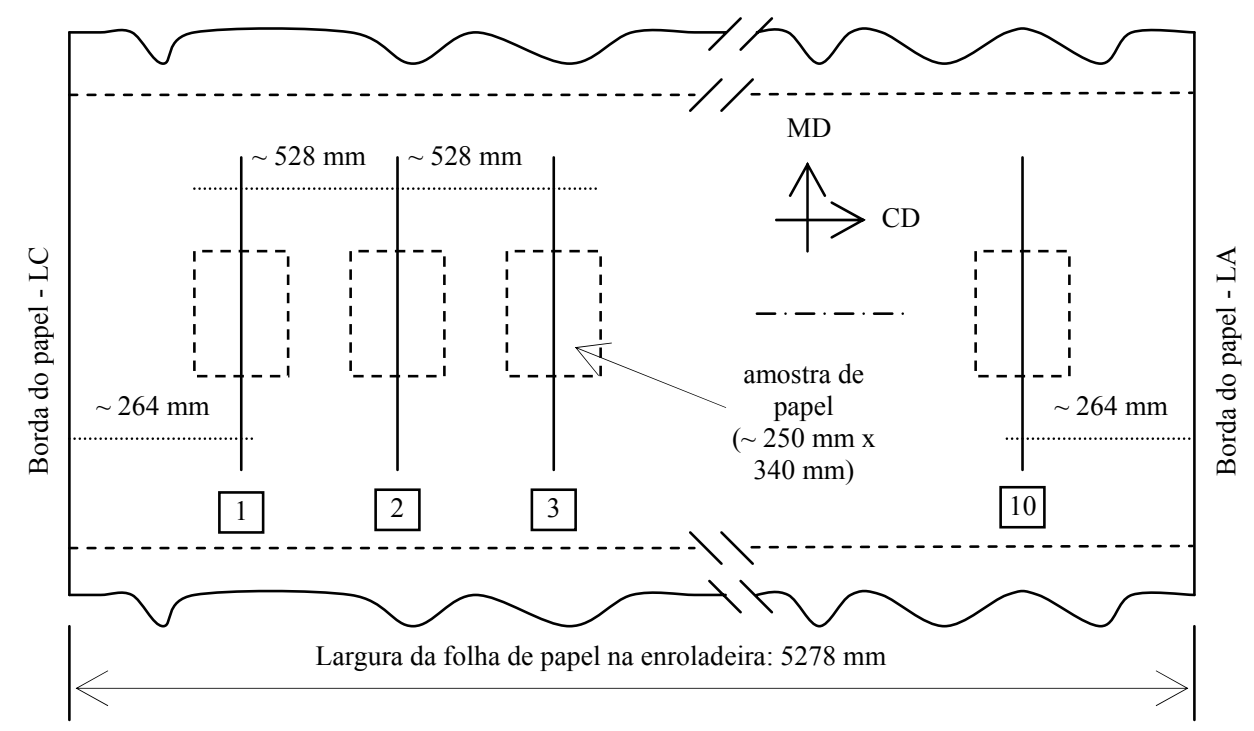

Figura 4.4. Representação esquemática do método usado na coleta de amostras da bobina "jumbo", para medição do encolhimento e da higroexpansibilidade transversais (CD) do papel.

A distribuição dos pontos de amostragem em 10 posições transversais da bobina “jumbo" permitiu examinar as características de encolhimento e higroexpansão do papel a partir de $140 \mathrm{~mm}$ de cada borda e em intervalos eqüidistantes adequadamente selecionados, que somaram aproximadamente $50 \%$ da largura da folha na enroladeira. A definição da quantidade de pontos de amostragem foi influenciada, também, pelo tempo requerido para cada teste de higroexpansibilidade - mínimo de 2 horas por posição de amostragem, para realizar o condicionamento completo das amostras nas etapas do processo de medição ${ }^{128}$. Desta forma, o tempo de teste requerido, considerando-se as 10 posições transversais examinadas, situou-se em torno de 20 a 25 horas.

b. Para medição do perfil de encolhimento transversal (CD) na largura total da folha, para avaliação da estabilidade dimensional diferencial do papel.

Para esta finalidade, uma faixa de papel com largura aproximada de $300 \mathrm{~mm}$ e comprimento igual à largura total da folha $(5300 \mathrm{~mm})$ foi retirada de uma bobina "jumbo", de forma que o corte estivesse alinhado, da melhor forma possível com a direção transversal (CD) da máquina de papel. Desta faixa, foram retiradas 53 tiras de papel com comprimento de $300 \mathrm{~mm}$ e largura de $100 \mathrm{~mm}$, sendo o lado mais longo correspondente à direção longitudinal (MD) da máquina de papel (ver Figura 4.5).

\footnotetext{
${ }^{128}$ As etapas de teste e tempos mínimos de condicionamento dos corpos de prova encontram-se especificados na norma ISO 8226-1 [International Organization for Standardization, 1994].
} 


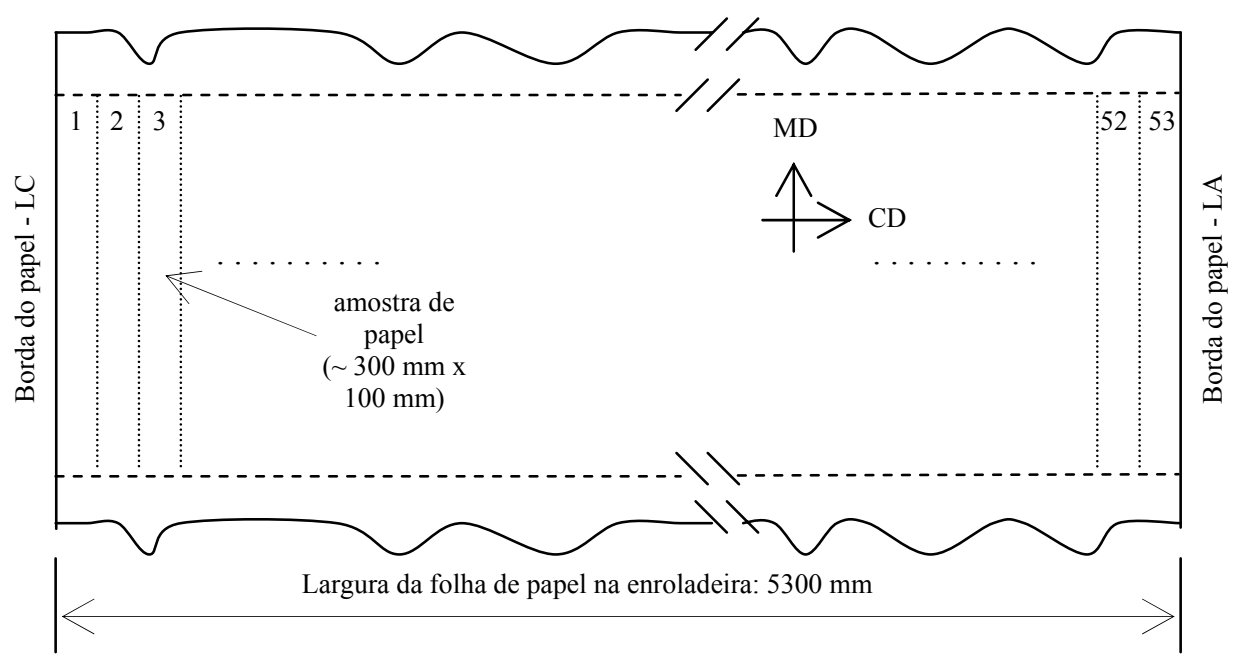

Figura 4.5. Representação esquemática do método usado na coleta de amostras da bobina "jumbo", para medição do encolhimento transversal (CD) na largura total da folha de papel na enroladeira.

\subsection{Determinação do perfil de encolhimento transversal (CD) do papel}

A Figura 4.6 mostra, em diagrama de blocos, as etapas do procedimento utilizado para determinação do perfil de encolhimento transversal (CD) do papel através da largura da folha.

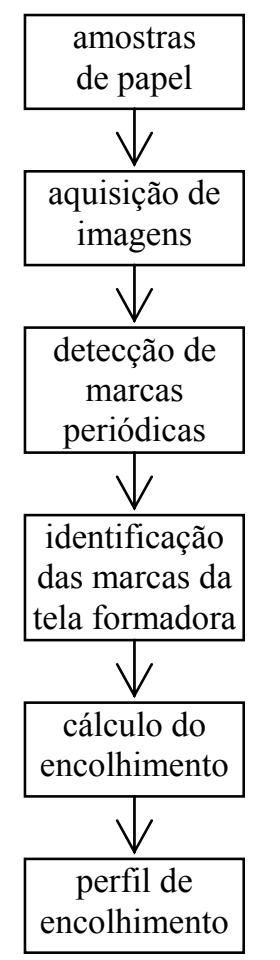

(coleta ao longo da direção transversal da bobina "jumbo")

(digitalização transmissiva em digitalizador fotográfico de mesa)

(processamento das imagens: transformada rápida bidimensional de Fourier, 2D-FFT)

(análise das imagens: seleção de pontos característicos no espectro de Fourier)

(computação dos dados selecionados no espectro para cada posição transversal)

(exibição gráfica do encolhimento nas posições transversais da máquina)

Figura 4.6. Procedimento utilizado para determinação do perfil do encolhimento transversal (CD) do papel. 
A etapa inicial consistiu na coleta de amostras de papel, $c f$. descrito na seção 4.1.2. Na etapa seguinte, as amostras foram escaneadas em um digitalizador de mesa convencional, para obtenção de imagens digitais monocromáticas ${ }^{129}$. Na seqüência, o processamento digital das imagens de cada amostra, por meio da transformada bidimensional rápida de Fourier (2D-FFT), permitiu identificar e medir o padrão das marcas criadas no papel pela tela formadora, no domínio de freqüências ${ }^{130}$. As fases seguintes consistiram da computação de dados extraídos do espectro de Fourier, cálculo do encolhimento transversal (CD) em cada posição de amostragem e representação gráfica do perfil transversal, por meio da utilização de um computador portátil convencional.

\subsubsection{Estação de trabalho para aquisição, processamento e análise de imagem para computação do perfil do encolhimento transversal (CD) do papel}

Um computador pessoal associado a um digitalizador fotográfico, $c f$. ilustrado na Figura 4.7, compuseram a estação de trabalho para aquisição, processamento e análise das imagens de papel. Atualmente, qualquer computador popular (desktop ou laptop) contém os elementos necessários para esta função, i.e., capacidade de processamento e armazenamento e módulo de interface para interatividade do usuário.

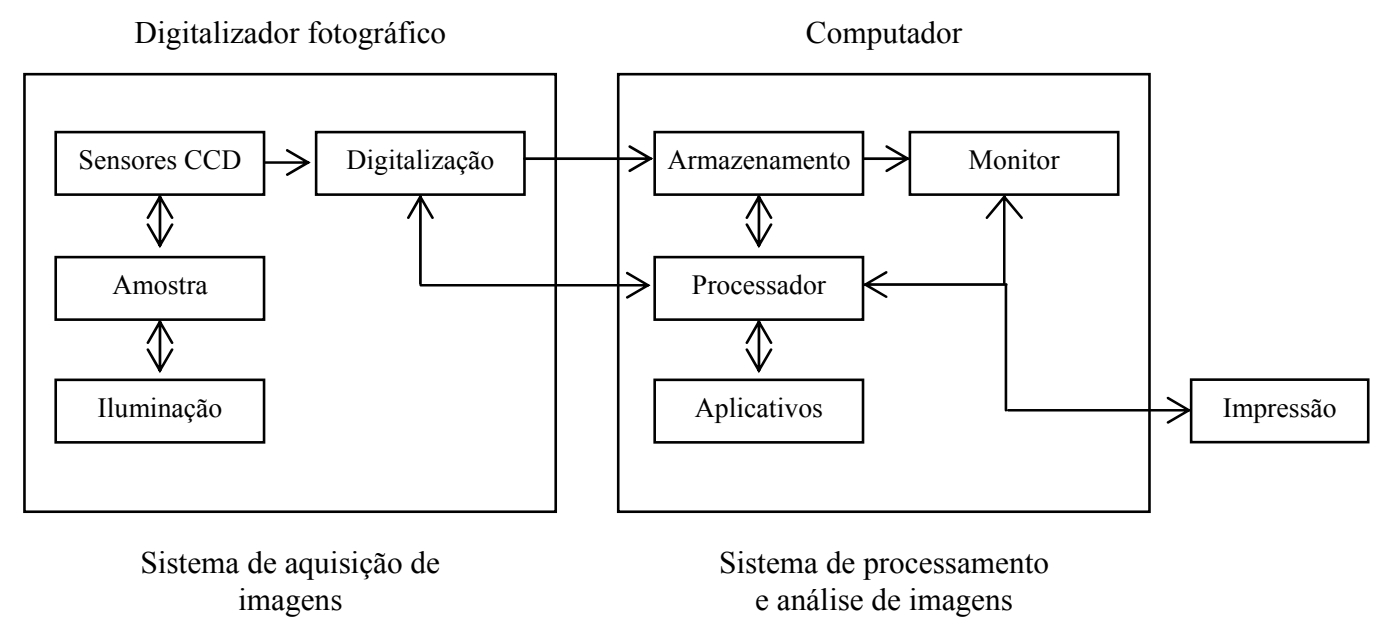

Figura 4.7. Estação de trabalho para análise de imagens de papel.

No computador da estação de trabalho, além do software de controle do digitalizador, foi carregado também um programa específico para processamento digital das imagens por

\footnotetext{
${ }^{129}$ Ver detalhes na subseção 4.2.2.

${ }^{130}$ Ver detalhes na subseção 4.2.3.
} 
meio da transformada rápida de Fourier, em ambiente MATLAB ${ }^{131}$. Os dados de saída deste programa principal são usados para computação e exibição do perfil do encolhimento transversal (CD) do papel, utilizando uma pasta de trabalho do aplicativo Microsoft Excel.

\subsubsection{Digitalização das amostras do papel}

As imagens digitais das amostras de papel foram obtidas por meio de um digitalizador fotográfico de mesa (flatbed scanner), modelo HP Scanjet G4050, configurado no modo de iluminação por transmissão de luz (digitalização transmissiva ${ }^{132}$ ), $c f$. ilustrado na Figura 4.8.

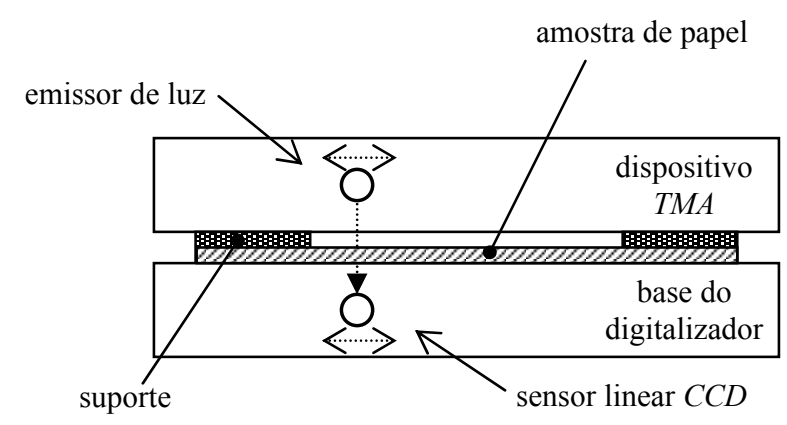

Figura 4.8. Esquema do digitalizador fotográfico configurado no modo de iluminação por transmissão de luz, utilizando o dispositivo TMA ${ }^{133}$

As imagens digitais monocromáticas foram armazenadas em formato $\mathrm{BMP}^{134}$, após digitalização com resolução de imagem de $400 \mathrm{ppi}^{135}$, nas dimensões de 512 x 512 pixels, correspondendo a uma área de visão aproximada de 32,5 x 32,5 mm, na direção transversal (CD) e longitudinal (MD), respectivamente, e com profundidade de cor de 8 bits, equivalendo a 256 níveis de escala de cinza.

Recursos automáticos do digitalizador, tais como autocorreção, brilho, meios-tons, sombra e nitidez foram mantidos desativados, a fim de evitar que interfiram nas marcas provenientes da tela formadora e, assim, facilitar sua identificação durante o processamento

\footnotetext{
${ }^{131}$ Ver descrição do programa no Apêndice C.

${ }^{132}$ Utiliza um adaptador para mídia transparente (TMA) montado na parte superior do digitalizador.

${ }^{133}$ Tramsparent Media Adapter (adaptador para mídias transparentes).

${ }^{134} \mathrm{O}$ formato BMP (bitmap) foi desenvolvido pela Microsoft para imagens mapeadas por bits.

${ }^{135}$ Pixels per inch (elementos de imagem por polegada).
} 
das imagens digitais. O parâmetro gama ${ }^{136}$ foi mantido com valor unitário (gama $\left.=1\right)$ em todas as varreduras. O suporte indicado no arranjo da Figura 4.8 foi utilizado com o objetivo de circunscrever a região de aquisição das imagens digitalizadas e manter as amostras de papel em posição plana e paralela em relação à base do digitalizador.

\subsubsection{Processamento das imagens das amostras de papel pela transformada de Fourier}

As imagens das amostras de papel foram processadas digitalmente pela transformada bidimensional rápida de Fourier (2D-FFT), ferramenta comumente utilizada para diagnósticos do papel e especificamente para identificação e medição de padrões repetitivos em vários campos de aplicação. A transformada rápida de Fourier consiste de um algoritmo particular da transformada discreta de Fourier, elaborado com a finalidade de minimizar o tempo de computação requerido para sua execução. Usada comumente para tratamento de funções discretas, tais como as imagens digitais, a 2D-FFT foi empregada de forma similar para identificação e medição da separação entre marcas periódicas produzidas no papel por telas formadoras, $c f$. mostram os trabalhos de Viitaharju e Niskanen [1993], Hoole et al. [1999], Antoine [2007] e I'Anson et al. [2008].

O padrão das marcas de tela formadora, presente nas amostras de papel examinadas neste estudo, pode ser reconhecido no espectro de Fourier por meio de seus picos de amplitude característicos. A detecção e a identificação das coordenadas espaciais desses picos foram inicialmente realizadas de forma manual, porém, em função do excessivo tempo demandado por esta operação, tornou-se clara a necessidade de recorrer a outro método, com o objetivo de obter as informações de forma mais rápida e automática. Desta forma, um programa específico de análise de imagem, denominado "PET1_0", foi desenvolvido por este autor em plataforma MATLAB ${ }^{137}$ para executar a transformada de Fourier das imagens do papel e exibir as coordenadas dos picos de amplitude de interesse. O programa mencionado encontra-se descrito em detalhes no Apêndice C. Baseia-se em um algoritmo de busca automática dos picos de amplitude em cada espectro de Fourier resultante do processamento individualizado das imagens das amostras de papel.

\footnotetext{
${ }^{136} \mathrm{O}$ fator gama representa o grau de contraste de uma imagem digital. Valores acima de 1 tendem a clarear a imagem e correspondentemente, valores abaixo de 1 produzem escurecimento. Quando gama $(\gamma)=1$, não há correção de contraste da imagem.

${ }^{137}$ MATLAB versão R2008b.
} 
A Figura 4.9 mostra um exemplo de imagem digitalizada de uma área aproximada de $32.5 \mathrm{~mm} \times 32.5 \mathrm{~mm}$ de uma amostra de papel reprográfico de $75 \mathrm{~g} . \mathrm{m}^{-2}$, fabricado na máquina descrita na subseção 4.1.1, obtida por transmissão de luz, com a borda vertical orientada na direção longitudinal (MD) e a face superior do papel (também denominada "lado feltro") direcionado para os sensores de imagem do digitalizador.

A Figura 4.10 mostra o espectro de amplitudes da imagem mostrada na Figura 4.9, obtido pela aplicação da transformada bidimensional rápida de Fourier (2D-FFT). Os pontos brilhantes (brancos) presentes no espectro de Fourier correspondem a picos de amplitude produzidos por variações periódicas no papel.

A seleção da resolução para digitalização da imagem de papel é importante, pois determina a posição dos picos no espectro de amplitude, a partir do qual são identificados os relativos ao encolhimento transversal (CD) do papel e a distorção da tela formadora na direção do eixo transversal (CD) da máquina. Resoluções baixas tendem a mover os picos em direção às bordas do espectro de amplitude, podendo desaparecer do campo espectral a partir de um limite mínimo. Ao contrário, altas resoluções tendem a deslocar os picos para a origem do espectro, podendo provocar a inclusão destes picos no agrupamento central, a partir de um certo limite superior de resolução, tornando-se difícil a sua detecção.

Os limites de resolução para digitalização das amostras de papel, a fimm de se evitar os riscos descritos acima foram demonstrados por este autor, no Apêndice F, onde se observa que a resolução mínima recomendada se expressa pela relação a seguir:

$$
\begin{aligned}
& R_{p p i(m d)}>\frac{56,4}{d_{u s(m d)}^{*}} \\
& R_{p p i(c d)}>\frac{50,8}{d_{u s(c d)}^{*}}
\end{aligned}
$$

onde:

$R_{p p i(m d)}, R_{p p i(c d)} \quad$ resoluções mínimas da imagem, na direção longitudinal (MD) e transversal (CD), respectivamente, ppi 


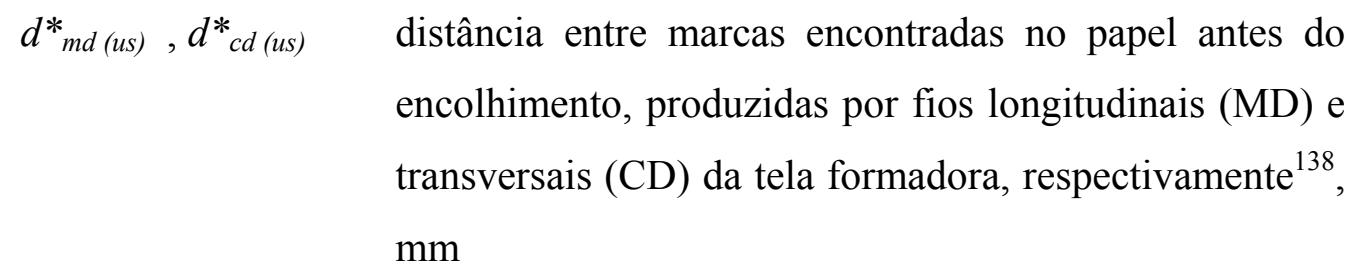

Por outro lado, a fim de posicionar os picos em uma região suficientemente afastada do agrupamento central e das bordas do espectro, em localização mais conveniente para observação e medição, $c f$. exemplo mostrado na Figura 4.10, o seguinte critério foi sugerido na metodologia descrita no Apêndice F:

$$
\begin{aligned}
& \frac{2,2 N}{d_{m d(u s)}^{*}} \times 10^{-1}<R_{p p i(m d)}<\frac{2,5 N}{d_{m d(u s)}^{*}} \times 10^{-1} \\
& \frac{2,2 N}{d_{c d(u s)}^{*}} \times 10^{-1}<R_{p p i(c d)}<\frac{2,5 N}{d_{c d(u s)}^{*}} \times 10^{-1}
\end{aligned}
$$

onde:

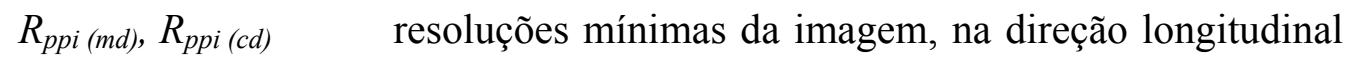 (MD) e transversal (CD), respectivamente, ppi
$d^{*}{ }_{m d(u s)}, d^{*}{ }_{c d(u s)} \quad$ distância entre marcas encontradas no papel antes do encolhimento, produzidas por fios longitudinais (MD) e transversais (CD) da tela formadora, respectivamente, $\mathrm{mm}$

$N$

número de pontos de amostragem da imagem na direção longitudinal (MD) e transversal (CD) ${ }^{139}$, pixels

A faixa final de resolução de imagem será resultado de compromisso entre as faixas recomendadas, i.e., definida pela intersecção das especificadas em (4.1), (4.2), (4.3) e (4.4).

\footnotetext{
${ }^{138}$ Correspondem às distâncias entre os fios longitudinais e entre os fios transversais da laje da tela formadora que faz contato com o papel (ver exemplos no Apêndice D). Pode ser obtida nas especificações técnicas do fabricante, ou por medição em amostra da tela formadora.

${ }^{139}$ As imagens tratadas neste estudo têm dimensões na forma de $2^{n} \times 2^{n}$ (sendo $n$ um número real e inteiro), a fim de se obter melhor desempenho do algoritmo de cálculo da 2D-FFT (ver subseção 3.4.7).
} 


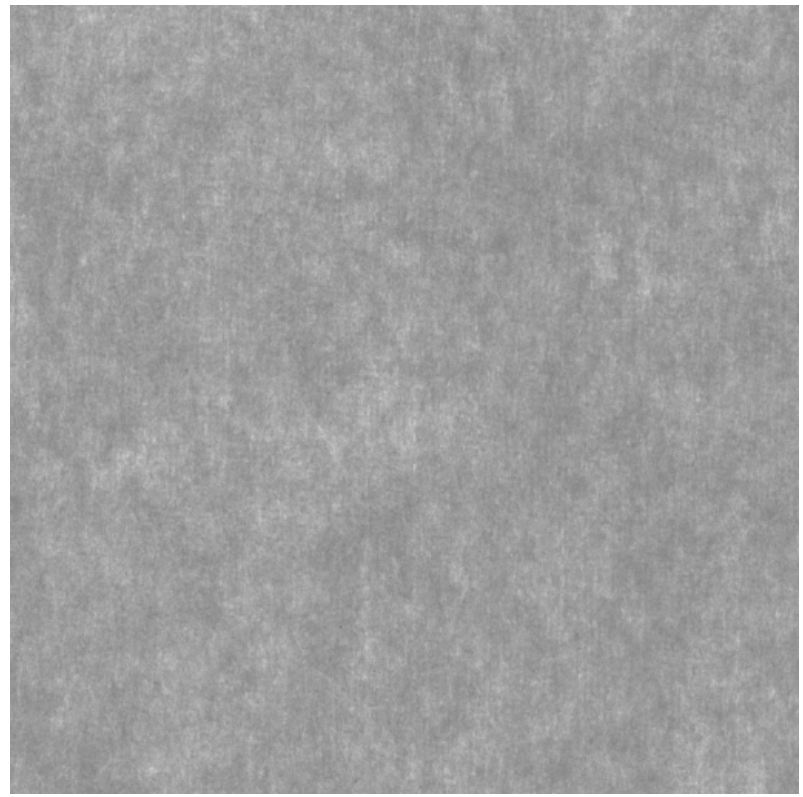

Figura 4.9. Imagem digitalizada de uma área de $32.5 \mathrm{~mm}$ x $32.5 \mathrm{~mm}$ de uma amostra de papel, com resolução de 400 ppi e formato de 512 pixels x 512 pixels, em escala de cinza de 256 níveis (8 bits), correspondendo à faixa de 0 (preto) a 255 (branco). A imagem foi obtida por transmissão de luz, com a face superior do papel voltada para os sensores de imagem do digitalizador e a borda vertical orientada na direção longitudinal (MD).

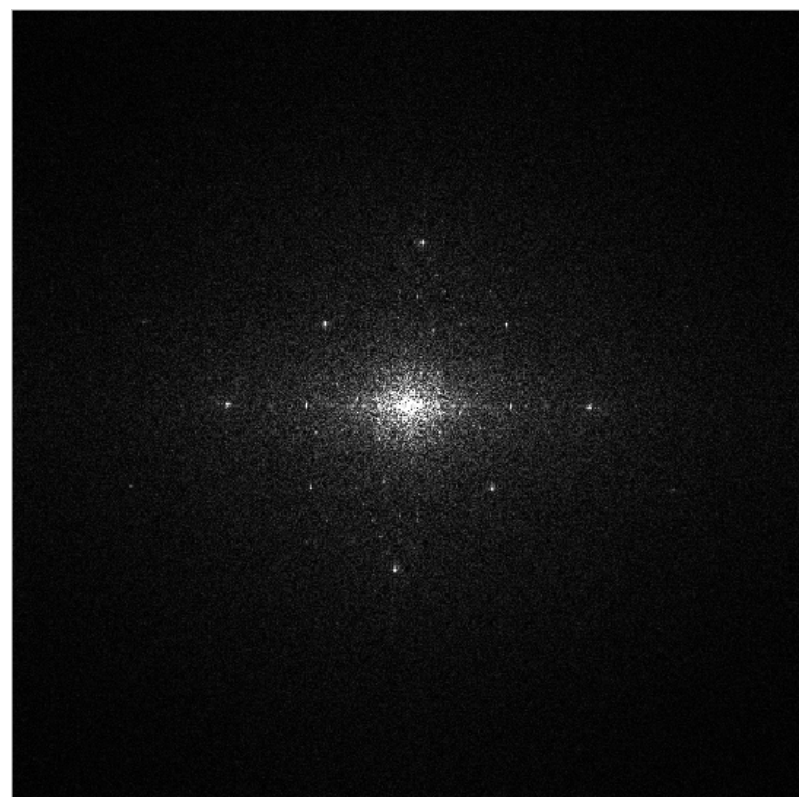

Figura 4.10. Espectro de amplitudes obtido da imagem mostrada na Figura 4.9, indicando pontos brilhantes (brancos) produzidos por variações periódicas no papel, tais como marcas criadas por telas formadoras. 
Os picos de amplitude destacados na Figura 4.11, denominados como "picos de encolhimento transversal (CD)" encontram-se próximos do eixo horizontal do espectro da 2D-FFT. Estes picos foram produzidos pelas marcas dos fios longitudinais (MD) da tela formadora e, portanto, utilizados para medir a separação relativa na direção transversal (CD), do padrão de marcação alinhado com direção longitudinal (MD). Um eventual ângulo de inclinação entre a linha que une estes picos à origem do espectro, denominado por " $\alpha$ " (ângulo alfa), e o eixo horizontal pode advir das seguintes situações: (a) a estrutura da tela formadora em uso na máquina de papel não possui fios longitudinais salientes na superfície em contato com o papel e, assim, marcas com alinhamento diagonal característicos do padrão de tecedura da tela, próximo à direção longitudinal (MD) foram detectadas, ou (b) o posicionamento da amostra de papel no digitalizador não resultou em alinhamento longitudinal (MD) perfeito, resultando em pequena inclinação vertical. Nos dois casos, o ângulo " $\alpha$ ” é utilizado para as devidas correções na medição da separação entre marcas longitudinais $(\mathrm{MD})^{140}$.

A Figura 4.12 mostra outro par de picos de amplitude realçados, agora próximos do eixo vertical do espectro da 2D-FFT, que recebem a denominação de "picos de distorção da tela formadora" e foram produzidos pela marcas dos fios transversais (CD) da tela formadora. Um eventual ângulo de inclinação entre a linha que une estes picos à origem do espectro, denominado por " $\beta$ " (ângulo beta), e o eixo vertical fornece uma indicação do grau de deformação da tela formadora em relação ao eixo transversal (CD) da máquina de papel, causada por cisalhamento da tela em operação, em cada ponto transversal (CD). O ângulo " $\beta$ " é também utilizado para correções na medição da separação entre marcas longitudinais $(\mathrm{MD})^{141}$.

Os pares de pontos destacados nas Figuras 4.11 e 4.12 são simétricos em relação à origem do espectro da 2D-FFT. Desta forma, apenas um deles, de cada direção (MD e CD), será utilizado na medição da separação transversal (CD) entre marcas produzidas pelos fios longitudinais (MD) da tela formadora. Os ângulos “ $\alpha$ ” e “ $\beta$ ” são utilizados para corrigir as distâncias detectada pela 2D-FFT, a fim de determinar suas projeções sobre o eixo transversal (CD), que representam as medidas de interesse para cálculo do encolhimento transversal (CD) do papel.

\footnotetext{
${ }^{140}$ Sobre a abordagem geométrica para as marcas produzidas pela tela formadora, ver detalhes na subseção 3.5.4. ${ }^{141}$ Idem nota 118.
} 


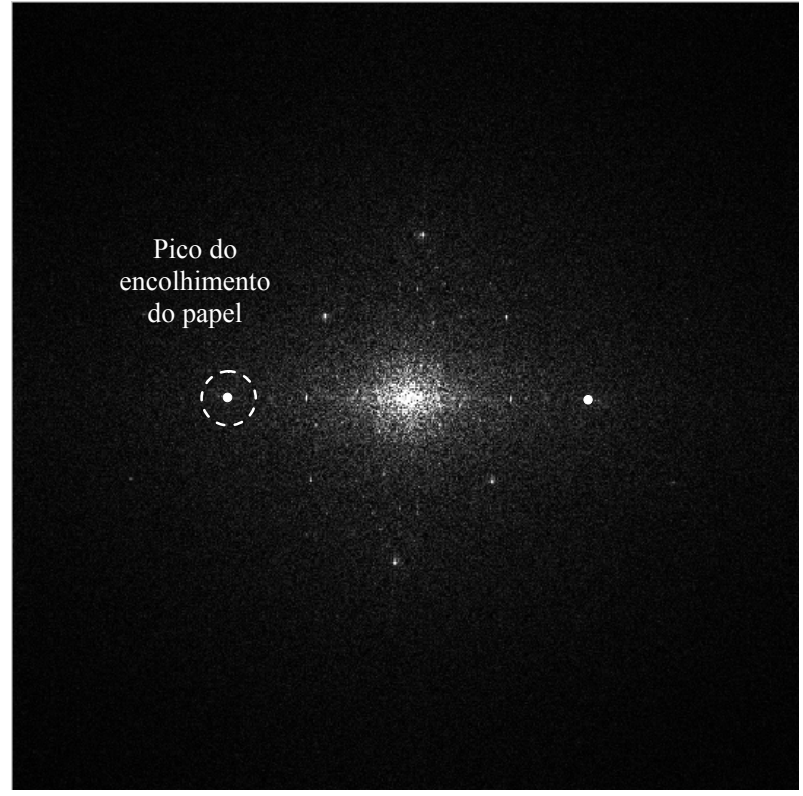

Figura 4.11. Picos de amplitude produzidos pelos fios longitudinais (MD) de uma tela formadora de tripla-camada, estilo $\mathrm{SSB}^{142}$, utilizados para medição da separação transversal $(\mathrm{CD})$ da marcas produzidas pela tela na direção longitudinal (MD).

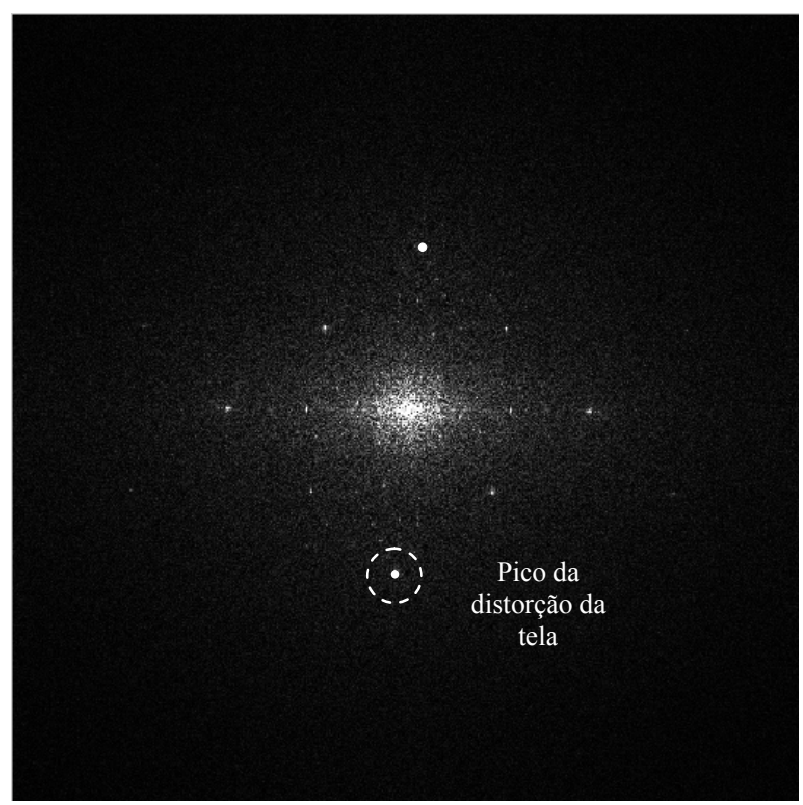

Figura 4.12. Picos de amplitude produzidos pelos fios transversais (CD) de uma tela formadora de tripla-camada, estilo SSB, utilizados para medição de eventuais distorções da tela em relação ao eixo transversal (CD) da máquina de papel.

${ }^{142}$ SSB (Self Supported Binding): sistema específico de tecelagem das telas formadoras. Ver subseção 3.5.2. 
A Figura 4.13 resume esquematicamente a posição dos picos de amplitude produzidos pelos fios longitudinais (MD), i.e., $p_{1}$ e $p^{\prime}{ }_{1}$ e pelos fios transversais (CD) da tela formadora, i.e., $p_{2}$ e $p^{\prime}{ }_{2}$, bem como os ângulos de inclinação entre as linhas que os une à origem do espectro de Fourier e os eixos vertical e horizontal, i.e., $\alpha$ e $\beta$, respectivamente. Por convenção, o ângulo $\alpha$ assume valores positivos para incrementos no sentido anti-horário. $\mathrm{O}$ ângulo $\beta$, contrariamente, assume valores positivos para incrementos no sentido horário.

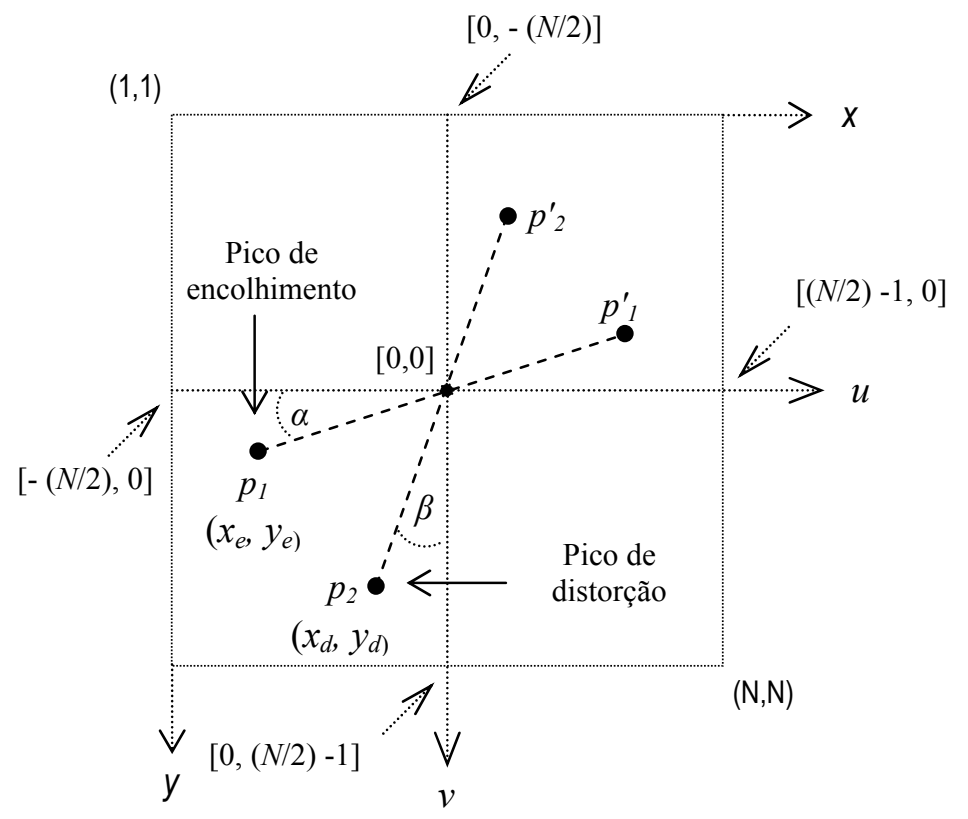

Figura 4.13. Representação esquemática de um espectro da 2D-FFT de uma imagem de papel com dimensões $N$ x $N$, indicando os picos de amplitude simétricos de encolhimento $\left(p_{1}\right.$ e $\left.p^{\prime}{ }_{l}\right)$, os picos de amplitude simétricos de distorção $\left(p_{2}\right.$ e $\left.p^{\prime}{ }_{2}\right)$ e os ângulos de inclinação $\alpha$ e $\beta$ em relação aos eixos horizontal e vertical, respectivamente. Os eixos $x$ e y representam o sistema de coordenadas espaciais e os eixos $u$ e $v$, o sistema de coordenadas de freqüência do espectro de Fourier.

\subsubsection{Determinação do encolhimento transversal (CD) médio do papel}

O encolhimento transversal (CD) médio do papel, também denominado encolhimento total, é calculado $c f$. expressão a seguir, a partir da largura inicial da folha tomada antes do encolhimento (e.g., na entrada da seção de secagem) e da largura final, tomada após o encolhimento (i.e., na enroladeira da máquina): 
$S_{m}=\left(1-\frac{L_{e n r}}{L_{i n i}}\right) \times 10^{2}$

onde:

$S_{m} \quad$ encolhimento médio da folha de papel, \%

$L_{\text {enr }} \quad$ largura final do papel, na enroladeira da máquina, $\mathrm{m}$

$L_{\text {ini }} \quad$ largura inicial do papel, na entrada da seção de secagem, m

Este parâmetro $\left(S_{m}\right)$ é utilizado para o cálculo do encolhimento transversal (CD) absoluto a partir do encolhimento transversal (CD) relativo encontrado em cada posição transversal $^{143}$. O encolhimento médio está relacionado com o encolhimento absoluto do papel, de acordo com a relação a seguir:

$S_{m}=\frac{\sum_{i=1}^{n} S_{a, i}}{n}$

onde:

$S_{m} \quad$ encolhimento médio da folha de papel, \%

$S_{a, i} \quad$ encolhimento transversal (CD) absoluto, \%

$n \quad$ numero de posições transversais amostradas

\subsubsection{Determinação do perfil do encolhimento transversal (CD) diferencial do papel}

O método usado para determinação do perfil do encolhimento transversal (CD) do papel envolve a medição da variação da distância entre as marcas periódicas encontradas mo papel, produzidas pela tela formadora no extremo úmido da máquina. Estas marcas são detectadas por meio de técnicas de análise de imagem, sendo que o tratamento das imagens digitais de papel pela transformada bidimensional rápida de Fourier (2D-FFT) leva à detecção de picos, no espectro de amplitude, característicos destas marcas periódicas, $c f$. metodologia descrita na subseção 4.2.3. A posição de um pico de amplitude, no espectro de Fourier, fornece uma medição direta da sua freqüência, possibilitando assim, determinar o período de repetição das marcas, i.e., a distância entre elas. Este processo aplicado a diferentes posições

\footnotetext{
${ }^{143} C f$. apresentado em detalhes na subseção 4.2.5.
} 
distribuídas ao longo da largura da folha, permite detectar variações entre as separações das marcas, a fim de traçar o perfil de encolhimento do papel.

A partir das coordenadas espaciais dos picos de amplitude, obtidas pela aplicação do programa PET1_0 e das considerações sobre a geometria das marcas produzidas por telas formadoras, voltadas para determinação do encolhimento transversal (CD) do papel, que se encontram detalhadamente apresentadas na subseção 3.5.3, este autor estabeleceu um algoritmo, para implantação em planilha Microsoft Excel, a fim de determinar o encolhimento transversal (CD) do papel em cada posição amostrada ao longo da largura da folha e exibir graficamente os perfis de contração diferencial, relativo e absoluto, $c f$. descrito nos próximos parágrafos.

\section{Seleção dos picos de amplitude de interesse}

Os picos de amplitude utilizados neste procedimento estão indicados na Figura 4.14, de forma realçada, para melhor visualização. O pico próximo ao eixo horizontal do espectro de Fourier foi considerado para determinação do encolhimento transversal (CD) do papel e da inclinação das linhas formadas pelas marcas da tela formadora, em relação a direção longitudinal (MD), designada pelo ângulo " $\alpha{ }_{i}$ ”. O pico de amplitude próximo ao eixo vertical foi considerado para medição de eventual distorção da tela formadora em relação à direção transversal da máquina (CD), por meio do ângulo " $\beta_{i}$ ". $O$ índice " $i$ ”, utilizado doravante, representa a i-ésima posição no perfil transversal, a partir do lado de comando da máquina de papel, dentre as " $n$ ” posições amostradas $(i=1 \ldots n)$.

Cálculo das distâncias euclidianas entre as posições dos picos de amplitude e a origem do espectro de Fourier:

De acordo com o padrão MATLAB de representação do espectro de Fourier por meio de uma imagem digital ${ }^{144}$, a origem do sistema de coordenadas de freqüência $(u, v)$ se encontra nas coordenadas espaciais $x=[(N / 2)+1]$ e $y=[(N / 2)+1]$, onde $N$ representa a dimensão da altura e da largura da imagem digital, dada em número de elementos de imagem (pixels). Assim, para uma imagem com dimensões de 512 pixels x 512 pixels, a origem do espectro de

\footnotetext{
${ }^{144}$ A imagem do espectro de Fourier tem as mesmas dimensões da imagem original da amostra de papel.
} 
freqüências $(u=0$ e $v=0)$ se localizará nas coordenadas espaciais $x=257$ e $y=257$. Isto ocorre, pois a correspondência entre a representação matricial convencional de uma imagem digital, $f(x, y)$, e a utilizada no programa MATLAB, $\mathrm{f}(x, y)$, ocorre na forma $x=(x+1)$ e $y=(y+1)$ e, portanto, $f(0,0) \leftrightarrow f(1,1)$.

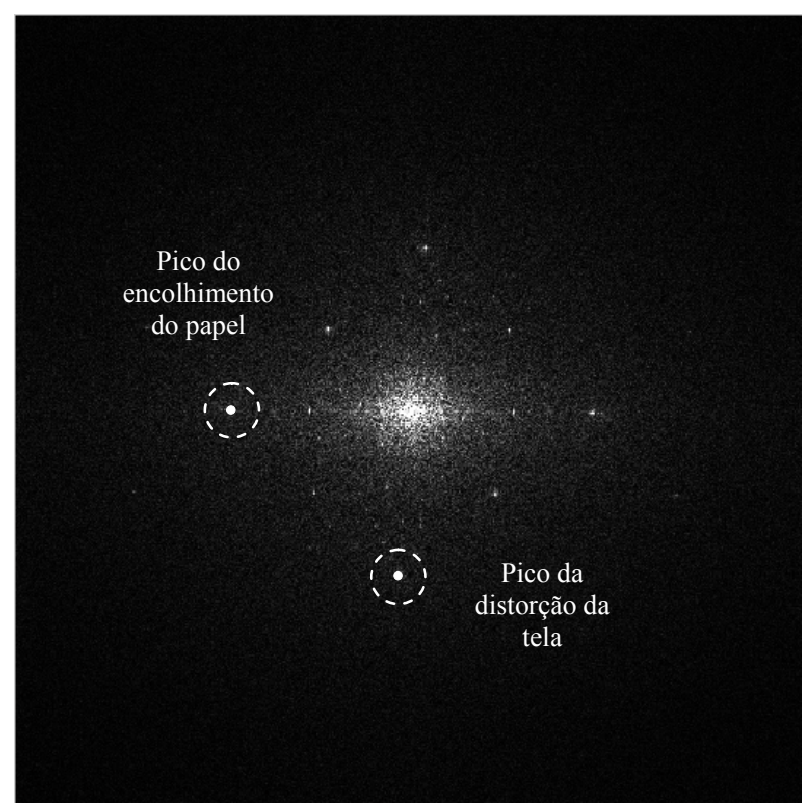

Figura 4.14. Picos de amplitude utilizados no processo de determinação do perfil de encolhimento transversal (CD) diferencial do papel.

A partir das coordenadas espaciais dos picos de amplitude de encolhimento, $x_{\mathrm{e}, i}$ e $y_{\mathrm{e}, i}$, encontradas pelo programa "PET1_0", obtém-se as distâncias entre as posições destes picos e a origem dos eixos de freqüência:

$$
d_{i}^{\prime}=\sqrt{\left[\left(\frac{N}{2}+1\right)-x_{e, i}\right]^{2}+\left[\left(\frac{N}{2}+1\right)-y_{e, i}\right]^{2}}
$$

onde:

$d_{i}^{\prime} \quad$ distância entre a posição do pico de encolhimento e a origem, pixels

$x_{\mathrm{e}, i} \quad$ coordenada no eixo $x$, do pico de encolhimento, no espectro de Fourier

$y_{\mathrm{e}, i} \quad$ coordenada no eixo $y$, do pico de encolhimento, no espectro de Fourier

$N$ dimensão vertical e horizontal da imagem, pixels 
Para o presente estudo, consideraram-se imagens quadradas, i.e., com $N$ elementos de imagem na vertical e na horizontal, na forma $2 \mathrm{n} \times 2^{\mathrm{n}}$, a fim de se obter melhor desempenho do algoritmo de cálculo da $2 \mathrm{D}-\mathrm{FFT}^{145}$

Determinação das freqüências características dos picos de amplitude identificados nos espectros de Fourier:

Conhecendo-se as coordenadas espaciais dos picos de amplitude, as coordenadas de freqüência destes mesmos picos são determinadas pelas relações a seguir:

$$
\begin{aligned}
& u_{e, i}=\left|\left(\frac{N}{2}+1\right)-x_{e, i}\right| \\
& v_{e, i}=\left|\left(\frac{N}{2}+1\right)-y_{e, i}\right|
\end{aligned}
$$

onde:

$u_{\mathrm{e}, i} \quad$ coordenada no eixo $u$, do pico de encolhimento, no espectro de Fourier

$v_{\mathrm{e}, i} \quad$ coordenada no eixo $v$, do pico de encolhimento, no espectro de Fourier

$x_{\mathrm{e}, i} \quad$ coordenada no eixo $x$, do pico de encolhimento, no espectro de Fourier

$y_{\mathrm{e}, i} \quad$ coordenada no eixo $y$, do pico de encolhimento, no espectro de Fourier

$N$ dimensão vertical e horizontal da imagem, pixels

Determinação do ângulo de inclinação das linhas de alinhamento das marcas da tela formadora, em relação ao eixo longitudinal (MD) e ângulo de distorção da tela formadora em relação ao eixo transversal $(C D)$ :

A partir das coordenadas espaciais dos picos de amplitude de distorção $\left(x_{\mathrm{e}, i}\right.$ e $\left.y_{\mathrm{e}, \mathrm{i}}\right)$, encontradas pelo programa "PET1_0", obtém-se:

${ }^{145}$ Ver subseção 3.4.7. 
$\alpha_{i}=\tan ^{-1}\left[\frac{y_{e, i}-\left(\frac{N}{2}+1\right)}{\left(\frac{N}{2}+1\right)-x_{e, i}}\right]$

onde:

$\alpha_{i} \quad$ ângulo de inclinação da marcas da tela formadora em relação à direção longitudinal (MD), grau

$x_{\mathrm{e}, i} \quad$ coordenada no eixo $x$, do pico de encolhimento no espectro de Fourier

$y_{\mathrm{e}, i} \quad$ coordenada no eixo $y$, do pico de encolhimento no espectro de Fourier

$N$ dimensão vertical e horizontal da imagem, pixels

A partir das coordenadas espaciais dos picos de amplitude de distorção $\left(x_{\mathrm{d}, i}\right.$ e $\left.y_{\mathrm{d}, i}\right)$, encontradas pelo programa "PET1_0", obtém-se:

$$
\beta_{i}=\tan ^{-1}\left[\frac{\left(\frac{N}{2}+1\right)-x_{d, i}}{y_{d, i}-\left(\frac{N}{2}+1\right)}\right]
$$

onde:

$\beta_{i} \quad$ ângulo de inclinação da marcas da tela formadora, em relação à direção transversal (CD), grau

$x_{\mathrm{d}, i} \quad$ coordenada no eixo $x$, do pico de distorção no espectro de Fourier

$y_{\mathrm{d}, i} \quad$ coordenada no eixo $y$, do pico de distorção no espectro de Fourier

$N$ dimensão vertical e horizontal da imagem, pixels

Determinação da separação entre as marcas da tela formadora, detectadas nas imagens das amostras de papel:

A distância de separação entre as linhas das marcas da tela formadora $\left(d_{i}^{*}\right)$, no domínio espacial, na direção determinada pelo ângulo $\alpha_{i}$, em relação ao eixo longitudinal (MD), em cada posição transversal, é determinada pela relação a seguir: 
$d_{i}^{*}=\frac{N \Delta x}{d_{i}^{\prime}}$

onde:

$d_{i}^{*} \quad$ distância entre as marcas longitudinais (MD), na direção determinada por $\alpha_{i}, \mathrm{~mm}$

$d_{i}^{\prime} \quad$ distância entre a posição do pico de encolhimento e a origem do espectro de amplitudes ( $c f$. equação 4.29), pixels

$N$ dimensão vertical e horizontal da imagem, pixels

$\Delta x \quad$ intervalo de amostragem da imagem do papel (dimensão do pixel), $\mathrm{mm}$

As distâncias entre os fios longitudinais presentes nas marcas da tela formadora detectadas no papel, após o encolhimento, são calculadas a partir de $d_{i}^{*} \alpha_{i}$ e $\beta_{i}$, de acordo com a expressão abaixo ${ }^{146}$ :

$$
l_{s, i}=\frac{d_{i}^{*}}{\cos \left(\alpha_{i}+\beta_{i}\right)}
$$

onde:

$l_{s, i} \quad$ distância entre fios longitudinais (MD), na marca do papel, $\mathrm{mm}$

$d_{i}^{*} \quad$ distância entre o alinhamento das marcas longitudinais (MD), medida pelo espectro de Fourier, na direção determinada por $\alpha_{i}, \mathrm{~mm}$

$\alpha_{i} \quad$ ângulo de inclinação da marcas em relação à direção longitudinal, grau

$\beta_{i} \quad$ ângulo de inclinação da marcas em relação à direção transversal, grau

Determinação do encolhimento transversal (CD) relativo e absoluto do papel:

As equações que seguem foram empregadas, a fim de determinar índices aproximados do encolhimento transversal (CD), relativo e absoluto, do papel:

\footnotetext{
${ }^{146}$ Ver subseção 3.5.3.
} 
Cálculo inicial do encolhimento transversal (CD) relativo:

$S_{r p, i}=\left[1-\frac{l_{s, i}}{\sum_{i=1}^{n} l_{s, i}\left(\frac{L_{s, i}}{L_{e n r}}\right)}\right] \times 10^{2}$

onde:

$S_{r p, i} \quad$ encolhimento transversal (CD) relativo (preliminar), \%

$l_{s, i} \quad$ distância entre fios longitudinais (MD), na marca do papel, $\mathrm{mm}$

$L_{s, i} \quad$ largura da seção transversal de papel amostrada, $\mathrm{m}$

$L_{\text {enr }} \quad$ largura da folha de papel na enroladeira, $\mathrm{m}$

Cálculo inicial do encolhimento transversal (CD) absoluto:

$S_{a p, i}=\left[1-\left(1-\frac{S_{r p, i}}{10^{2}}\right) \times\left(1-\frac{S_{m}}{10^{2}}\right)\right] \times 10^{2}$

onde:

$S_{a p, i} \quad$ encolhimento transversal (CD) absoluto (preliminar), \%

$S_{r p, i}$ encolhimento transversal (CD) relativo (preliminar), $\%$

$S_{m} \quad$ encolhimento médio da folha de papel $^{147}, \%$

A fim de melhorar a precisão do cálculo do encolhimento transversal (CD), um método interativo de correção foi aplicado, $c f$. descrito a seguir. $\mathrm{O}$ procedimento utiliza o cálculo inicial do encolhimento transversal (CD) para redimensionar alguns parâmetros, de forma mais precisa, para então reutilizá-los no cálculo final da contração do papel.

Partindo-se do encolhimento absoluto, calculado $c f$. equação (4.15), determina-se o ângulo de distorção da tela formadora, em relação ao eixo transversal (CD) da máquina, relativo à condição inicial do papel, i.e., antes do encolhimento na seção de secagem:

${ }^{147}$ Determinado $c f$. método indicado na subseção 4.2.4. 


$$
\beta_{u s, i}=\tan ^{-1}\left[\left(1-S_{a p, i}\right) \times \tan \beta_{s, i}\right]
$$

onde:

$\beta_{u s, i}$ ângulo de distorção da tela formadora, na marca do papel, antes do encolhimento, grau

$\beta_{s, i} \quad$ ângulo de distorção, na marca da tela formadora, após encolhimento do papel, grau

$S_{a p, i} \quad$ encolhimento absoluto do papel [cf. equação (4.15)], \%

Uma vez determinado o ângulo $\beta_{u s, i}$, encontra-se um fator de correção, a fim de se recalcular o encolhimento absoluto encontrado anteriormente:

$$
F_{c, i}=\frac{\cos \beta_{s, i}}{\cos \beta_{u s, i}}
$$

onde:

$F_{c, i} \quad$ fator de correção do encolhimento

$\beta_{s, i} \quad$ ângulo de distorção medido, após o encolhimento do papel, grau

$\beta_{u s, i}$ ângulo de distorção calculado, antes do encolhimento, grau

Correção da distância entre os fios longitudinais (MD) da tela formadora, na marca detectada no papel:

$$
l_{c, i}=l_{s, i} \times F_{c, i}
$$

onde:

$l_{c, i}$ distância corrigida entre fios longitudinais (MD) na marca da tela, $\mathrm{mm}$

$l_{s, i} \quad$ distância entre fios longitudinais na marca da tela formadora, medida após o encolhimento, $\mathrm{mm}$

$F_{c, i} \quad$ fator de correção do encolhimento [cf. equação (4.17)] 
Cálculo final do encolhimento transversal (CD) relativo do papel:

$$
S_{r, i}=\left[1-\frac{l_{c, i}}{\sum_{i=1}^{n} l_{c, i}\left(\frac{L_{s, i}}{L_{e n r}}\right)}\right] \times 10^{2}
$$

onde:

$S_{r, i} \quad$ encolhimento relativo do papel, $\%$

$l_{c, i}$ distância corrigida entre marcas de fios longitudinais (MD), $\mathrm{mm}$

$L_{s, i} \quad$ largura da seção transversal de papel amostrada, $\mathrm{m}$

$L_{\text {enr }} \quad$ largura da folha de papel na enroladeira, $\mathrm{m}$

Cálculo final do encolhimento transversal (CD) absoluto do papel:

$$
S_{a, i}=\left[1-\left(1-\frac{S_{r, i}}{10^{2}}\right) \times\left(1-\frac{S_{m}}{10^{2}}\right)\right] \times 10^{2}
$$

onde:

$S_{a, i} \quad$ encolhimento transversal (CD) absoluto, \%

$S_{r, i} \quad$ encolhimento transversal (CD) relativo do papel, \%

$S_{m} \quad$ encolhimento médio da folha de papel, \%

O procedimento apresentado é válido para situações em que as marcas detectadas no papel são provenientes de telas formadoras com teceduras similares ou diferentes, na face em contato com o papel. Quando as telas formadoras possuem estruturas similares, as marcas de ambas se confundem e se traduzem em um pico de amplitude no espectro de Fourier. O mesmo método pode ser utilizado no caso de marcas produzidas simultaneamente por telas formadoras com estruturas diferentes, situação em que tratamentos individuais para as marcas de cada tela devem ser considerados, desde a etapa de deteç̧ão dos respectivos picos de amplitude no espectro de Fourier. 


\section{3. $\quad$ Determinação da higroexpansibilidade do papel}

A medição da higroexpansibilidade do papel foi realizada em um higroexpansímetro laboratorial $^{148}$, com base no método de ensaio previsto na norma ISO 8226-1 [International Organization for Standardization, 1994]. O procedimento consiste em submeter corpos de prova retirados das amostras de papel a um condicionamento inicial com umidade relativa na câmara de teste de $22 \pm 3 \%{ }^{149}$, sem tensão e, posteriormente, a variações de umidade relativa, até atingir o equilíbrio, sob tensão constante, de $22 \pm 3 \%$ a $33 \pm 2 \%$ e, a seguir, de $33 \pm 2 \%$ a $66 \pm 2 \%{ }^{150}$, a fim de medir a variação no comprimento do papel causada pela mudança da umidade relativa entre os dois últimos patamares. A alteração de comprimento é, então, utilizada para calcular a higroexpansibilidade do papel, expressa em percentual do comprimento inicial, medido à umidade relativa de 50\%, de acordo com a expressão abaixo:

$$
X=\left[\frac{\left(\Delta l_{66}-\Delta l_{33}\right)}{l_{0}} \times \frac{33}{\left(R_{66}-R_{33}\right)}\right] \times 10^{-1}
$$

onde:

$X \quad$ higroexpansibilidade do papel, \%

$l_{0} \quad$ comprimento inicial do corpo de prova, $\mathrm{mm}$

$\Delta l_{33}$ variação no comprimento do corpo de prova, correspondente à variação da umidade relativa do ambiente, de $22 \pm 3 \%$ a $33 \pm 2 \%, \mu \mathrm{m}$

$\Delta l_{66}$ variação no comprimento do corpo de prova, correspondente à variação da umidade relativa do ambiente, de $22 \pm 3 \%$ a $66 \pm 2 \%, \mu \mathrm{m}$

$R_{33} \quad$ umidade relativa do ar medida no patamar de $33 \pm 2 \%$

$R_{66} \quad$ umidade relativa do ar medida no patamar de $66 \pm 2 \%$

Embora a norma ISO 8226-1 [International Organization for Standardization, 1994] não contemple o fator de correção expresso pelo termo [33/( $\left.\left.R_{66}-R_{33}\right)\right]$, na equação $(4.21)$,

\footnotetext{
${ }^{148}$ Laboratório do Departamento de Engenharia Química da FCT da Universidade de Coimbra, Portugal. Os ensaios de higroexpansibilidade foram realizados por pessoal da FCT, sob coordenação do Prof. Dr. Paulo Jorge Tavares Ferreira.

${ }^{149} \mathrm{O}$ condicionamento inicial é realizado à umidade relativa de $22 \pm 3 \%$, pelo período mínimo de $30 \mathrm{~min}$, com a finalidade de assegurar que todos os corpos de prova a serem testados se encontram em condição similar de umidade de equilíbrio, antes do inicio do ensaio de higroexpansibilidade.

${ }^{150} \mathrm{O}$ valor máximo de umidade de $66 \%$ foi determinado na norma ISO 8226-1, com o objetivo de mantê-lo abaixo de $68 \%$ e, assim, minimizar a influência da relaxação de tensões internas do papel durante a medição da higroexpansibilidade.
} 
sua utilização foi considerada, a fim de manter a variação média real de umidade relativa do ar incluída no cálculo da higroexpansibilidade do papel.

\subsubsection{O higroexpansímetro laboratorial}

O higroexpansímetro laboratorial utilizado consiste basicamente de três componentes: (a) uma câmara de teste com isolamento térmico, onde são colocados os corpos de prova; (b) um sistema de ar para alimentação da câmara de teste, com temperatura e umidade relativa controladas; e (c) um sistema computadorizado de aquisição e tratamento de dados com uma unidade de controle. A Figura 4.15 mostra o esquema ilustrativo do sistema de controle de umidade relativa e temperatura do ar insuflado na câmara de teste. A unidade de geração de ar tem a capacidade de produzir uma corrente de ar úmido saturado (efetuando a passagem do ar por uma torre de umidificação) e uma corrente de ar seco (promovendo a passagem do ar através de um leito de secagem). A umidade do ar na câmara de teste, medida por um sensor com precisão de $2 \%$, é controlada pela temperatura da água no fluxo dirigido para a coluna de umidificação (aquecedor 1) e pela posição da válvula de três vias, a qual regula a fração de ar que segue para o circuito de umidificação ou de secagem. A concepção da câmara de teste permite um escoamento uniforme do ar em todo o seu volume. O controle de temperatura é feito pela atuação nos aquecedores situados na linha de ar seco (aquecedor 2) e na linha de mistura de ar (aquecedor 3). Os corpos de prova são fixados verticalmente no interior da câmara de ensaio, por meio de grampos e as variações de comprimento, resultantes da variação da umidade relativa do ar, são medidas por um sensor linear de proximidade, a laser, com precisão mínima de $0,001 \mathrm{~mm}$. O sistema de aquisição de dados e o software de controle permitem que o operador visualize os resultados das medições de umidade do ar e de variação de comprimento dos corpos de prova e que sejam armazenadas para processamento futuro. $\mathrm{Na}$ Figura 4.16, encontra-se uma fotografia do equipamento utilizado para os ensaios de higroexpansibilidade.

\subsubsection{Medição da higroexpansibilidade do papel}

Para os ensaios de higroexpansibilidade, foram retirados 5 corpos de prova de cada amostra de papel $^{151}$, cada um com $15 \mathrm{~mm}$ de largura e comprimento aproximado de $100 \mathrm{~mm}$,

\footnotetext{
${ }^{151}$ Ver detalhes da amostragem do papel na subseção 4.1.2.
} 
sendo o lado mais longo correspondente à direção de interesse (MD ou CD). Os corpos de prova foram fixados verticalmente no interior da câmara de teste, por meio de grampos, sendo que os inferiores, que possuíam massa pré-determinada de $23 \pm 1,5 \mathrm{~g}$, mantiveram os corpos de prova tensionados com carga uniforme de $15 \pm 1 \mathrm{~N} . \mathrm{m}^{-1}$. A distância inicial entre o grampo superior e o inferior, corresponde ao comprimento inicial do corpo de prova $\left(l_{0}\right)$.

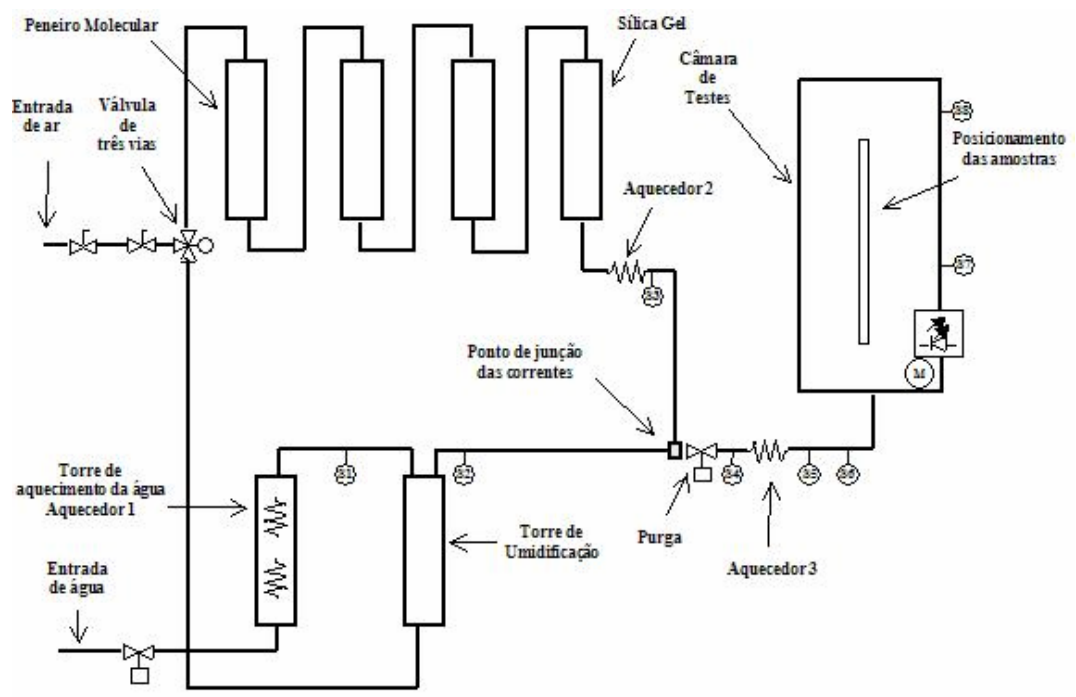

Figura 4.15. Sistema de controle da umidade relativa e da temperatura do ar na câmara de teste do higroexpansímetro.

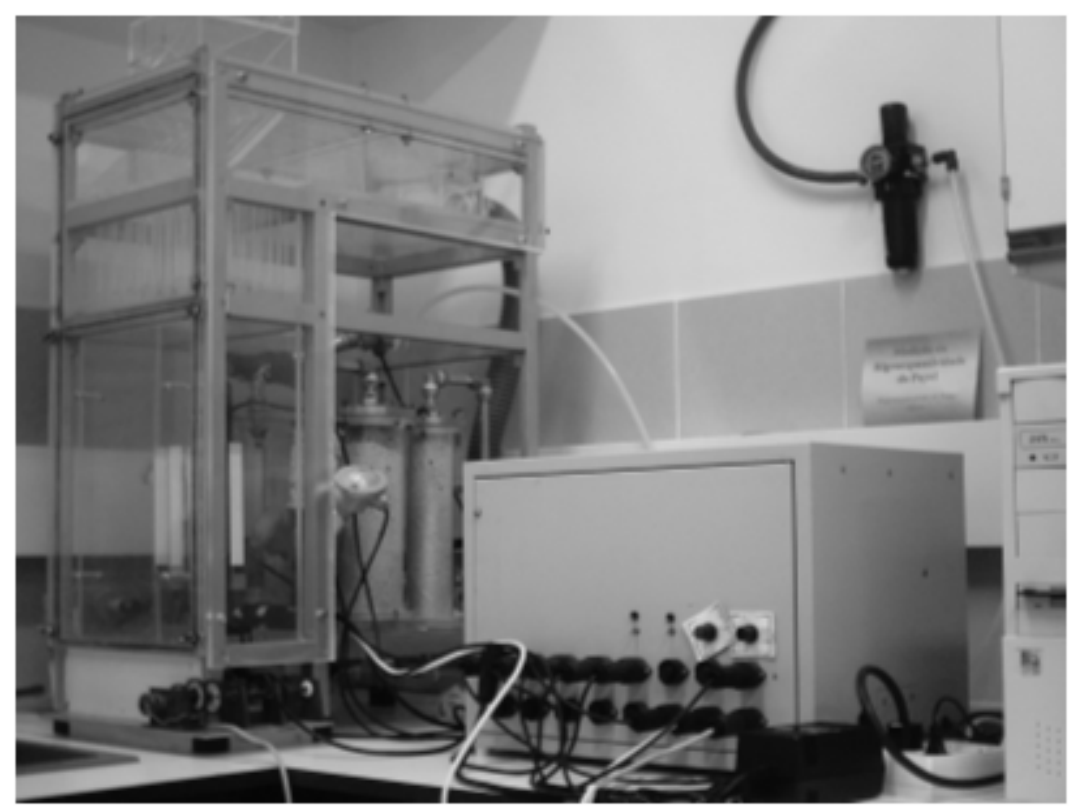

Figura 4.16. Higroexpansímetro do Departamento de Engenharia Química da Faculdade de Ciências e Tecnologia da Universidade de Coimbra, Portugal. 
A Tabela 4.1, a seguir, ilustra um resumo das etapas do procedimento utilizado para a medição de variação de comprimento das amostras de papel. Nas 10 posições amostradas, foram medidos 5 corpos de teste de cada, totalizando 50 medições de higroexpansibilidade.

Tabela 4.1. Etapas do procedimento de medição da higroexpansibilidade.

\begin{tabular}{clccc}
\hline Etapa & \multicolumn{1}{c}{ Operação } & $\begin{array}{c}\text { Tensão } \\
\left(\mathbf{N} . \mathbf{~ m}^{-1}\right)\end{array}$ & $\begin{array}{c}\text { Umidade Relativa } \\
\mathbf{( \% )}\end{array}$ & $\begin{array}{c}\text { Tempo mínimo } \\
(\mathbf{m i n})\end{array}$ \\
\hline 1 & $\begin{array}{l}\text { Medição do comprimento } \\
\text { inicial do corpo de teste }\left(l_{0}\right)\end{array}$ & $\begin{array}{c}\text { Sem } \\
\text { tensão }\end{array}$ & $50 \pm 2$ & 30 \\
2 & $\begin{array}{l}\text { Condicionamento inicial dos } \\
\text { corpos de teste }\end{array}$ & $\begin{array}{c}\text { Sem } \\
\text { tensão }\end{array}$ & $22 \pm 3$ & 30 \\
3 & $\begin{array}{l}\text { Medição da variação de } \\
\text { comprimento }-1^{\mathbf{0}} \text {.patamar }\end{array}$ & $15 \pm 1$ & $33 \pm 2$ & 30 \\
4 & $\begin{array}{l}\text { Medição da variação de } \\
\text { comprimento }-2^{\circ} \text {.patamar }\end{array}$ & $15 \pm 1$ & $66 \pm 2$ & 30 \\
\hline
\end{tabular}

A câmara de teste foi mantida na temperatura de $25 \pm 2{ }^{\circ} \mathrm{C}$ e a umidade relativa do ar, no seu interior, foi controlada nos patamares necessários para os ensaios, $c f$. Tabela 4.1. Na segunda etapa, a umidade relativa do ar foi mantida em $22 \pm 3 \%$, durante 60 minutos, para précondicionamento dos corpos de prova. A seguir, foi aplicada uma perturbação (em degrau) de $11 \%$, para elevar a umidade relativa do ar no interior da câmara para o nível de $33 \pm 2 \%$, onde foi mantida durante $90 \mathrm{~min}$. Nesta condição, as medições da variação de comprimento, realizadas pelo sensor de proximidade a laser, que se desloca continuamente na base dos corpos de prova, são registradas pelo sistema de aquisição de dados para uso futuro no cálculo da higroexpansibilidade. Para este nível de umidade relativa, foram utilizados 110 valores de variação de comprimento do corpo de prova, tomados a intervalos de tempo entre medições de $15 \mathrm{seg}$ a $20 \mathrm{seg}$, cujo valor médio representou a variação no comprimento do corpo de prova, desde a condição inicial de umidade relativa, de $22 \pm 3 \%$, até a condição de $33 \pm 2 \%$, correspondendo ao fator $\Delta l_{33}$.

Na próxima etapa, uma nova perturbação foi aplicada pelo sistema de controle, desta vez, para elevar o nível da umidade relativa no interior da câmara de teste para $66 \pm 2 \%$, no qual permaneceu durante 210 min. Para este nível de umidade, foram utilizados 210 valores de variação do comprimento do corpo de prova, tomados a intervalos de tempo entre medições de 15 seg a 20 seg, para determinação da variação do comprimento do corpo de prova, na condição de umidade relativa do ar de $66 \pm 2 \%\left(\Delta l_{66}\right)$. Os valores de umidade relativa 
do ar no interior da câmara foram medidos e registrados simultaneamente à medição e registro das variações do comprimento dos corpos de prova nos níveis de $33 \pm 2 \%$ e $66 \pm 2 \%$. Seus valores médios foram atribuídos aos termos $R_{33}$ e $R_{66}$, respectivamente.

\subsection{Avaliação da estabilidade dimensional do papel.}

O método utilizado para avaliação da estabilidade dimensional do papel consiste de análise gráfica por regressão linear simples, a fim de se determinar a correlação entre o grau de encolhimento e a higroexpansibilidade transversais (CD) do papel. Os resultados da relação estatítica entre os dois parâmetros permitem estabelecer um modo específico para análise do perfil transversal de encolhimento, de forma a possibilitar a predição das condições de estabalidade dimensional do papel ao longo das posições transversais, a partir das amostras coletadas na bobina "jumbo"

\subsubsection{Análise gráfica e regressão linear}

Os valores resultantes das medições do encolhimento e da higroexpansibilidade transversais $(\mathrm{CD})$ foram plotados em gráfico de dispersão, considerando o primeiro parâmetro como a variável de regressão e o segundo como a variável de resposta. A partir dos $n(n=50)$ pares de dados plotados no gráfico de dois eixos (higroexpansibilidade $v s$. encolhimento) estabelece-se o modelo para a função linear de correlação, da seguinte forma:

$$
X=k_{0}+k_{1} S_{a}+\varepsilon
$$

onde:

$X \quad$ higroexpansibilidade transversal (CD) do papel, \%

$k_{0} \quad$ intercepção no eixo de higroexpansibilidade, \%

$k_{1} \quad$ coeficiente de inclinação, $\% / \%$

$S_{a} \quad$ encolhimento transversal (CD) absoluto do papel, \%

$\varepsilon \quad$ componente de erro, $\%$

\footnotetext{
${ }^{152}$ Ver na seção 2.8, as relações entre encolhimento, higroexpansibilidade e a estabilidade dimensional do papel.
} 
O parâmetros da regressão $\left(k_{0}\right.$ e $\left.k_{1}\right)$, são determinados pelo método dos mínimosquadrados, $c f$. descrito a seguir:

$\hat{k}_{1}=S_{x y} / S_{x x}$

onde:

$\hat{k}_{1} \quad$ inclinação estimada pelos mínimos-quadrados, \%

e

$$
\begin{aligned}
& S_{x y}=\sum_{i=1}^{n} S_{a i} X_{i}-\left[\sum_{i=1}^{n} S_{a i} \sum_{i=1}^{n} X_{i} / n\right] \\
& S_{x x}=\sum_{i=1}^{n} S_{a i}^{2}-\left[\left(\sum_{i=1}^{n} S_{a i}\right)^{2} / n\right] \\
& \hat{k_{0}}=\bar{X}-\hat{k_{1}} \overline{S_{a}}
\end{aligned}
$$

onde:

$\hat{k_{0}} \quad$ interceptor estimado pelos mínimos-quadrados, $\%$

e

$$
\begin{aligned}
& \bar{X}=(1 / n) \sum_{i=1}^{n} X_{i} \\
& \bar{S}_{a}=(1 / n) \sum_{i=1}^{n} S_{a i}
\end{aligned}
$$

O modelo de regressão linear simples estimado pelo método dos mínimos-quadrados e ajustado para os dados medidos de encolhimento e higroexpansibilidade do papel assume, então, a seguinte forma:

$$
\hat{X}=\hat{k}_{0}+\hat{k}_{1} S_{a}
$$

onde os sobrescritos “^” indicam que o parâmetro foi estimado pelo método dos mínimosquadrados. 
As diferenças entre os valores de higroexpansibilidade medidos e os correspondentes na reta ajustada (resídual, $e_{i}$ ) são determinados para análise de adequação do modelo, de acordo com a expressão abaixo, relativa ao $i$-ésimo residual:

$$
e_{i}=X_{i}-\hat{X}_{i}=X_{i}-\left(\hat{k}_{0}+\hat{k}_{1} S_{a i}\right), i=1,2, \ldots, n
$$

Adicionalmente, o coeficiente de determinação $\left(R^{2}\right)$ foi calculado $c f$. expressão abaixo:

$$
R^{2}=1-\left(S S_{\operatorname{Re} s} / S S_{T}\right)
$$

onde:

$$
\begin{aligned}
& S S_{\mathrm{Re} s}=\sum_{i=1}^{n}\left(X_{i}-\hat{X}_{i}\right)^{2} \\
& S S_{T}=S S_{R}+S S_{\mathrm{Re} s} \\
& \mathrm{e} \\
& S S_{R}=\sum_{i=1}^{n}\left(\hat{X}_{i}-\bar{X}_{i}\right)^{2}
\end{aligned}
$$

O uso do método descrito acima permite analisar a extensão das faixas da folha que apresentam maior potencial de problemas de desempenho nas operações de conversão e usos subsequentes do papel, causados por insuficiência de estabilidade dimensional. A definição do conceito de classificação da qualidade deste parâmetro depende da utilização final prevista para o produto, devendo assim ser definida especificamente para cada caso. O indicador de limite de qualidade, a ser definido em função das condições descritas neste capítulo, pode ser expresso pela seguinte relação:

$$
E D_{\mathrm{ac}} \leftrightarrow\left[S_{a} \leq S_{a \max }\right]
$$

onde $E D_{\text {ac }}$ representa a porção de papel com estabilidade dimensional aceitável, desde que o valor do encolhimento absoluto $\left(S_{a}\right)$, apresente valor inferior ao máximo estipulado $\left(S_{a \text { max }}\right)$. 


\section{CAPÍtULO 5}

\section{PERFIS TRANSVERSAIS RESULTANTES E A CORRELAÇÃO ENTRE ENCOLHIMENTO E HIGROEXPANSIBILIDADE DO PAPEL}

Este capítulo apresenta os resultados obtidos na medição dos perfis do encolhimento e da higroexpansibilidade transversais (CD), utilizados para verificação da correlação entre estas propriedades e discussão do seu significado com relação à estabilidade dimensional do papel. Inicialmente, apresenta-se, para referência, o espectro de Fourier obtido de uma tela formadora de camada tripla (5.1), com o objetivo de mostrar as relações entre aspectos geométricos do entrelaçamento dos fios, no domínio espacial, e as posições dos picos de amplitude correspondentes no espectro de Fourier (domínio das freqüências). Apresentam-se também medições em posições ao longo da direção transversal da mesma tela, a fim de verificar seu perfil de uniformidade. A seguir, são apresentadas as imagens digitais das amostras de papel (5.2), o resultado do tratamento destas imagens por meio da transformada rápida de Fourier (2D-FFT) para análise, no domínio das freqüências (5.3). Na seqüência, são mostrados os resultados obtidos para os perfis de encolhimento (5.4) e higroexpansibilidade transversais (5.5) e para a correlação entre estes parâmetros (5.6), utilizada posteriormente como base para a avaliação da estabilidade dimensional ao longo da direção transversal (CD) do papel. Finalmente, apresenta-se um perfil do encolhimento transversal (CD) diferencial de uma amostra de papel tomada na largura total da folha (5.7), para avaliação de estabilidade dimensional.

\subsection{Espectro de Fourier característico de uma tela formadora de três camadas}

A Figura 5.1(b) mostra o espectro de Fourier obtido a partir da imagem digitalizada de uma seção de uma tela formadora de três camadas, estilo $\mathrm{SSB}^{153}$, retirada de máquina. Para melhor clareza, a Figura 5.1(a) ilustra o entrelaçamento característico dos fios longitudinais, transversais e de fixação, para este tipo de tela formadora, visto pelo lado de contato com o papel (tecedura em 2 quadros). O modelo SSB é tipicamente utilizado na produção de papel reprográfico, em máquinas de alta velocidade configuradas com formadores de tela dupla do tipo gap former.

\footnotetext{
${ }^{153}$ Para referência, ver subseção 3.5.2.
} 


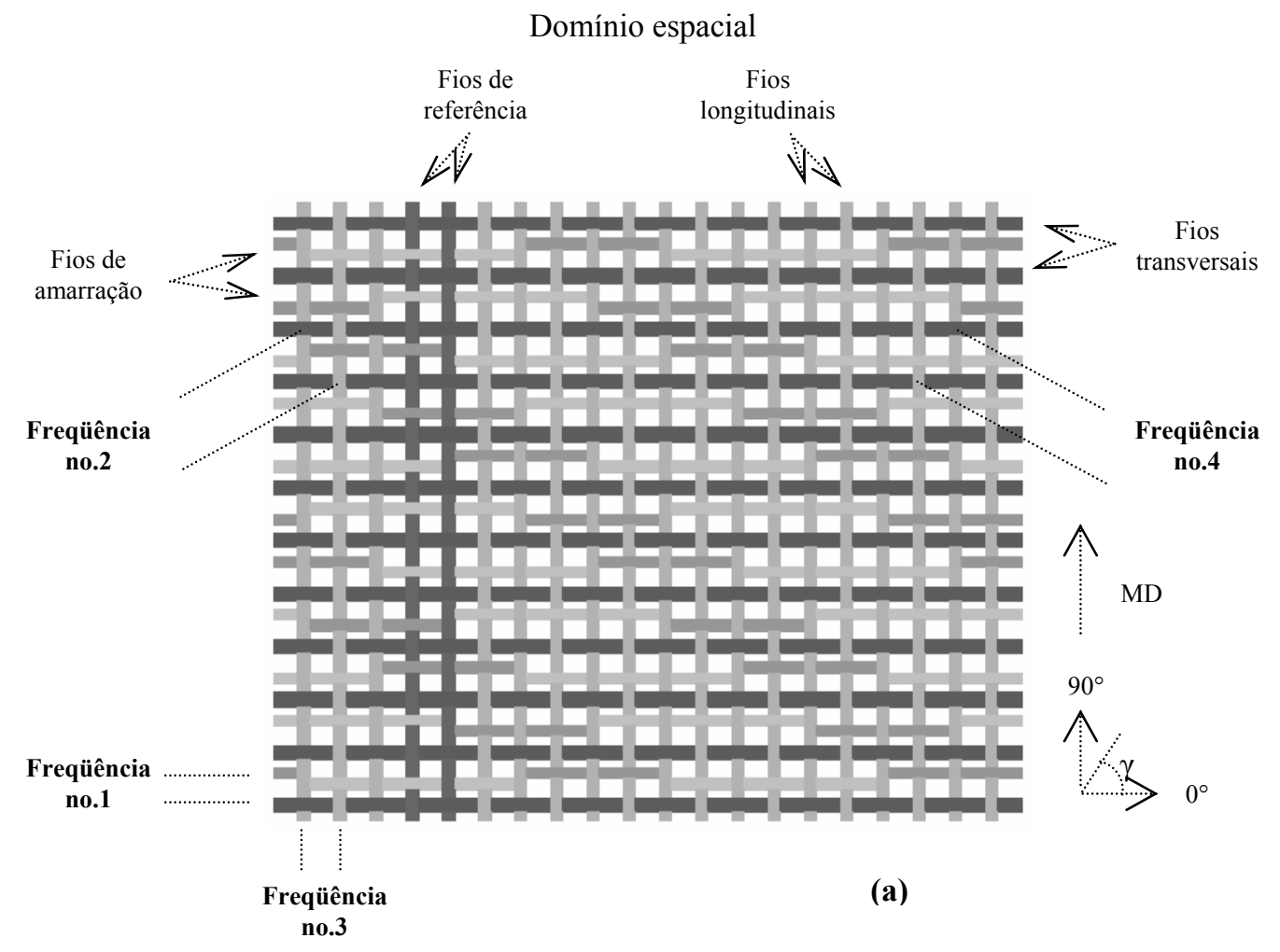

Domínio das freqüências

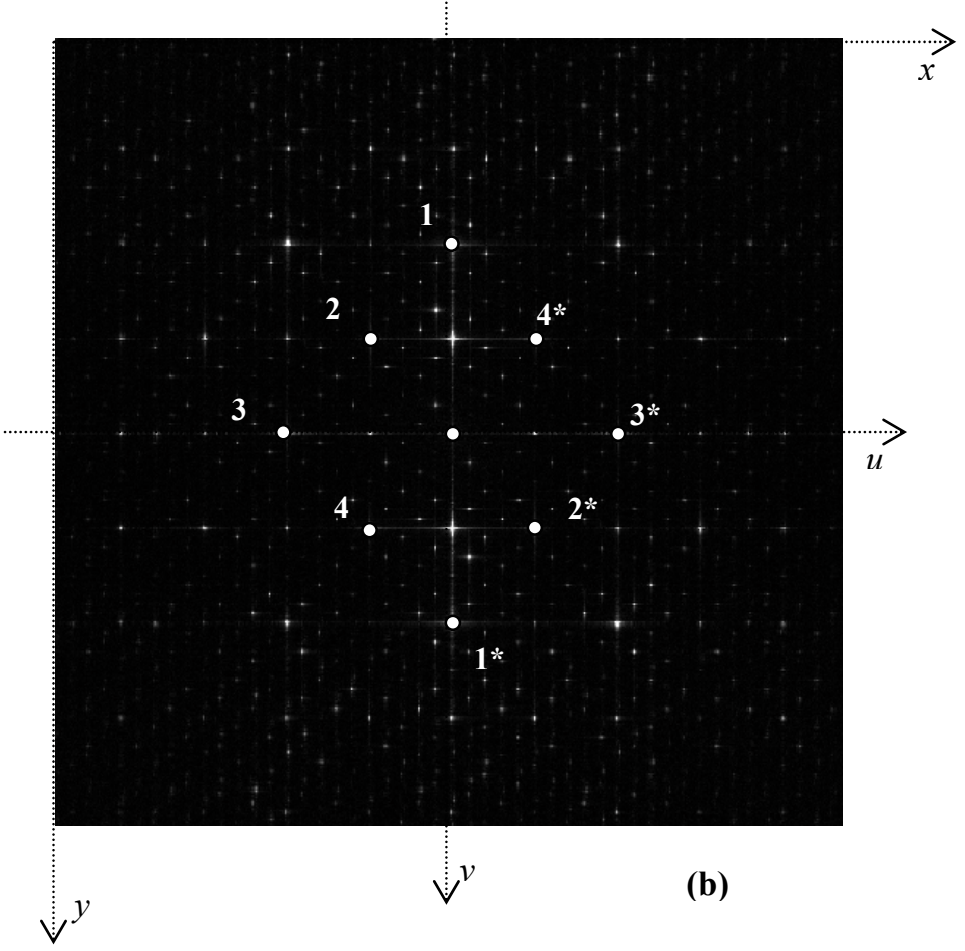

Figura 5.1. Ilustração da tecedura de uma tela formadora de três camadas (SSB) vista pelo lado de contato com o papel (a) e o espectro de Fourier correspondente (b), obtido a partir da sua imagem digital $c f$. indicada na Figura 5.3. Os pontos marcados com asterisco $(*)$ referem-se a pontos simétricos aos indicados com a mesma numeração. Os pontos foram destacados para melhor visualização. 
A Figura 5.2 mostra uma imagem monocromática digitalizada, de uma amostra de tela formadora, obtida por meio de um digitalizador de mesa configurado no modo reflexivo e utilizada para obtenção do espectro de amplitudes mostrado na Figura 5.1(b). A digitalização da tela formadora foi realizada em formato de 512 pixels x 512 pixels, com resolução de imagem de 400 ppi e profundidade de cor de 8 bits (256 níveis de cinza). O contraste da imagem mostrada foi realçado, a fim de melhorar sua visualização.

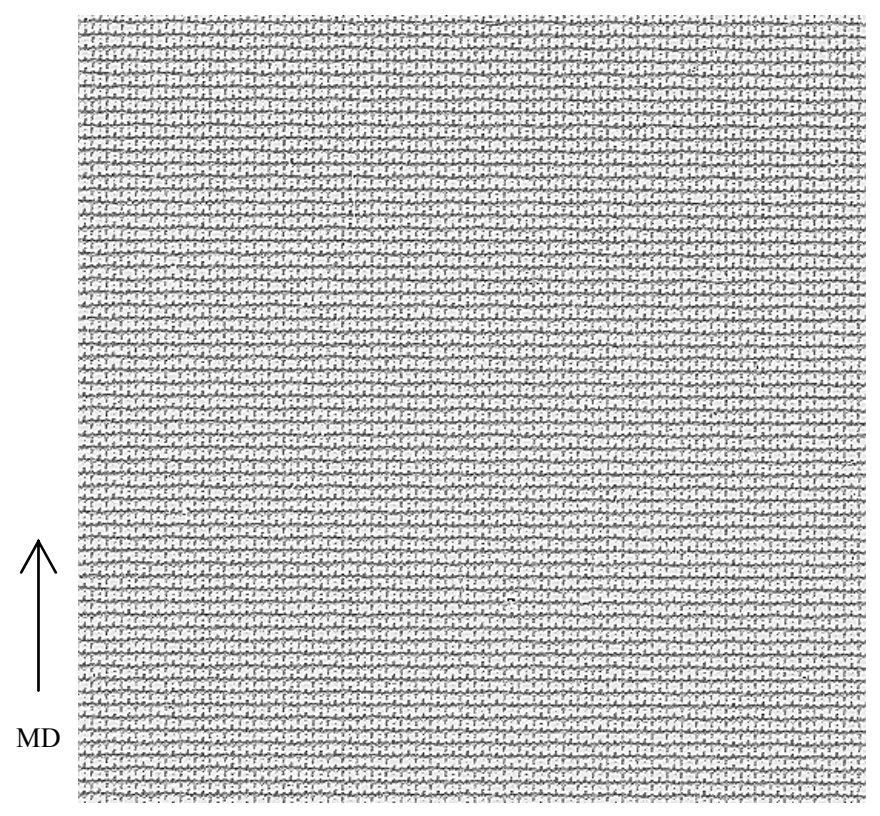

Figura 5.2. Imagem monocromática de uma amostra de tela formadora, obtida por digitalização com resolução de imagem de 400 ppi, no formato de 512 pixels x 512 pixels e com 8 bits de profundidade de cor (256 níveis de cinza). O contraste foi realçado para melhorar a visualização.

Os dados contidos na Tabela 5.1 referem-se às medições realizadas com uma amostra de tela formadora, conforme mencionado anteriormente, de onde se extraem informações estruturais, especificamente sobre a distribuição de fios longitudinais (MD) e transversais (CD), que caracterizam a superfície em contato com o papel no processo de formação da folha, i.e., são indicativos do padrão periódico das marcas produzidas sobre o papel. Os parâmetros $d_{i}{ }^{\prime}, d_{i}$ e $d_{i}{ }^{*}$ foram determinados utilizando-se as equações (3.68), (3.72) e (3.73), respectivamente ${ }^{154}$.

\footnotetext{
${ }^{154}$ Ver subseção 3.5.5.
} 
Tabela 5.1. Coordenadas espaciais $\left(x_{i}, y_{i}\right)$, freqüências características $\left(u_{i}, v_{i}\right)$, amplitudes relativas, distâncias entre fios longitudinais (MD) e transversais $(\mathrm{CD})$, distâncias diagonais da tela formadora $\left(d_{i}\right)$ e ângulo de orientação $(\gamma)$, referentes aos picos destacados no espectro de Fourier da Figura 5.1(b).

\begin{tabular}{|c|c|c|c|c|c|c|c|c|c|}
\hline \multirow{2}{*}{$\begin{array}{c}\text { Pico de } \\
\text { Amplitude } \\
(i) \\
\end{array}$} & \multicolumn{2}{|c|}{$\begin{array}{l}\text { Coordenadas } \\
\text { espaciais }\end{array}$} & \multicolumn{2}{|c|}{$\begin{array}{l}\text { Coordenadas de } \\
\text { freqüências }\end{array}$} & \multirow[t]{2}{*}{$\begin{array}{l}\text { Amplitude } \\
\text { relativa }\end{array}$} & \multirow{2}{*}{$\begin{array}{c}d_{i}^{\prime} \\
\text { [pixels] }\end{array}$} & \multirow{2}{*}{$\begin{array}{c}d_{i} \\
{[\text { pixels] }}\end{array}$} & \multirow{2}{*}{\multicolumn{2}{|c|}{$\begin{array}{c}d_{i}^{*} \quad \gamma_{i} \\
(\mathbf{m m})\left({ }^{\circ}\right)\end{array}$}} \\
\hline & $x_{i}$ & $y_{i}$ & $u_{i}$ & $v_{i}$ & & & & & \\
\hline 1 & 257 & 135 & 0 & -122 & 0.624 & 122.00 & 4.20 & 0.266 & 0 \\
\hline 2 & 204 & 196 & -53 & -61 & 0.483 & 80.81 & 6.34 & 0.402 & 41 \\
\hline 3 & 150 & 257 & -107 & 0 & 1.000 & 107.00 & 4.79 & 0.304 & 90 \\
\hline 4 & 203 & 318 & -54 & 61 & 0.502 & 81.47 & 6.28 & 0.399 & 13 \\
\hline
\end{tabular}

$\boldsymbol{d}_{i}{ }^{\prime}$ : Distâncias entre as posições dos picos de amplitude e a origem (centro) do espectro de Fourier [cf. Figura 5.1(b)].

$\boldsymbol{d}_{i}$ : Distâncias entre fios longitudinais (MD), fios transversais (CD) e separações diagonais, detectadas na imagem da tela formadora, medidas em pixels.

$\boldsymbol{d}_{i}{ }^{*}$ : Distâncias entre fios longitudinais (MD), fios transversais (CD) e separações diagonais, detectadas na imagem da tela formadora, medidas em milímetros $(\mathrm{mm})$.

$\gamma_{i}$ : Ângulo de alinhamento. Refere-se à orientação dos fios longitudinais (MD), transversais (CD) e das separações diagonais, $c f$. ilustração da Figura 5.1(a).

O ponto 1 no espectro de Fourier refere-se à freqüência associada ao espaçamento entre fios transversais (CD) da tela formadora. O ponto 3 corresponde ao espaçamento dos fios longitudinais (MD). A partir dos resultados de $d_{i}^{*}$ para estes pontos, pode-se estimar o número de fios por unidade de comprimento da tela por meio da expressão abaixo:

$$
\text { No. de fios } / \mathrm{cm}=\frac{1}{d_{i}^{*}} \times 10
$$

Assim, estima-se uma quantidade de 37 fios transversais (CD) $/ \mathrm{cm}\left(d_{i}^{*}=0,266 \mathrm{~mm}\right)$ e 33 fios longitudinais $/ \mathrm{cm}\left(d_{i}^{*}=0,304 \mathrm{~mm}\right)$. As distâncias indicadas para os pontos 2 e 4 representam diagonais resultantes da composição entre componentes nas direções longitudinal (MD) e transversal (CD). As magnitudes dos picos correspondentes aos elementos periódicos presentes no papel analisado indicam a intensidade destes componentes na imagem digitalizada. No caso da análise espectral de tela formadora, referem-se à intensidade dos elementos de imagem relativos aos fios e seus entrelaçamentos em cada posição ou, também, à combinação de efeitos. Esta particularidade aparece na Tabela 5.1, onde se observam as diferentes amplitudes relativas de cada ponto. Nota-se que o ponto 3, especialmente relevante para a medição do encolhimento transversal (CD) do papel, apresentou maior amplitude relativa, dentre os demais, destacando a intensidade das marcas produzidas pelos fios longitudinais (MD) da tela formadora no papel. 


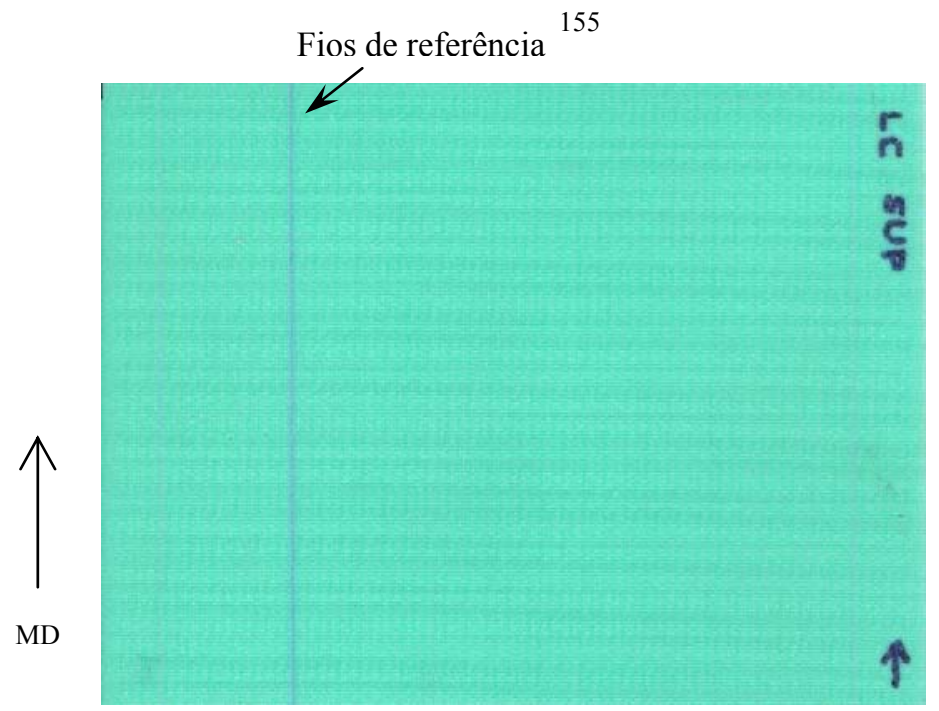

Figura 5.3. Fotogafia de uma tela formadora de três camadas, estilo SSB, vista pela face de contato com o papel.

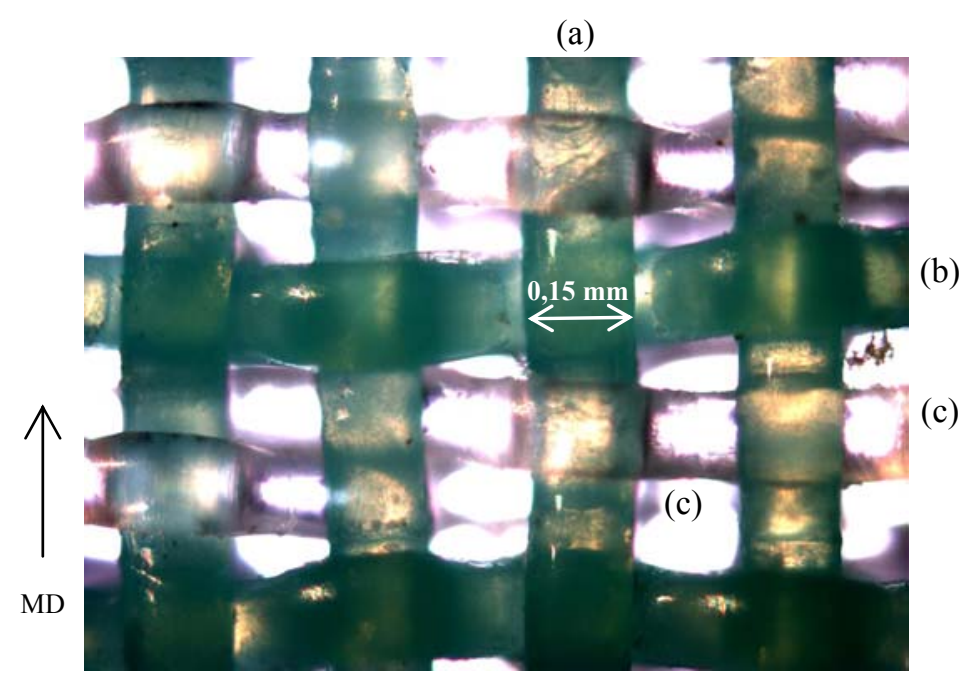

Figura 5.4. Imagem ampliada da tela formadora indicada na Figura 5.3. Observam-se os fios longitudinais (a), transversais (b) e os de ligação (c). A imagem original foi ampliada (100X) para visualização, em microscópio óptico Olympus modelo BX50F4, monitorado em computador por software de análise de imagens Image-Pro Plus ${ }^{156}$.

${ }^{155}$ Ver ilustração na Figura 5.1(a).

${ }^{156}$ Image-Pro Plus versão 4.1.0.0, Media Cybernetics, USA, 


\subsubsection{Uniformidade estrutural da tela formadora}

Medições da estrutura de uma tela formadora foram realizadas, por este autor, a fim de verificar sua uniformidade, nas direções longitudinal (MD) e transversal (CD), de onde se originam os dados referentes às separações entre as marcas dos fios, utilizadas no cálculo do encolhimento transversal (CD) do papel. As medições foram feitas em 4 amostras coletadas de posições uniformemente distribuídas na largura da tela formadora. Os resultados dessas medições encontram-se na Tabela 5.2 e estão mostrados graficamente na Figura 5.5.

Tabela 5.2. Parâmetros resultantes da análise de imagens de amostras de uma tela formadora, por meio da transformada de Fourier (2D-FFT), referente aos pontos 1 e 3 indicados na Figura 5.1(b).

\begin{tabular}{|c|c|c|c|c|c|c|c|c|}
\hline \multirow{2}{*}{$\begin{array}{l}\text { Posição da } \\
\text { Amostra* } \\
\text { (m) }\end{array}$} & \multicolumn{2}{|c|}{$\begin{array}{l}\text { Coordenadas } \\
\text { Espaciais } \\
\text { (ponto 1) }\end{array}$} & \multicolumn{2}{|c|}{$\begin{array}{l}\text { Coordenadas de } \\
\text { Freqüências } \\
\text { (ponto 1) }\end{array}$} & \multirow{2}{*}{$\begin{array}{c}d_{1}^{\prime} \\
{[\text { pixels }]}\end{array}$} & \multirow{2}{*}{$\begin{array}{c}d_{1} \\
{[\text { pixels }]}\end{array}$} & \multirow{2}{*}{$\begin{array}{c}d_{1}^{*} \\
(\mathrm{~mm})\end{array}$} & \multirow{2}{*}{$\begin{array}{l}\gamma_{1} \\
\left({ }^{\circ}\right)\end{array}$} \\
\hline & $x_{1}$ & $y_{1}$ & $u_{1}$ & $v_{1}$ & & & & \\
\hline 1.20 & 256 & 135 & -1 & -122 & 122.00 & 4.20 & 0.266 & 0 \\
\hline 2.40 & 257 & 135 & 0 & -122 & 122.00 & 4.20 & 0.266 & 0 \\
\hline 3.60 & 258 & 135 & 1 & -122 & 122.00 & 4.20 & 0.266 & 0 \\
\hline 4.80 & 259 & 135 & 2 & -122 & 122.02 & 4.20 & 0.266 & 1 \\
\hline \multirow[t]{2}{*}{$\begin{array}{l}\text { Posição da } \\
\text { Amostra (*) } \\
\text { (m) }\end{array}$} & \multicolumn{2}{|c|}{$\begin{array}{l}\text { Coordenadas } \\
\text { Espaciais } \\
\text { (ponto 3) }\end{array}$} & \multicolumn{2}{|c|}{$\begin{array}{l}\text { Coordenadas de } \\
\text { Freqüências } \\
\text { (ponto 1) }\end{array}$} & $d_{3}^{\prime}$ & $d_{3}$ & $d_{3} *$ & $\gamma_{3}$ \\
\hline & $x_{3}$ & $y_{3}$ & $u_{3}$ & $v_{3}$ & [pixels] & [pixels] & $(\mathrm{mm})$ & $\left({ }^{\circ}\right)$ \\
\hline 1,20 & 150 & 257 & -107 & 0 & 107.00 & 4.79 & 0.304 & 90 \\
\hline 2.40 & 150 & 257 & -107 & 0 & 107.00 & 4.79 & 0.304 & 90 \\
\hline 3,60 & 150 & 257 & -107 & 0 & 107.00 & 4.79 & 0.304 & 90 \\
\hline 4,80 & 150 & 257 & -107 & 0 & 107.00 & 4.79 & 0.304 & 90 \\
\hline \multicolumn{9}{|c|}{$\begin{array}{l}\boldsymbol{d}^{\prime} \text { : Distâncias entre as posições dos picos de amplitude e a origem (centro) do espectro de Fourier } \\
{[c f \text {. Figura } 5.1(\mathrm{~b})] \text {. }} \\
\boldsymbol{d} \text { : Distâncias entre fios longitudinais (MD), fios transversais (CD) e separações diagonais, detectadas } \\
\text { na imagem da tela formadora, medidas em pixels. } \\
\boldsymbol{d}^{*} \text { : Distâncias entre fios longitudinais (MD), fios transversais (CD) e separações diagonais, detectadas } \\
\text { na imagem da tela formadora, medidas em milímetros (mm). } \\
\gamma: \text { Ângulo de alinhamento. Refere-se à orientação dos fios longitudinais (MD), transversais (CD) e das } \\
\text { separações diagonais, } c f . \text { ilustração da Figura 5.1(a). } \\
\left({ }^{*}\right) \text { em relação à borda da tela formadora. }\end{array}$} \\
\hline
\end{tabular}

Os resultados obtidos para $\boldsymbol{d}^{*}$ (para os pontos 1 e 3 ) mostram a uniformidade da tela formadora examinada, nas duas direções [longitudinal (MD) e transversal (CD)]. Cabe relembrar que se trata de uma tela retirada de máquina, após certo ciclo de vida, que manteve a estabilidade dimensional. 
No gráfico mostrado na Figura 5.5, as separações entre os fios $\left(\boldsymbol{d}_{i}{ }^{*}\right)$, dispostos nas direções longitudinal (MD) e transversal (CD) da tela formadora, foram plotadas em função da localização dos pontos de coleta da amostra, a partir da borda correspondente ao lado de comando da máquina de papel.

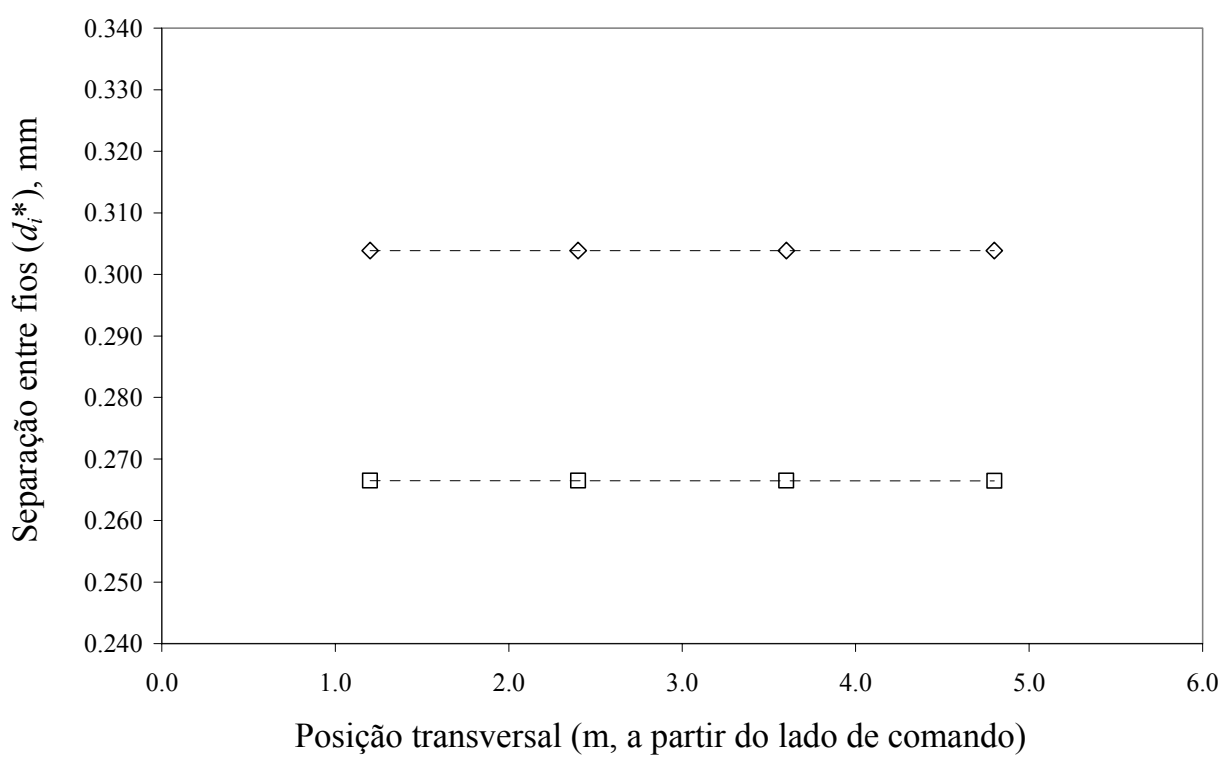

Figura 5.5. Separações entre os fios longitudinais $(\diamond)$ e entre fios transversais ( $\square$ ) da superfície correspondente ao lado de contato com o papel, em 4 pontos uniformemente distribuídos, ao longo da largura da tela formadora.

\subsection{Imagens digitalizadas das amostras de papel}

A Figura 5.6 mostra imagens digitais obtidas das amostras de papel, típicas para os 50 pontos avaliados para a composição do perfil transversal de encolhimento CD. No processo de aquisição das imagens, o digitalizador utilizado foi ajustado de forma a desativar os recursos disponíveis para otimização e realce das imagens, e.g., controle de autocorreção, brilho, sombra, nitidez e função gama (ajustada em valor unitário), a fim de evitar possíveis distorções nas imagens e mascaramento das marcas periódicas de interesse.

\subsection{Processamento das imagens pela transformada rápida de Fourier (2D-FFT)}

A Figura 5.7 representa uma imagem típica usada para a visualização do espectro de freqüências, resultante da aplicação da transformada rápida de Fourier (2D-FFT) nas imagens originais das amostras de papel (e.g., Figura 5.6). 


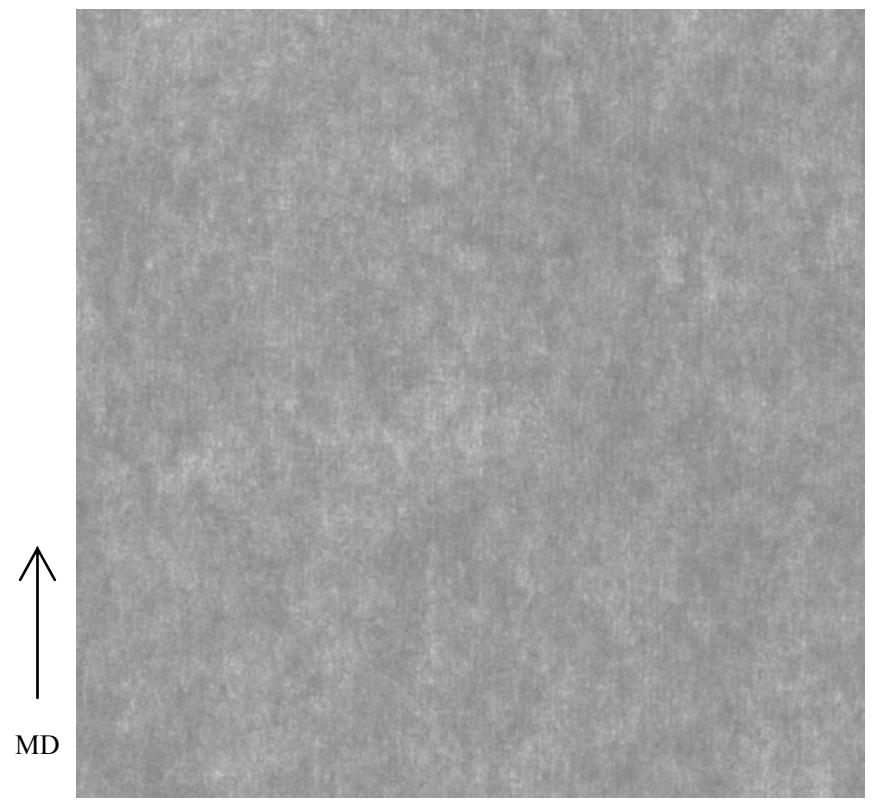

Figura 5.6. Imagem digital de amostra de papel, digitalizada em modo de transmissão de luz, no formato de 512 x 512 pixels (com resolução de 400 ppi) em 256 níveis de cinza. Papel reprográfico de $75 \mathrm{~g} \cdot \mathrm{m}^{-2}$, fabricado com pasta química branqueada de eucalipto.

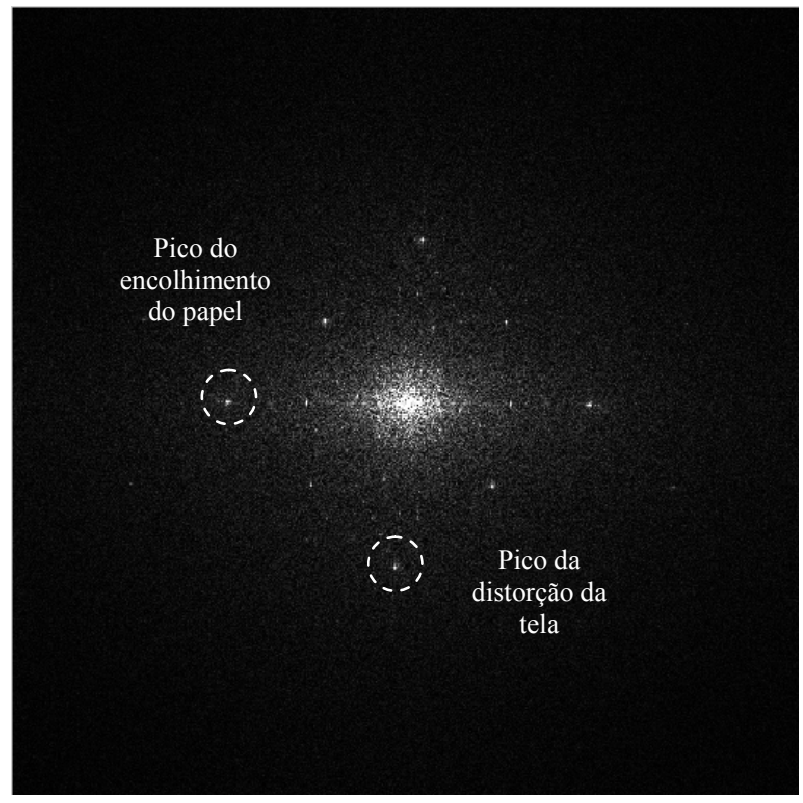

Figura 5.7. Espectro de freqüências da imagem digital da Figura 5.4, mostrando picos de amplitude (pontos mais claros) gerados por variações periódicas no papel e, em destaque, os picos de freqüência selecionados, para determinação de parâmetros de cálculo do encolhimento transversal (CD) do papel. 


\subsection{Perfil do encolhimento transversal (CD) do papel}

Na Tabela 5.3, encontram-se resultados de encolhimentos transversais (CD) medidos em 50 pontos, provenientes de 10 amostras de papel coletadas ao longo de uma bobina "jumbo", $c f$. descrito na subseção 4.1.2 (a). Os pontos de medição indicados na Tabela 5.3 correspondem a posições transversais da folha, numeradas seqüencialmente, iniciando-se no lado de comando (LC) da máquina de papel (correspondendo a 5 pontos de cada amostra).

Na Tabela 5.3, encontram-se também as coordenadas espaciais dos picos de amplitude detectados nos espectros de Fourier das 50 imagens correspondentes aos pontos considerados para a medição do perfil de encolhimento transversal (CD) do papel, por meio do programa de análise de imagem PET1_ ${ }^{157}$, desenvolvido particularmente para esta finalidade.

A partir das coordenadas dos picos próximos ao eixo horizontal do espectro de Fourier foram determinados os ângulos de inclinação das marcas do fios longitudinais (MD) da tela formadora $\left(\alpha_{i}\right)$ e os espaçamentos entre elas $\left(d^{*}\right.$ e $\left.l_{s}\right)$. As coordenadas dos picos próximos ao eixo vertical foram utilizadas para medição do ângulo correspondente a eventuais distorções da tela formadora $\left(\beta_{i}\right)$, em relação à direção transversal $(\mathrm{CD})$ da máquina de papel. Estes parâmetros foram utilizados para o cálculo dos encolhimentos transversais $(\mathrm{CD})$ relativos $\left(S_{r}\right)$ e absolutos $\left(S_{a}\right)$, também listados na Tabela 5.3.

O dimensionamento dos parâmetros mencionados no parágrafo anterior foram feitos de acordo com o algoritmo descrito na subseção 4.2.5, implementado em planilha Microsoft Excel. A mesma planilha foi utilizada para gerar os gráficos de variação, ao longo da direção transversal da máquina de papel, da separação entre as marcas da tela (Figura 5.8), dos ângulos de inclinação e distorção da tela formadora (Figura 5.9), do encolhimento relativo (Figura 5.10) do encolhimento absoluto (Figura 5.11) do papel.

Na Figura 5.8, encontra-se o perfil dos espaçamentos medidos entre as marcas dos fios longitudinais (MD) em cada corpo de prova, ao longo da direção transversal da máquina de papel. Observa-se que a distância entre tais marcas diminui a partir do centro em direção às bordas da folha, evidenciando o efeito do encolhimento transversal (CD) diferencial do papel.

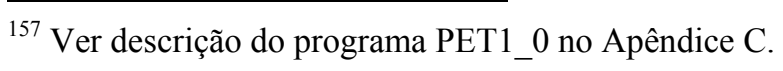


Tabela 5.3. Resultado dos perfis do encolhimento transversal (CD) relativo e absoluto, obtidos por meio de análise de imagens do papel. Velocidade da máquina de papel: $1256 \mathrm{~m} \cdot \mathrm{min}^{-1}$. Largura da folha: $5278 \mathrm{~mm}$ (continua).

\begin{tabular}{|c|c|c|c|c|c|c|c|c|c|c|c|c|}
\hline \multirow{2}{*}{ 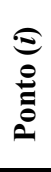 } & \multirow{2}{*}{$\begin{array}{c}\text { Posição } \\
\text { transv. } \\
(\mathrm{CD})^{158} \\
(\mathrm{~m})\end{array}$} & \multirow{2}{*}{$\begin{array}{c}\text { Largura } \\
\text { da } \\
\text { amostra } \\
\text { (m) }\end{array}$} & \multicolumn{4}{|c|}{$\begin{array}{c}\text { Coordenadas } \\
\text { no espectro de Fourier }\end{array}$} & \multicolumn{2}{|c|}{$\begin{array}{c}\text { Ângulos de } \\
\text { inclinação de fios }\end{array}$} & \multicolumn{2}{|c|}{$\begin{array}{c}\text { Separação } \\
\text { das marcas }\end{array}$} & \multicolumn{2}{|c|}{$\begin{array}{c}\text { Encolhimento } \\
\text { transversal (CD) }\end{array}$} \\
\hline & & & $x_{e, i}$ & $y_{e, i}$ & $x_{d, i}$ & $y_{d, i}$ & $\begin{array}{c}\alpha_{i} \\
\left({ }^{\circ}\right) \\
\end{array}$ & $\begin{array}{c}\boldsymbol{\beta}_{i} \\
\left(^{\circ}\right) \\
\end{array}$ & $\begin{array}{c}d_{i}{ }^{*} \\
(\mathrm{~mm}) \\
\end{array}$ & $\begin{array}{c}l_{s, i} \\
(\mathrm{~mm})\end{array}$ & $\begin{array}{l}S_{r, i} \\
(\%) \\
\end{array}$ & $\begin{array}{l}S_{a, i} \\
(\%) \\
\end{array}$ \\
\hline 1 & 0.1639 & 0.5278 & 151 & 263 & 261 & 374 & 3.24 & -1.96 & 0.3062 & 0.3063 & 3.75 & 9.28 \\
\hline 2 & 0.2139 & 0.5278 & 152 & 263 & 261 & 374 & 3.27 & -1.96 & 0.3091 & 0.3092 & 2.83 & 8.42 \\
\hline 3 & 0.2639 & 0.5278 & 152 & 263 & 261 & 374 & 3.27 & -1.96 & 0.3091 & 0.3092 & 2.83 & 8.42 \\
\hline 4 & 0.3139 & 0.5278 & 152 & 263 & 261 & 374 & 3.27 & -1.96 & 0.3091 & 0.3092 & 2.83 & 8.42 \\
\hline 5 & 0.3639 & 0.5278 & 153 & 263 & 261 & 374 & 3.30 & -1.96 & 0.3121 & 0.3122 & 1.90 & 7.54 \\
\hline 6 & 0.6917 & 0.5278 & 153 & 259 & 256 & 373 & 1.10 & 0.49 & 0.3126 & 0.3127 & 1.73 & 7.38 \\
\hline 7 & 0.7417 & 0.5278 & 153 & 259 & 256 & 374 & 1.10 & 0.49 & 0.3126 & 0.3127 & 1.73 & 7.38 \\
\hline 8 & 0.7917 & 0.5278 & 153 & 259 & 256 & 374 & 1.10 & 0.49 & 0.3126 & 0.3127 & 1.73 & 7.38 \\
\hline 9 & 0.8417 & 0.5278 & 153 & 259 & 256 & 374 & 1.10 & 0.49 & 0.3126 & 0.3127 & 1.73 & 7.38 \\
\hline 10 & 0.8917 & 0.5278 & 154 & 259 & 256 & 374 & 1.11 & 0.49 & 0.3156 & 0.3157 & 0.78 & 6.49 \\
\hline 11 & 1.2195 & 0.5278 & 155 & 256 & 252 & 373 & -0.56 & 2.47 & 0.3187 & 0.3189 & -0.21 & 5.55 \\
\hline 12 & 1.2695 & 0.5278 & 155 & 256 & 253 & 373 & -0.56 & 1.97 & 0.3187 & 0.3188 & -0.19 & 5.57 \\
\hline 13 & 1.3195 & 0.5278 & 155 & 256 & 252 & 373 & -0.56 & 2.47 & 0.3187 & 0.3189 & -0.21 & 5.55 \\
\hline 14 & 1.3695 & 0.5278 & 156 & 255 & 252 & 373 & -1.13 & 2.47 & 0.3218 & 0.3219 & -1.16 & 4.65 \\
\hline 15 & 1.4195 & 0.5278 & 156 & 254 & 251 & 373 & -1.70 & 2.96 & 0.3218 & 0.3218 & -1.13 & 4.68 \\
\hline 16 & 1.7473 & 0.5278 & 156 & 257 & 254 & 374 & 0.00 & 1.47 & 0.3219 & 0.3220 & -1.19 & 4.62 \\
\hline 17 & 1.7973 & 0.5278 & 156 & 257 & 254 & 374 & 0.00 & 1.47 & 0.3219 & 0.3220 & -1.19 & 4.62 \\
\hline 18 & 1.8473 & 0.5278 & 157 & 257 & 254 & 373 & 0.00 & 1.48 & 0.3251 & 0.3252 & -2.21 & 3.67 \\
\hline 19 & 1.8973 & 0.5278 & 157 & 257 & 254 & 374 & 0.00 & 1.47 & 0.3251 & 0.3252 & -2.21 & 3.67 \\
\hline 20 & 1.9473 & 0.5278 & 157 & 257 & 254 & 373 & 0.00 & 1.48 & 0.3251 & 0.3252 & -2.21 & 3.67 \\
\hline 21 & 2.2751 & 0.5278 & 156 & 257 & 255 & 373 & 0.00 & 0.99 & 0.3219 & 0.3219 & -1.18 & 4.64 \\
\hline 22 & 2.3251 & 0.5278 & 156 & 256 & 255 & 374 & -0.57 & 0.98 & 0.3219 & 0.3219 & -1.16 & 4.66 \\
\hline 23 & 2.3751 & 0.5278 & 157 & 256 & 255 & 374 & -0.57 & 0.98 & 0.3251 & 0.3251 & -2.17 & 3.70 \\
\hline 24 & 2.4251 & 0.5278 & 157 & 256 & 255 & 374 & -0.57 & 0.98 & 0.3251 & 0.3251 & -2.17 & 3.70 \\
\hline 25 & 2.4751 & 0.5278 & 157 & 256 & 255 & 374 & -0.57 & 0.98 & 0.3251 & 0.3251 & -2.17 & 3.70 \\
\hline 26 & 2.8029 & 0.5278 & 156 & 260 & 261 & 374 & 1.70 & -1.96 & 0.3218 & 0.3217 & -1.12 & 4.70 \\
\hline 27 & 2.8529 & 0.5278 & 157 & 260 & 261 & 374 & 1.72 & -1.96 & 0.3250 & 0.3250 & -2.13 & 3.75 \\
\hline 28 & 2.9029 & 0.5278 & 156 & 260 & 261 & 374 & 1.70 & -1.96 & 0.3218 & 0.3217 & -1.12 & 4.70 \\
\hline 29 & 2.9529 & 0.5278 & 156 & 260 & 261 & 374 & 1.70 & -1.96 & 0.3218 & 0.3217 & -1.12 & 4.70 \\
\hline 30 & 3.0029 & 0.5278 & 156 & 260 & 261 & 374 & 1.70 & -1.96 & 0.3218 & 0.3217 & -1.12 & 4.70 \\
\hline 31 & 3.3307 & 0.5278 & 157 & 262 & 264 & 373 & 2.86 & -3.45 & 0.3247 & 0.3247 & -2.04 & 3.83 \\
\hline 32 & 3.3807 & 0.5278 & 157 & 264 & 267 & 373 & 4.00 & -4.93 & 0.3243 & 0.3243 & -1.91 & 3.95 \\
\hline 33 & 3.4307 & 0.5278 & 156 & 262 & 264 & 374 & 2.83 & -3.42 & 0.3215 & 0.3215 & -1.03 & 4.78 \\
\hline 34 & 3.4807 & 0.5278 & 156 & 262 & 264 & 374 & 2.83 & -3.42 & 0.3215 & 0.3215 & -1.03 & 4.78 \\
\hline 35 & 3.5307 & 0.5278 & 156 & 262 & 265 & 374 & 2.83 & -3.91 & 0.3215 & 0.3215 & -1.04 & 4.77 \\
\hline 36 & 3.8585 & 0.5278 & 156 & 261 & 266 & 374 & 2.27 & -4.40 & 0.3216 & 0.3218 & -1.13 & 4.69 \\
\hline 37 & 3.9085 & 0.5278 & 156 & 261 & 266 & 373 & 2.27 & -4.44 & 0.3216 & 0.3218 & -1.13 & 4.68 \\
\hline 38 & 3.9585 & 0.5278 & 156 & 261 & 266 & 374 & 2.27 & -4.40 & 0.3216 & 0.3218 & -1.13 & 4.69 \\
\hline 39 & 4.0085 & 0.5278 & 155 & 261 & 266 & 373 & 2.25 & -4.44 & 0.3185 & 0.3186 & -0.14 & 5.62 \\
\hline 40 & 4.0585 & 0.5278 & 155 & 262 & 266 & 373 & 2.81 & -4.44 & 0.3184 & 0.3184 & -0.06 & 5.69 \\
\hline
\end{tabular}

$\boldsymbol{x}_{e, i}, \boldsymbol{y}_{e, i}$ : coordenadas de encolhimento do papel (pico de amplitude próximo ao eixo horizontal do espectro de Fourier).

$\boldsymbol{x}_{d, i}, \boldsymbol{y}_{d, i}:$ coordenadas de distorção da tela formadora (pico de amplitude próximo ao eixo vertical do espectro de Fourier) $\alpha_{i}$ : ângulos de inclinação das marcas da tela formadora em relação ao eixo horizontal da máquina de papel (MD), ${ }^{\circ}$

$\boldsymbol{\beta}_{i}$ : ângulos de inclinação das marcas da tela formadora em relação ao eixo transversal da máquina de papel (CD), ${ }^{\circ}$

$\boldsymbol{d}_{i} *$ : distâncias entre marcas da tela formadora, detectadas no papel acabado, mm

$\boldsymbol{l}_{\mathrm{s}, i}$ : distância entre os fios longitudinais (MD) das marcas da tela formadora, detectada no papel, $\mathrm{mm}$

$\boldsymbol{S}_{r, i}$ : encolhimento transversal (CD) relativo do papel.

$\boldsymbol{S}_{a, i}$ : encolhimento transversal (CD) absoluto do papel.

${ }^{158}$ A partir do lado de comando (LC) da máquina de papel. 
Tabela 5.3. Resultado dos perfis do encolhimento transversal (CD) relativo e absoluto, obtidos por meio de análise de imagens do papel. Velocidade da máquina de papel: $1256 \mathrm{~m} \cdot \mathrm{min}^{-1}$. Largura da folha: $5278 \mathrm{~mm}$ (final).

\begin{tabular}{|c|c|c|c|c|c|c|c|c|c|c|c|c|}
\hline \multirow{2}{*}{ 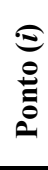 } & \multirow{2}{*}{$\begin{array}{c}\text { Posição } \\
\text { transv. } \\
(C D)^{159} \\
(m)\end{array}$} & \multirow{2}{*}{$\begin{array}{c}\text { Largura } \\
\text { da } \\
\text { amostra } \\
\text { (m) }\end{array}$} & \multicolumn{4}{|c|}{$\begin{array}{c}\text { Coordenadas } \\
\text { no espectro de Fourier }\end{array}$} & \multicolumn{2}{|c|}{$\begin{array}{c}\text { Ângulos de } \\
\text { inclinação de fios }\end{array}$} & \multicolumn{2}{|c|}{$\begin{array}{l}\text { Separação } \\
\text { das marcas }\end{array}$} & \multicolumn{2}{|c|}{$\begin{array}{l}\text { Encolhimento } \\
\text { transversal (CD) }\end{array}$} \\
\hline & & & $x_{e, i}$ & $y_{e, i}$ & $x_{d, i}$ & $y_{d, i}$ & $\begin{array}{c}\alpha_{i} \\
\left(^{\circ}\right)\end{array}$ & $\begin{array}{c}\boldsymbol{\beta}_{i} \\
\left({ }^{\circ}\right)\end{array}$ & $\begin{array}{c}d_{i}^{*} \\
(\mathrm{~mm})\end{array}$ & $\begin{array}{c}l_{s, i} \\
(\mathbf{m m})\end{array}$ & $\begin{array}{l}S_{r, i} \\
(\%)\end{array}$ & $\begin{array}{l}S_{a, i} \\
(\%)\end{array}$ \\
\hline 41 & 4.3863 & 0.5278 & 155 & 256 & 263 & 374 & -0.56 & -2.94 & 0.3187 & 0.3193 & -0.34 & 5.43 \\
\hline 42 & 4.4363 & 0.5278 & 155 & 256 & 263 & 374 & -0.56 & -2.94 & 0.3187 & 0.3193 & -0.34 & 5.43 \\
\hline 43 & 4.4863 & 0.5278 & 154 & 257 & 262 & 373 & 0.00 & -2.47 & 0.3157 & 0.3159 & 0.72 & 6.43 \\
\hline 44 & 4.5363 & 0.5278 & 154 & 256 & 262 & 374 & -0.56 & -2.45 & 0.3156 & 0.3160 & 0.68 & 6.39 \\
\hline 45 & 4.5863 & 0.5278 & 154 & 257 & 262 & 373 & 0.00 & -2.47 & 0.3157 & 0.3159 & 0.72 & 6.43 \\
\hline 46 & 4.9141 & 0.5278 & 153 & 262 & 268 & 374 & 2.75 & -5.37 & 0.3123 & 0.3124 & 1.83 & 7.47 \\
\hline 47 & 4.9641 & 0.5278 & 152 & 262 & 268 & 374 & 2.73 & -5.37 & 0.3093 & 0.3094 & 2.76 & 8.35 \\
\hline 48 & 5.0141 & 0.5278 & 152 & 262 & 268 & 373 & 2.73 & -5.42 & 0.3093 & 0.3094 & 2.76 & 8.35 \\
\hline 49 & 5.0641 & 0.5278 & 151 & 262 & 268 & 374 & 2.70 & -5.37 & 0.3064 & 0.3065 & 3.68 & 9.22 \\
\hline 50 & 5.1141 & 0.5278 & 151 & 262 & 268 & 373 & 2.70 & -5.42 & 0.3064 & 0.3065 & 3.68 & 9.22 \\
\hline
\end{tabular}

$\boldsymbol{x}_{e, i}, \boldsymbol{y}_{e, i}:$ coordenadas de encolhimento do papel (pico de amplitude próximo ao eixo horizontal do espectro de Fourier).

$\boldsymbol{x}_{d, i}, \boldsymbol{y}_{d, i}:$ coordenadas de distorção da tela formadora (pico de amplitude próximo ao eixo vertical do espectro de Fourier)

$\alpha_{i}$ : ângulos de inclinação das marcas da tela formadora em relação ao eixo horizontal da máquina de papel (MD), ${ }^{\circ}$

$\boldsymbol{\beta}_{i}$ : ângulos de inclinação das marcas da tela formadora em relação ao eixo transversal da máquina de papel (CD), ${ }^{\circ}$

$\boldsymbol{d}_{\boldsymbol{i}}{ }^{*}$ : distâncias entre marcas da tela formadora, detectadas no papel acabado, $\mathrm{mm}$

$\boldsymbol{l}_{s, i}$ : distâncias entre os fios longitudinais (MD) das marcas da tela formadora, detectadas no papel, $\mathrm{mm}$

$\boldsymbol{S}_{r, i}$ : encolhimento transversal (CD) relativo do papel.

$\boldsymbol{S}_{a, i}$ : encolhimento transversal (CD) absoluto do papel.

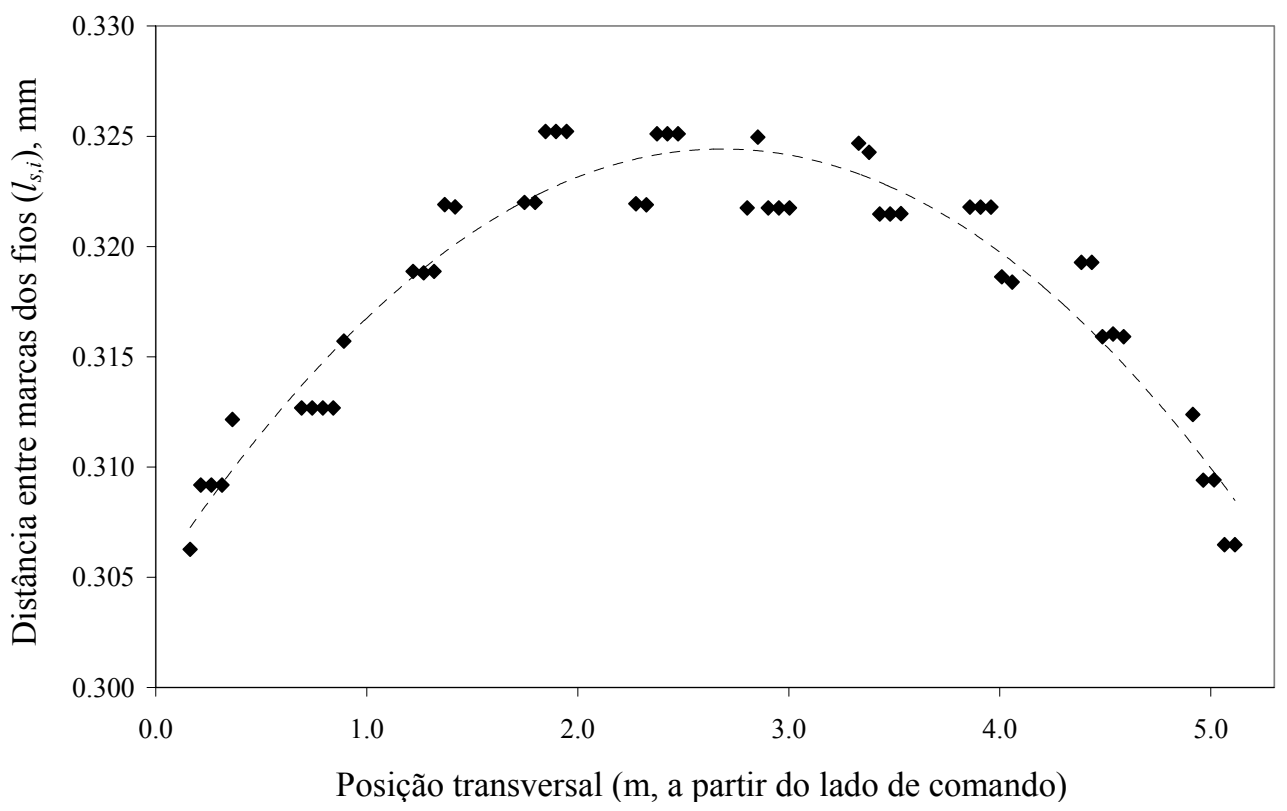

Figura 5.8. Distribuição do espaçamento entre as marcas dos fios longitudinais (MD) da tela formadora ao longo das posições transversais do papel. Velocidade da máquina de papel: $1256 \mathrm{~m} \cdot \mathrm{min}^{-1}$.

${ }^{159}$ A partir do lado de comando (LC) da máquina de papel. 
Os ângulos de alinhamento das marcas de tela formadora em relação à direção longitudinal $(\mathrm{MD})$, representados por $\alpha_{i}$, e os ângulos de distorção da tela em relação à direção transversal $(\mathrm{CD})$ da máquina de papel, representados por $\beta_{i}$, foram medidos e apresentaram variação ao longo da largura da folha $c f$. mostram os perfis transversais da Figura 5.9. Este resultado indica a irregularidade geométrica da tela formadora encontrada entre as posições investigadas. As distorções e desalinhamentos das marcas, i.e., das telas formadoras, ocorrem geralmente em função das diferenças das forças resultantes sobre elas, quando em operação no formador, onde se encontram girando tensionadas sobre rolos guiatela, em altas velocidades.

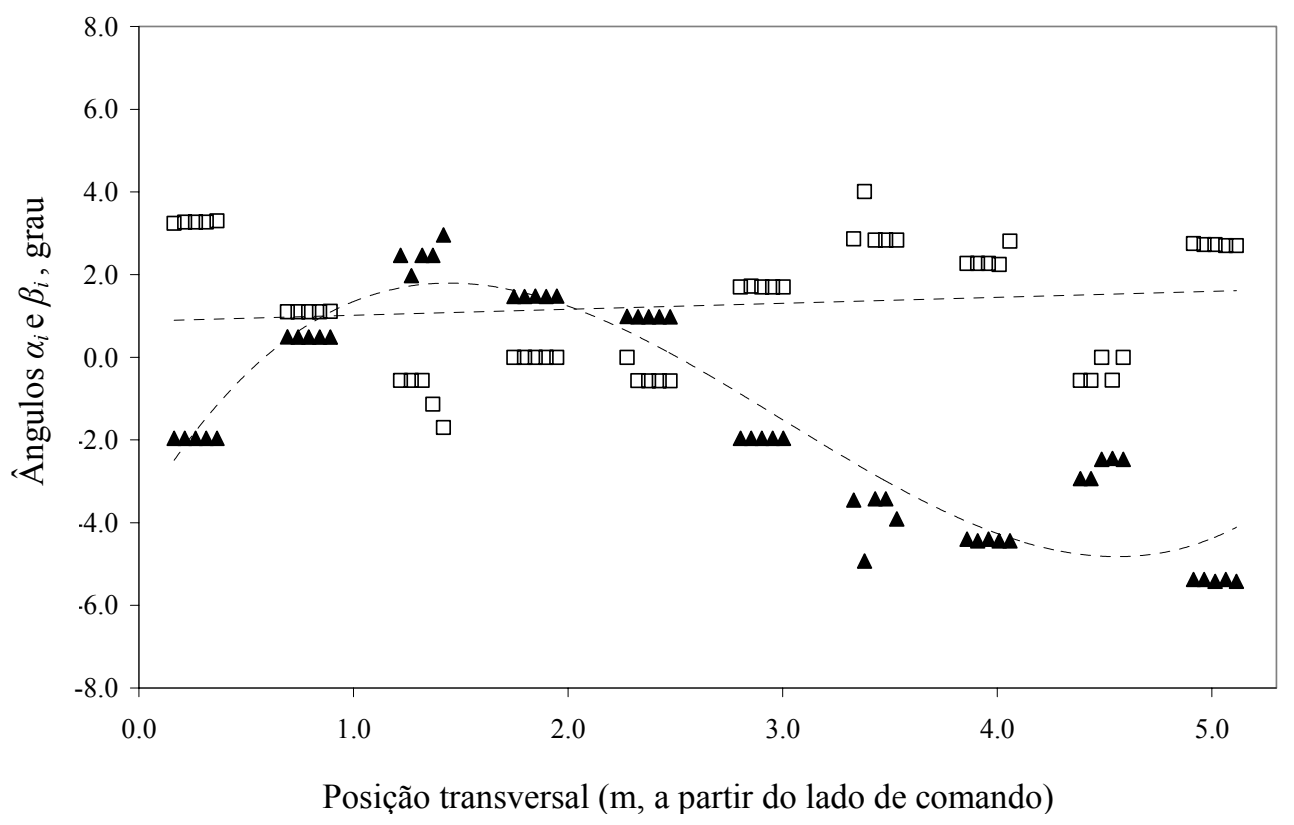

Figura 5.9. Distribuição dos ângulos de inclinação $\left(\alpha_{i}\right)$, representados com quadrados vazios $(\square)$ e de distorção $\left(\beta_{i}\right)$, representados com triângulos cheios $(\boldsymbol{\Delta})$, da tela formadora, ao longo das posições transversais. Velocidade da máquina de papel: $1256 \mathrm{~m} \cdot \mathrm{min}^{-1}$.

O método apresentado neste trabalho prevê uma compensação para impactos de desalinhamentos e distorções da tela formadora sobre a determinação dos espaçamentos entre marcas de fios longitudinais da tela formadora ${ }^{160}$, por meio da medição e consideração dos ângulos $\alpha_{i}$ e $\beta_{i}$, cf. expressão 4.13. Observa-se, entretanto, que os resultados obtidos, para o caso analisado, mostraram pequena influência destas distorções, uma vez que o termo $\cos \left(\alpha_{i}+\beta_{i}\right)$ permaneceu em um intervalo muito estreito, variando aproximadamente entre $-2 \mathrm{a}+2$ graus. 
As curvas mostradas nas Figuras 5.10 e 5.11 representam, respectivamente, os perfis do encolhimento transversal (CD) relativo e absoluto do papel, medidos através da largura da folha, na enroladeira da máquina.

Os resultados mostram uma acentuada contração transversal (CD) do papel, nas bordas da folha, que atinge magnitudes superiores a 9,0\%, equivalendo a aproximadamente $3,5 \%$ (pontos percentuais) acima do encolhimento médio de 5,75\%, calculado por meio da expressão (4.5), a partir de dados obtidos diretamente na máquina. Em outros termos, esses perfis revelam níveis de encolhimento transversal (CD) até 150\% superiores nas bordas da folha, quando comparados aos medidos na região central, onde foram encontrados os valores mínimos, da ordem de 3,7\%.

Esses resultados são consistentes com estudos revistos no Capítulo 2, que explicam a formação de perfis irregulares para o encolhimento transversal (CD) do papel, em função da configuração e das condições de operação da máquina de papel ${ }^{161}$. Os altos níveis de encolhimento transversal (CD) encontrados nas bordas da folha são coerentes com o esperado, pois a máquina de papel considerada neste estudo contém secadores dispostos em duas fileiras ${ }^{162}$, em grupos de secagem onde ocorrem os maiores níveis de contração do papel, i.e, situam-se em regiões onde o teor seco do papel é superior a $60 \%{ }^{163}$. Essa configuração representa certa deficiência com respeito à retenção da folha durante a secagem, pois neste arranjo, o papel encontra-se apenas parcialmente retido, facilitando a contração lateral. Adicionalmente, a relativamente alta orientação de fibras no papel investigado ${ }^{164}$, associada a inerente anisotropia das fibras, responsável pela predominante contração radial da fibra celulósica da ordem de 20 a 25 vezes maior que a axial ${ }^{165}$, colabora para a maximização da força de encolhimento ${ }^{166}$ na direção transversal $(C D)$ do papel. O valor médio elevado do encolhimento transversal (CD) do papel e a curva suave de perfil de variação transversal (como mostra a Figura 5.11), também são característicos de seções de secadores dispostos em duas fileiras, $c f$. mostram vários estudos comparativos sobre arranjos de secadores ${ }^{167}$.

\footnotetext{
${ }^{161}$ As seções 2.4 e 2.5 tratam da formação do perfil de encolhimento do papel e dos fatores que determinam suas características, tais como a configuração e as condições operacionais da máquina de papel.

${ }^{162}$ Ver esquema da máquina de papel na subseção 4.1.1.

${ }^{163}$ Ver detalhes sobre a influência da configuração da seção de secagem na subseção 2.5.1.

${ }^{164}$ Verificar no Apêndice A, nas propriedades do papel investigado, os valores de TSI e TSO, que revelam um alto grau de orientação de fibras.

${ }^{165}$ Ver, na seção 2.2, os aspectos fundamentais do encolhimento individual das fibras do papel.

${ }^{166}$ Definida pela expressão 2.6 (ver seção 2.4).

${ }^{167}$ Alguns estudos comparativos foram revistos na subseção 2.5.1.
} 


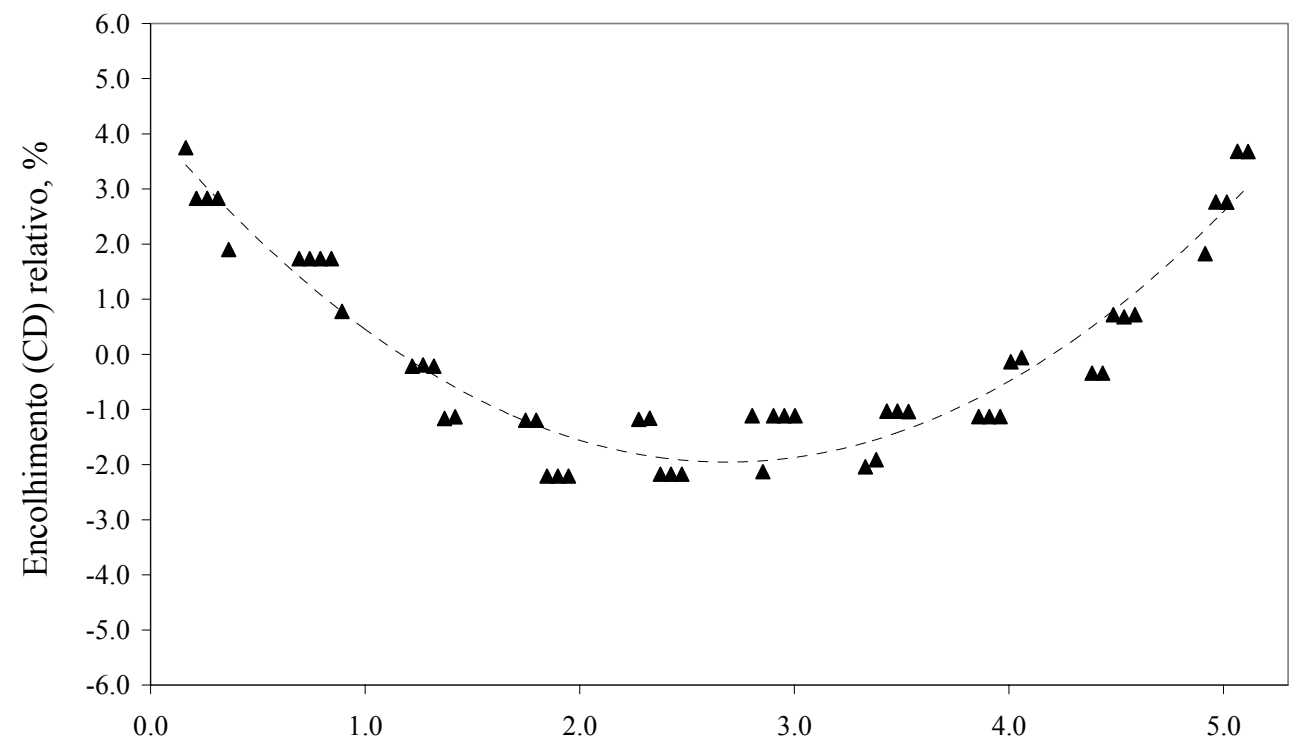

Posição transversal (m, a partir do lado de comando)

Figura 5.10. Perfil transversal do encolhimento CD relativo, obtido a partir de amostras de papel reprográfico de 75 g.m $\mathrm{m}^{-2}$, produzido com pasta química de fibras de eucalipto. Velocidade da máquina de papel: $1256 \mathrm{~m} \cdot \mathrm{min}^{-1}$.

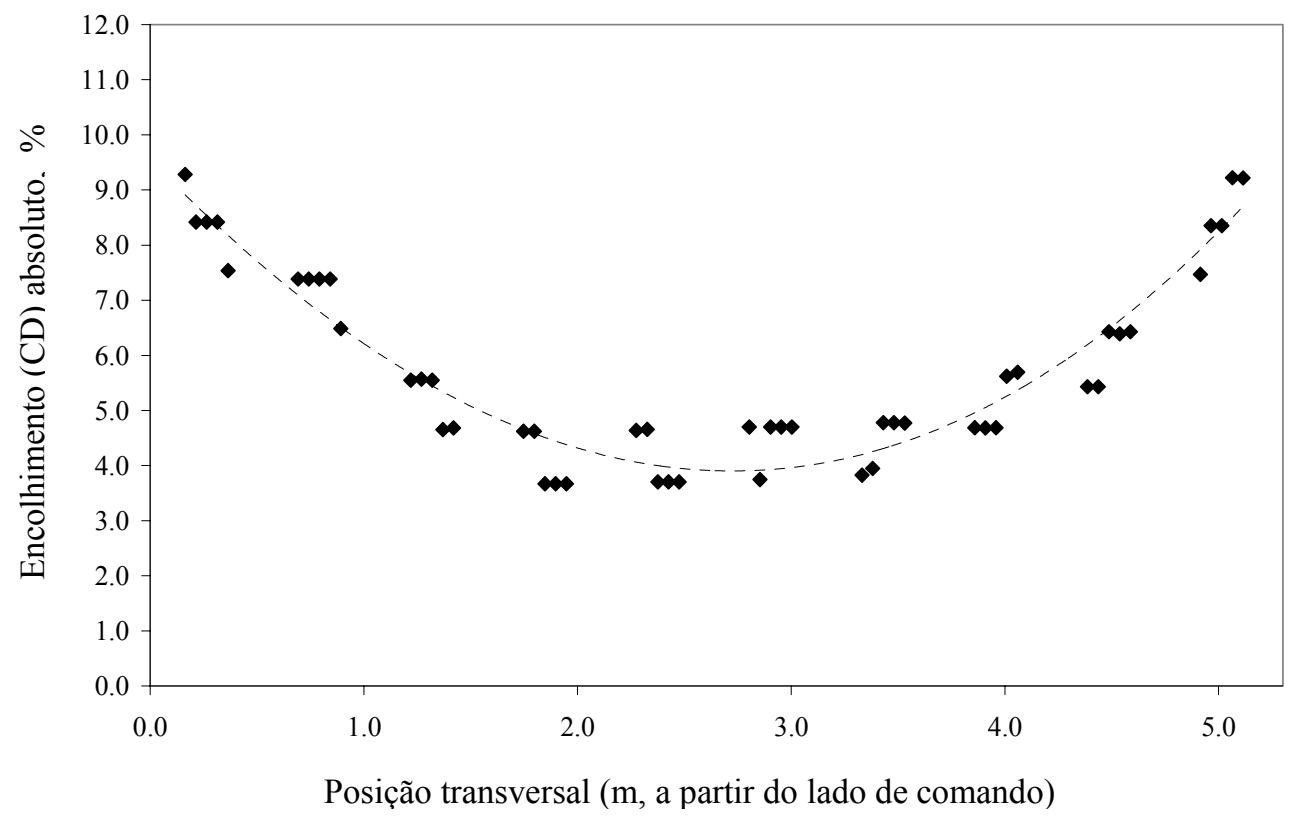

Figura 5.11. Perfil transversal do encolhimento $C D$ absoluto, obtido a partir de amostras de papel reprográfico de $75 \mathrm{~g} . \mathrm{m}^{-2}$, produzido com pasta química de fibras de eucalipto. Velocidade da máquina de papel: $1256 \mathrm{~m} \cdot \mathrm{min}^{-1}$. 


\subsection{Perfil da higroexpansibilidade transversal (CD) do papel}

A Tabela 5.4 e a Figura 5.12 mostram resultados de higroexpansibilidade transversal (CD) do papel, obtidos nas medições realizadas em amostras provenientes de uma bobina "jumbo" mencionada anteriormente, coletadas ao longo da direção transversal da folha $c f$. metodologia apresentada na subseção 4.1.2 (a). A higroexpansibilidade foi medida segundo a metodologia apresentada na seção 4.3, com base na norma ISO 8226-1:1994, que expressa a higroexpansibilidade por meio da higroexpansão percentual do papel ${ }^{168}$. Os resultados obtidos mostram valores de higroexpansibilidade crescentes, do centro em direção às bordas da folha, de forma similar ao perfil de encolhimento transversal (CD).

Tabela 5.4. Resultados das medições de higroexpansibilidade transversal (CD) realizadas nas amostras coletadas ao longo da largura da folha de papel.

\begin{tabular}{|c|c|c|}
\hline$\stackrel{\stackrel{\theta}{0}}{\stackrel{0}{0}}$ & $\begin{array}{l}\text { Posição } \\
\text { transv. } \\
(\mathrm{CD})^{169}\end{array}$ & $\begin{array}{c}\text { Higroexpansibilidade } \\
\text { transversal (CD) } \\
(\%)\end{array}$ \\
\hline 1 & 0.184 & 0.761 \\
\hline 2 & 0.224 & 0.750 \\
\hline 3 & 0.264 & 0.745 \\
\hline 4 & 0.304 & 0.722 \\
\hline 5 & 0.344 & 0.703 \\
\hline 6 & 0.712 & 0.753 \\
\hline 7 & 0.752 & 0.724 \\
\hline 8 & 0.792 & 0.694 \\
\hline 9 & 0.832 & 0.682 \\
\hline 10 & 0.872 & 0.660 \\
\hline 11 & 1.240 & 0.588 \\
\hline 12 & 1.280 & 0.596 \\
\hline 13 & 1.320 & 0.579 \\
\hline 14 & 1.360 & 0.531 \\
\hline 15 & 1.400 & 0.559 \\
\hline 16 & 1.767 & 0.582 \\
\hline 17 & 1.807 & 0.578 \\
\hline 18 & 1.847 & 0.558 \\
\hline 19 & 1.887 & 0.574 \\
\hline 20 & 1.927 & 0.510 \\
\hline 21 & 2.295 & 0.566 \\
\hline 22 & 2.335 & 0.585 \\
\hline 23 & 2.375 & 0.551 \\
\hline 24 & 2.415 & 0.550 \\
\hline 25 & 2.455 & 0.542 \\
\hline
\end{tabular}

\begin{tabular}{ccc}
\hline Posição & $\begin{array}{c}\text { Higroexpansibilidade } \\
\text { transv. } \\
\text { transversal (CD) } \\
\text { (CD) }\end{array}$ & $\begin{array}{c}\mathbf{1 7 0} \\
\text { (C) }\end{array}$ \\
\hline 26 & 2.823 & 0.465 \\
27 & 2.863 & 0.444 \\
28 & 2.903 & 0.463 \\
29 & 2.943 & 0.459 \\
30 & 2.983 & 0.448 \\
31 & 3.351 & 0.486 \\
32 & 3.391 & 0.497 \\
33 & 3.431 & 0.532 \\
34 & 3.471 & 0.527 \\
35 & 3.511 & 0.509 \\
36 & 3.879 & 0.540 \\
37 & 3.919 & 0.500 \\
38 & 3.959 & 0.520 \\
39 & 3.999 & 0.570 \\
40 & 4.039 & 0.590 \\
41 & 4.406 & 0.641 \\
42 & 4.446 & 0.623 \\
43 & 4.486 & 0.709 \\
44 & 4.526 & 0.657 \\
45 & 4.566 & 0.672 \\
46 & 4.934 & 0.681 \\
47 & 4.974 & 0.686 \\
48 & 5.014 & 0.685 \\
49 & 5.054 & 0.730 \\
50 & 5.094 & 0.721 \\
\hline & & \\
\hline
\end{tabular}

\footnotetext{
${ }^{168}$ Ver seção 4.3.

${ }^{169}$ A partir do lado de comando (LC) da máquina de papel.

${ }^{170}$ Idem à nota anterior.
} 


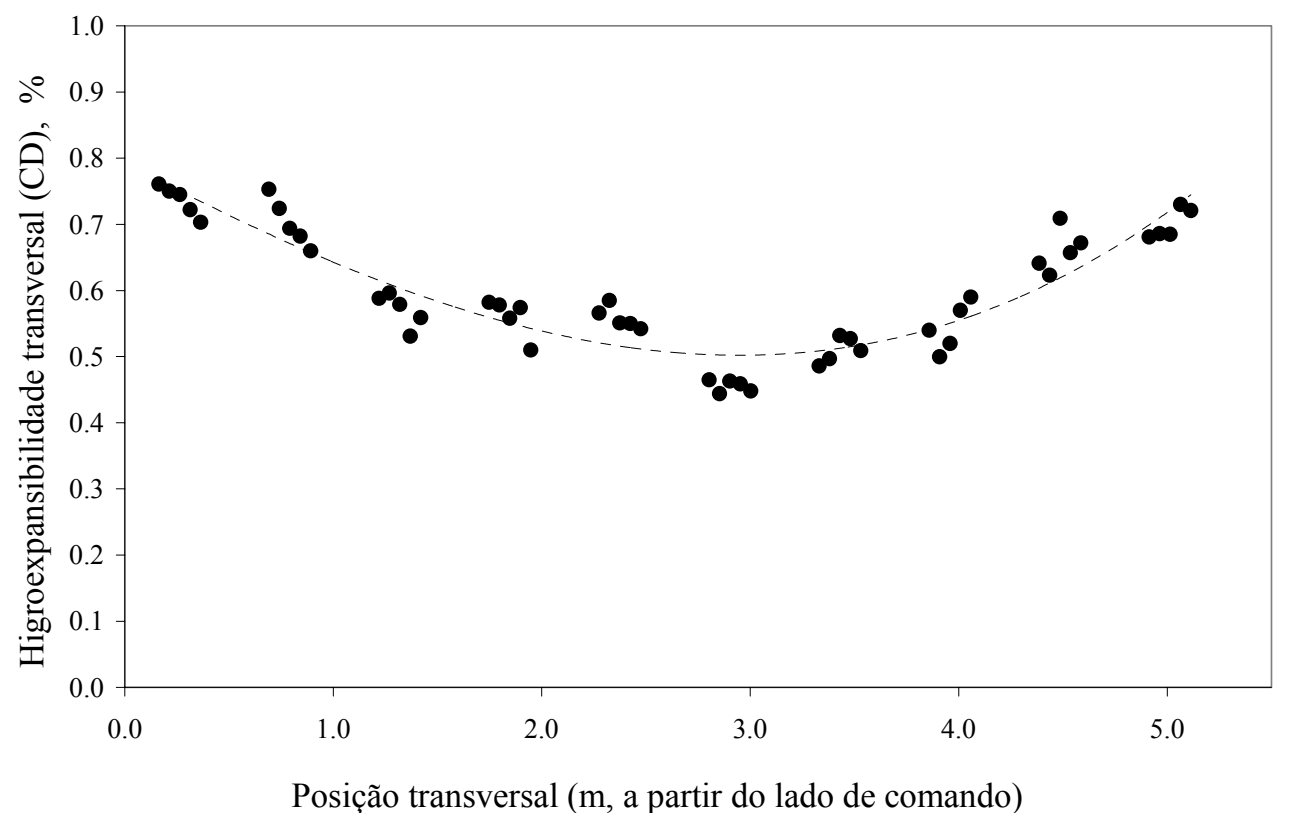

Figura 5.12. Perfil transversal da higroexpansibilidade $C D$, obtido a partir de amostras de papel reprográfico de $75 \mathrm{~g} . \mathrm{m}^{-2}$, produzido com pasta química de fibras de eucalipto. Velocidade da máquina de papel: $1256 \mathrm{~m} \cdot \mathrm{min}^{-1}$.

Nas bordas, a higroexpansibilidade transversal (CD) do papel atingiu valores em torno de $0.7 \%$, representando níveis aproximadamente $60 \%$ superiores aos mínimos, encontrados na região central da folha, que se situaram ao redor de $0.4 \%$.

O perfil de higroexpansibilidade transversal (CD) apresentado na Figura 5.12 indica a influência do encolhimento transversal (CD) irregular mostrado na Figuras 5.11. Ambos apresentam a mesma tendência, i.e., contém valores menores na região central da folha (onde o papel encontra-se mais retido durante a secagem) e valores crescentes em direção às bordas da folha (onde o papel encontra-se mais livre para se contrair). Os valores máximos da higroexpansibilidade encontram-se nas bordas da folha de papel, correspondendo às regiões de maior encolhimento transversal $(C D)^{171}$.

\subsection{Correlação entre encolhimento e higroexpansibilidade transversais (CD)}

A Figura 5.13 mostra graficamente a correlação entre o encolhimento (Figura 5.10) e a higroexpansibilidade (Figura 5.12) transversais (CD) do papel. Os resultados mostram uma

\footnotetext{
${ }^{171}$ Mais detalhes sobre os perfis de higroexpansibilidade na direção de fabricação (MD) e na direção transversal (CD) da máquina em questão, podem ser encontrados em estudo específico realizado por Mendes [2006].
} 
relação essencialmente linear entre os parâmetros. O coeficiente de determinação resultante da regressão linear $\left(\mathrm{R}^{2}=0,7795\right)$ aponta para uma correlação forte entre as duas propriedades. A equação de regressão encontrada $(y=0,0477 x+0,3257)$ sugere um valor não nulo de higroexpansibilidade mesmo para a situação de secagem com retenção total da folha de papel, i.e., com encolhimento transversal (CD) nulo. Os pontos situados no extremo direito do gráfico (Figura 5.13) correspondem às bordas do papel enquanto aqueles situados na extremidade esquerda correspondem às porções centrais da folha.

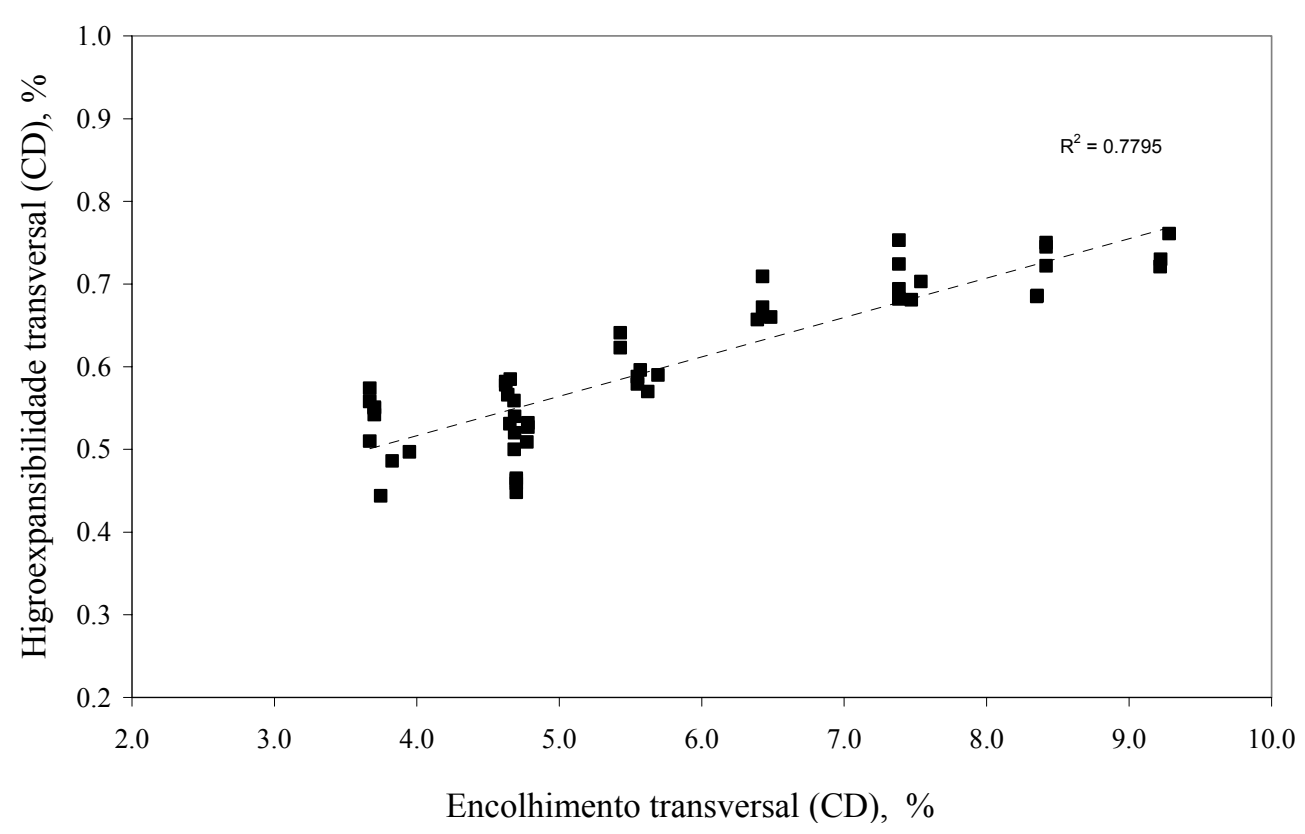

Figura 5.13. Correlação entre higroexpansibilidade e encolhimento transversal (CD), medida em amostras de papel reprográfico de 75 g.m. $\mathrm{m}^{-2}$ produzido com pasta química de fibras de eucalipto. Velocidade da máquina de papel: $1256 \mathrm{~m} \cdot \mathrm{min}^{-1}$.

\subsection{Medição do encolhimento transversal (CD) do papel na largura total da máquina}

Uma medição adicional do perfil do encolhimento transversal (CD) do papel, similar à apresentada na seção 5.4, foi realizada, porém, nesta versão, com máquina de papel em outra condição de operação, utilizando amostras obtidas $c f$. método descrito na subseção 4.1.2 (b). Para tal, foram consideradas 53 amostras coletas de posições uniformemente distribuídas através da bobina "jumbo", com largura de $100 \mathrm{~mm}$, o que possibilitou a obtenção de um perfil transversal com boa resolução, cobrindo a largura total da folha de papel. Os resultados das medições estão reunidos na Tabela 5.5. 
Tabela 5.5. Resultado dos perfis do encolhimento transversal (CD) relativo e absoluto, obtidos por meio de análise de imagens do papel. Velocidade da máquina de papel: $1362 \mathrm{~m} \cdot \mathrm{min}^{-1}$. Largura da folha: $5300 \mathrm{~mm}$ (continua).

\begin{tabular}{|c|c|c|c|c|c|c|c|c|c|c|c|c|}
\hline \multirow{2}{*}{ 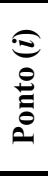 } & \multirow{2}{*}{$\begin{array}{c}\text { Posição } \\
\text { transv. } \\
(C D)^{172} \\
\text { (m) }\end{array}$} & \multirow{2}{*}{$\begin{array}{c}\text { Largura } \\
\text { da } \\
\text { amostra } \\
\text { (m) }\end{array}$} & \multicolumn{4}{|c|}{$\begin{array}{c}\text { Coordenadas } \\
\text { do espectro de Fourier }\end{array}$} & \multicolumn{2}{|c|}{$\begin{array}{c}\text { Ângulos de } \\
\text { inclinação de fios }\end{array}$} & \multicolumn{2}{|c|}{$\begin{array}{l}\text { Separação } \\
\text { das marcas }\end{array}$} & \multicolumn{2}{|c|}{$\begin{array}{r}\text { Encolhimento } \\
\text { transversal (CD }\end{array}$} \\
\hline & & & $x_{e}$ & $y_{e}$ & $x_{d}$ & $y_{d}$ & $\begin{array}{c}\alpha_{i} \\
\left(^{\circ}\right)\end{array}$ & $\begin{array}{c}\boldsymbol{\beta}_{i} \\
\left({ }^{\circ}\right)\end{array}$ & $\begin{array}{c}d_{i}^{*} \\
(\mathrm{~mm})\end{array}$ & $\begin{array}{c}l_{s, i} \\
(\mathbf{m m})\end{array}$ & $\begin{array}{c}S_{r, i} \\
(\%)\end{array}$ & $\begin{array}{l}S_{a, i} \\
(\%)\end{array}$ \\
\hline 1 & 0.050 & 0.100 & 140 & 256 & 248 & 363 & -0.49 & 4.85 & 0.278 & 0.279 & 4.12 & 8.99 \\
\hline 2 & 0.150 & 0.100 & 140 & 260 & 250 & 363 & 1.47 & 3.78 & 0.278 & 0.279 & 4.00 & 8.88 \\
\hline 3 & 0.250 & 0.100 & 141 & 259 & 250 & 364 & 0.99 & 3.74 & 0.280 & 0.281 & 3.23 & 8.15 \\
\hline 4 & 0.350 & 0.100 & 142 & 258 & 249 & 363 & 0.50 & 4.32 & 0.283 & 0.284 & 2.37 & 7.33 \\
\hline 5 & 0.450 & 0.100 & 142 & 258 & 248 & 363 & 0.50 & 4.85 & 0.283 & 0.284 & 2.30 & 7.26 \\
\hline 6 & 0.550 & 0.100 & 143 & 258 & 248 & 363 & 0.50 & 4.85 & 0.285 & 0.286 & 1.44 & 6.44 \\
\hline 7 & 0.650 & 0.100 & 143 & 258 & 247 & 363 & 0.50 & 5.39 & 0.285 & 0.287 & 1.36 & 6.37 \\
\hline 8 & 0.750 & 0.100 & 144 & 257 & 246 & 363 & 0.00 & 5.92 & 0.288 & 0.289 & 0.48 & 5.53 \\
\hline 9 & 0.850 & 0.100 & 144 & 259 & 247 & 363 & 1.01 & 5.39 & 0.288 & 0.289 & 0.39 & 5.45 \\
\hline 10 & 0.950 & 0.100 & 144 & 258 & 246 & 363 & 0.51 & 5.92 & 0.288 & 0.289 & 0.38 & 5.44 \\
\hline 11 & 1.050 & 0.100 & 144 & 255 & 244 & 363 & -1.01 & 6.99 & 0.288 & 0.289 & 0.50 & 5.56 \\
\hline 12 & 1.150 & 0.100 & 144 & 260 & 249 & 363 & 1.52 & 4.32 & 0.288 & 0.289 & 0.50 & 5.56 \\
\hline 13 & 1.250 & 0.100 & 144 & 258 & 247 & 363 & 0.51 & 5.39 & 0.288 & 0.289 & 0.48 & 5.53 \\
\hline 14 & 1.350 & 0.100 & 145 & 259 & 249 & 363 & 1.02 & 4.32 & 0.290 & 0.291 & -0.33 & 4.77 \\
\hline 15 & 1.450 & 0.100 & 145 & 257 & 247 & 363 & 0.00 & 5.39 & 0.290 & 0.291 & -0.34 & 4.76 \\
\hline 16 & 1.550 & 0.100 & 145 & 256 & 247 & 363 & -0.51 & 5.39 & 0.290 & 0.291 & -0.25 & 4.84 \\
\hline 17 & 1.650 & 0.100 & 145 & 257 & 249 & 363 & 0.00 & 4.32 & 0.290 & 0.291 & -0.19 & 4.90 \\
\hline 18 & 1.750 & 0.100 & 146 & 255 & 246 & 363 & -1.03 & 5.92 & 0.293 & 0.294 & -1.14 & 3.99 \\
\hline 19 & 1.850 & 0.100 & 146 & 259 & 250 & 363 & 1.03 & 3.78 & 0.293 & 0.294 & -1.16 & 3.98 \\
\hline 20 & 1.950 & 0.100 & 146 & 258 & 250 & 363 & 0.52 & 3.78 & 0.293 & 0.294 & -1.10 & 4.04 \\
\hline 21 & 2.050 & 0.100 & 146 & 256 & 249 & 363 & -0.52 & 4.32 & 0.293 & 0.293 & -1.03 & 4.10 \\
\hline 22 & 2.150 & 0.100 & 146 & 259 & 252 & 363 & 1.03 & 2.70 & 0.293 & 0.293 & -1.02 & 4.11 \\
\hline 23 & 2.250 & 0.100 & 146 & 256 & 249 & 363 & -0.52 & 4.32 & 0.293 & 0.293 & -1.03 & 4.10 \\
\hline 24 & 2.350 & 0.100 & 147 & 258 & 251 & 363 & 0.52 & 3.24 & 0.296 & 0.296 & -1.96 & 3.22 \\
\hline 25 & 2.450 & 0.100 & 147 & 259 & 253 & 363 & 1.04 & 2.16 & 0.296 & 0.296 & -1.89 & 3.29 \\
\hline 26 & 2.550 & 0.100 & 147 & 257 & 252 & 363 & 0.00 & 2.70 & 0.296 & 0.296 & -1.86 & 3.32 \\
\hline 27 & 2.650 & 0.100 & 147 & 257 & 252 & 363 & 0.00 & 2.70 & 0.296 & 0.296 & -1.86 & 3.32 \\
\hline 28 & 2.750 & 0.100 & 147 & 256 & 252 & 363 & -0.52 & 2.70 & 0.296 & 0.296 & -1.81 & 3.36 \\
\hline 29 & 2.850 & 0.100 & 147 & 256 & 253 & 363 & -0.52 & 2.16 & 0.296 & 0.296 & -1.78 & 3.39 \\
\hline 30 & 2.950 & 0.100 & 147 & 256 & 253 & 363 & -0.52 & 2.16 & 0.296 & 0.296 & -1.78 & 3.39 \\
\hline 31 & 3.050 & 0.100 & 147 & 257 & 255 & 363 & 0.00 & 1.08 & 0.296 & 0.296 & -1.77 & 3.40 \\
\hline 32 & 3.150 & 0.100 & 147 & 257 & 255 & 363 & 0.00 & 1.08 & 0.296 & 0.296 & -1.77 & 3.40 \\
\hline 33 & 3.250 & 0.100 & 147 & 257 & 255 & 363 & 0.00 & 1.08 & 0.296 & 0.296 & -1.77 & 3.40 \\
\hline 34 & 3.350 & 0.100 & 147 & 257 & 257 & 363 & 0.00 & 0.00 & 0.296 & 0.296 & -1.75 & 3.42 \\
\hline 35 & 3.450 & 0.100 & 147 & 258 & 258 & 363 & 0.52 & -0.54 & 0.296 & 0.296 & -1.75 & 3.42 \\
\hline 36 & 3.550 & 0.100 & 147 & 258 & 259 & 363 & 0.52 & -1.08 & 0.296 & 0.296 & -1.75 & 3.42 \\
\hline 37 & 3.650 & 0.100 & 147 & 257 & 258 & 363 & 0.00 & -0.54 & 0.296 & 0.296 & -1.75 & 3.41 \\
\hline 38 & 3.750 & 0.100 & 147 & 256 & 258 & 363 & -0.52 & -0.54 & 0.296 & 0.296 & -1.76 & 3.41 \\
\hline 39 & 3.850 & 0.100 & 146 & 257 & 259 & 363 & 0.00 & -1.08 & 0.293 & 0.293 & -0.85 & 4.27 \\
\hline 40 & 3.950 & 0.100 & 146 & 257 & 260 & 363 & 0.00 & -1.62 & 0.293 & 0.293 & -0.87 & 4.25 \\
\hline
\end{tabular}

$\boldsymbol{x}_{\boldsymbol{e}, i}, \boldsymbol{y}_{e, i}:$ coordenadas de encolhimento do papel (pico de amplitude próximo ao eixo horizontal do espectro de Fourier)

$\boldsymbol{x}_{d, i}, \boldsymbol{y}_{d, i}:$ coordenadas de distorção da tela formadora (pico de amplitude próximo ao eixo vertical do espectro de Fourier)

$\alpha_{i}$ : ângulos de inclinação das marcas da tela formadora em relação ao eixo horizontal da máquina de papel (MD), ${ }^{\circ}$

$\boldsymbol{\beta}_{i}$ : ângulos de inclinação das marcas da tela formadora em relação ao eixo transversal da máquina de papel (CD), ${ }^{\circ}$

$\boldsymbol{d}_{\boldsymbol{i}}$ *: distâncias entre marcas da tela formadora, detectadas no papel acabado, $\mathrm{mm}$

$\boldsymbol{l}_{\mathrm{s}, i}$ : distâncias entre os fios longitudinais (MD) das marcas da tela formadora, detectadas no papel, mm

$\boldsymbol{S}_{r, i}$ : encolhimento transversal (CD) relativo do papel

$\boldsymbol{S}_{a, i}$ : encolhimento transversal (CD) absoluto do papel

${ }^{172}$ A partir do lado de comando (LC) da máquina. 
Tabela 5.5. Resultado dos perfis do encolhimento transversal (CD) relativo e absoluto, obtidos por meio de análise de imagens do papel. Velocidade da máquina de papel: $1362 \mathrm{~m} \cdot \mathrm{min}^{-1}$. Largura da folha: $5300 \mathrm{~mm}$ (final).

\begin{tabular}{|c|c|c|c|c|c|c|c|c|c|c|c|c|}
\hline \multirow{2}{*}{$\stackrel{\varrho}{\stackrel{\Xi}{\Xi}}$} & \multirow{2}{*}{$\begin{array}{c}\text { Posição } \\
\text { (CD) }^{173} \\
\text { (m) }\end{array}$} & \multirow{2}{*}{$\begin{array}{c}\text { Largura } \\
\text { da } \\
\text { amostra } \\
\text { (m) }\end{array}$} & \multicolumn{4}{|c|}{$\begin{array}{c}\text { Coordenadas } \\
\text { do espectro de Fourier }\end{array}$} & \multicolumn{2}{|c|}{$\begin{array}{c}\text { Ângulos de } \\
\text { inclinação de fios }\end{array}$} & \multicolumn{2}{|c|}{$\begin{array}{l}\text { Separação } \\
\text { das marcas }\end{array}$} & \multicolumn{2}{|c|}{$\begin{array}{c}\text { Encolhimento } \\
\text { transversal (CD) }\end{array}$} \\
\hline & & & $x_{e}$ & $y_{e}$ & $x_{d}$ & $y_{d}$ & $\begin{array}{c}\alpha_{i} \\
\left({ }^{\circ}\right) \\
\end{array}$ & $\begin{array}{c}\beta_{i} \\
\left({ }^{\circ}\right) \\
\end{array}$ & $\begin{array}{c}d^{*} \\
(\mathrm{~mm}) \\
\end{array}$ & $\begin{array}{c}l_{s} \\
(\mathrm{~mm})\end{array}$ & $\begin{array}{c}S r \\
(\%) \\
\end{array}$ & $\begin{array}{c}S_{a} \\
(\%) \\
\end{array}$ \\
\hline 41 & 4.050 & 0.100 & 146 & 257 & 260 & 363 & 0.00 & -1.62 & 0.293 & 0.293 & -0.87 & 4.25 \\
\hline 42 & 4.150 & 0.100 & 146 & 256 & 260 & 363 & -0.52 & -1.62 & 0.293 & 0.293 & -0.90 & 4.23 \\
\hline 43 & 4.250 & 0.100 & 146 & 256 & 259 & 363 & -0.52 & -1.08 & 0.293 & 0.293 & -0.87 & 4.26 \\
\hline 44 & 4.350 & 0.100 & 145 & 256 & 259 & 363 & -0.51 & -1.08 & 0.290 & 0.290 & 0.03 & 5.11 \\
\hline 45 & 4.450 & 0.100 & 145 & 257 & 260 & 363 & 0.00 & -1.62 & 0.290 & 0.290 & 0.03 & 5.11 \\
\hline 46 & 4.550 & 0.100 & 145 & 258 & 262 & 363 & 0.51 & -2.70 & 0.290 & 0.290 & 0.01 & 5.09 \\
\hline 47 & 4.650 & 0.100 & 144 & 257 & 261 & 363 & 0.00 & -2.16 & 0.288 & 0.288 & 0.89 & 5.92 \\
\hline 48 & 4.750 & 0.100 & 144 & 255 & 260 & 363 & -1.01 & -1.62 & 0.288 & 0.288 & 0.87 & 5.90 \\
\hline 49 & 4.850 & 0.100 & 143 & 257 & 261 & 363 & 0.00 & -2.16 & 0.285 & 0.285 & 1.76 & 6.75 \\
\hline 50 & 4.950 & 0.100 & 142 & 256 & 261 & 363 & -0.50 & -2.16 & 0.283 & 0.283 & 2.58 & 7.53 \\
\hline 51 & 5.050 & 0.100 & 141 & 257 & 261 & 363 & 0.00 & -2.16 & 0.280 & 0.280 & 3.46 & 8.36 \\
\hline 52 & 5.150 & 0.100 & 141 & 255 & 259 & 363 & -0.99 & -1.08 & 0.280 & 0.280 & 3.47 & 8.37 \\
\hline 53 & 5.250 & 0.100 & 140 & 256 & 260 & 363 & -0.49 & -1.62 & 0.278 & 0.278 & 4.28 & 9.15 \\
\hline
\end{tabular}

$\boldsymbol{x}_{e, i}, \boldsymbol{y}_{e, i}:$ coordenadas de encolhimento do papel (pico de amplitude próximo ao eixo horizontal do espectro de Fourier) $\boldsymbol{x}_{d, i}, \boldsymbol{y}_{d, i}:$ coordenadas de distorção da tela formadora (pico de amplitude próximo ao eixo vertical do espectro de Fourier) $\alpha_{i}$ : ângulos de inclinação das marcas da tela formadora em relação ao eixo horizontal da máquina de papel (MD), ${ }^{\circ}$ $\boldsymbol{\beta}_{i}$ : ângulos de inclinação das marcas da tela formadora em relação ao eixo transversal da máquina de papel (CD), ${ }^{\circ}$ $\boldsymbol{d}_{i}{ }^{*}$ : distâncias entre marcas da tela formadora, detectadas no papel acabado, mm

$\boldsymbol{l}_{s, i}$ : distâncias entre os fios longitudinais (MD) das marcas da tela formadora, detectadas no papel, $\mathrm{mm}$

$\boldsymbol{S}_{r, i}$ : encolhimento transversal (CD) relativo do papel

$\boldsymbol{S}_{a, i}$ : encolhimento transversal (CD) absoluto do papel

Os resultados apresentados graficamente, a seguir, referentes à amostragem na largura total do papel são similares aos anteriormente apresentados na seção 5.4. A diferença maior se refere à obtenção de um perfil de encolhimento transversal (CD) com maior resolução, que oferece mais informação para fins de análise do perfil de estabilidade dimensional transversal (CD).

A variação do espaçamento entre as marcas dos fios longitudinais (MD) da tela formadora (Figura 5.14) e a distribuição dos ângulos de encolhimento e de deformação (Figura 5.15) apresentam as mesmas tendências encontradas nas medições anteriores (Figuras 5.8 e 5.9, respectivamente), confirmando no último gráfico, a hipótese de pequena torção da tela formadora em operação, evidenciada pelo perfil desenhado pelos valores dos ângulos $\beta_{i}$, na direção transversal $(C D)$ da máquina, mostrando uma linha com formato de " $S$ " (ver na Figura 5.15, os pontos indicados com o símbolo $\boldsymbol{\Delta}$ ).

\footnotetext{
${ }^{173}$ A partir do lado de comando (LC) da máquina.
} 


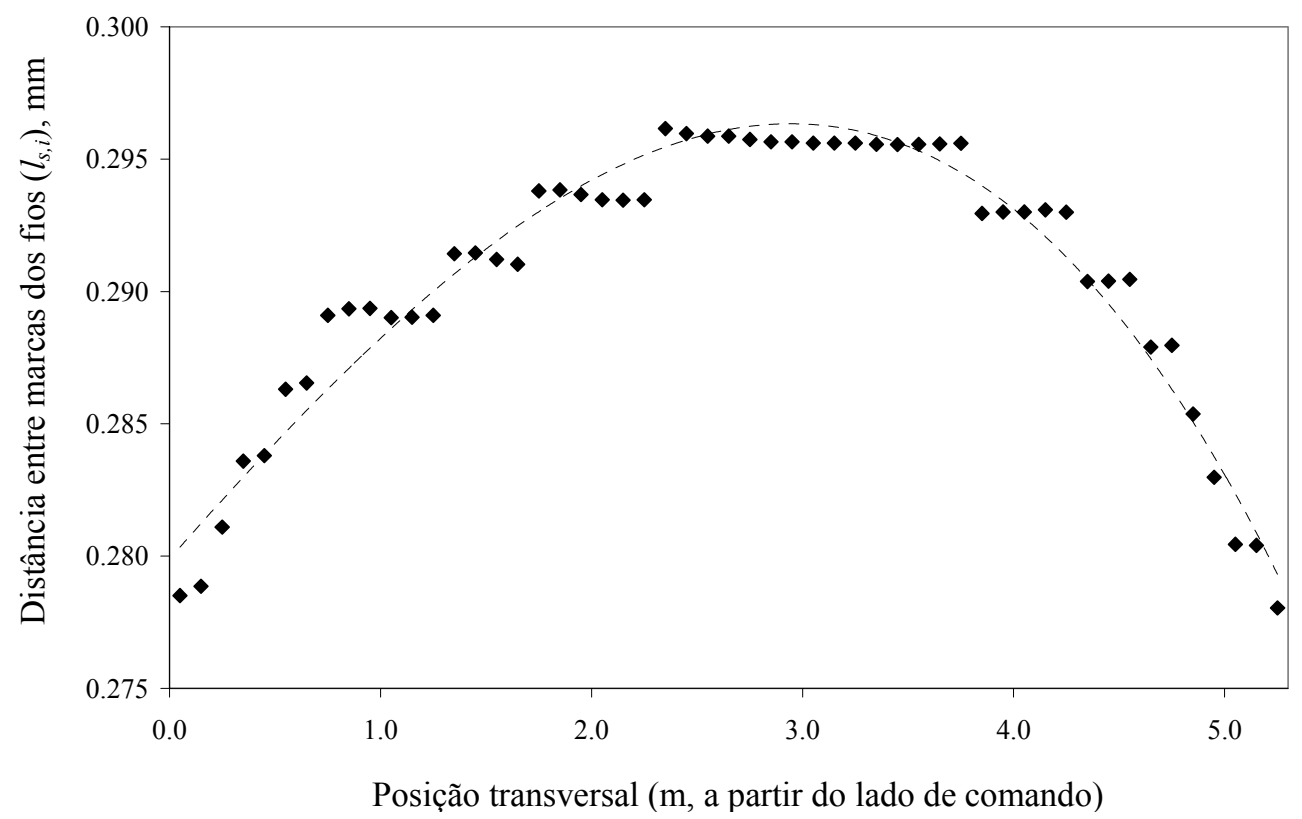

Figura 5.14. Distribuição do espaçamento entre as marcas dos fios longitudinais (MD) da tela formadora ao longo das posições transversais do papel. Velocidade da máquina de papel: $1362 \mathrm{~m} \cdot \mathrm{min}^{-1}$.

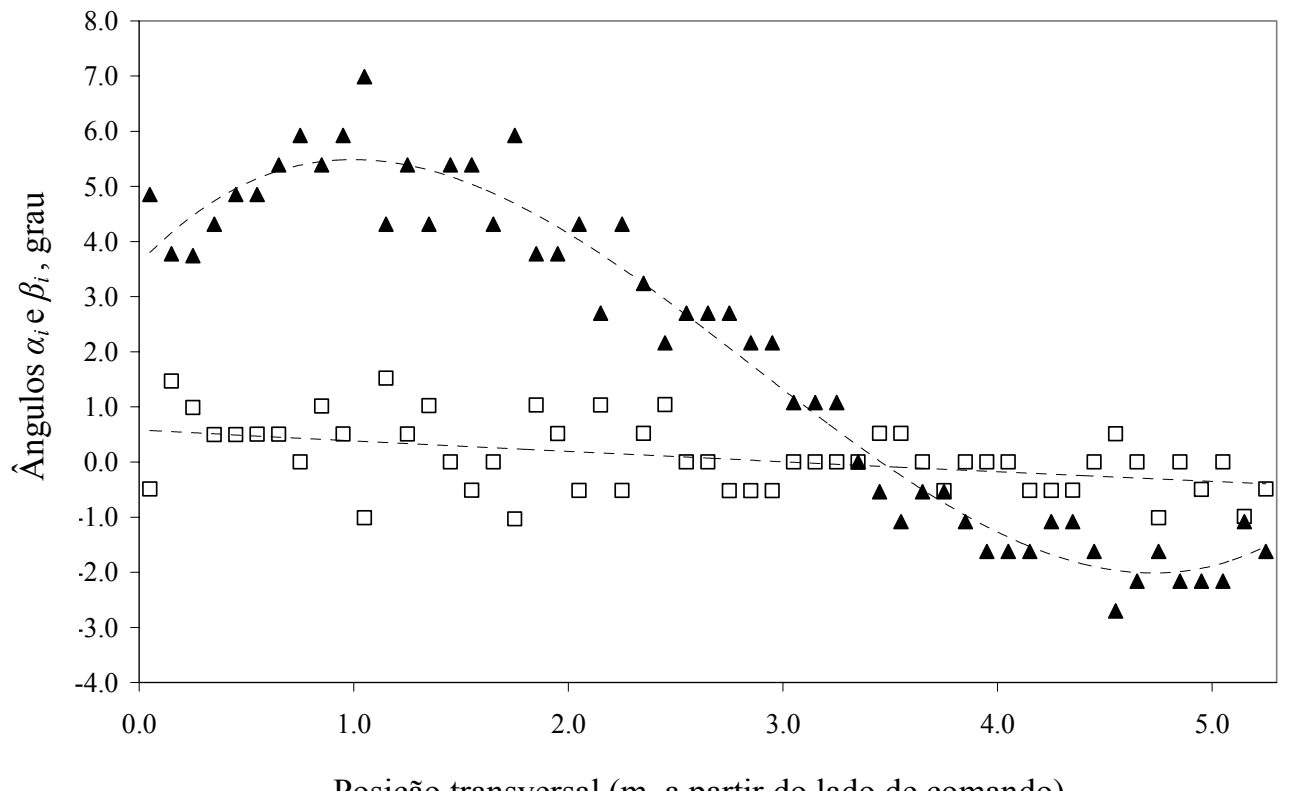

Figura 5.15. Distribuição dos ângulos de inclinação $\left(\alpha_{i}\right)$, representados com quadrados vazios $(\square)$ e de distorção $\left(\beta_{i}\right)$, representados com triângulos cheios $(\boldsymbol{\Delta})$, da tela formadora, ao longo das posições transversais. Velocidade da máquina de papel: $1362 \mathrm{~m} \cdot \mathrm{min}^{-1}$. 
As curvas mostradas nas Figuras 5.16 e 5.17 representam, respectivamente, os perfis do encolhimento transversal (CD) relativo e absoluto do papel, medidos a cada $100 \mathrm{~mm}$, através da largura total da folha, na enroladeira da máquina.

Os resultados mostram uma acentuada contração transversal (CD) do papel, nas bordas da folha, que atinge magnitudes superiores a 9,0\%, equivalendo a aproximadamente $4,0 \%$ (pontos percentuais) acima do encolhimento médio de 5,08\%, calculado por meio da expressão (4.5), a partir de dados obtidos diretamente na máquina. Em outros termos, esses perfis revelam níveis de encolhimento transversal (CD) até 180\% superiores nas bordas da folha, quando comparados aos medidos na região central, onde foram encontrados os valores mínimos, da ordem de 3,2\%.

Como no caso anterior, os resultados são também consistentes com a literatura revista, que explica a formação de perfis irregulares para o encolhimento transversal (CD) do papel, em função da configuração e das condições de operação da máquina de pape ${ }^{174}$. Os altos níveis de encolhimento transversal (CD) encontrados nas bordas da folha são coerentes com o esperado, pois o papel analisado foi produzido na mesma máquina de papel usada para as medições anteriores de encolhimento e higroexpansibilidade transversais (CD).

No caso específico da presente medição, observa-se claramente em função da maior resolução de amostragem, uma região bastante plana no perfil do encolhimento transversal (CD), situada na região central da folha e que se desloca em direção ao lado de acionamento (LA) da máquina de papel, oposto ao lado de comando (LC), coerente com o perfil transversal de $\mathrm{TSI}_{\mathrm{MD} / \mathrm{CD}}{ }^{175}$, mostrado na Figura 5.18(b). Na Figura 5.18(a) encontra-se o perfil do $\mathrm{TSO}_{\text {angle }}{ }^{176}$ [esses parâmetros foram medidos em amostras de papel retiradas simultaneamente da mesma bobina "jumbo", da qual se retiraram amostras para medição do perfil de encolhimento transversal (CD)].

$\mathrm{O} \mathrm{TSO}_{\text {angle }}$ funciona como uma indicação do alinhamento das fibras no papel, pois aponta a orientação do valor máximo de resistência mecânica do papel, indicada neste caso

\footnotetext{
${ }^{174}$ As seções 2.4 e 2.5 tratam da formação do perfil de encolhimento do papel e dos fatores que determinam suas características, tais como a configuração e as condições operacionais da máquina de papel.

${ }^{175} \mathrm{O}$ TSI representa a resistência à tração normalizada pela gramatura do papel. $\mathrm{O} \mathrm{TSI}_{\mathrm{MD} / \mathrm{CD}}$ representa a razão dentre os valores da propriedade medida na direção longitudinal (MD) e transversal (CD), respectivamente.

$176 \mathrm{O}$ parâmetro $\mathrm{TSO}_{\text {angle }}$ (Tensile Stiffness Orientation) indica o ângulo formado entre a direção do valor máximo de TSI (Tensile Stiffness Index) e a direção longitudinal (MD) da máquina de papel.
} 
pelo valor de TSI, em relação à direção longitudinal (MD) da máquina de papel. A Figura 5.18(a) mostra valores positivos de $\mathrm{TSO}_{\text {angle a }}$ partir do lado de comando (LC), cuja magnitude diminui em direção ao centro da máquina, voltando a crescer em seguida, porém com orientação contrária à anterior (agora com valores negativos), caracterizando um modo de operação no qual as principais correntes de fibras tendem a se deslocar em direção ao centro da máquina (forma geralmente utilizada para obtenção de maior resistência mecânica). O perfil de $\mathrm{TSI}_{\mathrm{MD} / \mathrm{CD}}$ mostra notoriamente a influência do encolhimento transversal (CD) do papel, pois regiões com maior encolhimento determinam reduções proporcionais de $\mathrm{TSI}_{\mathrm{CD}}$, que, por sua vez, produzem aumentos no $\mathrm{TSI}_{\mathrm{MD} / \mathrm{CD}}, c f$. mostrado no perfil da Figura 5.18(b). Este efeito reflete-se também sobre a estabilidade dimensional do papel, visto que o valor máximo da higroexpansibilidade transversal (CD) ocorre na direção perpendicular ao $\mathrm{TSO}_{\text {angle }}$ e de forma inversamente proporcional à magnitude do TSI ${ }_{\mathrm{CD}}$ [Lindblat; Fürst, 2001].

Os resultados de higroexpansibilidade transversal (CD) mostrados na Figura 5.12 estão bem alinhados com os princípios abordados no parágrafo anterior, o que permite inferir que o perfil de encolhimento mostrado na Figuras 5.16 ou 5.17 podem ser traduzidos em um perfil de higroexpansibilidade equivalente, com valores elevados nas bordas, diminuindo em direção ao centro da folha.

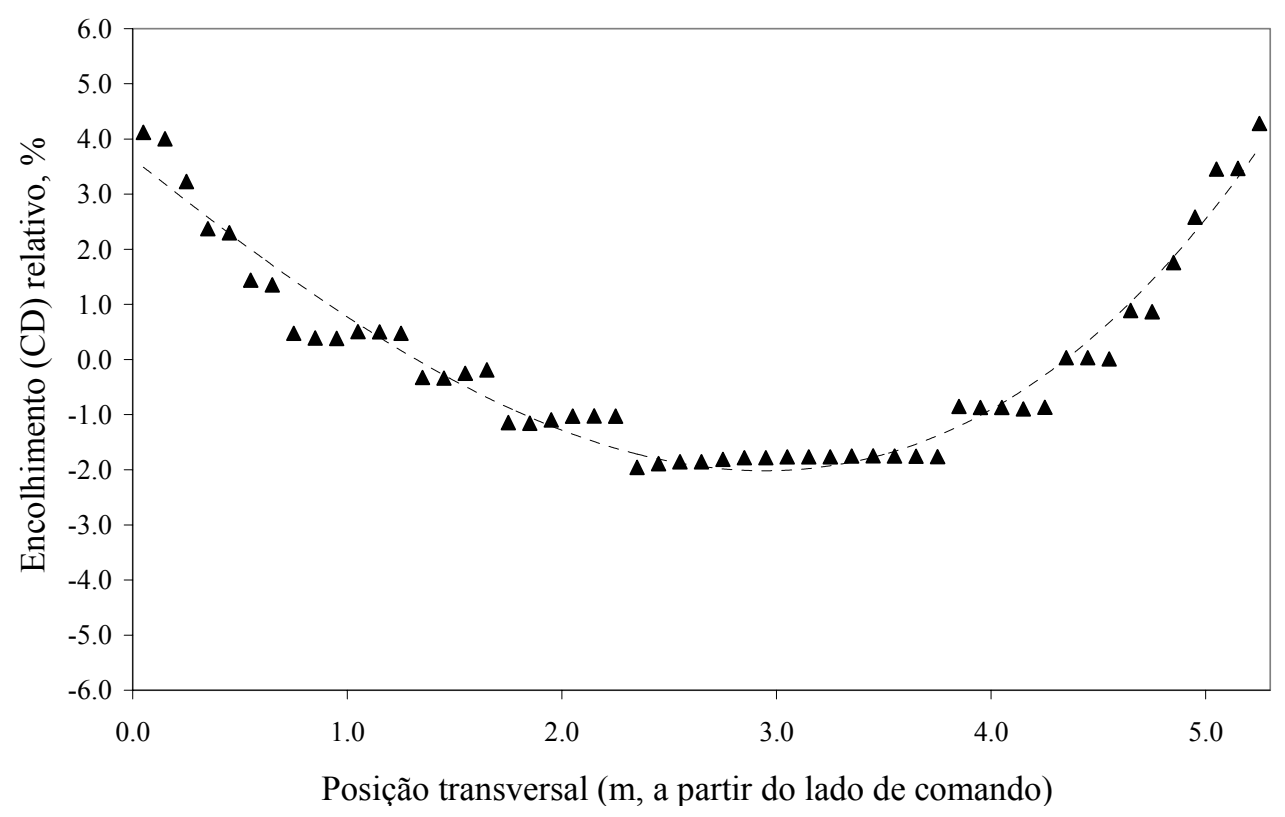

Figura 5.16. Perfil transversal do encolhimento CD relativo, obtido a partir de amostras de papel reprográfico de $75 \mathrm{~g} . \mathrm{m}^{-2}$, produzido com pasta química de fibras de eucalipto. Velocidade da máquina de papel: $1362 \mathrm{~m} \cdot \mathrm{min}^{-1}$. 


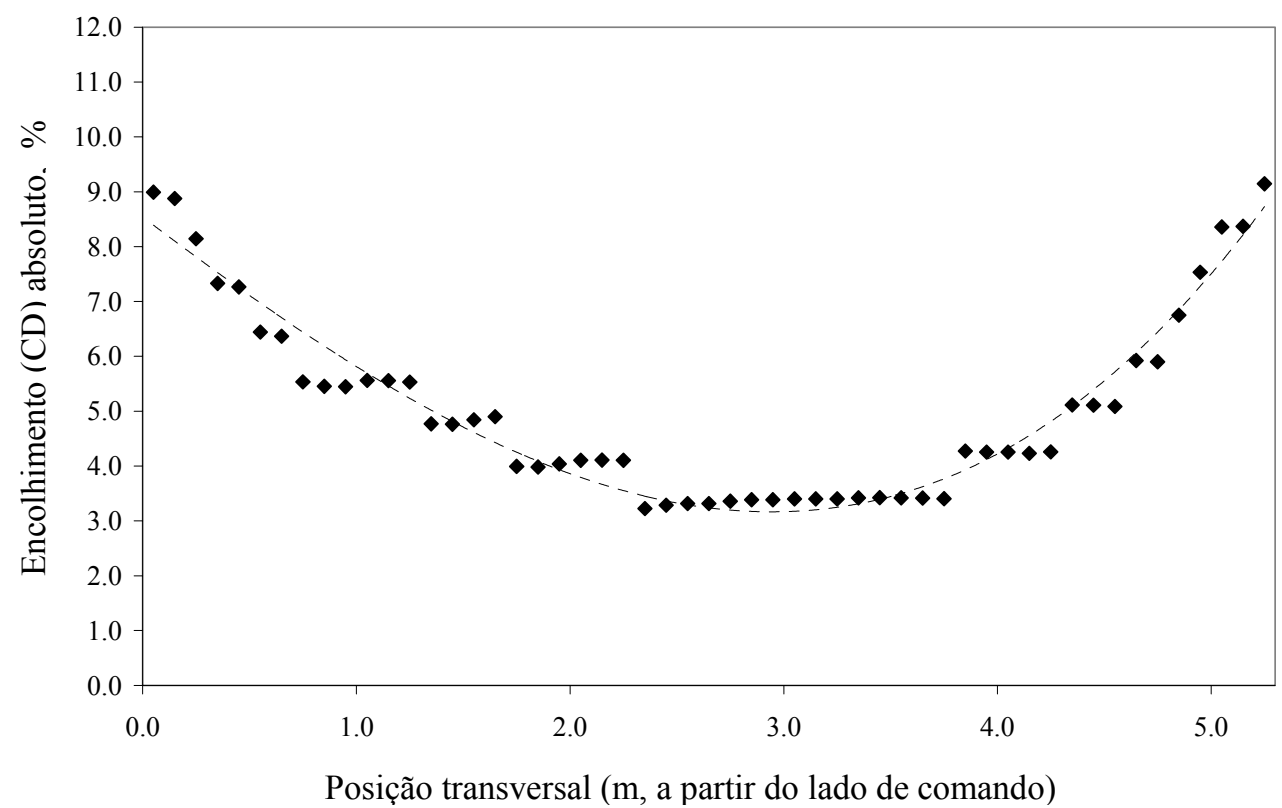

Figura 5.17. Perfil transversal do encolhimento $C D$ absoluto, obtido a partir de amostras de papel reprográfico de $75 \mathrm{~g} . \mathrm{m}^{-2}$, produzido com pasta química de fibras de eucalipto. Velocidade da máquina de papel: $1362 \mathrm{~m} \cdot \mathrm{min}^{-1}$.
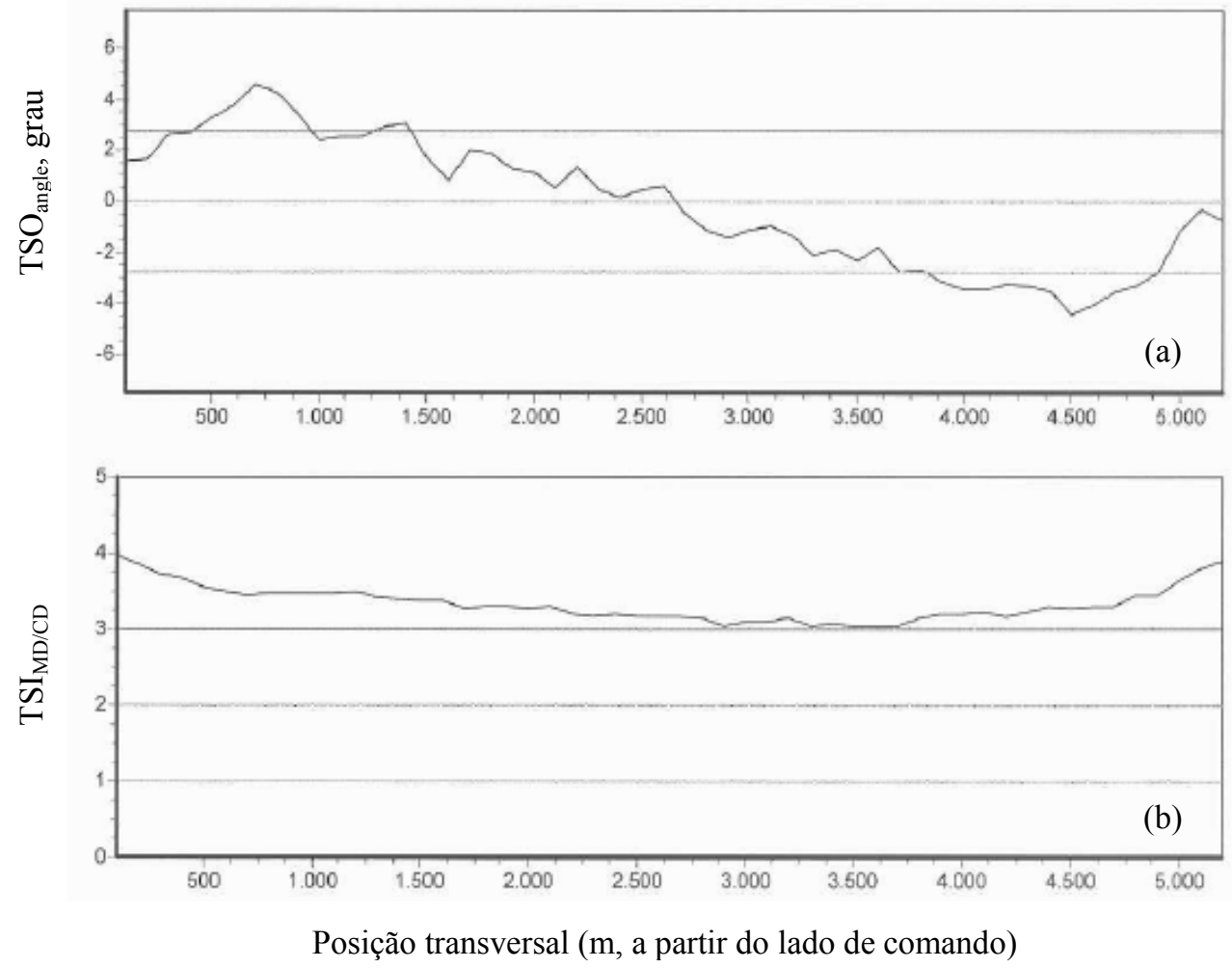

Figura 5.18. Perfis transversais de $\mathrm{TSO}_{\text {angle }}$ (a) e $\mathrm{TSI}_{\mathrm{MD} / \mathrm{CD}}$ (b), obtidos a partir de amostras de papel reprográfico de $75 \mathrm{~g} . \mathrm{m}^{-2}$, produzido com pasta química de fibras de eucalipto. Velocidade da máquina de papel: $1362 \mathrm{~m} \cdot \mathrm{min}^{-1}$. 
Os resultados apresentados neste capítulo mostram perfis irregulares do encolhimento transversal (CD) do papel, formados durante o processo de fabricação em uma máquina comercial e medidos em produtos acabados, prontos para uso final. Esses resultados mostram coerência com estudos realizados anteriormente, como os revistos e incluídos no Capítulo 2 do presente trabalho, demonstrando paralelamente a viabilidade do método utilizado por este autor para sua medição, cuja metodologia constante do Capítulo 4, aborda estudos específicos sobre a utilização de técnicas de análise de imagem, extraídos da literatura especializada e registrados na revisão desenvolvida no Capítulo 3.

Os perfis resultantes para o encolhimento e a higroexpansibilidade transversais (CD) e correlação verificada entre eles, serão retomados na próxima parte deste trabalho, dentro de uma abordagem específica sobre a significação e importância desses parâmetros para o diagnóstico da estabilidade dimensional do papel, ao longo da direção transversal (CD) da máquina. 


\section{CAPÍTULO 6}

\section{CONSIDERAÇÕES SOBRE O MÉTODO DE DIAGNÓSTICO DA ESTABILIDADE DIMENSIONAL DO PAPEL}

Este capítulo apresenta uma discussão mais específica sobre os resultados expostos no capítulo anterior, para sua aplicação em diagnósticos de estabilidade dimensional do papel. Inicialmente, apresenta aspectos fundametais, com base na literatura, para análise da correlação entre higroexpansibilidade e encolhimento do papel, destacando a contração transversal irregular da folha durante a etapa de secagem, no processo de fabricação, como fator preponderante na determinação da estabilidade dimensional do papel. Revisitando importantes trabalhos científicos publicados a respeito deste tema, encontra-se a base confirmatória da relevância da etapa de secagem na consolidação da estabilidade dimensional do papel fabricado em máquinas industriais (6.1). A seguir, discutem-se os aspectos do método utilizado e suas vantagens, que viabilizam a sua implementação em ambiente industrial (6.2). Na última parte deste capítulo, discute-se a aplicação do método proposto para, com base nos resultados obtidos, aplicá-lo em diagnósticos de estabilidade dimensional de papel reprográfico (6.3).

\subsection{Encolhimento e higroexpansibilidade (estabilidade dimensional) do papel}

As fibras celulósicas apresentam comportamento predominantemente higroscópico e sofrem deformações dimensionais significativas influenciadas pela modificação no seu teor de umidade. A absorção e dessorção de água produzem, respectivamente, dilatação e contração da estrutura das paredes das fibras. Na produção em máquinas industriais, o perfil irregular do encolhimento transversal (CD) interfere em várias propriedades do papel, tais como o módulo de elasticidade e a resistência à tração transversais (CD) que são menores nas bordas da folha e o alongamento e a higroexpansibilidade transversais (CD) que aumentam do centro em direção às extremidades da folha ${ }^{177}$.

Os resultados de medições da higroexpansibilidade e do encolhimento transversais (CD) do papel, apresentados no capítulo anterior, exibem uma correlação positiva e forte entre

\footnotetext{
${ }^{177}$ O Capítulo 2 apresenta uma revisão da literatura referente ao encolhimento transversal (CD) do papel durante a etapa de secagem, do processo de fabricação e seu efeito sobre as propriedades do produto acabado.
} 
os dois parâmetros, $c f$. demonstrada na Figura $5.13\left(\mathrm{R}^{2}=0,7795\right)$. Este resultado confirma estudos anteriores, desde o pioneiro trabalho de Nordman [1958], que encontrou uma relação diretamente proporcional e linear entre a higroexpansibilidade e o encolhimento do papel (mostrada na Figura 2.20), resultado também corroborado por trabalhos mais amplos e recentes, $c f$. citados no Capítulo 2, dentre os quais encontram-se as importantes contribuições de Salmén et al. [1987], (ver Figura 2.21), Nanri e Uesaka [1993], Fellers et al. [2003] e Juppi e Kaihovirta [2002, 2003] ${ }^{178}$.

A importância da correlação entre a higroexpansibilidade e o encolhimento do papel foi, significativamente, reconhecida na indústria, sob o foco de perspectivas de melhoria e controle da estabilidade dimensional do papel, determinando o desenvolvimento de novos projetos para as máquinas comerciais, a fim de minimizar o encolhimento transversal (CD) do papel, envolvendo especialmente soluções que visavam aumento de suporte e retenção da folha, desde a saída das prensas até a enroladeira. Estes novos conceitos, baseados principalmente na eliminação dos percursos livres (open draws) incluíram a utilização de rolos de sucção e caixas estabilizadoras a vácuo, a fím de aumentar a contenção do papel durante o processo de secagem. Tipicamente consistiram de baterias formadas por cilindros secadores dispostos em fileira única, como divulgado amplamente em diversas publicações, e.g., Wedel e Palazzolo [1987], Wedel [1989a, 1989b], Palazzolo [1990], Pulkowiski [1990, 1991], Ilvespa, Kuhassalo e Yli-Kauppila [1991], Sims Jr. e Grunder [1991], Asensio e Sayed-Yagoobi [1992], Rounds [1992], Wedel e Mendes [1992], Beloit [1999], Hoole et al. [1999], Juppi e Kaihovirta [2002, 2003], Constantino, I'Anson e Sampson [2005], Lipponen, Leppänen e Hämaäläinen [2009]. As novas configurações concebidas para as seções de secagem mostraram que o incremento na retenção do papel durante a secagem produz perfis de encolhimento $\mathrm{CD}$ mais planos, limitando a variação mais aguda a estreitas faixas próximas das bordas do papel, com a vantagem adicional de reduzir o valor médio do encolhimento CD e, correspondentemente, da higroexpansibilidade.

Retomando, no Capítulo 2, estudos encontrados na literatura sobre o mecanismo de encolhimento individual das fibras e do correspondente encolhimento macroscópico da rede de fibras, i.e., da folha de papel, encontra-se a fundamentação teórica, a fim de explicar os

\footnotetext{
${ }^{178}$ Ver subseção 2.8.2.
} 
resultados obtidos para a correlação entre os perfis diferenciais de higroexpansibilidade (Figura 5.12) e de encolhimento (Figura 5.11) transversais (CD), exibida na Figura 5.13.

O encolhimento das paredes das fibras, durante a fase de secagem do papel, é causado pela remoção de moléculas de água contidas nas interligações das fibrilas e micro-fibrilas ${ }^{179}$ localizadas no interior das paredes, que resulta na aproximação das estruturas celulares, em função da reorganização das ligações químicas internas por meio de pontes de hidrogênio. Este fenômeno foi estudado e confirmado sob diferentes enfoques por vários pesquisadores, e.g., Scalan ${ }^{180}$ [1974 apud Kajanto; Niskanen, 1998], Nanko e Oshawa ${ }^{181}$ [1989 apud Kiisknen; Paltakari; Pakarinen, 2000] e mais recentemente por Weise [1997].

As contrações das paredes das fibras geram tensões internas no papel, conhecidas por tensões de secagem, responsáveis pela força motora de encolhimento da rede de fibras. De acordo com Page e Tydeman [1962], durante a secagem, nos cruzamentos entre as fibras, o encolhimento transversal de uma produz tensões compressivas na direção axial da outra, com a qual está interligada, na rede estrutural do papel, provocando micro-compressões que determinam, desta forma, a transferência de encolhimento de uma fibra para a outra e, conseqüentemente, para toda a rede de fibras ${ }^{182}$. Este mecanismo de transmissão de deformações entre as fibras e a rede, i.e., a folha do papel, explica a forte correlação entre a higroexpansibilidade e o encolhimento do papel, dado que a dilatação das paredes fibrilares do papel durante a absorção de água é proporcional à contração sofrida durante a dessorção [Nordman, 1958; Gallay, 1973].

No perfil de higroexpansibilidade transversal (CD) mostrado na Figura 5.12, observase, portanto, o efeito conjugado da transmissão de deformações das fibras para a rede de fibras com o encolhimento transversal (CD) irregular do papel (cf. Figura 5.11), produzido durante a secagem em máquinas industriais convencionais com secadores dispostos em dois níveis, coincidentes com a etapa de encolhimento mais intenso do papel ${ }^{183}$.

\footnotetext{
179 Elementos filiformes presentes na estrutura da parede das fibras celulósicas, as quais agregam as microfibrilas, reunião de lamelas, onde se encontram as cadeias de moléculas de celulose.

${ }^{180}$ SCALLAN, A.M. The structure of the cell wall of wood: A Consequence of Anisotropic Inter-Microfibrillar Bonding. Wood Science, vol.6, n.3, p.266-271, 1974.

${ }^{181}$ NANKO, H.; OHSAWA, J. Mechanism of fibre bonding formation. In: BAKER, C.F.; PUTON, V.W. (Ed.). Fundamentals of Papermaking. London: MEP, 1989, vol.2, p.783-830.

${ }^{182}$ Ver mais detalhes sobre o mecanismo de encolhimento da estrutura do papel na seção 2.3.

${ }^{183}$ Ver na subseção 2.5.1, o efeito da configuração da seção de secagem de uma máquina comercial sobre o perfil de encolhimento transversal (CD) do papel.
} 


\subsection{Análise da estabilidade dimensional do papel}

A estabilidade dimensional do papel tem sido historicamente discutida com base na variação de diferentes propriedades, tais como encanoamento, hidroexpansão, absorção de umidade, encolhimento, contração térmica e higroexpansibilidade, sendo a última, a mais comumente associada a um indicador de estabilidade dimensional, com mostram, e.g., trabalhos clássicos citados nesta tese, tais como os de Nordman [1958], e Gallay [1973], Uesaka [1991], Nanco e Tada [1995] e, posteriormente, de Larsson e Wagberg [2008].

A seção precedente destaca uma marcante correlação entre a higroexpansibilidade e o encolhimento transversal (CD) do papel, em consonância com as conclusões de vários pesquisadores sobre a dependência da higroexpansibilidade com as condições de secagem e o grau de encolhimento sofrido pelo papel. Estas constatações representam a base para desenvolvimento de um procedimento específico, para implantação industrial, de diagnóstico de estabilidade dimensional por meio da medição do perfil de encolhimento do papel [o Apêndice E apresenta um procedimento industrial para medição do perfil diferencial de encolhimento transversal (CD) do papel]. A utilização do perfil do encolhimento transversal (CD), como mostrado a seguir, permite então, localizar regiões da folha de papel com potencial insuficiência de estabilidade dimensional. A partir do conhecimento prévio da destinação do papel e dos seus desempenhos históricos nos processos em que é aplicado, torna-se possível estabelecer limites máximos tolerados para o encolhimento, a fim de limitar a conseqüente instabilidade dimensional.

No exemplo indicado na Figura 6.1, linhas verticais de corte posicionadas nas laterais da folha, delimitam faixas da folha de papel com estabilidade dimensional adequada (região central) e imprópria (no caso, com extensão aproximada da $1 \mathrm{~m}$, em cada lado da folha), quando, em função do processo final de aplicação do papel, ficasse determinado que o encolhimento transversal (CD) máximo admissível estivesse limitado a uma banda de 5\%-6\%, considerando o desempenho do papel testado no presente trabalho ${ }^{184}$. A Figura 6.2 apresenta uma interpretação qualitativa do gráfico da Figura 6.1, em termos de estabilidade dimensional do papel reprográfico analisado. $\mathrm{O}$ eixo vertical indica estabilidade dimensional crescente em direção à diminuição do encolhimento transversal (CD) do papel.

\footnotetext{
${ }^{184}$ Rever a expressão (4.35), na subseção 4.11 .
} 


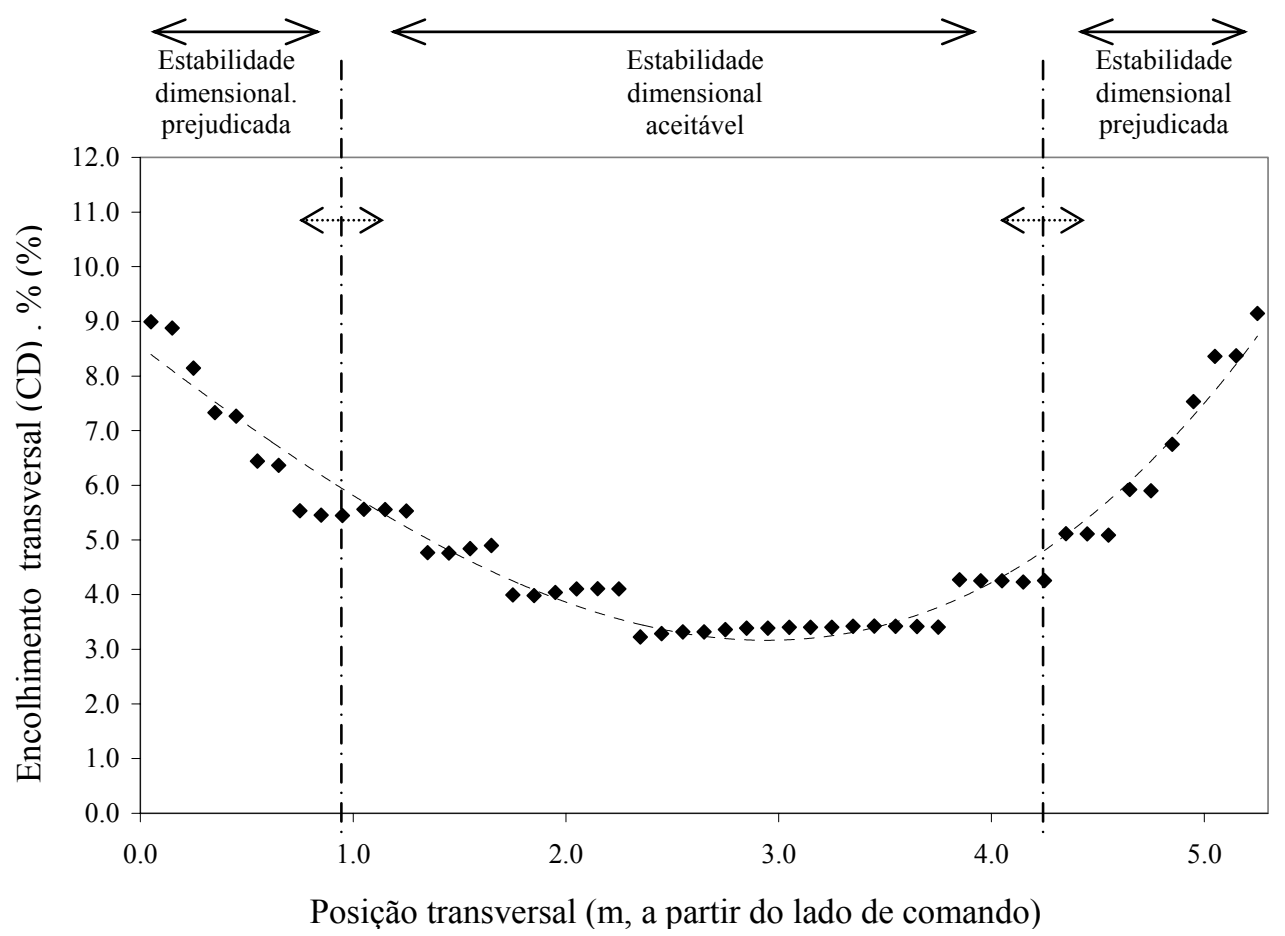

Figura 6.1. Perfil do encolhimento transversal (CD) absoluto, obtido a partir de amostras de papel reprográfico de 75 g.m $\mathrm{m}^{-2}$, produzido com pasta química branqueada de fibras de eucalipto, mostrando seleção de regiões em função da estabilidade dimensional. Velocidade da máquina: $1362 \mathrm{~m} / \mathrm{min}^{-1}$.

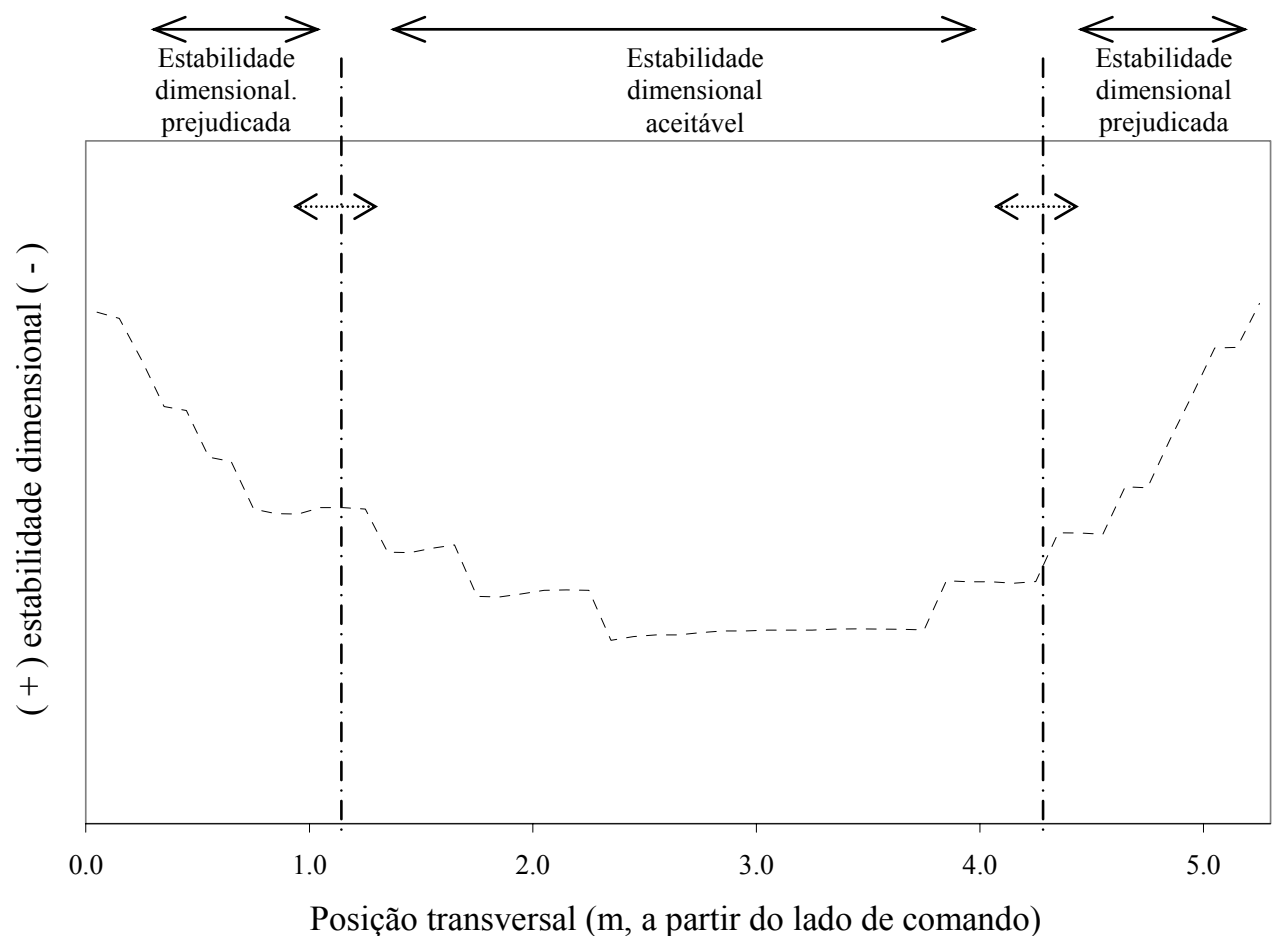

Figura 6.2. Interpretação qualitativa do gráfico da Figura 6.1 sob o ponto de vista de estabilidade dimensional resultante no papel reprográfico analisado. 
O método de avaliação de estabilidade dimensional proposto neste trabalho pressupõe o desconhecimento, a priori, da higroexpansibilidade do papel analisado. Entretanto, é intuitivo que partes da folha de papel onde foram encontrados altos valores de encolhimento transversal (CD) apresentarão maior potencial de falha no uso final, por deficiência de estabilidade dimensional. Esta análise pode ser feita rapidamente pelo supervisor de operação da máquina de papel, a fim de definir providências para minimizar o efeito indesejado, por meio da identificação de oportunidades, dentro das práticas convencionais que compõem o ajuste do processo de fabricação do papel, para redução do nível e a variabilidade do encolhimento transversal (CD) diferencial. Tais ações podem incluir principalmente: (a) o ajuste das condições operacionais da caixa de entrada e do formador, com a finalidade de alterar o grau de orientação de fibras e, conseqüentemente, na anisotropia da higroexpansão do papel, buscando melhor equilíbrio entre as propriedades na direção MD e CD do papel e (b) ajustes nas condições de operação da seção de secagem buscando maximizar a restrição ao encolhimento do papel (e.g., monitoramento da tensão das telas secadoras). Soluções mais radicais incluem a reforma da máquina, a fim de melhorar o suporte e retenção da folha (e.g. instalação de caixa de entrada com controle de perfil de gramatura por diluição e baterias com fileira única de secadores com suporte do papel por meio de rolos de sucção a vácuo ${ }^{185}$ ).

\subsection{Diagnóstico de estabilidade dimensional de papel por análise de imagem}

O método de diagnóstico de estabilidade dimensional do papel reprográfico proposto neste trabalho baseia-se fundamentalmente na medição do perfil de encolhimento transversal (CD) por meio da aplicação de técnica específica de análise de imagem, suportada pela transformada bidimensional rápida de Fourier (2D-FFT). Os resultados obtidos por este autor mostraram a viabilidade de aplicação do método, pois, além de adequado para implementação industrial, produz resultados consistentes e similares a trabalhos encontrados na literatura direcionada ao estudo do comportamento higro-dimensional do papel.

Este método desvincula o diagnóstico de estabilidade dimensional da necessidade de execução de medições da higroexpansibilidade do papel, oferecendo assim, uma solução mais exeqüível dentro da realidade industrial do setor de celulose e papel. Além deste aspecto, supera com vantagem os métodos tradicionais de medição do encolhimento transversal (CD)

\footnotetext{
${ }^{185}$ Ver, na subseção 2.5.1, o efeito da configuração dos grupos de secadores sobre o perfil de encolhimento transversal (CD) do papel.
} 
do papel, que têm como principais desvantagens, um consumo excessivo de tempo para sua realização, baixa resolução, pouca precisão e, também, restrições vinculadas a regras de saúde e segurança do trabalho. Constam, em geral, de práticas que exigem a marcação da folha no extremo úmido da máquina [e.g., pela aplicação de finas gotas de tinta sobre a folha em formação, $c f$. Wedel (1989a)] e uma trabalhosa medição da variação das separações entre as marcas, no papel acabado [Wadhams et al., 1991]. Esse tipo de medição, embora limitado e obsoleto, eventualmente encontra uso, porém seu emprego, na maioria das tentativas, resulta em frustração com relação aos resultados obtidos.

Com relação à medição da higroexpansibilidade para indicação da estabilidade dimensional do papel acabado, este método apresenta outros fatores limitantes, que também restringem sua aplicação corrente nas fábricas de papel. De fato, não se conhecem nos dias atuais, no setor brasileiro de celulose e papel, exemplos de prática freqüente de medição dessa propriedade. Tal situação, restritiva ao melhor controle de qualidade do produto, sobrevém a duas principais dificuldades encontradas nas fábricas de papel: a primeira refere-se à necessidade de aquisição de equipamento específico e sofisticado para tal fim, que não dispõe de fabricação nacional, representa um investimento significativo, requer manutenção especializada e técnicos treinados para cumprir os protocolos de amostragem e medição, que apresentam certa complexidade e demandam longo tempo para sua realização; a segunda indica que, mesmo nos casos de existência de medidores de higroexpansibilidade mais antigos, ainda remanescentes em algumas fábricas ou instituições, os longos tempos gastos para realização das medições, associados à exigência de acompanhamento de um laboratorista continuamente, têm levado tais práticas ao desuso.

As limitações indicadas acima provocam, em situações especiais, normalmente quando há persistência e recorrência de problemas de estabilidade dimensional com o papel fabricado, capazes de determinar devolução do produto ao fabricante, a busca de recursos externos tanto para suporte na definição de ações corretivas no processo de fabricação, como para o embasamento para assistência técnica ao cliente. A procura deste suporte leva, em geral, a contato com laboratórios especializados ou mesmo com instituições de ensino e pesquisa, cuja localização distante da fábrica de papel, estabelece novas dificuldades, tais como as relacionadas à comunicação, transporte de amostras de papel, tempo de resposta e falta de flexibilidade para repetição das medições após modificações ou ajustes de processo. A lenta realimentação do procedimento inviabiliza uma solução do problema em tempo 
satisfatório. O método proposto no presente trabalho representa mais facilidade, flexibilidade e rapidez de execução, em função de empregar protocolos de amostragem e medição mais simples que aqueles requeridos pelos métodos mencionados nos parágrafos anteriores.

O emprego de análise de imagem permite reconhecer e medir marcas determinísticas de telas formadoras impressas no papel durante formação da folha, diretamente no produto acabado. A aquisição de imagens das amostras de papel pode ser efetuada por meio de um digitalizador fotográfico de mesa, conectado a um computador convencional. O programa de análise de imagem "PET1_0" "186, criado por este autor, examina rapidamente as imagens de amostras coletas na direção transversal (CD) de uma bobina "jumbo" e retorna dados, que processados em uma planilha Excel, produzem perfis de encolhimento transversal (CD) diferencial do papel, como os mostrados nas Figuras 5.10 e 5.11 .

O procedimento analítico utilizado no presente método, para medição da geometria do padrão repetitivo das marcas da tela formadora impressas no papel, prevê correções no cálculo da separação entre as marcas dos fios longitudinais (MD), necessárias em função de desvios introduzidos por: (a) eventuais desalinhamentos no posicionamento das amostras de papel no digitalizador; (b) eventuais deformações da tela formadora em regime de operação na máquina de papel, caracterizadas por deslocamentos dos fios horizontais em relação à direção transversal (CD) da máquina de papel. Estas distorções, quando presentes, produzem certa aproximação adicional dos fios longitudinais da tela formadora, gerando distúrbios na medição da variação da separação entre eles, causada especificamente pelo encolhimento transversal (CD) do papel $^{187}$.

Relembrando a Figura $3.25^{188}$, da qual se repete uma parte na Figura 6.3 abaixo, observa-se que, no caso (a), mencionado acima (desalinhamento da amostra de papel no digitalizador), ocorre um incremento dos ângulos $\alpha$ e $\beta$, proporcional à inclinação das marcas da tela formadora na amostras de papel ${ }^{189}$. Denominando os ângulos incrementais de

\footnotetext{
${ }^{186}$ O programa PET1_0 está apresentado no Apêndice C.

187 O modelo geométrico utilizado para descrever a situação de eventual deformação da tela formadora, está abordado em detalhes na subseção 3.5.4. O conceito apresentado nesta subseção foi empregado no algorítmo de cálculo do encolhimento transversal (CD) descrito na subseção 4.2.5.

${ }^{188}$ Ver subseção 3.5.4.

${ }^{189} \mathrm{O}$ desalinhamento pode ser causado pela forma como a amostra foi colocada sobre a base do digitalizador, por desvios no corte dessas amostras ou mesmo pela associação dos dois fatores.
} 


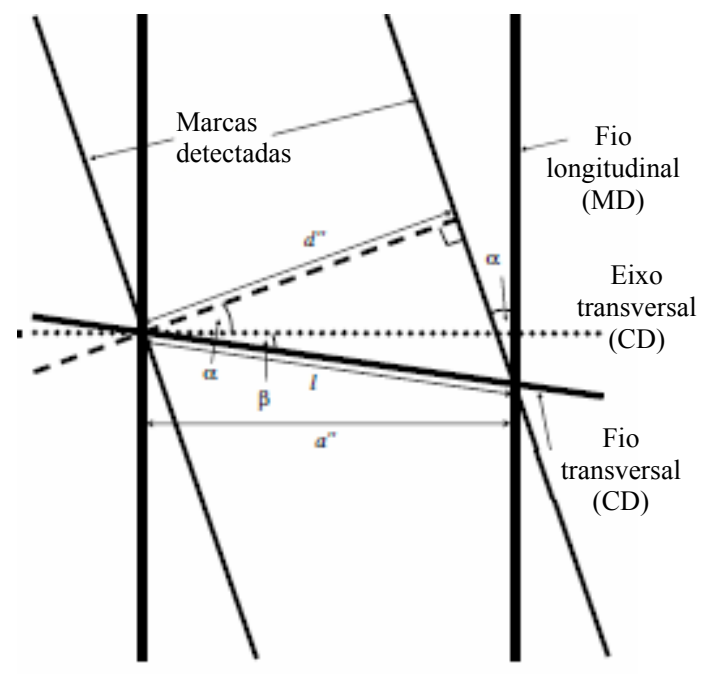

Figura 6.3. Geometria das marcas da tela formadora, $c f$. Figura 3.25 , para o caso de um desvio dos fios horizontais (CD) em relação ao eixo transversal da máquina de papel, no sentido horário, caracterizado pelo ângulo $\beta$.

desalinhamento por $\alpha^{*}$ e $\beta^{*}$, para fins desta análise, e retomando a equação (3.51), encontra-se a seguinte relação a seguir:

$$
l=\frac{d^{\prime \prime}}{\cos \left[\left(\alpha+\alpha^{*}\right)+\left(\beta+\beta^{*}\right)\right]}
$$

$\mathrm{Na}$ expressão acima, $\alpha$ e $\beta$ representam os ângulos intrínsecos de inclinação e de distorção das marcas dos fios longitudinais (MD) e transversais (CD) da tela formadora, respectivamente, $c f$. definido na subseção 3.5.4. Relembrando a convenção estabelecida para o sinal dos ângulos $\alpha$ e $\beta^{190}$, também definida na subseção 3.5.4 e estabelecendo-se a mesma disposição para os ângulos $\alpha^{*}$ e $\beta^{*}$, tem-se que, para o caso do desalinhamento da amostra no digitalizador:

$$
\begin{aligned}
& \left|\alpha^{*}\right|=\left|\beta^{*}\right| \\
& \alpha^{*}+\beta^{*}=0
\end{aligned}
$$

\footnotetext{
${ }^{190}$ A convenção de sinais especifica que o ângulo $\alpha$ será positivo para incrementos no sentido anti-horário, em relação ao eixo longitudinal (MD) e que o ângulo $\beta$ será positivo para incrementos no sentido horário, em relação ao eixo transversal $(\mathrm{CD})$ da máquina de papel.
} 
As expressões acima derivam do fato de que $\alpha^{*}$ e $\beta^{*}$ possuem a mesma magnitude e seus incrementos se dão na mesma direção, determinando sinais opostos entre eles. Portanto, na equação (6.1), estes ângulos se anulam:

$$
\cos \left[\left(\alpha+\alpha^{*}\right)+\left(\beta+\beta^{*}\right)\right]=\cos (\alpha+\beta)
$$

Desta forma, o modelo geométrico utilizado introduz uma compensação, nos casos de ocorrência de desalinhamento (inclinação) da amostra, durante a digitalização.

No caso (b), mencionado anteriormente [distorção da tela formadora na direção transversal (CD) da máquina de papel, caracterizada pelo ângulo $\beta$ ], o fator de correção para o cálculo de encolhimento transversal $(\mathrm{CD})$ do papel é feito $c f$. indicado, e.g., na equação (3.52), de onde vem que (ver Figura 6.3):

$$
a^{\prime \prime}=l \cos \beta
$$

A expressão acima mostra a compensação da distorção de fios transversais da tela formadora, na determinação da distância $a^{\prime \prime}$ (entre marcas de fios longitudinais da tela formadora), base para o cálculo do encolhimento transversal (CD), por meio do ângulo $\beta$ (indicado na Figura 6.3).

Os ângulos $\alpha$ e $\beta$ mencionados acima foram medidos em cada posição transversal analisada neste trabalho, sendo que os resultados destas medições compuseram os perfis mostrados nas Figuras 5.9 e 5.15. Em ambos os casos, as marcas produzidas pela tela formadora mostraram fios longitudinais essencialmente alinhados com a direção de fabricação da máquina (MD), fato caracterizado por baixos valores do ângulo $\alpha$. Nos dois casos, observou-se uma pequena distorção da tela formadora na direção transversal, caracterizada pelas pequenas magnitudes do ângulo $\beta$ e das diferenças entre os ângulos $\alpha$ e $\beta$, que, no caso, melhor caracterizam a distorção transversal. Nas duas medições mencionadas, apresentaram

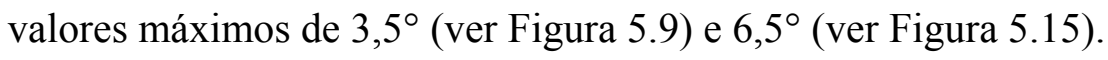

A geometria das marcas da tela formadora, mostradas na Figura 6.3, assume que o parâmetro $l$, que representa o comprimento dos ligamentos dos fios transversais (CD) entre 
cruzamentos com os fios longitudinais (MD) é fixo (na tela formadora e na marca no papel, antes do encolhimento). Adicionalmente, os ângulos $\alpha$ e $\beta$ possuem magnitudes usualmente menores que $10^{\circ}$, considerando para o primeiro, possibilidades de pequenos desvios em função da forma construtiva da tela formadora ou de desalinhamentos na digitalização da amostra e para o segundo, certa restrição, devido ao limite de flexibilidade da tela formadora nas direções longitudinal (MD) e transversal (CD). As telas formadoras são têxteis fabricados com precisão e sua rigidez, estabilidade dimensional e resistência ao estiramento diagonal, advêm principalmente da etapa de termo-fixação, durante o processo de fabricação. $O$ objetivo do tratamento térmico consiste em aliviar as tensões internas da tela tecida, com a finalidade de aumentar o módulo de elasticidade e a estabilidade dimensional e fixar sua forma construtiva ${ }^{191}$.

O rígido e controlado processo de fabricação atualmente utilizado determina, também, a uniformidade das telas formadoras, com respeito as distribuições (ou densidades) dos fios nas duas direções principais (MD e CD), as quais se mantém ao longo da sua vida útil. Esta característica está demonstrada por medições realizadas por este autor, cujos resultados se encontram no Capítulo $5^{192}$. A Figura 5.5 mostra um perfil constante dos espaçamentos entre fios longitudinais e entre fios transversais, medidos em quatro pontos ao longo da direção transversal de uma tela formadora retirada da máquina, após o transcurso da sua vida útil. Um resultado correlato havia sido encontrado por Miyata e Shinozaki [2003], que observaram em suas medições a inexistência de deformação plástica em uma tela secadora, após longo período de uso, na fabricação de papel reprográfico. Estes aspectos relevantes validam o procedimento de medição do encolhimento transversal do papel por meio das marcas de tela formadora impressas no papel durante a formação da folha.

Adicionalmente, as medições realizadas por este autor e listadas na Tabela $5.1^{193}$, mostram coerência nos resultados obtidos para os espaçamentos entre fios, os quais permitiram, a seguir, dimensionar a densidade de fios $($ fios $/ \mathrm{cm})$ nas duas direções principais da tela formadora (MD e CD), o que é consistente com os dados dimensionais obtidos sobre a tela formadora em questão, $c f$. indicado no Apêndice $\mathrm{D}^{194}$. Uma medição comprobatória final do espaçamento entre fios longitudinais (MD) da tela formadora, principal referência para a

\footnotetext{
${ }^{191}$ Para referência, verificar o tópico Fabricação das telas formadoras, contido na subseção 3.5.2.

${ }^{192}$ Ver subseção 5.1.1.

${ }^{193}$ Ver seção 5.1.

${ }^{194}$ Ver na Tabela D.1, dados do fabricante "A", referentes à tela formadora modelo 7120A65560.
} 
medição do encolhimento transversal (CD) do papel, realizada por este autor diretamente sobre uma amostra da tela, mostrou também coerência com o dado obtido por análise de imagem mostrados na Tabela 5.1, mencionada no início deste parágrafo. Observe-se na Figura 6.4, que o valor médio encontrado para a separação entre dois fios longitudinais (MD) foi de $0,306 \mathrm{~mm}$, plenamente comparável com o valor de $0,304 \mathrm{~mm}$, indicado na Tabela $5.1^{195}$.

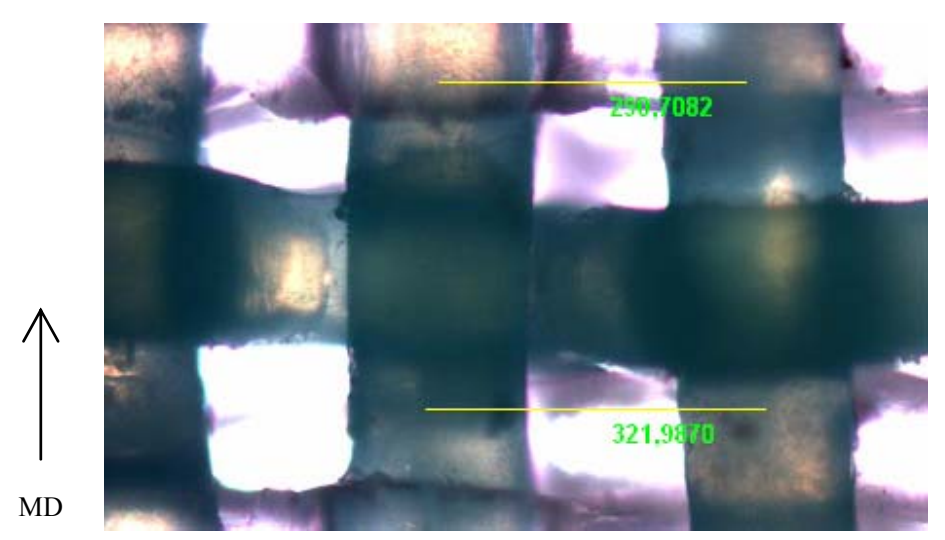

Figura 6.4. Imagem ampliada da tela formadora para medição da separação entre fios alinhados na direção longitudinal (MD). A imagem original foi ampliada (100X), para visualização, em microscópio óptico Olympus modelo BX50F4, monitorado em computador por software de análise de imagens ImagePro Plus ${ }^{196}$.

Finalmente, cabe esclarecer que o método apresentado pode ser aplicado para medição do encolhimento transversal (CD) do papel, tendo como base marcas de telas formadoras que possuam diferentes características construtivas, mesmo em formadores de tela dupla, do tipo gap formers. Em situações com a mencionada, as marcas das duas telas poderão ser detectadas por meio da técnica de análise de imagem e utilizadas para o cálculo do encolhimento do papel, individualmente ou em conjunto, pela composição do valor médio resultante de cada medição. No caso especifico analisado no presente trabalho, as telas formadoras em operação na máquina de papel, tinham essencialmente as mesmas configurações estruturais referentes às faces em contato com o papel (ambas com tecedura de

\footnotetext{
${ }^{195}$ Dado referente ao pico de amplitude n. 3 do espectro de Fourier (separação entre fios longitudinais da tela formadora).

${ }^{196}$ Image-Pro Plus versão 4.1.0.0, Media Cybernetics, USA,
} 
2 quadros ${ }^{197}$ ). Desta forma, as marcas da tela formadoras encontradas nas duas faces do papel se sobrepuseram, apresentando um espectro de Fourier característico de marcas produzidas somente por uma tela formadora.

${ }^{197}$ Esta situação foi comprovada, por este autor, por meio da medição de localização dos picos de amplitude referentes à distribuição de fios longitudinais (MD) e transversais (CD), no espectro de Fourier, em amostras de telas formadoras provenientes da posição superior e posição inferior do formador da máquina de papel. 


\section{CAPÍTULO 7}

\section{CONCLUSÃO}

Um dos principais objetivos dos fabricantes de papel consiste em atingir metas crescentes de uniformidade e consistência do produto destinado ao usuário final. Na etapa de secagem do processo de fabricação, ocorre um encolhimento maior nas regiões laterais que nas regiões centrais da folha de papel. Este fenômeno, por conseqüência, pode causar deterioração, em diversas magnitudes das propriedades do papel nessas áreas de maior contração, dentre as quais se destaca a estabilidade dimensional. Tendo em vista a melhoria da qualidade do produto, a possibilidade de medir o perfil do encolhimento transversal (CD) diferencial do papel, a fim de permitir a verificação da influência dos diferentes parâmetros envolvidos nas operações de fabricação sobre o mencionado perfil, transforma-se em eficiente ferramenta para um controle sistêmico em direção à obtenção de melhores níveis de uniformidade de estabilidade dimensional para o papel.

A presente tese apresenta um método para diagnóstico e monitoramento da variação da estabilidade dimensional transversal (CD) ao longo da largura da folha de papel, por meio do levantamento do perfil de encolhimento na mesma direção, utilizando-se para isso, das técnicas de análise de imagem suportadas pela transformada rápida bidimensional de Fourier (2D-FFT), a fim de detectar marcas periódicas deixadas no papel pelas telas formadoras. Neste trabalho, o autor demonstra a viabilidade de implementação do método de medição e análise no ambiente industrial das fábricas de papel, dada a sua adequação, provida pelo abrandamento da rigidez de protocolos de amostragem e medição (comum em métodos convencionais de análise da estabilidade dimensional do papel), como mostra o procedimento industrial desenvolvido especialmente para esta finalidade e apresentado neste trabalho.

As características próprias do procedimento proposto se traduzem em vantagens reais, e.g., sobre os métodos tradicionais de medição de higroexpansibilidade em sofisticados equipamentos, pois emprega uma configuração simplificada de instrumentos, contendo um digitalizador fotográfico de mesa, para captação de imagens das amostras de papel, e um computador comum, como estação de trabalho e, adicionalmente, requer um tempo para execução do levantamento de um perfil de encolhimento transversal (CD) bastante inferior 
àquele necessário para realização da medição tradicional do perfil de higroexpansibilidade, utilizando-se de um higroexpansímetro.

Além de apresentar um método exeqüível e adequado para implantação em instalações industriais de fábricas de papel, este trabalho oferece contribuições para os estudos já realizados na área de análise de imagem aplicada a diagnósticos do papel e, particularmente, para a medição das marcas periódicas de telas formadoras existentes nos papéis produzidos em máquinas industriais. O presente trabalho colabora também para um aumento da base de dados de propriedades de papel reprográfico produzido com pasta branqueada de fibras de eucalipto brasileiro, o que raramente se encontra na literatura, especialmente sobre as propriedades ligadas ao comportamento da higroexpansão de papéis fabricados com a matéria prima mencionada.

Trabalhos publicados a partir do final da década de 1980 [Praast e Göttsching, 1987a, 1990, 1995; I'Anson, 1990, 1995a, 1995b, 2008], trouxeram o arcabouço da medição de marcas de tela formadora baseadas por técnicas de análise de imagem, porém apresentavam apenas resultados obtidos. Neste sentido, a contribuição do presente trabalho se estendeu a detalhar o método de medição, apresentando desde recomendações para a adequada seleção da resolução de imagem a ser usada no procedimento de digitalização das amostras de papel, a fim de posicionar de forma conveniente, os picos de amplitude referentes às marcas de tela formadora no espectro de Fourier, até o desenvolvimento de um programa de análise de imagem específico para automatizar a detecção e extração de informações dos picos de amplitude citados, necessárias para o cálculo do encolhimento transversal (CD) do papel. A utilização dos dois recursos descritos acima evita erros potenciais induzidos pela consideração inadequada da resolução de imagem e seleção manual de picos de amplitude no espectro de Fourier que resultariam em resultados falsos no cálculo de encolhimento do papel, como sugerido em artigos anteriormente publicados.

O presente trabalho traz, também, uma atualização sobre a aplicação de técnicas de tratamento de imagens para o reconhecimento de marcas da estrutura de telas formadoras, agora especificamente para telas de três camadas estilo SSB, que atualmente representam a recomendação para fabricação de papéis gráficos (nos quais se incluem os reprográficos) em formadores de duas telas do tipo gap formers. A análise geométrica detalhada da tecedura característica deste tipo de tela formadora permitiu estabelecer faixas apropriadas de 
resolução de imagem, para a digitalização da amostras de papel e definir os filtros digitais para detecção dos picos de amplitude no espectro de Fourier contidos no programa de análise de imagens desenvolvido especificamente para este trabalho, conforme mencionado no parágrafo anterior. Este programa de análise de imagem detalhadamente apresentado, apesar de ter sido desenvolvido, no âmbito acadêmico, em ambiente $M A T L A B$, poderá certamente ser reescrito em outras linguagens de programação mais convenientes, a fim de atender a necessidades especificas em aplicações industriais (e.g., na linguagem $C++$, comercialmente utilizada em grande escala).

Ainda, com referência ao estudo particular da tela formadora utilizada, este trabalho apresenta uma averiguação da sua uniformidade estrutural, que se mostrou constante ao longo da direção transversal, mesmo após uso continuado em máquina, durante o período de vida útil. Esta constatação foi primordial para a consolidação de confiabilidade para o método proposto de medição do encolhimento transversal (CD) diferencial do papel.

A continuidade do presente estudo prevê a estruturação e construção de protótipo para um instrumento laboratorial, a fim de automatizar completamente o processo de medição de encolhimento do papel, expandindo assim sua aplicação, de forma mais apropriada para uso nos meios industriais. No instrumento em questão, amostras da largura total da folha de papel poderão ser utilizadas para captação e processamento automáticos de imagens digitalizadas em pontos previamente programados, referentes às posições constituintes do perfil de encolhimento ao longo da direção transversal da máquina de papel.

Finalmente, cabe destacar a possibilidade de utilização do presente trabalho como referência metodológica para investigação do comportamento higroexpansivo voltado para o diagnóstico de estabilidade dimensional de outros tipos de papel, produzidos em formadores com diferentes configurações e modelos de telas formadoras. 


\section{REFERÊNCIAS}

ADANUR, S. Forming. In: Paper Machine Clothing, Lancaster: Technomic Publising Company, Inc., 1997, cap.2, p.33-152.

AIDUN, C.K. Hydrodynamics of streaks on the forming table. Tappi Journal, vol.80, n.8, p.157-162, 1997.

ALBANY INTERNATIONAL. Forming: Formation and Drainage. In: Felts and Fabrics. Albany: Albany International, 1976, cap.4, sec.18, p. 60. Paper Machine
Felts and Fabrics. Albany: Albany International, 1976, cap.4, sec.18, p.60.

ANTOINE, C. Wire marking and its effect upon print-through perception of newsprint. Appita Journal, v.60, n.3, p.196-203, 2007.

ASENSIO, M.C.; SEYED-YAGOOBI, J. Theoretical drying study of single-tier versus conventional two-tiered dryer configurations. Tappi Journal, vol.75, n.10, p. 203-211, 1992.

BACK, E.L.; KLINGA, L.O. The Effect of Heat Treatment on Internal Stresses and Permanent Dimensional Changes of Paper. Tappi, vol.46, n.5, p.284-288, 1963 a.

. Reactions in Dimensional Stabilization of Paper and Fibre Building Board by Heat Treatment. Svensk Papperstidning, vol.66, n.19, p.745-753, 1963 b.

BARROS, E. H. J. S. A Study of Forming Fabrics. 2002. 76 p. Essay (Master Program in Pulp and Paper) - Université du Quebec à Trois-Rivières, 2002.

BELOIT TECHNOLOGIES, INC (Wilmington, Del.). Gregory L. Wedel. Restraint dryer for the drying end of a papermaking machine and a method thereof. US 5.933.979, 10 Aug.1999.

BERAN, R.L. The Evaluation and Selection of Forming Fabrics. Tappi Journal, vol.62, n.4, p.39-44, 1979.

BERNIÉ, J.P.; DOUGLAS, W.J.M. Local grammage distribution and formation of paper by light transmission image analysis. Tappi Journal, vol.79, n.1, p.193-202, 1996.

BOSTRÖM, B. How to Measure Dimensional Stability. Paper Technology, p.45-50, Nov.2001.

BRACELPA. Relatório Anual 2009/2010 (Estatísticas BRACELPA). São Paulo: BRACELPA, 2010, 60 p. Disponível em www.bracelpa.org.br. Acesso em 08 dez. 2010. 
BRASHER, A. Image Analysis. In: PAPER TEST METHODS - WHAT'S NEW?, 1992, Leatherhead. Proceedings... Leatherhead: Pira International, 1992, 18p.

BRIGHAM, E.O. The Fast Fourier Transform and its Applications. Upper Saddle River: Prentice Hall, 1988, 448 p., ISBN 0-13-307505-2.

CASEY, J.P. Properties of Paper. In: Pulp and Paper Chemistry and Chemical Technology, 2nd ed. New York: Wiley \& Sons, 1966, vol.III: Paper Testing and Converting, cap. XVII, p.1251-1519.

CAUFIELD, D.F. Dimensional Stability of Paper: Papermaking Methods and Stabilization of Cell Walls. In: WOOD SCIENCE SEMINAR 1: STABILIZATION OF THE WOOD CELL WALL, 1987, East Lansing. Proceedings... East Lansing: Suchsland, O. (ed.), 1988, p. 87-98.

CHANCE, J.L. Restrained Drying: Commercial Experience. Appita, vol.45, n.2 p.131-133, 1992.

COOLEY, J.W.; TURKEY, J.W. An algorithm for the machine calculation of complex Fourier series. Mathematics of Computation, vol.19, n.90, p.297-301, 1965.

CONSTANTINO, R.P.A.; I'ANSON, S.J.; SAMPSON, W.W. The effect of machine conditions and furnish properties on paper CD shrinkage profile. In: FUNDAMENTAL RESEARCH SYMPOSIUM, 13.; SESSION 2: PRESSING AND DRYING, 2005, Cambridge. Proceedings... Cambridge: FRC, 2005. p.283-306.

CRESSON, T.; LUNER, P. Description of the Spatial Gray Level Dependence Method algorithm. Tappi Journal, p.220-222, Dec. 1990. Tappi Journal, p.153-159, Jul. 1990.

CRESSON, T. TOMIMASU, H.; LUNER, P. Characterization of paper formation: Part 1: sensing paper formation.

DAHL, C.K.; MINKKINEN, P.; ESBENSEN, K.H. Image analytical monitoring of paper quality: a feasibility study. Tappi Journal, vol.5, n.11, p.18-24, 2006.

DANILEWICZ, A. Image analysis - a laboratory tool. In: IMAGE ANALYSIS - WHAT'S IN IT FOR YOU?, 1991, Leatherhead. Proceedings... Leatherhead: Pira International, 1991, 35p.

DINIZ, J.M.B.F.; GIL, M.H., CASTRO, J.A.A.M. Hornification - its origins and interpretation in wood pulps. Wood Science Technology, vol.37, p.489-494, 2004. 
DINIZ, P.S.R.; SILVA, E.A.B.; LIMA NETTO, S. Transformadas Discretas. In:

Processamento Digital de Sinais: Projeto e Análise de Sistemas. Porto Alegre: Bookman, 2004 , cap.3, p. 101-159.

DOWLING, M. et al. The strength of periodic press section marks in paper. Tappi Journal, vol.4, n.4, p.9-14, 2005.

EKLUND, D. Dimensional stability of paper from different types of pulps. Papper och trä, n.2, p.153-161, 1969.

ENOMAE, T.; HAN, Y.H.; ISOGAI, A. Fiber orientation distribution of paper surface calculated by image analysis. Tianjin Keji Daxue Xuebao, vol. 19, supp.2, p.51-57, 2004.

. Non destructive examination of fiber orientation distribution of paper surface by image analysis. Nordic Pulp and Paper Research Journal, vol.21, n.2, p.253-259, 2006.

ENOMAE, T.; KUGA, S. Methodology to use flat-bed image scanner for formation analysis of paper. Japan Tappi Journal, vol.56, n.4, p.549-556, 2002.

FAGERHOLM, L. Dryer fabrics. In: KARLSSON, M. (Ed.). Papermaking Part 2, Drying. Helsink: Fapet Oy, 2000, cap.12, p.433-457. (Papermaking Science and Technology, Book 9).

FELLERS, C. et al. Condbelt drying and linerboard performance. In: TAPPI INTERNATIONAL PAPER PHYSICS CONFERENCE, 2003, Victoria. Proceedings... Norcross: TAPPI, 2003, p.143-150.

FIADEIRO et al. The Surface Measurement of Fibre Orientation Anisotropy and Misalignment Angle by Laser Diffraction. Journal of Pulp and Paper Science, vol.28, n.10, 2002.

FOREL, F. et al. Effects of Forming Fabric Design on Drainage, Paper Quality and Linting - Pilot Machine Trials. In: TAPPI PAPERCON'09 CONFERENCE, 2009, St. Louis. Proceedings... Norcross: TAPPI, 2009, 18p.

GALLAY, W. Stability of Dimensions and Forms of Paper (first part). Tappi, vol.56, n.11, p.54-63, 1973a. $1973 \mathrm{~b}$. Stability of Dimensions and Forms of Paper (second part). Tappi, vol.56, n.12, p.90-95, 
GATES, E.R.; KENWORTHY, I.C. Effects of drying shrinkage and fibre orientation on some physical properties of paper. Paper Technology, vol.4, n.5, p.485-492, 1963.

GESS, J.M.; Wilson, P.H. Problems Related to Paper. In: Papermaking Process. Atlanta: TAPPI PRESS, 2001, cap.6, p.135-149. Troubleshooting the

GONZALEZ, R.C.; WOODS, R.E. Digital Image Processing. 3rd ed. Upper Saddle River: Pearson Prentice Hall, 2008. 954p.

GONZALEZ, R.C.; WOODS, R.E.; EDDINS, S.L. Digital Image Processing using MATLAB. Upper Saddle River: Pearson Prentice Hall, 2004. 609p.

GUESAlAGA, A. et al. On-Line Measurement of Paper Shrinkage for Monitoring and Quality Control. Pulp \& Paper Canada, vol.95, n.7, p.36-39, 1994.

GUESALAGA, A.R.; CABEZAS, F.M.; GOTTSCHALK, C. Measuring physical properties of paper with an on-line visual sensor. Measurement Science \& Techonology, vol.8, n.5, p.574-580, 1997.

HAARLA, A. Printing and writing papers. In: PAULAPURO, H. (Ed.). Paper and Board Grades. Helsink: Fapet Oy, 2000, cap.1, p.13-53. (Papermaking Science and Technology, Book 18).

HAMMING, R.W. The Fast Fourier Transform. In: . Numerical Methods for Scientists and Engineers. $2^{\text {nd }}$ ed. New York: Dover Publications, 1987, cap. 33, p. 539-547.

HANSSON, P.; MANNEBERG, G. Fourier optic online measurement of the dimensional variations in paper. Optical Engineering, vol.38, n.10, p.1683-1687, 1999.

HAY, S. Forming Fabrics for graphic papers. Twogether / Voith Paper, n.13, p.47-51, 2002.

HEIKKILÄ, P.; TIMOFEEV, O.; KIISKINEN, H. Multicylinder dryer. In: KARLSSON, M. (Ed.). Papermaking Part 2, Drying. Helsink: Fapet Oy, 2000, cap.3, p.85-125. (Papermaking Science and Technology, Book 9).

HENDER, B. Warp Exchange Technology: Pushing the Limits of Forming Fabric Performance. PrintForm EX Technical Article. Disponível em: <http://www.printform. voithpaper.com/vf_en_printform_technical-article.htm>. Acesso em: 20 abr. 2009. 
HIRN, U.; LECHTHALER, M.; BAUER, W. Registration and point wise correlation of local paper properties. Nordic Pulp and Paper Research Journal, vol.23, n.4, p.374-381, 2008.

HOOLE, S. Paper Diagnostics: Using the Eureka System to identify periodic sheet mark. Twogether / Voith Paper, n.14, p.58-60, 2002.

HOOLE, S.M. et al. CD Shrinkage Profiles of Paper - Experiments on a Commercial Paper Machine. Paper Technology, p.63-70, Dec.1999.

HOOLE, S.M.; I'ANSON, S.J.; HOYLAND, R.W. CD Shrinkage Profiles on a Commercial Paper Machine. In: PAPER SCIENCE RESEARCH FORUM, 2000, Manchester. Proceedings... Manchester, 2000. p.1-11.

HUMPHREY, K. Image analysis. Surrey: Pira International, 1998. 126 p. (Pira reviews of Pulp and Paper technology).

HUYCK.WANGNER (Xerium Technologies, Inc.). Forming Fabrics. Disponível em: $<$ http:// www.xerium.com/huyckwangnerasia/products/pulpPaperIndustry/formingFabrics.aspx $>$. Acesso em: 13 ago. 2010.

I'ANSON, S. Identification of periodic marks in paper and board by image analysis using two dimensional fast Fourier transforms: Part 1: The basics. Tappi Journal, vol.78, n.3, p.113-119, 1995a.

Identification of periodic marks in paper and board by image analysis using two dimensional fast Fourier transforms: Part 2: Forming and press section marks. Tappi Journal, vol.78, n.7, p.97-106, 1995b.

. Analysis of Paper and Dryer Fabric Surfaces using 3D Laser Technology: Wire, Roll and Fabric Marks, Roughness of Paper and Surface Volume of Fabrics. In: PTS SYMPOSIUM: IMAGE ANALYSIS FOR QUALITY ASSURANCE AND ENHANCED PRODUCTIVITY. Proceedings... PTS, 1998, p.1-9.

FFT Filtering Control 1.1 - Shrinkage Profile Control (SP3_4). Manchester, 2008. Personal pages. Disponível em: <http://personalpages.manchester.ac.uk/staff/Steve.I'Anson/FFC /FFC_home.html>. Acesso em: 09 nov. 2008.

I'ANSON, S.J. The fundamentals of digital image analysis and its application to paper and board making problems. UMIST, Manchester, 2001. Disponível em: $<\mathrm{http}: / /$ pygard.ps.umist.ac. uk/ ianson>. Acesso em: 07 maio 2009. 
. Analysis of the Periodic Components of Paper Structure. Institute of Physics, London. Jan. 2004. Newsletter, p.17. Disponível em: <http://www.iop.org/activity/groups/subject/ pgs/Newsletter/file_7766.pdf>. Acesso em: 19 jan. 2009.

I'ANSON, S.J.; EGHTERATI, A. A method for quantitative anlysis of $\mathrm{TiO}_{2}$ floculation in paper by image analysis. Tappi Journal, vol.75, n.11, p.169-174, 1992.

I'ANSON, S.J. et al. The use of image analysis to measure dimensional changes during paper manufacturing. In: IEE COLLOQUIUM ON COMPUTER IMAGE PROCESSING AND PLANT CONTROL, 1990, London. Proceedings... London: IEE, 1990, p.6/1-6/4.

. Estimation of the profile of the cross-machine shrinkage of paper. Measurement Science

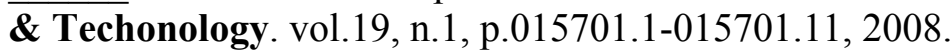

I'ANSON, S.J.; KROPHOLLER, H.W. Enhancing Visibility of Wire Mark by Image Analysis. Journal of Pulp and Paper Science, vol.17, n.1, p.J22-J26, 1991.

I'ANSON, S.J.; SAMPSON, W.W. Fourier domain analysis of 2D stochastic textures to yield scale dependent variance statistics at arbitrary scales. UMIST, Manchester, 2001. Disponível em: < http://pygarg.ps.umist.ac.uk/sampson>. Acesso em: 21 abr. 2006.

Determination of spatial domain formation statistics using the Fast Fourier Transform. Paperi ja Puu - Paper and Timber, vol.85, n.7, p.403-408, 2003.

- Estimating Paper Machine CD Shrinkage from Headbox Actuator Data. Paper Techology, vol.45, n.1, p.25-29, 2004.

ILVESPA, H.; KUHASALO, A.; YLI-KAUPPILA, J. Single-Felted Drying Boosts Paper Machine Efficiency, Paper Quality. Pulp \& Paper, vol.65, n.3, p.134-136, 1991.

INTERNATIONAL ORGANIZATION FOR STANDARDIZATION. ISO 8226-1: Paper and board Measurement of hygroexpansivity - Part 1: Hygroexpansivity up to a maximum relative humidity of $68 \%$. Geneva. 1994. 12p.

JAYME, G. Properties of Wood Celluloses: II. Determination and Significance of Water Retention Value. Tappi, vol.41, n.11, p.180A-183A, 1958.

JACKSON, T.G.; ROTHBARD, D.R. Exploring frequency space: Applying the 2D-FFT. TAPPI PROCESS \& PRODUCT QUALITY CONFERENCE, 1999, Anaheim. Proceedings ... Norcross: TAPPI, 1999, 30p. 
JOHANSSON, P.A.; ALEXIS, R. Improvement in Runnability and Printability of Paper and Board. In: EUCEPA SYMPOSIUM, 1992, Budapest. Proceedings... Budapest: Papir, 1992, vol.1, p.144-148.

JOHNSON, D.B. Retention and Drainage of Multi-Layer Fabrics. Pulp and Paper Canada, vol.87, n.5, p.56-59, 1986.

JORDAN. B. D. Is line-scan analysis of formation flawed? Tappi Journal, v.67, n.11, p.118-119, 1984.

JORDAN, B.D.; NGUYEN, N.G. Emulating the Tappi Dirt Count with a microcomputer. Journal of Pulp and Paper Science, vol.14, n.1, p.116-118, 1988.

JUPPI, K.; KAIHOVIRTA, J. Paper quality control in a dryer section. In: INTERNATIONAL CONFERENCE ON NEW AVAILABLE TECHNOLOGIES, 7., 2002, Stockholm. Proceedings... Stockholm: SPCI, 2002. p.55-59.

. The effect of the dryer section on paper quality: the benefits of reducing the wet draw.

Pulp \& Paper Canada, v.104, n.5, p.T131-T134, 2003.

KAESTNER, A.P.; NILSON, C.M. Estimating the relative shrinkage profile of newsprint. Optical Engineering, vol.42. n.5, p.1467-1475, 2003.

KAJANTO, I.; NISKANEN, K. Dimensional stability. In: NISKANEN, K. (Ed.). Paper Physics. Helsink: Fapet Oy, 1998, cap.7, p.233-260. (Papermaking Science and Technology, Book 16).

KATO, K.L.; CAMERON, R.E. A review of the relationship between thermally-accelerated ageing of paper and hornification. Cellulose, vol.6, n.1, p.23-40, 1999.

KELLOMÄKI, M.; JETSU, P. Grainninesss for formation. In: TAPPI INTERNATIONAL PAPER PHYSICS CONFERENCE, 2003, Victoria. Proceedings... Norcross: TAPPI, 2003, p.193-200.

KERSHAW, C. Structurally bound Forming Fabrics (SSB Fabrics). Press Release. Disponível em: <http://www.heimbach.com/fileadmin/user_upload/HEIMBACH_DAM/2000_PA/2200_Ve reffentlichungen/2210_PDFs/25_Structurally_bound_Forming_Fabrics.p.pdf $>$. Acesso em: $24 \overline{\mathrm{fev}}$. 2010.

KIISLINEN, H.; PALTAKARI, J.; PAKARINEN, P. Drying and paper quality. In: KARLSSON, M. (Ed.). Papermaking Part 2, Drying. Helsink: Fapet Oy, 2000, cap.10, p.332-368. (Papermaking Science and Technology, Book 9). 
KILPELÄINEN, R. et al. Forming Fabrics. In: PAULAPURO, H. (Ed.). Papermaking Part 1, Stock Preparation and Wet End. Helsink: Fapet Oy, 2000, cap.7, p.253-283. (Papermaking Science and Technology, Book 8).

KIVIRANTA et al. Drying of paperboard and packaging grades. In: KARLSSON, M. (Ed.). Papermaking Part 2, Drying. Helsink: Fapet Oy, 2000, cap.6, p.186-207. (Papermaking Science and Technology, Book 9).

KOUKOULAS, A.A.; NGUYEN, N.; JORDAN, B.D. Measuring Fabric Mark in Board Using Image Analysis. Journal of Pulp and Paper Science, vol.20, n.8, p. J220-J225, 1994.

KUNNAS, L. et al. The effect of Condbelt drying on the structure of fiber bonds. In: TAPPI PAPERMAKERS CONFERENCE, 1993. Proceedings... Norcross: TAPPI, 1993, p.335-345. Tappi Journal, vol.76, n.4, p.95-104.

LARSON, P.A. et al. A novel approach to study the hydroexpansion mechanism of paper using spray technique. Nordic Pulp and Paper Research Journal, vol. 24, n.4, p.371-380, 2009.

LAVRYKOV, S.; LYNE, O.L.; RAMARAO, B.V. A mathematical model for the transient hygroexpansivity of copy paper. In: TAPPI INTERNATIONAL PAPER PHYSICS CONFERENCE, 2003, Victoria. Proceedings... Norcross: TAPPI, 2003, p.273-276.

LIF, J.O. et al. Characterizing the In-Plane Hygroexpansivity of Paper by Electronic Speckle Photography. Journal of Pulp and Paper Science, vol.21, n.9, p.J302-J309, 1995.

LINDBLAT, G.; FÜRST, T. The Ultrassonic Measuring Technology on Paper and Board. 1st ed. Kista: Lorentz \& Wettre, 2001. 98p.

LINDEM, P.E. Biaxial hygroexpansion of newsprint paper. Nordic Pulp and Paper Research Journal, vol.10, n.3, p.167-173 e 182, 1995.

LIPPONEN, P.; LEPPÄNEN, T.; HÄMÄLÄINEN, J. On teh role of drying cross-machine shrinkage on paper cockling phenomenon. Nordic Pulp and Paper Research Journal, vol.24, n.1, p.60-65, 2009.

LOBOSCO, V.; NORMAN, B.; ÖSLUND, S. Modelling of forming and densification of fibre mats in twin-wire formers. Nordic Pulp and Paper Research Journal, vol.20, n.1, p.16-23, 2005 .

LYNE, L.M.; GALLAY, W. The effect of drying and heating on the swelling of cellulose fibers and paper strength. Tappi, vol.33, n.9, p.429-435, 1950. 
MacGREGOR, M.A. The technical challenges of making better paper - preparing for 21st century. In: TAPPI ENGINEERING CONFERENCE, 1992, Boston. Proceedings... Atlanta: TAPPI PRESS, vol.1, p.39-54.

2001.

. Some impacts of paper making on paper structure. Paper Technology, p.30-44, Apr.

MacGREGOR, M.A.; CORNNERS, T.E. Image analysis of an LWC paper reveals wire mark in the print density variations. In: TAPPI ENGINEERING CONFERNCE, 1987, New Orleans. Proceedings... Atlanta: TAPPI PRESS, 1987, 21p.

MÄKELÄ, P. Analysis of the paper web during its passage through the drying section. In: TAPPI INTERNATIONAL PAPER PHYSICS CONFERENCE, 2003, Victoria. Proceedings... Norcross: TAPPI, 2003, p.151-155.

MATTIJSSEN, J. Effective forming fabric concepts - for economical paper and board production. Twogether / Voith Paper, n.23, p.52-55, 2007.

. Expand the operating window: The new PrintForm / MultiForm Horizon product range. Twogether / Voith Paper, n.25, p.44-46, 2008.

MAURO, E.C.; WADHAMS, K.R.; WELLSTEAD, P.E. On and off-line measurement of paper shrinkage. In: INTERNATIONAL CONFERENCE ON CONTROL, 1994, Coventry. Proceedings... Herts: IET, 1994, p.1229-1234.

MENDES, A.H.T. Higroexpansibilidade de papel reprográfico produzido com fibras de eucalipto em máquina industrial. 2006. 141p. Dissertação (Mestrado em Engenharia) - Escola Politécnica, Departamento de Engenharia Química, Universidade de São Paulo, 2006.

MIYATA, H.; SHINOZAKI, M. Studies on Change of Wire-Marks on Paper. Sen'I Gakkaishi, vol.59, n.8, p.311-318, 2003.

NANKO, H.; ASANO, S.; OHSAWA, J. Shrinking behavior of pulp fibers during drying. TAPPI INTERNATIONAL PAPER PHYSICS CONFERENCE, 1991, Kona. Proceedings... Norcross: TAPPI, 1991, p. 365-374.

NANKO, H.; OHSAWA, J. Scanning Laser Microscopy of the Drying Process of Wet Web. Journal of Pulp and Paper Science, vol.16, n.1, p.J6-J12, 1990. 
NANKO, H.; TADA, Y. Mechanism of hygroexpansion of paper. In: TAPPI INTERNATIONAL PAPER PHYSICS CONFERENCE, 1995, Niagara-on-the-Lake. Proceedings... Norcross: TAPPI, 1995, p.159-171.

NANKO, H.; WU, J. Mechanism of paper shrinkage during drying. In: TAPPI INTERNATIONAL PAPER PHYSICS CONFERENCE, 1995, Niagara-on-the-Lake. Proceedings... Norcross: TAPPI, 1995, p.103-113.

NANRI, Y.; UESAKA, T. Dimensional stability of mechanical pulps - drying shrinkage and hygroexpansivity. Tappi Journal, vol.76, n.6, p.62-66, 1993.

NISKANEN, K.; KÄRENLAMPI. In-plane tensile properties. In: NISKANEN, K. (Ed.). Paper Physics. Helsink: Fapet Oy, 1998, cap.5, p.139-191. (Papermaking Science and Technology, Book 16).

NORDMAN, L.S. Laboratory Investigations into the Dimensional Stability of Paper. Tappi, vol.41, n.1, p.23-30, 1958.

NORMAN, B.; SÖDERBERG, D. Overview of forming literature, 1990-2000. In: FUNDAMENTAL RESEARCH SYMPOSIUM, 12., SESSION 3: FORMING, 2001, Oxford. Proceedings... Cambridge: FRC, 2001, p.431-558.

OITTINEN, P.; SAARELMA, H. (Ed.). Electronic Printing. In: Printing. Helsink: Fapet Oy, 1998, cap.6, p.173-191. (Papermaking Science and Technology, Book 13).

OLOFSSON, K.; MOLIN, N.E.; KYOSTI, A. Mechanical properties of corrugated board as studied by holographic interferometry. Tappi Journal, p.86-93, Oct. 1992.

OLSON, J.L.; HANARP, L.R. Surface structure and uniformity of paper machine clothing: Topography goes beyond smoothness measurement. Pulp \& Paper Canada, vol.93, n.5. p.T127-T131, 1992.

PAGE, D.H.; TYDEMAN, P. A. A new theory of the shrinkage, structure and properties of paper. In: Bolan, F. (Ed.). The Formation and Structure of Paper. London: B.P.\&B.M.A, 1962, vol.1, p.397-413.

. Physical process occurring during the drying phase. In: BOLAN, F. (Ed.). Consolidation of the paper web. London: B.P.\&B.M.A., 1966, vol.1, p.371-392.

PALAZZOLO, S. No-draw drying. In: TAPPI ENGINEERING CONFERENCE, 1990. Proceedings... Norcross: TAPPI, 1990, p.915-918. Tappi Journal, p.225-228, Sep. 1990. 
PAUKKU, J.; PAROLA, M. Measurement Method and Analysis of Dynamic Dimensional Stability of Paper Web. In: TAGA ANNUAL TECHNICAL CONFERENCE, 56., 2004, San Antonio. Proceedings... TAGA, 2004, 17p.

PHILLIPS, B.R.; I'ANSON, S.J.; HOOLE, S.M. CD shrinkage profiles of paper - curve fitting and quantitative analysis. Appita Journal. Vol.55, n.3, p.235-239, 2002.

PORCHIA, L.F. Formadores. In: Curso de Especialização em Papel e Celulose PECE/EPUSP, Módulo PC 008 - Máquina de Papel Seção 4, 2004, Limeira. Apresentações de aula...São Paulo: CENTRE, 2004. 1 CD-ROM.

PRAAST, H. Image Analysis - A Tool for Pulp and Paper Testing. Part II. Das Papier, v.50, n.10A, p.V97-V101, 1996.

PRAAST, H.; GÖTTSCHING L. Analysis of Wire Marks in Light Transmission. Das Papier, vol.41, n.3, p.105-120, 1987

. Marking and formation of printing paper. Das Papier, v.41, n.10A, p.V167-V182, 1987.

. Detailed Analysis of Geometry and Intensity of Wire Marks. Das Papier, v.44, n.10, p.529-537, 1990.

. Differencial CD Shrinkage of Paper Webs. Das Papier, vol.49, n.4, p.151-161, 1995.

PRAAST, H.; GREVE, T.; GÖTTSCHING. The image analyzer and its Application for the Analysis of Paper. Das Papier, vol.40, n.4, p.141-150, 1986.

PRESS, W.H. et al. Fast Fourier Transform. In: Numerical Recipes: The Art of Scientific Computing. 3rd ed. Cambridge: Cambridge University Press, 2007. cap.12, p.600-639.

PULKOWISKI, J.H. Operating results with the Bel-Champ single tier dryer. In: TAPPI ENGINEERING CONFERENCE, 1990. Proceedings... Norcross: TAPPI, 1990, p.393-398.

. Restraint drying with the Bel-Champ single tier dryer. In: CPPA Annual Meeting, Montreal, 1991. Proceedings ... Montreal: CPPA, 1991, 6p.

RANCE, H.F. Effect of water removal on sheet properties. Tappi, vol. 37, n.12, p.640-654, 1954. 
ROGOWSKI, D. Identification and elimination of roughness patterns in coated products. Tappi Journal, vol.78, n.5. p.189-198, 1995.

ROUNDS, D.A. Runnability and restraint in a single-tier dryer section. Pulp \& Paper Canada, vol.23, n.1, p.T-11-T16, 1992.

RÜHL, T.; HÖHSL, M. Development aimed at meeting multiple customer goals: Newsprint paper at the highest speeds and of excellent quality. Twogether / Voith Paper, n.26, p.38-41, 2008.

SALMÉN, L.; FELLERS, C.; HTUN, M. The in-plane and out-of-plane hygroexpansional properties of paper. In: Punton, V. (Ed.). Papermaking Raw Materials. London: MEP, 1985, vol.2, p.511-527.

. The development and release of dried-in stress in paper. Nordic Pulp and Paper Research Journal, vol.2, n.2, p.44-48, 1987.

ROY, R. N. Modern Developments in Forming Fabric Designs and their Application in the Paper Industry. IPPTA Journal, vol.21, n.4, p.95-102, 2009.

SALMÉN, L. et al. The implications of fiber and sheet structure for the hygroexpansivity of paper. Nordic Pulp and Paper Research Journal, vol.2, n.4, p.127-131, 1987.

SALMINEN, L.I.; ALAVA, M.J. Simulation of network shrinkage. Nordic Pulp and Paper Research Journal, vol.17, n.2, p.105-110, 2002.

SCOTT, D.; BLISS T. Image analysis: a primer. In: TAPPI DEINKING SHORT COURSE, 1993, Indianapolis. Proceedings... Atlanta: TAPPI PRESS, 1993. 11 p.

SCOTT, W.E.; ABOTT J.C.; TROSSET S. The influence of Environment on Paper Properties. In: $\overline{\text { p.111-122. }}$

Properties of papers: An introduction, 2nd ed., Atlanta: TAPPI PRESS, 1995, cap.6,

SETTERHOLM, V.C.; CHILSON, W.A. Drying restraint - Its Effect on the Tensile Properties of 15 Different Pulps. Tappi, vol.48, n.11, p.634-640, 1965.

SETTERHOLM, V.; KUENZI, E.W. Fiber Orientation and Degree of Restraint during Drying: Effect on Tensile Anisotropy of Paper Handsheets. Tappi, vol.53, n.10, p.1915-1920, 1970.

SIMS JR., D.N.; GRUNDER, T.K. Enhanced runnability and improved sheet properties with a single-tier dryer section. In: TAPPI ENGINEERING CONFERENCE, 1991. Proceedings... Norcross: TAPPI, 1991, p. 313-319. 
SHANDS, J.A.; GENCO, J.M. Cross machine variations of paper curl on a twin wire machine. Tappi Journal, vol.71, n.9, p.165-169, 1988.

SZIKLA, Z. PAULAPURO, H. Changes in z-direction density distribution of paper in wet pressing. Journal of Pulp and Paper Science, vol.15, n.1, p.11-17, 1989.

TAYLOR, C.J. Forming a quality sheet on a robust fabric, the perfect combination: Forming fabric PrintForm / MultiForm HR. Twogether / Voith Paper, n.26, p.42-44, 2008.

TECHNICAL ASSOCIATION OF THE PULP AND PAPER INDUSTRY. UM 256: Water Retention Value. Norcross, 1981.

TIP 0804-09: Basic Guidelines for Image Analysis Measurements. Norcross, 2001. 3p.

. T 402 sp-08: Standard conditioning and testing atmospheres for paper, board, pulp handsheets and related products. Norcross, 2008. 5p.

TOMIMASU, H. et al. Comparison of four paper imaging techniques: $\beta$-radiography, electrography, lighr transmission and X-radiography. Tappi Journal, p.165-176, July 1991.

TYDEMAN, P.A.; WEMBRIDGE, D.R.; PAGE, D.H. Transverse shrinkage of individual fibres by micro-radiography. In: BOLAN, F. (Ed.). Consolidation of the paper web. London: B.P.\&B.M.A., 1966, vol.1, p.119-144.

UESAKA, T. Dimensional Stability of Paper: Upgrading Paper Performance in End Use. Journal of Pulp and Paper Science, vol.17, n.2, p.J39-J46, 1991.

. Dimensional stability and environmental effects on paper properties. In: Mark, E.M. at al (Ed.). Handbook of Physical Testing of Paper. 2nd ed. New York: Marcel Dekker, 2002, vol.1, cap.3, p.115-171.

UESAKA, T. et al. History-dependent dimensional stability of paper. Rheologica Acta, vol.28, n.3, p.238-245, 1989.

UESAKA, T.; MOSS, S.; NANRI, Y. The characterization of hygroexpansivity of paper. In: TAPPI INTERNATIONAL PAPER PHYSICS CONFERENCE, 1991, Kona. Proceedings... Norcross: TAPPI, 1991, p.613-622.

. The characterization of hygroexpansivity of paper. Journal of Pulp and Paper Science, vol.18, n.1, p.J11-J16, 1992. 
General formula for hygroexpansion of paper. Journal of Materials Science, vol. 29, n.9, p.2373-2377, 1994.

UESAKA, T.; QI, D. Hygroexpansivity of paper: Effects of fiber-to-fiber bonding. Journal of Pulp and Paper Science, vol.20, n.6, p.J175-J179, 1994.

VAINIO, A.; PAULAPURO, H. Interfiber bonding and fiber segment activation in paper. BioResources, vol.2, n.3, p.442-458, 2007.

VILLFORTH, K.; SCHABEL, S. Wire marks analysis - estimation of web deformation. In: BIENNIAL JOHAN GULLISCHEN COLLOQUIUM, 5., Helsinki, 2005. Proceedings... Helsink: PI, 2005, p.53-59.

VIITAHARJU, P.H.; NISKANEN, K.J. Dried-in shrinkage profiles of paper webs. Tappi Journal, vol.76, n.8, p.129-134, 1993.

WADHAMS, K.R. et al. The measurement of differential CD shrinkage. Paper Technology, p.36-38, Jan. 1991.

WAHLSTRÖM, T. Influence of shrinkage and stretch during drying on paper properties. Paper Tecnology, vol.41, n.6, p.39-46, 2000.

WAHLSTRÖM, T. et al. Numerical modeling of the cross direction shrinkage profile in a dryer section, a first approach. In: TAPPI INTERNATIONAL PAPER PHYSICS CONFERENCE, 1999, San Diego. Proceedings...Norcross: TAPPI, 1999, p.1-15.

WAHLSTRÖM, T.; LIF, J.O. Dryer Section Simulator for Laboratory Investigations of Shrinkage Profile. In: TAPPI INTERNATIONAL PAPER PHYSICS CONFERENCE, 2003, Victoria. Proceedings... Norcross: TAPPI, 2003, p.169-174.

WALLER, M.H. On-line papermaking sensors: an historical perspective. In: FUNDAMENTAL RESEARCH SYMPOSIUM: SESSION 5: SENSORS AND MEASUREMENT, 12., 2001, Oxford. Proceedings... Cambridge: FRC, 2001, p.785-895.

WATANABE, M.; SAWA, Y.; ABE, Y. Study on the heat contraction behaviour of paper. Appita Journal, v.44, n.3, p.205-208, 1991.

WATERHOUSE, J.F. Paper properties and converting. IPC Technical Paper Series, n.162, 8p., 1985. 
WEAVEXX CORPORATION (Xerium Technology, Inc.). Forming Fabric Terminology. Disponível em: <http:/www.xerium.com/weavexx/Files/PDF/Forming/Forming\%20Fabric\% 20Terminology.pdf>. Acesso em: 14 ago. 2010.

WEDEL, G.L. No-draw drying restraint. Tappi Journal, p.93-97, Apr. 1989a.

. Drying restraint in a single-tier dryer section. In: TAPPI ANNUAL MEETING, 1989. Proceedings... TAPPI, 1989b. p.23-28.

WEDEL, G.L.; MENDES, A.H.T. Bel-Run: A secagem com suporte total da folha. In: CONGRESSO ANUAL DE CElUlose E PAPEL, 25., 1992, São Paulo. Anais... São Paulo: ABTCP, 1992, p.607-617.

WEDEL, G.L.; PALAZZOLO, S. Advances in dryer section runnability. Tappi Journal, p.65-69, Sep. 1987.

WEISE, U. Characterization and mechanisms of changes in wood pulp fibers caused by water removal. 1997. PhD Thesis. Helsinki University of Technology, Helsinki, Helsinki, 1997.

WEISE, U.; MANOLEY, T.; PAULAPURO, H. Quantification of water in different states of interaction with wood pulp fibres. Cellulose, vol.3, n.4, p.189-202, 1996.

WESTERKAMP, A. Forming Fabrics. In: HOLIK, H. (Ed.). Handbook of Paper and Board. Weinheim: WILEY-VCH, 2006. cap. 6, p.243-248. 


\section{APÊNDICE A PROPRIEDADES DO PAPEL REPROGRÁFICO - I}

Tabela A.1. Resultados de medições de propriedades realizadas em amostras de papel reprográfico de 75 g.m ${ }^{-2}$, utilizado neste trabalho, referente à produção com velocidade de máquina de $1256 \mathrm{~m} \cdot \mathrm{min}^{-1}$ e largura do papel na enroladeira de $5278 \mathrm{~mm}$ [Mendes, 2006]. (continua)

\begin{tabular}{|c|c|c|c|c|c|c|}
\hline \multirow{2}{*}{ Propriedades do papel } & & \multicolumn{5}{|c|}{ Posição transversal na enroladeira (a partir do LC) } \\
\hline & & 1 & 2 & 3 & 4 & 5 \\
\hline$\overline{\text { Gramatura, g.m }}{ }^{-2}$ & & 77,7 & 77,5 & 77,4 & 77,1 & 77,2 \\
\hline Espessura, $\mu \mathrm{m}$ & & 96 & 97 & 98 & 99 & 100 \\
\hline Corpo $($ bulk $), \mathrm{cm}^{3} \cdot \mathrm{g}^{-1}$ & & 1,24 & 1,26 & 1,25 & 1,27 & 1,30 \\
\hline \multirow[t]{2}{*}{ Umidade $^{198}, \%$} & $0^{\prime}$ & 3,9 & 3,6 & 3,6 & 3,8 & 4,0 \\
\hline & $30^{\prime}$ & 6,5 & 7,0 & 6,8 & 6,6 & 7,3 \\
\hline Carga Mineral, \% & & 17,9 & 18,2 & 18,1 & 17,9 & 18,0 \\
\hline Formação - índice, g.m -2 $^{2}$ & & 4,81 & 4,92 & 5,05 & 4,89 & 4,86 \\
\hline Formação, específica, $\mathrm{g}^{1 / 2} \cdot \mathrm{m}^{-1}$ & & 0,55 & 0,56 & 0,58 & 0,55 & 0,56 \\
\hline $\mathrm{TSO}^{\circ}{ }^{\circ}$ (grau) & MD & $-5,20$ & $-6,56$ & $-3,40$ & $-1,06$ & $-1,88$ \\
\hline TSI & $\mathrm{MD} / \mathrm{CD}$ & 3,34 & 3,18 & 3,11 & 3,03 & 2,86 \\
\hline Porosidade (Gurley) s $/ 100 \mathrm{ml}$ & & 11,6 & 11,4 & 11,2 & 10,9 & 11,2 \\
\hline \multirow[t]{2}{*}{ Aspereza (Bendtsen) $\mathrm{ml} \cdot \mathrm{min}^{-1}$} & LF & 173 & 195 & 185 & 211 & 200 \\
\hline & LT & 178 & 188 & 188 & 214 & 211 \\
\hline \multirow[t]{3}{*}{ Resistência à Tração, $\mathrm{kN} \cdot \mathrm{m}^{-1}$} & MD & 5,74 & 5,29 & 6,19 & 5,81 & 5,98 \\
\hline & $\mathrm{CD}$ & 1,64 & 1,68 & 1,75 & 1,77 & 2,00 \\
\hline & $\mathrm{MD} / \mathrm{CD}$ & 3,50 & 3,15 & 3,54 & 3,29 & 2,99 \\
\hline \multirow[t]{2}{*}{ Índice de Tração, N.m.g ${ }^{-1}$} & MD & 73,84 & 68,31 & 80,01 & 75,30 & 77,50 \\
\hline & $\mathrm{CD}$ & 21,12 & 21,72 & 22,59 & 22,89 & 25,90 \\
\hline \multirow[t]{2}{*}{ Alongamento, $\%$} & MD & 2,6 & 2,5 & 2,6 & 2,6 & 2,4 \\
\hline & $\mathrm{CD}$ & 8,5 & 7,7 & 7,4 & 6,5 & 6,2 \\
\hline \multirow[t]{2}{*}{ Energia absorvida na tração, $\mathrm{J}^{-\mathrm{m}^{-2}}$} & MD & 99,1 & 87,8 & 107,8 & 101,3 & 96,3 \\
\hline & $\mathrm{CD}$ & 108,9 & 100,8 & 99,8 & 88,5 & 96,5 \\
\hline \multirow[t]{2}{*}{ Rigidez à tração, $\mathrm{kN} \cdot \mathrm{m}^{-1}$} & MD & 619,3 & 596,9 & 638,8 & 628,0 & 651,9 \\
\hline & $\mathrm{CD}$ & 136,5 & 148,8 & 159,2 & 162,3 & 188,0 \\
\hline \multirow[t]{2}{*}{ Módulo de Elasticidade, GPa } & MD & 6,45 & 6,09 & 6,59 & 6,41 & 6,52 \\
\hline & $\mathrm{CD}$ & 1,42 & 1,52 & 1,64 & 1,66 & 1,88 \\
\hline \multirow[t]{2}{*}{ Comprimento Auto-Ruptura, km } & MD & 7,53 & 6,96 & 8,16 & 7,68 & 7,90 \\
\hline & $\mathrm{CD}$ & 2,15 & 2,21 & 2,30 & 2,33 & 2,64 \\
\hline \multirow[t]{2}{*}{ Resistência ao Rasgo, gf } & MD & 54,3 & 54,8 & 53,2 & 54,3 & 55,8 \\
\hline & $\mathrm{CD}$ & 69,5 & 71,1 & 69,3 & 67,6 & 65,1 \\
\hline \multirow[t]{2}{*}{ Rigidez (Taber), gf.cm } & MD & 2,05 & 2,05 & 2,17 & 2,11 & 2,17 \\
\hline & $\mathrm{CD}$ & 0,64 & 0,67 & 0,73 & 0,73 & 0,80 \\
\hline Resistência Estouro (Mullen), kPa & & 211,0 & 212,9 & 226,2 & 222,1 & 233,7 \\
\hline \multirow{2}{*}{ Higroexpansibilidade, $\%$} & MD & 0,151 & 0,126 & 0,123 & 0,136 & 0,148 \\
\hline & $\mathrm{CD}$ & 0,736 & 0,702 & 0,570 & 0,560 & 0,558 \\
\hline
\end{tabular}

${ }^{198}$ Valores iniciais e após 30 minutos de condicionamento no ambiente do laboratório. 
Tabela A.1. Resultados de medições de propriedades realizadas em amostras de papel reprográfico de 75 g.m ${ }^{-2}$, utilizado neste trabalho, referente à produção com velocidade de máquina de $1256 \mathrm{~m} \cdot \mathrm{min}^{-1}$ e largura do papel na enroladeira de $5278 \mathrm{~mm}$ [Mendes, 2006]. (final)

\begin{tabular}{|c|c|c|c|c|c|c|}
\hline \multirow{2}{*}{ Propriedades do papel } & & \multicolumn{5}{|c|}{ Posição transversal da enroladeira (a partir do LC) } \\
\hline & & 6 & 7 & 8 & 9 & 10 \\
\hline \multicolumn{2}{|l|}{$\overline{\text { Gramatura, g.m }{ }^{-2}}$} & 76,96 & 76,85 & 77,06 & 77,02 & 77,23 \\
\hline \multicolumn{2}{|l|}{ Espessura, $\mu \mathrm{m}$} & 99 & 100 & 100 & 98 & 98 \\
\hline \multicolumn{2}{|l|}{ Corpo (bulk), $\mathrm{cm}^{3} \cdot \mathrm{g}^{-1}$} & 1,29 & 1,29 & 1,30 & 1,27 & 1,24 \\
\hline \multirow[t]{2}{*}{ Umidade $^{199}, \%$} & $0^{\prime}$ & 3,8 & 3,5 & 3,4 & 3,4 & 3,3 \\
\hline & $30^{\prime}$ & 7,4 & 7,3 & 7,0 & 7,2 & 7,1 \\
\hline \multicolumn{2}{|l|}{ Carga Mineral, \% } & 17,9 & 18,3 & 18,5 & 18,7 & 18,5 \\
\hline \multicolumn{2}{|l|}{ Formação - índice, g.m² } & 4,79 & 5,08 & 4,69 & 4,93 & 4,95 \\
\hline \multicolumn{2}{|l|}{ Formação, específica, $\mathrm{g}^{1 / 2} \cdot \mathrm{m}^{-1}$} & 0,55 & 0,59 & 0,54 & 0,57 & 0,57 \\
\hline \multicolumn{2}{|l|}{$\mathrm{TSO}^{\circ}{ }^{\circ}$ (grau) } & $-1,48$ & $-3,23$ & $-2,62$ & 1,60 & $-2,68$ \\
\hline$T S I$ & $\mathrm{MD} / \mathrm{CD}$ & 2,81 & 2,93 & 3,04 & 3,14 & 3,40 \\
\hline \multicolumn{2}{|l|}{ Porosidade (Gurley) s/100ml } & 10,6 & 11,16 & 11,24 & 10,80 & 12,04 \\
\hline \multirow[t]{2}{*}{ Aspereza (Bendtsen) $\mathrm{ml} \cdot \mathrm{min}^{-1}$} & LF & 206 & 205 & 203 & 204 & 235 \\
\hline & $\mathrm{LT}$ & 199 & 210 & 209 & 205 & 222 \\
\hline \multirow[t]{3}{*}{ Resistência à Tração, $\mathrm{kN} \cdot \mathrm{m}^{-1}$} & MD & 5,50 & 5,73 & 5,47 & 5,67 & 5,66 \\
\hline & $\mathrm{CD}$ & 1,87 & 1,84 & 1,93 & 1,70 & 1,56 \\
\hline & $\mathrm{MD} / \mathrm{CD}$ & 2,94 & 3,12 & 2,84 & 3,33 & 3,62 \\
\hline \multirow[t]{2}{*}{ Índice de Tração, N.m.g ${ }^{-1}$} & MD & 72,6 & 74,6 & 71,0 & 73,6 & 73,3 \\
\hline & $\mathrm{CD}$ & 24,6 & 23,9 & 25,0 & 22,1 & 20,3 \\
\hline \multirow[t]{2}{*}{ Alongamento, $\%$} & MD & 2,3 & 2,3 & 2,5 & 2,4 & 2,4 \\
\hline & $\mathrm{CD}$ & 5,2 & 6,3 & 6,3 & 7,0 & 8,6 \\
\hline \multirow[t]{2}{*}{ Energia absorvida na tração, $\mathrm{J} \mathrm{m}^{-2}$} & MD & 85,9 & 89,2 & 90,9 & 93,5 & 92,1 \\
\hline & $\mathrm{CD}$ & 75,0 & 89,1 & 94,2 & 91,7 & 103,9 \\
\hline \multirow[t]{2}{*}{ Rigidez à tração, kN.m-1 } & MD & 648,8 & 649,4 & 625,1 & 618,5 & 628,7 \\
\hline & $\mathrm{CD}$ & 175,7 & 167,9 & 182,7 & 151,0 & 131,3 \\
\hline \multirow[t]{2}{*}{ Módulo de Elasticidade, GPa } & MD & 6,55 & 6,56 & 6,25 & 6,31 & 6,55 \\
\hline & $\mathrm{CD}$ & 1,77 & 1,70 & 1,83 & 1,54 & 1,37 \\
\hline \multirow[t]{2}{*}{ Comprimento Auto-Ruptura, km } & MD & 7,29 & 7,60 & 7,24 & 7,50 & 7,47 \\
\hline & $\mathrm{CD}$ & 2,48 & 2,44 & 2,55 & 2,25 & 2,07 \\
\hline \multirow[t]{2}{*}{ Resistência ao Rasgo, gf } & MD & 52,6 & 53,9 & 56,4 & 55,3 & 55,7 \\
\hline & $\mathrm{CD}$ & 65,6 & 66,1 & 65,9 & 68,7 & 66,0 \\
\hline \multirow[t]{2}{*}{ Rigidez (Taber), gf.cm } & MD & 2,18 & 2,17 & 2,12 & 2,06 & 1,98 \\
\hline & $\mathrm{CD}$ & 0,78 & 0,76 & 0,76 & 0,74 & 0,65 \\
\hline \multicolumn{2}{|l|}{ Resistência Estouro (Mullen), $\mathrm{kPa}$} & 241,7 & 218,3 & 210,4 & 200,7 & 204,3 \\
\hline \multirow[t]{2}{*}{ Higroexpansibilidade, $\%$} & MD & 0,135 & 0,134 & 0,124 & 0,134 & 0,144 \\
\hline & $\mathrm{CD}$ & 0,456 & 0,510 & 0,544 & 0,660 & 0,700 \\
\hline
\end{tabular}

${ }^{199}$ Valores iniciais e após 30 minutos de condicionamento no ambiente do laboratório. 


\section{APÊNDICE B \\ PROPRIEDADES DO PAPEL REPROGRÁFICO - II}

Tabela B.1. Resultados de medições de propriedades realizadas em amostras de papel reprográfico de $75 \mathrm{~g} . \mathrm{m}^{-2}$, utilizado neste trabalho, referente à produção com velocidade de máquina de $1362 \mathrm{~m} \cdot \mathrm{min}^{-1}$ e largura do papel na enroladeira de $5300 \mathrm{~mm}^{200}$.

\begin{tabular}{|c|c|c|c|c|c|c|}
\hline \multirow[t]{2}{*}{ Propriedades do papel } & & \multicolumn{5}{|c|}{ Posição transversal da enroladeira (a partir do LC) } \\
\hline & & 1 & 2 & 3 & 4 & 5 \\
\hline$\overline{\text { Gramatura, g.m }{ }^{-2}}$ & & 74,4 & 74,5 & 74,3 & 75,0 & 75,2 \\
\hline Espessura, $\mu \mathrm{m}$ & & 100 & 100 & 99 & 99 & 100 \\
\hline Corpo (bulk), $\mathrm{cm}^{3} \cdot \mathrm{g}^{-1}$ & & 1,34 & 1,34 & 1,33 & 1,32 & 1,33 \\
\hline Umidade, $\%$ & & 3,6 & 3,6 & 3,5 & 3,6 & 3,6 \\
\hline Carga Mineral, \% & & 16,9 & \multicolumn{4}{|c|}{ (média das posições 1-3-5) } \\
\hline Formação - índice, g.m ${ }^{-2}$ & & n.d. & n.d. & 3,27 & n.d. & n.d. \\
\hline Formação, específica, $\mathrm{g}^{1 / 2} \cdot \mathrm{m}^{-1}$ & & n.d. & n.d. & 0,38 & n.d. & n.d. \\
\hline$T S O,{ }^{\circ}$ (grau) & MD & $-4,45$ & $\min$ & $+4,59$ & máx & (ver perfil) \\
\hline$T S I$ & $\mathrm{MD} / \mathrm{CD}$ & 3,34 & \multicolumn{4}{|c|}{ (valor médio transversal - ver perfil) } \\
\hline Porosidade (Gurley), s/100ml & & 15,6 & \multicolumn{4}{|c|}{ (média das posições 1 a 5) } \\
\hline Opacidade, \% (ISO) & & n.d. & n.d. & 91,2 & n.d. & n.d. \\
\hline Aspereza (Bendtsen) ml.min ${ }^{-1}$ & LF & 165 & \multicolumn{4}{|c|}{ (média das posições 1-3-5) } \\
\hline & LT & 152 & \multicolumn{4}{|c|}{ (média das posições 1-3-5) } \\
\hline \multirow[t]{3}{*}{ Resistência à Tração, kN.m ${ }^{-1}$} & MD & n.d. & n.d. & 6,98 & n.d. & n.d. \\
\hline & $\mathrm{CD}$ & n.d. & n.d. & 2,00 & n.d. & n.d. \\
\hline & $M D / C D$ & n.d. & n.d. & 3,49 & n.d. & n.d. \\
\hline \multirow[t]{2}{*}{ Índice de Tração, N.m.g $g^{-1}$} & $M D$ & n.d. & n.d. & 93,9 & n.d. & n.d. \\
\hline & $C D$ & n.d. & n.d. & 26,9 & n.d. & n.d. \\
\hline \multirow[t]{2}{*}{ Alongamento, $\%$} & MD & n.d. & n.d. & 1,97 & n.d. & n.d. \\
\hline & $\mathrm{CD}$ & n.d. & n.d. & 6,40 & n.d. & n.d. \\
\hline \multirow[t]{2}{*}{ Resistência ao Rasgo, gf } & MD & n.d. & n.d. & 45 & n.d. & n.d. \\
\hline & $\mathrm{CD}$ & n.d. & n.d. & 64 & n.d. & n.d. \\
\hline \multirow[t]{2}{*}{ Rigidez (Taber), gf.cm } & MD & n.d. & n.d. & 2,95 & n.d. & n.d. \\
\hline & $\mathrm{CD}$ & n.d. & n.d. & 0,88 & n.d. & n.d. \\
\hline Resistência Estouro (Mullen), $\mathrm{kPa}$ & & n.d. & n.d. & 292 & n.d. & n.d. \\
\hline Encanoamento $(\mathrm{Curl}), \mathrm{mm}$ & Simplex T & 25,0 & n.d. & 17,0 & n.d. & 19,3 \\
\hline (teste de impressão $\mathrm{T}=$ tela, $\mathrm{F}=$ feltro) & Duplex F & 19,5 & n.d. & 20,0 & n.d. & 22,0 \\
\hline
\end{tabular}

${ }^{200}$ Dados fornecidos pelo laboratório de testes físicos da fábrica de papel. 

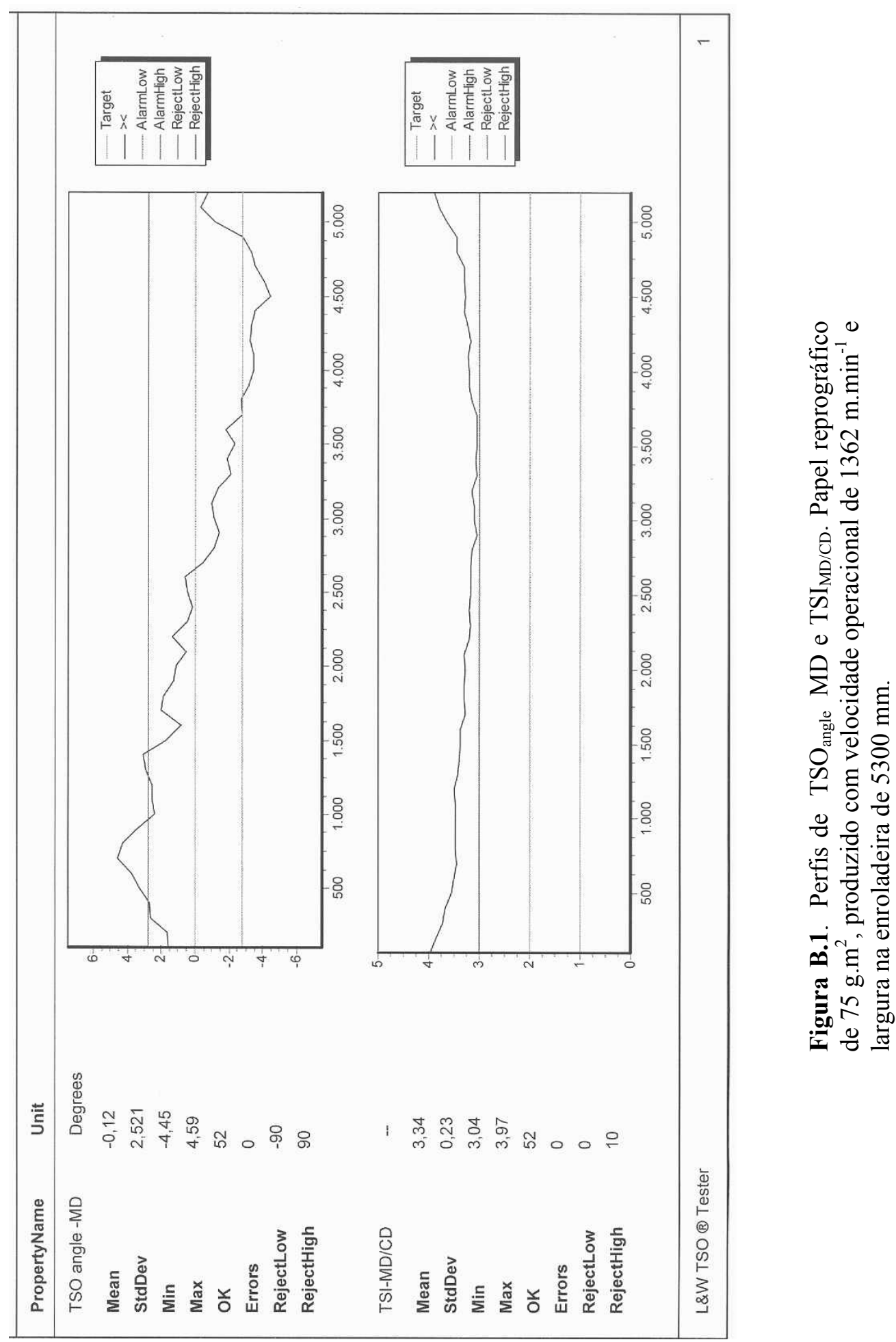


\section{APÊNDICE C \\ PROGRAMA DE ANÁLISE DE IMAGEM}

O programa aplicado para análise das imagens das amostras de papel foi desenvolvido pelo autor da presente tese em linguagem MATLAB ${ }^{201}$, versão R2008b, utilizando principalmente os módulos dedicados ao processamento de imagens digitais, contidos no aplicativo $\mathrm{IPT}^{202}$. O programa criado, denominado PET1_0.m, recupera as imagens digitais armazenadas em pasta de trabalho específica (e.g., C:\...MATLAB), executa a transformada de Fourier (2D-FFT) e localiza os picos de amplitude de interesse contidos no espectro de amplitudes (referentes a marcas produzidas pelas telas formadoras), cujas coordenadas são usadas em processamento posterior, para determinação do encolhimento transversal (CD) do papel.

\section{C.1. Módulos do programa}

Os principais módulos utilizados no programa para tratamento das imagens digitais correspondem a funções obtidas no aplicativo IPT do MATLAB. Tais funções estão listadas, a seguir, incluindo uma breve descrição ${ }^{203}$.

FFT2 Transformada bidimensional rápida de Fourier.

FFT2 $(\mathrm{X})$ retorna a transformada discreta de Fourier da matriz "X" (e.g., matriz da imagem digital a ser processada), utilizando o algoritmo da transformada rápida de Fourier. A matriz resultante tem a mesma dimensão da matriz-imagem original.

ABS Valor absoluto.

ABS $(\mathrm{X})$ retorna o valor absoluto dos elementos da matriz " $\mathrm{X}$ ". Quando "X" contém números complexos, a função $\operatorname{ABS}(\mathrm{X})$ retorna a magnitude (módulo) dos seus elementos.

\footnotetext{
${ }^{201}$ MATLAB significa Matrix Laboratory (laboratório de matrizes). Consiste de linguagem de alto desempenho para computação técnica. Produto da MathWorks, EUA.

${ }^{202} \mathrm{O}$ aplicativo IPT (Image Processing Toolbox) compõe-se de funções e arquivos (M-functions e M-files) que aumentam a capacidade e flexibilidade do ambiente MATLAB para desenvolvimento de soluções para processamento de imagens digitais.

${ }^{203}$ Informações mais detalhadas sobre as funções encontram-se no diretório de ajuda do IPT.
} 
FFTSHIFT Desloca o componente de freqüência zero para o centro do espectro de Fourier. FFTSHIF (X) permuta o primeiro com o terceiro e o segundo com quarto quadrantes do espectro obtido com FFT2. Esta função é útil para a visualização da transformada de Fourier com o componente contínuo (freqüência zero) localizado no centro da imagem do espectro.

IMSHOW Exibe imagem em forma gráfica.

IMSHOW (I) exibe a imagem "I" em níveis de cinza. IMSHOW (I, [LOW HIGH]) exibe a imagem "I" em escala de cinza, especificando a faixa para "I" em [LOW HIGH]. O valor LOW (ou qualquer valor inferior a LOW) é exibido como preto. O valor HIGH (ou qualquer valor superior a HIGH) é exibido como branco.

POLY2MASK Converte o polígono que contém uma área de interesse em máscara.

POLY2MASK $(\mathrm{X}, \mathrm{Y}, \mathrm{M}, \mathrm{N})$ determina a máscara binária da região de interesse a partir do polígono que encerra tal área, representado pelos vetores " $\mathrm{X}$ " e " $Y$ ". As dimensões da máscara são definidas pelos parâmetros "M" e "N". Os elementos de imagem (pixels) contidos pelo polígono $(\mathrm{X}, \mathrm{Y})$ recebem valor "1". Aqueles situados externamente ao polígono $(\mathrm{X}, \mathrm{Y})$ recebem valor " 0 ".

FIND Localiza os índices de elementos não-nulos.

FIND (X) retorna os índices lineares correspondentes a elementos não-nulos da matriz "X", que podem representar uma expressão lógica. Esta função é utilizada no programa de análise de imagem, em conjunto com MAX (X), a fim de localizar os picos de amplitude de interesse no espectro de Fourier.

MAX Maior valor.

MAX $(\mathrm{X})$ corresponde ao vetor-linha que contém o elemento máximo de cada coluna da matriz " $\mathrm{X}$ ".

Outras Incluem funções auxiliares utilizadas no programa, tais como INPUT para entrada e FPRINTF para impressão de dados, IMREAD para leitura de imagens a partir de arquivos gráficos e PAUSE, para visualização momentânea das imagens dos espectros de Fourier. 


\section{C.2. Parâmetros do programa}

\section{C.2.1. Parâmetros de entrada.}

Alguns parâmetros devem ser definidos pelo usuário, no início da execução do programa. Referem-se basicamente a especificações das imagens digitais e seleção de contraste para visualização do espectro de Fourier.

IMGINI Número inicial do conjunto de imagens do papel (e.g., para a primeira imagem da seqüência, denominada "img1.bmp", IMGINI=1).

IMGFIN Número final do conjunto de imagens do papel (e.g., para a última imagem da seqüência, denominada “img50.bmp”, IMGFIN = 50).

IMGPRE Prefixo da designação dos arquivos do conjunto de imagens (e.g., para a imagem "img1.bmp", IMGPRE = “img”).

IMGEXT Extensão (formato) correspondente aos arquivos das imagens (e.g., no arquivo de imagem “img1.bmp”, IMGEXT = “.bmp”).

PIXHOR Dimensão horizontal da imagem digital (CD) em pixels.

PIXVER Dimensão vertical da imagem digital (MD) em pixels.

DIMHOR Dimensão espacial horizontal da imagem digital ( $\mathrm{mm})$.

DIMVER Dimensão espacial vertical da imagem digital (mm).

IMGRES Resolução da imagem digital em pixels por polegada ( $p p i)$.

FATCON Fator de contraste, ajustado pelo usuário, para visualização da imagem do espectro de Fourier, que corresponde a um divisor para os valores das amplitudes de cada ponto (e.g., FATCON =1000). 


\section{C.2.2. Parâmetros pré-definidos}

Os parâmetros pré-definidos listados abaixo se referem a características construtivas de uma tela formadora e de premissas sobre os ângulos máximos de inclinação encontrados nas marcas em relação à direção longitudinal (MD) da máquina e na distorção da tela em relação à direção transversal $(\mathrm{CD})$ da máquina. Os parâmetros referentes à malha e à trama ${ }^{204}$ da tela formadora são determinados a partir de especificações estruturais de telas formadoras, tais como as indicadas na Tabela D.1 do Apêndice D. Na próxima seção deste apêndice encontra-se uma abordagem mais detalhada sobre esses parâmetros.

FABMES Malha de referência da tela formadora, relativa à superfície de contato com o papel [quantidade de fios longitudinais (MD) / $\mathrm{cm}$ ].

FABCON Trama de referência da tela formadora, relativa à superfície de contato com o papel [quantidade de fios transversais $(\mathrm{CD}) / \mathrm{cm}$ ].

FABFAC Fator de modulação de faixa para as malhas e tramas de referência. Usado para ajustar o tamanho da região de busca de picos de amplitude, no espectro de Fourier, a fim de compensar eventuais variações nos parâmetros FABMES (malha) e FABCON (trama). As faixas de malhas e tramas cobertas pelo programa ficam compreendidas nos seguintes intervalos:

Malhas:

De [1- $(F A B F A C / 100)]$ x FABMES a $[1+(F A B F A C / 100)]$ x FABMES

Tramas:

De $[1-(F A B F A C / 100)]$ x FABCON a $[1+(F A B F A C / 100)]$ x FABCON

ANGALF Representa o valor máximo para o ângulo " $\alpha$ "205 - inclinação das marcas de tela formadora em relação ao eixo longitudinal (MD) da máquina de papel para fins de configuração do programa.

\footnotetext{
${ }^{204}$ Ver características de uma tela formadora na subseção 3.5.2.

${ }^{205}$ Ver aspectos geométricos das telas formadoras na seção 4.2 e Figura C.1.
} 
ANGBET Representa o valor máximo para o ângulo " $\beta$ "206 - inclinação das marcas de tela formadora em relação ao eixo longitudinal (MD) da máquina de papel para fins de configuração do programa.

GRAENC Representa o grau máximo de encolhimento transversal (CD) do papel, para fins de configuração do programa.

\section{C.3. Determinação da área de busca dos picos amplitude no espectro de Fourier ${ }^{207}$.}

A Figura C.1 ilustra esquematicamente as máscaras utilizadas para filtragem e delimitação das áreas do espectro de Fourier que contém picos de amplitude de interesse, i.e., aquele referente ao encolhimento transversal do papel [situado na direção do eixo horizontal de freqüências (i.e., eixo $u$ ) $-c f$. polígono $\mathrm{n}^{\mathrm{o}}$ 1] e à eventual distorção da tela formadora [situado na direção do eixo vertical de freqüências (i.e., eixo $v$ ) $-c f$. polígono $\mathrm{n}^{\mathrm{o}} 2$ ]. As máscaras de filtragem são definidas por polígonos que contém os vértices abaixo, $c f$. indicado na Figura C.1:

$$
\begin{aligned}
& \text { Polígono } n^{\mathrm{o}} \text { 1: }\left[\left(\mathrm{x}_{\mathrm{fe} 1}, \mathrm{y}_{\mathrm{fe} 1}\right) ;\left(\mathrm{x}_{\mathrm{fe} 2}, \mathrm{y}_{\mathrm{fe} 2}\right) ;\left(\mathrm{x}_{\mathrm{fe} 3}, \mathrm{y}_{\mathrm{fe} 3}\right) ;\left(\mathrm{x}_{\mathrm{fe} 4}, \mathrm{y}_{\mathrm{fe} 4}\right)\right] \\
& \text { Polígono } \left.\left.\mathrm{n}^{\mathrm{o}} \text { 2: [( } \mathrm{x}_{\mathrm{fd} 1}, \mathrm{y}_{\mathrm{fd} 1}\right) ;\left(\mathrm{x}_{\mathrm{fd} 2}, \mathrm{y}_{\mathrm{fd} 2}\right) ;\left(\mathrm{x}_{\mathrm{fd} 3}, \mathrm{y}_{\mathrm{fd} 3}\right) ;\left(\mathrm{x}_{\mathrm{fd} 4}, \mathrm{y}_{\mathrm{fd} 4}\right)\right]
\end{aligned}
$$

A determinação das coordenadas acima, indicadas para os polígonos $n^{\circ} 1$ e $n^{\circ} 2$, é feita em função das propriedades das imagens digitais das amostras de papel, associadas aos dados construtivos da telas formadoras e a parâmetros de ajuste usados para modular a área coberta pelas máscaras de filtragem.

Tomando-se os parâmetros de entrada e os parâmetros pré-determinados listados nas subseções precedentes (C.2.1 e C.2.2), têm-se que:

a. determinação das coordenadas do centro do espectro de Fourier ( $\left.\mathrm{xe}_{0} \underline{\mathrm{y}}_{2} \mathrm{y}_{0}\right)$ :

$$
\begin{aligned}
& \mathrm{x}_{\mathrm{eo}}=(P I X H O R / 2)+1 \\
& \mathrm{y}_{\mathrm{eo}}=(P I X V E R / 2)+1
\end{aligned}
$$

\footnotetext{
${ }^{206}$ Idem à nota anterior.

${ }^{207}$ Ver aspectos geométricos da tela formadora na seção 4.2.
} 
$\underline{\text { b. determinação da distância de referência entre o centro do espectro de Fourier e o }}$ pico de amplitude referente às marcas longitudinais da tela formadora $\left(d^{\prime}{ }^{m d}\right)$ :

$d^{\prime}{ }_{m d}=2,54 \times$ PIXHOR $\times$ FABMES / IMGRES

c. determinação dos vértices do polígono $n^{\circ} 1$ :

$\mathrm{x}_{\mathrm{fe} 1}=\mathrm{x}_{\mathrm{eo}}-\left\{d^{\prime}{ }_{m d} \mathrm{x}[1-(F A B F A C / 100)]\right\}$

$\mathrm{x}_{\mathrm{fe} 2}=\mathrm{x}_{\mathrm{eo}}-\left\{d^{\prime}{ }_{m d} \mathrm{x}[1+(F A B F A C / 100)] /[1-(G R A E N C / 100)]\right\}$

$\mathrm{x}_{\mathrm{fe} 3}=\mathrm{x}_{\mathrm{fe} 2}$

$\mathrm{x}_{\mathrm{fe} 4}=\mathrm{x}_{\mathrm{fe} 1}$

$\mathrm{y}_{\mathrm{fe} 1}=\mathrm{y}_{\mathrm{feo}}-\left\{d^{\prime}{ }_{m d} \mathrm{x}[1+(F A B F A C / 100)] /[1-(G R A E N C / 100)] \mathrm{x} \operatorname{sen}(A N G A L F)\right\}$

$\mathrm{y}_{\mathrm{fe} 2}=\mathrm{y}_{\mathrm{fe} 1}$

$\mathrm{y}_{\mathrm{fe} 3}=\mathrm{y}_{\mathrm{feo}}+\left\{d^{\prime}{ }_{m d} \mathrm{x}[1+(F A B F A C / 100)] /[1-(G R A E N C / 100)] \mathrm{x} \operatorname{sen}(A N G A L F)\right\}$

$y_{\mathrm{fe} 4}=y_{\mathrm{fe} 3}$

d. determinação da distância de referência entre o centro do espectro de Fourier e $O$ pico de amplitude referente às marcas transversais da tela formadora $\left(d^{\prime} c d\right)$ :

$d^{\prime}{ }_{c d}=2,54 \times$ PIXVER $\times$ FABCON / IMGRES

e. determinação dos vértices do polígono $n^{\circ} 2$ :

$\mathrm{x}_{\mathrm{fd} 1}=\mathrm{x}_{\mathrm{eo}}+\left\{d^{\prime}{ }_{c d} \mathrm{x}[1+(F A B F A C / 100)] \mathrm{x} \operatorname{sen}(A N G B E T)\right\}$

$\mathrm{x}_{\mathrm{fd} 2}=\mathrm{x}_{\mathrm{eo}}-\left\{d^{\prime}{ }_{c d} \mathrm{x}[1+(F A B F A C / 100)] \mathrm{x} \operatorname{sen}(A N G B E T)\right\}$ 
$\mathrm{X}_{\mathrm{fd} 3}=\mathrm{X}_{\mathrm{fd} 2}$

$\mathrm{X}_{\mathrm{fd} 4}=\mathrm{X}_{\mathrm{fd} 1}$

$\mathrm{y}_{\mathrm{fd} 1}=\mathrm{y}_{\mathrm{eo}}+\left\{d^{\prime}{ }_{c d} \mathrm{x}[1-(F A B F A C / 100)]\right\}$

$y_{\mathrm{fd} 2}=y_{\mathrm{fd} 1}$

$\mathrm{y}_{\mathrm{fd} 3}=\mathrm{y}_{\mathrm{eo}}+\left\{d^{\prime}{ }_{c d} \mathrm{x}[1+(F A B F A C / 100)]\right\}$

$\mathrm{y}_{\mathrm{fd} 4}=\mathrm{y}_{\mathrm{fd} 3}$

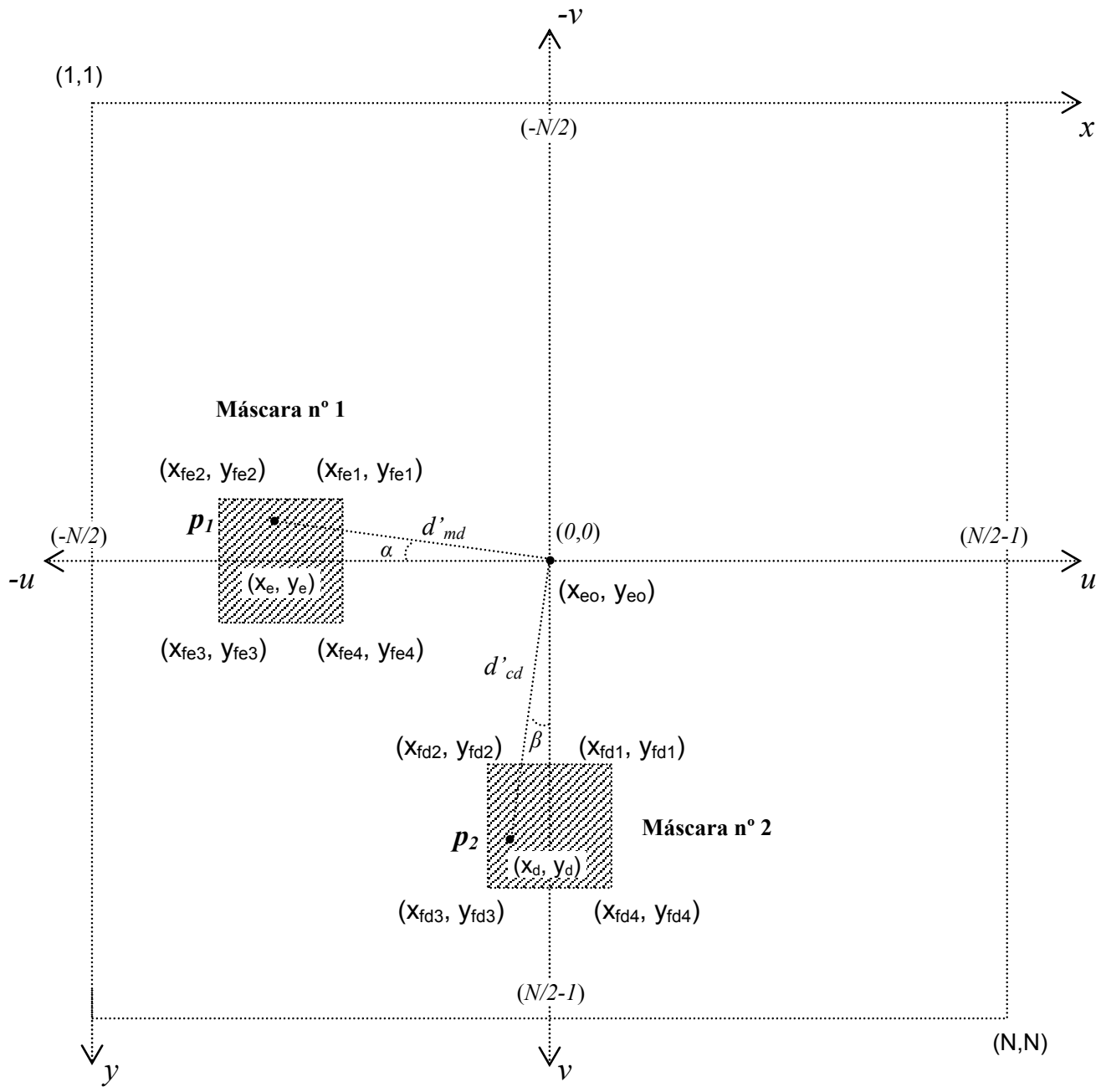

Figura C.1. Representação esquemática do espectro de Fourier de uma imagem digital com dimensões $N \times \mathrm{x}$, indicando as máscaras usadas para delimitação das áreas onde se encontram os picos de amplitude referentes ao encolhimento do papel e à eventual distorção da tela formadora. As coordenadas espaciais estão representadas com fonte arial e as de freqüência com times new roman itálico. 


\section{C.4. Alertas}

A fim de evitar erros de dimensionamento das máscaras de filtragem, o programa contém sub-rotinas de verificação dos dados de entrada referentes às dimensões e à resolução das imagens digitais, bem como da adequação do tamanho das máscaras ao espaço espectral.

Caso não haja coerência entre os parâmetros de entrada relativos ao tamanho da imagem $[\mathrm{mm}]$, da quantidade de elementos de amostragem [pixels] e da resolução [ppi], a seguinte mensagem de erro será mostrada:

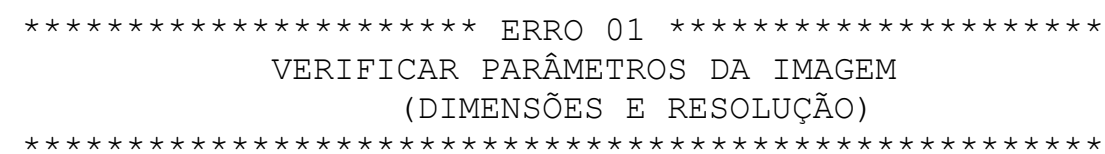

Os parâmetros mencionados acima devem satisfazer as seguintes relações:

$$
\begin{aligned}
& \text { DIMHOR }=\text { PIXHOR } \times(25,4 / \text { IMGRES }) \\
& \text { DIMVER }=\text { PIXVER } \times(25,4 / \text { IMGRES })
\end{aligned}
$$

Caso o tamanho das máscaras de filtragem exceda os limites do espaço espectral, ou seja, quando as coordenadas $\mathrm{x}_{\mathrm{fe} 2}$ e $\mathrm{x}_{\mathrm{fe} 3}$ assumirem valores menores que "1" ou quando as coordenadas $\mathrm{y}_{\mathrm{fd} 3}$ e $\mathrm{y}_{\mathrm{fd} 4}$ assumirem valores maiores que "PIXVER", a seguinte mensagem de erro será mostrada:

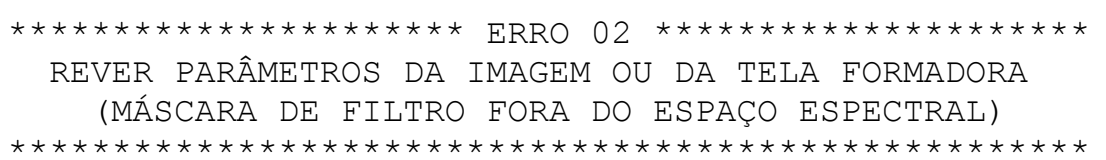

A fim de corrigir esta ocorrência, a resolução da imagem (IMGRES) deve ser ajustada para novo escaneamento, com a finalidade de se adequar os parâmetros dimensionais característicos da tela formadora. Esta mensagem está normalmente associada à resolução (ppi) insuficiente para a imagem analisada. 


\section{C.5. Implementação}

\section{C.5.1. Fluxograma do programa}

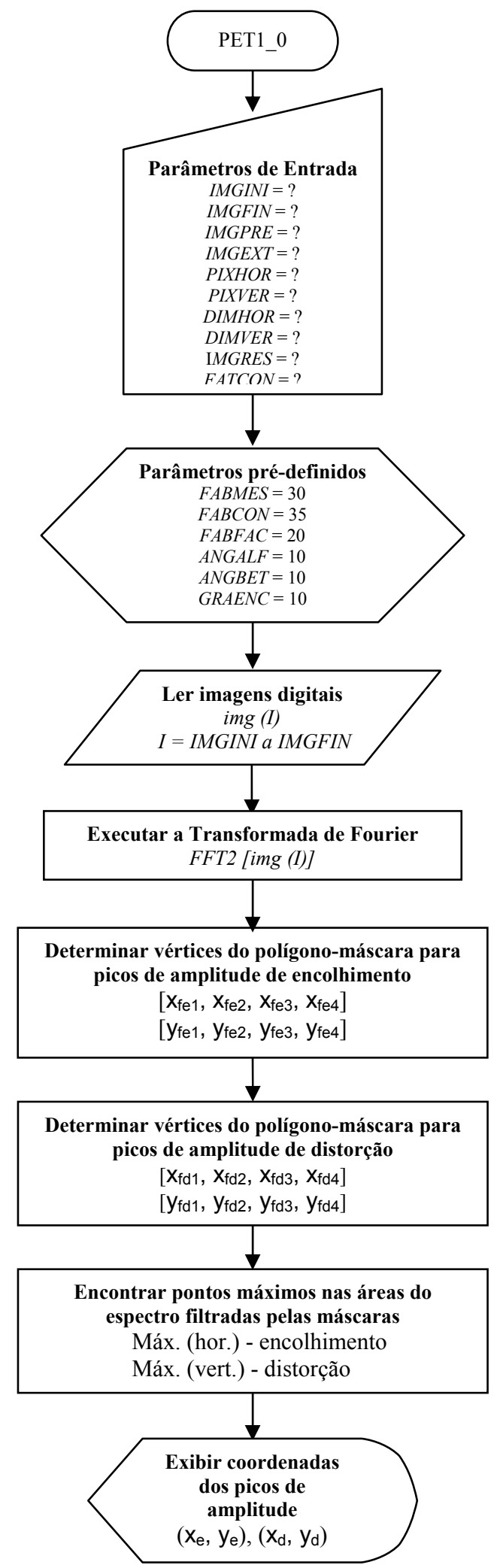

Figura C.2. Fluxograma simplificado do programa de análise de imagens utilizado no procedimento de determinação do encolhimento transversal (CD) do papel. 


\section{C.5.2. Listagem do programa}

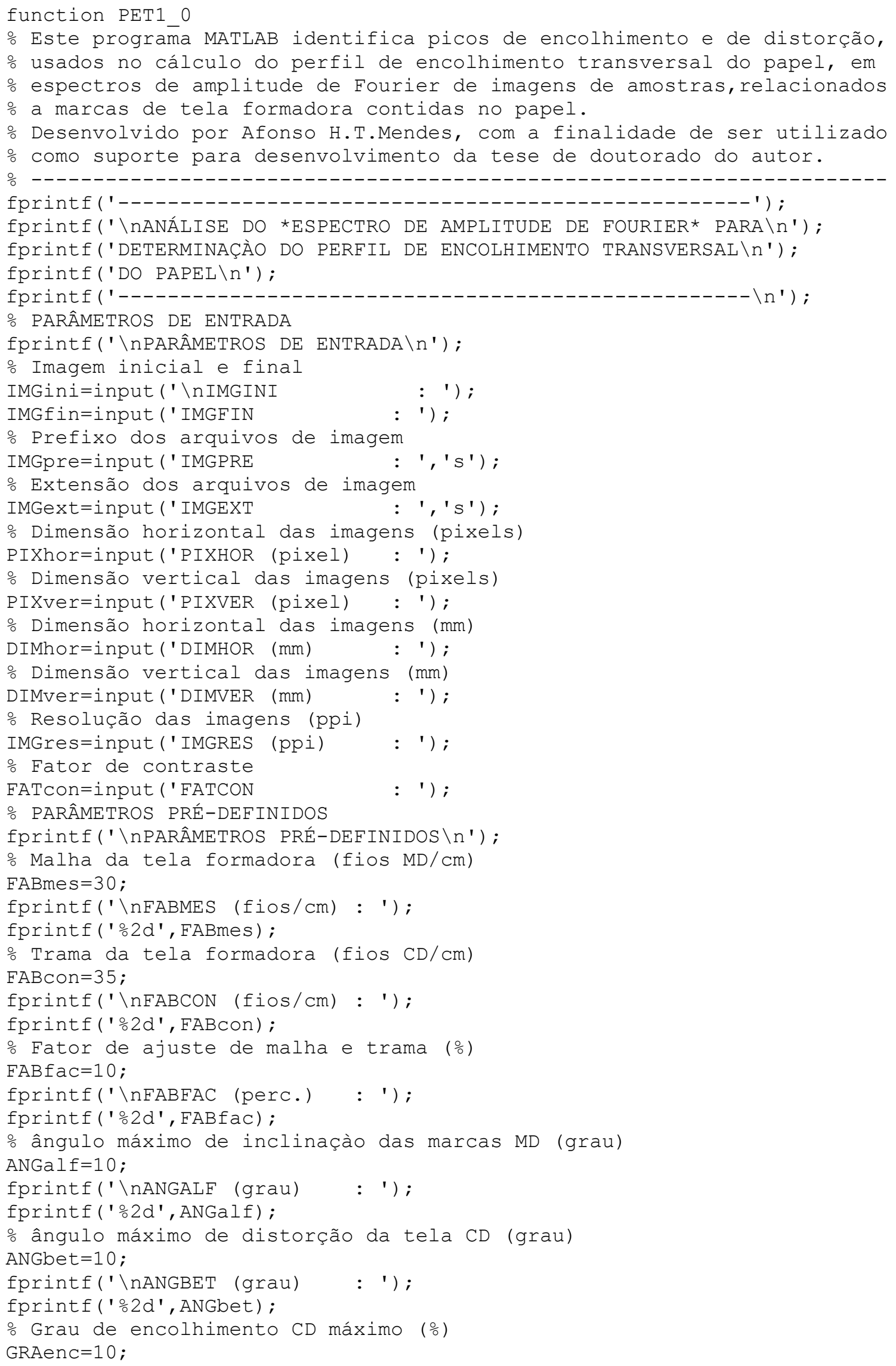




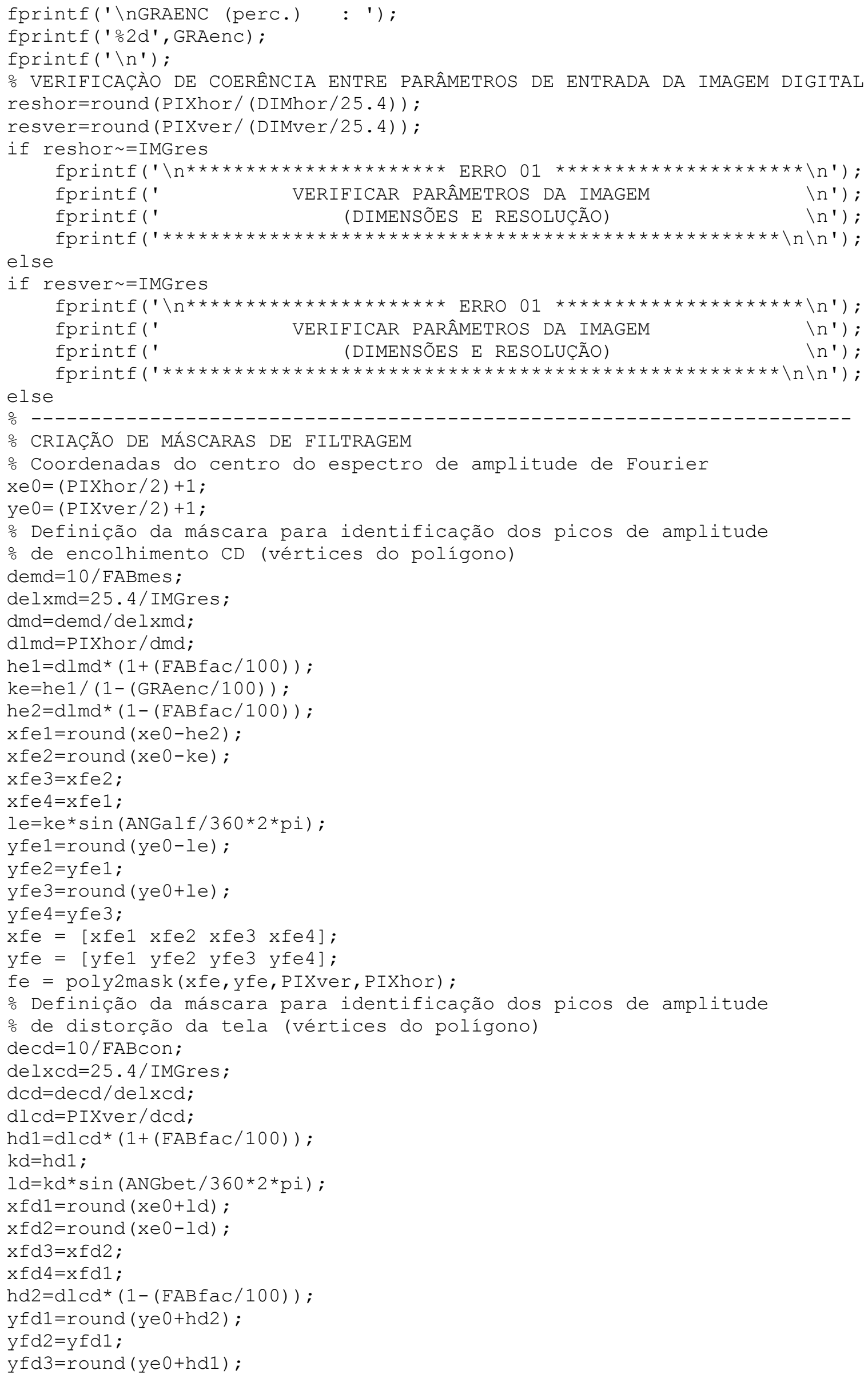




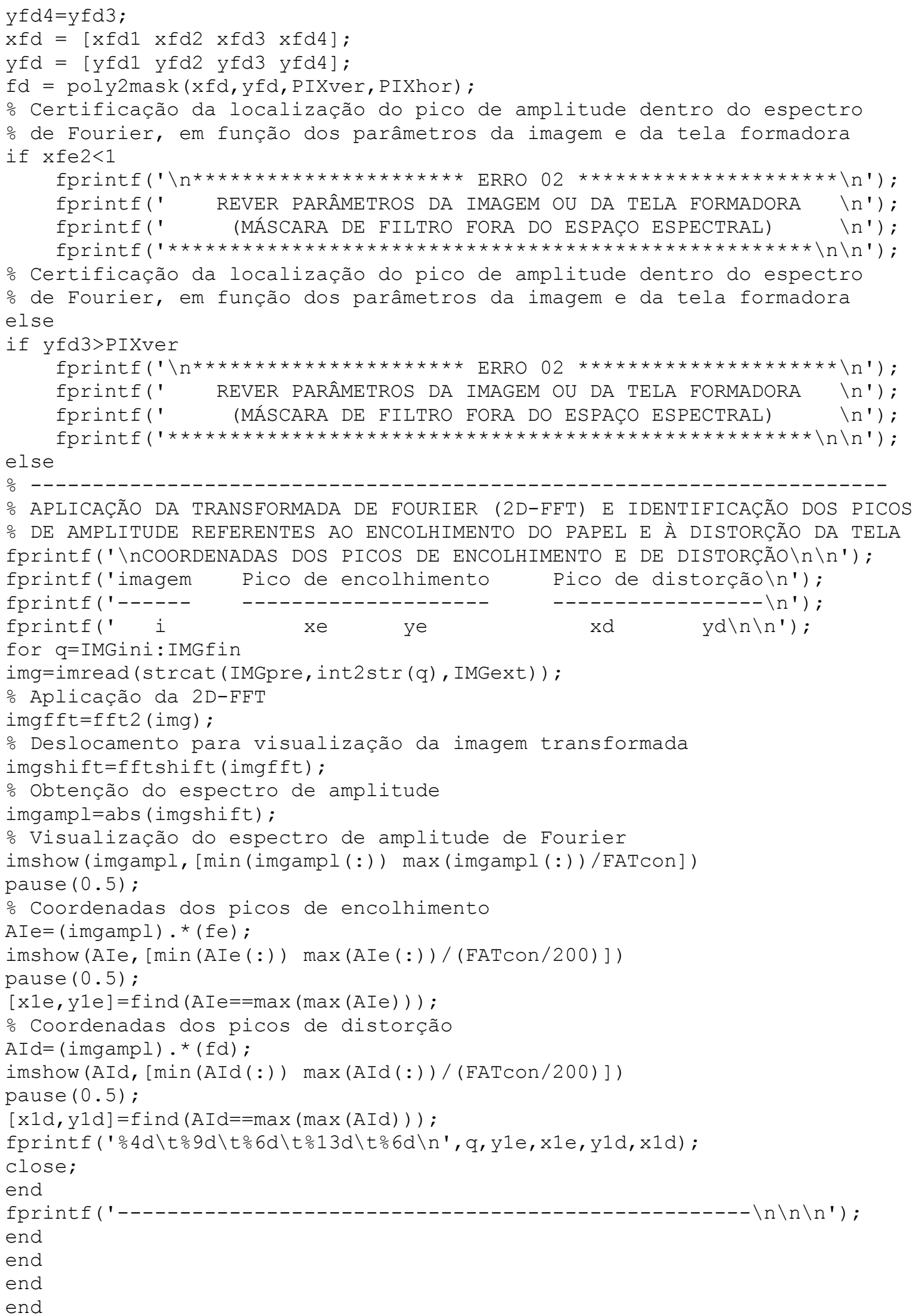




\section{APÊNDICE D}

\section{DADOS ESTRUTURAIS DE TELAS FORMADORAS DE TRIPLA LAJE (SSB)}

A tabela a seguir reúne dados construtivos típicos de telas formadoras produzidas por diversos fabricantes, selecionadas aquelas usualmente aplicadas em formadores de tela dupla, na produção de papéis de impressão [Adanur, 1997; Nogueira, 2010 (informação verbal) ${ }^{208}$; Pecorare, 2010 (informação verbal) ${ }^{209}$ ].

\section{D.1. Fatores principais para caracterização das telas formadoras ${ }^{210}$}

\section{D.1.1 Índice de suporte de fibras $\left(\mathrm{FSI}^{211}\right)$}

$$
F S I=\frac{2}{3}\left(a \times n_{M D}+2 \times b \times n_{C D}\right)
$$

onde:

$a$ fator de suporte, referente aos fios longitudinais.

$b \quad$ fator de suporte, referente aos fios transversais presentes na face em contato com o papel.

$n_{M D} \quad$ quantidade de fios longitudinais (MD) / pol. de comprimento da tela

$n_{C D} \quad$ quantidade de fios transversais (CD) / pol. de largura da tela

\section{D.1.2. Índice de drenagem $\left(\mathrm{DI}^{212}\right)$}

$$
D I=b \times P \times n_{C D} \times 10^{-3}
$$

onde:

$b \quad$ fator de suporte, referente aos fios transversais presentes na face da tela em contato com o papel.

$P \quad$ permeabilidade ao ar da tela, $\mathrm{cfm} / \mathrm{ft}^{2}$

$n_{C D} \quad$ quantidade de fios transversais $(\mathrm{CD}) /$ pol. de largura da tela

\footnotetext{
${ }^{208}$ Informação fornecida por Nogueira (Tamfelt) em evento do setor de papel e celulose, em 2010.

${ }^{209}$ Informação fornecida por Pecorare (Voith) sobre aspectos técnicos de telas formadoras, em 2010.

${ }^{210}$ Detalhes sobre fatores de caracterização encontram-se na subseção 3.5.2.

${ }^{211}$ Fiber Support Index: índice de suporte de fibra.

${ }^{212}$ Drainage Index: índice de drenagem
} 
Tabela D.1. Características técnicas de telas formadoras de tripla-laje (TL), estilo $\mathrm{SSB}^{213}$, comumente utilizadas em formadores de tela dupla do tipo Gap Formers $^{214}$ (continua)

\begin{tabular}{|c|c|c|c|c|c|c|}
\hline Fabricante & & & "A" & "A" & "B" & "B" \\
\hline Código & & & $7120 \mathrm{~A} 65560$ & 7120A66542 & F35603GMO & F35654GMO \\
\hline Tecedura (sup./inf.) & & quadros & $2 / 5$ & $2 / 5$ & $2 / 5$ & $2 / 5$ \\
\hline Razão de fios (sup./inf.) & & & $2: 1$ & $2: 1$ & $2: 1$ & $2: 1$ \\
\hline Malha x Trama & & $\mathrm{cm}^{-1}$ & $66,0 \times 55,5$ & $66,4 \times 54,2$ & $61,0 \times 50,0$ & $68,0 \times 51,6$ \\
\hline Malha sup. & MD & $\mathrm{cm}^{-1}$ & 33,0 & 33,2 & 30,5 & 34,0 \\
\hline Malha inf. & MD & $\mathrm{cm}^{-1}$ & 33,0 & 33,2 & 30,5 & 34,0 \\
\hline Trama sup. & CD & $\mathrm{cm}^{-1}$ & 37,0 & 36,1 & 30,0 & 31,0 \\
\hline Fios de amarração & $\mathrm{CD}$ & $\mathrm{cm}^{-1}$ & 18,5 & 18,1 & 10,0 & 10,3 \\
\hline Trama inf. & $\mathrm{CD}$ & $\mathrm{cm}^{-1}$ & 18,5 & 18,1 & 20,0 & 20,6 \\
\hline Diâmetro fio sup. & MD & $\mathbf{m m}$ & 0,14 & 0,14 & 0,13 & 0,12 \\
\hline Diâmetro fio inf. & $\mathrm{MD}$ & $\mathrm{mm}$ & 0,18 & 0,18 & 0,21 & 0,18 \\
\hline Diâmetro fio sup. 1 & CD & $\mathbf{m m}$ & 0,15 & 0,13 & 0,13 & 0,12 \\
\hline Diâmetro fio sup. 2 & CD & $\mathbf{m m}$ & $\mathbf{0 , 1 3}$ & $\mathbf{0 , 1 3}$ & $\mathbf{0 , 1 3}$ & 0,12 \\
\hline Diâmetro fio amarração & $\mathrm{CD}$ & $\mathrm{mm}$ & 0,13 & 0,13 & 0,13 & 0,12 \\
\hline Diâmetro fio inf. & $\mathrm{CD}$ & $\mathrm{mm}$ & 0,27 & 0,27 & 0,25 & 0,25 \\
\hline Espessura & & $\mathrm{mm}$ & 0,84 & 0,79 & 0,76 & 0,70 \\
\hline Permeabilidade & & $\mathrm{m}^{3} \cdot \mathrm{m}^{-2} \cdot \mathrm{h}^{-1}$ & 5530 & 5450 & 5500 & 5500 \\
\hline Índice de suporte de fibra & FSI & & 181 & 178 & 187 & 198 \\
\hline Índice de drenagem & DI & & 32,9 & 31,6 & 31 & 37 \\
\hline Volume livre & & $\mathrm{ml} . \mathrm{m}^{-2}$ & 494 & 463 & 441 & 417 \\
\hline Gramatura & & g.m ${ }^{-2}$ & 468 & 451 & 440 & 390 \\
\hline Área aberta & & $\%$ & 25,9 & 28,4 & 29,0 & 29,4 \\
\hline Pontos de contato & & & 1221 & 1199 & 1220 & 1405 \\
\hline Compr. médio das aberturas & $\mathrm{mm}$ & & 0,130 & 0,147 & 0,120 & 0,122 \\
\hline Larg. Média das aberturas & $\mathrm{mm}$ & & 0,163 & 0,161 & 0,198 & 0,174 \\
\hline Razão larg./compr. & & & 1,25 & 1,10 & 1,65 & 1,43 \\
\hline
\end{tabular}

${ }^{213}$ SSB: Self Support Binding (ver subseção 3.5.2).

${ }^{214}$ Descrito na subseção 4.1.1. 
Tabela D.1. Características técnicas de telas formadoras de tripla-laje (TL), estilo $\mathrm{SSB}^{215}$, comumente utilizadas em formadores de tela dupla do tipo Gap Formers (final)

\begin{tabular}{|c|c|c|c|c|c|c|}
\hline Fabricante & & & "C" & "D" & "E" & "F" \\
\hline Código & & & 555151038 & $5000 \mathrm{H}$ & H3573 & INT \\
\hline Tecedura (sup./inf.) & & quadros & $2 / 5$ & $2 / 5$ & $2 / 5$ & $2 / 6$ \\
\hline Razão de fios (sup./inf.) & & & $2: 1$ & $2: 1$ & $2: 1$ & $3: 2$ \\
\hline Malha x Trama & & $\mathrm{cm}^{-1}$ & $60,0 \times 57,0$ & $59,0 \times 55,2$ & $58,2 \times 53,1$ & $58,0 \times 48,4$ \\
\hline Malha sup. & MD & $\mathbf{c m}^{-1}$ & 30,0 & 29,5 & 29,1 & 29,0 \\
\hline Malha inf. & MD & $\mathrm{cm}^{-1}$ & 30,0 & 29,5 & 29,1 & 29.0 \\
\hline Trama sup. & CD & $\mathbf{c m}^{-1}$ & 38,0 & 36,8 & 35,4 & 36,3 \\
\hline Fios de amarração & $\mathrm{CD}$ & $\mathrm{cm}^{-1}$ & 19,0 & 18,4 & 17,7 & 12,1 \\
\hline Trama inf. & $\mathrm{CD}$ & $\mathrm{cm}^{-1}$ & 19,0 & 18,4 & 17,7 & 24,2 \\
\hline Diâmetro fio sup. & MD & $\mathbf{m m}$ & 0,13 & $\mathbf{0 , 1 3}$ & 0,13 & 0,13 \\
\hline Diâmetro fio inf. & MD & $\mathrm{mm}$ & 0,21 & 0,21 & 0,21 & 0,21 \\
\hline Diâmetro fio sup. 1 & CD & $\mathbf{m m}$ & $\mathbf{0 , 1 3}$ & 0,13 & $\mathbf{0 , 1 7}$ & 0,15 \\
\hline Diâmetro fio sup. 2 & CD & $\mathbf{m m}$ & 0,13 & $\mathbf{0 , 1 3}$ & $\mathbf{0 , 1 7}$ & 0,15 \\
\hline Diâmetro fio amarração & $\mathrm{CD}$ & $\mathrm{mm}$ & 0,13 & 0,13 & 0,13 & 0,15 \\
\hline Diâmetro fio inf. & $\mathrm{CD}$ & $\mathrm{mm}$ & 0,30 & 0,30 & 0,37 & 0,30 \\
\hline Espessura & & $\mathrm{mm}$ & 0,87 & n.d. & n.d. & n.d. \\
\hline Permeabilidade & & $\mathrm{m}^{3} \cdot \mathrm{m}^{-2} \cdot \mathrm{h}^{-1}$ & 5483 & 5500 & 3997 & 4700 \\
\hline Índice de suporte de fibra & FSI & & 179 & n.d. & n.d. & n.d. \\
\hline Índice de drenagem & DI & & 33,5 & n.d. & n.d. & n.d. \\
\hline Volume livre & & $\mathrm{ml} . \mathrm{m}^{-2}$ & n.d. & n.d. & n.d. & n.d. \\
\hline Gramatura & & g.m ${ }^{-2}$ & n.d. & n.d. & n.d. & n.d. \\
\hline Área aberta & & $\%$ & 30,8 & n.d. & n.d. & n.d. \\
\hline Pontos de contato & & & 1140 & n.d. & n.d. & n.d. \\
\hline Compr. médio das aberturas & $\mathrm{mm}$ & & 0,133 & n.d. & n.d. & n.d. \\
\hline Larg. Média das aberturas & $\mathrm{mm}$ & & 0,203 & n.d. & n.d. & n.d. \\
\hline Razão larg./compr. & & & 1,53 & n.d. & n.d. & n.d. \\
\hline
\end{tabular}

${ }^{215}$ SSB: Self Support Binding (ver subseção 3.5.2). 


\section{APÊNDICE E \\ PROCEDIMENTO INDUSTRIAL PARA MEDIÇÃO DO PERFIL DE ENCOLHIMENTO TRANSVERSAL (CD) DO PAPEL}

Este apêndice apresenta um guia básico, contendo instruções para medição do perfil de encolhimento transversal (CD) do papel, ao longo da largura da máquina. O procedimento compõe-se das etapas de coleta e preparação das amostras, de digitalização, de processamento e análise das imagens digitais e de definição e exibição do perfil transversal.

\section{E.1. Coleta e preparação das amostras de papel}

As amostras de papel são retiradas de uma bobina jumbo, recém formada na enroladeira da máquina de papel, desprezando-se as primeiras camadas de folha, de forma a selecionar uma região sem imperfeições, tais como rasgos, rugas e furos.

1. Retirar três faixas de papel com largura aproximada de $300 \mathrm{~mm}$ e comprimento igual à largura total da folha. O corte deve estar alinhado, da melhor maneira possível, com a direção transversal (CD) da máquina (i.e., paralelamente ao eixo axial da estanga de suporte da bobina jumbo), conforme ilustrado na Figura E.1.

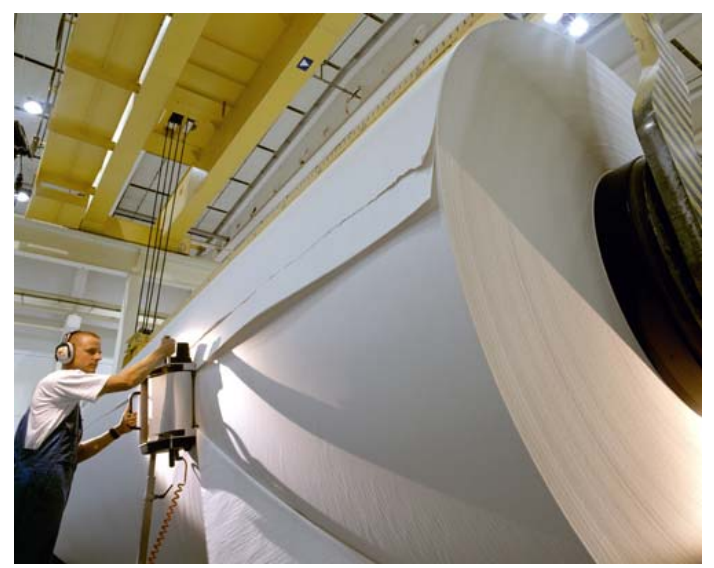

Figura E.1. Coleta de uma faixa de papel ao longo da direção transversal da bobina jumbo, com auxílio do equipamento auxiliar de corte [fonte: Lorentzen $\&$ Wettre, $\left.2010^{216}\right]$

\footnotetext{
${ }^{216}$ Ilustração disponível em http://1-w.com.datakultur.net/images/stories/LorentzenWettre/PDF_product_info/ LW_Profile_Sample_Cutter_148.pdf. Acesso: 16 jan 2011.
} 
2. Imediatamente após a retirada das faixas de papel, inserir os pequenos rolos formados durante o corte (ver Figura E.1) em embalagem plástica, para posterior transporte para o laboratório.

3. Registrar os dados de operação de máquina de papel e dos testes físicos do papel produzido no horário da coleta, para referência futura.

4. Na bancada do laboratório (ambiente condicionado a $23^{\circ} \mathrm{C} / 50 \% \mathrm{RH}$ ), abrir os rolos de papel retirados da bobina jumbo, a fim de realizar o corte de amostras na direção transversal da máquina. Marcar nas faixas de papel as extremidades correspondentes ao lado de comando (LC) e ao lado de acionamento (LA) da máquina e a face inferior do papel (também denominado "lado tela"). Usar uma faixa de papel para as medições e reservar as demais para uso futuro, se necessário.

5. Cortar e numerar as amostras (tiras de papel, com o lado mais longo paralelo à direção de fabricação), a partir da extremidade LC, em seqüência crescente até a extremidade LA. A largura das amostras será determinada em função da resolução desejada para o perfil de encolhimento. Tipicamente, terão $100 \mathrm{~mm}$ de largura e $300 \mathrm{~mm}$ de comprimento nas posições correspondentes às bordas do papel (em torno de $1 \mathrm{~m}$ de cada lado da máquina), aumentando, a seguir, para $200 \mathrm{~mm}$ e até 300-400 mm na região central, de forma a conjugar o número de amostras com a largura total da folha, preferencialmente com quantidade ímpar de amostras, que serão mantidas em embalagem plástica até o momento do uso. A Figura E.2 mostra um exemplo de rolos de faixas de papel retiradas da bobina jumbo e conjuntos de amostras cortadas com dimensões de $100 \mathrm{~mm}$ x $300 \mathrm{~mm}$.

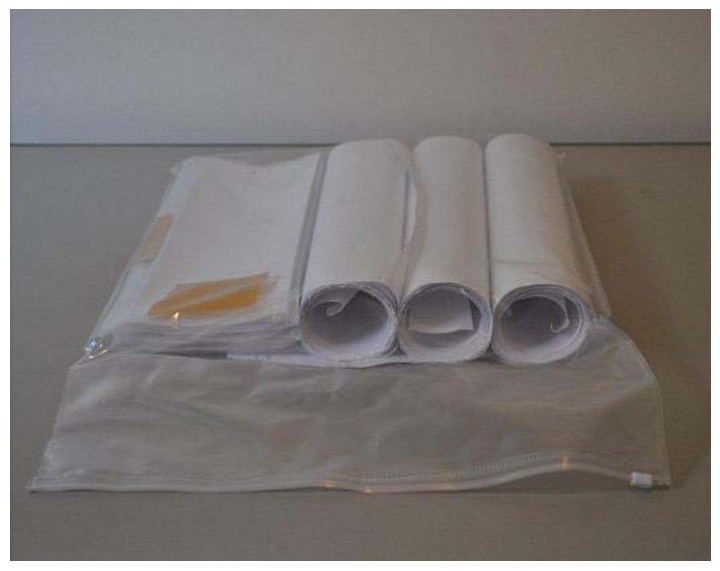

Figura E.2. Faixa de papel de $300 \mathrm{~mm}$ x $5300 \mathrm{~mm}$, retirada da bobina jumbo e enrolada e amostras cortadas com dimensões de $100 \mathrm{~mm}$ x $300 \mathrm{~mm}$. 


\section{E.2. Digitalização das amostras de papel}

A Figura E.3 mostra uma estação de trabalho constituída por um computador portátil acoplado a um digitalizador fotográfico de mesa.

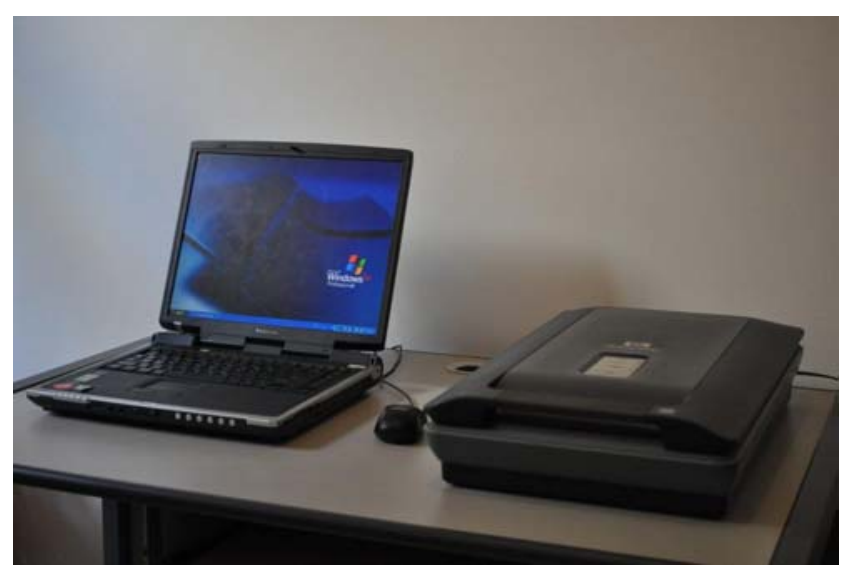

Figura E.3. Estação de trabalho para digitalização das amostras de papel composta por um computador acoplado a um digitalizador de mesa.

1. As amostras previamente cortadas são colocadas sobre a base do digitalizador, sob a máscara de suporte e limitação de campo. Nesta operação, as amostras deverão ser localizadas de forma que suas bordas fiquem, da melhor maneira possível, alinhadas paralelamente às bordas da base do digitalizador. A Figura E.4 mostra um exemplo onde se vê a amostra (papel branco) disposta sob a máscara do digitalizador.

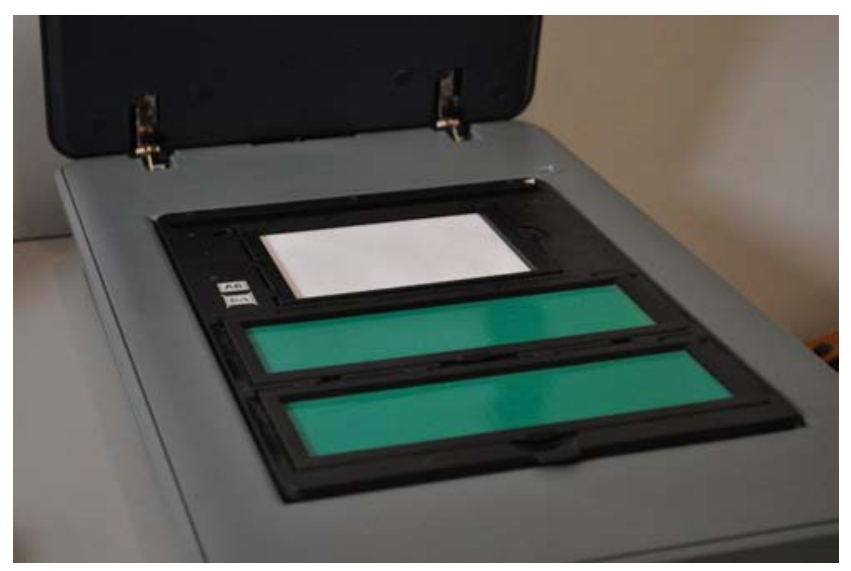

Figura E.4. Amostra (papel branco) disposta no digitalizador de mesa, sob a máscara de suporte (acessório original do digitalizador). 
2. Selecionar e carregar os parâmetros de configuração, para digitalização das amostras. Usar uma resolução de imagem em torno de $400 \mathrm{ppi}^{217}$ e dimensionar as imagens com 512 pixels x 512 pixels. A dimensão espacial das imagens é calculada de acordo com a seguinte expressão:

$$
D_{\mathrm{HV}}=\left(25,4 / R_{\mathrm{ppi}}\right) \times 512
$$

onde:

$D_{\mathrm{HV}}$ dimensão espacial da imagem, horizontal e vertical, $\mathrm{mm}$

$R_{\text {ppi }} \quad$ resolução da imagem, ppi

3. Desativar todas as opções de correção de imagem do digitalizador, tais como brilho, sombra, nitidez, auto-correção, etc. Ver na Figura E.5, um exemplo de configuração para digitalização das imagens de papel, que pode ser armazenada e recuperada no momento da aquisição das imagens.

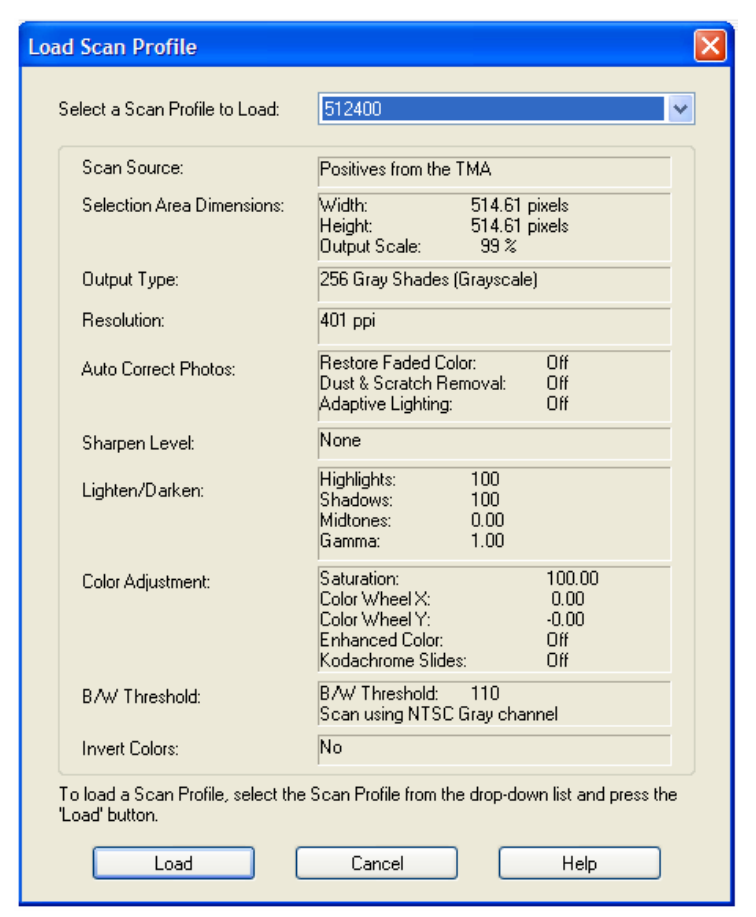

Figura E.5. Exemplo de configuração do perfil de digitalização, para aquisição de imagens digitais das amostras de papel.

\footnotetext{
${ }^{217}$ Este valor é adequado para análise de papel produzido com telas formadoras em que a camada em contato com o papel apresenta tecedura de 2 quadros, como é comum na produção de papel reprográfico em formadores de dupla tela do tipo gap former.
} 
4. A Figura E.6 mostra propriedades típicas de uma imagem digitalizada de uma amostra de papel, conforme padrão deste procedimento. O modo de cor deve ser selecionado para escala de cinza com 256 níveis ( 8 bits).

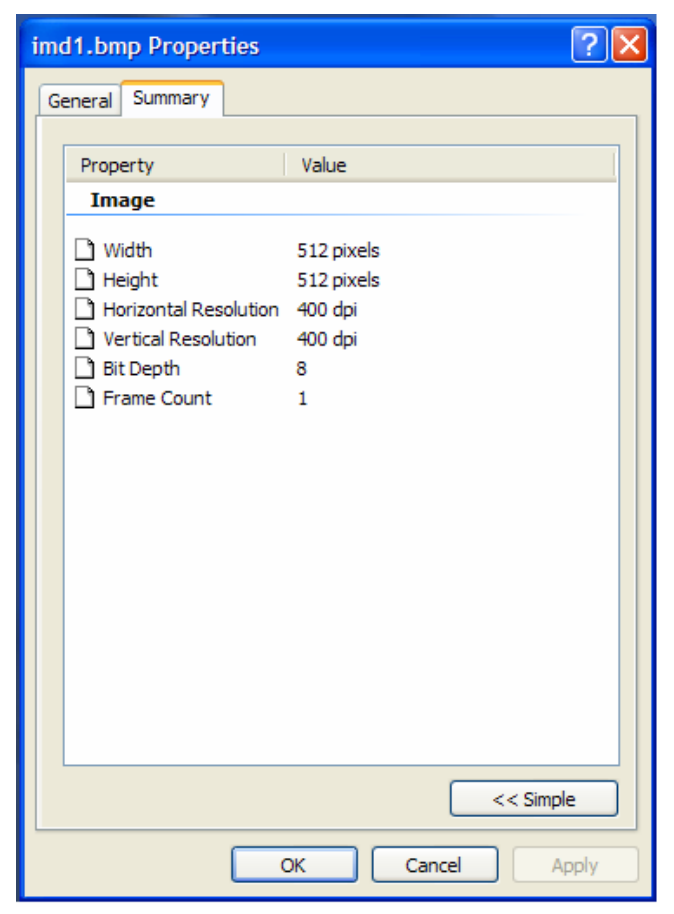

Figura E.6. Propriedades típicas de uma imagem digital de amostra de papel, conforme padrão deste procedimento (denominada imd1.bmp).

5. Digitalizar as amostras de papel, usando o software próprio do digitalizador selecionado, atribuindo a cada arquivo de imagem uma designação seqüencial, em extensão .bmp ou .tif, com o formato abaixo (ver exemplo no cabeçalho da ilustração contida na Figura E.6):

$\begin{array}{ll}\text { Prefixo: } & \text { imd } \\ \text { No. de seqüência: } & 1,2, \ldots, N \quad \text { (N: quantidade total de imagens) } \\ \text { Extensão: } & . b m p\end{array}$

Portanto, a designação completa do arquivo da primeira imagem será: imd1.bmp. As imagens são armazenadas em pasta de trabalho (e.g., C:\...MATLAB), para recuperação futura, na etapa de processamento. Na Figura E.7 encontra-se um exemplo de visualização de uma imagem de papel digitalizada. 


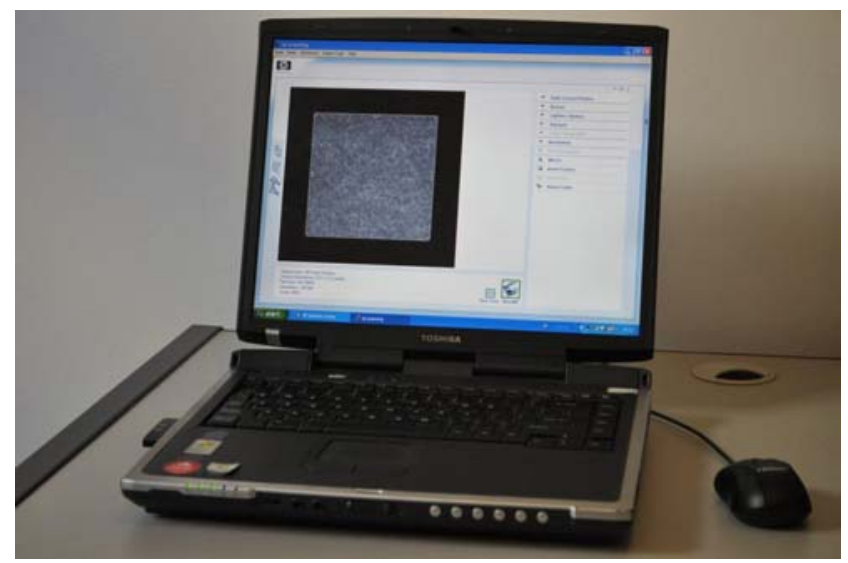

Figura E.7. Visualização de uma imagem digital de papel com dimensões de 512 pixels x 512 pixels, digitalizada em escala de cinza de 256 níveis.

\section{E.3. Processamento e análise das imagens das amostras de papel}

O processamento e análise das imagens preveem a utilização do software MATLAB e seu aplicativo $\mathrm{IPT}^{218}$, para aplicação do programa de análise de imagem denominado PET1_0.m ${ }^{219}$, desenvolvido especificamente para esta finalidade. Os dados obtidos a partir do programa PET1_0.m são transportados para uma planilha Excel (PET1_0.xls ${ }^{220}$ ) configurada para o cálculo e exibição gráfica do perfil de encolhimento transversal.

1. Terminada a digitalização e armazenamento das imagens de papel, passar para o ambiente MATLAB, no mesmo computador e acessar o programa de análise de imagem, digitando "PET1_0" na janela de comando do MATLAB (ver exemplo de visualização na Figura E.9) . Seguir as instruções disponíveis na tela para entrada de parâmetros e assegurar-se de que está sendo apontada a mesma pasta de trabalho selecionada para armazenamento das imagens (e.g., C:\...MATLAB).

2. O programa PET1_0 automaticamente recupera as imagens arquivadas na pasta de trabalho, aplica a transformada bidimensional rápida de Fourier (2D-FFT) e

\footnotetext{
${ }^{218}$ IPT: Image Processing Toolbox.

${ }^{219}$ Uma explicação detalhada do programa PET1_0.m e dos parâmetros de entrada encontra-se disponível no Apêndice C. Os parâmetros pré-definidos foram ajustados para as características típicas de telas formadoras de tripla-camada, estilo SSB, comumente utilizada na fabricação de papel reprográfico em formadores do tipo gap formers. O programa poderá ser ajustado para outros tipos de telas formadoras, recurso que foge do escopo do presente trabalho.

${ }^{220}$ A planilha PET1_0.xls foi desenvolvida para incorporar o algoritmo de cálculo do encolhimento transversal (CD) do papel, conforme apresentado na subseção 4.2 .7 e exibição gráfica do perfis de encolhimento relativo e absoluto, encontrados ao longo da largura da máquina.
} 
identifica os picos de amplitude de interesse no espectro de Fourier e registra suas coordenadas espaciais, para uso na etapa seguinte de processamento ${ }^{221}$. A Figura E.8 ilustra imagens típicas geradas pelo programa PET1_0 durante a execução da transformada de Fourier e da seqüência de identificação de picos de amplitude no espectro de freqüências.

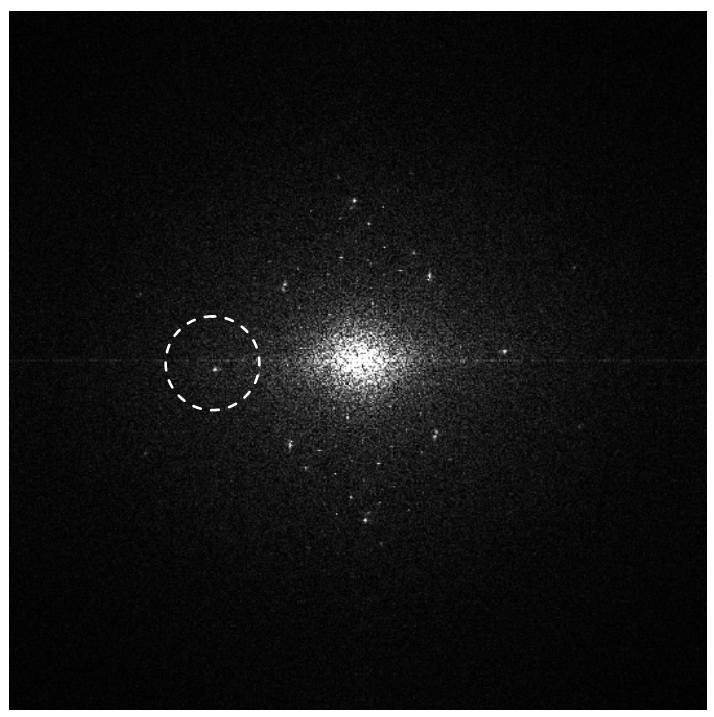

(a)

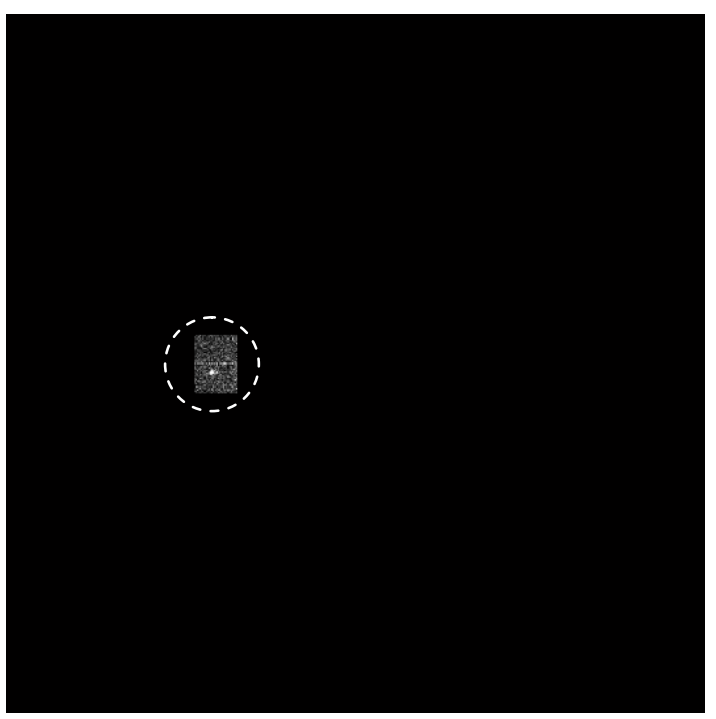

(b)

Figura E.8. Visualização do espectro da transformada de Fourier da imagem imd1.bmp (propriedades indicadas na Figura E.6) em (a), e da máscara-filtro para identificação de pico de amplitude de interesse em (b).

${ }^{221}$ O método completo de aplicação de transformada de Fourier para a finalidade mencionada encontra-se na subseção 4.2.7. 
3. Transportar os dados de saída gerados pelo programa PET1_0.m (coordenadas dos picos de amplitude) para a planilha de cálculo PET1_0.xls. A Figura E.9 ilustra uma tela do programa mencionado, mostrando os parâmetros de entrada, parâmetros pré-definidos e dados de saída para algumas imagens do papel analisado.

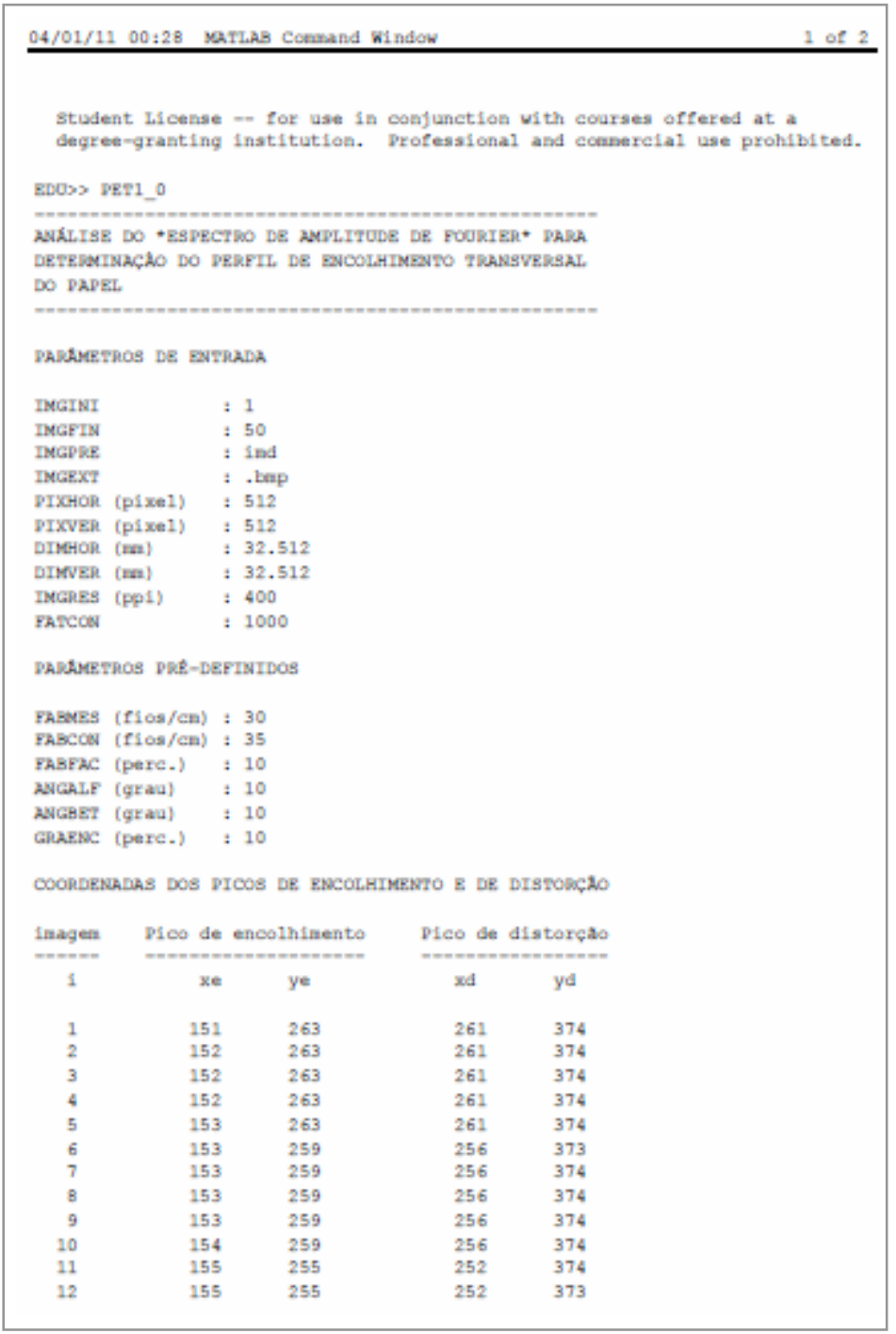

Figura E.9. Exemplo de visualização de tela durante processamento do programa PET1_0, os parâmetros de entrada digitados pelo operador, os parâmetros pré--definidos (default) e dados de saída para as doze primeiras imagens analisadas.

4. Após inserção das coordenadas dos picos de amplitude, introduzir os demais dados solicitados na planilha PET1_0.xls, tais como as posições transversais dos pontos [distâncias a partir do lado de comando (LC) da máquina de papel], as larguras das amostras utilizadas, a quantidade e a especificação das imagens. 
5. A seguir, os perfis de encolhimento relativo e absoluto serão gerados na planilha. O perfil de encolhimento absoluto é determinado a partir do dado de encolhimento total do papel. Ver exemplo na Figura E.10 e na Figura E.11, a seguir.

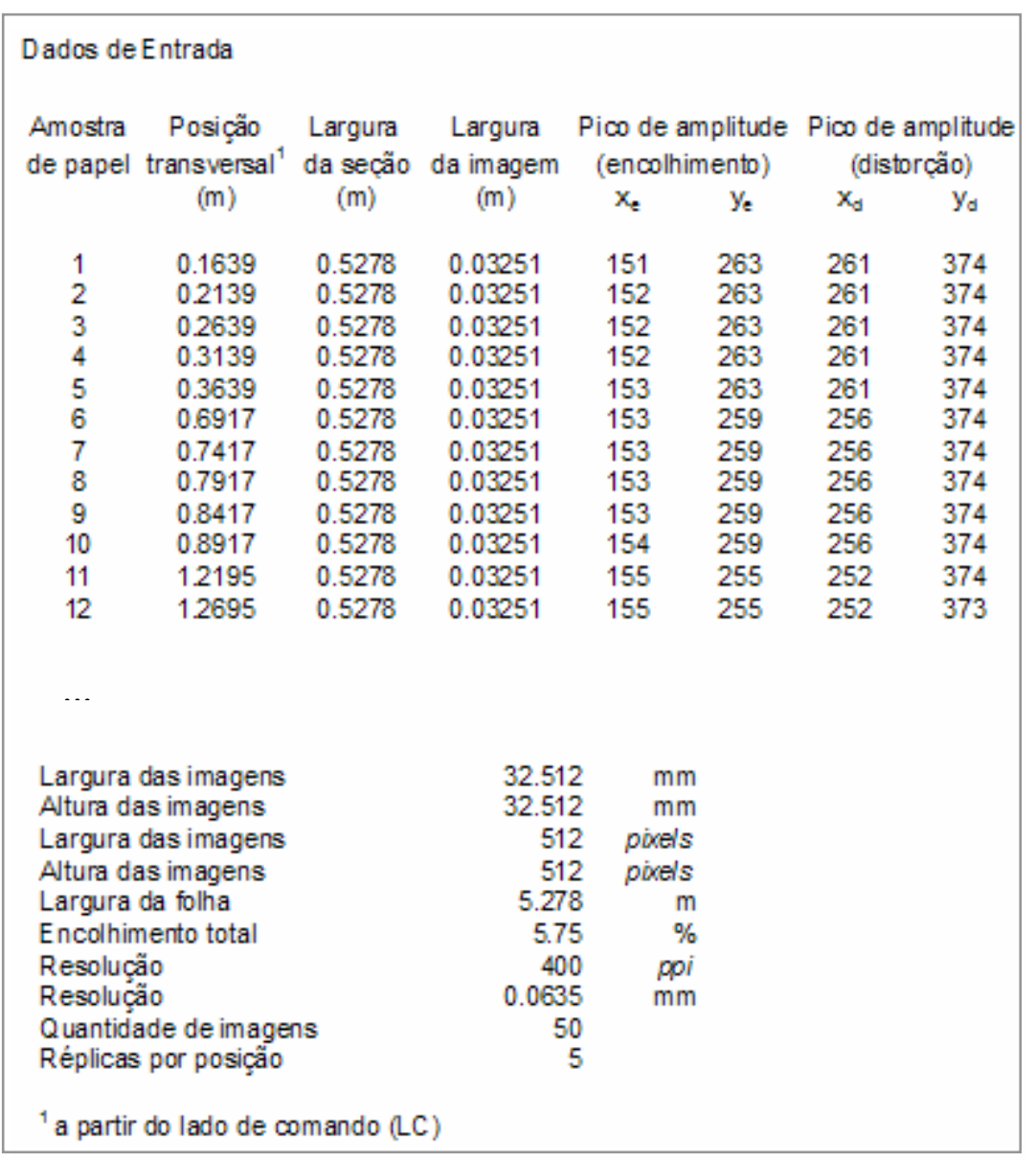

(a)

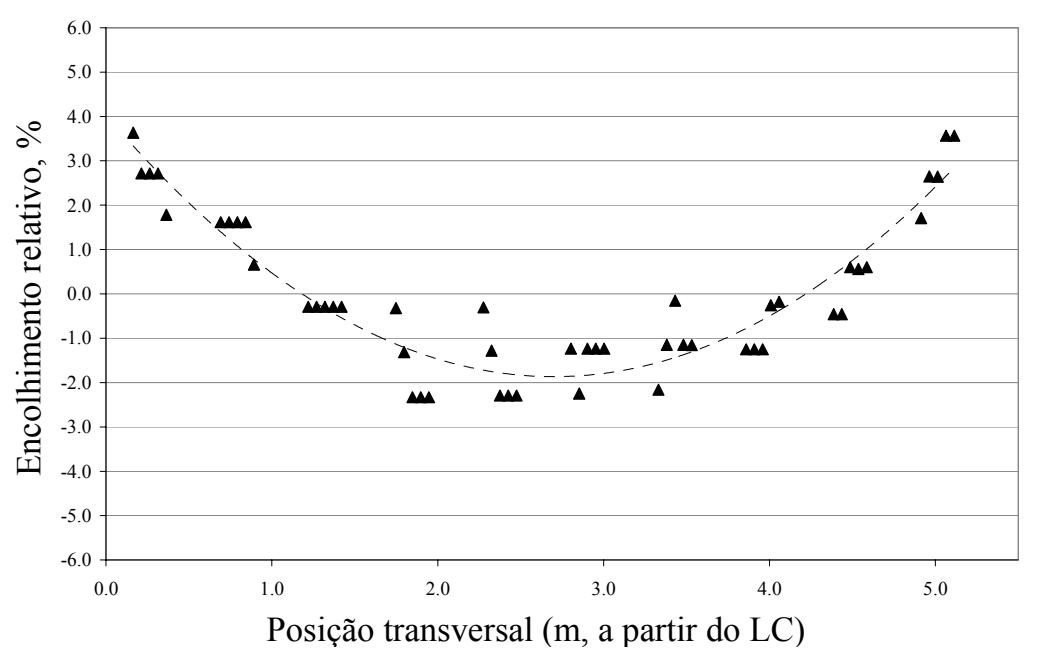

(b)

Figura E.10. Exemplo de visualização da planilha PET1_0.xls em (a) e do perfil de encolhimento transversal (CD) relativo em (b). 


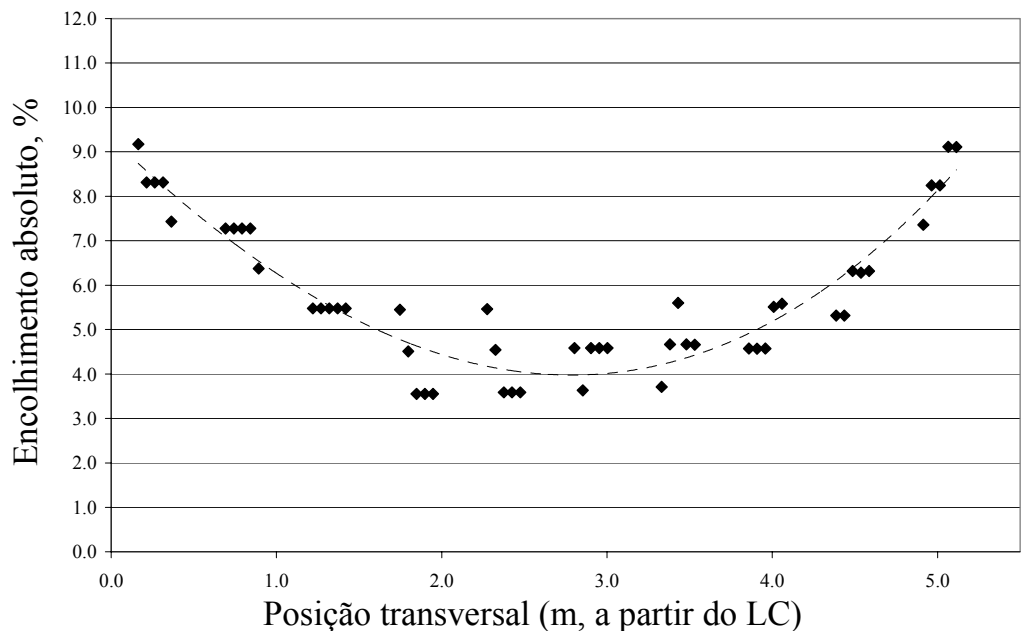

Figura E.11. Exemplo de perfil do encolhimento transversal (CD) absoluto do papel obtido por análise de imagem. 


\section{APÊNDICE F \\ SELEÇÃO DA RESOLUÇÃO DE IMAGEM PARA DETECÇÃO DE MARCAS DE TELAS FORMADORAS}

A seleção da resolução de imagem desempenha importante fator na viabilização da análise do encolhimento transversal (CD) do papel por meio da transformada de Fourier, $c f$. análise deste autor, em contraposição com que estabeleceram Hoole et al. (1999), ao enfatizar apenas o tamanho da imagem (no domínio espacial, comumente definido em milímetros) como fator preponderante. De forma comum, a literatura disponível sobre identificação de marcas de tela formadora no papel não trata desta questão em detalhes, apresentando apenas dados parciais dos parâmetros fundamentais das imagens utilizadas nos trabalhos publicados. Neste sentido, I'Anson (1995a) abordando também a questão do tamanho da imagem, menciona apenas que a dimensão do elemento de imagem deve ser inferior à dimensão do padrão periódico de interesse.

De acordo com Hoole et al. (1999), o tamanho das imagens define a localização dos picos de amplitude referentes ao encolhimento transversal do papel e a eventuais deformações da tela formadora no espectro de Fourier, estabelecendo que imagens muito grandes levam os picos para fora dos limites do espectro, enquanto imagens muito pequenas os levam para o agrupamento central do espectro, dificultando sua detecção, podendo conseqüentemente levar a medições incorretas. Porém, é a resolução espacial da imagem digital (i.e., o tamanho do pixel) que se constitui, de fato, no principal parâmetro determinante da posição dos picos de amplitude no espectro de Fourier, de forma independente da quantidade de pixels contida na imagem (i.e., do tamanho da imagem), $c f$. demonstrado a seguir.

Considerando as imagens digitais genéricas com dimensões $N \times N, c f$. representação esquemática mostrada na Figura F.1, e retomando o exposto na subseção 3.5.5, tem-se que:

$$
\begin{aligned}
& d_{m d}=\frac{N}{d_{m d}^{\prime}} \\
& d_{m d}^{*}=\frac{N}{d_{m d}^{\prime}} \Delta x
\end{aligned}
$$


onde:

$d_{m d}$ distância entre as marcas longitudinais (MD) da tela formadora, pixels

$d_{m d}^{*} \quad$ distância entre as marcas longitudinais (MD) da tela formadora, mm

$d_{m d}^{\prime} \quad$ distância entre o pico de amplitude referente a marcas longitudinais (MD) da tela formadora e o centro do espectro de Fourier, pixels

$N \quad$ número de elementos da imagem, pixels

$\Delta x \quad$ resolução de imagem, $\mathrm{mm}$

e, de forma similar, no eixo perpendicular ao anterior:

$d_{c d}=\frac{N}{d_{c d}^{\prime}}$

$d_{c d}^{*}=\frac{N}{d_{c d}^{\prime}} \Delta x$

onde:

$d_{c d} \quad$ distância entre as marcas transversais (CD) da tela formadora, pixels

$d_{c d}^{*} \quad$ distância entre as marcas transversais $(\mathrm{CD})$ da tela formadora, $\mathrm{mm}$

$d_{c d}^{\prime} \quad$ distância entre o pico de amplitude referente a marcas transversais (CD) da tela formadora e o centro do espectro de Fourier, pixels

$N \quad$ número de elementos da imagem, pixels

$\Delta x \quad$ resolução de imagem, $\mathrm{mm}$

Sabendo-se que para um pico de amplitude, referente ao encolhimento transversal (CD) do papel, representado na Figura F.1 pelo ponto $p_{1}$, que pode situar-se no primeiro ou no quarto quadrante do espectro de amplitudes de Fourier ${ }^{222}$ :

$$
d_{m d}^{\prime} \leq \frac{N}{2}
$$

\footnotetext{
${ }^{222}$ Para o caso mais crítico, em que $\alpha=0^{\circ}$.
} 
(a)

domínio espacial

$f(x, y)$
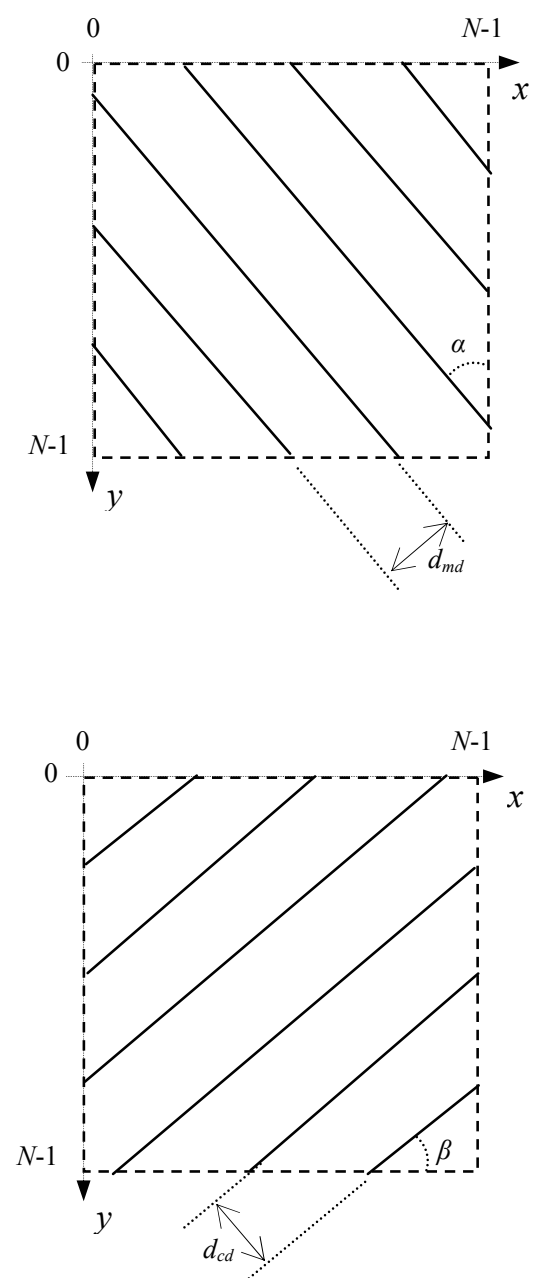

(a)

(b)

domínio de freqüências

$F(u, v)$
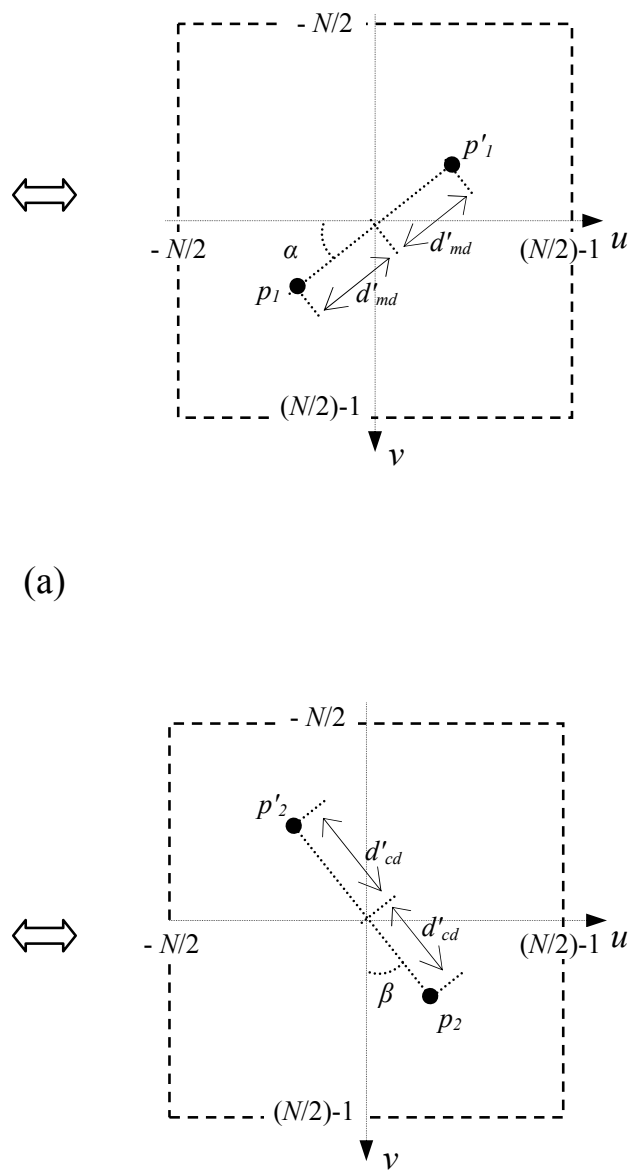

(b)

Figura F.1. Esquema de uma imagem digital representando marcas longitudinais (a) e transversais (b) encontradas no papel acabado, provenientes de uma tela formadora, no domínio espacial, à esquerda e seus respectivos espectros de Fourier (no domínio das freqüências), à direita. O ângulo $\alpha$ representa a inclinação das marcas provenientes de fios longitudinais em relação à direção longitudinal (MD) e $\beta$ a inclinação de fios transversais em relação à direção transversal da máquina de papel. Os parâmetros $d_{m d}$ e $d_{c d}$ representam as distâncias entre marcas de fios longitudinais e transversais respectivamente, no papel acabado (em pixels). Os parâmetros $d_{m d}^{\prime}$ e $d_{c d}^{\prime}$ representam as distâncias entre os picos de amplitude referentes às marcas longitudinais e transversais, respectivamente, e o centro do espectro. Os picos de amplitude estão representados pelos pontos $p_{1}$ e $p_{2}$ (e seus simétricos $p^{\prime}{ }_{1} \mathrm{e} p_{2}{ }_{2}$ ). 
e que, similarmente, para um pico de amplitude usado na medição de eventual distorção da tela formadora, representado pelo ponto $p_{2}$, que pode situar-se no terceiro ou no quarto quadrante do espectro ${ }^{223}$ :

$$
d_{c d}^{\prime} \leq \frac{N}{2}-1
$$

vem que:

$$
\begin{aligned}
& \frac{N \Delta x}{d_{m d}^{*}} \leq \frac{N}{2} \\
& \frac{N \Delta x}{d_{c d}^{*}} \leq \frac{N}{2}-1
\end{aligned}
$$

e, por conseguinte:

$$
\Delta x \leq \frac{d_{m d}^{*}}{2}
$$

$$
\Delta x \leq \frac{d_{c d}^{*}}{2} \frac{(N-1)}{N}
$$

sendo que a expressão (F.8) pode simplificada para a forma ${ }^{224}$ :

$$
\Delta x \leq \frac{d_{c d}^{*}}{2}
$$

O valor de $\Delta x$ será arbitrado de acordo com a condição mais crítica, em função das magnitudes dos parâmetros $d^{*}{ }_{m d}$ e $d^{*}{ }_{c d}{ }^{225}$ (o menor entre eles corresponde à condição principal para determinação de $\Delta x$ ).

\footnotetext{
${ }^{223}$ No caso mais crítico, em que $\beta=0^{\circ}$.

${ }^{224}$ Pois $[(N-1) / N] \approx 1$.

${ }^{225}$ Dependem do tipo estrutural da tela formadora considerada.
} 
Como a resolução de uma imagem digital encontra-se comumente expressa em $p^{2} i^{226}$, que se relaciona com $\Delta x c f$. relação a seguir:

$$
\Delta x=\frac{25,4}{R_{p p i}}
$$

onde:

$\Delta x \quad$ resolução de imagem, $\mathrm{mm}$

$R_{p p i} \quad$ resolução de imagem, $p p i$

vem que a seleção da resolução de imagem em $p p i$, denominada por $R_{p p i}$, deve ser governada pelas seguintes relações:

$$
\begin{aligned}
& R_{p p i(m d)}>\frac{50,8}{d_{m d}^{*}} \\
& R_{p p i(c d)}>\frac{50,8}{d_{c d}^{*}}
\end{aligned}
$$

Os valores de $d^{*}{ }_{m d}$ e $d^{*}{ }_{c d}$ não são conhecidos a priori, dado que representam distâncias entre marcas, da tela formadora, presentes no papel acabado, i.e., após o encolhimento sofrido durante a etapa de secagem. Porém, seus valores podem ser estimados, a partir do encolhimento máximo avaliado para o papel nas direções de interesse (MD e CD). Assim, podem-se estabelecer as seguintes relações:

$$
\begin{aligned}
& 1-\frac{S_{m d}}{10^{2}}=\frac{d_{m d}^{*}}{d_{m d(u s)}^{*}} \\
& 1-\frac{S_{c d}}{10^{2}}=\frac{d_{c d}^{*}}{d_{c d(u s)}^{*}}
\end{aligned}
$$

onde:

\footnotetext{
${ }^{226}$ Pixels per inch (ppi): elementos de imagem por polegada.
} 


$\begin{array}{ll}S_{m d}, S_{c d} & \text { encolhimento do papel nas direções MD e CD, } \\ & \text { respectivamente, \% } \\ d^{*}{ }_{m d}, d^{*}{ }_{c d} & \text { distância entre marcas, de fios longitudinais (MD) e } \\ & \text { transversais (CD) da tela formadora, respectivamente, } \\ & \text { encontradas no papel acabado, mm } \\ & \text { distância entre marcas, de fios longitudinais (MD) e } \\ d^{*}{ }_{m d}(u s), d^{*}{ }_{c d(u s)} & \text { transversais (CD) da tela formadora, respectivamente, } \\ & \text { encontradas no papel antes do encolhimento }{ }^{227}, \text { mm }\end{array}$

Relembrando que o encolhimento do papel na direção longitudinal (MD), $S_{m d}$, durante a fase de secagem, é praticamente nulo ${ }^{228}$, e que na direção transversal (CD), $S_{c d}$, comumente atinge valores $<10 \%{ }^{229}$, assume-se, para fins de determinação da resolução mínima de imagem, que ${ }^{230}$ :

$$
\begin{aligned}
& d_{m d}^{*}=0,9 \times d_{m d(u s)}^{*} \\
& d_{c d}^{*}=d_{c d(u s)}^{*}
\end{aligned}
$$

Substituindo as expressões (F.15) e (F.16), acima, em (F.11) e (F.12), vem que:

$$
\begin{aligned}
& R_{p p i(m d)}>\frac{56,4}{d_{m d(u s)}^{*}} \\
& R_{p p i(c d)}>\frac{50,8}{d_{c d(u s)}^{*}}
\end{aligned}
$$

As expressões acima mostram as condições mínimas de contorno para seleção da resolução de imagem a ser usada para escaneamento das amostras de papel, a fim de garantir que os picos de amplitude de interesse se localizem dentro dos limites do espectro de Fourier.

\footnotetext{
${ }^{227}$ Correspondentes às distâncias entre fios longitudinais e fios transversais da face da tela formadora que faz contato com o papel (ver exemplos no Apêndice D).

${ }^{228}$ Devido ao tensionamento do papel na direção de fabricação (MD). Ver seção 2.1.

${ }^{229} C f$. resultados de Hoole [2002], $c f$. mencionado por I'Anson et al [2008] e também $c f$. apurado nos resultados das medições realizadas neste trabalho.

${ }^{230}$ Considerando o valor mínimo de $d^{\prime}$ md, na hipótese de $S_{m d}=10 \%$.
} 
Os valores dos parâmetros $d^{*}{ }_{m d}(u s)$ e $d^{*}{ }_{c d}(u s)$ podem ser obtidos diretamente em folhas de dados de fabricantes de telas formadoras ou estimados a partir da análise estrutural (medição) da tela considerada.

A fim de posicionar os picos de amplitude em uma região suficientemente afastada do agrupamento central de picos de amplitude e das bordas do espectro de Fourier e, portanto, mais conveniente para visualização e medição, e.g., aproximadamente entre $2 / 5$ e $3 / 5$ da faixa do espectro compreendida entre a origem e a borda, o seguinte critério pode ser adotado:

$$
\begin{aligned}
& \frac{2,2 N}{d_{m d(u s)}^{*}} \times 10^{-1}<R_{p p i(m d)}<\frac{2,5 N}{d_{m d(u s)}^{*}} \times 10^{-1} \\
& \frac{2,2 N}{d_{c d(u s)}^{*}} \times 10^{-1}<R_{p p i(c d)}<\frac{2,5 N}{d_{c d(u s)}^{*}} \times 10^{-1}
\end{aligned}
$$

onde:

$$
R_{p p i(m d)}, R_{p p i(c d)}
$$

resoluções da imagem, na direção longitudinal (MD) e transversal (CD), respectivamente, ppi

$$
d^{*}{ }_{m d}(u s), d^{*} c d(u s)
$$
distância entre marcas encontradas no papel antes do encolhimento, produzidas por fios longitudinais (MD) e transversais (CD) da tela formadora, respectivamente ${ }^{231}$, $\mathrm{mm}$

$N$ número de pontos de amostragem da imagem na direção longitudinal (MD) e transversal (CD) ${ }^{232}$, pixels

A faixa final recomendada para a resolução de imagem será resultante de um compromisso entre as faixas identificadas anteriormente, i.e., definida pela intersecção das especificações expressas por (F.11), (F.12), (F.19) e (F.20).

\footnotetext{
${ }^{231}$ Os valores de $d^{*}{ }_{u s(m d)}$ e de $d^{*}{ }_{u s(c d)}$ podem ser obtidos diretamente em folhas de dados de fabricantes de telas formadoras ou estimadas a partir da análise estrutural (medição) da tela considerada.

${ }^{232}$ As imagens tratadas neste estudo têm dimensões na forma de $2^{n} \times 2^{n}$ (sendo $n$ um número real e inteiro), a fim de se obter melhor desempenho do algoritmo de cálculo da 2D-FFT (ver subseção 3.4.7).
} 
Considerando-se uma tela de tripla-camada, estilo $\mathrm{SSB}^{233}$, tipicamente utilizada em formadores do tipo gap former ${ }^{234}$, encontrados comumente na fabricação de papel reprográfico, têm-se os seguintes parâmetros (informação pessoal) ${ }^{235}$ :

$$
\begin{gathered}
d_{m d(u s)}^{*} \approx 0,3030 \mathrm{~mm} \\
d_{c d(u s)}^{*} \approx 0,2857 \mathrm{~mm}
\end{gathered}
$$

Ainda, considerando-se uma imagem digital com dimensões $N=512$ pixels, pela aplicação das considerações expressas em (F.11), (F.12), (F.19) e (F.20) encontra-se:

$$
\begin{aligned}
& 372 p p i<R_{p p i(m d)}<422 p p i \\
& 394 p p i<R_{p p i(c d)}<448 p p i
\end{aligned}
$$

Os resultados acima sugerem que uma resolução de imagem adequada para análise das marcas da tela formadora especificada, será $R_{p p i}=400 \mathrm{ppi}$.

\footnotetext{
233 SSB: Self Supported Binding (padrão estrutural em que os fios de amarração entre lajes da tela formadora têm, também, função de suporte da folha de papel).

${ }^{234}$ Ver Figura 4.3 na subseção 4.1.1.

${ }^{235}$ Munhoz, M. Dados de tela formadora aplicada em formador gap former, para produção de papel reprográfico. Mensagem recebida por ahmendes@uol.com.brem 18 jan. 2011.
} 


\section{APÊNDICE G}

\section{CONDIÇÕES TÍPICAS DE OPERAÇÃO DA MÁQUINA DE PAPEL INDUSTRIAL}

Os dados, a seguir, mostram condições típicas de operação da máquina de papel industrial investigada, na produção de papel reprográfico [Mendes, 2006].

\section{Massa de papel}

Composição nominal:

$48 \%$ massa refinada

$21 \%$ massa recuperada

$12 \%$ refugo próprio

$19 \%$ carga mineral

Refinação:

$410 \mathrm{CSF}$

Velocidade da máquina

Telas formadoras:

1202 m.min. ${ }^{-1}$

Enroladeira:

1256 m.min. ${ }^{-1}$

\section{Gramatura do papel}

Enroladeira:

76,4 g.m $\mathrm{m}^{-2}$

\section{Umidade do papel}

Antes da prensa de colagem:

$3,0 \%$

Enroladeira:

\section{Espessura do papel}

Enroladeira:

$86 \mu \mathrm{m}$

\section{Largura do papel}

Saída da prensa:

Saída da pré-secagem:

$5.297 \mathrm{~mm}$

Enroladeira:

\section{Caixa de entrada}

Razão Jato/Tela:

1,02

Consistência da massa:

$0,94 \%$

pH da massa:

8,0

Abertura do lábio:

$11,8 \mathrm{~mm}$

Pressão:

2,3 bar 


\section{Formador}

Vácuo / rolo formador:

$-0,620 \mathrm{mca}$

Vácuo / rolo couch:

$-4,5$ bar ( $1^{\mathrm{a}}$. zona); $-6,7$ bar ( $2^{\mathrm{a}}$. zona)

Vácuo / Caixa D:

$1^{\mathrm{a}}$. zona

$-1,1 \mathrm{mca}$

$2^{\mathrm{a}}$. zona

$-2,0$ mca

$3^{\mathrm{a}}$ zona

$-2,9$ mca

skimmer

$-0,25$ bar

Caixa de alto vácuo:

$-4,6$ bar

Altura da caixa "D":

$16,2 \mathrm{~mm}$

Pressão lâminas desaguadoras:

$1^{\mathrm{a}} 1,5$ bar; $2^{\mathrm{a}} 1,8$ bar

$3^{\mathrm{a}} 2,1$ bar; $4^{\mathrm{a}} 2,5$ bar

Tensão nas telas formadoras:

$8.8 \mathrm{kN} / \mathrm{m}$

\section{Prensas}

Carga linear:

$1^{\mathrm{a}}$ prensa
$2^{\mathrm{a}}$ prensa
$3^{\mathrm{a}}$ prens
$4^{\mathrm{a}}$ prena

$70 \mathrm{kN} \cdot \mathrm{m}^{-1}$

$90 \mathrm{kN} \cdot \mathrm{m}^{-1}$

$690 \mathrm{kN} \cdot \mathrm{m}^{-1}$

$55 \mathrm{kN} \cdot \mathrm{m}^{-1}$

Vácuo / rolo sucção:

$1^{\mathrm{a}}$ zona
$2^{\mathrm{a}}$ zona

$-6,0 \mathrm{mca}$

$-3,5 \mathrm{mca}$

Vácuo / caixas sucção dos feltros:

$-5,0 \mathrm{mca}$

Tensão nos feltros:

$4,0 \mathrm{kN} \cdot \mathrm{m}^{-1}$

\section{Secadores}

Pressão de vapor:

\begin{tabular}{|c|c|c|}
\hline \multirow[t]{5}{*}{ pré-secagem } & Sec. 1 & fechado \\
\hline & Sec. 2 & $-1,0$ bar \\
\hline & Sec. 3 & $-0,3$ bar \\
\hline & Sec. 4,5 & $-0,2$ bar \\
\hline & Sec. 6,7 e $8-11$ & $+0,1$ bar \\
\hline & Sec. 12-19 & $+0,3$ bar \\
\hline & Sec. $20-37$ & $+2,7$ bar \\
\hline \multirow[t]{5}{*}{ pós-secagem } & Sec. 38 & 0 bar \\
\hline & Sec. 39 & 0 bar \\
\hline & Sec. 40 & $+0,4$ bar \\
\hline & Sec. 41-51 & 0,9 bar \\
\hline & Sec. $42-52$ & $2,4 \mathrm{bar}$ \\
\hline
\end{tabular}


Tensão nas telas secadoras:

$$
\begin{array}{ll}
1^{\mathrm{o}} \text { e } 7^{\mathrm{o}} \text { grupos } & 4,5-5,0 \mathrm{kN} \cdot \mathrm{m}^{-1} \\
\text { demais grupos } & 2,7-3,2 \mathrm{kN} \cdot \mathrm{m}^{-1}
\end{array}
$$

\section{Prensa de Colagem}

Solução de amido:

$\begin{array}{ll}\text { temperatura } & 50{ }^{\circ} \mathrm{C} \\ \text { viscosidade } & 50 \mathrm{cps} \\ \text { concentração } & 9,8 \% \\ \text { aplicação } & 32,7 \mathrm{~kg} \cdot \text { ton }^{-1}\end{array}$

Pressão de carga:

lado comando

5,5 bar

lado acionamento

6,0 bar

\section{Calandra}

Pressão de carga:

lado comando

29,5 bar

lado acionamento

29,5 bar

Pressão linear:

18,2 kN.m ${ }^{-1}$

\section{Enroladeira}

Pressão alavancas:

lado comando

25 bar

lado acionamento

26 bar

\section{Vestimentas}

Formador:

posição superior

posição inferior

Prensas: rolo pick-up

$$
\begin{aligned}
& 1^{\mathrm{a}} \text { prensa } \\
& 2^{\mathrm{a}} \text { e } 3^{\mathrm{a}} \text { prensas } \\
& 4^{\mathrm{a}} \text { prensa } \\
& \text { prensa sapata }
\end{aligned}
$$

Secadores:

$$
\begin{aligned}
& 1^{\circ} \text { grupo } \\
& 2^{\circ} \text { grupo } \\
& 3^{\circ} \text { grupo } \\
& 4^{\circ} \text { grupo superior } \\
& 4^{\circ} \text {. grupo inferior } \\
& 5^{\circ} \text { grupo superior } \\
& 5^{\circ} \text { grupo inferior } \\
& 6^{\circ} \text { grupo superior } \\
& 6^{\circ} \text { grupo inferior } \\
& 7^{\circ} \text { grupo } \\
& 8^{\circ} \text { grupo superior } \\
& 8^{\circ} \text { grupo inferior }
\end{aligned}
$$

tela tripla, 480 g.m $\mathrm{m}^{-2}, 372 \mathrm{cfm} . \mathrm{ft}^{-2}$

tela tripla, 450 g.m $\mathrm{m}^{-2}, 376 \mathrm{cfm} . \mathrm{ft}^{-2}$

feltro $2+1,1849$ g.m $\mathrm{m}^{-2}, 60 \mathrm{cfm} . \mathrm{ft}^{-2}$

feltro $1+1,1275 \mathrm{~g} \cdot \mathrm{m}^{-2}, 61 \mathrm{cfm} \cdot \mathrm{ft}^{-2}$

feltro $2+1,1554$ g.m $\mathrm{m}^{-2}, 42 \mathrm{cfm} . \mathrm{ft}^{-2}$

feltro $2+1$

manta ranhurada

tela secadora, 1100 g.m ${ }^{-2}, 120 \mathrm{cfm} . \mathrm{ft}^{-2}$

tela secadora, 1100 g.m $\mathrm{m}^{-2}, 150 \mathrm{cfm} . \mathrm{ft}^{-2}$

tela secadora, 1100 g.m $\mathrm{m}^{-2}, 130 \mathrm{cfm} . \mathrm{ft}^{-2}$

tela secadora, 1787 g.m $\mathrm{m}^{-2}, 250 \mathrm{cfm} . \mathrm{ft}^{-2}$

tela secadora, 1785 g.m $\mathrm{m}^{-2}, 200 \mathrm{cfm} . \mathrm{ft}^{-2}$

tela secadora, 1756 g.m $\mathrm{m}^{-2}, 300 \mathrm{cfm} . \mathrm{ft}^{-2}$

tela secadora, 1746 g.m $\mathrm{m}^{-2}, 300 \mathrm{cfm} . \mathrm{ft}^{-2}$

tela secadora, 1756 g.m $\mathrm{m}^{-2}, 350 \mathrm{cfm} . \mathrm{ft}^{-2}$

tela secadora, 1800 g.m $\mathrm{m}^{-2}, 350 \mathrm{cfm} . \mathrm{ft}^{-2}$

tela secadora, 1100 g.m $\mathrm{m}^{-2}, 120 \mathrm{cfm} . \mathrm{ft}^{-2}$

tela secadora, 1700 g.m $\mathrm{m}^{-2}, 290 \mathrm{cfm} . \mathrm{ft}^{-2}$

tela secadora, 1700 g.m $\mathrm{m}^{-2}, 290 \mathrm{cfm} . \mathrm{ft}^{-2}$ 